Thesis submitted for the degree of

Doctor of Philosophy

at the University of Leicester

by

Paulo Alexandre Aleixo BSc.(Hons)

Department of Psychology

University of Leicester

December 1992 
UMI Number: U050038

All rights reserved

\section{INFORMATION TO ALL USERS}

The quality of this reproduction is dependent upon the quality of the copy submitted.

In the unlikely event that the author did not send a complete manuscript and there are missing pages, these will be noted. Also, if material had to be removed, a note will indicate the deletion.

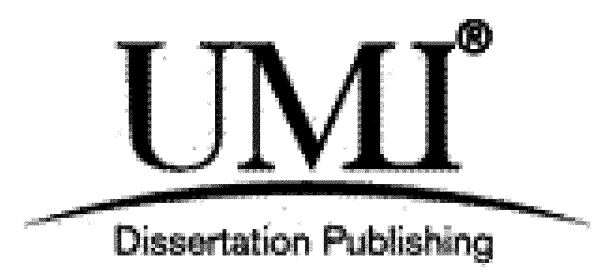

UMI U050038

Published by ProQuest LLC 2015. Copyright in the Dissertation held by the Author. Microform Edition (c) ProQuest LLC.

All rights reserved. This work is protected against unauthorized copying under Title 17, United States Code.

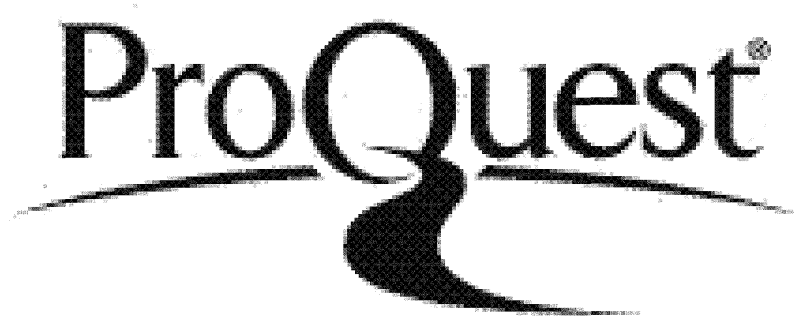

ProQuest LLC

789 East Eisenhower Parkway

P.O. Box 1346

Ann Arbor, MI 48106-1346 


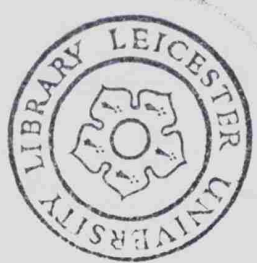

7501440648 


\title{
Personality and Moral Reasoning in Young Offenders
}

\author{
Paulo A. Aleixo
}

The studies presented in this thesis, examined the differences in personality, moral reasoning maturity, intellectual capacity, and family background variables in convicted male young offenders and controls. In addition, the relationship between these variables and self-reported offending behaviour was investigated.

The main aim of the investigations was to test predictions from the theories of criminality proposed by H. J. Eysenck $(1964 ; 1970 ; 1977)$ and Kohlberg (1969) which associate offending behaviour with lower moral reasoning maturity and the personality characteristics of high psychoticism, extraversion and neuroticism.

Results suggested that both official and self-reported measures of offending were related to high psychoticism and extraversion, lower moral reasoning maturity, lower intelligence (perhaps through mediation by moral reasoning and lower socio-economic status). Neuroticism was not found to be important in predicting offending in the age group used, but was assumed to be involved in older individuals when offending behaviour had developed into a habit. These variables were also found to interact to predict offending behaviours. Some of these variables (notably extraversion and neuroticism) were found to be related to specific types of offending.

It was concluded that support for H. J. Eysenck and Kohlberg's theories of criminality was found and initial steps were taken in incorporating the various factors found to be associated with offending into a testable model of offending behaviour.

Additionally, a study investigating response bias to moral reasoning and personality tests and another examining personality and moral reasoning in disturbed children are reported. 


\section{CONTENTS}

Acknowledgements

CHAPTER 1

Introduction

1.1 Moral Reasoning

1.2 Eysenck's Theory of Criminality 25

1.3 Other Explanations of Criminality 42

1.4 Self-Reported Delinquency 49

1.5 Predictions and Hypotheses 53

CHAPTER 2

Method

2.1 Study Population

2.2 Design and Materials $\quad 56$

2.3 Procedure $\quad 60$

2.4 Analysis $\quad 61$

CHAPTER 3

Results

63

3.1 Large Sample and Sub-groups

Descriptions

3.2 Group Comparisons

133

3.3 Personality Variables as Independent

Variables

3.4 Multiple Regression Analysis

186

3.5 Qualitative Descriptions of Moral

200

Reasoning Results

CHAPTER 4

4.1 Personality and Moral Reasoning in

Severely Disturbed and Disruptive

Children

4.2 Response Bias and Lay Conceptions of

Personality and Moral Reasoning in

Young Offenders

CHAPTER 5

Discussion 


\section{Acknowledgements}

I must thank the many people which made this thesis possible, and hope that this doesn't sound too much like an Oscar acceptance speech.

First of all I'd like to thank Claire for all her love and support throughout this ordeal, especially since she was in the throes of a thesis herself. Secondly I'd like to thank Clive Hollin, who supervised the research and write-up, for introducing me to this fascinating topic and for his support throughout (I hope Clive will forgive me for referring to him as 'Hollin' in the thesis, it seems that this is the sort of thing academics do to people they know quite well, and I would certainly never do it to his face!). I'd also like to thank David Hargreaves for taking up the position of supervisor when Clive left Leicester University for greener pastures, and for his help and support. John Beckett of Leicester University computer centre deserves a special thank-you for his invaluable help with the statistical analysis.

Of course, none of this research would have been possible without the cooperation and help of the staff and residents at the institutions which I visited, nowhere was I refused help.

While I received a great deal of help in the completion of this thesis, obviously any errors or omissions can only be attributed to my own deranged mind for which I take full responsibility.

Finally I must thank Chris Nicklin for hiding an envelope in a book! 


\section{CHAPTER 1}

\section{Introduction}

A major goal of criminological study is the development of accurate theories of crime causation. Criminologists have sought to collect facts about crime and offending and to interpret them in a scientific manner. To this end the facts have been organised into verifiable hypotheses with a view to develop these into fully fledged theories of the causes of crime.

It should be noted, however, that the theories of crime which will be adopted are dependent on the discipline of a particular theorist; a sociologist will draw upon sociological concepts, an economist on economic concepts, a psychologist on psychological concepts and so on. In addition, within each discipline not all theorists will agree with their explanations, the aspects which are considered important depend on an individual's stance within their discipline.

Siegal (1986) divided theories of crime causation into two basic groups: those which focus on individual traits, and those which are based on sociological concepts. In the former stance crime is either a function of freewill choice made by the individual, or it is due to personal psychological or biological maladaption, or both. Within this group, Siegal reviewed classical, neo-classical, and biological theories.

In the sociological stance, Siegal included social contract, social process and social conflict theories. This approach holds that crime is a result of the structure, process and conflicts of social living.

Hollin (1989), reviewed theories which had specifically employed a psychological approach. He identified four basic types of psychological explanations for crime causation: 
psychoanalytic theories, learning theories, cognitive theories and control theories. While it is beyond the scope of the present review to detail all of the theories suggested in psychology, it is worth noting Hollin's criticism of psychological approaches in general. Hollin (1989) noted (like Toch, 1979), that much of psychological research and theory on criminal behaviour has attempted to isolate the variables (i.e. 'causes') which produce criminal behaviour. These causes have included biological factors such as genes or psychological factors such as personality. In a similar way sociological explanations have relied on social factors (rather than psychological factors) to explain crime. Other theories have attempted complex interactions between a variety of social, biological and psychological factors.

While the scientific approach generally taken to test these 'causes' in psychological investigations, provides a great deal of information relating to crime, it also has some practical and theoretical limitations. Firstly, there are practical problems since a very large number of variables are thought to be important in crime (Burt, 1925). Even if it were possible to accurately measure all of these, control of such large number of variables would be impossible in scientific research. Secondly, many psychological investigations attempt to explain crime in psychological theories rather then criminological theories, therefore crime becomes a defense mechanism, or failed maternal attachment rather than a phenomenon worthy of explanation in its own right. Faced with this conclusion, Hollin (1989) suggested that psychological explanations of crime need to take into account a wider variety of environmental and personal variables and to explain findings with reference to criminological theories.

Within psychological research there already exist two influential theories which attempt to explain crime by reference to a large variety of factors, the theories of $\mathrm{H}$. J. Eysenck $(1964,1970,1977)$ and Kohlberg (1958). Both these theories draw on factors ranging from biological to cognitive principles, and have rarely been studied in 
combination. It may be that studying the application of both these theories to offending behaviour together with other environmental factors (such as family background) could go some way to taking into account the large variety of variables postulated to be related to crime. It needs to be pointed out however, that the stances posited by these theories are certainly not endorsed by all psychological researchers. Indeed, many researchers would criticise key aspects of both theories. It is not the purpose of the present review to discuss these criticisms, it is sufficient to acknowledge that both theories have some theoretical shortcomings and to discuss the empirical findings relating to the theories' predictions. 


\section{1 - MORAL REASONING}

Research into the development of moral reasoning has been led by the theories of Piaget (1932) and Kohlberg (1969), both of which take a cognitive-developmental approach.

Piaget's theory was derived from his account of the development of logical thinking. He conceptualised moral development as the development of an understanding of social 'rules' within a pre-defined framework. In order to study this he examined children's understanding of simpler rules that had more relevance to them, such as in games which they played. After questioning children of varying ages about games of marbles, he reported three broad categories in the developmental changes in the comprehension of rules, which he described as two major stages of moral development: the morality of constraint, and the morality of cooperation (Piaget, 1932). In the first stage, a child tends to externalise moral rules and treat them as immutable absolutes. In the second stage children perceive the nature of rules as more flexible and a system of mutual cooperation develops when making moral decisions. Some degree of overlap between the two stages was suggested by Piaget, whereby the contrasting moralities of constraint and cooperation coexist in the same child and development is conceived as the second stage gradually succeeding the first.

Kohlberg (1958, 1963a, 1963b, 1964, 1966, 1969) went further with his own developmental theory, and expanded Piaget's stages into six stages, grouped into three levels. The three levels are known as the pre-conventional, the conventional and the postconventional reasoning levels. The term 'conventional' is used to refer to the degree to which an individual is conforming to and upholding the rules, expectations and conventions of society or authority just because they exist. Within each level there are two 
stages, the second one being a more advanced and organised form of the general perspective of each of the levels. The levels and stages are described below:

\section{i) Level 1: Pre-Conventional Reasoning}

- at this level the individual has not yet arrived at an understanding of societal rules and regulations. Moral reasoning is dominated by hedonistic considerations and conformity to the rules of authority. The individual sees rules and social expectations as external to the self.

Stage 1: The individual's moral reasoning is concerned with the avoidance of punishment and obedience to perceived authority.

Stage 2: Moral reasoning at this stage is seen as hedonistic, where an individual is solely concerned with pursuing his or her own needs based on the balance of reward and punishment.

ii) Level 2: Conventional Reasoning

- The individual realises the reciprocal nature of rules, and decisions are made on the basis of maintaining social contracts.

Stage 3: An awareness of the needs of others develops where relationships are seen as the important factor in moral reasoning.

Stage 4: An understanding of societal rules develops, where moral reasoning is concerned with upholding society's rules (i.e. laws) for the sake of maintaining society.

iii) Level 3: Post-Conventional (or Principled) Reasoning

- the individual understands and basically accepts society's rules. However, this is based on accepting the general moral principles that underlie these rules. In certain 
circumstances these principles come into conflict with society's rules and here the individual would judge by principle rather than rule.

Stage 5: The idea of a contract between the individual and society develops, whereby society's rules are seen as resulting from a consensus by its members. However, under certain circumstances rules can be broken.

Stage 6: The individual acts on the basis of self-chosen ethical principles. While societal rules are valid because they rest on these principles they are superseded when conflict occurs.

Kohlberg also applied Piaget's principles to his developmental stage model. He proposed that as they age, individuals pass through these stages in a sequential manner and that at any one time in development an individual is reasoning in terms which belong to either two adjacent stages or just to one. The movement through the stages is progressive from stage one to stage six, but not in the opposite direction, and not everyone reaches the upper stages. This movement describes a development from concrete to more abstract reasoning. Each change from one stage to another represents a reintegration of the earlier one and is therefore said to be a qualitative change in moral thought.

Kohlberg suggests that an individual has a preference for the highest stage reasoning which he or she has attained and that this supersedes any lower stage reasoning previously obtained. He does state, however that institutions and sub-cultures (such as schools and prisons) can develop their own moral reasoning climate which may be above or below that of an individual. In such cases the stage of reasoning of an individual can be increased or decreased depending on the surrounding moral climate (Higgins et al., 1984). 


\section{The Development of Moral Reasoning}

Kohlberg saw the development of moral stages as a sequence in the development of personality (Kohlberg, 1976). Before individuals can pass through the various stages of moral reasoning they must pass through the stages of logical development as described by Piaget (1967), and the stages of social perspective or social perception or role taking (see Selman, 1976).

Piaget (1967) proposed that intellectual development is seen as passing through the intuitive, the concrete operational and the formal operational stages through the processes of assimilation and accommodation of information received by the individual. Since moral reasoning involves the process of reasoning, it follows that the advanced stages of moral reasoning cannot be achieved without advanced logical reasoning. However, while logical development is a necessary condition for moral development, it is not sufficient in itself. Thus it is possible for an individual to be at a higher logical stage than the parallel moral stage, but not be at a higher moral stage than the equivalent logical stage.

After the stages of logical development come the five stages of social perspective, also known as social perception or role taking (e.g. Byrne, 1975). These stages describe the level at which a person sees others, interprets their thoughts and feelings, and sees their own place in society. These are very close, to moral stages but they do not deal with choices of right and wrong. It follows that before moral decisions can be made at a particular level, the corresponding level of social perspective must first be achieved, which in turn relies on a certain level of logical development.

Thus the development of a particular moral stage must be preceded firstly by the achievement of a particular level of logical thinking and then followed by a corresponding level of social perspective. The mechanisms by which these stages are achieved are assumed by Kohlberg to be similar to those proposed by Piaget, namely assimilation and 
subsequent accommodation of information of a logical, social and moral nature received by a particular individual.

The final step in this developmental sequence is that of moral behaviour. To act in a morally 'high' manner requires a high moral reasoning stage. However, noting the difference between cognition and action, an individual can reason in a principled (stages 5 and 6) manner but not live up to this reasoning in their behaviour. A variety of factors are said to influence whether a person will act in a manner appropriate to their moral stage, but moral stage is said to be a good predictor of moral action (Kohlberg, 1976).

\section{The Measurement of Moral Reasoning}

The main method which has been used to measure the stages of moral development by Kohlberg and his colleagues is the Moral Judgement Scale, later revised as the Moral Judgement Interview (Colby et al. 1987). The purpose of this scale is to determine the stage at which an individual reasons morally. Because of the hierarchical nature of the moral reasoning stages the scale also provides a measure of the maturity of an individual's moral judgement.

The Moral Judgement Interview (MJI: Colby et al. 1987) takes the form of an oral interview. The interviewee is asked a minimum of 21 probing questions relating to their reasoning with regard to three moral dilemmas. A moral dilemma is a story which creates a conflict between two moral issues. A frequently quoted example of one of the moral dilemmas involves a man named Heinz who must decide whether to break the law in order to steal a very expensive drug which may save his dying wife. This moral dilemma creates a conflict between the issues of the law and of life, and the subject is asked to decide what Heinz should do and to justify their decision.

Throughout the interview the interviewer encourages the subject to respond freely and asks probing questions to elicit further decisions and explanations all of which are 
recorded for later scoring. For example, after being told the Heinz dilemma story, he subject will be asked: ' What if Heinz does not love his wife? Should he steal the drug for her? Why or why not?'. It is assumed that the changes made to the original dilemma by these questions directly challenge the interviewee to reflect and to justify further their moral decisions. The interviewer may also ask for clarification on certain points made by the interviewee. In this, way the interviewer builds up a picture of the interviewee's moral reasoning.

An interview can last from half an hour to two hours depending on the interviewee's vagueness, the interviewer's persistence or a combination of these factors.

Scoring of the MJI is based not on the respondent's specific decisions for each of the moral dilemmas (e.g 'Heinz should steal the drug') but on the reasoning given to support that decision (e.g. 'Because Heinz loves his wife'). Scoring involves assigning a moral reasoning stage to each of a respondent's responses. The stages assigned to each of the responses go towards calculating the total moral reasoning score. The total score is given in two ways: the first provides a measure of the maturity of moral reasoning, the Moral Maturity Score; the second is the Global Stage Score which provides an overall stage at which an individual reasons morally, this can be either a 'pure' stage (i.e. stages 1 to 6) or it may be a transitional stage (i.e. one between two pure stages). Each of these scores can be used for different research purposes. Training to conduct an interview and score the responses usually involves a great deal of practice and expertise which is acquired through the participation in an intensive workshop given by the Kohlberg research group. Because of the open ended nature of the interview it also becomes a very time consuming procedure, both to administer and to score. 


\section{Evidence for and Critique of Kohlberg's Theory}

Since its conception in 1958 , Kohlberg's work has been incorporated into mainstream psychology and moral development has become a major theoretical and research area (Brown and Herrnstein, 1975). The theory itself has received a combination of positive research support (e.g. Rest, 1980; Colby et al., 1983; Colby, 1978) and substantial critique (e.g. Gilligan, 1982; Kurtines and Greif; 1974; Levine, 1979).

The criticisms of the theory vary from methodological problems with the measuring instrument (Kurtines and Greif, 1974), to theoretical debate on the nature of the individualism inherent in the theory [see Gibbs and Schnell, (1985) for a brief review].

Overall, however the most impressive empirical evidence for the theory comes from the 20 year longitudinal study by Colby et al. (1983) which strongly supports the properties of the stages and other general assertions of the theory. In addition, the recent publication of a scoring manual for the MJI (Colby et al., 1987) which details norms, validity and reliability scores for the MJI, finally lays to rest many of the criticisms to the theory which are couched in the vagueness of the measuring instrument (again see Kurtines and Greif, 1974).

\section{Other Measures of Moral Reasoning}

As was noted above, the manual for the MJI has finally been published and has been found to constitute a highly acceptable research instrument which demonstrates high test-retest, parallel form and interrater reliability (Colby et al. 1987; Gibbs, Widaman and Colby, 1982). It also satisfies the concept of a stage structure inherent in Kohlberg's theory, as well as meeting many of the predictions.

Nonetheless, the MJI still requires a considerable amount of time, effort and money for its effective use. As was noted earlier, training to conduct the interviewing and the scoring is very intense and must be administered in a workshop format by experienced 
trainers. The insistence on this intensive training has led certain critics of Kohlberg's theory to state that it discourages independent research and hence the development and scrutiny of the theory's finer points (e.g., Kurtines and Greif, 1974).

Partially because of these limitations, certain researchers have attempted to develop tests of moral judgement which do not make these demands on both researchers and participants. These tests are all based on either recognition or evaluation of moral arguments (Bloom, 1977; Enright, Franklin and Manheim, 1980; Gibbs and Widaman, 1982; Gibbs, Widaman and Colby, 1982; Hogan, 1970; Hogan and Dickstein, 1972; Maitland and Goldman, 1974; Page and Bode, 1980; Rest, 1979; Rest et al. 1974; Taylor, 1978). However, most of these tests have received minimal attention in the literature and hence have not been validated; there are two exceptions, namely the Defining Issues Test (DIT; Rest, 1979) and the Sociomoral Reflection Measure (SRM; Gibbs and Widaman, 1982).

The DIT is a multiple choice questionnaire made up of six moral dilemma stories each followed by twelve statements. One of the dilemmas is the Heinz and the drug story described above, followed by statements which concern the dilemma. For example, one of the item states: 'whether the laws of a community are going to be upheld' another asks: 'Isn't it only natural for a loving husband to take so much care of his wife that he'd steal?'. The respondent's task is to decide on the importance of each of the statements and rank the items in terms of which are the most important in making a decision. Each of the item statements is classified as belonging to one particular moral stage. It is assumed that those respondents who assign a high rank to high stage items are at a more mature stage of moral reasoning than those subjects who rank highly lower stage items.

The DIT has been used in over 500 studies and a great deal of standardization of the test has taken place. It has been shown to have a relatively high test-retest reliability and a high internal consistency. The test has also demonstrated a change from low to high 
moral reasoning stage of the same individuals over time, and some validity has been provided by showing that groups of individuals who would be predicted to have different scores do in fact score differently. In addition, it has been found that DIT scores have higher correlations with theoretically similar variables such as cognitive development, than with dissimilar variables such as personality (Martin, Shafto and Van Deinse, 1977; Moon, 1986; Rest, 1979; Rest, 1986).

Recognition tests like the DIT offer some distinct advantages over the MJI, since they can be group administered and scored by computer so that individual interviews and intensive training are not necessary. However, these tests cannot be an adequate substitute for the spontaneous response production of the MJ. Furthermore, the low correlations between the DIT and the MJI for age controlled samples (Davison and Robbins, 1978; McGolgan, 1975) lead to the conclusion, as Rest et al. (1974) noted, that the tests cannot be regarded as equivalent. In fact the DIT was not constructed as an alternative to the MJI, since both tests actually start out from a slightly different theoretical standpoint (Rest, 1975). The DIT measures the evaluation of moral arguments, while the MJ measures the reasoning behind moral arguments.

Faced with the finding that the DIT could not be seen as an alternative to the MI, Gibbs, Widaman and Colby (1982) embarked upon the creation and validation of a group administrable, self-taught scoring test equivalent to the MJI, which also kept the spontaneous production element of the MJI. This test is known as the Sociomoral Reflection Measure (SRM).

Gibbs et al. used the term 'Sociomoral Reflection' rather than Moral Judgement for several reasons. 'Sociomoral' rather than 'moral' is used to denote the Kohlbergian emphasis on 'social interaction as the context for defining that which is morally right' (Gibbs, Widaman and Colby, 1982, p. 897); and 'reflection' is used to indicate that the 'judgement' studied 'pertains to the thoughtful consideration of reasons for certain 
decisions and values' (p. 897). In essence the term 'Sociomoral Reflection' was coined to encompass specifically the moral judgement assessed by the MJI and the SRM.

The SRM is a pen and paper questionnaire which consists of two moral dilemma stories (e.g, Heinz and the drug). Respondents are either read aloud these stories or read them themselves, and asked to indicated what the protagonist should or should not do (e.g. steal or not steal the drug), and to provide reasons for their decision. Following each of these stories are standard probing questions which tap a particular moral issue (e.g., How important is it for a husband to steal to save his wife? and why?). In total, eight moral issues - affiliation, life, law and property, legal justice, conscience, family affiliation contract and property - are tapped by the questions following the dilemmas. Typically, an SRM testing session can last from 45 minutes to slightly over an hour, but can, of course, be administered to fairly large groups. The written or taped responses to these various probing questions (which are the same for all respondents) are later scored by reference to the manual. The scoring involves matching criterion responses in the manual to those given by the respondent. Proficiency in scoring can be achieved by studying the manual and by practising with the examples provided.

The main difference between the SRM and the MJI is that the SRM classifies numerically only the first four of Kohlberg's stages, whereas the MJI classifies five. In the SRM stage five is not assigned a numerical value but is described as the 'theoretical principles' orientation of moral development. The authors of the SRM disagree with Kohlberg that the higher stages of moral judgement can be spontaneously produced without exposure to complex philosophical issues and they go on to note that only a small percentage (less than 10\%) of individuals in Kohlberg's own studies achieved stage five of moral reasoning (Kohlberg, 1981).

Gibbs, Widaman, and Colby (1982) conducted extensive validation procedures on the SRM. They found an acceptable degree of interrater reliability (from $r=0.63$ to 0.98 ) 
even when the raters were self-taught by using the instructions in the scoring manual.

They also found the test-retest and parallel form of the test reliability to be high ( $r=0.87$ or greater). A high degree of internal consistency was also obtained ( $r=0.85$ to 0.96 ).

Overall the SRM was found to have good concurrent validity with the MJI. When age was partialled out the correlation between the two tests was $r=0.50$ which is significant at the 0.001 level. The SRM also had good construct validity since it was able to distinguish between young and older subjects effectively, and socio-economic status was found to correlate positively with the results of the SRM. Both these findings are predicted by the theory and therefore confirm the validity of the SRM.

Gibbs, Widaman and Colby (1982) concluded that the SRM is psychometrically robust so as to constitute a valuable contribution to the assessment of moral judgement. They do point out, however that the SRM is neither a substitute for the richness and depth of the MJI nor the strict objectivity of the DIT. The SRM does offer an alternative that in certain circumstances will be most useful since it has certain advantages over the other methods and thus it should facilitate research into the development of moral judgement.

More recently, further reliability and validity for the SRM were provided by Nilsson et al. (1989) in a cross-cultural study conducted in Sweden. This study concluded that while the reliability and validity measures for the SRM were of a lower magnitude for the Swedish sample than the original American sample reported by Gibbs, Widaman and Colby (1982), the scores for validity and reliability were nonetheless highly acceptable.

\section{Moral Judgement and Criminal Conduct}

Kohlberg's theory of moral judgement has been applied to many behaviours which could be described as 'moral'. Perhaps the most influential and controversial of these was the application of the theory to criminal or delinquent behaviour (Jurkovic, 1976;

Kohlberg, 1958). 
Since moral reasoning theory rests on justifications for moral reasoning and hence moral behaviour, it follows that the circumstances under which an individual will justify breaking the law depends on the moral stage of that individual. At stage one law breaking is seen as morally plausible if the law breaker does not get punished; at stage two it is plausible if the gains outweigh the risks; at stage three law breaking is plausible if it helps to maintain relationships; at stage four law-breaking is seen as morally correct if it helps to sustain society or is sanctioned by social institutions; at stage five law breaking is possible if it helps to maintain basic human rights or if it furthers social justice. It becomes apparent that the circumstances under which law breaking would be regarded as morally plausible are more frequent at the lower stages than at the higher stages. The theory therefore predicts that those who offend will be at a lower stage of moral reasoning than those who do not offend.

\section{Evidence from Previous Studies}

The main way of testing this hypothesis is to compare the moral reasoning of offenders with that of non-offenders. A body of experimental evidence has built up which in general suggests that offenders reason at lower levels than non-offenders (see reviews in Blasi, 1980; Jennings, Kilkenny, and Kohlberg, 1983; Jurkovic, 1980; Nelson, Smith and Dodd, 1990; Thornton, 1987). However, certain differences between the studies influence the kind of results obtained.

In a recent review Thornton (1987) divided studies into four groups depending on how delinquency had been defined. The first group included the majority of studies that had used an official measure of delinquency: that is, they compared the moral judgement of individuals who had been convicted and incarcerated for their offending with that of individuals not convicted for a criminal offence. These studies generally show that 
delinquents reason at lower stages of moral reasoning than matched non-delinquents (e.g. Jennings et al., 1983).

Thornton's second group consisted of those studies that used self-reported measures of delinquency: in other words, participants were given a list of delinquent acts, were asked whether they had engaged in any of them, and were then classified according to the number which admitted. These studies generally found very little relationship between self-reported delinquency and moral judgement stages (Emler et al., 1978; Lanza-Kaduce et al., 1983; Renwick and Emler, 1984; Tsujimoto and Nardi, 1978).

The third group used behavioural ratings of participants as their index of delinquency: for instance teachers might be asked to identify those pupils who were badly behaved. Thornton reported two studies which showed that more advanced moral reasoning is related to better conduct ratings (Marston, 1978; McColgan, 1975).

The fourth group of studies used some form of behavioural measure. These studies typically involve an experimental situation which tempts participants to engage in acts of minor delinquency; they are then classified in terms of the number of times they succumb to temptation. The majority of studies in this category show that advanced moral reasoning is associated with less cheating on the behavioural tests (Krebs, 1967; Leming, 1978; Malinowski, 1978; Schwartz et al., 1969). Thornton concluded that the way in which delinquency is classified influences the results obtained from a given study.

Perhaps the most influential review of moral reasoning and delinquency was conducted by Blasi (1980). This review included 15 studies that investigated the relationship between moral reasoning and delinquency. Blasi noted four problems which were associated with the studies in this area.

Firstly, all the studies assumed a degree of congruity between the moral reasoning and moral behaviour of delinquents as is assumed to exist for non-delinquents. However, there is a possibility that at least some delinquents may be characterised by inconsistency 
rather than consistency, and thus there would be a breakdown of the mechanisms which mediate between thought and behaviour. Hence, especially in delinquents, there may not be a direct relation between moral thoughts and moral actions.

Secondly, he noted (like Thornton, 1987) that the definition of delinquency must affect the outcome of a study. While all the studies Blasi examined used official measures of delinquency, in other words convicted offenders, he suggested that these definitions were too broad and non-specific to be indicators of moral behaviour. He instead advocated the approach of Kantner (1976) who took account of types of offences carried out. In support of this notion he quoted from an unpublished study by Kohlberg and Freundlich (1977) who argued for and provided preliminary evidence that different types of offence could be related to different moral judgement stages. For instance drug offenders may show higher moral stages than other convicted inmates (Thornton and Reid, 1982). However, none of the studies quoted by Blasi used non-convicted indices of delinquency as reported by Thornton (1987).

Thirdly, Blasi (1980), pointed out that while most studies match the non-delinquent sample for variables which may be associated with moral judgement (e.g age, socioeconomic status, intelligence), few take account of possible delinquency present in the control samples. He argued that this is especially necessary the more closely delinquents and non-delinquents are matched on other measures.

Finally, Blasi (1980) also noted the variety of measures of moral reasoning used by different studies. While many used the Moral Judgement Interview (MJ) some used tests derived from this and a few used measures of their own. In addition to this, the complexity of the MJ (described earlier) and the fact that it has undergone many revisions meant that some studies used variations or different versions of the MJI. These problems led Blasi to suggest that there is little comparability across most studies. 
Overall, Blasi (1980) concluded that the findings from the literature do support the notion that moral judgement is associated with delinquent behaviour, although he had some reservations. Firstly, he noted that the association was most often found in studies which used the MJI and not found when other, objective, measures of moral reasoning were used. He did not offer an explanation for this phenomenon but did suggest that this finding be used in planning future research. Secondly, he noted that there is variability to the moral reasoning stage used by delinquents, although on average they tend to use pre-conventional reasoning. As a final statement Blasi pointed out that 'Moral reasoning is an important aspect of delinquency but does not offer alone the explanation of this aberrant behaviour' (p. 12).

The reservation regarding the measure of moral reasoning used is worth exploring further. As was noted in the above discussion of measures of moral judgement, a distinction is often made between production and evaluation measures of moral arguments (Gibbs, Widaman, and Colby, 1982; Rest, 1975). Evaluation measures of moral judgement, such as the Defining Issues Test (DIT), typically tend to be classified as 'objective' measures, while Kohlbergian theory relies on the production and explanation of moral arguments. While the production and evaluation of moral reasoning are no doubt related, they cannot be considered the same psychological phenomenon. Individuals will tend to accept moral arguments from stages that are above their own, and there is some evidence to suggest that delinquents also react differently to non-delinquents on measures of moral reasoning evaluation (Thornton, 1987).

With this point in mind, it should be noted that the MJI is a cumbersome test for research on delinquency, due to its length and complexity as discussed earlier. However, a suitable alternative to the MJI which can be considered less cumbersome and more 'objective', but which still retains a production element exists in the form of the Sociomoral Reasoning Measure (SRM; Gibbs and Widaman, 1982; Gibbs, Widaman and 
Colby, 1982). It follows, therefore, that a review of studies using the SRM to study the relationship between moral reasoning and delinquency would contribute to the present discussion.

Gibbs, Widaman and Colby (1982) included a delinquency study in their original validation of the SRM. They found that a convicted delinquent sample scored significantly lower on sociomoral reasoning maturity than a non-delinquent sample when age and socioeconomic status were taken into account. They also found that while the majority of nondelinquents were at either stage 3 or 4 of moral judgement, the delinquent sample were all at either stages 2 or 3 . Gibbs, Widaman and Colby used these findings to add to the construct validity of the SRM, since the theory predicted that differences in moral judgement should exist between delinquents and non-delinquents.

Gavaghan, Arnold and Gibbs (1983) studied Blasi's (1980) noted difference between production and recognition measures of moral reasoning. They used the SRM as the production measure of moral reasoning, and the Sociomoral Reflection Objective Measure (SROM: Gibbs, Arnold, Morgan et al., 1984), to measure recognition of moral reasoning. In an analysis which controlled for socio-economic status, age, and IQ, Gavaghan et al. (1983) found that delinquents could be distinguished from non-delinquents by the SRM but not by the SROM. They concluded that either delinquents are delayed in the production but not the recognition of moral reasoning; or alternatively delinquents are less verbally fluent than non-delinquents and therefore are at a disadvantage when completing the SRM. However, Gibbs, Arnold, Ahlborn et al. (1984) provided evidence to suggest that the SROM has little reliability when applied to delinquents.

Gibbs, Arnold, Ahlborn et al. (1984) found that the SRM consistently differentiated between convicted delinquents and non-delinquents, even after relevant variables (age, SES, IQ) were controlled for by covariance analysis. They also found that the SROM did not distinguish between these groups after relevant variables were controlled for. 
While the present review is not exhaustive, it does present the major studies carried out on delinquents' moral reasoning using the SRM. It seems that this instrument has been largely ignored in the delinquency literature although it has been used fairly extensively in other areas of moral judgement research. It could be argued that the SRM involves a high degree of verbal fluency to be competently completed, so that delinquents who tend to have low verbal fluency would obtain lower scores. However, the SRM has been used successfully in certain intervention techniques with delinquents, without recourse to verbal fluency training. In a study involving incarcerated delinquents, Gibbs, Arnold, Ahlborn et al. (1984) found that the SRM could discern an increase in the moral reasoning stage of delinquents who had participated in a short program designed to increase their level of moral reasoning. It seems unlikely that the programme used (involving eight sessions of peer discussions on moral issues) could have substantially increased the verbal fluency of the delinquents, and more likely that the programme increased awareness of moral issues. However, Gibbs, Arnold, Ahlborn et al. (1984) failed to use an adequate control group, so the issue of verbal fluency is not fully resolved and should be borne in mind in further research.

It is now worth returning to the general discussion of previous studies which have examined the relationship between moral reasoning and delinquency.

Nelson, Smith and Dodd (1990), conducted a meta-analysis of 15 studies which had specifically tested the hypothesis of moral reasoning immaturity in delinquents. They found strong support for the position that delinquents are more immature in their moral reasoning than non-delinquents. They also suggested that their results provided support for the argument that different methodologies do not influence the results of such studies. This is counter to the assertions of Blasi (1980) and Jurkovic (1980), who suggested that the many methodological differences and flaws within the empirical literature limit the amount of confidence which can be placed on the findings of individual studies. In 
conclusion, Nelson et al. (1990) noted the lack of investigation into other important issues concerning delinquency and moral reasoning. They advocated the investigation into types of offences (cf. Kantner, 1976, 1985), the effects of personality, behavioural and contextual variables (Gilligan, 1977), and use of longitudinal studies to investigate whether delinquents have arrested moral reasoning or are developmentally slower.

Hollin $(1989,1990)$ also noted that many studies have not accounted for behavioural and personality correlates of moral judgement, and that no account had been taken of type of offence. He also noted that research in the main focuses on the content rather than the process of moral development, assuming thereby that process is related to content and hence lower moral stage could be the cause of anti-social behaviour. However as Ross and Fabiano (1985) pointed out 'One can argue eloquently and convincingly about social/moral issues yet have a personal set of values which are entirely self-serving, hedonistic or anti-social' (p. 169). Hollin (1989) further cast doubt on the universality of the assumption that moral reasoning is related to moral behaviour by referring to studies which have shown that individuals are capable of behaving in ways which they know or believe to be wrong (Asch, 1952; Milgram, 1963).

Lee and Prentice (1988) investigated the issue of the effect of behavioural and personality variables [later mentioned both by Hollin (1989) and by Nelson, Smith and Dodd (1990)] on the moral reasoning of offenders. Lee and Prentice found that while delinquents had lower moral reasoning stages than non-delinquents (measured by a reduced version of the MJI, no differences in moral judgement were apparent between three delinquent subgroups (divided into psychopathic, neurotic and subcultural groups). They also found that moral reasoning was not affected by either empathy or social cognition. Obviously, further efforts are required to identify those personality and behavioural variables which are related to moral judgement. 
Thornton (1987) proposed three possible explanations for the relationship between moral reasoning and delinquent behaviour and in so doing identified some possible flaws with Kohlberg's theory. Firstly, Thornton noted that the moral reasoning of offenders may reflect the subculture they inhabit - i.e., the general delinquent subculture or the prison subculture - rather than their personal views. However, he also quoted some studies which seemed to refute this possibility in finding that delinquents involved in subcultures had similar moral reasoning to non-delinquents and those delinquents that integrated less with the prison subculture displayed the lowest moral reasoning stages (Jurkovic and Prentice, 1977; Thornton, 1981).

Secondly Thornton (1987) noted that the effect of coming from a single parent family, which is both common in delinquents and related to moral judgement development (Daum and Bieliauskas, 1983; Hoffman, 1971; Judd, 1980), has not been taken into account in most studies. This could constitute an explanation which has not been explored thus far.

Thirdly he discounted the possibility that delinquents could be regressing to an earlier moral reasoning stage in an effort to explain their delinquent behaviour. He discounted this possibility since some studies (e.g., Rholes et al., 1982) have been able to induce an advance in the stages of moral reasoning, but none have induced a regression to a lower stage of reasoning.

Overall, while the general position seems to be that delinquents do reason less maturely than non-delinquents, there are a number of criticisms which are applicable to most studies in this area. These can be summarised as: a) ignoring the heterogeneity of offender populations, in terms of offence type, personality, behavioural characteristics and so on; b) inadequate controls for delinquency in control groups; c) the variety and type of measures of moral reasoning used; and d) ignoring the possible effects of incarceration (i. e. the effect of the prison subculture on moral reasoning). In addition, it is still not clear 
what processes are involved in bridging the gap between moral thought and moral action, and whether these processes are the same in offenders and non-offenders.

The heterogeneity of offender populations is particularly important in view of the findings of several studies showing that differences in moral reasoning exist between males and females.

\section{Sex Differences in Moral Reasoning}

Several studies have investigated sex differences in relation to Kohlberg's theory of moral development in non-convicted and/or convicted populations. For example Holstein (1976), investigating non-offenders, found that males were at more advanced stages of moral reasoning than females. Holstein attributed this difference to females' greater use of stage three arguments because this stage appears to emphasise those traits which are seen as stereotypically female. This assertion was backed by Gilligan (1982) who said that 'The very traits that traditionally have defined the 'goodness' of women, their care for and sensitivity to the needs of others, are those that mark them as deficient in moral development' (p. 18). In essence, these authors are arguing that there is a sex bias favouring males in Kohlberg's moral stage theory. In contrast, Gibbs, Arnold and Burkhart (1984) suggested that, while women may be oriented to empathy and caring, this is not necessarily reflected in moral reasoning stage differences. Comprehensive reviews of the literature by Rest (1979) and Walker (1984) concluded that most studies do not show a sex difference in stage level of moral judgement. Similar findings were reported by Friedman, Robinson, and Friedman (1987).

DeWolfe, Jackson and Winterberger (1988) examined sex differences in moral reasoning in male and female convicted offenders. Using the SRM, they found that female offenders reasoned morally at a lower stage than male offenders. However, they noted that incarcerated female offenders are likely to be highly selected on several psychological and 
social factors (possibly more so than incarcerated male offenders) and therefore the results of this study cannot be generalised to non-convicted populations. This suggests that the male and female offenders used in this study were not adequately matched, and therefore the results cannot be regarded as valid.

The results of the studies presented within this section suggest that whilst there may be evidence for sex differences in moral reasoning amongst offenders, there is less evidence for such sex differences in non-convicted populations. 


\section{2 - EYSENCK'S THEORY OF CRIMINALITY}

A theory of criminality that has received a great deal of attention is that proposed by H. J. Eysenck $(1964 ; 1970 ; 1977)$ with summaries from H. J. Eysenck $(1987,1984)$ and H. J. Eysenck and Gudjonsson (1989). This theory attempts to link together genetic factors, a causal theory, and personality. Central to its theme is Eysenck's theory of

personality (H. J. Eysenck, 1959; H. J. Eysenck and S. B. G. Eysenck, 1968) and therefore it is worth summarising this theory before going on to discuss its application to criminality.

\section{Eysenck's System of Personality}

Eysenck proposed a trait theory of personality suggesting that personality could be described by three dimensions: Extraversion-Introversion (known as E), Neuroticismstability (known as N), and Psychoticism (P). Each of these dimensions is seen as a continuum with most individuals lying in the middle. The exact position of an individual on each of the scales is determined by an interaction between biological and social factors. A standard psychometric test, the Eysenck Personality Questionnaire (EPQ; H. J. Eysenck and S. B. G. Eysenck, 1975; S. B. G. Eysenck, H. J. Eysenck, and Barrett, 1985) which asks for yes/no responses to certain questions describing behaviours determined by $\mathrm{P}, \mathrm{E}$ or $\mathrm{N}$, is used to derive scores on each of the three dimensions. An individual's position on the dimensions can be plotted as shown for the $\mathrm{E}$ and $\mathrm{N}$ scales in figure 1. 
Figure 1 - Eysenck's Personality Dimension of Extraversion and Neuroticism (from Hollin, 1989)

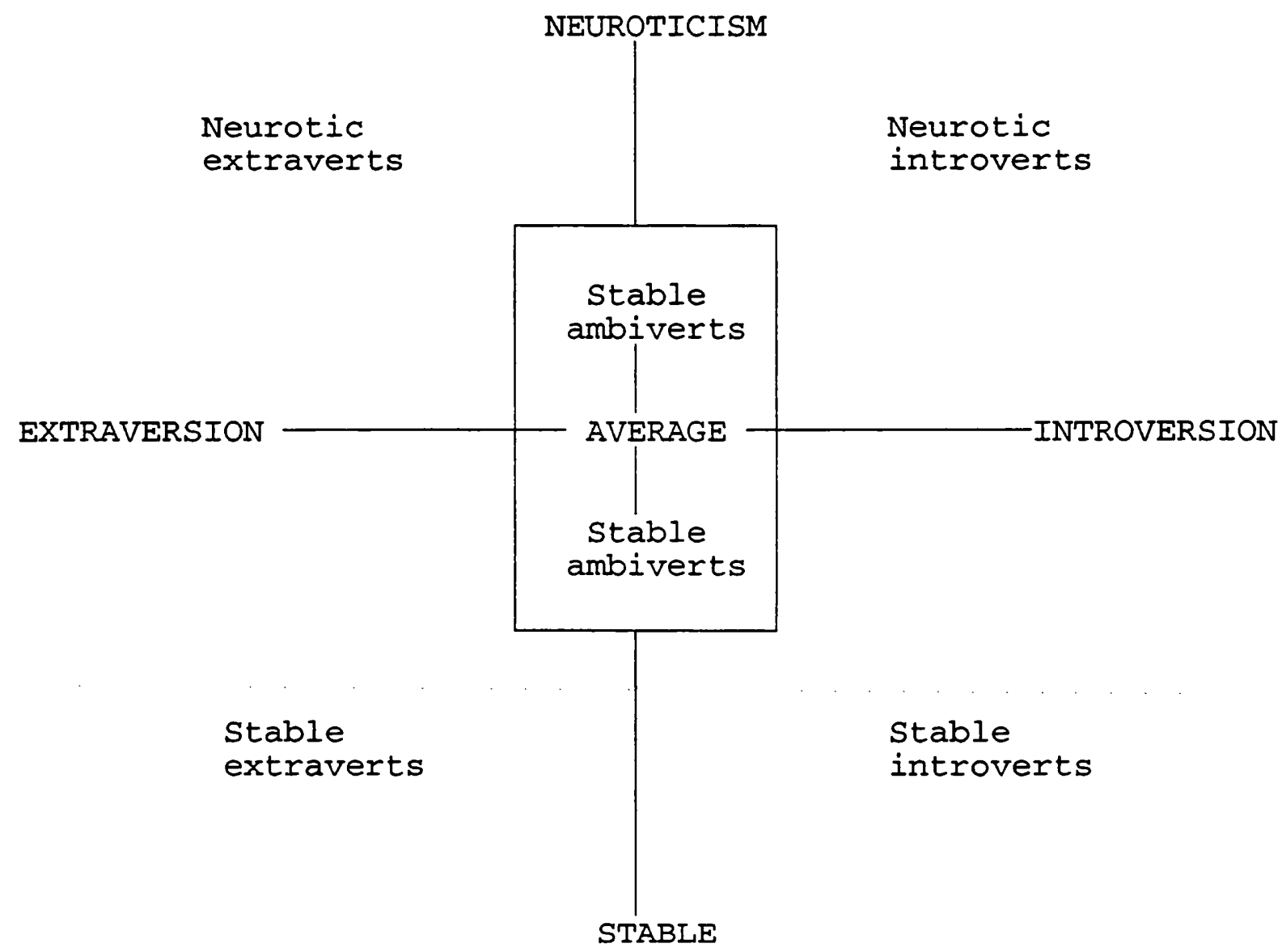

Extraversion (E) Scale - the extraversion scale runs from high (extravert) to low (introvert). The 'typical' extravert is sociable, lively, active, assertive, sensation-seeking, care-free, dominant, surgent and venturesome. The 'typical' introvert shows the opposite set of characteristics.

Neuroticism Scale (N) - this scale also runs from high (neurotic) to low (stable). The 'typical' high neurotic is anxious, depressed, tense, irrational, shy, moody, emotional and has guilt feelings and low self-esteem. The low $\mathrm{N}$ scorer shows the opposite set of these characteristics. 
Psychoticism Scale (P) - similarly, this scale runs from high (psychotic) to low (normal).

The 'typical psychotic is aggressive, cold, egocentric, impersonal; impulsive, antisocial, unempathic, creative, and tough-minded. The low P scorer will show the opposite to these characteristics.

The above descriptions represent idealised extremes of each of the personality dimensions and the majority of individuals will exhibit traits which represent scores somewhere in the middle of each of the dimensions.

In addition, the EPQ also measures to what extent a respondent answers the questions according to social desirability. This is known as the Lie scale (L), which in essence is a measure of social desirability bias in the responses to the questionnaire, and distinguishes between those responding honestly and those faking 'good' responses.

The trait system employed by Eysenck in describing the personality theory, advocates an interaction between traits, as dispositional characteristics, and environmental situations relevant to response styles following these dispositions $(\mathrm{H}$. J. Eysenck and Gudjonsson, 1989).

There are several characteristics of the personality dimensions for which $\mathrm{H}$. J. Eysenck cites evidence. Firstly, he suggests that these dimensions are of primary importance in determining temperament and all three dimensions appear in several other measures of personality (H. J. Eysenck and M. W. Eysenck, 1985; Royce and Powell, 1983). Secondly, he suggests that the three dimensions of personality are universal as far as different national, racial, and cultural groups are concerned, based on cross-cultural and cross-national studies (H. J. Eysenck and S. B. G. Eysenck, 1983; Barrett and S. B. G. Eysenck, 1984). Thirdly, there is evidence to support the assumption that individuals' scores on the dimensions remain consistent over time (Conley, 1984; 1985). Fourthly, a biological/genetic underpinning is posited for the three personality dimensions. Studies by H. J. Eysenck $(1981,1982)$ and H. J. Eysenck and M. W. Eysenck (1985) suggest that 
over $50 \%$ of the variance for $\mathrm{P}, \mathrm{E}$ and $\mathrm{N}$ is genetic in nature. Following on from this, there is evidence to support the notion that there are strong biological/genetic determinants of the behaviours associated with each dimension $(\mathrm{H}$. J. Eysenck and M. W. Eysenck, 1985). More details of this aspect of the theory are discussed later.

Finally, the implication of the theory that certain personality scores should be associated with certain behaviours, such as sexual behaviour, clinical neurosis, and criminality has also received considerable support (H. J. Eysenck, 1973; 1976; 1977).

\section{Personality and Crime}

H. J. Eysenck's personality theory is applied to criminality via a suggested explanation for socialization. H. J. Eysenck (1977) suggests that socialised behaviour ('conscience' or 'morality') is essentially mediated by Pavlovian or classical conditioning. Anti-social behaviour, he states, is controlled and reduced in an individual's behaviour set through conditioning. Parents and educators will provide punishment for anti-social behaviours performed by a child, hence anti-social behaviour will become associated with punishment and so will not be engaged in by the child.

Two possible explanations for the child not obtaining adequate socialization are suggested by the theory. Firstly, the child may not receive adequate conditioning against anti-social behaviour, or may even receive reinforcement for anti-social behaviour from the parents. Secondly, individuals may differ in their susceptibility to the process of classical conditioning.

It is to this last point that Eysenck's theory directs itself. The suggestion is made that personality will effect the degree to which individuals can be successfully conditioned and hence socialised.

The extraversion scale is posited to be related to cortical arousal. Extraverts are under-aroused thus their behaviour is directed towards increasing this arousal to an optimal 
level. Introverts are over-aroused and hence behave in ways which reduce this arousal. Extraverts are held to condition less easily and effectively since environmental punishment will not have a strong impact, hence poor socialisation with regard to the control of antisocial behaviour will result. On the other hand introverts will condition extremely well for exactly the opposite reasons.

Neurotics are characterised by labile autonomic nervous systems which react very strongly to painful or unpleasant stimuli. High $\mathbf{N}$ individuals are anxious and moody while low $\mathrm{N}$ individuals are calm and even tempered even under stress. The high anxiety of neurotics is said to interfere with the process of conditioning. Therefore high $\mathrm{N}$ will be associated with higher levels of anti-social behaviour since it produces the least effective conditioning; conversely, low $\mathrm{N}$ will be conducive to effective conditioning.

It can be seen, therefore, that the High E-High $\mathrm{N}$ personality combination (neurotic extraverts) will lead to the poorest levels of conditioning. Such individuals are least likely to be adequately socialised and thus it is argued will be over-represented in criminal populations. The reverse is true for the Low E-Low N combination (Stable introverts) which will be highly socialised and thus under-represented in criminal populations. The personality combinations of Low E-High $\mathrm{N}$ (neurotic introverts) and High E-Low N (stable extraverts) will lie somewhere in the middle of a conditionability continuum. The proportion of individuals with the latter two personality combinations should be found in equal amounts in offender and non-offender populations.

The contribution of $\mathrm{P}$ to personality, conditioning and its biological nature has been less well described. It is posited to be related to clinical psychoses such as schizophrenia which is assumed to have a genetic component. While the $\mathrm{P}$ dimension is wider ranging than clinical psychoses, in essence it can be seen as a measure of an individual's genetic predisposition for clinical psychosis. Two factors link high $\mathrm{P}$ scoring to criminal conduct: the fact that there appears to be considerable excess of psychopathy and criminality in the 
biological relatives of schizophrenic individuals (H. J. Eysenck and S. B. G. Eysenck, 1976); and the over-representation of clinically psychotic individuals in offender populations (H. J. Eysenck and S. B. G. Eysenck, 1976). In addition, as was described above, High P scorers are characterised by traits which suggest anti-social behaviour and attitudes. Thus, it is argued that High P scorers will also be over-represented in delinquent populations especially in those offenders who have engaged in anti-social crimes.

In total, the High P-High E-High N personality combination is predicted to be overrepresented in criminal populations, particularly those which involve anti-social crimes. It is also predicted that High P-High $\mathrm{E}$ individuals also tend to engage in more risk taking, sensation seeking and impulsive behaviour in an effort to raise their arousal levels to an optimum level. While it is true that these arousing behaviours can be anti-social they may also take other forms, such as engaging in sporting activities.

It should be noted that $\mathrm{H}$. J. Eysenck only directs his theory to crimes which are anti-social in nature, and he does recognise other motivations for crime such as politics, impulses, crimes committed by those which are intellectually disadvantaged and so on. $\mathrm{H}$. J. Eysenck (1987) also notes that there are difficulties in relating 'anti-social' behaviour to other definitions of delinquency, like official conviction.

\section{Research Findings}

Partially because the theory has some controversial elements (such as its reliance on classical conditioning), and partially because it provides many testable hypotheses, a great deal of empirical research has been carried out on the theory since its inception.

Early studies which attempted to study the relationship between personality and crime were summarised by Passingham (1972). The general outcome of these studies was mixed, while the some agreed with the hypothesis, others did not and overall the support was not strong. H. J. Eysenck and Gudjonsson (1989) dismissed this early research as the 
studies were beset with methodological problems such as small sample sizes, employing incorrect measuring instruments, and not testing the theory directly.

H. J. Eysenck and Gudjonsson (1989) confine their review to more recent studies which used appropriate measuring instruments and directly tested the hypothesis that offenders would score higher on the dimensions of $\mathrm{P}, \mathrm{E}$ and $\mathrm{N}$ than non-offenders. The basic format of many of these later studies took the form of comparing the personalities of a delinquent group (usually convicted and incarcerated) and a non-delinquent group (not convicted) matched for age, socio-economic status and intelligence. A particularly impressive study reported by H. J. Eysenck (1977) involved the comparison of 1,870 male prisoners to 1,987 male controls. The results showed that prisoners were significantly higher on $\mathrm{P}, \mathrm{E}$ and $\mathrm{N}$ than the controls as would be predicted by the theory.

However, other studies have not provided such overwhelming support for the theory and the general position is still equivocal. There are various reviews available but the overall position suggests that there is unanimous support for the contention that offenders will score higher on $\mathrm{P}$, and most studies show that offender samples score higher on $\mathrm{N}$ (Bartol, 1980; H. J. Eysenck, 1977; H. J. Eysenck, 1987; H. J. Eysenck and Gudjonsson, 1989; Feldman, 1977; Powell, 1977). The evidence for E, however, is mixed, some studies show that $E$ is higher in offender groups while others show no relationship or that $E$ is actually lower in offenders (Hollin, 1989). The pattern is similar for both young offenders and adult offenders, although there is some suggestions that the scales are differentially important at different ages (H. J. Eysenck and Gudjonsson, 1989).

This broad position, however, cannot constitute a definitive answer to $\mathrm{H}$. J. Eysenck's theory because, as many authors have pointed out (Hollin, 1989; H. J. Eysenck and Gudjonsson, 1989), there are several methodological points which have been ignored in the majority of these studies. Firstly no account of the heterogeneity of offenders has been taken; secondly the possible effects of incarceration on the personality scores of 
offenders has been largely ignored and thirdly few studies have controlled for delinquency or anti-social behaviour in control groups.

Studies which deal with the subject of the possible effects of incarceration of offenders have used self-reported measures of offending or anti-social behaviour on nonconvicted groups of individuals (see chapter 1.4 for more details). These are lists of criminal or anti-social acts and respondents are asked to indicate how many of them they have committed. Thus the experimental design involves either correlating personality scores for each of the three scales or dividing up the self-reported scores into high and low and looking at the differences in personality scores between these two groups. In the process these approaches have made mute the point regarding delinquency in control groups since no official measures, based on conviction, are used to define anti-social or delinquent behaviour.

Studies which have looked at the effect of the heterogeneity of criminal groups have taken two approaches. Firstly many studies have looked at the variety of offences committed by offender populations, since not all offending involves anti-social behaviour, and different types of offences are predicted to be associated with different personality combinations. Secondly, many researchers (e.g. McGurk and McDougall, 1981) have noted that the hypothesis requires a combination of High P, High $\mathrm{E}$ and High $\mathrm{N}$ to predict anti-social behaviour, since it is the interaction of the various scales which is the essence of the theory. Thus studying the scales separately would not necessarily produce support for the theory. 


\section{Self-Reported Delinquency Studies}

Self-reported delinquency studies have been undertaken in an effort to define delinquency in ways other than those related to official conviction and incarceration. One of the problems associated with this definition is that there is evidence to suggest that the process of imprisonment itself can lead to changes in personality characteristics typically involving an increase in neuroticism and a decrease in extraversion (McCue, Booth and Root, 1976). This change can be attributed to both the pressures placed on individuals through incarceration as well as to the inapplicability of social items of the measuring instrument (EPQ in most studies) while imprisoned (e.g. 'Can you easily get some life into a rather dull party?'). Secondly, official measures of offending via conviction go through many selection processes (actually being caught, the police deciding to press for conviction, trial processes and so on) and it is believed that the majority of crimes are undetected (Hood and Sparkes, 1970). Self-reported questionnaires where a list of offences are presented to individuals and they are asked to report how many they have engaged in, are intended to provide a truer picture of offence history in non-delinquents (i.e., those which haven't been convicted). In addition if used on delinquent samples these questionnaires also provide a truer picture of convicted individuals' offence history.

Furnham and Thompson (1991) provide a brief review of studies which have tested H. J. Eysenck's theory using self-reported delinquency (SRD) measures. Some of these (e.g. Allsop and Feldman, 1976; Jamison, 1980, Silva et al. 1987) show support for the theory, in that either high SRD scorers scored higher on $\mathrm{P}, \mathrm{E}$, and $\mathrm{N}$ than low scorers or the three scales correlated significantly and positively with SRD scores.

However, some studies do not provide support for the theory. Furnham (1984) found that high SRD scorers had high P and E scores but found a negative correlation between N and SRD. Similarly, Rushton and Chrisjohn (1981) found that only P and E correlated positively with SRD, but not N. Powell (1977) found that P correlated with 
SRD but that significant correlations were only found with $\mathrm{E}$ and $\mathrm{N}$ within certain age groups. Furnham and Thompson (1991) found that while there was a significant positive correlation between $\mathrm{P}$ and SRD, statistical significance was not achieved for the correlations between $\mathrm{E}$ and $\mathrm{N}$.

Again, the results using SRD measurements are equivocal and no clear picture is found. The only clear finding seems to be that high $\mathrm{P}$ is a strong predictor of high SRD scores. This finding hardly seems surprising as many of the items of the EPQ which measure P refer to delinquency itself. As Furnham and Thompson (1991) state 'It seems almost tautological to say that psychoticism is linked to criminality because the measurement of the former includes items that look very much like the latter.' (p. 586). The position regarding $\mathrm{E}$ is less firm, and that of $\mathrm{N}$ is, in some cases, actually the opposite to that predicted (i.e. low $\mathrm{N}$ associated with high $\mathrm{SRD}$ scores).

Many of these discrepancies can, probably be attributed to the SRD scales used by the studies. Many of the studies did not use scales which directly tested illegality; while some focused on immoral and antisocial acts. The psychometric properties of some of the SRD scales used have not been adequately established. In addition, there are strong arguments against popularly used scales such as those developed by Gibson (1967) and Shapland et al. (1975). A more thorough discussion of self-reported delinquency measures is included in chapter 1.4 , but it is sufficient to note at this point that the way SRD is measured can have a strong effect on the results obtained.

\section{Heterogeneity Studies}

As was noted earlier,the heterogeneity of criminal populations has been accounted for either by studying the three personality scales in combination or by investigating types of offences. 
Studies which have attempted to take account the heterogeneity of personalities in offender samples were reviewed by Gibbons (1975), who concluded that the majority of these had not been completely successful. Allsopp and Feldman $(1975,1976)$ found some support for the contention that $\mathrm{P}, \mathrm{E}$, and $\mathrm{N}$ in combination could be related to offending. Perhaps the most promising approach to studying these is through the application of factorial and clustering statistical techniques. The strongest evidence from the clustering studies comes from McGurk and McDougall (1981) who conducted a cluster analysis of the personalities on 100 convicted delinquents and 100 non-delinquent college pupils. They found four personality clusters in each group: both delinquent and non-delinquent groups contained Low E-High $\mathrm{N}$ and High E-Low $\mathrm{N}$ types, but the clusters predicted to be related to offending (High E-High $\mathrm{N}$ and High P-High E-High $\mathrm{N}$ ), were only found in the delinquent sample. The Low E-Low $\mathrm{N}$ combination that the theory predicts would be absent from offender populations was indeed only found in the non-delinquent students. McEwan (1983) attempted to replicate these results in a different delinquent group but used no control group. He also found four clusters, but using a more rigorous definition of 'high' and 'low' he obtained rather different clusters to McGurk and McDougall. While the nature of some of the clusters were in line with H. J. Eysenck's theory the critical High P-High E-High $\mathrm{N}$ cluster was not found. Another study by McKewan and Knowles (1984) again found four clusters in the personalities of a delinquent sample group, these clusters were different again, but this time found a High P-High E-High $\mathrm{N}$ cluster. Table 1.2(1) shows a summary the clusters found in these cluster analysis studies. 
Table 1.2(1) - Summary of Cluster studies of Eysenck's Theory

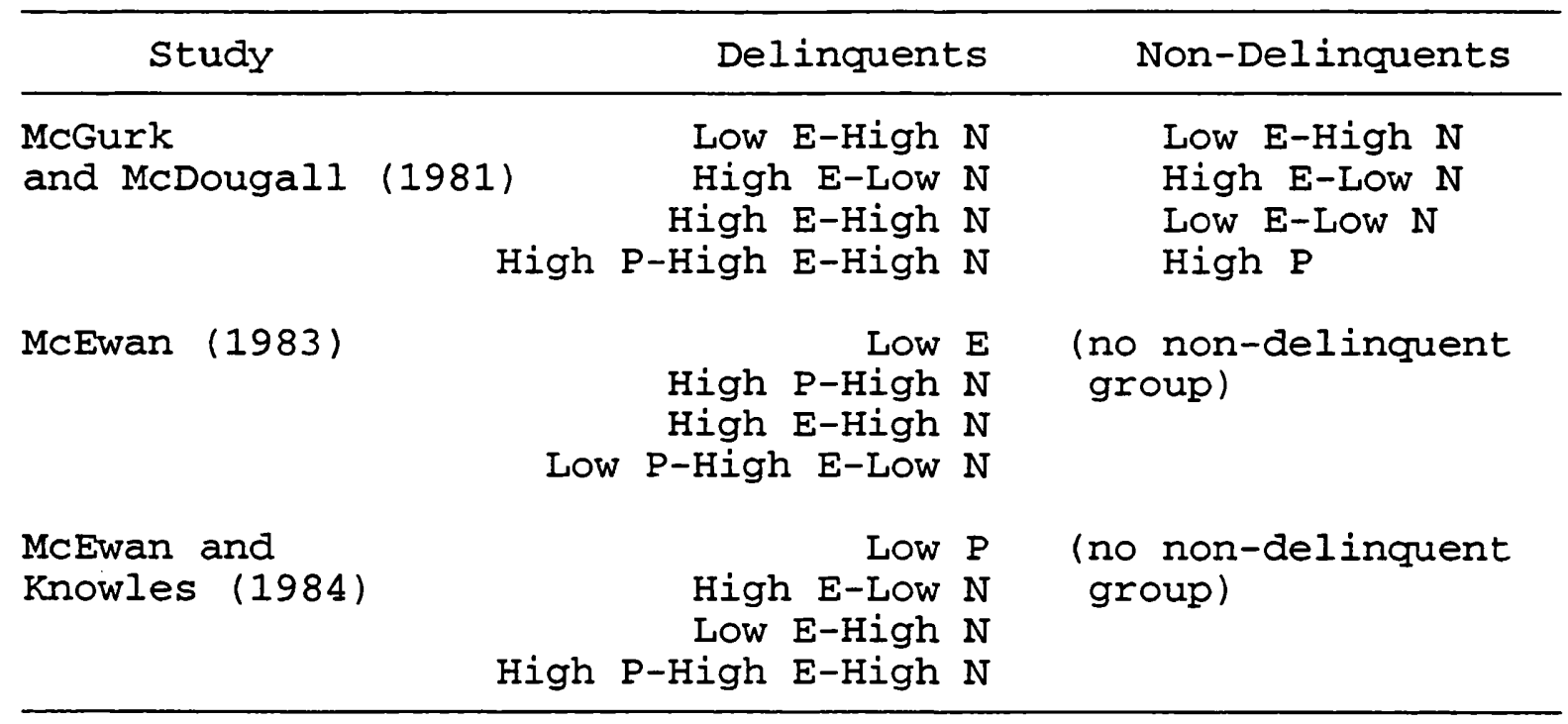

(from Hollin, 1989)

These 'cluster studies' suggest that clustering may be a viable technique for studying H. J. Eysenck's predictions, but as H. J. Eysenck and Gudjonsson (1989) point out some of the clusters found using this technique do not support the predictions made.

Sinclair and Chapman (1973) carried out a factor analysis on prisoners' personalities and found two major factors. The first seemed to represent the dimension of working-class criminality, where a high scorer would be categorised by low intelligence, lower age, and given to drink, violence and offending with peers. This type of criminal would fit with the theory's predictions. The second factor seemed to depict the socially inadequate individual which would tend to be older, neurotic, introverted, with a psychiatric history and poor contact with his wife and family. This individual would offend impulsively or sometimes violently while drunk.

H. J. Eysenck and Gudjonsson (1989) point out that the inadequate type of individuals may make up a large proportion of prison inmates and that these would not fit in with H. J. Eysenck's theory. The differentiation between the active and the inadequate offender is one that should be borne in mind in future studies. 


\section{Studies of Offence Type}

With regard to the relation between type of offence and personality, many studies have examined the prediction that different crimes are related to different personality scoring patterns. S. B. G. Eysenck, Rust, and H. J. Eysenck (1977) studied five separate groups of offenders: conmen, criminals against property, violent criminals, inadequate criminals, and a group not specialising in one type of crime. They found different patterns of $\mathrm{P}, \mathrm{E}$, and $\mathrm{N}$ for these groups, with conmen having a lower $\mathrm{P}$ score than the rest of the groups. The inadequate criminal described above had high $\mathrm{P}$, high $\mathrm{N}$ and low $\mathrm{E}$ while the classic high $\mathrm{P}$, high $\mathrm{E}$, high $\mathrm{N}$ type was found in the group not specialising in any particular type of crime. Mitchell et al. (1980) found that violent delinquent behaviour was more frequently associated with low trait anxiety than non-violent behaviour. Schwenkmezger (1983) found that conmen had much lower values on measures of impulsivity, risk-taking, dominance and excitement than either offenders against property or violent offenders. Both these studies generally support the findings of S. B. G. Eysenck, Rust, and H. J. Eysenck (1977).

Many studies described by H. J. Eysenck (1977) showed that murderers tend to be introverted, while professional gunmen are extremely extraverted, thus showing that even a single offence category may require further sub-division in order to understand the theory correctly. Rahman and Hussain (1984) studied female prisoners in Bangladesh and also found that murderers tended to be introverted while other categories of offenders (those involved in prostitution, fraud, kidnapping, and possession of illegal firearms) tended to have high E scores. In general Rahman and Hussain found that female offenders had much higher $\mathrm{P}$ and $\mathrm{N}$ scores than controls. McEwan (1983) found that offenders with high P scores were more likely to have preconvictions than the other cluster groups.

In contrast, Hidelang et al. (1981) found little support for the theory since they identified high $\mathrm{E}$ and high $\mathrm{N}$ pattern in individuals engaging in general delinquency but not 
in those associated with major theft and aggression. McEwan and Knowles (1984) also failed to show any significant variation in offence type across their four clusters.

Yet again, the results do not provide clear evidence for the theory although many of these studies could be criticised for the same reasons as those relating to the general studies mentioned earlier. In addition, those studies which have studied heterogeneity have ignored other aspects of delinquents which also vary within a criminal population (such as socio-cognitive processes, contextual effects and so on) which may interact with personality to result in delinquent behaviour. In other words, the heterogeneity of offenders is not confined to personality or to offence type.

In summary, the findings of studies of H. J. Eysenck's theory of criminality have provided some general support. However, many of the studies carried out have criticisms in common. Firstly, most studies have ignored the heterogeneity of offenders (in terms of personality, offence type and other individual differences); secondly, many studies have also not accounted for delinquency in non-incarcerated control groups; and thirdly, the possible effects of incarceration have not been introduced into research designs.

\section{Personality, Moral Judgement and Criminal Behaviour}

It has now been established that two of the major theories on the causes of delinquent behaviour (H. J. Eysenck's criminal personality theory, 1977; and Kohlberg's moral reasoning theory, 1976) have both received a degree of support but none of it unanimous. Both the theories have also been criticised on a variety of methodological and theoretical grounds. It is worth noting that the criticisms of both these research areas are remarkably similar. Both types of studies have been criticised for ignoring heterogeneity, incarceration effects and delinquency in control groups. There are two possible explanations for the results found in support of both the theories, firstly each theory may be accounting for different types of delinquents; or secondly the two aspects inherent in 
the theories (personality and moral reasoning) are interacting in some way that is associated with delinquent behaviour.

The latter suggestion seems feasible since both the theories deal with different aspects of an individual's behaviour, but still have certain elements in common. H. J. Eysenck's theory deals with the acquisition of morality through conditioning which is mediated by a genetically determined level of arousal which in turn is expressed in personality. Kohlbergian theory is based on reasoning which is acquired and used when the decision to offend takes place. Research has suggested that criminal behaviour has genetic, learning and cognitive components (Binder, 1988). Therefore it seems possible that the delinquent personality (i.e. high $\mathrm{P}, \mathrm{E}$, and $\mathrm{N}$ ) could provide the biological and learning component for engaging in delinquent behaviour and immature moral reasoning could provide the cognitive element. Another reason for considering the two theories together is that they both provide variables which the literature suggests are related to offending and hence could be the source of the heterogeneity which has been one of the main criticisms levelled at both theories.

A possible way in which the two variables of personality and moral reasoning may interact is also suggested within the theories. High moral reasoning must first require acquisition of knowledge of what constitutes socially acceptable behaviour. Eysenckian socialisation processes based on conditioning could provide the method by which this knowledge is first acquired. Since certain personality combinations such as high P, E, and $\mathrm{N}$ condition less well than others for the reasons described earlier, it could be expected that these individuals will also not develop moral reasoning beyond the preconventional level, where rules are seen as imposed by others. In addition, punishment for behaving badly would not have a great impact on those with this personality combination, since they are chronically underaroused. For this reason, punishment, the probability of which tends to be the basis for moral reasoning in preconventional individuals, would not act as an 
effective deterrent against committing an anti-social act. Hence, the individual would reason in favour of carrying out that behaviour on the understanding that the punishment does not seem very likely or very severe.

Furthermore, certain of the traits of individuals scoring high on $\mathrm{P}$ (such as lack of empathy and selfishness) seem to reflect pre-conventional moral reasoning which is characterised by a hedonistic perspective.

Two studies have investigated the relationship between moral reasoning and Eysenckian personality descriptions. Addad and Leslau (1990) found that criminals were higher than controls on neuroticism and immoral judgement, but not on extraversion. This study, however, did not include a measure of $\mathrm{P}$, did not use a production measure of moral reasoning as advocated by many researchers (Blasi, 1980; Gibbs, Widaman and Colby, 1982; Rest, 1975), did not investigate the personality scales in combination, and did not take account the effects of incarceration or type of offence. Furnham and Barratt (1988) found no difference in moral judgement between delinquents and controls, but found that both $\mathrm{E}$ and $\mathrm{P}$ were higher in delinquents. The effects of $\mathrm{N}$ were less clear, with some evidence that the scores on this scale were higher in delinquents than one of their controls. Again, this study used a recognition measure of moral reasoning (the Defining Issues Test) rather than a production measure, did not look at the personality scales in combination, and did not take account of the effects of incarceration or type of offence. One study which is relevant here but which did not investigate Kohlberg's theory directly, was conducted by Martin (1985). He investigated the effect of values on personality and found support for the notion that socialised values were present in low $\mathrm{E}$ and $\mathrm{P}$ scorers while the values which opposed social norms were present in high $\mathrm{E}$ and $\mathrm{P}$ scorers. The position of $\mathrm{N}$ was again less clear. While this study provides some support for the notion that moral reasoning and personality are both related to crime, the amount of moral reasoning elements present in the 'values' is unknown. This study can also be criticised in terms of 
the same shortcomings common to both the Addad and Leslau (1990) and the Furnham and Barratt (1988) studies.

The lack of adequately controlled research into the subject of moral reasoning, personality and crime leads to the conclusion that the relationship between the two theories is far from clear. 


\section{3 - OTHER EXPLANATIONS OF CRIMINALITY}

West (1982) summarised the findings of the Cambridge study in delinquent development which followed nearly 400 males from age eight to age 25 , by which time a third of the group had acquired a criminal conviction record. The study found five factors which best predicted future delinquency in the subjects:

1) Coming from a low income family

2) Coming from a large sized family (four or more other surviving children born to the boy's mother up to his tenth birthday).

3) Having parents considered by social workers to have performed their child-rearing duties unsatisfactorily.

4) Having below-average intelligence on testing (an IQ of 90 or less on Raven's Matrices Test).

5) Having a parent with a criminal record.

While these factors may not seem particularly enlightening many of them reflect long standing findings within the criminological literature, and many of these represent whole research areas in their own right. This is especially true of the third factor, intelligence.

\section{Intelligence and Delinquency}

The proposed link between crime and intelligence has a long history which dates back to Lombroso (1876) and his associates in the nineteenth century. Systematic testing of offenders' intelligence began with Goddard (1914) who using the Binet-Simon intelligence test reported that the percentages of 'feebleminded' delinquent individuals ranged from high $(89 \%)$ to low $(28 \%)$. Sutherland (1931) reviewed the position and reported that up to that time 350 studies of the intelligence of delinquents had been carried 
out in the United States. He concluded that as intelligence tests became more sophisticated, the percentage of low intelligence individuals in criminal populations decreased and he suggested that this downward trend would continue.

Sutherland's (1931) conclusions coupled with the fact that criminology had by this time abandoned unitary causes in favour of more complex theories, led to the general assumption that little could be gained from the study of intelligence in criminals. The few studies which did investigate this relationship often found mixed results or very small differences between the intelligence of offenders and non-offenders (e.g. Caplan, 1965; Merrill, 1947; Woodward, 1955). Many researchers concluded that any differences between the intelligence of offenders and non-offenders were due to differences in SES and race rather than due to intelligence directly.

In the sixties and seventies, research into the intellectual capacity of offenders began once more to take place. Currently, the position is one which acknowledges the lower intelligence of offenders regardless of differences in other variables.

In a review, Hirschi and Hindelang (1977) stated that 'IQ is related to official delinquency and that, it is as important in predicting official delinquency as social class or race'. Hirschi (1969) found a significant association between IQ and self-reported delinquency even after allowing for the influence of race and social status. As reported above, the Cambridge study (West and Farrington, 1977) also found a strong association between criminality and IQ. Quay (1987), concluded that there is on average an 8 point difference in IQ between offenders and non-offenders. More recent research further supports these findings (Moffitt et al., 1981; Moffitt and Silva, 1989; Reichel and Magnusson, 1988; and see review by Reichel, 1987).

None of these researchers suggest a direct causal relationship between intelligence and criminality. Rutter and Giller (1983) suggested two possible routes. The first is that low IQ leads to educational failure which creates low self-esteem and emotional 
disturbance, which in turn leads to conduct disorders and delinquency. While there is some evidence to support this notion (Keilitz and Dunivant, 1986) the explanation does not account for studies which suggest the associations are present in pre-school ages (Richman et al., 1982; West and Farrington, 1977). The second explanation is that IQ and delinquency share a common origin which could be a biological, social or familial influence; or another individual factor such as temperament (Offord et al., 1978). Quay (1987) questioned the notion that the relationship between IQ and delinquency is mediated through schools. He suggested instead that low intelligence puts a child at a disadvantage in social interactions which leads to troublesome and eventually delinquency, in other words low IQ encourages school failure and is exacerbated by school failure.

A potential criticism of the association between IQ and crime is that the relationship may be present in those incarcerated because offenders of low IQ are more likely to be arrested. However, the relationship is also present in self-reported delinquency (Hirschi and Hindelang, 1977; West and Farrington, 1977; and review by Reichel, 1987) and thus the validity of this criticism is seriously undermined.

Another complication, is that intelligence is negatively correlated to psychoticism as measured by the Eysenck Personality Questionnaire (H. J. Eysenck and S. B. G. Eysenck, 1976). Since Psychoticism is strongly positively correlated with delinquency, it could be a mediator between intelligence and crime. No studies have addressed this notion directly, but since correlations between psychoticism and criminality tend to be higher than those between intelligence and criminality, H. J. Eysenck and Gudjonsson (1989) argue that psychoticism could be the more important factor in predicting criminality irrespective of intelligence. Extraversion also shows a small correlation with intelligence, positive in primary school children and this becomes negative in secondary school children $(\mathrm{H}$. $\mathrm{J}$. Eysenck and S. B. G. Eysenck, 1975). Neuroticism shows no correlation with intelligence (H. J. Eysenck and S. B. G. Eysenck, 1975). The correlations of intelligence with these 
personality variables have obvious implications for ascertaining causal relationships between both personality and intelligence and offending behaviour.

It should be pointed out that while research findings suggest that on average offenders have lower IQ's this means that some offenders will have average or above average IQ scores, especially considering that there is only an 8 point IQ discretion between offenders and non-offenders. It appears unlikely that this small difference will involve a large qualitative difference in intellect between the two groups. This finding also does not imply that offenders are mentally handicapped, since this condition involves social functioning as well as IQ.

\section{Family Background and Criminality}

The remaining four factors predictive of delinquency in the Cambridge study (West, 1982) all relate to an individual's family background. This is also an area which has received a great deal of research attention both from psychology and sociology.

Many specific factors concerning 'deficits' in family background have been postulated to increase the likelihood of delinquent behaviour in young people, e.g. parental discipline (Pulkkinen, 1983; West and Farrington, 1973); positive parenting factors such as encouraging the development of standards of behaviour (Elliott et al., 1982; West and Farrington, 1977); parental supervision (McCord, 1978, 1979; West and Farrington, 1973); and parental criminality (Farrington, Grundy and West, 1975; Robins et al., 1975). However, aside from specific parental behaviours, criminality has also been found to be associated with general family sociodemographic factors. These include socioeconomic status (SES), parental absence (broken homes), and family size.

Snyder and Patterson (1987) reported that a modest association exists between low socioeconomic backgrounds and increased delinquency, for both official (e.g. Wadsworth, 1979) and self-reported delinquency (Elliott and Ageton, 1980). SES appears to be most 
important in predicting serious criminal acts (Rutter and Giller, 1983). This association is not direct however, since various studies have found that when parenting skills are taken into account the correlation between social class and delinquency diminishes or disappears (Farrington, 1979), and additionally delinquency is also associated with families which are not of low socioeconomic status (e.g. McCord, 1979; Robins, 1978; West and Farrington, 1973).

Gibson (1969) and Rutter (1971) both found that greater delinquency was found in those individuals which came from broken homes. However, delinquency is also increased in unbroken but discordant and conflict ridden homes (Power et al., 1974), so it could be that the discordance is the problem rather than the parental absence or divorce per se. McCord (1978) found that the association between broken homes and delinquency diminished when parenting skills were taken into account.

Fergusson et al. (1990) reported that consistent, but small, correlations exist between a general disadvantaged family background and an increased likelihood of delinquency. Their concept of disadvantaged background was defined by measures of SES, family income level, family emotional and social support and parental child-rearing practices. They concluded that a disadvantaged social background creates a generalised vulnerability to behavioural problems (i.e. delinquency) in the child. Kolvin et al. (1988) reached a similar conclusion that a 'deprived background' early in life leads to an increased risk of offending later on.

Thus, it seems clear that family deprivation is a factor strongly associated with criminality. What the evidence does not suggest, is a causal relationship between these two factors, it seems rather that general sociodemographic characteristics are indicative of other mediating variables (such as parental child-rearing practices).

A further complication was identified by Farrington et al. (1988), who looked at the individuals who had taken part in the Cambridge study and had been predicted to become 
offenders (by the five factors summarised by West, 1982) but who had not in fact been convicted. The study concluded that individual factors such as shyness and aggression levels acted in a protective manner against conviction. This study shows two points, firstly that sociodemographic factors (and intelligence) are not sufficient to induce delinquent behaviour, and secondly that other factors can supersede the effects of a deprived background. It seems that an interaction between factors is the key to understanding the development of delinquent behaviour.

It is notable that this was a similar conclusion to that reached during the earlier discussion of more complex psychological theories of criminality (Personality and Moral Judgement). In other words, the evidence for unitary causes of crime is not sufficient to suggest any one (or two) explanations, and therefore research must attempt to focus on a combination of factors to produce more complex theories of criminality which include both individual and demographic variables. Once again, the explanation for discrepancies in the research findings lies in the heterogeneity of the delinquent population.

\section{Demographic Variables and Delinquency}

A great deal of research has been carried out into the association of delinquency and the three major demographic factors of age, gender (sex), and ethnicity (race). Research has been undertaken using national crime statistics, surveys of official records, and self-report surveys. Both cross-sectional and longitudinal designs have been used.

Farrington (1987) reviewed the available data on the demographics of delinquency. For age, he concluded that delinquency increases to a peak somewhere between 15 and 17 and then decreases for both males and females and for the most common types of offences. In general, the incidence, and prevalence of commission of serious offences are considerably greater for males than for females, this is true for all ages and for whites and blacks separately. For ethnicity, Farrington concluded that especially for females and for 
serious offences, the prevalence of official delinquency is greater for blacks than for whites, but no differences exist for incidence of official delinquency or for either prevalence or incidence of self-reported delinquency. There are also some indications that certain ethnic groups (Asians in England and in the United States) have lower delinquency rates than whites.

While various explanations exist for these associations, Farrington (1987) concluded that none adequately explain research findings. 


\section{4 - SELF-REPORTED DELINQUENCY}

In the history of psychological research into criminal behaviour, most research has concerned itself with official definitions of offending. In other words, studies have used convicted and mostly incarcerated individuals to represent criminality. However, as was noted earlier, there are a number of problems with using this definition of offending. It is known that delinquency and criminal behaviour is much more widespread than official records suggest; not only do most crimes go undetected, there are also many factors which come into effect before an individual is convicted and incarcerated and there is also some evidence to suggest that these factors are not uniformly applied to all individuals or all offences (see Hollin, 1989). If an individual crime is detected by the police, many factors are involved before the person who committed the offence is convicted, and the same crimes do not always result in incarceration in a secure unit. Further, if variables associated with offending are being investigated there may be a confounding effect of the incarceration itself (e.g. personality characteristics may be effected by imprisonment).

As a result, researchers have turned to self-reported measures (SRD) of delinquency in an effort to account of the problems of official measures of criminality. Virtually all SRD measures have used (and continue to use) the offence checklist format developed by Short and Nye (1957). In this format, a series of short descriptions of a particular type of anti-social and/or criminal behaviour are presented to the subject who has to state whether he or she has engaged in that behaviour (ever or during some specified time interval). In some cases the subject is required to indicates how frequently he or she has engaged in particular behaviours. The score on these scales represents either the total number of behaviours engaged in or may collect frequency counts for engagement in particular behaviours. 
For many years, there was controversy over the reliability, validity and precision of SRD measures. However, the study by Hindelang, Hirschi and Weis (1981) that concluded that the reliability and validity of self-reported measures of delinquency compare favourably to other standard measures employed by social scientists seemed to resolve the controversy. However, Huizinga and Elliott (1986) and Elliott and Huizinga (1988) have disagreed with this conclusion. They pointed out that many researchers tend not to refer to the reliability and validity of the SRD measure with reference to the particular sample or population used, and suggested that SRD measures should not be considered reliable and valid in all situations. In addition, they noted other, more fundamental, problems associated with the procedures employed to standardise SRD measures.

Huizinga and Elliott (1986) suggested that while the levels of reliability recorded for self-report measures compare favourably to other measures used in psychology, the methods used to test reliability may be inappropriate when measuring offending. In addition, they noted that the levels of reliability which may be appropriate for certain research purposes may not be for others such as changes over time and individual differences.

Validation of SRD measures may also be in doubt, as they have relied on official measures of crime as the validation criterion. Since the validity of official measures of delinquency is also in doubt, correlations between these and SRD scores do not constitute adequate validation procedures. Many important validity issues have also not been addressed such as the potentially serious effects of variation in item wording (Chaiken, Chaiken and Rolph, 1982; Hindelang et al., 1981; Schuman and Presser, 1981); inappropriate classification of behaviours or offences by respondents (Elliott and Huizinga, 1983); high levels of trivial events being reported (Gold and Reimer, 1975; Huizinga and Elliott, 1986); and double counting of single events (Elliott, 1982). In general the focus has been on under-reporting with relatively little attention given to problems of over- 
reporting (e.g. Weis, 1986). In addition, there is evidence to suggest that the validity of SRD measures is different for different races (Bachman et al., 1987; Hindelang et al., 1981; Huizinga and Elliott, 1986; Weis, 1986). There is also evidence of serious levels of under-reporting of certain offences, such as sex offences (Abel et al., 1983) and tax evasion (Hessing et al., 1988). Finally, there is considerable confusion over types of measures used in particular studies (e.g., prevalence, incidence, frequency rates) and the adequacy of various approaches to scaling or scoring SRD measures. Elliott and Huizinga (1988) concluded that considerable room for improvement exists in improving SRD measures.

In order to conduct a long-term study into the prevalence and incidence of delinquent behaviour (the National Youth Survey) Elliot, Huizinga and associates produced a measure of SRD taking the above criticisms into account (Elliott and Ageton, 1980; Elliott and Huizinga, 1983; Huizinga and Elliott, 1986). So far the National Youth Survey (NYS) has run for 12 years and has provided a great deal of data concerning delinquency. In addition, the NYS has examined the issues of reliability and validity of SRD measures.

\section{Methods of Administration}

It has often been assumed that the best way to administer SRD measures is in a self-administered, anonymous manner, rather than in a non-anonymous interview format. However, research does not support this contention. Hindelang et al. (1981) found no differences in test-retest reliability between anonymous and non-anonymous methods both as interviews and questionnaires. They also found that all these methods had similar correlations with official measures of offending. The authors concluded that differences between research findings are not due to differences in the administration method employed. However, these authors noted that self-administered tests are more prone to higher levels of missing data: similar results were reported by Bale (1979), and Sudman 
and Bradburn (1982). On the other hand, Bayless, Boesel and Piper (1978) and Gold (1966) reported than interview data produced more valid self-report data than questionnaires.

In a review, Elliott and Huizinga (1988) concluded that considering the finding by Weis (1986) that face-to-face interviews may reduce race differences in underreporting of certain offences, interviewing techniques may be the safest method. They also acknowledged that self-administered measures are also viable although the potential problems of increased missing data and difficulties in interpretation of the questions by the respondents may make this procedure less profitable for certain research purposes. In addition, they noted the potential in using telephone surveys and computer assisted procedures for measuring SRD. 


\section{5 - PREDICTIONS AND HYPOTHESES}

The studies presented in this thesis examined H. J. Eysenck's personality types, moral reasoning, intelligence and family background in convicted young offenders and non-offenders, the results of which can be seen in chapter 3 . In addition, as the studies reported in chapter 4 show, these variables were also investigated in relation to disturbed young offenders, and response biases to the psychometric tests used were also investigated.

Criminality was defined both in official terms (i.e. conviction) and in self-reported delinquency scores.

Based on the theory of criminality by H. J. Eysenck $(1964,1970,1977)$ and previous research findings, it was predicted that convicted individuals would have higher scores on psychoticism $(P)$, neuroticism $(N)$, and extraversion $(E)$ than non-convicted individuals, with no differences between the groups on their lie score (L). However, it was expected that these differences would be more apparent in personality combinations. In other words, it was expected that a larger proportion of individuals in the convicted group would have a personality combination of high $\mathrm{P}, \mathrm{E}$ and $\mathrm{N}$, but it was expected that the combination would be relatively absent in the non-convicted group, and the reverse would be true for a low $\mathrm{P}, \mathrm{E}$, and $\mathrm{N}$ personality combination. Based both on previous research findings and Kohlberg's theory of moral development (Kohlberg, 1969), the convicted offenders were also predicted to have significantly lower moral reasoning stages and maturity than the non-convicted group. Intelligence was also expected to differ between the two groups, with the convicted group having lower intelligence than the non-convicted group. The convicted group was also expected to come from a lower socio-economic status background and to have had a larger number of siblings before the age of ten.

In relation to self-reported delinquency, it was expected that high $\mathrm{P}, \mathrm{E}$ and $\mathrm{N}$ scores would be associated with high self-reported delinquency. The lie scale (L) was used as an 
extra 'personality' variable measuring social desirability. It was expected that $\mathrm{L}$ would be positively associated with self-reported delinquency and would therefore act as a check for the potential social desirability bias to the self-reported delinquency instrument. Lower stages of moral reasoning and lower intelligence were expected to be associated with higher self-reported delinquency. Lower socio-economic status and larger families were also expected to be associated with higher self-reported delinquency. In addition, those with the personality combination of High P, E, and $\mathrm{N}$ were expected to have higher selfreported delinquency scores than those with other personality combinations.

The variables of personality, moral reasoning, intelligence and family background were also expected to be associated with each other and to interactively predict selfreported delinquency in the results of various multiple regression analysis. 


\section{CHAPTER 2}

\section{METHOD}

\section{1 - Study Population}

In total 209 young people took part in the study. These were divided into two main groups.

The first comprised of 101 male young offenders, all convicted and serving sentences of less than 4 years at a young offenders institution. These individuals were volunteers drawn from the allocation unit of a large young offenders institution. Their ages ranged from 16.5 to 21.58 years, with a mean of 19.14 years and standard deviation of $1.12 .87 \%$ were of British ethnic origin, $6 \%$ were of other ethnic origins, and $7 \%$ could not be classified according to ethnic origin.

The second group was of 108 young people who were used as the comparison group. Of these, 75 were undergraduate psychology students who received course credits for taking part, and 33 were volunteer school students of psychology and sociology. In total there were 33 males and 75 females. Their ages ranged from 16 to 21.83 years with a mean age of 19.56 , standard deviation of 1.07 . $83.02 \%$ were of British ethnic origin , and $16.98 \%$ were of other ethnic origins.

These 209 individuals were used to form five separate sample groups for the purpose of the study. The groups were as follows:

a) Whole Sample - all the 209 participants were used as a large sample of young people. In total 134 were male and 75 were female, and their ages ranged from 16 to 21.83 years and with a mean of 19.36 years and a standard deviation of $1.11 .87 .90 \%$ were of British ethnic origin, and $12.10 \%$ were of other ethnic origins.

b) Male Offenders - the 101 convicted offenders as described above. 
c) Male Controls - 33 participants from the comparison group, with ages ranging from 16 to 21.83 years and with a mean of 19.87 years and a standard deviation of $1.12 .81 .25 \%$ were of British ethnic origin, and $18.75 \%$ were of other ethnic origins.

d) Female controls - 75 individuals from the comparison group. Their ages ranged from 17.42 to 21.83 and with a mean of 19.42 years and a standard deviation of 1.07 . $83.78 \%$ were of British ethnic origin, and $16.22 \%$ were of other ethnic origins.

e) Male and Female control combined - the 108 individuals from the comparison group proper.

\section{2 - Design and Materials}

In all participants completed four standard self-administered psychological tests, and an additional background information questionnaire. Each individual was presented with these materials in a randomised order to control for order and fatigue effects.

a) Short Scale of the Eysenck Personality Questionnaire - Revised (H. J. Eysenck, S. B. G. Eysenck, and Barrett, 1985), this is a yes/no personality questionnaire which provides four scores per respondent - Psychoticism, Extraversion, Neuroticism, and Lie scale. The original form of this test (H. J. Eysenck and S. B. G. Eysenck, 1975) is one of the most extensively used and assessed personality inventories (H. J. Eysenck, 1970; H. J. Eysenck and Zuckerman, 1978; Furnham, 1981). The revised version improved the psychometric weaknesses of the test, by increasing the reliability of the P scale. The changes to the test also increased the size of the original scale to 100 items, therefore, for the purposes of this research where time constraints applied, the short scale of the test comprising 48 items was deemed more appropriate. 
b) Sociomoral Reflection Measure (SRM; Gibbs and Widaman, 1982). This is a pencil and paper production-task measure of reflective moral thought. The questionnaire entails 15 questions that probe respondent's reasoning values and decisions pertaining to two dilemmas. There are corresponding dilemmas for the two forms (A and B) of the instrument. Each form consists of eight normative values, or norms. The first dilemma of either form permits the elicitation of justifications for five norms: affiliation (marital and friendship), life (saving a life form A; living even when one doesn't want to, form B), law (and property), legal justice, and conscience. The second dilemma of either form elicits justifications for three norms: family affiliation, contract, and property. Ratings of the highest level (pure stage or transitional level) of respondent's justifications are made for each of the eight norms.

Overall SRM protocol ratings are derived from the scores on the eight norms. Two primary types of overall ratings are produced: a) modal stage, which is the stage most frequently used by an individual in the protocol responses (stage $1,2,3$, or 4) and b) the Sociomoral Maturity Score (SRMS), a psychometrically more differentiated rating that extends from 100 to 400 . The SRMS can be converted to a 10 point Global stage scale (SRMS ratings 100 to $125=$ Stage $1 ; 126-149=$ transition $1[2] ; 150-174=$ transition $2[1]$; $175-225=$ stage $2 ;$ etc.)

The SRM was designed to serve as a group-administrable counterpart to the Moral Judgement Interview (MJ; Colby et al., 1983; 1987), which is based on Kohlberg's stage theory of moral judgement development. Previous studies have established acceptable reliability (generally correlations in the $\mathrm{r}=0.70$ and higher) and validity (correlations between the SRM and MJI $r=0.85$, with age partialled out $r=0.50$ ). The SRM has also found correlations with age and educational level (see Gibbs and Widaman, 1982; Gibbs, Widaman and Colby, 1982). 
Reliability of scoring in the present study was achieved by randomly selecting a sample of 20 completed tests for second blind scoring. Correlation coefficients were calculated between the first and second scores allocated, and it was found that for Modal score $\mathrm{r}=0.45, \mathrm{p}<0.05$; for SRMS $\mathrm{r}=0.83, \mathrm{p}<0.0001$; and for Global score $\mathrm{r}=0.73, \mathrm{p}<0.0004$, which are acceptable according to the scoring manual for the SRM.

Due to the fact that the test was originally produced for an American population, in this study form B of the test was deemed more appropriate for use with British individuals, since form A contains concepts less familiar to British individuals (such as references to a child going to camp). In addition, small changes were made to wordings in the test which consisted only of replacing references to Dollars with references to Pounds.

c) Self-Reported Delinquency measure (SRD, Elliott and Ageton, 1980; Elliott et al., 1983; Huizinga and Elliott, 1981). This measure required yes/no and overall frequency responses over a period of one year to questions pertaining to engaging in various offence behaviours. The offences were representative of the full range of offenses reported in official crime statistics in the United States (Uniform Crime Reports, UCR). However, nearly all the items involves a violation of British criminal statutes.

The SRD measure also included two items pertaining to the use of 'hard' and 'soft' drugs. These were included to reflect the use by Elliott et al. (1983) of a separate measure of alcohol and drug use. In total, 40 items were presented to the participants. The measure produced three scores:

1) a general delinquency score (SRD) ranging from 0 for low delinquency to 40 indicating high delinquency, 2) Number of crimes committed against the person (PER), made up of nine items from the main scale pertaining to violent offending, a score of 0 indicated low violent offending and nine indicated high violent offending, 3) Property crimes (THEFT) made up of seven of the items in the scale pertaining to property crimes (see Elliott et al. 
1983), where 0 low rates of theft and 7 indicated high rates of theft. The frequency counts were not included in the final analysis due to a high rate of non-completion, and perceived inaccuracies (such as writing 'a lot' for an estimate of frequency) in this part of the scale. For the experimental comparisons in the study, the yes/no responses were deemed adequate.

This measure has correlations of test-retest reliabilities between 0.70 to 0.95 . With regards to validity, Huizinga and Elliott (1986), conclude that while the measure is not error free, the validity of this measure is as good or better than of other measures routinely employed by social scientists.

d) Raven's Standard Progressive Matrices (SPM; Raven, Court and Raven, 1985). This is a non-verbal, figure completion, test of intellectual capacity. The SPM is a test of a person's capacity at the time of the test to apprehend meaningless figures, see the relations between them, conceive the nature of the figure completing each system of relations presented, and thus develop a systematic method of reasoning. The scale consists of 60 problems divided into five sets of 12 . In each set the correct answer to the first problem is as near as possible self-evident. The problems which follow become progressively more difficult. The order of the items provides the standard training in the method of working. To ensure sustained interest and freedom from fatigue, the figures in each problem are boldly presented, accurately drawn and, as far as possible, pleasing to look at.

The scale was designed to cover the widest possible range of mental ability and to be equally useful with persons of all ages, whatever their education, nationality or physical condition. The scale produces a score between 0 indicating low mental ability and 60 indicating high mental ability. These scores can also be converted into one of five intelligence grades according to norms present in the manual, which give an indication of the intellectual capability of the respondents compared against their age group. The grades 
are described thus: grade I - 'intellectually superior'; grade II - 'definitely above the average in intellectual capacity'; grade III - 'intellectually average'; grade IV - 'definitely below average in intellectual capacity'; and grade V - 'intellectually defective'.

Raven's progressive matrices have been found to have high reliability and validity, although variations in age, possibly sex and the homogeneity of the sample used limit some of the high validity measures quoted in research findings (see Raven, Court and Raven, 1985).

e) A final questionnaire elicited general information from the participants. This pertained to age, sex, ethnic origin, their age at leaving school, father's and mother's occupations, and the people with whom they lived up to and after the age of ten.

Social Class and socio-economic group were ascertained from father's occupation (or mother's if father not employed or deemed more appropriate) using the categories set out by the Office of Population Censuses and Surveys (1991). The number of siblings living with the child up to the age of ten and after this age were also ascertained. School leaving age was converted into number of full years of education, assuming that they entered school at 5 years of age (unless other information indicated otherwise). Ethnic origin was divided into five categories following standard department of social security categories: African, Asian, Caribbean, English/Scottish/Welsh/Irish, other European and other Countries. A copy of this questionnaire is included in appendix A.

\section{3 - Procedure}

The participants were presented with all the above tests in a randomised order and asked to complete the questions as honestly as possible. There was no time limit given for completion but it was emphasised that individual's should not deliberate over any one question. All respondents were informed that there were no 'correct' answers, were 
reassured that all responses would be treated with strict anonymity, and they should not write their names anywhere on the questionnaires.

\section{4 - Analysis}

The results were subjected to an exploratory analysis. Initially, frequency and percentage counts, means, standard deviations and Pearsons $\mathrm{r}$ correlation coefficients were calculated for all the combinations of the variables, in each of the five sample groups. After this initial analysis, deeper analysis was carried out based on the results from the correlations and means. The analysis which followed were analyses of variance, regression analysis and cluster analysis.

Analyses of variance were performed to test for significant differences between the male offenders and the male controls, female controls, and the male and female controls combined. In addition, differences in the means between the male and female controls were also tested. These comparisons were conducted for the demographic variables, the personality variables, intelligence, moral reasoning variables, and offending history variables. In addition, the variables of age and education were used as co-variates in subsequent analysis of co-variance, in order to control for the potentially mitigating effects of these variables.

The three personality variables of $\mathrm{P}, \mathrm{E}$, and $\mathrm{N}$ were divided into three equal bands: high, middle and low; where scores between $0-4$ were classified as low, 5-8 as middle, and 9-12 as high. One way analyses of variance were calculated to test for differences in the means between the three levels of each personality variable on the other variables collected (demographics, moral reasoning and intelligence). This analysis was conducted for the whole sample group, the male offender sample, and the control group comprising both males and females. 
Multiple regression analysis was performed using general self-reported delinquency (SRD), crimes committed against the person (PER), and number of thefts (THEFT) upon which the remainder of the variables were regressed. This procedure was carried out for each of the five sample groups. This analysis was undertaken to determine the extent to which the other variables contributed towards the overall amount of delinquency.

Ward's cluster analysis (Ward, 1963) was also performed on the four personality variables (P, E, N, and $L$ ) obtained from the $E P Q$, for the male offender, and the control group comprising of both male and female individuals. Once personality clusters had been identified and described, the means for the other variables in each cluster were compared using analysis of variance.

Finally, qualitative description of the responses to the SRM was carried out, in order to illustrate the moral reasoning stages and to examine irregular responses produced by the participants. 


\section{CHAPTER 3}

\section{RESULTS}

\section{1 - LARGE SAMPLE AND SUB-GROUPS DESCRIPTIONS}

\section{Introduction}

Initial analysis of the data collected consisted of overall descriptions of the variables. This involved calculation of means and standard deviations, frequency counts of categorical data, and correlations between all the variables in the large whole sample and the sub-groups: male offenders, male controls, female controls, and the combined sample group.

The aim of this analysis was to identify the results which required further analysis as well as to identify how the variables interacted with each other.

\section{Results - Means and Standard Deviations}

Means and standard deviations were calculated for all the subjects in each of the sample groups, they are shown in the following tables. 
Table 3.1(1) - Means and Standard Deviations for the 18 dependent variables for the five sample groups

\begin{tabular}{|c|c|c|c|c|c|c|}
\hline & & $\begin{array}{l}\text { WHOLE } \\
\text { SAMPLE } \\
(\mathrm{N}=209)\end{array}$ & $\begin{array}{c}\text { MALE } \\
\text { OFFENDERS } \\
(\mathrm{N}=101)\end{array}$ & $\begin{array}{c}\text { MALE } \\
\text { CONTROLS } \\
(\mathrm{N}=33)\end{array}$ & $\begin{array}{l}\text { FEMALE } \\
\text { CONTROLS } \\
(\mathrm{N}=75)\end{array}$ & $\begin{array}{l}\text { MALE AND } \\
\text { FGMALE CONTROLS } \\
(N=108)\end{array}$ \\
\hline AGE & $\begin{array}{l}x \\
S D\end{array}$ & $\begin{array}{r}19.36 \\
1.11\end{array}$ & $\begin{array}{r}19.14 \\
1.12\end{array}$ & $\begin{array}{r}19.87 \\
1.12\end{array}$ & $\begin{array}{r}19.42 \\
1.02\end{array}$ & $\begin{array}{r}19.56 \\
1.07\end{array}$ \\
\hline EDU & $x$ & 12.17 & 10.52 & 13.97 & 13.41 & 13.58 \\
\hline & SD & 1.96 & 1.37 & 1.20 & 1.00 & 1.09 \\
\hline \multirow[t]{2}{*}{ ETHN } & $x$ & 2.86 & 2.98 & 2.76 & 2.75 & 2.75 \\
\hline & SD & 0.62 & 0.35 & 0.83 & 0.74 & 0.76 \\
\hline \multirow[t]{2}{*}{ CIASS } & $x$ & 2.53 & 3.06 & 2.16 & 2.19 & 2.18 \\
\hline & SD & 1.02 & 0.96 & 1.04 & 0.85 & 0.90 \\
\hline \multirow[t]{2}{*}{ SEG } & $x$ & 6.38 & 8.17 & 5.13 & 5.17 & 5.16 \\
\hline & SD & 3.58 & 3.14 & 3.19 & 3.45 & 3.36 \\
\hline \multirow[t]{2}{*}{ SIB } & $x$ & 1.64 & 1.70 & 1.70 & 1.54 & 1.59 \\
\hline & SD & 1.32 & 1.52 & 1.45 & 0.95 & 1.13 \\
\hline \multirow[t]{2}{*}{ SIB10 } & $x$ & 1.30 & 1.29 & 1.42 & 1.24 & 1.30 \\
\hline & SD & 1.18 & 1.18 & 1.52 & 1.00 & 1.18 \\
\hline \multirow[t]{2}{*}{ RAV } & $x$ & 45.09 & 39.02 & 51.84 & 50.21 & 50.70 \\
\hline & SD & 9.79 & 8.79 & 6.28 & 7.14 & 6.90 \\
\hline \multirow[t]{2}{*}{$\mathbf{P}$} & $x$ & 3.75 & 4.74 & 3.21 & 2.71 & 2.86 \\
\hline & SD & 2.45 & 2.53 & 1.58 & 2.17 & 2.02 \\
\hline \multirow[t]{2}{*}{$\mathbf{E}$} & $x$ & 8.45 & 8.71 & 7.85 & 8.37 & 8.21 \\
\hline & SD & 3.25 & 3.05 & 3.48 & 3.41 & 3.43 \\
\hline \multirow[t]{2}{*}{$\mathbf{N}$} & $x$ & 6.33 & 6.05 & 6.15 & 6.76 & 6.57 \\
\hline & SD & 3.19 & 3.21 & 3.49 & 3.01 & 3.16 \\
\hline \multirow[t]{2}{*}{ I } & $x$ & 3.14 & 3.24 & 2.64 & 3.24 & 3.06 \\
\hline & SD & 2.29 & 2.45 & 2.23 & 2.09 & 2.14 \\
\hline \multirow[t]{2}{*}{ SRD } & $x$ & 16.29 & 21.92 & 13.70 & 10.29 & 11.33 \\
\hline & SD & 8.35 & 7.31 & 5.64 & 5.33 & 5.63 \\
\hline \multirow[t]{2}{*}{ PER } & $x$ & 2.45 & 3.84 & 1.67 & 1.04 & 1.23 \\
\hline & SD & 2.06 & 2.03 & 1.16 & 0.99 & 1.08 \\
\hline \multirow[t]{2}{*}{ THEFT } & $x$ & 3.19 & 5.28 & 2.36 & 0.91 & 1.35 \\
\hline & $\mathrm{SD}$ & 2.60 & 1.89 & 1.65 & 1.25 & 1.54 \\
\hline \multirow[t]{2}{*}{ MODAI } & $x$ & 5.01 & 4.18 & 5.50 & 5.55 & 5.53 \\
\hline & $S D$ & 1.11 & 0.92 & 0.80 & 0.92 & 0.88 \\
\hline \multirow[t]{2}{*}{ SRMS } & $x$ & 297.78 & 252.46 & 324.19 & 327.60 & 326.58 \\
\hline & $\mathrm{SD}$ & 47.33 & 33.55 & 31.59 & 27.23 & 28.50 \\
\hline \multirow[t]{2}{*}{ GLOBAL } & $x$ & 6.94 & 5.65 & 7.69 & 7.80 & 7.77 \\
\hline & SD & 1.43 & 1.05 & 1.03 & 0.90 & 0.94 \\
\hline
\end{tabular}

\section{Results - Frequencies and Percentages}

Frequency counts and percentages were calculated for all the categorical data collected in the whole sample group, the male offender group and the male and female group combined. The variables used were ethnic group (ETHN), social class (CLASS), socio-economic group (SEG), intelligence grade (intelligence score converted into one of 
five categories; Raven, Court and Raven, 1985), modal and global stage of moral reasoning.

\section{Demographic Variables}

The tables below show the proportion and percentage of individuals within each sample group for the demographic variables social class and socioeconomic group (SEG).

Table 3.1(2) - Frequencies and Percentages for Social Class categories for the five sample groups

\begin{tabular}{lcccccc}
\hline SOCIAL & $\begin{array}{l}\text { WEOLE } \\
\text { SAMPLE } \\
\text { CINASS }\end{array}$ & $\begin{array}{c}\text { MALE } \\
\text { OFFENDERS } \\
(\mathrm{N}=167)\end{array}$ & $\begin{array}{c}\text { MALE } \\
\text { CONTROLS } \\
(\mathrm{N}=30)\end{array}$ & $\begin{array}{c}\text { FEMALE } \\
\text { CONTROLS } \\
(\mathrm{N}=71)\end{array}$ & $\begin{array}{c}\text { MALE AND } \\
\text { FEMALE CONTROLS } \\
(\mathrm{N}=101)\end{array}$ \\
\hline $\mathbf{1}$ & Freq & 28 & 05 & 08 & 15 & 23 \\
& 8 & 16.80 & 07.58 & 26.67 & 21.13 & 22.77 \\
2 & Freq & 54 & 09 & 12 & 33 & 45 \\
& 8 & 32.30 & 13.64 & 40.00 & 46.48 & 44.55 \\
3 & Freq & 59 & 34 & 07 & 18 & 25 \\
& 8 & 35.30 & 51.52 & 23.33 & 25.35 & 24.75 \\
4 & Freq & 20 & 13 & 02 & 05 & 07 \\
& 8 & 12.00 & 19.70 & 06.67 & 07.04 & 06.93 \\
5 & Freq & 06 & 05 & 01 & 00 & 01 \\
& 8 & 03.60 & 07.58 & 03.33 & 00.00 & 00.99 \\
\hline
\end{tabular}

Table 3.1(2) shows that the majority of the participants in the whole group came from middle class backgrounds (classes 2 and 3). The participants in the sub-groups other than the male offender group came from social class 2 , whereas the majority of male offenders came from social class 3. 
Table 3.1(3) - Frequencies and Percentages for Socio-Economic Group (SEG)

categories for the five sample groups

\begin{tabular}{|c|c|c|c|c|c|c|}
\hline \multicolumn{2}{|c|}{$\begin{array}{l}\text { SOCIO } \\
\text { ECONOMIC } \\
\text { GROUP }\end{array}$} & $\begin{array}{l}\text { WEOLE } \\
\text { SAMPLE } \\
(\mathrm{N}=169)\end{array}$ & $\begin{array}{c}\text { MALE } \\
\text { OFFENDERS } \\
(\mathrm{N}=68)\end{array}$ & $\begin{array}{c}\text { MALE } \\
\text { CONTROLS } \\
(\mathrm{N}=30)\end{array}$ & $\begin{array}{l}\text { FEMALE } \\
\text { CONTROLS } \\
(\mathrm{N}=71)\end{array}$ & $\begin{array}{l}\text { MALE AND } \\
\text { FEMALE CONTROLS } \\
(\mathrm{N}=101)\end{array}$ \\
\hline 1 & $\begin{array}{c}\text { Freq } \\
\frac{g}{8}\end{array}$ & $\begin{array}{l}20 \\
11.80\end{array}$ & $\begin{array}{l}02 \\
02.94\end{array}$ & $\begin{array}{l}04 \\
03.96\end{array}$ & $\begin{array}{l}14 \\
13.86\end{array}$ & $\begin{array}{l}18 \\
10.65\end{array}$ \\
\hline 2 & $\begin{array}{c}\text { Freq } \\
\frac{\gamma}{\gamma}\end{array}$ & $\begin{array}{c}14 \\
08.30\end{array}$ & $\begin{array}{l}03 \\
04.41\end{array}$ & $\begin{array}{l}04 \\
03.96\end{array}$ & $\begin{array}{c}07 \\
06.93\end{array}$ & $\begin{array}{c}11 \\
06.51\end{array}$ \\
\hline 3 & $\begin{array}{c}\text { Freq } \\
\frac{8}{\gamma}\end{array}$ & $\begin{array}{c}01 \\
00.60\end{array}$ & $\begin{array}{c}01 \\
01.47\end{array}$ & $\begin{array}{c}00 \\
00.00\end{array}$ & $\begin{array}{c}00 \\
00.00\end{array}$ & $\begin{array}{c}00 \\
00.00\end{array}$ \\
\hline 4 & $\begin{array}{c}\text { Freq } \\
\frac{8}{\partial}\end{array}$ & $\begin{array}{c}27 \\
16.00\end{array}$ & $\begin{array}{l}04 \\
05.88\end{array}$ & $\begin{array}{c}08 \\
07.92\end{array}$ & $\begin{array}{c}15 \\
14.85\end{array}$ & $\begin{array}{c}23 \\
13.61\end{array}$ \\
\hline 5 & $\begin{array}{c}\text { Freq } \\
\frac{o}{\gamma}\end{array}$ & $\begin{array}{c}17 \\
10.10\end{array}$ & $\begin{array}{c}03 \\
04.41\end{array}$ & $\begin{array}{c}04 \\
03.96\end{array}$ & $\begin{array}{l}10 \\
09.90\end{array}$ & $\begin{array}{c}14 \\
08.28\end{array}$ \\
\hline 6 & $\begin{array}{c}\text { Freq } \\
\frac{8}{8}\end{array}$ & $\begin{array}{l}17 \\
10.10\end{array}$ & $\begin{array}{l}09 \\
13.24\end{array}$ & $\begin{array}{l}01 \\
00.99\end{array}$ & $\begin{array}{l}07 \\
06.93\end{array}$ & $\begin{array}{l}08 \\
04.73\end{array}$ \\
\hline 7 & $\begin{array}{c}\text { Freq } \\
\frac{8}{0}\end{array}$ & $\begin{array}{c}03 \\
01.80\end{array}$ & $\begin{array}{c}03 \\
04.41\end{array}$ & $\begin{array}{c}00 \\
00.00\end{array}$ & $\begin{array}{c}00 \\
00.00\end{array}$ & $\begin{array}{c}00 \\
00.00\end{array}$ \\
\hline 8 & $\begin{array}{c}\text { Freq } \\
8\end{array}$ & $\begin{array}{c}01 \\
00.60\end{array}$ & $\begin{array}{c}00 \\
00.00\end{array}$ & $\begin{array}{c}00 \\
00.00\end{array}$ & $\begin{array}{c}01 \\
00.99\end{array}$ & $\begin{array}{c}01 \\
00.59\end{array}$ \\
\hline 9 & $\begin{array}{c}\text { Freq } \\
8\end{array}$ & $\begin{array}{c}34 \\
20.10\end{array}$ & $\begin{array}{c}21 \\
30.88\end{array}$ & $\begin{array}{c}06 \\
05.94\end{array}$ & $\begin{array}{c}07 \\
06.93\end{array}$ & $\begin{array}{c}13 \\
07.69\end{array}$ \\
\hline 10 & $\begin{array}{c}\text { Freq } \\
\frac{8}{\gamma}\end{array}$ & $\begin{array}{c}13 \\
07.70\end{array}$ & $\begin{array}{c}09 \\
13.24\end{array}$ & $\begin{array}{c}01 \\
00.99\end{array}$ & $\begin{array}{c}03 \\
02.97\end{array}$ & $\begin{array}{c}04 \\
02.37\end{array}$ \\
\hline 11 & $\begin{array}{c}\text { Freq } \\
\frac{8}{8}\end{array}$ & $\begin{array}{c}10 \\
05.90\end{array}$ & $\begin{array}{c}06 \\
08.82\end{array}$ & $\begin{array}{c}02 \\
01.98\end{array}$ & $\begin{array}{c}02 \\
01.98\end{array}$ & $\begin{array}{c}04 \\
02.37\end{array}$ \\
\hline 12 & $\begin{array}{c}\text { Freq } \\
\frac{8}{\gamma}\end{array}$ & $\begin{array}{c}09 \\
05.30\end{array}$ & $\begin{array}{c}05 \\
07.35\end{array}$ & $\begin{array}{c}00 \\
00.00\end{array}$ & $\begin{array}{c}04 \\
03.96\end{array}$ & $\begin{array}{c}04 \\
02.37\end{array}$ \\
\hline 13 & $\begin{array}{c}\text { Freq } \\
\frac{8}{8}\end{array}$ & $\begin{array}{c}01 \\
00.60\end{array}$ & $\begin{array}{c}00 \\
00.00\end{array}$ & $\begin{array}{c}00 \\
00.00\end{array}$ & $\begin{array}{c}01 \\
00.00\end{array}$ & $\begin{array}{c}01 \\
00.59\end{array}$ \\
\hline 14 & $\begin{array}{c}\text { Freq } \\
\frac{8}{\gamma}\end{array}$ & $\begin{array}{c}00 \\
00.00\end{array}$ & $\begin{array}{c}00 \\
00.00\end{array}$ & $\begin{array}{c}00 \\
00.00\end{array}$ & $\begin{array}{c}00 \\
00.00\end{array}$ & $\begin{array}{c}00 \\
00.00\end{array}$ \\
\hline 15 & $\begin{array}{c}\text { Freq } \\
\frac{\%}{\%}\end{array}$ & $\begin{array}{c}00 \\
00.00\end{array}$ & $\begin{array}{c}00 \\
00.00\end{array}$ & $\begin{array}{c}00 \\
00.00\end{array}$ & $\begin{array}{c}00 \\
00.00\end{array}$ & $\begin{array}{c}00 \\
00.00\end{array}$ \\
\hline 16 & $\begin{array}{c}\text { Freq } \\
\frac{8}{8}\end{array}$ & $\begin{array}{c}02 \\
01.20\end{array}$ & $\begin{array}{c}02 \\
02.94\end{array}$ & $\begin{array}{c}00 \\
00.00\end{array}$ & $\begin{array}{c}00 \\
00.00\end{array}$ & $\begin{array}{c}00 \\
00.00\end{array}$ \\
\hline
\end{tabular}

In the whole group sample the majority of participants came from socio-economic groups 1, 2, 4 to 6 and 9. For the combined control group all the subjects were in SEG's 1 to 13 only. The majority of the participants in the control groups tended to come from higher SEG's than the male offenders which were more concentrated in the lower SEGs. 


\section{Moral Reasoning}

The tables below show the proportion and percentage of individuals reasoning at each of the modal and global stages of moral reasoning for each of the sample groups

Table 3.1(4) - Frequencies and Percentages for Modal stages of Moral Reasoning for the five sample groups

\begin{tabular}{|c|c|c|c|c|c|c|}
\hline \multicolumn{2}{|c|}{$\begin{array}{l}\text { MODAL } \\
\text { STAGE }\end{array}$} & $\begin{array}{l}\text { WHOLE } \\
\text { SAMPLE } \\
(\mathrm{N}=169)\end{array}$ & $\begin{array}{c}\text { MALE } \\
\text { OFFENDERS } \\
(\mathrm{N}=64)\end{array}$ & $\begin{array}{c}\text { MALE } \\
\text { CONTROLS } \\
(\mathrm{N}=31)\end{array}$ & $\begin{array}{l}\text { FEMALE } \\
\text { CONTROIS } \\
(\mathrm{N}=74)\end{array}$ & $\begin{array}{l}\text { MALE AND } \\
\text { F EMALE CONTROLS } \\
(\mathrm{N}=105)\end{array}$ \\
\hline 1 & $\begin{array}{c}\text { Freq } \\
\frac{8}{8}\end{array}$ & $\begin{array}{l}00 \\
00.00\end{array}$ & $\begin{array}{l}00 \\
00.00\end{array}$ & $\begin{array}{l}00 \\
00.00\end{array}$ & $\begin{array}{l}00 \\
00.00\end{array}$ & $\begin{array}{l}00 \\
00.00\end{array}$ \\
\hline $1 / 2$ & Freq & 01 & 01 & 00 & 00 & 00 \\
\hline & $\stackrel{\circ}{\%}$ & 00.60 & $\begin{array}{l}01.56 \\
20\end{array}$ & $\begin{array}{c}00.00 \\
00\end{array}$ & 00.00 & 00.00 \\
\hline 2 & $\begin{array}{c}\text { Freq } \\
\frac{o}{8}\end{array}$ & $\begin{array}{c}21 \\
12.40\end{array}$ & $\begin{array}{c}20 \\
31.25\end{array}$ & $\begin{array}{c}00 \\
00.00\end{array}$ & $\begin{array}{l}01 \\
01.35\end{array}$ & $\begin{array}{c}01 \\
00.95\end{array}$ \\
\hline $2 / 3$ & $\begin{array}{c}\text { Freq } \\
\frac{8}{8}\end{array}$ & $\begin{array}{c}14 \\
08.30\end{array}$ & 12 & 01 & 01 & 02 \\
\hline 3 & Freq & 96 & 31 & 18 & 47 & 65 \\
\hline & 8 & 56.80 & 48.44 & 58.06 & 63.51 & 61.90 \\
\hline $3 / 4$ & Freq & 14 & 00 & 07 & 07 & 14 \\
\hline & 8 & 08.30 & 00.00 & 22.58 & 09.46 & 13.33 \\
\hline 4 & Freq & 23 & 00 & 05 & 18 & 23 \\
\hline & & & 00.00 & & & \\
\hline
\end{tabular}

The whole sample group had modal stages ranging from transition stage $1 / 2$ to stage 4 with over 50 per cent of the sample in stage 3 . For the male offenders the majority of individual's were reasoning at stage 3 the same as the majority in the control groups, but unlike the control groups, none of the male offenders had reasoning over stage 3. 
Table 3.1(5) - Frequencies and Percentages for Global stages of Moral Reasoning for the five sample groups

\begin{tabular}{|c|c|c|c|c|c|c|}
\hline \multicolumn{2}{|c|}{$\begin{array}{l}\text { GLOBAL } \\
\text { STAGE }\end{array}$} & $\begin{array}{l}\text { WHOLE } \\
\text { SAMPLE } \\
(\mathrm{N}=170)\end{array}$ & $\begin{array}{c}\text { MALE } \\
\text { OFFENDERS } \\
(\mathrm{N}=65)\end{array}$ & $\begin{array}{c}\text { MALE } \\
\text { CONTROLS } \\
(\mathrm{N}=31)\end{array}$ & $\begin{array}{l}\text { FEMALE } \\
\text { CONTROLS } \\
(\mathrm{N}=74)\end{array}$ & $\begin{array}{l}\text { MALE AND } \\
\text { FEMALE CONTROLS } \\
(\mathrm{N}=101)\end{array}$ \\
\hline 1 & $\begin{array}{c}\text { Freq } \\
\frac{\gamma}{\delta}\end{array}$ & $\begin{array}{l}00 \\
00.00\end{array}$ & $\begin{array}{l}00 \\
00.00\end{array}$ & $\begin{array}{l}00 \\
00.00\end{array}$ & $\begin{array}{l}00 \\
00.00\end{array}$ & $\begin{array}{l}00 \\
00.00\end{array}$ \\
\hline $1(2)$ & Freq & 00 & 00 & 00 & 00 & 00 \\
\hline & $\frac{8}{8}$ & 00.00 & 00.00 & 00.00 & 00.00 & 00.00 \\
\hline $2(1)$ & $\begin{array}{c}\text { Freq } \\
\frac{8}{8}\end{array}$ & $\begin{array}{c}00 \\
00.00\end{array}$ & $\begin{array}{c}00 \\
00.00\end{array}$ & $\begin{array}{l}00 \\
00 \quad 00\end{array}$ & $\begin{array}{l}00 \\
00 \quad 00\end{array}$ & $\begin{array}{l}00 \\
0000\end{array}$ \\
\hline 2 & Freq & 13 & 13 & 00 & 00 & 00 \\
\hline & 8 & 07.60 & 20.00 & 00.00 & 00.00 & 00.00 \\
\hline $2(3)$ & Freq & 14 & 13 & 00 & 01 & 01 \\
\hline & 8 & 08.20 & 20.00 & 00.00 & 01.35 & 00.99 \\
\hline $3(2)$ & Freq & 29 & 25 & 04 & 00 & 04 \\
\hline & 8 & 17.10 & 38.46 & 12.90 & 00.00 & 03.96 \\
\hline 3 & Freq & 54 & 14 & 09 & 31 & 40 \\
\hline & $\%$ & 31.80 & 21.54 & 29.03 & 41.89 & 39.60 \\
\hline $3(4)$ & Freq & 37 & 00 & 11 & 26 & 37 \\
\hline & $\gamma^{-}$ & 21.80 & 00.00 & 35.48 & 35.14 & 36.63 \\
\hline $4(3)$ & Freq & 20 & 00 & 06 & 14 & 20 \\
\hline & 8 & 11.80 & 00.00 & 19.35 & 18.92 & 19.80 \\
\hline 4 & Freq & 03 & 00 & 01 & 02 & 03 \\
\hline & 8 & 01.80 & 00.00 & 03.23 & 02.70 & 02.97 \\
\hline
\end{tabular}

Table 3.1(5) shows that the male offenders had global reasoning stages from stage 2 to stage 3 , with the majority in stage $3(2)$. In contrast, the control groups range from stages $2(3)$ to 4 with the majority in stages 3.

\section{Intelligence}

The table below shows the proportion and percentage of individuals in each of five classifications of intelligence. The grades of intelligence are described below, and were calculated according to instructions in the manual for Raven's progressive matrices (Raven, Court and Raven, 1985). 
Table 3.1(6) - frequencies and Percentages for Intelligence categories for the five sample groups

\begin{tabular}{|c|c|c|c|c|c|c|}
\hline \multicolumn{2}{|c|}{ GRADE } & $\begin{array}{l}\text { WHOLE } \\
\text { SAMPLE } \\
(N=199)\end{array}$ & $\begin{array}{l}\text { MALE } \\
\text { OFFENDERS } \\
(\mathrm{N}=93)\end{array}$ & $\begin{array}{c}\text { MALE } \\
\text { CONTROLS } \\
(\mathrm{N}=30)\end{array}$ & $\begin{array}{l}\text { FBMALE } \\
\text { CONTROIS } \\
(\mathrm{N}=74)\end{array}$ & $\begin{array}{l}\text { MALE AND } \\
\text { FHMALE CONTROLS } \\
(\mathrm{N}=106)\end{array}$ \\
\hline$I$ & $\begin{array}{c}\text { Freq } \\
8\end{array}$ & $\begin{array}{l}39 \\
19.60\end{array}$ & $\begin{array}{l}03 \\
03.23\end{array}$ & $\begin{array}{l}14 \\
46.67\end{array}$ & $\begin{array}{l}22 \\
29.73\end{array}$ & $\begin{array}{l}36 \\
33.96\end{array}$ \\
\hline II & $\begin{array}{c}\text { Freq } \\
\frac{8}{\delta}\end{array}$ & $\begin{array}{c}48 \\
24.10\end{array}$ & $\begin{array}{c}07 \\
07.53\end{array}$ & $\begin{array}{c}11 \\
36.67\end{array}$ & $\begin{array}{c}30 \\
40.54\end{array}$ & $\begin{array}{c}41 \\
38.68\end{array}$ \\
\hline III & $\begin{array}{c}\text { Freq } \\
\frac{8}{\delta}\end{array}$ & $\begin{array}{c}76 \\
38.20\end{array}$ & $\begin{array}{c}52 \\
55.91\end{array}$ & $\begin{array}{c}06 \\
20.00\end{array}$ & $\begin{array}{c}18 \\
24.32\end{array}$ & $\begin{array}{c}24 \\
22.64\end{array}$ \\
\hline IV & $\begin{array}{l}\text { Freq } \\
\frac{8}{8}\end{array}$ & $\begin{array}{c}30 \\
15.10\end{array}$ & $\begin{array}{c}26 \\
27.96\end{array}$ & $\begin{array}{c}01 \\
03.33\end{array}$ & $\begin{array}{c}03 \\
04.05\end{array}$ & $\begin{array}{c}04 \\
03.77\end{array}$ \\
\hline $\mathbf{v}$ & $\begin{array}{l}\text { Freq } \\
\frac{8}{\gamma}\end{array}$ & $\begin{array}{c}06 \\
03.00\end{array}$ & $\begin{array}{c}05 \\
05.38\end{array}$ & $\begin{array}{c}00 \\
00.00\end{array}$ & $\begin{array}{c}01 \\
01.35\end{array}$ & $\begin{array}{c}01 \\
00.94\end{array}$ \\
\hline
\end{tabular}

Table 3.1(6) shows that the majority of individuals in the whole sample were of grade III intelligence, i.e intellectually average. A greater percentage of the male offenders were of grade IV and V (below average) intelligence when compared to the control groups which had a greater percentage of grades I and II intelligence (above average).

\section{Results - Correlational Analyses}

\section{Whole Sample}

Pearson's product moment correlations of the data collected from the whole sample group revealed several statistically significant correlation coefficients.

\section{Demographic Variables}

Table 3.1(7) gives results for all the correlation coefficients calculated in the whole sample group. 
Table 3.1(7) - Correlation Coefficients for Demographic Variables in the whole sample

\begin{tabular}{|c|c|c|c|c|c|c|c|}
\hline & $\mathbf{A G E}$ & סDE & ETHN & CLASS & SEG & SIB & SIB10 \\
\hline AGE & I & $0.39 * *$ & -0.06 & $-0.16 *$ & -0.05 & 0.03 & 0.09 \\
\hline סD & $0.39 * \star$ & i & -0.05 & $-0.43 * \star$ & $-0.37 * \star$ & -0.03 & -0.01 \\
\hline ETEN & 0.06 & -0.05 & I & -0.02 & -0.08 & $-0.16 *$ & $-0.21 \star$ \\
\hline CIASS & $-0.16 \star$ & $-0.43 * \star$ & -0.02 & I & $-0.68 * *$ & 0.09 & 0.06 \\
\hline SEG & 0.05 & $-0.68 * *$ & -0.08 & $0.68 * *$ & I & 0.07 & 0.04 \\
\hline SIB & 0.0 & -0.03 & $-0.16 *$ & 0.09 & 0.07 & I & $0.73 *$ \\
\hline SIB10 & 0.09 & -0.01 & $-0.21 * \star$ & 0.06 & 0.04 & $0.73 * \star$ & I \\
\hline RAV & $0.20 * \star$ & $0.52 * \star$ & -0.02 & $-0.45 * *$ & $-0.37 * *$ & -0.03 & 0.00 \\
\hline $\mathbf{P}$ & -0.01 & $-0.38 * \star$ & 0.08 & $0.19 *$ & $0.25 * \star$ & 0.17 * & $0.17 *$ \\
\hline $\mathbf{E}$ & -0.08 & -0.01 & 0.03 & -0.11 & -0.06 & -0.08 & -0.11 \\
\hline $\mathbf{N}$ & 0.03 & 0.12 & -0.06 & 0.09 & 0.16 * & 0.08 & -0.04 \\
\hline I & $-0.15^{\star}$ & -0.13 & 0.01 & 0.05 & 0.02 & 0.05 & 0.07 \\
\hline SRD & -0.02 & $-0.49 * *$ & $0.19 * \star$ & $0.28 * \star$ & $0.31 * \star$ & 0.03 & -0.09 \\
\hline PER & -0.09 & $-0.52 \star \star$ & 0.11 & $0.30 * *$ & $0.34 * *$ & -0.02 & -0.06 \\
\hline THEFT & -0.05 & $-0.58 * \star$ & $0.21 * \star$ & $0.35 * \star$ & $0.32 * \star$ & 0.07 & -0.04 \\
\hline MODAL & 0.17 * & $0.55^{*}$ * & -0.13 & $-0.29 * *$ & $-0.31 * *$ & -0.01 & 0.05 \\
\hline SRMS & 0.16 * & $0.60 * \star$ & -0.12 & $-0.40 * \star$ & $-0.38 * *$ & -0.02 & 0.05 \\
\hline GLOBAI & 0.16 * & $0.58 * *$ & -0.13 & $-0.39 * *$ & $-0.39 * *$ & 0.01 & 0.06 \\
\hline
\end{tabular}

${ }^{\star} \underline{p}<0.05 \quad *{ }^{*} \underline{p}<0.01$

Age (AGE): Age was found to correlate positively with:

1) Years in education (EDU, $r=0.39, \mathrm{p}<0.0005)$ indicating that as age increased so did the number of years spent in education.

2) Non-verbal intelligence as measured by Raven's progressive matrices (RAV, $\mathrm{r}=0.20, \mathrm{p}<0.001)$ indicating that the older an individual was the greater his/her intellectual capacity.

3) Modal stage of sociomoral reasoning (MODAL, $r=0.17, p<0.05$ ), sociomoral reflection maturity (SRMS, $\mathrm{r}=0.16, \mathrm{p}<0.05$ ) and global stage of sociomoral reasoning (GLOBAL, $\mathrm{r}=0.16, \mathrm{p}<0.05$ ) in all three cases showing that the older a participant was the greater his/her maturity in moral reasoning.

Age was found to correlate negatively with:

1) Social class (CLASS, $r=-0.16, p<0.05$ ) indicating that the older a participant was, the higher the social class to which he/she belonged. 
2) Lie scale for the Eysenck's personality questionnaire ( $\mathrm{L}, \mathrm{r}=-0.15, \mathrm{p}<0.05$ ) showing that the older a participant was, the less likely he/she was to respond in a socially desirable manner.

Years spent in education (EDU): Years in education correlated positively with:

1) Age (AGE, $r=0.39, p<0.0005$ ), showing that as age increased so did the number of years spent in education.

2) Non-verbal intelligence as measured by Raven's progressive matrices (RAV, $\mathrm{r}=0.52, \mathrm{p}<0.0005$ ), as the number of years spent in education increased so did an individual's intelligence.

3) Modal (MODAL, r=0.55, p<0.0005) and global (GLOBAL, r=0.58, $\mathrm{p}<0.0005$ ) stage of moral reasoning and sociomoral reasoning maturity (SRMS, $r=0.60, p<0.0005$ ): the greater the number of years spent in education, the greater an individual's maturity of sociomoral reasoning.

Education level correlated negatively with:

1) Social Class (CLASS, $r=-0.43, p<0.0005$ ) and Socio-economic group (SEG, $r=-$ $0.37, \mathrm{p}<0.0005)$, the lower the social and economic standing of an individual the fewer years he/she had spent in education.

2) Psychoticism ( $\mathrm{P}, \mathrm{r}=-0.38, \mathrm{p}<0.0005)$, the fewer years spent in education the greater a participant's psychoticism.

3) Self-reported delinquency ( $S R D, r=-0.49, p<0.0005$ ), crimes committed against the person (PER, $r=-0.52, \mathrm{p}<0.0005$ ) and against property (THEFT, $\mathrm{r}=-0.58, \mathrm{p}<0.0005$ ): the larger the number of years spent in education the less a participant tended to have committed any kind of crime.

Ethnic Origin (ETHN): correlated significantly with:

1) Self-reported delinquency $(\mathrm{SRD}, \mathrm{r}=0.19, \mathrm{p}<0.01)$ and crimes against property (THEFT, $r=0.21, p<0.005$ ) but not with crimes against the person (PER, $r=0.02, p>0.05$ ) 
indicating that those from non-minority ethnic groups were more likely to have committed general delinquent acts and thefts, but not crimes against the person.

2) The number of siblings before (SIB, $r=-0.16, p<0.05$ ), and after (SIB10, $r=-0.21$, $\mathrm{p}<0.005)$ the age of ten: if an individual was from a minority ethnic group he or she was also more likely to come from a larger family.

Social Class (CLASS): was found to correlate significantly positively with the following variables:

1) Socio-economic group (SEG, $r=0.68, \mathrm{p}<0.0005$ ): the lower a participant's social class the higher his/her SEG.

2) Psychoticism ( $\mathrm{P}, \mathrm{r}=0.19, \mathrm{p}<0.05)$ : the higher the participants' social class the lower their psychoticism.

3) Self-reported delinquency ( $S R D, r=0.35, p<0.0005$ ), crimes against the person (PER, $r=0.30, p<0.0005$ ), and against property (THEFT, $r=0.35, p<0.0005$ ): the lower the participants' social class the greater the amount of delinquency they had committed.

Social class also created significant positive correlations with:

1) Age (AGE, $r=-0.16, p<0.05$ ): the lower the participants' social class the younger they tended to be.

2) Years in education (EDU, $r=-0.43, p<0.0005$ ): the lower the participants' social class the fewer years they had spent in education.

3) Non-verbal intelligence (RAV, $r=-0.45, \mathrm{p}<0.0005$ ): the lower the participants' social class the lower their intelligence tended to be.

4) Modal (MODAL, $r=-0.29, p<0.0005$ ) and Global (GLOBAL, $r=-0.40, p<0.0005$ ) stage of sociomoral reasoning, and sociomoral reasoning maturity (SRMS, $r=-0.40$, $\mathrm{p}<0.0005)$ : the lower the participants' social class the less the mature their sociomoral reasoning tended to be.

Socio Economic Group (SEG): significant positive correlations were found with: 
1) Social Class (CLASS, $r=0.68, p<0.0005$ ): the lower the participants' social class the lower their socio-economic group tended to be.

2) Psychoticism ( $P, r=0.25, p<0.005)$ : the lower the participants' socio-economic group the greater their psychoticism tended to be.

3) Neuroticism (N, r=0.16, p<0.05): the lower the participants' socio-economic group the greater their neuroticism tended to be.

4) Self reported delinquency ( $S R D, r=0.30, p<0.0005$ ), crimes against the person (PER, $r=0.31, p<0.0005$ ), and against property (THEFT, $r=0.35, p<0.0005$ ): the lower the participants' socio-economic group the greater the amount of delinquency they had tended to have committed.

Several significant negative correlations were also found:

1) Years of education (EDU, $r=-0.38, p<0.0005)$ : the lower the participants' socioeconomic group the fewer years they had been spent in education.

2) Non-verbal intelligence (RAV, $r=-0.37, p<0.0005)$ : the lower the participants' socio-economic group the lower their intelligence tended to be.

3) Modal (MODAL, r=-0.31, p<0.0005), and Global (GLOBAL, $r=-0.38, p<0.0005$ ) stage of sociomoral reasoning, as well as sociomoral reasoning maturity (SRMS, $r=-0.38$, 0.0005): the lower the participants' socio economic group the less mature their sociomoral reasoning tended to be.

Number of siblings: both measures of family size, the number of siblings before (SIB) and after the age of ten (SIB10) correlated negatively with:

1) Ethnic origin (SIB vs. ETHN, $r=-0.16, p<0.05$, SIB10 vs. ETHN, $r=-0.21$, $\mathrm{p}<0.005)$ : the greater the participants' family size the more likely they were to belong to an ethnic minority.

These two measures (SIB and SIB10) correlated positively with: 
1) Psychoticism (SIB and P, r=0.17, p<0.05, SIB 10 and $P, r=0.17, p<0.05$ )

indicating that the greater the participants' psychoticism the more likely they were to belong to a large family.

Both these measures (SIB and SIB10) correlated positively with each other $(r=0.73$, $\mathrm{p}<0.0005)$

Psychological Variables - Personality

Table 3.1(8) gives the correlation coefficients calculated pertaining to the personality variables: Psychoticism (P), Extraversion (E), Neuroticism (N) and the Lie (L) scale.

Table 3.1(8) - Correlation Coefficients for Personality Variables in the whole sample

\begin{tabular}{|c|c|c|c|c|}
\hline VARIABLES & $\mathbf{P}$ & $\mathbf{E}$ & $\mathbf{N}$ & I \\
\hline $\mathbf{A G E}$ & -0.01 & -0.08 & 0.03 & $-0.15 *$ \\
\hline סDE & $-0.38 * \star$ & -0.01 & 0.12 & -0.13 \\
\hline ETEN & 0.08 & 0.03 & -0.06 & 0.01 \\
\hline CIASS & $0.19 *$ & -0.11 & 0.09 & 0.05 \\
\hline SEG & $0.25 * *$ & -0.06 & $0.16 *$ & 0.02 \\
\hline SIB & $0.17 *$ & -0.08 & 0.08 & 0.05 \\
\hline SIB10 & 0.17 * & -0.11 & -0.04 & 0.07 \\
\hline RAV & $-0.29 * *$ & 0.08 & 0.08 & $-0.14 *$ \\
\hline $\mathbf{P}$ & / & 0.05 & $-0.20 * *$ & -0.10 \\
\hline $\mathbf{5}$ & 0.05 & 1 & $-0.28 * *$ & -0.08 \\
\hline $\mathbf{N}$ & $-0.20 * *$ & $-0.28 * *$ & I & -0.04 \\
\hline I & -0.10 & -0.08 & -0.04 & / \\
\hline SRD & $0.54 * *$ & $0.19 *$ * & -0.09 & $-0.33 * \star$ \\
\hline PER & $0.37 * \star$ & 0.18 * & -0.07 & $-0.27 \star \star$ \\
\hline THEFT & $0.50 * *$ & 0.11 & -0.09 & $-0.18 * *$ \\
\hline MODAL & $-0.20 * \star$ & 0.03 & 0.03 & -0.04 \\
\hline SRMS & $-0.30 * *$ & -0.07 & 0.08 & -0.10 \\
\hline GLOBAI & $-0.28 * *$ & -0.06 & 0.06 & -0.08 \\
\hline
\end{tabular}

${ }^{*} \mathrm{p}<0.05 \quad * \star \mathrm{p} p<0.01$

Psychoticism $(\mathrm{P})$ : was found to correlate negatively at a significant level with several of the other psychological variables: 
1) Non-verbal intelligence as measured by Raven's progressive matrices (RAV, r=$0.29, \mathrm{p}<0.0005)$ : the greater the participants' intelligence the lower their psychoticism.

2) Neuroticism $(\mathrm{N}, \mathrm{r}=-0.20, \mathrm{p}<0.005)$ : the greater the participants' neuroticism the lower their psychoticism tended to be.

3) Modal moral reasoning stage (MODAL, $r=-0.20, p<0.01$ ): The more psychoticism an individual displayed the more likely that individual was to reason at a lower moral stage.

4) The sociomoral reflection maturity measure (SRMS, $r=-0.30, p<0.0005$ ): the greater the participants' psychoticism the less mature their sociomoral reasoning tended to be.

5) Global moral reasoning stage (GLOBAL, $r=-0.28, p<0.005$ ): the greater the participants' psychoticism the lower their moral reasoning stage tended to be.

The P scale was also found to correlate negatively with years spent in education (EDU, $\mathrm{r}=-0.38, \mathrm{p}<0.005)$ : The fewer the years the participants had spent in education the greater their psychoticism tended to be.

Positive correlation coefficients were obtained between P and the following variables:

1) Social Class (CLASS, $r=0.19, p<0.05$ ): The lower the participants' social class, the higher their psychoticism tended to be.

2) Socio-Economic Group ( $S E G, r=0.25, p<0.005$ ): the lower the participants' SEG, the higher their psychoticism tended to be.

3) Both the number of siblings before the age of $10(\mathrm{SIB}, \mathrm{r}=0.17, \mathrm{p}<0.05)$ and after the age of ten (SIB10, $r=0.17, \mathrm{p}<0.05)$ : Both measures indicating that the greater the participants' number of siblings the higher their psychoticism tended to be.

4) On all three measures of self reported delinquency ( $\mathrm{SRD}, \mathrm{r}=0.54, \mathrm{p}<0.0005)$, crimes against the person (PER, $r=0.37, \mathrm{p}<0.0005$ ), and theft (THEFT, $\mathrm{r}=0.50, \mathrm{p}<0.0005$ ): 
Which indicates that the higher the participants' psychoticism the greater their level of self-reported delinquency of all three types.

Extraversion (E): Extraversion correlated significantly with only three variables:

1) Neuroticism ( $N, r=-0.28, p<0.0005)$ : the greater the participants' extraversion the greater their neuroticism tended to be.

2) Self-reported delinquency ( $S R D, r=0.18, p<0.01)$ and crimes against the person (PER, $\mathrm{r}=0.18, \mathrm{p}<0.05$ ) : The greater the participants' neuroticism, the greater the amount of delinquency they had carried out.

Neuroticism (N): Neuroticism only correlated significantly with three measures:

1) Socio-Economic Group (SEG, $r=0.16, p<0.05$ ): The lower the participants' socioeconomic group the higher their neuroticism tended to be.

2) Psychoticism ( $P, r=-0.20, p<0.005)$ : The higher the participants' psychoticism the lower their neuroticism tended to be.

3) Extraversion $(E, r=-0.28, p<0.0005)$ : The higher the participants' neuroticism, the higher their extraversion tended to be.

Lie scale: The Lie scale of the Eysenck Personality questionnaire correlated negatively with five other variables:

1) Age (AGE, $r=-0.15, p<0.05$ ), showing that the older the participants were, the less likely they were to respond in a socially desirable manner.

2) Non-verbal intelligence as measured by Raven's progressive matrices (RAV, r=$0.14, p<0.05)$, suggesting that the greater the participants' intelligence, the less likely they were to respond in a socially desirable manner.

3) Self-reported delinquency ( $S R D, r=-0.33, p<0.0005$ ), crimes against the person (PER, $\mathrm{r}=-0.27, \mathrm{p}<0.0005$ ), and property crimes (THEFT, $\mathrm{r}=-0.18, \mathrm{p}<0.05)$ : indicating that as the more the participants' responded in a socially desirable manner, the greater the likelihood that they had committed more crimes. 
Psychological Variables - Intelligence (RAV)

Non-verbal intelligence as measured by Raven's standard progressive matrices

(Raven, Court and Raven, 1985) revealed several significant correlation coefficients. Table 3.1(9) shows the results.

Table 3.1(9) - Correlation Coefficients for Intelligence and sociomoral reasoning variables in the whole sample

\begin{tabular}{|c|c|c|c|c|}
\hline & RAV & MODAL & SRMS & GLOBAL \\
\hline AGE & $0.46 * \star$ & $0.17 *$ & $0.16 *$ & $0.16 *$ \\
\hline סDE & $0.52 * \star$ & $0.55 * \star$ & $0.60 * \star$ & $0.58 * *$ \\
\hline ETHN & -0.02 & -0.13 & -0.12 & -0.13 \\
\hline CIASS & $-0.45 * \star$ & $-0.29 * *$ & $-0.40 * \star$ & $-0.39 * *$ \\
\hline SEG & $-0.37 * *$ & $-0.31 * \star$ & $-0.38 * \star$ & $-0.38 * \star$ \\
\hline SIB & -0.03 & -0.01 & -0.02 & 0.01 \\
\hline SIB10 & 0.00 & 0.05 & 0.05 & 0.06 \\
\hline RAV & 1 & $0.47 * \star$ & $0.67 * \star$ & $0.62 * *$ \\
\hline $\mathbf{P}$ & $-0.29 * \star$ & $-0.20 * \star$ & $-0.30 * \star$ & $-0.28 * *$ \\
\hline $\mathbf{E}$ & 0.08 & 0.03 & -0.07 & -0.06 \\
\hline$\overline{\mathbf{N}}$ & 0.08 & 0.03 & 0.08 & 0.06 \\
\hline I & $-0.14 *$ & -0.04 & -0.10 & -0.08 \\
\hline SRD & $-0.33 * *$ & $-0.44 * \star$ & $-0.54 * \star$ & $-0.50 * *$ \\
\hline PER & $-0.33 * *$ & $-0.43 * \star$ & $-0.54 * \star$ & $-0.50 * *$ \\
\hline THEFT & $-0.45 * *$ & $-0.50 * *$ & $-0.65 * \star$ & $-0.62 * \star$ \\
\hline MODAI & $0.47 * \star$ & I & $0.73 * \star$ & $0.73 * *$ \\
\hline SRMS & $0.67 * \star$ & $0.73 * *$ & / & $0.96 * \star$ \\
\hline GLOBAL & $0.62 * \star$ & $0.73 * \star$ & $0.96 * \star$ & I \\
\hline
\end{tabular}
$*^{2} \underline{0}<0.05 \quad * * \underline{p}<0.01$

The following significant positive correlations were found in relation to intelligence:

1) Age (AGE, $r=0.20, p<0.01$ ): The older the participants were, the greater their intelligence tended to be.

2) Years in education (EDU, $r=0.52, p<0.0005$ ): The longer the participants had spent in education, the greater their intelligence tended to be.

3) Modal (MODAL, $r=0.47, p<0.0005$ ) and global (GLOBAL, $r=0.62, p<0.0005$ ) sociomoral reasoning stage and sociomoral reasoning maturity (SRMS, $r=0.67, \mathrm{p}<0.0005$ ): the greater the participants' intelligence, the greater their sociomoral reasoning maturity. 
Intelligence correlated significantly negatively with the following variables:

1) Social Class (CLASS, $r=-0.45, p<0.0005$ ) and socio-economic group ( $\mathrm{SEG}, \mathrm{r}=-$ $0.37, \mathrm{p}<0.0005)$, the lower the participants' social standing the lower their intelligence.

2) Psychoticism ( $P, r=-0.29, p<0.0005)$ : the greater the psychoticism the lower the intelligence of the individual.

3) Lie scale ( $\mathrm{L}, \mathrm{r}=-0.14, \mathrm{p}<0.05)$ : the greater the participants' intelligence, the less likely they were to respond in a socially desirable manner.

4) Self-reported delinquency ( $S R D, r=-0.32, p<0.0005$ ), crimes committed against the person (PER, $r=-0.33, \mathrm{p}<0.0005$ ), and against property (THEFT, $\mathrm{r}=-0.45, \mathrm{p}<0.0005$ ): the greater the participants' intelligence, the lower their general delinquency level tended to be.

$\underline{\text { Psychological Variables - Sociomoral Reflection (Moral Reasoning) }}$

All three measures of sociomoral reflection, Modal stage (MODAL), sociomoral reflection maturity measure (SRMS) and Global stage (GLOBAL); correlate with only the following variables positively (please refer to table 3.1(9) for details of $r$ values and significance levels):

1) Age (AGE): indicating that the older the participants, the greater their maturity of sociomoral reasoning.

2) Years spent in education (EDU): suggesting that as the longer the participants had spent in education, the greater their maturity of sociomoral reasoning.

3) Non-verbal intelligence as measured by Raven's progressive matrices (RAV): indicating that the higher the intelligence of the participants, the greater their sociomoral reasoning maturity tended to be.

All three measures produced significant positive correlations with each other.

The remaining significant correlations were all found to be negative: 
1) Social Class (CLASS) and socio-economic group (SEG): The lower the participants' social class, the less mature their sociomoral reasoning tended to be.

2) Psychoticism (P): the higher the participants' psychoticism, the lower their sociomoral reasoning stage tended to be.

3) Self reported delinquency (SRD), crimes committed against the person (PER) and property (THEFT): showing that the lower the participants' moral reasoning stage, the greater the number of crimes they tended to have committed.

\section{Offending History}

The offending history of the participants was represented in three measures: Self Reported Delinquency (SRD), crimes committed against the person (PER) and crimes committed against property (THEFT). Table 3.1(10) shows the resulting coefficients. 
Table 3.1(10) - Correlation Coefficients for Offending History Variables in the whole sample

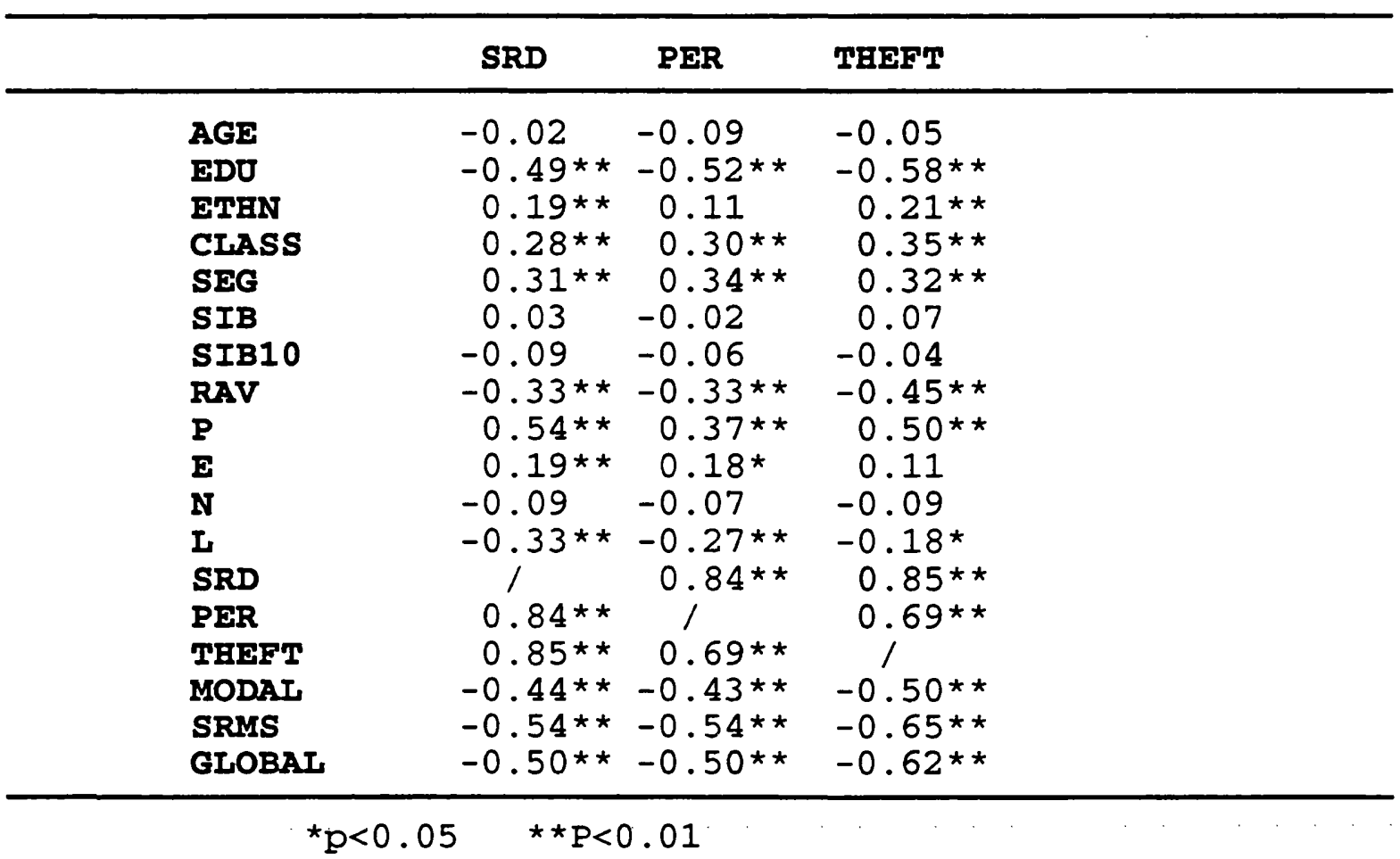

Self-Reported Delinquency (SRD): produced significant positive correlations with:

1) Ethnic origin $(E T H N, r=0.19, p<0.05)$ : indicating that those individuals who offended least tended to come from ethnic minorities.

2) Social Class (CLASS, $r=0.28, p<0.0005$ ) and socio-economic group (SEG, $\mathrm{r}=0.31, \mathrm{p}<0.0005$ ): the lower the participants' social standing the greater the amount of crime they tended to have committed.

3) Psychoticism ( $P, r=0.54, p<0.0005)$ : the greater the participants' psychoticism, the more delinquent they tended to have been.

4) Extraversion ( $E, r=0.19,0.05)$ : the greater the participants' extraversion, the more offending they tended to have carried out.

5) Crimes against the person ( $P E R, r=0.84, p<0.0005$ ) and against property (THEFT, $\mathrm{r}=0.85, \mathrm{p}<0.0005$ ): the greater the amount of general delinquency committed by the participants, the greater the number of property and violent crimes they had committed.

The following negative significant correlations were also found: 
1) Years of education (EDU, $r=-0.49, p<0.0005$ ): the more years the participants had spent in education the less delinquency they tended to have committed.

2) Lie scale ( $\mathrm{L}, \mathrm{r}=-0.33, \mathrm{p}<0.0005)$ : the more delinquent an individual was, the less likely he/she was to respond in a socially desirable manner.

3) Non-verbal intelligence (RAV, $r=-0.33, p<0.0005)$ : the greater the participants' intelligence, the less delinquency they tended to have committed.

4) Modal (MODAL, $r=-0.45, p<0.0005$ ) and Global (GLOBAL, $r=-0.50, p<0.0005$ ) stage of moral reasoning as well as sociomoral reasoning maturity (SRMS, $r=-0.45$, $\mathrm{p}<0.0005)$ : the greater the participants' sociomoral reasoning maturity, the less general delinquency they tended to have committed.

Crimes against the Person (PER): correlated positively with the following variables:

1) Social Class (CLASS, $r=0.30, p<0.0005$ ), and socio-economic group (SEG, $\mathrm{r}=0.37, \mathrm{p}<0.0005)$ : the lower the participants' social standing, the greater the number of crimes they had committed against the person.

2) Psychoticism ( $P, r=0.37, p<0.0005)$ : the greater the participants' psychoticism, the more crimes they tended to have committed against the person.

3) Extraversion (E, $r=0.18, p<0.0005)$ : the greater the participants' extraversion, the greater the number of crimes against the person they tended to have committed.

4) Self-reported delinquency ( $S R D, r=0.84, p<0.0005)$ and crimes against property (THEFT, $r=0.69, p<0.0005$ ): the greater the number of crimes against persons the participants had committed, the greater the number of other types of delinquency they tended to have committed.

The following significant negative correlations were also found:

1) Years in education (EDU, $r=-0.52, p<0.0005$ ): the more time the participants had spent in education, the fewer crimes against people they tended to have committed. 
2) Non-verbal intelligence ( $R A V, r=-0.33, p<0.0005)$ : the greater the participants' intelligence, the fewer crimes against the person they tended to have committed.

3) Lie scale ( $\mathrm{L}, \mathrm{r}=-0.27, \mathrm{p}<0.0005$ ): the greater the participants' tendency to respond in a socially desirable manner, the fewer crimes against the person they tended to have committed.

4) Modal (MODAL, r=-0.43, $\mathrm{p}<0.0005$ ) and Global (GLOBAL, $\mathrm{r}=-0.50, \mathrm{p}<0.0005$ ) moral reasoning stage, as well as sociomoral reasoning maturity (SRMS, $r=-0.54$, $\mathrm{p}<0.0005)$ : the greater the participants' maturity in sociomoral reasoning, the fewer crime against the person they tended to have committed.

Crimes against Property (THEFT): correlated significantly positively with the following variables:

1) Ethnic group (ETHN, $r=0.21, p<0.005)$ : indicating that fewer thefts tended to have been committed by participants from minority ethnic groups.

2) Social Class (CLASS $r=0.35, p<0.0005$ ) and socio- economic group (SEG, $\mathrm{r}=0.32, \mathrm{p}<0.0005)$ : the greater the participants' social standing, the greater the amount of thefts they tended to have committed.

3) Psychoticism ( $P, r=0.50, p<0.0005)$ : as psychoticism increased the amount of theft also increased.

4) Self Reported Delinquency ( $S R D, r=0.85, p<0.0005$ ) and crimes committed against the person (PER $r=0.69, \mathrm{p}<0.0005$ ): the greater the number of crimes against property the participants had committed, the greater the tendency that they had also committed other types of crime.

The following significant negative correlations were found with crimes against property:

1) Years in education (EDU, $r=-0.58, \mathrm{p}<0.0005$ ): the more years the participants had spent in education, the fewer thefts they tended to have committed. 
2) Non-verbal intelligence (RAV, $r=-0.45, p<0.0005)$ : the greater the participants' intelligence, the fewer thefts they tended to have committed.

3) Lie scale $(\mathrm{L}, \mathrm{r}=-0.18, \mathrm{p}<0.0005)$ : the more the participants tended to respond in a socially desirable manner, the fewer thefts they had committed.

4) Modal (MODAL r=-0.50, $\mathrm{p}<0.0005)$ and global (GLOBAL, $r=-0.62, \mathrm{p}<0.0005)$ stages and maturity (SRMS, $r=-0.62, p<0.0005)$ of sociomoral reasoning: the greater the participants' maturity in sociomoral reasoning, the fewer thefts they tended to have committed.

\section{Male Offenders}

Pearson's product moment correlations were found to be significant between the following variables within the sample of male young offenders.

\section{Demographic Variables}

Several significant correlation coefficients were found with demographic variables: years spent in education (EDU) ethnic origin (ETHN), social class (CLASS) and socioeconomic group (SEG), and number of siblings before the age of ten (SIB) and after the age of ten (SIB10). No significant correlations were found with the variable age (AGE). The details are shown in table 3.1(11). 
Table 3.1(11) - Correlation Coefficients for Demographic Variables in the male young offender sample

\begin{tabular}{lccccccc}
\hline & AGE & EDU & ETHN & CLASS & \multicolumn{1}{c}{ SEG } & \multicolumn{1}{c}{ SIB } & \multicolumn{1}{c}{ SIBI0 } \\
\hline AGE & $/$ & 0.20 & -0.05 & -0.15 & 0.03 & -0.13 & -0.03 \\
EDD & 0.20 & $/$ & 0.05 & -0.08 & 0.08 & 0.02 & -0.06 \\
ETHN & -0.05 & 0.05 & $/$ & $0.28 *$ & 0.19 & -0.15 & -0.16 \\
CIASS & -0.15 & -0.08 & $0.28 *$ & $/$ & $0.55 * *$ & 0.00 & 0.06 \\
SEG & 0.03 & 0.08 & 0.19 & $0.55^{\star} *$ & $/$ & 0.01 & 0.06 \\
SIB & -0.13 & 0.02 & -0.15 & 0.00 & 0.01 & $/$ & $0.62 * *$ \\
SIB10 & -0.03 & -0.06 & -0.16 & 0.06 & 0.06 & $0.62 * *$ & $/$ \\
RAV & 0.07 & 0.02 & -0.05 & -0.23 & -0.08 & -0.02 & -0.05 \\
P & -0.11 & $-0.33 * *$ & -0.02 & 0.24 & 0.20 & 0.18 & $0.27 *$ \\
E & -0.05 & 0.04 & 0.00 & -0.20 & -0.13 & -0.04 & -0.14 \\
N & 0.02 & 0.19 & -0.03 & -0.15 & 0.04 & 0.09 & -0.02 \\
I & -0.08 & -0.05 & 0.11 & -0.03 & 0.00 & 0.07 & 0.11 \\
SRD & -0.03 & -0.10 & 0.03 & 0.10 & 0.01 & -0.05 & -0.16 \\
PER & -0.02 & -0.06 & 0.02 & 0.34 & 0.08 & -0.10 & -0.09 \\
THEFT & -0.02 & -0.15 & -0.06 & 0.06 & -0.04 & 0.02 & -0.08 \\
MODAL & 0.05 & 0.23 &. & 0.07 & 0.09 & 0.21 & 0.21 \\
SRMS & 0.11 & 0.02 &. & -0.16 & -0.04 & 0.18 & 0.19 \\
GLOBAI & 0.10 & 0.02 &. & -0.14 & -0.02 & 0.22 & $0.25 *$ \\
\hline
\end{tabular}

${ }^{*} \underline{p}<0.05 \quad *{ }^{*} \mathrm{p}<0.01 \quad$. indicates missing value

Years of Education (EDU): was found to correlate significantly only with

Psychoticism ( $\mathrm{P}, \mathrm{r}=-0.33, \mathrm{p}<0.005)$ : the greater the offenders' psychoticism the fewer years they tended to have been spent in education.

Ethnic Origin (ETHN): the only significant correlation found, which was positive, was that with Social Class (CLASS, $r=0.28, p<0.05$ ): indicating that those offenders from the higher social classes tended to be associated with ethnic minority groups. No correlations were possible with the Moral Reasoning Variables due to a large number of missing values.

Social class (CLASS): significant positive correlations were found with:

1) Ethnic Origin $(E T H N, r=0.28, p<0.05)$ : showing that those offenders from the higher social classes tended to also be of minority ethnic origin.

2) Socio Economic Group (SEG, $r=0.55, \mathrm{p}<0.0005$ ): the lower the offenders' social class, the lower their SEG tended to be. 
Socio-Economic Group (SEG): correlated significantly only with Social Class (CLASS, $\mathrm{r}=0.55, \mathrm{p}<0.0005$ ): showing that the higher the offenders' socio economic group the higher their social class tended to be.

Number of Siblings:- the two measures of family size, number of siblings before (SIB) and after (SIB10) the age of ten correlated significantly only with each other $(\mathrm{r}=0.62, \mathrm{p}<0.0005)$ : indicating that the larger the offenders' family before the age of ten, the larger their family after that age.

\section{Psychological Variables}

Several significant correlation coefficients were found between the psychological variables measured: intelligence, personality and moral reasoning; and the other variables, within the male offender sample group.

\section{Personality}

Table 3.1(12) shows the correlation coefficients relating to the four personality variables: Psychoticism (P), Extraversion (E), Neuroticism (E), and the Lie (L) score. 
Table 3.1(12) - Correlation Coefficients for Personality Variables in the male young offender sample

\begin{tabular}{lccrr}
\hline & $\mathbf{P}$ & $\mathbf{E}$ & \multicolumn{1}{c}{$\mathbf{N}$} & \multicolumn{1}{c}{$\boldsymbol{I}$} \\
\hline AGE & -0.11 & -0.05 & 0.02 & -0.08 \\
EDU & $-0.33^{*}$ & 0.04 & 0.19 & -0.05 \\
ETHN & -0.02 & 0.00 & -0.03 & 0.11 \\
CIASS & 0.24 & -0.20 & -0.15 & -0.03 \\
SEG & 0.20 & -0.13 & 0.04 & 0.00 \\
SIB & 0.18 & -0.04 & 0.09 & 0.07 \\
SIB10 & $0.27 *$ & -0.14 & -0.01 & 0.11 \\
RAV & -0.14 & $0.23 *$ & 0.10 & -0.21 \\
P & $/$ & -0.03 & -0.16 & -0.10 \\
E & -0.03 & $/$ & -0.20 & -0.12 \\
N & -0.16 & -0.20 & $/$ & -0.09 \\
I & -0.10 & -0.12 & -0.09 & $/$ \\
SRD & $0.42 * *$ & 0.16 & -0.03 & $-0.45 * \star$ \\
PER & 0.20 & $0.25 *$ & -0.03 & -0.42 \\
THEFT & $0.37 * \star$ & 0.10 & -0.05 & -0.24 \\
MODAL & 0.01 & 0.17 & 0.04 & 0.03 \\
SRMS & 0.06 & 0.11 & -0.22 & -0.22 \\
GLOBAI & 0.11 & 0.12 & -0.18 & -0.18 \\
\hline
\end{tabular}

${ }^{\star} \mathrm{p}<0.05 \quad * * \mathrm{p}<0.01$

Psychoticism (P): a significant negative correlation was found with years of education (EDU, $\mathrm{r}=-0.33, \mathrm{p}<0.005$ ): the greater the offenders' psychoticism the fewer years they had spent in education.

Significant positive correlations were found with:

1) The number of siblings after the age of ten (SIB10, $r=0.27, p<0.05$ ): the larger the offenders' family after the age of ten, the greater their psychoticism, but no relationship was found with the number of siblings before the age of ten.

2) Self Reported Delinquency ( $S R D, r=0.42, p<0.0005)$ and crimes committed against property (THEFT, $r=0.37, \mathrm{p}<0.0005$ ): the greater the offenders' psychoticism the greater their general delinquency and number of thefts they had committed.

Extraversion (E): only resulted in two significant positive correlations:

1) Non-verbal Intelligence (RAV, $r=0.23, p<0.05$ ): the greater the offenders' extraversion, the greater their intelligence tended to be. 
2) Crimes against the Person (PER, $r=0.25, p<0.05$ ): the greater the offenders' extraversion the greater the number of violent crimes they tended to have committed.

Neuroticism $(\mathrm{N})$ : No significant coefficients were obtained with this personality score.

Lie Scale $(\mathrm{L})$ : significant negative correlations were found with the following variables:

1) Non-Verbal Intelligence ( $R A V, r=-0.21, p<0.05)$ : the greater the offenders' intelligence the lower their tendency to respond in a socially desirable manner.

2) Self Reported Delinquency ( $S R D, r=-0.45, p<0.0005$ ), crimes of property (THEFT, $r=-0.24, p<0.05$ ) and violent crimes (PER, $r=-0.42,0.0005)$ : the greater the offenders general delinquency level, the lower their tendency to respond in a socially desirable manner.

\section{Intelligence (RAV)}

Table 3.1(13) shows the correlation coefficients for non-verbal intelligence as measured by Raven's standard progressive matrices (Raven, Court and Raven, 1985). 
Table 3.1(13) - Correlation Coefficients for Intelligence and sociomoral reasoning variables in the male young offender sample

\begin{tabular}{|c|c|c|c|c|}
\hline & RAV & MODAL & SRMS & GLOBAI \\
\hline AGE & 0.07 & 0.05 & 0.11 & 0.10 \\
\hline ED & 0.02 & 0.23 & 0.02 & 0.02 \\
\hline ETHN & -0.05 & & . & \\
\hline CIASS & -0.23 & 0.07 & -0.16 & -0.14 \\
\hline SEG & -0.08 & 0.09 & -0.04 & -0.02 \\
\hline SIB & -0.02 & 0.21 & 0.18 & 0.22 \\
\hline SIB10 & -0.05 & 0.21 & 0.19 & $0.25 *$ \\
\hline RAV & 1 & $0.24 *$ & $0.54 * *$ & $0.44 * *$ \\
\hline P & -0.14 & 0.01 & 0.06 & 0.11 \\
\hline $\mathbf{E}$ & 0.23 * & 0.17 & 0.11 & 0.12 \\
\hline $\mathbf{N}$ & 0.10 & 0.04 & $0.12^{\circ}$ & 0.05 \\
\hline I & -0.21 & 0.03 & -0.22 & -0.18 \\
\hline SRD & 0.13 & -0.10 & 0.23 & 0.16 \\
\hline PER & 0.20 & -0.07 & 0.17 & 0.18 \\
\hline TEEFT & 0.02 & -0.19 & 0.01 & -0.07 \\
\hline MODAI & $0.24 *$ & / & $0.45 * *$ & $0.38 * *$ \\
\hline SRMS & $0.55 * *$ & $0.45 * \star$ & / & $0.92 * *$ \\
\hline GLOBAI & $0.44 * \star$ & $0.38 * \star$ & $0.92 * \star$ & / \\
\hline
\end{tabular}

${ }^{*} \mathrm{p}<0.05 \quad * \star \mathrm{p}<0.01$

Four significant positive correlations were found:

1) Extraversion $(E, r=0.23, p<0.05)$ : the greater the offenders' intelligence, the greater their extraversion tended to be.

2) Modal (MODAL, r=0.24, $\mathrm{p}<0.05$ ) and Global (GLOBAL, $\mathrm{r}=0.44, \mathrm{p}<0.0005$ ) stage; and maturity of sociomoral reasoning ( $S R M S, r=0.54, p<0.0005$ ): the greater the offenders' intelligence the more mature their sociomoral reasoning.

Only one significant negative correlation was found with the Lie scale ( $\mathrm{L}, \mathrm{r}=-0.21$, $\mathrm{p}<0.05)$ : the greater the offenders' intelligence the lower their tendency to respond in a socially desirable manner. 


\section{Sociomoral Reflection (Moral Reasoning)}

Table 3.1(13) shows the correlation coefficients pertaining to the three measures of sociomoral reflection: Modal (MODAL) and Global (GLOBAL) stage and sociomoral reflection maturity score (SRMS).

Modal Stage (MODAL): three significant positive correlations were found:

1) Non-Verbal Intelligence ( $R A V, r=0.24, p<0.05$ ): the greater the offenders' intelligence the higher their moral reasoning stage tended to be.

2) Global stage (GLOBAL, $r=0.38, p<0.0005)$ and sociomoral reflection maturity (SRMS, 0.45, $\mathrm{p}<0.0005$ ): the higher the offenders' modal stage of moral reasoning, the their maturity of sociomoral reflection.

Sociomoral Reflection Maturity (SRMS): three significant positive correlations were found:

1) Non-Verbal Intelligence ( $R A V, r=0.55, p<0.0005$ ): the greater the offenders' intelligence, the greater their moral reasoning maturity tended to be.

2) Global stage (GLOBAL, $r=0.92, p<0.0005$ ) and modal stage (MODAL, 0.45, $\mathrm{p}<0.0005)$ : the greater the offenders' sociomoral reflection maturity, the higher their global and modal stage of sociomoral reasoning.

Global Stage (GLOBAL): four significant positive correlations were found:

1) Number of siblings after the age of ten (SIB10, $r=0.25, \mathrm{p}<0.05)$ : the larger the offenders' family after the age of 10 , the higher their global stage of reasoning.

2) Non-Verbal Intelligence ( $R A V, r=0.44, p<0.0005$ ): the greater the offenders' intelligence, the higher their global moral reasoning stage tended to be.

3) Modal stage (MODAL, $r=0.38, p<0.005$ ) and sociomoral reflection maturity (SRMS, 0.92, $\mathrm{p}<0.0005$ ): the higher the offenders' global stage of moral reasoning, the greater their maturity of moral reasoning and the higher their global stage of moral reasoning tended to be. 


\section{Offending History}

Table 3.1(14) shows the Pearson's correlation coefficients found for the three measures of offending history: Self-reported delinquency (SRD), crimes against the person (PER) and property crimes (THEFT).

Table 3.1(14) - Correlation Coefficients for Offending History Variables in the male young offender sample

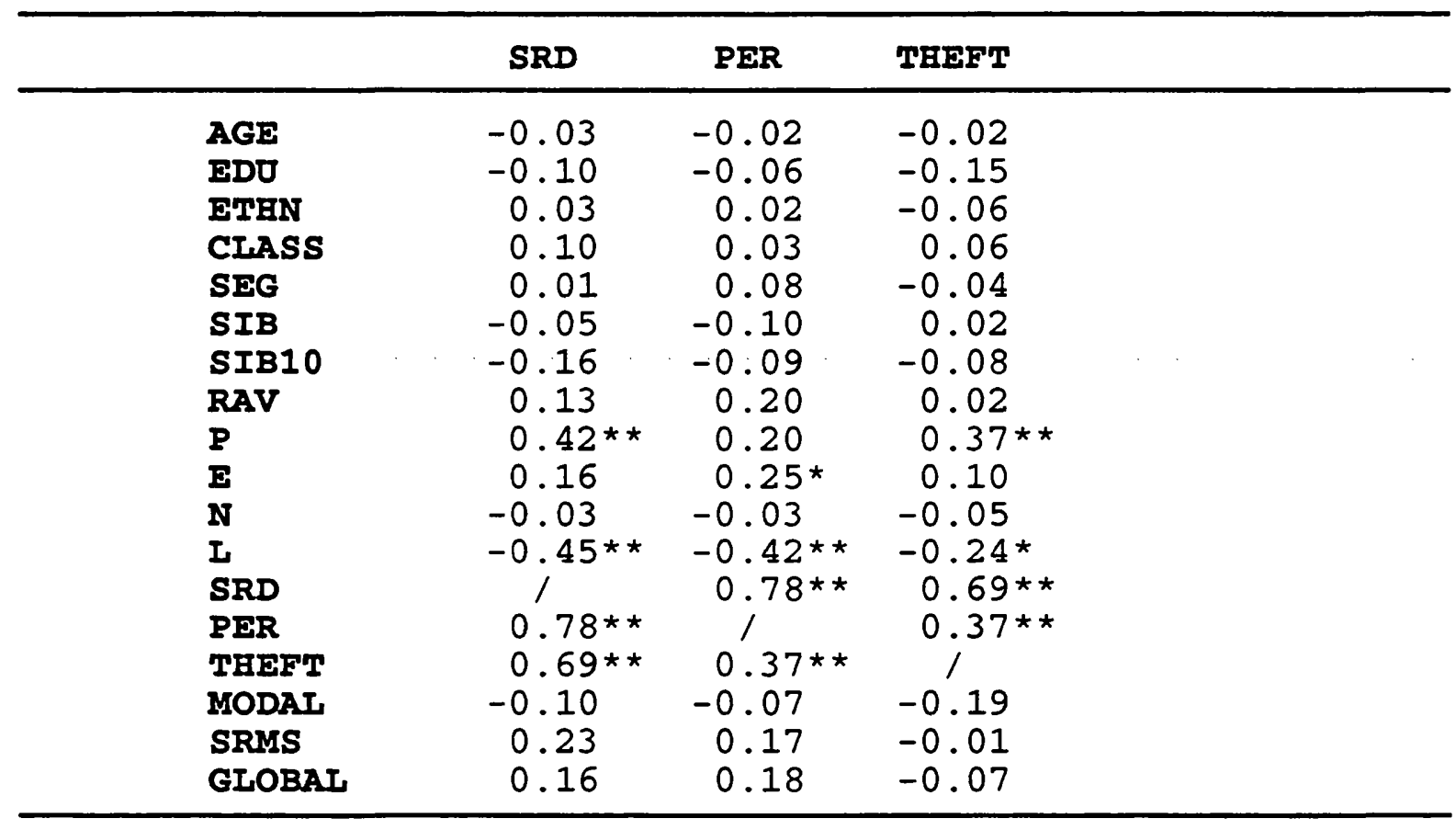

$$
{ }^{*} \underline{p}<0.05 \quad *{ }^{2} \underline{p}<0.01
$$

Self Reported Delinquency (SRD): correlated significantly positively with:

1) Psychoticism (P, $r=0.42, p<0.0005)$ : the greater the offenders' psychoticism the more general offending they tended to commit.

2) Crimes against the person ( $P E R, r=0.78, p<0.0005$ ) and against property (THEFT, $r=0.69, \mathrm{p}<0.0005$ ): the greater the offenders' general delinquency level, the greater the number of other offence types they tended to have committed. 
Self-reported Delinquency correlated significantly negatively only with the Lie scale $(\mathrm{L}, \mathrm{r}=-0.45, \mathrm{p}<0.0005)$ : the greater the offenders' general delinquency level, the lower their tendency to respond in a socially desirable manner.

Crimes Against the Person (PER): correlated significantly positively with:

1) Extraversion ( $E, r=0.25, p<0.05)$ : the greater the offenders' extraversion, the more violent crimes they tended top have committed.

2) Crimes against property (THEFT, r=0.37, p<0.0005) and self reported delinquency $(S R D, r=0.78, p<0.0005):$ the greater the number of violent crimes the offenders' had committed, greater the number of other offence types they tended to have committed.

Only one significant negative correlation was obtained with the Lie scale (L, r=$0.24, \mathrm{p}<0.05)$ : the greater the offenders' tendency to respond in a socially desirable manner, the greater the number of violent crimes they tended to have committed.

Crimes against Property (THEFT): three significant positive correlations were obtained:

1) Psychoticism ( $P, r=0.37, p<0.005)$ : the greater the offenders' psychoticism, the greater the number of crimes against property they tended to have committed.

2) Self Reported Delinquency (SRD, $r=0.69,0.0005$ ) and crimes against the person (PER, $r=0.37,0.0005)$ : the greater the number of thefts the offenders had committed, the greater their general delinquency level and number of violent crimes they had carried out.

One significant negative correlation was obtained with the Lie scale $(\mathrm{L}, \mathrm{r}=-0.24$, $\mathrm{p}<0.05)$ : the greater the number of thefts committed by the offenders, the lower their tendency to respond in a socially desirable manner. 


\section{$\underline{\text { Male Controls }}$}

Correlation coefficients were calculated for all the variables collected in the male control sample.

\section{Demographic Variables}

Table 3.1(15) shows the correlation coefficients pertaining to the demographic: age (AGE), years spent in education (EDU), ethnic origin (ETHN), social class (CLASS), socio-economic group (SEG), number of siblings before the age of ten (SIB) and after the age of ten (SIB10).

Table 3.1(15) - Correlation Coefficients for Demographic Variables in the male control sample

\begin{tabular}{|c|c|c|c|c|c|c|c|}
\hline & AGE & סDE & ETHN & CIASS & SEG & SIB & SIB10 \\
\hline AGE & / & $0.75 * \star$ & 0.29 & -0.10 & -0.12 & 0.28 & 0.20 \\
\hline EDO & $0.75 * \star$ & I & 0.41 & -0.30 & $-0.42 *$ & 0.05 & 0.01 \\
\hline ETHN & 0.29 & $0.41 *$ & I & -0.10 & -0.28 & -0.06 & -0.11 \\
\hline CLASS & -0.10 & -0.30 & -0.30 & I & $0.75 * \star$ & 0.05 & 0.07 \\
\hline SEG & -0.12 & -0.42 * & -0.28 & $0.75 * \star$ & / & -0.03 & 0.02 \\
\hline SIB & 0.28 & 0.05 & -0.06 & 0.05 & -0.03 & I & $0.93 * *$ \\
\hline SIB10 & 0.20 & 0.01 & -0.11 & 0.07 & 0.02 & $0.93 * \star$ & / \\
\hline RAV & 0.26 & 0.30 & -0.03 & -0.28 & -0.09 & -0.05 & -0.07 \\
\hline $\mathbf{P}$ & 0.31 & 0.14 & 0.23 & -0.09 & -0.02 & 0.12 & 0.00 \\
\hline $\boldsymbol{E}$ & -0.07 & 0.13 & -0.01 & $-0.38 *$ & -0.15 & -0.19 & -0.06 \\
\hline $\mathbf{N}$ & -0.01 & -0.05 & -0.03 & $0.54 * \star$ & 0.42 * & 0.08 & 0.05 \\
\hline I & -0.17 & -0.32 & -0.08 & 0.29 & 0.19 & 0.12 & 0.07 \\
\hline SRD & 0.25 & 0.10 & 0.24 & -0.35 & -0.25 & 0.16 & 0.10 \\
\hline PER & -0.16 & -0.19 & 0.04 & -0.34 & -0.29 & 0.07 & 0.05 \\
\hline THEFT & 0.32 & 0.25 & 0.34 & -0.03 & -0.02 & 0.19 & 0.14 \\
\hline MODAI & 0.00 & 0.02 & -0.10 & $-0.38 *$ & -0.28 & 0.15 & 0.08 \\
\hline SRMS & 0.08 & 0.08 & -0.14 & -0.28 & -0.06 & 0.07 & 0.09 \\
\hline GLOBAI & 0.08 & 0.03 & -0.24 & -0.34 & -0.12 & 0.15 & 0.11 \\
\hline
\end{tabular}

${ }^{*} \mathrm{p}<0.05 \quad * * \mathrm{p}<0.01$

Age (AGE): the only significant correlation found with age in this sample group was a positive correlation with years spent in education (EDU, $r=0.75, p<0.0005$ ): 
indicating that the older the male controls were, the more years they had spent in education.

Years in Education (EDU): two significant positive correlations were found with:

1) Age (AGE, $r=0.75, p<0.005)$ : the older the participants, the more years they had spent in education.

2) Ethnic origin (ETHN, $r=0.41, p<0.05)$ : the male control participants from nonminority ethnic groups, tended to have spent more years in education.

Only one significant negative correlation was found, that with socio-economic group (SEG, $r=-0.42, p<0.05$ ): the lower the male controls' the socio-economic standing, the fewer years they had spent in education.

Ethnic Origin (ETHN): only one significant correlation was obtained, which was positive, that with years of education (EDU, $r=0.41, p<0.05$ ): those participants from nonminority ethnic groups had spent more years in education.

Social Class (CLASS): two significant positive correlations were found:

1) Socio-economic group ( $\mathrm{SEG}, \mathrm{r}=0.75, \mathrm{p}<0.0005$ ): the higher the male control participants' social class the higher their socio-economic group tended to be.

2) Neuroticism (N, $r=0.54, p<0.005)$ : the higher the participants' social class the lower their neuroticism tended to be.

Two significant negative correlations were also found:

1) Extraversion $(E, r=-0.38, p<0.05)$ : the higher the participants' social class, the greater their extraversion tended to be.

2) Modal stage of moral reasoning (MODAL, $\mathrm{r}=-0.38, \mathrm{p}<0.05$ ): the higher the participants' social class the higher their stage of moral reasoning tended to be.

Socio-economic Group (SEG): two significant positive correlations were found:

1) Social Class (CLASS, $r=0.75, p<0.0005$ ): the higher the male control participants' SEG the higher their social class tended to be. 
2) Neuroticism (N, $r=0.42, p<0.05)$ : the higher the male control participants' SEG the lower their neuroticism tended to be.

Only one significant negative correlation was found, that with years of education (EDU, $r=-0.42, p<0.05)$ : the lower the male control participants' SEG, the fewer years they tended to have spent in education.

Number of siblings: the number of siblings before (SIB) and after the age of ten (SIB10) correlated only with each other $(r=0.93, p<0.0005)$ : the larger the male controls' family before the age of ten, the larger it tended to be after that age.

\section{Psychological Variables}

Correlation coefficients were calculated for the psychological variables collected, namely personality, intelligence, and moral reasoning.

\section{$\underline{\text { Personality }}$}

Significant correlations were found with the four personality variables:

Psychoticism (P), Extraversion (E), Neuroticism (N) and the Lie scale (L). Table 3.1(16) shows the resulting coefficients and indicates those which were found to be significant. 
Table 3.1(16) - Correlation Coefficients for Personality Variables in the male control sample

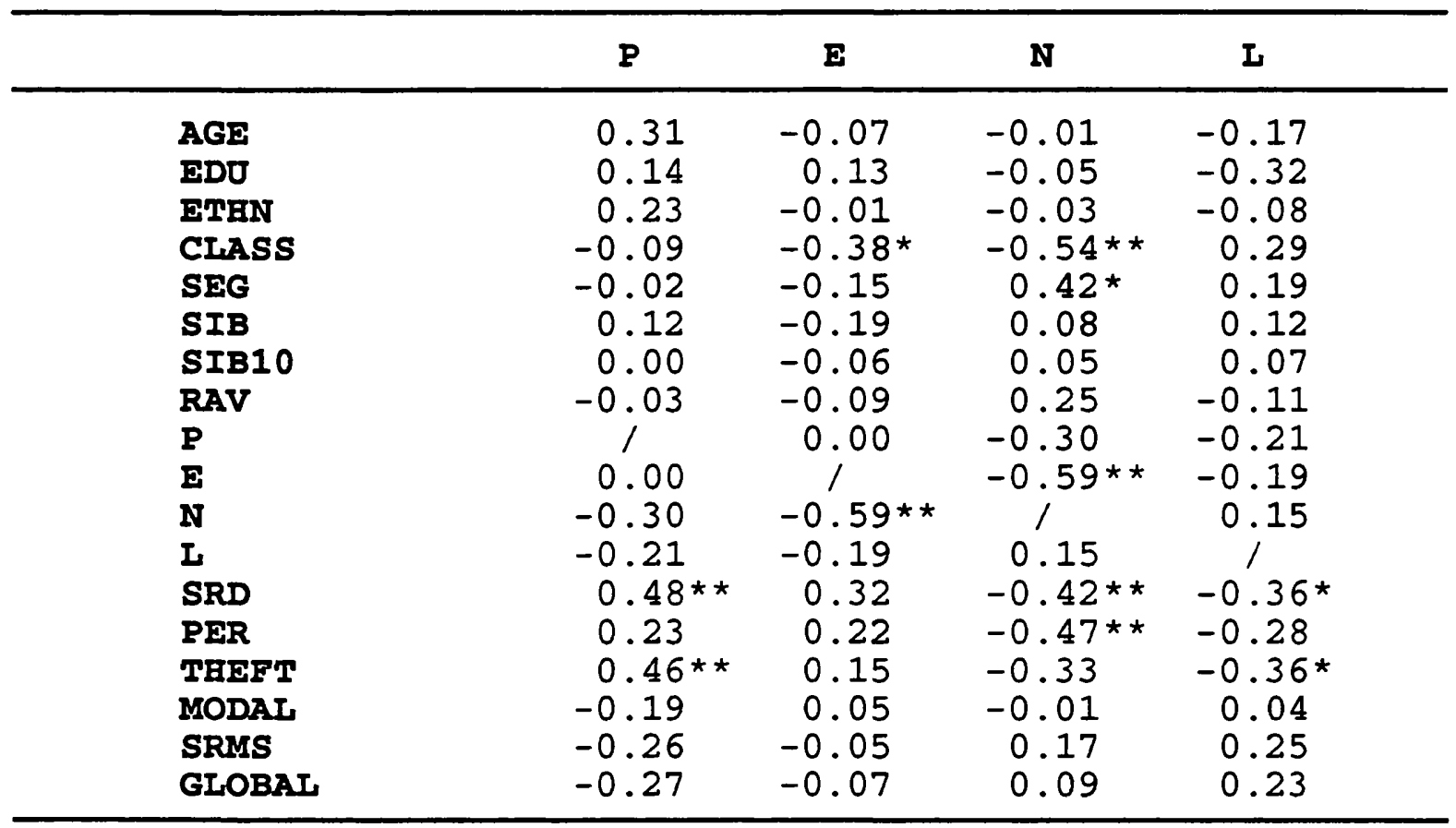

${ }^{*} \mathrm{p}<0.05 \quad{ }^{*} \mathrm{E} \mathrm{p}<0.01$

Psychoticism $(\mathrm{P})$ : only two positive correlations were found, which were positive:

1) Self-Reported Delinquency ( $S R D, r=0.48, p<0.005$ ): the greater the male controls' psychoticism, the greater the amount of general delinquency they tended to have carried out.

2) Crimes of Property (THEFT, $r=0.46, p<0.001$ ): the greater the male controls' psychoticism, the greater the amount of theft they tended to have carried out.

Extraversion (E): only two correlations were found, both of which were negative:

1) Social Class (CLASS, $r=-0.38, p<0.03$ ): the higher the male controls' social class, the higher their extraversion tended to be.

2) Neuroticism (N, $r=-0.59, p<0.0005)$ : the higher the male controls' extraversion the higher their neuroticism tended to be.

Neuroticism (N): two significant positive correlations were found: 
1) Social Class (CLASS, $r=0.54, p<0.005$ ): the higher the male controls social class, the lower their neuroticism tended to be.

2) Socio-economic group ( $\mathrm{SEG}, \mathrm{r}=0.42, \mathrm{p}<0.05$ ): the higher the male controls' socio-economic group, the lower their neuroticism tended to be.

Three significant negative correlations were found:

1) Extraversion ( $E, r=-0.59, p<0.0005)$ : the higher the male controls' extraversion, the lower their neuroticism tended to be.

2) Self-reported delinquency $(\mathrm{SRD}, \mathrm{r}=-0.42, \mathrm{p}<0.05)$ : the higher the male controls' neuroticism, the lower the amount of general delinquency they tended to have committed.

3) Crimes against the person (PER, $r=-0.47, p<0.01$ ): the higher the male controls' neuroticism, the fewer violent crimes they tended to have committed.

Lie Scale (L): only two significant correlations were found, both of which were negative:

1) Self-reported Delinquency ( $S R D, r=-0.36, p<0.05$ ): the greater the male controls' general delinquency level, the lower their tendency to respond in a socially desirable manner.

2) Crimes of Property (THEFT, $r=-0.36, p<0.05$ ): the greater the number of thefts the male controls had carried out, the lower their tendency to respond in a socially desirable manner.

\section{Intelligence}

Non-verbal intelligence as measured by Raven's standard progressive matrices (Raven, Court and Raven, 1985) produced several significant correlations which are shown in table 3.1(17). 
Table 3.1(17) - Correlation Coefficients for Intelligence and sociomoral reasoning variables in the male control sample

\begin{tabular}{lcccc}
\hline & RAV & MODAL & SRMS & GLOBAI \\
\hline AGE & 0.26 & 0.00 & 0.08 & 0.08 \\
EDU & 0.30 & 0.02 & 0.08 & 0.03 \\
ETHN & -0.03 & -0.10 & -0.14 & -0.24 \\
CLASS & -0.28 & $-0.38 *$ & -0.28 & -0.34 \\
SEG & -0.09 & -0.28 & -0.06 & -0.12 \\
SIB & -0.05 & 0.15 & 0.07 & 0.15 \\
SIB10 & -0.07 & 0.08 & 0.09 & 0.11 \\
RAV & 1 & 0.25 & $0.47 * *$ & $0.37 *$ \\
P & -0.03 & -0.19 & -0.26 & -0.27 \\
E & -0.09 & 0.05 & -0.05 & -0.07 \\
N & 0.25 & -0.14 & 0.17 & 0.09 \\
I & -0.11 & 0.04 & 0.25 & 0.23 \\
SRD & -0.16 & -0.06 & $-0.42 *$ & -0.29 \\
PER & -0.35 & 0.12 & $-0.44 *$ & -0.28 \\
THEFT & -0.22 & 0.08 & $-0.41 *$ & -0.33 \\
MODAL & 0.25 & $/$ & $0.62 * *$ & $0.74 * *$ \\
SRMS & $0.45 * *$ & $0.62 * *$ & $/$ & $0.94 * *$ \\
GLOBAL & $0.37 *$ & $0.74 * *$ & $0.94 * *$ & $/$ \\
\hline
\end{tabular}

$$
{ }^{*} p<0.05 \quad \star * p<0.01
$$

Intelligence (RAV): only two significant correlations were found, which were positive:

1) Sociomoral reflection maturity (SRMS, $r=0.47, p<0.01$ ): the greater the male controls' intelligence, the greater their sociomoral reasoning maturity tended to be.

2) Global stage of moral reasoning (GLOBAL, $r=0.37, p<0.05$ ): the greater the male controls' intelligence the higher their global stage of moral reasoning tended to be.

Sociomoral Reflection (Moral Reasoning)

The three measures of sociomoral reflection: Modal (MODAL) and Global (GLOBAL) stage and sociomoral reflection maturity (SRMS) were found to produce significant positive correlations (table 3.1(17) shows the correlation coefficients).

Modal Stage (MODAL): modal stage of moral reasoning resulted in three significant correlations, one negative and two positive: 
1) Social Class (CLASS, $r=-0.38, p<0.05$ ): the higher the male controls' social class, the higher their modal stage of moral reasoning tended to be.

2) Sociomoral reasoning maturity ( $S R M S, r=0.62, p<0.0005$ ): the higher the male controls' modal stage of moral reasoning, the greater their moral reasoning maturity tended to be.

3) Global stage of moral reasoning (GLOBAL, $r=0.74, p<0.0005)$ : the higher the male controls' modal stage of moral reasoning, the higher their global stage of moral reasoning tended to be.

Sociomoral Reasoning Maturity (SRMS): the following significant positive correlations were found:

1) Intelligence ( $R A V, r=0.47, p<0.01$ ): the greater the male controls' intelligence, the greater their sociomoral reasoning maturity.

2) Modal stage of moral reasoning (MODAL, $r=0.62, p<0.0005$ ): the greater the male controls' sociomoral reasoning maturity, the higher their modal stage of reasoning tended to be.

3) Global stage of moral reasoning (GLOBAL, $r=0.94, p<0.0005$ ): the higher the male controls' sociomoral reasoning maturity, the higher their global stage of moral reasoning tended to be.

Three significant negative correlations also resulted:

1) Self-reported Delinquency ( $S R D, r=-0.43, p<0.05$ ): the greater the male controls' sociomoral reasoning maturity the lower their general delinquency level tended to be.

2) Crimes against persons (PER, $r=-0.44, p<0.05$ ): the greater the male controls' sociomoral reasoning maturity the fewer violent crimes they tended to have committed.

3) Property crimes (THEFT, $r=-0.42, \mathrm{p}<0.05$ ): the greater the male controls' sociomoral reasoning maturity the more thefts they tended to have committed. 
Global Stage of Moral Reasoning (GLOBAL): only three correlation coefficients proved significant upon analysis:

1) Intelligence ( $R A V, r=0.37, p<0.05)$ : the greater the male controls' intelligence, the higher their global stage of moral reasoning tended to be.

2) Modal stage of moral reasoning (MODAL, $r=0.74, p<0.0005$ ): the higher the male controls' modal stage of moral reasoning, the higher their global stage of moral reasoning tended to be.

3) Sociomoral reasoning Maturity (SRMS, $r=0.94, p<0.0005$ ): the higher the male controls' sociomoral reasoning maturity, the higher their global stage of moral reasoning tended to be.

\section{Offending History}

Table 3.1(18) shows the Person's correlation coefficients calculated for the male control sample, pertaining to the offending history variables: self-reported delinquency (SRD); crimes committed against the person (PER); and crimes committed against property (THEFT). 
Table 3.1(18) - Correlation Coefficients for Offending History Variables in the male control sample

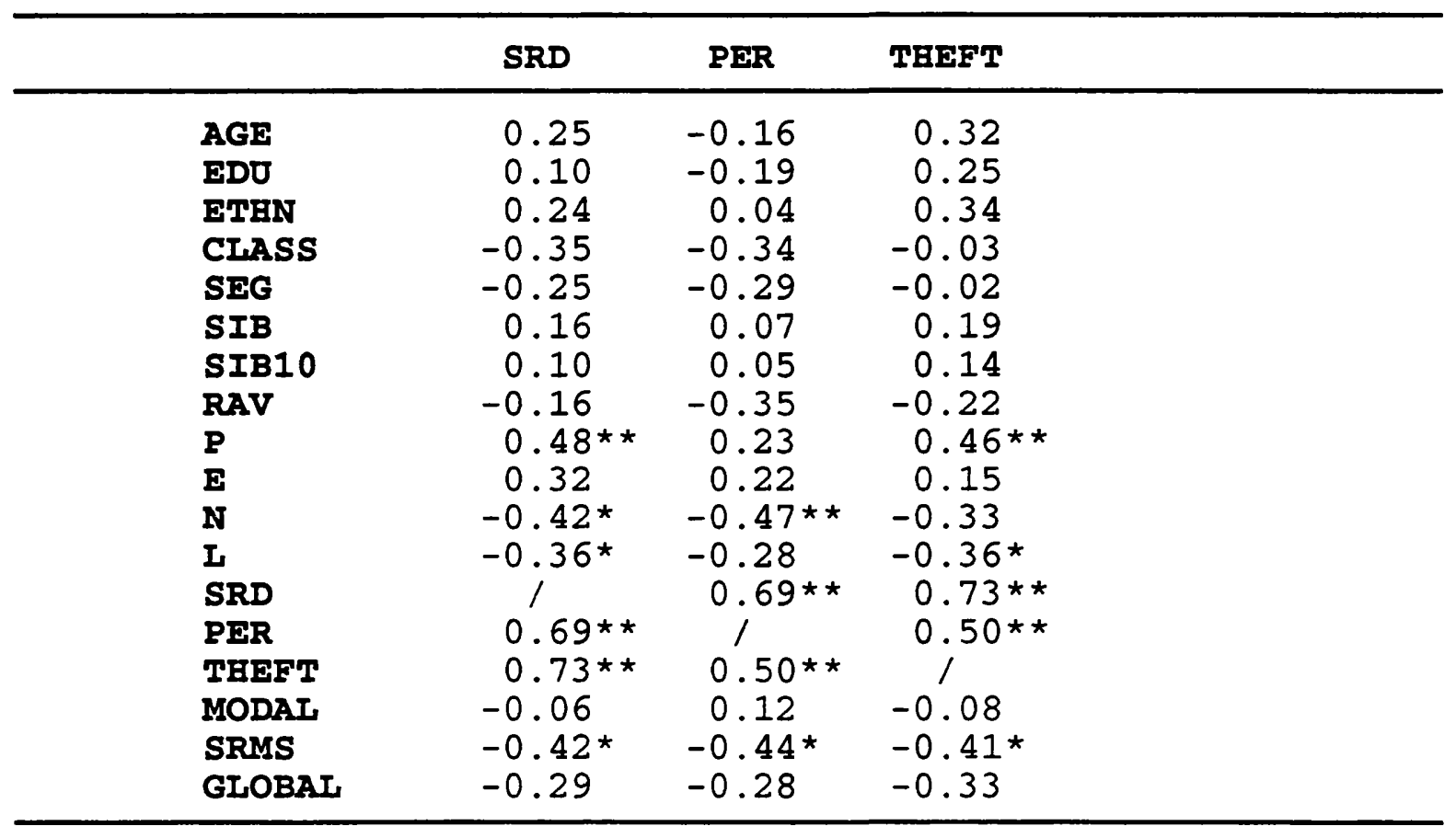

${ }^{*} \mathrm{p}<0.05 \quad *{ }^{*} \mathrm{p}<0.01$

Self-Reported Delinquency (SRD): three significant positive correlations were found:

1) Psychoticism ( $\mathrm{P}, \mathrm{r}=0.48, \mathrm{p}<0.005)$ : the higher the male controls' psychoticism, the greater their general delinquency level tended to be.

2) Crimes against the person ( $P E R, r=0.69, p<0.0005$ ): the greater the male controls' general delinquency level, the more violent crimes they tended to have committed.

3) Property crimes (THEFT, $r=0.73, p<0.0005$ ): the greater the male controls general delinquency level, the more thefts they tended to have committed.

Three significant negative correlations were also found:

1) Neuroticism ( $\mathrm{N}, \mathrm{r}=-0.42, \mathrm{p}<0.05)$ : the greater the male controls' neuroticism, the lower their general delinquency level tended to be.

2) Lie scale $(L, r=-0.36, p<0.05)$ : the greater the male controls' tendency to respond in a socially desirable manner, the lower their general delinquency level tended to be. 
3) Sociomoral Reflection Maturity (SRMS, r=-0.42, $p<0.05$ ): the greater the male controls' sociomoral reasoning maturity, the lower their general delinquency level tended to be.

Crimes against the Person (PER): four significant correlations were obtained, two positive and two negative:

1) Neuroticism (N, $r=-0.47, p<0.01)$ : the greater the male controls' neuroticism, the fewer violent crimes they tended to have committed.

2) Sociomoral reflection Maturity (SRMS, $r=-0.44, p<0.05$ ): the greater the male controls' sociomoral reflection maturity the fewer crimes against the person they tended to have committed.

3) Self-reported Delinquency ( $S R D, r=0.69, p<0.0005)$ : the greater the male controls' general delinquency, the more violent crimes they tended to have committed.

4) Property crimes (THEFT, $r=0.50, p<0.005$ ): the more violent crimes the male controls had committed, the more thefts they tended to have committed.

Property Offences (THEFT): three significant positive correlations were found:

1) Psychoticism ( $P, r=0.46, p<0.01)$ : the greater the male controls' psychoticism, the more thefts they tended to have committed.

2) Self-Reported Delinquency ( $S R D, r=0.73, p<0.0005$ ): the greater the male controls' general delinquency level, the more thefts they tended to have committed.

3) Crimes against the Person (PER, $r=0.50, p<0.005$ ): the more violent crimes the male controls had committed, the more thefts they tended to have committed.

Two significant negative correlations were also found:

1) Lie Scale ( $\mathrm{L}, \mathrm{r}=-0.36, \mathrm{p}<0.05)$ : the greater the tendency to respond in a socially desirable manner, the more thefts they tended to have committed.

2) Sociomoral Reflection Maturity (SRMS, r=-0.41, p<0.05): the greater the male controls' sociomoral maturity the fewer thefts they tended to have committed. 


\section{Female Controls}

Correlation coefficients were calculated for all the variables within the female control sample.

\section{Demographic Variables}

The correlation coefficients for the demographic variables collected: age (AGE), years in education (EDU), ethnic origin (ETHN), social class (CLASS), socio-economic group (SEG), and number of siblings before (SIB) and after (SIB10) the age of ten; are shown in table 3.1(19). 
Table 3.1(19) - Correlation Coefficients for Demographic Variables in the female control sample

\begin{tabular}{|c|c|c|c|c|c|c|c|}
\hline & AGE & EDD & ETHN & CIASS & SEG & SIB & SIB10 \\
\hline AGE & I & $0.56 * *$ & -0.19 & -0.01 & 0.07 & 0.21 & 0.17 \\
\hline ED & $0.56 * \star$ & / & 0.11 & $-0.25 *$ & -0.15 & -0.03 & 0.02 \\
\hline ETEN & -0.19 & 0.11 & / & $-0.36 * *$ & $-0.32 * \star$ & $-0.36 * *$ & -0.38 \\
\hline CLASS & -0.01 & $-0.25^{\star}$ & $-0.36 * \star$ & / & $0.62 \star \star$ & 0.22 & 0.06 \\
\hline SEG & 0.09 & -0.15 & $-0.32 * \star$ & $0.62 * \star$ & I & 0.19 & 0.05 \\
\hline SIB & 0.21 & -0.03 & $-0.36 * \star$ & 0.22 & 0.17 & I & $0.80 * \star$ \\
\hline SIB10 & 0.17 & 0.02 & $-0.38 * \star$ & 0.06 & 0.05 & $0.80 * *$ & 1 \\
\hline RAV & 0.08 & 0.23 & $0.35 * *$ & $-0.34 * \star$ & $-0.32 * \star$ & 0.01 & 0.06 \\
\hline $\mathbf{P}$ & 0.22 & -0.06 & -0.03 & -0.07 & 0.10 & 0.16 & 0.16 \\
\hline $\mathbf{E}$ & -0.07 & 0.05 & 0.05 & 0.00 & -0.06 & -0.09 & -0.11 \\
\hline $\bar{N}$ & 0.05 & -0.01 & -0.07 & 0.21 & 0.26 * & 0.06 & -0.14 \\
\hline I & -0.21 & -0.14 & -0.03 & -0.03 & -0.07 & -0.05 & 0.03 \\
\hline SRD & 0.29 * & 0.03 & 0.05 & 0.10 & 0.21 & 0.02 & -0.20 \\
\hline PER & 0.22 & -0.08 & -0.15 & 0.23 & $0.25^{\star}$ & 0.01 & -0.12 \\
\hline THEFT & 0.25 * & 0.01 & 0.08 & 0.19 & 0.07 & 0.04 & -0.21 \\
\hline MODAI & 0.12 & 0.24 * & 0.01 & -0.12 & -0.23 & $-0.24^{\star}$ & -0.09 \\
\hline SRMS & -0.09 & 0.17 & 0.20 & -0.16 & $-0.31 * \star$ & -0.13 & -0.06 \\
\hline GLOBAI & -0.03 & 0.18 & 0.19 & -0.13 & $-0.31 * \star$ & -0.13 & -0.11 \\
\hline
\end{tabular}

${ }^{*} \mathrm{p}<0.05 \quad *{ }^{*} \mathrm{p}<0.01$

Age (AGE): only three significant correlations were found, all of which were positive:

1) Years spent in education (EDU, $r=0.56, p<0.0005$ ): the older the female control participants the more years they tended to have spent in education.

2) Self-Reported Delinquency ( $S R D, r=0.29, p<0.05$ ): the older the participants the more crimes they tended to have committed.

3) Property Crimes (THEFT, $r=0.25, p<0.05$ ): the older the participants, the more thefts they tended to have committed.

Years Of Education (EDU): three significant correlations were found one negative the others positive:

1) Social Class (CLASS, $r=-0.25, p<0.05$ ): the higher the participants' social class, the more years they had spent in education. 
2) Age (AGE, $r=0.56, p<0.0005$ ): the older the participants, the more years they tended to have spent in education.

3) Modal stage of moral reasoning (MODAL, $r=0.24, p<0.05$ ): the more years the participants had spent in education, the higher their modal stage of moral reasoning tended to be.

Ethnic Origin (ETHN): four significant negative correlations were found:

1) Social Class (CLASS, $r=-0.36, p<0.005$ ): the higher the participants' social class, the less likely they were of belonging to an ethnic minority.

2) Socio-economic Group ( $S E G, r=-0.32, p<0.01$ ): the higher the participants' social and economic standing the less likely they were of belonging to ethnic minority.

3) Number of siblings before (SIB, $r=-0.36, p<0.005)$ and after (SIB10, r=-0.38, $\mathrm{p}<0.001)$ the age of ten: those participants who belonged to ethnic minorities also tended to have larger families.

One significant positive correlation was obtained with Intelligence ( $\mathrm{RAV}, \mathrm{r}=0.35$, $\mathrm{p}<0.0005)$ : the greatest intelligence came from those participants belonging to non-minority ethnic groups.

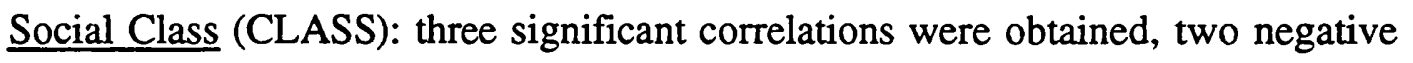
and on positive:

1) Years of Education (EDU, $r=-0.36, p<0.005$ ): the higher the social class the more years had been spent in education.

2) Intelligence $(\mathrm{RAV}, \mathrm{r}=-0.34, \mathrm{p}<0.005)$ : the greatest intelligence came from those participants from the higher social classes.

3) Socio-economic Group (SEG, $r=0.62, \mathrm{p}<0.0005$ ): the higher the participants' social class, the higher their Socio-Economic Group tended to be.

Socio-Economic Group (SEG): four significant negative correlations were found: 
1) Ethnic Origin (ETHN, $r=-0.32, p<0.01$ ): the higher the participants' SEG, the more likely they were of having a non-minority ethnic origin.

2) Intelligence $(\mathrm{RAV}, \mathrm{r}=-0.32, \mathrm{p}<0.01)$ : the more intelligent participants tended to come from the higher SEG's.

3) Sociomoral Reflection Maturity (SRMS, r=-0.31, p<0.01): the higher SEG participants also tended to have more mature sociomoral reflection.

4) Global Stage of Moral Reasoning (GLOBAL, $r=-0.31, p<0.01$ ): the higher SEG participants also tended to have higher global stages of moral reasoning.

Three significant positive correlations were also obtained:

1) Social Class (CLASS, $r=0.62, p<0.0005$ ): the higher the participants' social class the higher their SEG tended to be.

2) Neuroticism (N, r=0.26, $p<0.0005)$ : the higher the participants' SEG the lower their neuroticism tended to be.

3) Crimes against the Person (PER, $r=0.25, p<0.05$ ): the higher the participants' Socio-Economic Group, the fewer violent crimes they tended to have committed.

Number of Siblings before the age of ten (SIB): three significant correlations were calculated, two negative and one positive:

1) Ethnic Origin (ETHN, r=-0.36, p<0.01): those participants from minority ethnic groups also tended to have a larger number of siblings.

2) Modal Stage of Moral Reasoning (MODAL, $r=-0.24, p<0.05$ ): the greater the number of siblings the participants had, the lower their modal stage of moral reasoning.

3) Number of siblings after the age of ten (SIB10, $r=0.80, p<0.0005)$ : the larger the participants' family before the age of ten, the larger it tended to be after that age.

Number of Siblings after the age of ten (SIB10): two significant correlations were found, one positive and one negative. 
1) Number of siblings before the age of ten (SIB, $r=0.80, p<0.0005$ ): the larger the participants' family before the age of ten, the larger it tended to be after that age.

2) Ethnic Origin (ETHN, $r=-0.38, p<0.001$ ): the participants from minority ethnic groups also tended to have a larger number of siblings.

\section{Psychological Variables - Personality}

Significant correlations were found with the four personality variables:

Psychoticism (P), Extraversion (E), Neuroticism (N) and the Lie scale (L). Table 3.1(20) shows the resulting coefficients and indicates those which were found to be significant.

Table 3.1(20) - Correlation Coefficients for Personality Variables in the female control sample

\begin{tabular}{|c|c|c|c|c|}
\hline & $\mathbf{P}$ & $\mathbf{E}$ & $\mathbf{N}$ & L \\
\hline AGE & 0.22 & -0.07 & 0.05 & -0.21 \\
\hline סDE & -0.06 & 0.05 & -0.01 & -0.14 \\
\hline ETHN & -0.03 & 0.05 & -0.07 & -0.03 \\
\hline CIASS & -0.08 & 0.00 & 0.21 & -0.03 \\
\hline SEG & -0.10 & -0.06 & $0.26^{\star}$ & -0.07 \\
\hline SIB & 0.16 & -0.09 & 0.06 & -0.05 \\
\hline SIB10 & 0.16 & -0.11 & -0.14 & 0.03 \\
\hline RAV & 0.03 & 0.16 & -0.15 & -0.03 \\
\hline $\mathbf{P}$ & / & 0.12 & -0.19 & -0.13 \\
\hline $\mathbf{E}$ & 0.12 & I & -0.22 & -0.02 \\
\hline $\mathbf{N}$ & -0.19 & -0.22 & / & -0.08 \\
\hline I & -0.13 & -0.02 & -0.08 & / \\
\hline SRD & $0.37 * *$ & 0.21 & 0.17 & $-0.54 * *$ \\
\hline PER & 0.11 & 0.07 & $0.28 *$ & $-0.39 * *$ \\
\hline THEFT & $0.28 *$ & 0.10 & 0.25 * & $-0.47 * \star$ \\
\hline MODAI & 0.13 & 0.15 & -0.06 & -0.08 \\
\hline SRMS & 0.00 & 0.07 & -0.10 & -0.10 \\
\hline GLOBAI & -0.03 & 0.10 & -0.03 & -0.09 \\
\hline
\end{tabular}

${ }^{\star} \mathrm{p}<0.05 \quad * * \mathrm{p}<0.01$

Psychoticism (P): only two significant correlations resulted:

1) Self-Reported Delinquency ( $S R D, r=0.37, p<0.005$ ): the greater the participants' psychoticism, the greater their general delinquency level tended to be. 
2) Property Crime (THEFT, $r=0.28, p<0.005$ ): the greater the participants' psychoticism, the greater the number of thefts they tended to have carried out.

Extraversion (E): no significant correlations were found with this personality variable.

Neuroticism $(\mathrm{N})$ : three significant correlations were obtained, all of which were positive:

1) Socio-Economic Group (SEG, $r=0.28, p<0.005$ ): those participants from higher Socio-economic Groups also tended to score lower on neuroticism than those from lower Socio-economic Groups.

2) Crimes against the Person (PER, $r=0.28, p<0.05$ ): those participants with high neuroticism also tended to have committed more violent crimes.

3) Property Crimes (THEFT, $r=0.25, p<0.05$ ): the greater the participants' neuroticism, the more thefts they tended to have committed.

Lie Scale (L): three significant negative correlations were found:

1) Self-Reported Delinquency ( $S R D, r=-0.54, p<0.0005)$ : the greater the tendency to respond in a socially desirable manner, the lower their general delinquency level tended to be.

2) Crimes against the Person (PER, $r=-0.39, p<0.001$ ): the greater the tendency to respond in a socially desirable manner, the fewer violent crimes they tended to have committed.

3) Property Crimes (THEFT, $r=-0.47, p<0.0005$ ): the greater the tendency to respond in a socially desirable manner, the fewer thefts they tended to have committed. 


\section{Intelligence}

Non-verbal intelligence as measured by Raven's standard progressive matrices

(Raven, Court and Raven, 1985) produced several significant correlations as shown in table $3.1(21)$.

Table 3.1(21) - Correlation Coefficients for Intelligence and Sociomoral Reasoning variables in the female control sample

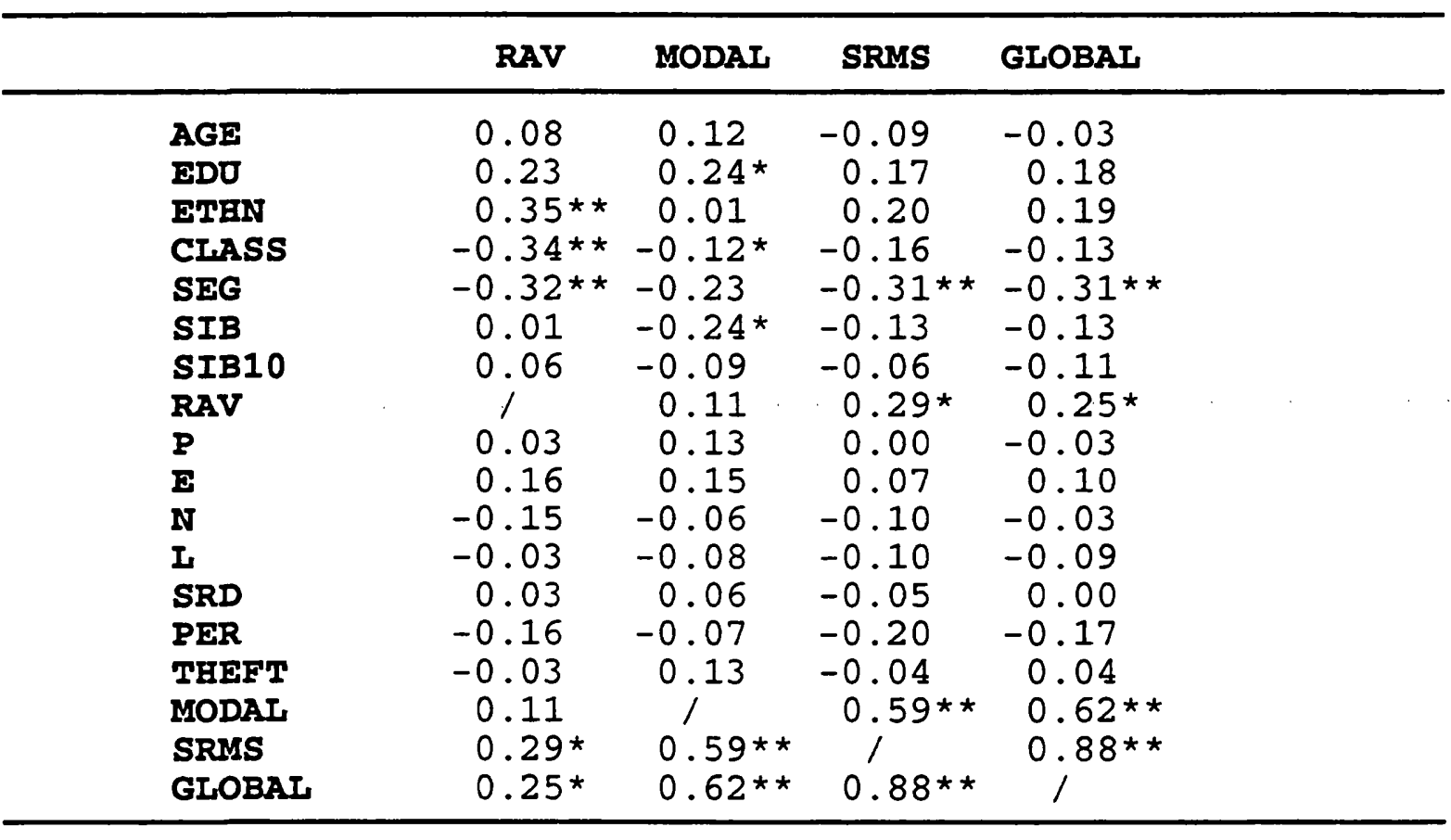

$$
* \mathfrak{p}<0.05 \quad * * \mathfrak{p}<0.01
$$

Intelligence (RAV): three significant positive correlations were found:

1) Ethnic Origin (ETHN, $r=0.35, p<0.005$ ): the higher the participants' intelligence, the more likely they were to come from a non-minority ethnic background.

2) Sociomoral Reflection Maturity (SRMS, $r=0.29, \mathrm{p}<0.05$ ): the greater the participants' intelligence the greater their sociomoral reasoning maturity tended to be.

3) Global Stage of Moral reasoning (GLOBAL, $r=0.25, p<0.05$ ): the higher the female control participants' intelligence the higher their global stage of moral reasoning tended to be.

Two significant negative correlations were also found: 
1) Social Class (CLASS, $r=-0.43, p<0.005$ ): those female controls from higher social classes, also tended to have higher intelligence.

2) Socio-economic Group (SEG, $r=-0.32, p<0.01$ ): those female controls from a higher SEG, also tended to have higher intelligence.

Sociomoral Reflection (Moral Reasoning)

Table 3.1(21) shows the correlation coefficients pertaining to the three measures of sociomoral reflection: Modal (MODAL) and Global (GLOBAL) stage and Sociomoral Reflection Maturity (SRMS).

Modal Stage of Sociomoral Reasoning (MODAL): four significant correlations were found:

1) Years in education (EDU, $r=0.24, p<0.05$ ): the longer the female controls had spent in education, the higher their modal stage of moral reasoning tended to be.

2) Sociomoral Reflection Maturity (SRMS, $r=0.59, \mathrm{p}<0.0005$ ): the higher the female controls' modal stage the greater their maturity of sociomoral reasoning tended to be.

3) Global stage of Moral Reasoning (GLOBAL, $r=0.88, p<0.0005$ ): the higher the female controls' modal stage moral reasoning, the higher, their global stage of moral reasoning tended to be.

4) Number of siblings before the age of ten (SIB, $r=-0.24, p<0.05)$ : the larger the female controls' family from childhood, the lower their modal stage of moral reasoning tended to be.

Sociomoral Reflection Maturity (SRMS): four significant correlations were found:

1) Socio-economic Group (SEG, $r=-0.31, p<0.01$ ): the higher the female controls' socio-economic group, the greater their sociomoral reasoning maturity tended to be. 
2) Intelligence $(\mathrm{RAV}, \mathrm{r}=0.29, \mathrm{p}<0.05)$ : the greater the female controls' intelligence, the greater their sociomoral reasoning maturity tended to be.

3) Modal stage (MODAL, $r=0.59, \mathrm{p}<0.0005)$ : the greater the female controls' sociomoral reasoning maturity, the higher their modal stage of sociomoral reasoning tended to be.

4) Global stage (MODAL, $r=0.88, p<0.0005$ ): the greater the female controls' sociomoral maturity, the higher their global stage of sociomoral reasoning tended to be.

Global Stage of Moral Reasoning (GLOBAL): four significant correlations were obtained:

1) Socio-Economic Group (SEG, $r=-0.31, \mathrm{p}<0.01$ ): the higher the female controls' socio-economic group, the higher their Global stage of moral reasoning tended to be.

2) Intelligence (RAV, r=-0.25, p<0.05): the greater the female controls' intelligence, the higher their Global stage of moral reasoning tended to be.

3) Modal stage (MODAL, $r=0.62, p<0.0005)$ : the higher the female controls' Global stage of moral reasoning, the higher their Modal stage of moral reasoning tended to be.

4) Sociomoral Reflection Maturity (SRMS, $r=0.88, p<0.0005$ ): the greater the female controls' sociomoral reasoning maturity, the higher their global stage of sociomoral reasoning tended to be.

\section{Offending History}

Table 3.1(22) shows the Pearson's correlation coefficients found within the female control sample, for the three measures of offending history: self-reported delinquency (SRD), crimes against the person (PER), and crimes against property (THEFT). 
Table 3.1(22) - Correlation Coefficients for Offending History Variables in the female control sample

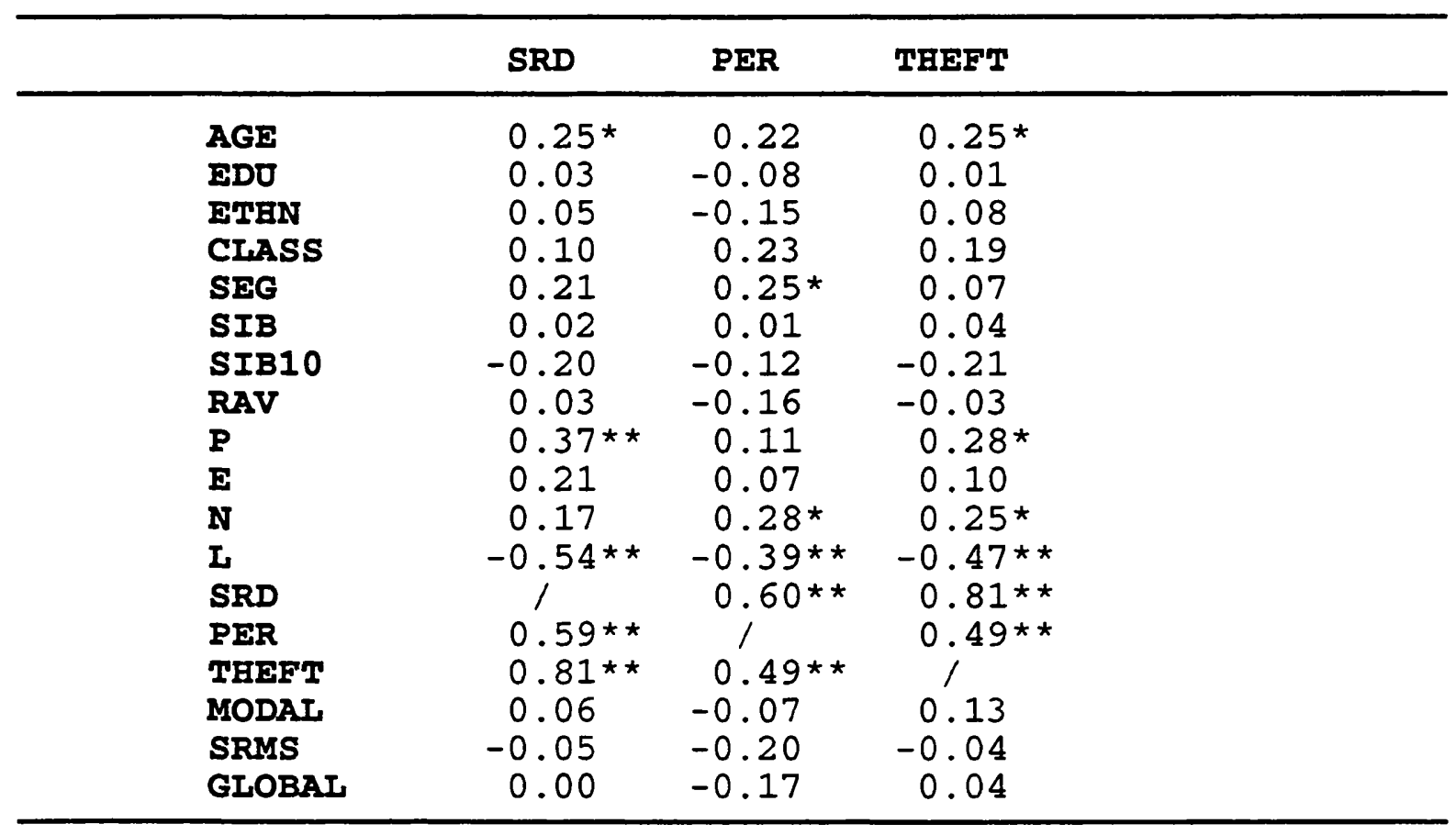

${ }^{*} \underline{\mathrm{P}}<0.05 \quad * \star \underline{\mathrm{p}}<0.01$

Self-Reported Delinquency (SRD): five significant correlations were found:

1) Age (AGE, $r=0.29, p<0.05$ ): the older the participants were, the more crimes they tended to have committed.

2) Psychoticism ( $P, r=0.37, p<0.005)$ : the greater the female controls' psychoticism, the greater their delinquency level tended to be.

3) Lie Scale ( $L, r=-0.54, p<0.0005)$ : the lower the female controls' tendency to respond in a socially desirable manner, the lower their general delinquency level tended to be.

4) Crimes against the person (PER, $r=0.59, \mathrm{p}<0.0005$ ): the greater the female controls' general delinquency level, the more violent crimes they tended to have committed.

5) Property Crimes (THEFT, $r=0.81, p<0.0005)$ : the greater the female controls' general delinquency level, the more property crimes tended to have committed.

Crimes against the Person (PER): five significant correlations were found: 
1) Socio-economic Group (SEG, $r=0.25, \mathrm{p}<0.05$ ): those female controls from higher socio-economic groups, tended to commit fewer violent crimes.

2) Neuroticism $(\mathrm{N}, \mathrm{r}=0.28, \mathrm{p}<0.05)$ : the greater the female controls' neuroticism, the more crimes against the person they tended to have committed.

3) Lie Scale ( $L, r=-0.39, p<0.001)$ : the greater the female controls' tendency to respond in a socially desirable manner, the fewer violent crimes they tended to have committed.

4) Self-Reported Delinquency ( $S R D, r=0.59, \mathrm{p}<0.0005$ ): the greater the female controls' general delinquency level, the more violent crimes they tended to have committed.

5) Property Crimes (THEFT, $r=0.49, \mathrm{p}<0.0005$ ): the greater the number of violent crimes the female controls had committed, the more property crimes they tended to have committed.

Property Crimes (THEFT): six significant correlations were found:

1) Age (AGE, $r=0.25, p<0.05$ ): the older the participants, the more thefts they tended to have committed.

2) Psychoticism ( $P, r=0.28, p<0.05)$ : the greater the female controls' psychoticism, the more thefts they tended to have committed.

3) Neuroticism $(\mathrm{N}, \mathrm{r}=0.25, \mathrm{p}<0.05)$ : the greater the female controls' neuroticism, the more thefts they tended to have committed.

4) Lie Scale ( $L, r=-0.47, p<0.0005$ ): the greater the female controls' tendency to respond in a socially desirable manner, the fewer property crimes they tended to have committed.

5) Self-Reported Delinquency ( $S R D, r=0.81, p<0.0005$ ): the greater the female controls' general delinquency level, the more property crimes they tended to have committed. 
6) Crimes against the person (PER, $r=0.49, p<0.0005$ ): the greater the number of violent crimes committed by the female controls, the more property crimes they tended to have committed.

\section{Male and Female Controls}

Correlation coefficients were calculated for all the variables within the male and female control samples combined. This sample is referred to throughout as the 'control group'.

\section{Demographic Variables}

The correlation coefficients for the demographic variables collected, namely age (AGE), years in education (EDU), ethnic origin (ETHN), social class (CLASS), socioeconomic group (SEG), and number of siblings before (SIB) and after (SIB10) the age of ten; are shown in table 3.1(23). 
Table 3.1(23) - Correlation Coefficients for Demographic Variables in the male and female control samples combined

\begin{tabular}{|c|c|c|c|c|c|c|c|}
\hline & AGE & סDE & ETHN & CLASS & SEG & SIB & SIB10 \\
\hline $\mathbf{G E}$ & 1 & $0.64 * \star$ & -0.02 & -0.04 & 0.02 & 0.24 * & 0.19 \\
\hline סDD & $0.64 * \star$ & / & $0.21 *$ & $-0.27 * *$ & $-0.23 *$ & 0.01 & 0.02 \\
\hline DTHN & -0.02 & 0.21 * & / & $-0.26 * \star$ & $-0.31 * *$ & $-0.23 *$ & $-0.26 * \star$ \\
\hline CLASS & -0.04 & $-0.27 * *$ & $-0.26 * \star$ & I & $0.66 * *$ & 0.14 & 0.06 \\
\hline SEG & 0.02 & $-0.23 *$ & $-0.31 * *$ & $0.66 * *$ & I & 0.10 & 0.03 \\
\hline SIB & 0.24 * & 0.01 & $-0.23 *$ & 0.14 & 0.10 & I & $0.87 * *$ \\
\hline SIB10 & 0.19 & 0.02 & $-0.26 * \star$ & 0.06 & -0.03 & $0.87 * \star$ & I \\
\hline RAV & 0.15 & $0.26 * \star$ & $0.23 *$ & $-0.32 * *$ & $-0.26 * *$ & 0.00 & 0.02 \\
\hline $\mathbf{P}$ & $0.26 * *$ & 0.03 & 0.04 & -0.08 & 0.07 & 0.15 & 0.11 \\
\hline $\mathbf{E}$ & -0.09 & 0.06 & 0.03 & -0.13 & -0.09 & -0.13 & -0.09 \\
\hline $\mathbf{N}$ & 0.01 & -0.05 & -0.06 & $0.33 * *$ & $0.31 * \star$ & 0.06 & -0.06 \\
\hline I & $-0.21 \star$ & $-0.23 *$ & -0.05 & 0.08 & 0.01 & 0.01 & 0.04 \\
\hline SRD & $0.32 * \star$ & 0.12 & 0.11 & -0.06 & 0.07 & 0.09 & -0.06 \\
\hline PER & 0.13 & -0.06 & -0.08 & 0.02 & 0.09 & 0.05 & -0.03 \\
\hline THEFT & $0.33 * \star$ & $0.19 *$ & 0.16 & 0.08 & 0.03 & 0.12 & -0.01 \\
\hline MODAL & 0.08 & 0.16 & -0.02 & $-0.20 *$ & $-0.24 *$ & -0.09 & -0.03 \\
\hline SRMS & -0.04 & 0.12 & 0.08 & $-0.20 *$ & $-0.23 *$ & -0.05 & 0.00 \\
\hline GLOBAI & 0.00 & 0.11 & 0.03 & $-0.21 *$ & $-0.26 * *$ & -0.01 & -0.02 \\
\hline
\end{tabular}

$\star \underline{p}<0.05 \quad * * \underline{p}<0.01$

Age (AGE): five significant positive correlations were found:

1) Years in education (EDU, $r=0.64, p<0.0005$ ): the older the control group participants were, the more years they tended to have spent in education.

2) Number of siblings before the age of ten (SIB, $r=0.24, p<0.05$ ): the older the controls were, the more siblings they tended to have.

3) Psychoticism ( $P, r=0.26, p<0.01)$ : the older the controls were, the greater their psychoticism tended to be.

4) Self-Reported Delinquency ( $S R D, r=0.32, p<0.001$ ): the older the control group participants were, the more delinquent they tended to be.

5) Crimes against property (THEFT, $r=0.33, p<0.001$ ): the older the participants were, the more thefts they tended to have committed. 
Only one significant negative correlation was found, with the Lie scale $(L, r=-0.21$, $\mathrm{p}<0.05)$ : the older the participants were, the lower their tendency to respond in a socially desirable manner.

Years of Education (EDU): four significant positive correlations were obtained:

1) Age (AGE, $r=0.64, p<0.0005$ ): the older the controls were, the more years they tended to have spent in education.

2) Ethnic Origin (ETHN, r=0.21, p<0.05): the controls from non-minority ethnic groups, tended to have spent more years in education.

3) Intelligence $(\mathrm{RAV}, \mathrm{r}=0.26, \mathrm{p}<0.01)$ : the more years the controls had spent in education, the more intelligent they tended to be.

4) Property Crimes (THEFT, $r=0.19, \mathrm{p}<0.05$ ): the more years the participants had spent in education, the more thefts they tended to have committed.

Three significant negative correlations were also found:

1) Social Class (CLASS, $r=0.27, p<0.01$ ): those controls from higher social classes also tended to have spent had more years in education.

2) Socio-economic Group (SEG, $r=-0.23, p<0.05$ ): those participants from higher socio-economic groups tended to have spent more years in education.

3) Lie Scale ( $L, r=-0.23, p<0.05)$ : the more years the participants had spent in education, the lower their tendency to respond in a socially desirable manner.

Ethnic Origin (ETHN): four significant negative correlations were found:

1) Social Class (CLASS, $r=-0.26, p<0.01$ ): participants from non-minority ethnic groups, also tended to come from higher social classes.

2) Socio-economic Group (SEG, $r=-0.26, p<0.01$ ): participants from non-minority ethnic groups, also tended to come from higher socio-economic groups. 
3) Number of siblings before (SIB, $r=-0.23, p<0.05$ ) and after (SIB10, $r=-0.26$, $\mathrm{p}<0.01)$ the age of ten: larger families tended to occur in those participants from ethnic minority backgrounds.

One significant positive correlation was found, with years spent in education (EDU, $\mathrm{r}=0.21, \mathrm{p}<0.05)$ : the controls belonging to non-minority ethnic groups, tended to have spent more years in education.

Social Class (CLASS): six significant negative correlations were found:

1) Years spent in education (EDU, $r=-0.27, p<0.01$ ): the participants from higher social classes, tended to have spent more years in education.

2) Ethnic Origin (ETHN, r=-0.26, $\mathrm{p}<0.01)$ : participants from non-minority ethnic groups, tended to come from higher social classes.

3) Intelligence ( $R A V, r=-0.32, p<0.005)$ : those participants from the higher social classes, also tended to be more intelligent.

4) Modal stage of moral reasoning (MODAL, $r=-0.20, p<0.05$ ): those participants from higher social classes also tended to have higher modal stages of sociomoral reasoning.

5) Sociomoral Reflection Maturity (SRMS, $r=-0.20, p<0.05$ ): those participants from higher social classes also tended to be more mature in their sociomoral reflection.

6) Global Stage of moral reasoning (GLOBAL, $r=-0.21, p<0.05$ ): those participants from higher social classes also tended to have higher global stages of sociomoral reasoning.

Two significant positive correlations were also found:

1) Socio-economic Group (SEG, $r=0.66, p<0.0005$ ): the higher the participants' social class, the higher their socio-economic group tended to be.

2) Neuroticism ( $, r=0.33, p<0.001$ ): the higher the participants' social class, the lower their neuroticism tended to be. 
Socio-economic Group (SEG): four significant negative correlations were found:

1) Years of education (EDU, $r=-0.23, p<0.05$ ): the higher the participants' socioeconomic group, the more years they tended to have spent in education.

2) Ethnic Origin (ETHN, $r=-0.31, p<0.005)$ : those participants from higher socioeconomic groups, tended to come from non-minority ethnic groups.

3) Intelligence (RAV, $r=-0.26, p<0.01)$ : those participants from higher socioeconomic groups, also tended to have greater intelligence.

4) Modal stage of moral reasoning (MODAL, $r=-0.24, p<0.05$ ): the higher the participants' socio-economic group, the higher their modal stage of sociomoral reasoning tended to be.

5) Sociomoral Reflection Maturity (SRMS, $r=-0.23, \mathrm{p}<0.05$ ): the higher the participants' socio-economic group, the greater their sociomoral maturity tended to be.

6) Global Stage of moral reasoning (GLOBAL, $r=-0.26, p<0.01$ ): the higher the participants' socio-economic group the higher their global stage of moral reasoning tended to be.

Two significant positive correlations were also found:

1) Social Class (CLASS, $r=0.66, p<0.0005$ ): the higher the participants' social class, the higher their socio-economic group tended to be.

2) Neuroticism (N, $r=0.31, p<0.005)$ : the higher the participants' socio-economic group, the lower their neuroticism tended to be.

Number of Siblings before the age of ten (SIB): only three significant correlations were found:

1) Age (AGE, $r=0.24, p<0.05$ ): the older the participants were, the more siblings before the age of ten they tended to have. 
2) Number of siblings after the age of ten (SIB10, $r=0.88, p<0.0005)$ : the greater the number of siblings before the age of ten the participants had, the greater the number they tended to have after that age.

3) Ethnic Origin (ETHN, r=-0.23, p<0.05): those participants from minority ethnic groups also tended to have the greatest number of siblings.

Number of Siblings after the age of ten (SIB10): only two significant correlations were found:

1) Ethnic Origin (ETHN, $r=-0.26, p<0.01)$ : those participants from ethnic minorities also tended to have the greatest number of siblings.

2) Number of siblings before the age of ten (SIB, $r=0.88, p<0.0005)$ : the greater the number of siblings before the age of ten the participants in this sample group had, the greater the number they tended to have after that age.

\section{Psychological Variables - Personality}

Significant correlations were found with the four personality variables:

Psychoticism (P), Extraversion (E), Neuroticism (N) and the Lie scale (L). Table 3.1(24) shows the resulting coefficients and indicates those which were found to be significant. 
Table 3.1(24) - Correlation Coefficients for Personality Variables in the male and

female control samples combined

\begin{tabular}{|c|c|c|c|c|}
\hline & $\mathbf{P}$ & $\mathbf{E}$ & $\mathbf{N}$ & I \\
\hline $\mathbf{A G E}$ & $0.26 * *$ & -0.09 & 0.01 & $-0.21 *$ \\
\hline סD & 0.03 & 0.06 & -0.05 & $-0.23 *$ \\
\hline ETHN & 0.04 & 0.03 & -0.06 & -0.05 \\
\hline CInsS & -0.08 & -0.13 & $0.33 * \star$ & 0.08 \\
\hline SEG & 0.07 & -0.09 & $0.31 * \star$ & 0.01 \\
\hline SIB & 0.15 & -0.13 & 0.06 & 0.01 \\
\hline SIB10 & 0.11 & -0.09 & -0.06 & 0.04 \\
\hline RAV & 0.03 & 0.08 & -0.04 & -0.07 \\
\hline $\mathbf{P}$ & 1 & 0.08 & $-0.22 \star$ & -0.16 \\
\hline $\mathbf{E}$ & 0.08 & I & $-0.33 \star \star$ & -0.06 \\
\hline$\overline{\mathbf{N}}$ & -0.22 * & $-0.33 * \star$ & I & 0.01 \\
\hline I & -0.16 & -0.06 & 0.01 & 1 \\
\hline SRD & $0.41 * \star$ & $0.21 *$ & -0.06 & $-0.50 * \star$ \\
\hline PER & 0.16 & 0.10 & -0.02 & $-0.37 * *$ \\
\hline TEEFT & $0.34 * *$ & 0.07 & -0.02 & $-0.43 * \star$ \\
\hline MODAL & 0.06 & 0.12 & -0.04 & -0.05 \\
\hline SRMS & -0.07 & 0.03 & 0.00 & 0.03 \\
\hline GLOBAL & -0.10 & 0.04 & 0.02 & 0.03 \\
\hline
\end{tabular}

${ }^{*} \mathrm{p}<0.05 \quad * * \mathrm{p}<0.01$

Psychoticism $(\mathrm{P})$ : four significant correlations were found:

1) Age (AGE, $r=0.26, p<0.01$ ): the older a participant was, the higher his/her psychoticism tended to be.

2) Self-Reported Delinquency ( $S R D, r=0.41, p<0.0005$ ): the greater the participants' psychoticism, the more delinquency they tended to have committed.

3) Property Crimes (THEFT, $r=0.34, p<0.0005)$ : the greater the participants' psychoticism, the more thefts they tended to have committed.

4) Neuroticism (N, r=-0.22, p<0.05): the greater the participants' psychoticism, the greater their neuroticism tended to be.

Extraversion (E): only two significant correlations were found:

1) Neuroticism (N, r=-0.33, $\mathrm{p}<0.0005)$ : the greater the participants' extraversion, the greater their neuroticism tended to be.

2) Self-reported delinquency ( $S R D, r=0.21, p<0.05)$ : the more extraverted a participant was, the more delinquent he or she tended to be. 
Neuroticism $(\mathrm{N})$ : four significant correlations were found:

1) Social Class (CLASS, $r=0.33, p<0.001$ ): the higher the participants' social class, the greater their neuroticism tended to be.

2) Socio-economic Group (SEG, $r=0.31, p<0.005$ ): the higher the participants' socio-economic group, the greater their neuroticism tended to be.

3) Psychoticism ( $\mathrm{P}, \mathrm{r}=-0.22, \mathrm{p}<0.05)$ : the greater the participants' psychoticism, the greater their neuroticism tended to be.

4) Extraversion $(E, r=-0.33, p<0.0005)$ : the greater the participants' extraversion, the greater their neuroticism tended to be.

Lie Scale $(\mathrm{L})$ : five significant correlations were found, all of which were negative:

1) Age (AGE, $r=-0.21, p<0.05$ ): the older the participants were, the lower their tendency to respond in a socially desirable manner was.

2) Years of Education (EDU, $r=-0.23, p<0.05$ ): the more years the participants had spent in education, the lower their tendency to respond in a socially desirable manner was.

3) Self-Reported Delinquency ( $S R D, r=-0.50, p<0.0005$ ): the higher the participants' tendency to respond in a socially desirable manner, the lower their general delinquency level tended to be.

4) Crimes against the person (PER, $r=-0.37, p<0.0005$ ): the higher the participants' tendency to respond in a socially desirable manner, the fewer violent crimes they tended to have carried out.

5) Property Crimes (THEFT, $r=-0.43, \mathrm{p}<0.0005$ ): the higher the participants' tendency to respond in a socially desirable manner, the fewer thefts they tended to have committed. 
Psychological Variables - Intelligence

Non-verbal intelligence as measured by Raven's standard progressive matrices

(Raven Court and Raven, 1985) produced several significant correlations as shown in table $3.1(25)$.

Table 3.1(25) - Correlation Coefficients for Intelligence and sociomoral reasoning variables in the male and female control samples combined

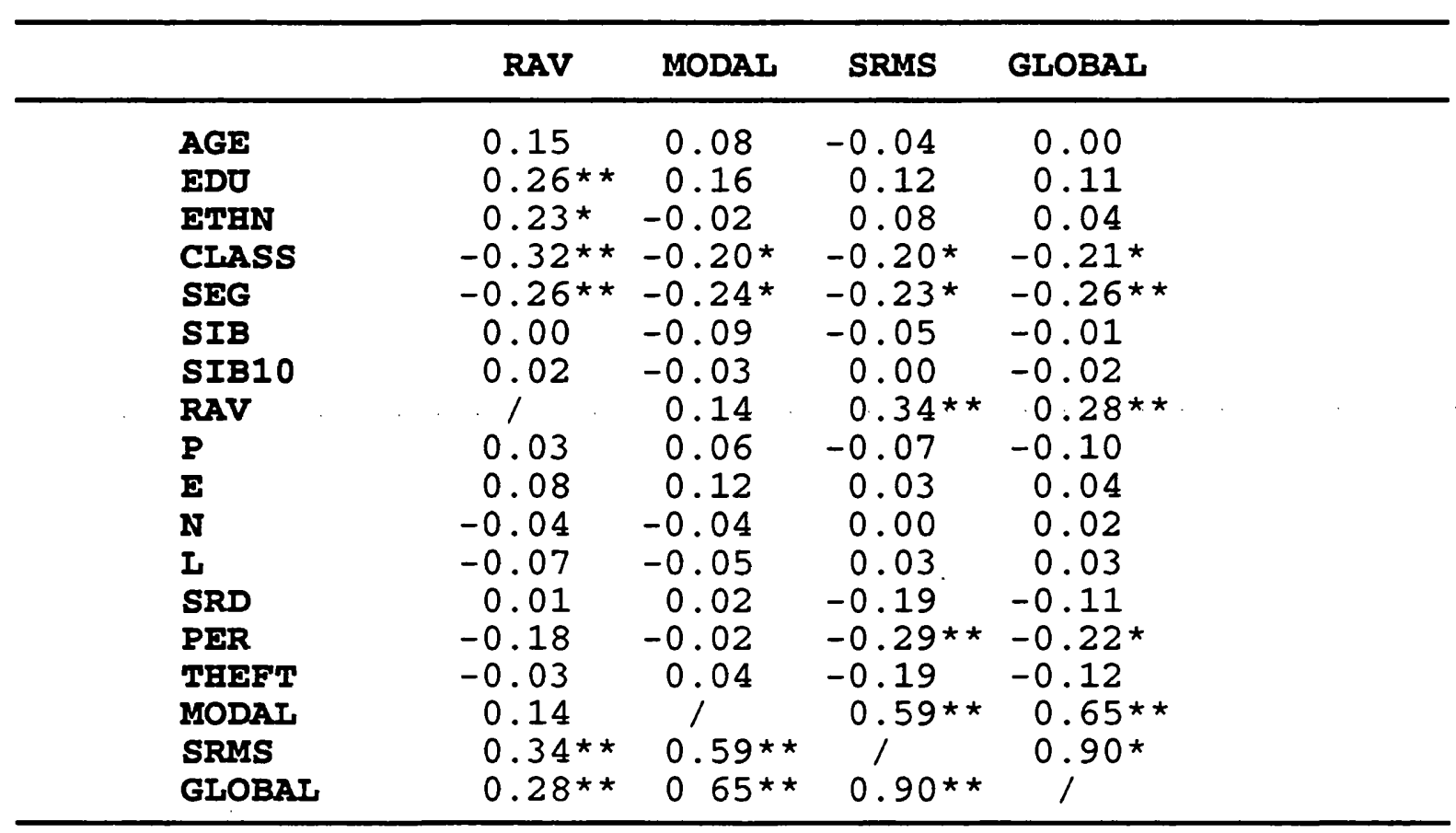

${ }^{*} \underline{\underline{p}}<0.05 \quad{ }^{*} \underline{\underline{p}}<0.01$

Intelligence (RAV): six significant correlation coefficients were found:

1) Years of Education (EDU, $r=0.26, p<0.01$ ): the more years the participants had spent in education, the greater their intelligence tended to be.

2) Ethnic Origin (ETHN, $r=0.23, \mathrm{p}<0.05)$ : those participants from non-minority ethnic groups also tended to be more intelligent.

3) Sociomoral Reflection Measure ( $\mathrm{SRMS}, \mathrm{r}=0.34, \mathrm{p}<0.0005$ ): the greater the participants' intelligence, the more mature their sociomoral reasoning tended to be. 
4) Global stage of moral reasoning (GLOBAL, $r=0.28, p<0.005$ ): the more intelligent the participants were, the higher their global stage of sociomoral reasoning tended to be.

5) Social Class (CLASS, $r=-0.32, p<0.005$ ): those participants from higher social classes also tended to be the most intelligent.

6) Socio-economic Group (SEG, $r=-0.26, p<0.01$ ): those participants from higher socio-economic groups also tended to have higher intelligence scores.

Psychological Variables - Sociomoral Reflection (Moral Reasoning)

The three measures of sociomoral reflection: Modal (MODAL) and Global (GLOBAL) stage and Sociomoral Reflection Maturity (SRMS) were found to produce significant positive correlations (table $3.1(25)$ shows all the correlation coefficients calculated).

Modal Stage of Sociomoral Reasoning (MODAL): four significant correlations were found:

1) Social Class (CLASS, $r=-0.20, p<0.05$ ): the participants from higher social classes tended to have the highest modal stage of reasoning.

2) Socio-economic Group (SEG, $r=-0.24, \mathrm{p}<0.05$ ): the participants from higher socio-economic groups, tended to have higher modal stages of reasoning.

3) Sociomoral Reflection Maturity (SRMS, $r=0.59, \mathrm{p}<0.0005$ ): the higher the participants' modal stage of sociomoral reasoning, the higher their sociomoral reasoning maturity tended to be.

4) Global stage of moral reasoning (GLOBAL, $r=0.65, p<0.0005$ ): the higher the participants' modal stage, the higher their global stage of sociomoral reasoning tended to be. 
Sociomoral Reflection Maturity (SRMS): six significant correlations were obtained, three positive and three negative:

1) Social Class (CLASS, $r=-0.20, p<0.05$ ): the participants belonging to higher social classes, tended to have the greater sociomoral reasoning maturity.

2) Socio-economic Group (SEG, $r=-0.23, p<0.05$ ): the participants from higher socio-economic groups, tended to have the greater sociomoral reasoning maturity.

3) Crimes against the Person (PER, $r=-0.29, p<0.0005)$ : those participants with higher sociomoral maturity tended to have committed fewer violent crimes.

4) Intelligence ( $R A V, r=0.34, p<0.0005$ ): the greater the participants' intelligence, the higher their sociomoral maturity tended to be.

5) Modal stage of Moral Reasoning (MODAL, $\mathrm{r}=0.59, \mathrm{p}<0.0005$ ): the higher the participants' modal stage of sociomoral reasoning, the higher their sociomoral maturity tended to be.

6) Global Stage of Moral Reasoning (GLOBAL, $r=0.90$., $p<0.0005$ ): the higher the participants' modal stage, the higher their global stage of moral reasoning tended to be.

Global Stage of Moral Reasoning (GLOBAL): six significant correlations were obtained, three positive and three negative:

1) Intelligence ( $\mathrm{RAV}, \mathrm{r}=0.28, \mathrm{p}<0.005)$ : the greater the participants' intelligence, the higher their Global stage of moral reasoning tended to be.

2) Modal Stage of Moral Reasoning (MODAL, $r=0.65, p<0.0005$ ): the higher the participants' modal stage, the higher their global stage of sociomoral reasoning tended to be.

3) Sociomoral Reflection Maturity (SRMS, $r=0.90$., $p<0.0005$ ): the higher the participants' modal stage, the higher their global stage of moral reasoning tended to be.

4) Social Class (CLASS, $r=-0.21, p<0.05$ ): the higher the participants' social class, the higher their Global stage of moral reasoning tended to be. 
5) Socio-economic Group (SEG, $r=-0.26, p<0.01$ ): the higher the participants' socio-economic group, the higher their Global stage of moral reasoning tended to be.

6) Crimes against the person (PER, $r=-0.22, p<0.05$ ): the higher the participants' global stage of moral reasoning, the fewer violent crimes they tended to have committed.

\section{Offending History}

Table 3.1(26) shows the Pearson's correlation coefficients calculated for the offending history variables of the male and female control samples combined.

Table 3.1(26) - Correlation Coefficients for Offending History Variables in the male and female control samples combined

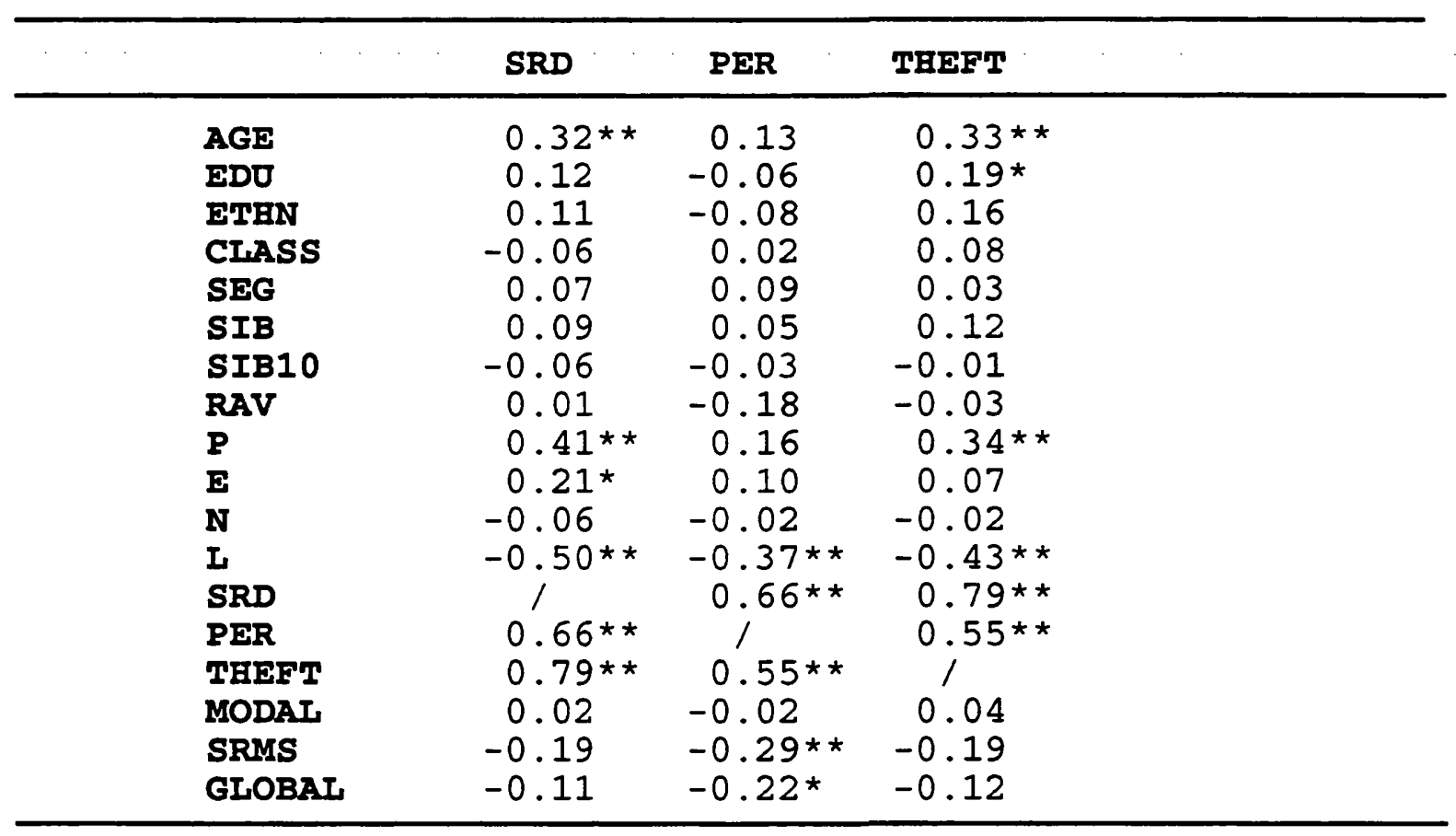

${ }^{*} \underline{p}<0.05 \quad * * \underline{p}<0.01$

Self-Reported Delinquency (SRD): six significant correlations were found, only one was negative:

1) Age (AGE, $r=0.32, p<0.001$ ): the older the participants were, the more delinquency they tended to have carried out. 
2) Psychoticism ( $\mathrm{P}, \mathrm{r}=0.41, \mathrm{p}<0.0005)$ : the greater the participants' psychoticism, the greater their delinquency level tended to be.

3) Extraversion ( $E, r=0.21, p<0.05)$ : the greater the participants' extraversion, the greater their delinquency level tended to be.

4) Crimes against the Person (PER, $r=0.66, p<0.0005)$ : the greater the general delinquency level of the participants, the more crimes against the person they tended to have committed.

5) Property Crimes (THEFT, $r=0.79, p<0.0005$ ): the more delinquent the participants were, the more thefts they tended to have committed.

6) Lie Scale ( $L, r=-0.50, p<0.0005$ ): the greater the participants' general delinquency level, the lower their tendency to respond in a socially desirable manner.

Crimes against the Person (PER): five significant correlations were obtained, two of these were positive:

1) Property Crimes (THEFT, $r=0.55, p<0.0005$ ): the more thefts the participants had committed, the more crimes against the person they tended to have committed.

2) Self-Reported Delinquency ( $S R D, r=0.66, p<0.0005)$ : the greater the participants' general delinquency level, the more crimes against the person they tended to have committed.

3) Lie Scale ( $\mathrm{L}, \mathrm{r}=-0.37, \mathrm{p}<0.0005$ ): the greater the number of crimes against the person the participants had committed, the lower their tendency to respond in a socially desirable manner.

4) Sociomoral Reflection Maturity (SRMS, $r=-0.29, \mathrm{p}<0.005$ ): the more mature the participants' sociomoral reflection, the fewer crimes against the person they tended to have committed. 
5) Global Stage of Moral Reasoning (GLOBAL, $r=-0.29, p<0.02$ ): the higher the participants' global stage of sociomoral reasoning, the fewer violent crimes they tended to have committed.

Property Crimes (THEFT): six significant correlations were found, only one was negative:

1) Age (AGE, $r=0.33, p<0.001$ ): the older the participants were, the more thefts they tended to have committed.

2) Years of Education (EDU, $r=0.19, \mathrm{p}<$ ).05): the years the participants had spent in education, the more thefts they tended to have committed.

3) Psychoticism ( $\mathrm{P}, \mathrm{r}=0.34, \mathrm{p}<0.0005)$ : the greater the participants' psychoticism, the more thefts they tended to have committed.

4) Self-Reported Delinquency ( $S R D, r=0.79, p<0.0005$ ): the more delinquency the participants had engaged in, the more thefts they tended to have committed.

5) Crimes against the Person (PER, $r=0.55, \mathrm{p}<0.0005$ ): the more thefts the participants had carried out, the more crimes against the person they tended to have committed.

6) Lie Scale ( $L, r=-0.43, p<0.0005$ ): the greater the participants' tendency to respond in a socially desirable manner, the fewer thefts they tended to have carried out. 


\section{Summary/Discussion}

The results of the large scale correlation analysis carried out yielded many results which generally support both H. J. Eysenck's and Kohlberg's theories, the main focuses of the present study. In addition, several of the correlational results provide evidence to support the predicted relationships between intellectual capacity and criminality, and certain demographic variables and criminality. Furthermore, some of the correlations calculated suggest that certain of these variables are related to each other.

This section is intended to summarise the findings presented in the above results section. In order to do this, the findings are summarised in sections pertaining to the variables which were of interest to the investigation. Since the emphasis of the present study was to investigate the predictions of the theories regarding the variables mentioned and offending behaviour, the most relevant correlations were those involving the self reported offending scores: self-reported delinquency (SRD), crimes against the person/violent offending (PER) and crimes of property/theft (THEFT). Therefore it is these correlations which are focused on in the following sections.

\section{Personality}

Several of the correlations found provided support for predictions made from Eysenck's theory. However, the degree to which the theory was supported varied from one personality variable to the next.

In all sample groups Psychoticism (P) correlated significantly positively with both self-reported delinquency score (SRD) and number of thefts committed. This fits with the predictions of H. J. Eysenck's theory which suggests that those individuals with high $\mathrm{P}$ scores would commit more criminal acts. However with regard to the number of violent crimes committed, only in the whole sample group was the predicted significant positive correlation found. This prediction was not upheld within any of the sample sub-groups. 
With regard to extraversion (E) the findings were less clear. While generally the results suggested that high $\mathrm{E}$ scorers tended to commit more offences, this was by no means unanimous in all sample groups or in all types of offending. Within the whole sample group, predicted positive correlations were actually found between $E$ and both selfreported delinquency (SRD) and violent offences (PER). In the male offender group, only the predicted positive correlation between $\mathrm{E}$ and violent offences was found. The only other predicted correlation was found in the combined control group, which was between $\mathrm{E}$ and self-reported delinquency score (SRD). In both the male and the female control groups, no significant correlations were found with E. It is of note that no significant positive correlations were found between E and thefts committed (THEFT) in any of the sample groups, as would be predicted by H. J. Eysenck's theory.

The relationship between Neuroticism and offending was less clear still. No significant correlations at all were found in the whole sample, the male offender sample and the combined control sample groups. In the female control sample group a predicted significant positive correlation was found between $\mathrm{N}$ and violent offending but not with any other of the offending history variables. However, in the male control group, a significant negative correlation was found between $\mathrm{N}$ and violent offending; suggesting, contrary to predictions from H. J. Eysenck's theory, that those individuals with low neuroticism tend to commit a greater number of violent offences. The findings that both self-reported delinquency and thefts were not related to $\mathrm{N}$ in any of the sample groups are notable.

With regard to the Lie (L) scale, in all sample groups except the male control group, all three measures of offending history (SRD, THEFT, and PER) correlated significantly negatively with L, suggesting that those individuals who responded honestly to the Eysenck Personality Questionnaire (EPQ) did the same in the self-reported delinquency questionnaire. The exception to this was found in the male control sample 
group, where no significant correlation was found between $L$ and violent offending (PER), while the correlations between $\mathrm{L}$ and both self-reported delinquency score (SRD) and thefts (THEFT) were negative, in line with the correlations found in the other sample groups.

\section{Moral Reasoning}

Several of the correlations found in the various sample groups provided some support for Kohlberg's prediction that offending behaviour is associated with less mature moral reasoning.

The strongest support for the theory was found in the correlations calculated for the whole sample group. Here all three measures of moral reasoning (MODAL stage, SRMS, and GLOBAL stage) correlated negatively and significantly with all three measures of offending history (SRD, PER and THEFT). This suggests, as predicted by Kohlberg's theory, that the more mature an individual's moral reasoning ability the more delinquent acts will be performed by that individual.

However, the findings for the whole sample group were not fully supported by the results of the correlations calculated in the sample sub-groups. In the male offender and the female control groups no significant correlations were found between the offending history variables and the moral reasoning variables. In the male control group predicted negative correlations were obtained between SRMS and all the offending history variables but no other significant correlations were found. In the combined control group, only violent offending produced significant correlations. These, which were in the predicted negative direction, were between violent offending and both SRMS and global stage of moral reasoning. 


\section{Intelligence}

The predicted negative correlations between intelligence score (RAV) and the three offending history variables (SRD, PER and THEFT) were found only in the whole sample group results. In the sample sub-groups no significant correlations were obtained between these variables.

\section{Demographic Variables}

The various demographic variables collected yielded several correlations which fitted predictions based on previous research findings.

Age, is a variable which has been predicted to be associated with an increase in the amount of delinquency, with a peak at ages 15 to 17 (Farrington, 1987). It was not predicted that age would not be strongly associated with delinquency as the amount of delinquency was believed to vary across within the relatively small age ranged used in the present study. This was reflected in the results to the correlations. For the whole sample, the male offender and the male control groups no significant correlations were found between age and the offending history variables (SRD, PER and THEFT). In the female control group significant positive correlations were found between age and self-reported delinquency score (SRD) and thefts committed (THEFT). These results were also found in the combined control group. While only some correlations were found, they were all in the predicted direction, in other words they suggested that the older the participants the more they tended to have offended.

Education level was also found, as predicted, to be related to offending in the results of the correlation analyses. In the whole sample group significant negative correlations were found between education (EDU) and all three of the offending history variables. In all the remaining sub-group samples the only significant correlation between education level and offending history was found in the combined control group. This was 
a positive correlation between education and thefts committed (THEFT). While the support for the notion that greater offending behaviour is associated with lower educational level is not unanimous in all the correlations found, it is present.

There were two variables which measured family size were number of siblings before the age of ten (SIB) and number of siblings after the age of ten (SIB10). Previous research (West, 1982) suggested that a larger family size would be associated with greater offending behaviour. No evidence to support this finding was found in the correlations calculated in the present study. All the correlations between the offending history variables (SRD, PER, THEFT) and the two family size variables in all of the sample groups were found to be non-significant.

Socio-economic status (SES) was measured using the variables social class (CLASS) and socio-economic group (SEG). The predicted positive correlations between both the SES variables and the offending history variables were found in the whole group sample. However, these findings were not supported by results in the sample sub-groups except in the female control group where a predicted positive correlation was found between SEG and crimes against the person/violent offending (PER); in all other cases no significant correlations were found between SES and offending behaviour. This supports, to a certain extent, previous research findings that suggest that SES is associated with offending behaviour (Snyder and Patterson, 1987).

\section{Interaction of Variables}

Some evidence was provided by the correlations obtained to suggest that personality variables are related to moral reasoning variables. This evidence related only to psychoticism (P), where in the whole sample group a significant negative correlation was found between $\mathrm{P}$ and all three moral reasoning variables. However, no significant correlations between $\mathrm{P}$ and moral reasoning was found in any of the remaining sample 
groups. Furthermore, no significant correlations were found between extraversion, neuroticism or the lie scale and moral reasoning in any of the sample groups.

Intelligence was also found to be related to both moral reasoning and some personality variables. A predicted (ל̀. J. Eysenck and Gudjonsson, 1989) significant negative correlation was found between $\mathrm{P}$ and intelligence score in the whole sample group, suggesting that those individuals who have higher $\mathrm{P}$ scores tend to be less intelligent. In the offender group a significant positive correlation was found between $\mathrm{E}$ and intelligence score suggesting that more extraverted individuals tend to be more intelligent, which was not predicted. No other significant correlations were found between personality and intelligence.

Moral reasoning was found to be strongly associated with intelligence as would be expected (Kohlberg, 1976), whereby more intelligent individuals tend to be more mature in their moral reasoning. This was supported in both the whole sample and the male offender groups where all three moral reasoning variables were found to correlate significantly positively with intelligence score. In the remaining three sample groups significant positive correlations were found between intelligence score and both sociomoral reflection maturity (SRMS) and global stage of moral reasoning (GLOBAL), but not with modal stage of moral reasoning.

In conclusion, it can be seen that many of the correlations reported in this section support predictions made from previous literature which will be examined further in the main discussion section (chapter 5). 


\section{2 - GROUP COMPARISONS}

\section{Introduction}

In this section, analyses of variance and co-variance were calculated in order to test predictions that there would be differences in personality, moral reasoning, intelligence and some demographic variables between the convicted offender sample and the comparison groups. Also tested for significance were the differences between the male and female control sample groups, which indicated some of the variables which needed to be used as co-variates. All the possible combinations of comparison sample groups (i.e. male controls, female controls, and combined controls) were compared against the convicted offender group to account for any effects due to gender differences in the comparison group (as the convicted individuals were all male).

The results of the group comparisons are reported in terms of the variables to which the analyses referred, namely: demographic variables, personality variables, intelligence, moral reasoning variables and offending history variables.

\section{Demographic Variables}

The demographic variables of age, education (EDU), social class (CLASS), socioeconomic group (SEG), number of siblings before (SIB) and after the age of ten (SIB10) were subjected to analysis of variance between the groups: Male offenders and male non-offenders, male offenders and female non-offenders, male offenders and male and female non-offenders combined and between male and female non-offenders.

\section{Analyses of Variance (ANOVA)}

The means, standard deviations, $\mathrm{F}$ values and significance levels are reported in the following tables. 
Table 3.2(1) - Means and Standard deviations for the demographic variables for the male offenders and male controls and the results for the ANOVAs carried out

\begin{tabular}{|c|c|c|c|c|c|}
\hline & & $\begin{array}{c}\text { MALE } \\
\text { OFFENDERS } \\
(\mathrm{N}=101)\end{array}$ & $\begin{array}{c}\text { MALE } \\
\text { CONTROLS } \\
(\mathrm{N}=33)\end{array}$ & $d f$ & F value \\
\hline AGE & $\begin{array}{l}x \\
S D\end{array}$ & $\begin{array}{r}19.14 \\
1.12\end{array}$ & $\begin{array}{r}19.87 \\
1.12\end{array}$ & 1,126 & $10.57 *$ \\
\hline EDO & $\begin{array}{l}x \\
S D\end{array}$ & $\begin{array}{r}10.52 \\
1.37\end{array}$ & $\begin{array}{r}13.97 \\
1.20\end{array}$ & 1,122 & $159.39 * *$ \\
\hline CIASS & $\begin{array}{l}x \\
S D\end{array}$ & $\begin{array}{l}3.06 \\
0.96\end{array}$ & $\begin{array}{l}2.16 \\
1.04\end{array}$ & 1,97 & $17.71 * \star$ \\
\hline SEG & $\begin{array}{l}x \\
\text { SD }\end{array}$ & $\begin{array}{l}8.17 \\
3.14\end{array}$ & $\begin{array}{l}5.13 \\
3.19\end{array}$ & 1,99 & $19.98 * *$ \\
\hline SIB & $\begin{array}{l}x \\
S D\end{array}$ & $\begin{array}{l}1.70 \\
1.52\end{array}$ & $\begin{array}{l}1.70 \\
1.45\end{array}$ & 1,125 & 0.00 \\
\hline SIB10 & $\begin{array}{l}x \\
\text { SD }\end{array}$ & $\begin{array}{l}1.29 \\
1.18\end{array}$ & $\begin{array}{l}1.42 \\
1.52\end{array}$ & 1,124 & 0.27 \\
\hline
\end{tabular}

${ }^{*} p<0.05 ;{ }^{* *} p<0.001$

Table 3.2(1) shows that four significant results were obtained with some of the demographic variables when male offenders and controls were compared. The male control group was found, on average, to be significantly older than the male offender group $(F(1,126)=10.57, p<0.025)$, the mean number of years spent in education was significantly less for male offenders than non-offenders $(F(1,122)=159.39, p<0.005)$ by just over three years. Male offenders came from significantly lower social classes ( $F(1$, $97)=17.71, \mathrm{p}<0.0005)$ and lower socio-economic groups $(\mathrm{F}(1,99)=19.98, \mathrm{p}<0.0005)$ than male controls. No significant differences were found in the number of siblings in each of the two groups. 
Table 3.2(2) - Means and Standard deviations for the demographic variables for the male offenders and female controls and the results for the ANOVAs carried out

\begin{tabular}{|c|c|c|c|c|c|}
\hline & & $\begin{array}{c}\text { MALE } \\
\text { OFFENDERS } \\
(\mathrm{N}=101)\end{array}$ & $\begin{array}{l}\text { FEMALE } \\
\text { CONTROLS } \\
(\mathrm{N}=75)\end{array}$ & $d f$ & F value \\
\hline AGE & $\begin{array}{l}x \\
S D\end{array}$ & $\begin{array}{r}19.14 \\
1.12\end{array}$ & $\begin{array}{r}19.42 \\
1.02\end{array}$ & 1,167 & 2.81 \\
\hline סDE & $\begin{array}{l}x \\
S D\end{array}$ & $\begin{array}{r}10.52 \\
1.37\end{array}$ & $\begin{array}{r}13.41 \\
1.00\end{array}$ & 1,165 & 232.53 * \\
\hline CLASS & $\begin{array}{l}x \\
\text { SD }\end{array}$ & $\begin{array}{l}3.06 \\
0.96\end{array}$ & $\begin{array}{l}2.19 \\
0.85\end{array}$ & 1,138 & $31.90 * *$ \\
\hline SEG & $\begin{array}{l}x \\
S D\end{array}$ & $\begin{array}{l}8.17 \\
3.14\end{array}$ & $\begin{array}{l}5.17 \\
3.45\end{array}$ & 1,140 & 29.44 * \\
\hline SIB & $\begin{array}{l}x \\
S D\end{array}$ & $\begin{array}{l}1.70 \\
1.52\end{array}$ & $\begin{array}{l}1.54 \\
0.95\end{array}$ & 1,166 & 0.64 \\
\hline SIB10 & $\begin{array}{l}x \\
S D\end{array}$ & $\begin{array}{l}1.29 \\
1.18\end{array}$ & $\begin{array}{l}1.24 \\
1.00\end{array}$ & 1,165 & 0.07 \\
\hline
\end{tabular}

${ }^{*} \mathrm{p}<0.05 ; \quad * \star \mathrm{p}<0.001$

Table 3.2(2) shows the significant differences between the means for the variables obtained in the male offender and female non-offender groups. The female controls had spent significantly longer in education than the male offenders $(F(1,165)=232.53$, $\mathrm{p}<0.0005)$. Male offenders came from significantly lower social classes $(F(1,138)=31.90$, $\mathrm{p}<0.0005)$ and lower socio-economic groups $(\mathrm{F}(1,140)=29.44, \mathrm{p}<0.0005)$ than the female controls. No significant differences were found in age or the number of siblings between the two groups. 
Table 3.2(3) - Means and Standard deviations for the demographic variables for the male offenders and Male and female controls combined and the results for the ANOVAs carried out

\begin{tabular}{|c|c|c|c|c|c|}
\hline & & $\begin{array}{c}\text { MAIE } \\
\text { OFFENDERS } \\
(\mathrm{N}=101)\end{array}$ & $\begin{array}{c}\text { MALE AND FHMALE } \\
\text { CONTROLS } \\
(\mathrm{N}=108)\end{array}$ & $d f$ & F value \\
\hline $\mathbf{A G E}$ & $\begin{array}{l}x \\
S D\end{array}$ & $\begin{array}{r}19.14 \\
1.12\end{array}$ & $\begin{array}{r}19.56 \\
1.07\end{array}$ & 1,200 & $7.45 *$ \\
\hline סDE & $\begin{array}{l}x \\
S D\end{array}$ & $\begin{array}{r}10.52 \\
1.37\end{array}$ & $\begin{array}{r}13.58 \\
1.09\end{array}$ & 1, 197 & $306.74 * *$ \\
\hline CIASS & $\begin{array}{l}x \\
S D\end{array}$ & $\begin{array}{l}3.06 \\
0.96\end{array}$ & $\begin{array}{l}2.18 \\
0.90\end{array}$ & 1,169 & $36.43 * *$ \\
\hline SEG & $\begin{array}{l}x \\
S D\end{array}$ & $\begin{array}{l}8.17 \\
3.14\end{array}$ & $\begin{array}{l}5.16 \\
3.36\end{array}$ & 1,171 & $35.44 * *$ \\
\hline SIB & $\begin{array}{l}x \\
S D\end{array}$ & $\begin{array}{l}1.70 \\
1.52\end{array}$ & $\begin{array}{l}1.59 \\
1.13\end{array}$ & 1,199 & 0.37 \\
\hline SIB10 & $\begin{array}{l}x \\
S D\end{array}$ & $\begin{array}{l}1.29 \\
1.18\end{array}$ & $\begin{array}{l}1.30 \\
1.18\end{array}$ & 1,198 & 0.007 \\
\hline
\end{tabular}

${ }^{*} \mathrm{p}<0.05 ; * * \mathrm{p}<0.001$

Table 3.2(3) shows the significant differences found between the male offenders and the male and female control groups combined. The male and female control group was found to be significantly older than the male offenders $(F(1,200)=7.45, p<0.01)$; the male offenders had spent significantly fewer years in education than the control group $(\mathrm{F}(1,197)=306.74, \mathrm{p}<0.0005)$; male offenders came from significantly lower social classes $(\mathrm{F}(1,169)=36.43, \mathrm{p}<0.0005)$ and lower socio-economic groups $(\mathrm{F}(1,171)=35.44$, $\mathrm{p}<0.0005)$ than the control group. No significant differences were found in the number of siblings in the two groups. 
Table 3.2(4) - Means and Standard deviations for the demographic variables for the Male and female controls and the results for the ANOVAs carried out

\begin{tabular}{|c|c|c|c|c|c|}
\hline & & $\begin{array}{c}\text { MALE } \\
\text { CONTROLS } \\
(\mathrm{N}=33)\end{array}$ & $\begin{array}{l}\text { FEMALE } \\
\text { CONTROLS } \\
(\mathrm{N}=75)\end{array}$ & $d f$ & F value \\
\hline AGE & $\begin{array}{l}x \\
S D\end{array}$ & $\begin{array}{r}19.87 \\
1.12\end{array}$ & $\begin{array}{r}19.42 \\
1.02\end{array}$ & 1,105 & 4.23 * \\
\hline סDE & $\begin{array}{l}x \\
\text { SD }\end{array}$ & $\begin{array}{r}13.97 \\
1.20\end{array}$ & $\begin{array}{r}13.41 \\
1.00\end{array}$ & 1,105 & $6.10 *$ \\
\hline CIASS & $\begin{array}{l}x \\
S D\end{array}$ & $\begin{array}{l}2.16 \\
1.04\end{array}$ & $\begin{array}{l}2.19 \\
0.85\end{array}$ & 1,101 & 0.03 \\
\hline SEG & $\begin{array}{l}x \\
S D\end{array}$ & $\begin{array}{l}5.13 \\
3.19\end{array}$ & $\begin{array}{l}5.17 \\
3.45\end{array}$ & 1,101 & 0.00 \\
\hline SIB & $\begin{array}{l}x \\
S D\end{array}$ & $\begin{array}{l}1.70 \\
1.45\end{array}$ & $\begin{array}{l}1.54 \\
0.95\end{array}$. & 1,105 & 0.43 \\
\hline SIB10 & $\begin{array}{l}x \\
S D\end{array}$ & $\begin{array}{l}1.42 \\
1.52\end{array}$ & $\begin{array}{l}1.24 \\
1.00\end{array}$ & 1,105 & 0.53 \\
\hline
\end{tabular}

${ }^{*} \mathrm{p}<0.05 ; * * \mathrm{p}<0.001$

Table 3.2(4) shows the results of the ANOVA's carried out to examine the differences obtained between the male and female control groups. The male controls were found to be significantly older than the female controls $(F(1,105)=4.23, p<0.05)$; the male controls were also found to have spent significantly marginally more years in education than the female controls $(F(91,105)=6.10, p<0.05)$. No other significant differences were obtained between these two groups.

\section{Personality Variables}

The differences between the sample groups on the four personality variables obtained, Psychoticism (P), Extraversion (E), Neuroticism $(\mathrm{N})$ and the Lie score $(\mathrm{L})$ were analysed using Analyses of variance. 


\section{Analyses of Variance (ANOVA)}

The differences between the male offenders and the three comparison groups (male controls, female controls and combined controls) were analysed for significance and the results are shown in the tables below.

Table 3.2(5) - Means and Standard deviations for the personality variables for the Male offenders and male controls and the results for the ANOVAs carried out

\begin{tabular}{|c|c|c|c|c|c|}
\hline & & $\begin{array}{c}\text { MALE } \\
\text { OFFENDERS } \\
(\mathrm{N}=101)\end{array}$ & $\begin{array}{c}\text { MALE } \\
\text { CONTROLS } \\
(\mathrm{N}=33)\end{array}$ & $d f$ & $F$ value \\
\hline $\mathbf{P}$ & $\begin{array}{l}x \\
\text { SD }\end{array}$ & $\begin{array}{l}4.74 \\
2.53\end{array}$ & $\begin{array}{l}3.21 \\
1.58\end{array}$ & 1,127 & $10.61 *$ \\
\hline $\boldsymbol{E}$ & $\begin{array}{l}x-1 \\
x\end{array}$ & $\begin{array}{l}2.35 \\
8.71 \\
3.05\end{array}$ & $\begin{array}{l}1.20 \\
7.85 \\
3.48\end{array}$ & 1,127 & 1.82 \\
\hline $\mathbf{N}$ & $\begin{array}{l}x \\
\text { SD }\end{array}$ & $\begin{array}{l}6.05 \\
3.21\end{array}$ & $\begin{array}{l}6.15 \\
3.49\end{array}$ & 1,127 & 0.02 \\
\hline I & $\begin{array}{l}x \\
S D\end{array}$ & $\begin{array}{l}3.24 \\
2.45\end{array}$ & $\begin{array}{l}2.64 \\
2.23\end{array}$ & 1,127 & 1.56 \\
\hline
\end{tabular}

$\star p<0.05 ; * \star p<0.001$

Table 3.2(5) shows that only one difference was found to be significantly different with regard to personality variables between the male offenders and male controls. The only significant difference was found with regard to $\mathrm{P}$, the male offenders had a higher $\mathrm{P}$ score than the male non-offenders $(F=10.61, p<0.005)$. 
Table 3.2(6) - Means and Standard deviations for the personality variables for the Male offenders and Female controls and the results for the ANOVAs carried out

\begin{tabular}{|c|c|c|c|c|c|}
\hline & & $\begin{array}{c}\text { MALE } \\
\text { OFFENDERS } \\
(\mathrm{N}=101)\end{array}$ & $\begin{array}{l}\text { FEMALE } \\
\text { CONTROLS } \\
(\mathrm{N}=75)\end{array}$ & $d f$ & F value \\
\hline $\mathbf{P}$ & $\begin{array}{l}x \\
S D\end{array}$ & $\begin{array}{l}4.74 \\
2.53\end{array}$ & $\begin{array}{l}2.17 \\
2.17\end{array}$ & 1,169 & $30.70 * *$ \\
\hline $\mathbf{E}$ & $\begin{array}{l}x \\
S D\end{array}$ & $\begin{array}{l}8.71 \\
3.05\end{array}$ & $\begin{array}{l}8.37 \\
3.41\end{array}$ & 1,169 & 0.46 \\
\hline $\mathbf{N}$ & $\begin{array}{l}x \\
S D\end{array}$ & $\begin{array}{l}6.05 \\
3.21\end{array}$ & $\begin{array}{l}6.76 \\
3.01\end{array}$ & 1,169 & 2.16 \\
\hline I & $\begin{array}{l}x \\
S D\end{array}$ & $\begin{array}{l}3.24 \\
2.45\end{array}$ & $\begin{array}{l}3.24 \\
2.09\end{array}$ & 1,169 & 0.00 \\
\hline
\end{tabular}

${ }^{*} \mathrm{p}<0.05 ; * * \mathrm{p}<0.001$

Table 3.2(6) shows that only the difference in the P score means between male offenders and female controls was found to be significant. Male offenders had significantly higher $\mathrm{P}$ scores than the female controls $(\mathrm{F}(1,169)=30.70, \mathrm{p}<0.0005)$.

Table 3.2(7) - Means and Standard deviations for the personality variables for the Male offenders and Male and Female controls combined and the results for the ANOVAs carried out

\begin{tabular}{|c|c|c|c|c|c|}
\hline & & $\begin{array}{l}\text { MALE } \\
\text { OFFENDERS } \\
(\mathrm{N}=101)\end{array}$ & $\begin{array}{l}\text { MALE AND FEMALE } \\
\text { CONTROLS } \\
(\mathrm{N}=108)\end{array}$ & $d f$ & F value \\
\hline $\mathbf{P}$ & $\begin{array}{l}x \\
S D\end{array}$ & $\begin{array}{l}4.74 \\
2.53\end{array}$ & $\begin{array}{l}2.86 \\
2.02\end{array}$ & 1,202 & $34.79 * *$ \\
\hline $\mathbf{E}$ & $\begin{array}{l}x \\
S D\end{array}$ & $\begin{array}{l}8.71 \\
3.05\end{array}$ & $\begin{array}{l}8.21 \\
3.43\end{array}$ & 1,202 & 1.18 \\
\hline $\mathbf{N}$ & $\begin{array}{l}x \\
\text { SD }\end{array}$ & $\begin{array}{l}6.05 \\
3.21\end{array}$ & $\begin{array}{l}6.57 \\
3.16\end{array}$ & 1,202 & 1.37 \\
\hline $\mathbf{I}$ & $\begin{array}{l}x \\
\text { SD }\end{array}$ & $\begin{array}{l}3.24 \\
2.45\end{array}$ & $\begin{array}{l}3.06 \\
2.14\end{array}$ & $1, \quad 202$ & 0.33 \\
\hline
\end{tabular}

${ }^{*} \mathrm{p}<0.05 ; \quad *{ }^{*} \mathrm{p}<0.001$

Table 3.2(7) shows that again only one of the personality variables, $\mathrm{P}$, was found to be a significant difference between the two groups of male offenders and the male and 
female controls combined. The male offenders were found to have significantly higher $P$ scores than the combined male and female control group $(F(1,202)=34.79, p<0.0005)$.

Table 3.2(8) - Means and Standard deviations for the personality variables for the Male and Female controls and the results for the ANOVAs carried out

\begin{tabular}{|c|c|c|c|c|c|}
\hline & & $\begin{array}{c}\text { MALE } \\
\text { CONTROLS } \\
(\mathrm{N}=33)\end{array}$ & $\begin{array}{l}\text { FEMALE } \\
\text { CONTROLS } \\
(\mathrm{N}=75)\end{array}$ & $d f$ & F value \\
\hline $\mathbf{P}$ & $\begin{array}{l}X \\
S D\end{array}$ & $\begin{array}{l}3.21 \\
1.58\end{array}$ & $\begin{array}{l}2.71 \\
2.17\end{array}$ & 1,106 & 1.45 \\
\hline $\mathbf{E}$ & $\begin{array}{l}x \\
S D\end{array}$ & $\begin{array}{l}7.85 \\
3.48\end{array}$ & $\begin{array}{l}8.37 \\
3.41\end{array}$ & 1,106 & 0.54 \\
\hline $\mathbf{N}$ & $\begin{array}{l}x \\
S D\end{array}$ & $\begin{array}{l}6.15 \\
3.49\end{array}$ & $\begin{array}{l}6.76 \\
3.01\end{array}$ & 1,106 & 0.85 \\
\hline I & $\begin{array}{l}x \\
\text { SD }\end{array}$ & $\begin{array}{l}2.64 \\
2.23\end{array}$ & $\begin{array}{l}3.24 \\
2.09\end{array}$ & 1,106 & 1.83 \\
\hline
\end{tabular}

${ }^{*} \mathrm{p}<0.05 ; * \star \mathrm{p}<0.001$

Table 3.2(8) shows that there were no significant differences between the male and female control groups with regard to personality variables showing that no differences can be accounted for by sex differences.

\section{Analysis of Co-Variance (ANCOVA)}

The significant and non-significant differences found between the various sample groups on the above ANOVAs could be accounted for not by the offender status of each sample group, but by significant differences in demographic variables between the groups [as shown in tables 3.2(1) to 3.2(4)]. For this reason, analyses of co-variance were carried out for these combinations using the relevant significant demographic variables as simultaneous co-variates. Only the difference in $\mathrm{P}$ between the male and female control groups showed a difference in significance when demographic variables were co-varied. The results of this analyses is shown in the table below. In all other cases no differences 
in significance were found when significant differences in demographic variables were simultaneously co-varied.

Table 3.2(9) - Means and Standard deviations for Psychoticism for the Male and Female controls and the results of the ANCOVA carried out with age and education as co-variates

\begin{tabular}{cccccc}
\hline & $\begin{array}{c}\text { MALE } \\
\text { CONTROLS } \\
(\mathrm{N}=33)\end{array}$ & $\begin{array}{c}\text { FHMALE } \\
\text { CONTROLS } \\
(\mathrm{N}=75)\end{array}$ & df & F value \\
\hline $\mathrm{P}$ & $\mathrm{x}$ & 3.21 & 2.71 & 2,104 & $4.18^{*}$ \\
& $\mathrm{SD}$ & 1.58 & 2.17 & & \\
\hline
\end{tabular}

${ }^{\star} \mathrm{p}<0.001$

Table 3.2(9) shows that in contrast to table 3.2(8) that the male controls score significantly higher on $\mathrm{P}$ than the female controls $(\mathrm{F}(1,104)=4.18, \mathrm{p}<0.001$. This result suggests that there is a sex difference in P score but this was masked by age and educational differences in the ANOVA carried out earlier.

\section{Moral Reasoning and Intelligence}

The three measures of moral reasoning: modal stage (MODAL), sociomoral reasoning maturity score (SRMS) and global stage (GLOBAL) were subjected to analysis of variance for the combinations of the four sub-groups of the subject sample. In addition, the same analysis was carried out with reference to the intelligence score (RAV).

\section{Analyses of Variance (ANOVA)}

The differences between the male offenders and the three comparison groups (male controls, female controls and combined controls) were analysed for significance and the results are shown in the tables below. 
Table 3.2(10) - Means and Standard deviations for the Intelligence and Moral

Reasoning variables for the Male offenders and Male controls and the results for the ANOVAs carried out

\begin{tabular}{|c|c|c|c|c|c|}
\hline & & $\begin{array}{c}\text { MALE } \\
\text { OFFENDERS } \\
(\mathrm{N}=101)\end{array}$ & $\begin{array}{c}\text { MALE } \\
\text { CONTROLS } \\
(\mathrm{N}=33)\end{array}$ & $d f$ & F value \\
\hline RAV & $\begin{array}{l}x \\
\text { SD }\end{array}$ & $\begin{array}{r}39.02 \\
8.79\end{array}$ & $\begin{array}{r}51.84 \\
6.82\end{array}$ & 1,129 & $58.31 * \star$ \\
\hline MODAI & $\begin{array}{l}x \\
S D\end{array}$ & $\begin{array}{l}4.18 \\
0.92\end{array}$ & $\begin{array}{l}5.50 \\
0.80\end{array}$ & 1,97 & $48.32 * *$ \\
\hline SRMS & $\begin{array}{l}x \\
S D\end{array}$ & $\begin{array}{r}252.46 \\
33.55\end{array}$ & $\begin{array}{r}324.19 \\
31.59\end{array}$ & 1,98 & $103.19 * *$ \\
\hline GLOBAI & $\begin{array}{l}x \\
\text { SD }\end{array}$ & $\begin{array}{l}5.65 \\
1.05\end{array}$ & $\begin{array}{l}7.69 \\
1.03\end{array}$ & 1,98 & $83.44 * *$ \\
\hline
\end{tabular}

${ }^{*} \mathrm{p}<0.05 ; \quad * \star \mathrm{p}<0.001$

Table 3.2(10) shows that all the moral reasoning variables showed significant differences and the same was true for intelligence between the male offenders and controls groups. The male controls scored significantly higher on the intelligence score than the male offenders $(F(1,129)=58.31, p<0.0005)$. The male control group had significantly higher modal stage of sociomoral reasoning than the male offender group $(F(1,97)=48.32$, $\mathrm{p}<0.0005)$. The male control group also had significantly more mature sociomoral reasoning than the male offender group $(F(1,98)=103.19, \mathrm{p}<0.0005)$. The male group also had a significantly higher global stage of sociomoral reasoning than the male offender group $(\mathrm{F}(1,98)=83.44, \mathrm{p}<0.0005)$. 
Table 3.2(11) - Means and Standard deviations for the Intelligence and Moral

Reasoning variables for the Male offenders and Female controls and the results for the ANOVAs carried out

\begin{tabular}{|c|c|c|c|c|c|}
\hline & & $\begin{array}{c}\text { MALE } \\
\text { OFFENDERS } \\
(\mathrm{N}=101)\end{array}$ & $\begin{array}{l}\text { FEMALE } \\
\text { CONTROLS } \\
(\mathrm{N}=75)\end{array}$ & $d f$ & F value \\
\hline RAV & $\begin{array}{l}x \\
\text { SD }\end{array}$ & $\begin{array}{r}39.02 \\
8.79\end{array}$ & $\begin{array}{r}50.21 \\
7.14\end{array}$ & 1,172 & $81.06 * *$ \\
\hline MODAL & $\begin{array}{l}x \\
S D\end{array}$ & $\begin{array}{l}4.18 \\
0.92\end{array}$ & $\begin{array}{l}5.55 \\
0.92\end{array}$ & 1,140 & $78.23 * \star$ \\
\hline SRMS & $\begin{array}{l}x \\
S D\end{array}$ & $\begin{array}{r}252.46 \\
33.55\end{array}$ & $\begin{array}{r}327.60 \\
27.23\end{array}$ & 1,141 & 217.94 * \\
\hline GLOBAI & $\begin{array}{l}x \\
S D\end{array}$ & $\begin{array}{l}5.56 \\
2.45\end{array}$ & $\begin{array}{l}7.80 \\
2.09\end{array}$ & 1,141 & $174.56 * *$ \\
\hline
\end{tabular}

${ }^{\star} \mathrm{p}<0.05 ; \quad{ }^{*} \mathrm{p}<0.001$

Table 3.2(11) shows that all the moral reasoning variables showed significant differences and the same was true for intelligence between the male offender and female control groups. The female controls scored significantly higher on the intelligence score than the male offenders

$(\mathrm{F}(1,172)=81.06, \mathrm{p}<0.0005)$. The female control group had significantly higher modal stage of sociomoral reasoning than the male offender group $(F(1,140)=78.23, p<0.0005)$. The female control group also had significantly more mature sociomoral reasoning than the male offender group $(F(1,141=217.94, p<0.0005)$. The female group also had a significantly higher global stage of sociomoral reasoning than the male offender group $(\mathrm{F}(1,141=174.56, \mathrm{p}<0.0005)$. 
Table 3.2(12) - Means and Standard deviations for the Intelligence and Moral

Reasoning variables for the Male offenders and Male and Female controls combined and the results for the ANOVAs carried out

\begin{tabular}{|c|c|c|c|c|c|}
\hline & & $\begin{array}{c}\text { MALE } \\
\text { OFFENDERS } \\
(\mathrm{N}=101)\end{array}$ & $\begin{array}{l}\text { MALE AND FEMALE } \\
\text { CONTROLS } \\
(\mathrm{N}=108)\end{array}$ & $d f$ & F value \\
\hline RAV & $\begin{array}{l}x \\
\text { SD }\end{array}$ & $\begin{array}{r}39.02 \\
8.79\end{array}$ & $\begin{array}{r}50.70 \\
6.90\end{array}$ & 1,205 & $113.36 * *$ \\
\hline MODAL & $\begin{array}{l}x \\
S D\end{array}$ & $\begin{array}{l}4.18 \\
0.92\end{array}$ & $\begin{array}{l}5.53 \\
0.88\end{array}$ & 1,172 & $93.76 * *$ \\
\hline SRMS & $\begin{array}{l}x \\
S D\end{array}$ & $\begin{array}{r}252.46 \\
33.55\end{array}$ & $\begin{array}{r}326.58 \\
28.50\end{array}$ & 1,173 & 244.74 * \\
\hline GLOBAL & $\begin{array}{l}x \\
S D\end{array}$ & $\begin{array}{l}5.65 \\
1.05\end{array}$ & $\begin{array}{l}7.77 \\
0.94\end{array}$ & 1,173 & $193.81 * *$ \\
\hline
\end{tabular}

${ }^{*} p<0.05 ; * \star p<0.001$

Table 3.2(12) shows that all the moral reasoning variables showed significant differences and the same was true for intelligence between the male offender group and the male and female combined control groups. The combined controls scored significantly higher on the intelligence score than the male offenders $(F(1,205)=113.36, p<0.0005)$. The combined control group had significantly higher modal stage of sociomoral reasoning than the male offender group $(F(1,172)=93.76, p<0.0005)$. The combined control group also had significantly more mature sociomoral reasoning than the male offender group $(\mathrm{F}(1,173=244.74, \mathrm{p}<0.0005)$. The combined group also had a significantly higher global stage of sociomoral reasoning than the male offender group $(F(1,173=193.81, p<0.0005)$. 
Table 3.2(13) - Means and Standard deviations for the Intelligence and Moral

Reasoning variables for the Male and Female controls and the results for the ANOVAs carried out

\begin{tabular}{|c|c|c|c|c|c|}
\hline & & $\begin{array}{c}\text { MALE } \\
\text { CONTROLS } \\
(\mathrm{N}=33)\end{array}$ & $\begin{array}{l}\text { FEMALE } \\
\text { CONTROLS } \\
(\mathrm{N}=75)\end{array}$ & $d f$ & F value \\
\hline RAV & $\begin{array}{l}x \\
\text { SD }\end{array}$ & $\begin{array}{r}51.84 \\
6.28\end{array}$ & $\begin{array}{r}50.21 \\
7.14\end{array}$ & 1,105 & 1.25 \\
\hline MODAL & $\begin{array}{l}x \\
S D\end{array}$ & $\begin{array}{l}5.50 \\
0.80\end{array}$ & $\begin{array}{l}5.55 \\
0.92\end{array}$ & 1,105 & 0.06 \\
\hline SRMS & $\begin{array}{l}x \\
S D\end{array}$ & $\begin{array}{r}324.19 \\
31.59\end{array}$ & $\begin{array}{r}327.60 \\
27.23\end{array}$ & 1,105 & 0.32 \\
\hline GLOBAI & $\begin{array}{l}x \\
S D\end{array}$ & $\begin{array}{l}7.69 \\
2.23\end{array}$ & $\begin{array}{l}7.80 \\
2.09\end{array}$ & 1,105 & 0.32 \\
\hline
\end{tabular}

${ }^{*} \mathrm{p}<0.05 ; * \star \mathrm{p}<0.001$

Table 3.2(13) shows that no significant differences were apparent between the male and female sample groups with regard to intelligence and moral reasoning variables. This indicates that these differences cannot be accounted for by sex differences.

\section{Analyses of Co-Variance (ANCOVA)}

The significant and non-significant differences found between the various sample groups on the above ANOVAs could be accounted for not by the offender status of each sample group, but by significant differences in demographic variables between the groups [as shown in tables 3.2(1) to 3.2(4)]. For this reason, analyses of co-variance were carried out for these combinations using the relevant significant demographic variables as simultaneous co-variates. Only the difference in Intelligence (RAV) between the male and female control groups showed a difference in significance when demographic variables were co-varied. The results of this analyses is shown in the table 3.2(13.1). In all other cases no differences in significance were found when significant differences in demographic variables were simultaneously co-varied. 
Table 3.2(13.1) - Means and Standard deviations for Intelligence (RAV) for the Male and Female controls and the results of the ANCOVA carried out with age and education as co-variates

\begin{tabular}{llrrll}
\hline & $\begin{array}{c}\text { MALE } \\
\text { CONTROLS } \\
(\mathrm{N}=33)\end{array}$ & $\begin{array}{c}\text { FEMALE } \\
\text { CONTROLS } \\
(\mathrm{N}=75)\end{array}$ & df & $F$ value \\
\hline RAV & $x$ & 51.84 & 50.21 & 1,104 & $2.73 *$ \\
& $S D$ & 6.28 & 7.14 & & \\
\hline
\end{tabular}

${ }^{*} p<0.05$

Table 3.2(13.1) shows that in contrast to table 3.2(13) that the male controls scored significantly higher on intelligence (RAV) than the female controls $(F(1,104)=2.73, p<0.05$. This result suggests that there is a sex difference in the intelligence score but this was masked by age and educational differences in the ANOVA carried out earlier.

\section{Offending History Variables}

The three measures of offending history: self-reported delinquency (SRD), crimes against the person (PER) and property crimes (THEFT) were subjected to analysis of variance for the combinations of the four sub-groups of the subject sample.

\section{Analyses of Variance (ANOVA)}

The differences between the male offenders and the three comparison groups (male controls, female controls and combined controls) were analysed for significance and the results are shown in the tables below. 
Table 3.2(14) - Means and standard deviations for the offending history variables for the male offenders and male controls and the results of the ANOVAs carried out

\begin{tabular}{|c|c|c|c|c|c|}
\hline & & $\begin{array}{c}\text { MALE } \\
\text { OFFENDERS } \\
(\mathrm{N}=101)\end{array}$ & $\begin{array}{c}\text { MALE } \\
\text { CONTROLS } \\
(\mathrm{N}=33)\end{array}$ & $d f$ & F value \\
\hline SRD & $\begin{array}{l}x \\
\text { SD }\end{array}$ & $\begin{array}{r}21.92 \\
7.31\end{array}$ & $\begin{array}{r}13.70 \\
5.64\end{array}$ & 1,126 & $34.60 * *$ \\
\hline PER & $\begin{array}{l}x \\
S D\end{array}$ & $\begin{array}{l}3.84 \\
2.03\end{array}$ & $\begin{array}{l}1.67 \\
1.16\end{array}$ & 1,126 & $33.97 * *$ \\
\hline TEEFT & $\begin{array}{l}x \\
S D\end{array}$ & $\begin{array}{l}5.28 \\
1.89\end{array}$ & $\begin{array}{l}2.36 \\
1.65\end{array}$ & 1,126 & $62.23 * \star$ \\
\hline
\end{tabular}

${ }^{*} \mathrm{p}<0.05 ; * * \mathrm{p}<0.001$

Table 3.2(14) shows that all the offending history variables showed significant differences between male offenders and male control sample groups. Male offenders committed significantly more general delinquency $(S R D, F(1,126)=34.60, p<0.001)$, crimes against the person (PER, $\mathrm{F}(1,126)=33.97, \mathrm{p}<0.001$ ), and property crimes (THEFT, $\mathrm{F}(1,126)=62.23, \mathrm{p}<0.001)$ than the male controls

Table 3.2(15) - Means and standard deviations for the offending history variables for the male offenders and female controls and the results of the ANOVA's carried out

\begin{tabular}{llrrrll}
\hline & $\begin{array}{c}\text { MALE } \\
\text { OFFENDERS } \\
(N=101)\end{array}$ & $\begin{array}{c}\text { FEMALE } \\
\text { CONTROLS } \\
(\mathrm{N}=75)\end{array}$ & df & F value \\
\hline SRD & $x$ & 21.92 & 10.92 & 1,168 & $133.75 * \star$ \\
& SD & 7.31 & 5.33 & & \\
PER & $x$ & 3.84 & 1.04 & 1,168 & $120.31 * \star$ \\
& SD & 2.03 & 0.99 & & & \\
THEFT & $X$ & 5.28 & 0.91 & 1,168 & $298.73 * \star$ \\
& SD & 1.89 & 1.25 & & \\
\hline
\end{tabular}

${ }^{*} \mathrm{p}<0.05 ; * * \mathrm{p}<0.001$

Table 3.2(15) shows that all the offending history variables showed significant differences between the male offender and female control sample groups. The female controls committed significantly fewer general offences (SRD, $F(1,168)=133.75, p<0.001)$, 
crimes against the person (PER, $\mathrm{F}(1,168)=120.31$, $\mathrm{p}<0.001$ ), and thefts (THEFT, $\mathrm{F}(1$, 168) $=298.73, \mathrm{p}<0.001$ ) than the male offenders.

Table 3.2(16) - Means and standard deviations for the offending history variables for the male offenders and male and female controls combined and the results of the ANOVAs carried out

\begin{tabular}{|c|c|c|c|c|c|}
\hline & & $\begin{array}{l}\text { MALE } \\
\text { OFFENDERS } \\
(\mathrm{N}=101)\end{array}$ & $\begin{array}{l}\text { MALE AND FEMALE } \\
\text { CONTROIS } \\
(\mathrm{N}=108)\end{array}$ & $d f$ & F value \\
\hline SRD & $\begin{array}{l}x \\
S D\end{array}$ & $\begin{array}{r}21.92 \\
7.31\end{array}$ & $\begin{array}{r}11.33 \\
5.63\end{array}$ & 1,201 & 135.57 ** \\
\hline PER & $\begin{array}{l}x \\
\text { SD }\end{array}$ & $\begin{array}{l}3.84 \\
2.03\end{array}$ & $\begin{array}{l}1.23 \\
1.08\end{array}$ & 1,201 & 135.27 ** \\
\hline THEFT & $\begin{array}{l}x \\
\text { SD }\end{array}$ & $\begin{array}{l}5.28 \\
1.89\end{array}$ & $\begin{array}{l}1.35 \\
1.54\end{array}$ & 1,201 & 267.18 ** \\
\hline
\end{tabular}

${ }^{*} p<0.05 ; \quad{ }^{*} p<0.001$

Table 3.2(16) again shows that all three offending history variables showed significant differences between the male offenders and the male and female control groups combined. The male offenders committed significantly more general delinquency (SRD, $F(1,201)=135.57, p<0.001)$, crimes against the person $(P E R, F(1,201)=135.27, p<0.001)$, and thefts (THEFTS, $F(1,201)=267.18, \mathrm{p}<0.001)$ than the male and female control group. 
Table 3.2(17) - Means and standard deviations for the offending history variables for the male and female controls and the results of the ANOVAs carried out

\begin{tabular}{|c|c|c|c|c|c|}
\hline & & $\begin{array}{c}\text { MALE } \\
\text { CONTROLS } \\
(\mathrm{N}=33)\end{array}$ & $\begin{array}{l}\text { FEMALE } \\
\text { CONTROLS } \\
(\mathrm{N}=75)\end{array}$ & $d f$ & F value \\
\hline SRD & $\begin{array}{l}x \\
S D\end{array}$ & $\begin{array}{r}13.70 \\
5.64\end{array}$ & $\begin{array}{r}10.92 \\
5.33\end{array}$ & 1,106 & $9.01 *$ \\
\hline PER & $\begin{array}{l}x \\
S D\end{array}$ & $\begin{array}{l}1.67 \\
1.16\end{array}$ & $\begin{array}{l}1.04 \\
0.99\end{array}$ & 1,106 & $8.21 *$ \\
\hline THEFT & $\begin{array}{l}x \\
S D\end{array}$ & $\begin{array}{l}2.36 \\
1.65\end{array}$ & $\begin{array}{l}0.91 \\
1.25\end{array}$ & 1,106 & $8.21 *$ \\
\hline
\end{tabular}

${ }^{\star} \mathrm{p}<0.05 ; * \star \mathrm{p}<0.001$

Table 3.2(17) shows that all the offending history variables showed significant differences between the male and female control groups, although at lower significance levels for the differences in the other combinations of sub-groups. Male controls committed significantly more general delinquency $(S R D, F(1,106)=9.01, p<0.05)$, crimes against the person (PER, $F(1,106)=8.21, \mathrm{p}<0.05)$, and thefts (THEFT, $F(1,106)=8.21$, $\mathrm{p}<0.05)$ than female controls.

\section{Analysis of Co-Variance (ANCOVA)}

The significant and non-significant differences found between the various sample groups on the above ANOVAs could be accounted for not by the offender status of each sample group, but by significant differences in demographic variables between the groups [as shown in tables 3.2(1) to 3.2(4)]. For this reason, analyses of co-variance were carried out for these combinations using the relevant significant demographic variables as simultaneous co-variates. In all cases no differences in significance were found when significant differences in demographic variables were simultaneously co-varied. This suggests that any significance found in the differences in offending history variables 
between the various sample groups could not be accounted for by demographic differences alone.

\section{Summary/Discussion}

An overall impression of the group comparison results, suggests that convicted offenders showed significant differences from the control groups. Several of these differences were in keeping with predictions from both theory and previous findings.

This was especially true for moral reasoning, where in all cases the convicted offenders were found to be functioning at less mature stages of moral reasoning than the control groups, as would be predicted from Kohlberg's theory. These results could not be accounted for solely as a result of higher intelligence or a greater number of years spent in education on the part of the comparison groups, as was revealed by the relevant analyses of co-variance. It is possible to convert the average sociomoral reflection maturity score (SRMS) into a global stage score (Gibbs and Widaman, 1982). This shows that the offenders were reasoning at major-minor transition stage $3(2)$, while the combined control group was two stage categories above these at major-minor transition stage 3(4).

The convicted offenders were also found to have significantly lower intelligence than the control groups, which could not be accounted for in terms of differences in educational level between the offenders and the comparison groups.

The differences in personality between offenders and controls were less marked. While psychoticism (P) was significantly higher for the convicted individuals than for any of the control groups, there were no significant differences in extraversion (E) and neuroticism (N). H. J. Eysenck's theory would predict higher P scores in offenders, it would also predict higher $\mathrm{E}$ and $\mathrm{N}$ scores in offenders which were not found in the present study. 
Some significant differences in demographic/family background variables were also found. The offenders tended to come from more socially and economically deprived backgrounds, and had spent fewer years in education than the comparison groups. A prediction which was not clearly upheld concerned family size (measured by number of siblings before (SIB) and after (SIB10) the age of ten), where no differences were found between the convicted offenders and the controls. Furthermore, the offender group was found to be significantly younger than both the male and combined controls, but not the female controls. These findings could account for the differences in psychoticism, moral reasoning and intelligence between the male offenders and the male and combined controls.

However, the analyses of co-variance, calculated for each of the group comparisons, showed that the convicted offenders' higher psychoticism, lower moral reasoning and intelligence were still significantly different when demographic differences were controlled.

The main discussion in chapter 5 covers the group comparison results in more depth. 


\section{3 - PERSONALITY VARIABLES AS INDEPENDENT VARIABLES}

\section{Introduction}

Various predictions were made of the nature of the scoring in the three personality variables with respect to offending. Some of these predictions were dealt with in the descriptions and group comparison sections.

However, the pattern of scoring of psychoticism (P), extraversion (E), neuroticism (N) is of utmost importance to the theory proposed by H. J. Eysenck, since the three variables are hypothesised to interact with each other to result in a greater tendency to engage in criminal activity. As commented on by various researchers (e.g. McGurk and McDougall, 1981) most of the previous research has ignored the heterogeneity of personality types within the offending population. Most of the data provided to investigate Eysenck's theory have employed analyses similar to those found in sections 3.1 and 3.2 which have looked at $\mathrm{P}, \mathrm{E}$, and $\mathrm{N}$ in isolation of each other.

This section reports the results of analyses which were undertaken in an attempt to investigate the pattern of personality types within both the offender and comparison groups and to explore how the other variables collected (demographics, moral reasoning, intelligence and offending history) vary across the different personality combinations.

This investigation was undertaken in two ways. Firstly, the sample groups were divided into high, middle and low scorers of P, E and N. Where High indicated a score of 9 or over, middle a score between 5 and 8 and low a score lower than or equal to 4 .

Differences in demographics, moral reasoning, intelligence and offending history were analysed for significance using one-way analyses of variance within each of the personality scores $(\mathrm{P}, \mathrm{E}$, or $\mathrm{N})$ in the whole sample group, the convicted offenders, and the combined comparison group. This analysis was carried out to determine if the high scorers of the 
personality variables (who were predicted to offend the most) were masked in the earlier analyses by the low and middle range scorers.

The second analysis undertaken involved Ward's (1963) method of cluster analyses upon the four personality variables (P, E, $N$ and $L)$. This was intended to identify clusters of personality types as performed by McGurk and McDougall (1981), McEwan (1983) and McEwan and Knowles (1984) in both the convicted offenders and the combined comparison groups. The comparison of the clusters obtained in both groups by this method would enable a more direct investigation of the prediction that the combination of High $\mathrm{P}, \mathrm{E}$ and $\mathrm{N}$ would be more prevalent in convicted offender populations.

In addition, one way analyses of variance were conducted to identify significance in the differences in other variables (demographics, moral reasoning, intelligence, offending history) between the clusters of personality variables found in each sample group.

\section{Division of Personality Variables into High, Middle and Low}

\section{Analysis of Variance}

More complex analysis of the results, based on the results reported in sections 3.1 and 3.2, were conducted where personality variables $(P, E, N)$ were divided into high middle and low scores. These were then used as independent variables and analyses of variance were carried out with these independent variables to analyse the differences in the dependent variables between the three levels of each of the three personality scores. The tables below show the means and standard deviations for each of these groups and the results of the ANOVA's carried out. 
Whole Sample Group Results

Table 3.3(1) - The means and standard deviations for the 18 dependent variables for the three levels of the P Scale for the whole sample group and the results of the ANOVAs carried out

\begin{tabular}{|c|c|c|c|c|c|c|}
\hline & & $\begin{array}{c}\text { LOW } \\
(\mathrm{N}=138)\end{array}$ & $\begin{array}{c}\text { P SCORE } \\
\text { MIDDLE } \\
(\mathrm{N}=56)\end{array}$ & $\begin{array}{c}\text { BIGH } \\
(\mathrm{N}=10)\end{array}$ & df & F value \\
\hline AGE & $\begin{array}{l}x \\
S D\end{array}$ & $\begin{array}{r}19.41 \\
1.11\end{array}$ & $\begin{array}{r}19.22 \\
1.18\end{array}$ & $\begin{array}{r}19.55 \\
0.89\end{array}$ & 2,195 & 0.66 \\
\hline EDU & $\begin{array}{l}x \\
S D\end{array}$ & $\begin{array}{c}12.63 a \\
1.61\end{array}$ & $\begin{array}{c}11.43 a \\
1.79\end{array}$ & $\begin{array}{l}9.78 \mathrm{a} \\
4.15\end{array}$ & 2,193 & $16.05 * * \star$ \\
\hline CLASS & $\begin{array}{l}x \\
S D\end{array}$ & $\begin{array}{l}2.41 a \\
0.95\end{array}$ & $\begin{array}{l}2.86 a \\
1.18\end{array}$ & $\begin{array}{l}2.20 \\
0.84\end{array}$ & 2,164 & $3.33 \star$ \\
\hline SEG & $\begin{array}{l}x \\
S D\end{array}$ & $\begin{array}{l}5.83 a \\
3.57\end{array}$ & $\begin{array}{l}7.50 a \\
3.13\end{array}$ & $\begin{array}{l}7.67 \\
5.47\end{array}$ & 2,166 & $3.95 *$ \\
\hline SIB & $\begin{array}{l}x \\
\text { SD }\end{array}$ & $\begin{array}{l}1.48 a \\
1.33\end{array}$ & $\begin{array}{l}2.02 a \\
1.22\end{array}$ & $\begin{array}{l}1.67 \\
1.32\end{array}$ & 2,195 & $3.31 *$ \\
\hline SIB10 & $\begin{array}{l}x \\
S D\end{array}$ & $\begin{array}{l}1.16 \\
1.15\end{array}$ & $\begin{array}{l}1.56 \\
1.13\end{array}$ & $\begin{array}{l}1.44 \\
1.42\end{array}$ & 2,194 & 2.30 \\
\hline RAV & $\begin{array}{l}x \\
\text { SD }\end{array}$ & $\begin{array}{c}46.61 \mathrm{ab} \\
9.50\end{array}$ & $\begin{array}{c}42.93 a \\
8.95\end{array}$ & $\begin{array}{l}38.80 \mathrm{~b} \\
12.70\end{array}$ & 2,200 & $5.33 \star \star$ \\
\hline $\mathbf{P}$ & $\begin{array}{l}x \\
\text { SD }\end{array}$ & $\begin{array}{l}2.35 a \\
1.24\end{array}$ & $\begin{array}{l}6.14 \mathrm{a} \\
1.14\end{array}$ & $\begin{array}{l}9.60 a \\
0.84\end{array}$ & 2,201 & $327.63 * * \star$ \\
\hline $\mathbf{E}$ & $\begin{array}{l}x \\
S D\end{array}$ & $\begin{array}{l}8.22 \\
3.50\end{array}$ & $\begin{array}{l}9.10 \\
2.46\end{array}$ & $\begin{array}{l}7.80 \\
3.46\end{array}$ & 2,201 & 1.68 \\
\hline $\mathbf{N}$ & $\begin{array}{l}x \\
\text { SD }\end{array}$ & $\begin{array}{l}6.77 a \\
3.15\end{array}$ & $\begin{array}{l}5.46 a \\
3.00\end{array}$ & $\begin{array}{l}5.10 \\
3.75\end{array}$ & 2,201 & 4.24 * \\
\hline 工 & $\begin{array}{l}x \\
\text { SD }\end{array}$ & $\begin{array}{l}3.30 \\
2.21\end{array}$ & $\begin{array}{l}2.59 \\
2.03\end{array}$ & $\begin{array}{l}4.00 \\
3.89\end{array}$ & 2,201 & 2.73 \\
\hline SRD & $\begin{array}{l}x \\
\text { SD }\end{array}$ & $\begin{array}{c}13.63 a \\
7.67\end{array}$ & $\begin{array}{c}21.56 \mathrm{~b} \\
6.85\end{array}$ & $\begin{array}{c}26.60 \mathrm{ab} \\
7.34\end{array}$ & 2,197 & 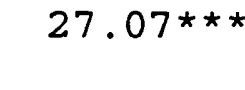 \\
\hline PER & $\begin{array}{l}x \\
S D\end{array}$ & $\begin{array}{l}1.95 a \\
1.89\end{array}$ & $\begin{array}{l}3.52 a \\
2.02\end{array}$ & $\begin{array}{l}3.30 \\
2.16\end{array}$ & 2,197 & $13.75 * \star \star *$ \\
\hline THEFT & $\begin{array}{l}x \\
\text { SD }\end{array}$ & $\begin{array}{l}2.43 a \\
2.48\end{array}$ & $\begin{array}{l}4.56 \mathrm{~b} \\
2.14\end{array}$ & $\begin{array}{l}5.70 \mathrm{ab} \\
1.89\end{array}$ & 2,197 & $21.58 * \star \star *$ \\
\hline MODA工 & $\begin{array}{l}x \\
\text { SD }\end{array}$ & $\begin{array}{l}5.15 \\
1.09\end{array}$ & $\begin{array}{l}4.68 \\
1.04\end{array}$ & $\begin{array}{l}4.67 \\
1.50\end{array}$ & 2,170 & 3.19 \\
\hline SRMS & $\begin{array}{l}x \\
\text { SD }\end{array}$ & $\begin{array}{c}306.10 a \\
45.53\end{array}$ & $\begin{array}{c}278.10 a \\
44.02\end{array}$ & $\begin{array}{r}276.44 \\
59.82\end{array}$ & $2, \quad 171$ & $6.84 * \star$ \\
\hline GLOBAI & $\begin{array}{l}x \\
\text { SD }\end{array}$ & $\begin{array}{l}7.16 a \\
1.40\end{array}$ & $\begin{array}{l}6.38 a \\
1.25\end{array}$ & $\begin{array}{l}6.56 \\
1.88\end{array}$ & 2,171 & $5.28 * \star$ \\
\hline
\end{tabular}

${ }^{*} \mathrm{p}<0.05 * * \mathrm{p}<0.01 * * * \mathrm{p}<0.001$

(Means with the same letter are significantly different from each other)

Table 3.3(1) shows that when the P scores were divided into three levels of high middle and low scores some significant differences were found between these three groups. 
The high P group had attended significantly fewer years of education than either the middle or low P groups and the middle P group had attended less years of school than the low $\mathrm{P}$ group $(\mathrm{F}(2,193)=16.05, \mathrm{p}<0.001)$. The middle $\mathrm{P}$ group came from a significantly lower class $(\mathrm{F}(2,164)=3.33, \mathrm{p}<0.05)$ and socio-economic group $(\mathrm{F}(2,166)=3.95, \mathrm{p}<0.05)$ than the low $\mathrm{P}$ group but the differences on social class and socio-economic group between the middle and low groups were found to be non-significant. The middle $\mathrm{P}$ group was found to have a significant larger number of siblings than the low $\mathrm{P}$ group $(\mathrm{F}(2$, $195)=3.31, \mathrm{p}<0.05)$, no significant differences were found between the high $\mathrm{P}$ group and the other two groups on the number of siblings. The low $\mathrm{P}$ group was found to be significantly more intelligent than both the middle and high $\mathrm{P}$ groups $(\mathrm{F}(2,200)=5.33$, $\mathrm{p}<0.01$ ), no differences proved significant between the middle and low $\mathrm{P}$ groups on intelligence. The high $\mathrm{P}$ group scored significantly higher on $\mathrm{P}$ than both the middle and low $\mathrm{P}$ groups, and the middle $\mathrm{P}$ group scored higher on $\mathrm{P}$ than the low $\mathrm{P}$ group (F2, $201)=327.63, \mathrm{p}<0.001$ ). The low $\mathrm{P}$ group scored significantly higher on $\mathrm{N}$ than the middle $P$ group $(F(2,201)=4.24, p<0.05)$, but no differences in $N$ were found between the high $P$ group and the other two groups. A significant difference was found between the three groups on self-reported delinquency $(\mathrm{SRD})(\mathrm{F}(2,197)=27.07, \mathrm{p}<0.001)$. Tukey's post-hoc test revealed that the low $\mathrm{P}$ group committed significantly fewer crimes than both the middle and high $\mathrm{P}$ groups, but no significant difference was found between the high and middle $\mathrm{P}$ groups. The number of crimes committed against the person also showed a significant difference $(F(2,197)=13.75, \mathrm{p}<0.001)$ and a Tukey test showed that the low $P$ group committed fewer violent crimes than the middle P group but no other differences between the three groups were significant. Another significant difference was found in the number of thefts committed by the three groups $(F(2,197)=21.58, p<0.001)$, and a Tukey test showed that the low $\mathrm{P}$ group committed significantly fewer thefts than the middle or high $\mathrm{P}$ groups. No significant difference was found between the high and middle $\mathrm{P}$ group. 
The low $\mathrm{P}$ group was significantly more mature in sociomoral reasoning $(F(2,171)=6.84$, $\mathrm{p}<0.01)$ and at a higher global stage of sociomoral reasoning $(\mathrm{F}(2,171)=5.28, \mathrm{p}<0.01)$ than the middle $\mathrm{P}$ group, no differences in sociomoral reasoning were found to be present between the high $\mathrm{P}$ group and the other two groups. 
Table 3.3(2) - The means and standard deviations for the 18 dependent variables for the three levels of the $E$ Scale for the whole sample group and the results of the ANOVAs carried out

\begin{tabular}{|c|c|c|c|c|c|c|}
\hline & & $\begin{array}{l}\text { LOW } \\
(\mathrm{N}=31)\end{array}$ & $\begin{array}{c}\text { E SCORE } \\
\text { MIDDLE } \\
(\mathrm{N}=55)\end{array}$ & $\begin{array}{l}\text { HIGB } \\
(\mathrm{N}=118)\end{array}$ & df & F value \\
\hline AGE & $\begin{array}{l}x \\
S D\end{array}$ & $\begin{array}{r}19.58 \\
1.09\end{array}$ & $\begin{array}{r}19.31 \\
1.15\end{array}$ & $\begin{array}{r}19.33 \\
1.10\end{array}$ & 2,195 & 0.69 \\
\hline סDE & $\begin{array}{l}x \\
S D\end{array}$ & $\begin{array}{r}12.39 \\
1.78\end{array}$ & $\begin{array}{r}12.04 \\
1.86\end{array}$ & $\begin{array}{r}12.20 \\
2.07\end{array}$ & 2,193 & 0.31 \\
\hline CIASS & $\begin{array}{l}x \\
\text { SD }\end{array}$ & $\begin{array}{l}2.69 \\
0.97\end{array}$ & $\begin{array}{l}2.62 \\
1.13\end{array}$ & $\begin{array}{l}2.42 \\
0.98\end{array}$ & 2,164 & 1.08 \\
\hline SEG & $\begin{array}{l}x \\
S D\end{array}$ & $\begin{array}{l}6.31 \\
3.18\end{array}$ & $\begin{array}{l}6.62 \\
3.80\end{array}$ & $\begin{array}{l}6.16 \\
3.63\end{array}$ & 2,166 & 0.25 \\
\hline SIB & $\begin{array}{l}x \\
S D\end{array}$ & $\begin{array}{l}1.84 \\
1.34\end{array}$ & $\begin{array}{l}1.70 \\
1.10\end{array}$ & $\begin{array}{l}1.54 \\
1.40\end{array}$ & 2,195 & 0.78 \\
\hline SIB10 & $\begin{array}{l}x \\
\text { SD }\end{array}$ & $\begin{array}{l}1.45 \\
1.39\end{array}$ & $\begin{array}{l}1.49 \\
1.10\end{array}$ & $\begin{array}{l}1.13 \\
1.11\end{array}$ & 2,194 & 2.24 \\
\hline RAV & $\begin{array}{l}x \\
\text { SD }\end{array}$ & $\begin{array}{l}44.19 \\
12.56\end{array}$ & $\begin{array}{r}43.85 \\
9.80\end{array}$ & $\begin{array}{r}46.13 \\
8.80\end{array}$ & 2,200 & 1.22 \\
\hline $\mathbf{P}$ & $\begin{array}{l}x \\
\text { SD }\end{array}$ & $\begin{array}{l}3.10 \\
2.56\end{array}$ & $\begin{array}{l}3.87 \\
2.50\end{array}$ & $\begin{array}{l}3.86 \\
2.39\end{array}$ & 2,201 & 1.28 \\
\hline $\mathbf{E}$ & $\begin{array}{l}x \\
\text { SD }\end{array}$ & $\begin{array}{l}2.29 a \\
1.37\end{array}$ & $\begin{array}{l}7.07 a \\
1.14\end{array}$ & $\begin{array}{c}10.70 \mathrm{a} \\
1.11\end{array}$ & 2,201 & 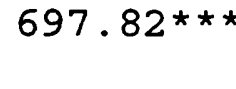 \\
\hline $\mathbf{N}$ & $\begin{array}{l}x \\
\text { SD }\end{array}$ & $\begin{array}{l}8.26 \mathrm{ab} \\
3.50\end{array}$ & $\begin{array}{l}6.49 a \\
2.96\end{array}$ & $\begin{array}{l}5.75 b \\
3.02\end{array}$ & 2,201 & $8.28 * \star *$ \\
\hline $\mathbf{I}$ & $\begin{array}{l}x \\
\text { SD }\end{array}$ & $\begin{array}{l}3.94 \\
2.82\end{array}$ & $\begin{array}{l}3.07 \\
2.23\end{array}$ & $\begin{array}{l}2.97 \\
2.14\end{array}$ & 2,201 & 2.27 \\
\hline SRD & $\begin{array}{l}x \\
\text { SD }\end{array}$ & $\begin{array}{c}12.42 \mathrm{a} \\
8.33\end{array}$ & $\begin{array}{r}15.37 \\
7.87\end{array}$ & $\begin{array}{c}17.72 a \\
8.27\end{array}$ & 2,197 & $5.58 * \star$ \\
\hline PER & $\begin{array}{l}x \\
\text { SD }\end{array}$ & $\begin{array}{l}1.58 a \\
1.46\end{array}$ & $\begin{array}{l}2.24 \\
2.13\end{array}$ & $\begin{array}{l}2.77 a \\
2.10\end{array}$ & 2,197 & $4.56 *$ \\
\hline TEEFT & $\begin{array}{l}x \\
S D\end{array}$ & $\begin{array}{l}2.13 a \\
2.45\end{array}$ & $\begin{array}{l}3.26 \\
2.63\end{array}$ & $\begin{array}{l}3.40 a \\
2.59\end{array}$ & 2,197 & $3.01 *$ \\
\hline MODAT & $\begin{array}{l}x \\
\text { SD }\end{array}$ & $\begin{array}{l}5.15 \\
1.03\end{array}$ & $\begin{array}{l}4.79 \\
1.19\end{array}$ & $\begin{array}{l}5.07 \\
1.10\end{array}$ & 2,170 & 1.18 \\
\hline SRMS & $\begin{array}{l}x \\
S D\end{array}$ & $\begin{array}{r}311.89 \\
39.84\end{array}$ & $\begin{array}{r}293.42 \\
53.13\end{array}$ & $\begin{array}{r}295.96 \\
46.59\end{array}$ & 2,171 & 1.46 \\
\hline GLOBAI & $\begin{array}{l}x \\
S D\end{array}$ & $\begin{array}{l}7.33 \\
1.21\end{array}$ & $\begin{array}{l}6.74 \\
1.59\end{array}$ & $\begin{array}{l}6.93 \\
1.41\end{array}$ & 2,171 & 1.44 \\
\hline
\end{tabular}

${ }^{*} p<0.05 \quad * * p<0.01 * \star * p<0.001$

(Means with the same letter are significantly different from each other)

Table 3.3(2) shows that there were some significant differences between the three levels of the E score of the whole sample group. The high E group scored significantly higher on $\mathrm{E}$ than both the middle and low $\mathrm{E}$ groups, and the middle $\mathrm{E}$ group scored significantly higher on $\mathrm{E}$ than the low $\mathrm{E}$ group $(\mathrm{F}(2,201)=697.82, \mathrm{p}<0.001)$. The low $\mathrm{E}$ 
group also scored significantly higher on $\mathrm{N}$ than both the middle and low $\mathrm{E}$ groups $(\mathrm{F}(2$, $201)=8.28, \mathrm{p}<0.001)$, but no significant difference was found between the middle and high E groups. The amount of self reported delinquency (SRD) was found to vary significantly across the three levels of $E(F(2,197)=5.58, p<0.01)$. Tukey's post-hoc comparisons revealed that the low E group committed less crime than the high $\mathrm{E}$ group. No significant differences were found between the middle group and either the low or the high E group. Another significant difference was found in the number of crimes committed against the person $(F(2,197)=4.56, \mathrm{p}<0.05)$. Tukey's post-hoc comparisons test showed that the low E group committed significantly fewer crimes against the person than the high E group but no significant differences were apparent between the middle E group and either the low or the high E group. The low E group also committed fewer thefts than the high E group $(F(2,197)=3.01, p<0.05)$, but no significant differences were found between the middle $\mathrm{E}$ group and either of the other two groups. 
Table 3.3(3) - The means and standard deviations for the 18 dependent variables for the three levels of the $\mathbf{N}$ Scale for the whole sample group and the results of the ANOVAs carried out

\begin{tabular}{|c|c|c|c|c|c|c|}
\hline & & $\begin{array}{l}\text { LOW } \\
(\mathrm{N}=72)\end{array}$ & $\begin{array}{c}\text { N SCORE } \\
\text { MIDDLE } \\
(N=73)\end{array}$ & $\begin{array}{c}\text { BIGB } \\
(N=59)\end{array}$ & df & F value \\
\hline AGE & $\begin{array}{l}x \\
S D\end{array}$ & $\begin{array}{r}19.31 \\
1.20\end{array}$ & $\begin{array}{r}19.44 \\
1.00\end{array}$ & $\begin{array}{r}19.33 \\
1.14\end{array}$ & 2,195 & 0.24 \\
\hline סDD & $\begin{array}{l}x \\
S D\end{array}$ & $\begin{array}{r}11.82 \\
2.39\end{array}$ & $\begin{array}{r}12.41 \\
1.64\end{array}$ & $\begin{array}{r}12.36 \\
1.69\end{array}$ & 2,193 & 1.97 \\
\hline CIASS & $\begin{array}{l}x \\
S D\end{array}$ & $\begin{array}{l}2.53 \\
1.02\end{array}$ & $\begin{array}{l}2.37 \\
1.06\end{array}$ & $\begin{array}{l}2.70 \\
0.96\end{array}$ & 2,164 & 1.34 \\
\hline SEG & $\begin{array}{l}x \\
S D\end{array}$ & $\begin{array}{l}5.82 \\
3.59\end{array}$ & $\begin{array}{l}6.37 \\
3.44\end{array}$ & $\begin{array}{l}6.85 \\
3.80\end{array}$ & 2,166 & 1.11 \\
\hline SIB & $\begin{array}{l}x \\
S D\end{array}$ & $\begin{array}{l}1.49 \\
1.17\end{array}$ & $\begin{array}{l}1.74 \\
1.48\end{array}$ & $\begin{array}{l}1.67 \\
1.28\end{array}$ & 2,195 & 0.65 \\
\hline SIB10 & $\begin{array}{l}x \\
S D\end{array}$ & $\begin{array}{l}1.26 \\
1.14\end{array}$ & $\begin{array}{l}1.35 \\
1.05\end{array}$ & $\begin{array}{l}1.22 \\
1.33\end{array}$ & 2,194 & 0.20 \\
\hline RAV & $\begin{array}{l}x \\
S D\end{array}$ & $\begin{array}{r}44.36 \\
9.64\end{array}$ & $\begin{array}{r}43.83 \\
9.52\end{array}$ & $\begin{array}{l}45.54 \\
10.16\end{array}$ & 2,200 & 0.45 \\
\hline $\mathbf{P}$ & $\begin{array}{l}x \\
S D\end{array}$ & $\begin{array}{l}4.38 a \\
2.54\end{array}$ & $\begin{array}{l}3.60 \\
2.40\end{array}$ & $\begin{array}{l}3.15 a \\
2.27\end{array}$ & 2,201 & $4.36 \star$ \\
\hline $\mathbf{E}$ & $\begin{array}{l}x \\
S D\end{array}$ & $\begin{array}{l}9.25 a \\
2.73\end{array}$ & $\begin{array}{l}8.92 b \\
2.79\end{array}$ & $\begin{array}{l}6.88 \mathrm{ab} \\
3.84\end{array}$ & 2,201 & $10.72 * \star \star \star$ \\
\hline $\mathbf{N}$ & $\begin{array}{l}x \\
S D\end{array}$ & $\begin{array}{l}2.78 a \\
1.10\end{array}$ & $\begin{array}{l}6.67 a \\
1.13\end{array}$ & $\begin{array}{c}10.24 a \\
1.07\end{array}$ & 2,201 & $744.95 * \star \star *$ \\
\hline $\boldsymbol{I}$ & $\begin{array}{l}X \\
S D\end{array}$ & $\begin{array}{l}3.26 \\
2.33\end{array}$ & $\begin{array}{l}3.18 \\
2.26\end{array}$ & $\begin{array}{l}2.95 \\
2.29\end{array}$ & 2,201 & 0.32 \\
\hline SRD & $\begin{array}{l}x \\
S D\end{array}$ & $\begin{array}{c}18.01 \mathrm{a} \\
8.38\end{array}$ & $\begin{array}{c}14.61 \mathrm{a} \\
7.40\end{array}$ & $\begin{array}{r}16.07 \\
9.08\end{array}$ & 2,197 & $3.01 *$ \\
\hline PER & $\begin{array}{l}x \\
\text { SD }\end{array}$ & $\begin{array}{l}2.76 \\
2.17\end{array}$ & $\begin{array}{l}2.10 \\
1.85\end{array}$ & $\begin{array}{l}2.44 \\
2.12\end{array}$ & 2,197 & 1.84 \\
\hline TEEFT & $\begin{array}{l}x \\
S D\end{array}$ & $\begin{array}{l}3.79 a \\
2.56\end{array}$ & $\begin{array}{l}2.52 \mathrm{a} \\
2.48\end{array}$ & $\begin{array}{l}3.15 \\
2.66\end{array}$ & 2,197 & 4.32 * \\
\hline MODAL & $\begin{array}{l}x \\
S D\end{array}$ & $\begin{array}{l}4.93 \\
1.16\end{array}$ & $\begin{array}{l}5.02 \\
1.02\end{array}$ & $\begin{array}{l}5.10 \\
1.19\end{array}$ & 2,170 & 0.30 \\
\hline SRMS & $\begin{array}{l}x \\
S D\end{array}$ & $\begin{array}{r}291.69 \\
50.81\end{array}$ & $\begin{array}{r}297.73 \\
46.35\end{array}$ & $\begin{array}{r}304.83 \\
44.76\end{array}$ & 2,171 & 1.06 \\
\hline GLOBAL & $\begin{array}{l}x \\
S D\end{array}$ & $\begin{array}{l}6.78 \\
1.52\end{array}$ & $\begin{array}{l}6.90 \\
1.35\end{array}$ & $\begin{array}{l}7.17 \\
1.41\end{array}$ & 2,171 & 1.08 \\
\hline
\end{tabular}

${ }^{*} \mathrm{p}<0.05 * * \mathrm{p}<0.01 * * * \mathrm{p}<0.001$

(Means with the same letter are significantly different from each other)

Table 3.3(3) shows that some significant differences were found between the three levels of the $\mathrm{N}$ score. The low $\mathrm{N}$ group scored significantly higher on $\mathrm{P}$ than the high $\mathrm{N}$ group $(F(2,201)=4.36, p<0.05)$, no significant differences were found between the middle $\mathrm{N}$ group and the other two groups. The low $\mathrm{N}$ group scored significantly higher on $\mathrm{E}$ than 
both the middle and low $\mathrm{N}$ groups $(\mathrm{F}(2,201)=10.72, \mathrm{p}<0.001)$, but no significance was found to the difference in $\mathrm{E}$ between the middle and high $\mathrm{E}$ groups. The high $\mathrm{N}$ group scored higher on $\mathrm{N}$ than both the middle and low $\mathrm{N}$ groups, and the middle $\mathrm{N}$ group scored significantly higher on $\mathrm{N}$ than the low $\mathrm{N}$ group $(\mathrm{F}(2,201)=744.95, \mathrm{p}<0.001)$. The low $\mathbf{N}$ group committed significantly more crime than the middle $\mathrm{N}$ group $(\mathrm{F}(2,197)=3.01$, $\mathrm{p}<0.05$ ) but no significant differences were found in the number of crimes committed between the high $\mathrm{N}$ group and either of the other two groups. The low $\mathrm{N}$ group also committed significantly more thefts than the middle $N$ group $(F(2,197)=4.32, p<0.05)$, but no significant differences were found between the high $\mathrm{N}$ group and either the low or the middle $\mathbf{N}$ group. No significant differences were found in the number of crimes committed against the person.

\section{Male Offender Sample Group}

With regard to the $\mathrm{P}$ scale, it was not possible to calculate analyses of variance for the high, middle and low scorers in the male offender group. This was the case since only 8 participants fell into the high $\mathrm{P}$ category, thus invalidating any analyses of variance which might be calculated. 
Table 3.3(4) - The means and standard deviations for the 18 dependent variables for the three levels of the E Scale for the male offender sample group and the results of the ANOVAs carried out

\begin{tabular}{|c|c|c|c|c|c|c|}
\hline & & $\begin{array}{l}\text { LOW } \\
(\mathrm{N}=10)\end{array}$ & $\begin{array}{c}\text { E SCORE } \\
\text { MIDDLE } \\
(\mathrm{N}=27)\end{array}$ & $\begin{array}{c}\text { BIGB } \\
(\mathrm{N}=59)\end{array}$ & df & F value \\
\hline AGE & $\begin{array}{l}x \\
\text { SD }\end{array}$ & $\begin{array}{r}19.59 \\
1.34\end{array}$ & $\begin{array}{r}18.95 \\
1.12\end{array}$ & $\begin{array}{r}19.14 \\
1.08\end{array}$ & 2,69 & 1.05 \\
\hline שDD & $\begin{array}{l}x \\
\text { SD }\end{array}$ & $\begin{array}{r}10.30 \\
0.67\end{array}$ & $\begin{array}{r}10.46 \\
0.95\end{array}$ & $\begin{array}{r}10.57 \\
1.65\end{array}$ & 2,67 & 0.04 \\
\hline CLASS & $\begin{array}{l}x \\
S D\end{array}$ & $\begin{array}{l}3.33 \\
0.52\end{array}$ & $\begin{array}{l}3.32 \\
1.11\end{array}$ & $\begin{array}{l}2.87 \\
0.95\end{array}$ & 2,45 & 1.46 \\
\hline SEG & $\begin{array}{l}x \\
\text { SD }\end{array}$ & $\begin{array}{l}8.00 \\
1.55\end{array}$ & $\begin{array}{l}8.89 \\
3.02\end{array}$ & $\begin{array}{l}7.76 \\
3.47\end{array}$ & 2,46 & 0.66 \\
\hline SIB & $\begin{array}{l}x \\
S D\end{array}$ & $\begin{array}{l}1.70 \\
1.49\end{array}$ & $\begin{array}{l}1.89 \\
1.15\end{array}$ & $\begin{array}{l}1.57 \\
1.67\end{array}$ & 2,69 & 0.50 \\
\hline SIB10 & $\begin{array}{l}x \\
S D\end{array}$ & $\begin{array}{l}1.30 \\
1.49\end{array}$ & $\begin{array}{l}1.74 a \\
1.10\end{array}$ & $\begin{array}{l}1.00 \mathrm{a} \\
1.04\end{array}$ & 2,68 & 4.43 * \\
\hline RAV & $\begin{array}{l}x \\
\text { SD }\end{array}$ & $\begin{array}{l}33.10 a \\
11.30\end{array}$ & $\begin{array}{r}37.96 \\
9.74\end{array}$ & $\begin{array}{c}40.68 a \\
7.35\end{array}$ & 2,74 & $3.64 *$ \\
\hline $\mathbf{P}$ & $\begin{array}{l}x \\
\text { SD }\end{array}$ & $\begin{array}{l}5.00 \\
3.13\end{array}$ & $\begin{array}{l}4.78 \\
2.59\end{array}$ & $\begin{array}{l}4.68 \\
2.43\end{array}$ & 2,74 & 1.15 \\
\hline $\mathbf{E}$ & $\begin{array}{l}x \\
\text { SD }\end{array}$ & $\begin{array}{l}2.00 a \\
1.56\end{array}$ & $\begin{array}{l}6.96 a \\
1.13\end{array}$ & $\begin{array}{c}10.64 a \\
1.13\end{array}$ & 2,74 & $277.60 * \star \star$ \\
\hline $\mathbf{N}$ & $\begin{array}{l}x \\
S D\end{array}$ & $\begin{array}{l}7.00 a \\
4.52\end{array}$ & $\begin{array}{l}6.33 \\
2.95\end{array}$ & $\begin{array}{l}5.76 a \\
3.09\end{array}$ & 2,74 & $6.04 * \star$ \\
\hline I & $\begin{array}{l}x \\
\text { SD }\end{array}$ & $\begin{array}{l}4.40 \\
3.86\end{array}$ & $\begin{array}{l}3.22 \\
2.39\end{array}$ & $\begin{array}{l}3.05 \\
2.16\end{array}$ & 2,74 & 0.87 \\
\hline SRD & $\begin{array}{l}x \\
\text { SD }\end{array}$ & $\begin{array}{r}20.70 \\
7.38\end{array}$ & $\begin{array}{r}19.88 \\
8.11\end{array}$ & $\begin{array}{r}23.30 \\
6.66\end{array}$ & 2,70 & 0.62 \\
\hline PER & $\begin{array}{l}x \\
\text { SD }\end{array}$ & $\begin{array}{l}2.80 \\
1.69\end{array}$ & $\begin{array}{l}3.46 \\
2.34\end{array}$ & $\begin{array}{l}4.23 \\
1.85\end{array}$ & 2,70 & 2.38 \\
\hline THEFT & $\begin{array}{l}x \\
\text { SD }\end{array}$ & $\begin{array}{l}4.70 \\
2.41\end{array}$ & $\begin{array}{l}5.31 \\
1.95\end{array}$ & $\begin{array}{l}5.39 \\
1.79\end{array}$ & 2,70 & 0.62 \\
\hline MODAI & $\begin{array}{l}x \\
S D\end{array}$ & $\begin{array}{l}4.17 \\
0.98\end{array}$ & $\begin{array}{l}3.73 \\
0.96\end{array}$ & $\begin{array}{l}4.31 \\
0.87\end{array}$ & 2,46 & 2.27 \\
\hline SRMS & $\begin{array}{l}x \\
S D\end{array}$ & $\begin{array}{r}256.83 \\
37.80\end{array}$ & $\begin{array}{r}237.33 \\
40.28\end{array}$ & $\begin{array}{r}255.93 \\
29.74\end{array}$ & 2,47 & 1.71 \\
\hline GLOBAL & $\begin{array}{l}x \\
S D\end{array}$ & $\begin{array}{l}5.83 \\
0.98\end{array}$ & $\begin{array}{l}5.07 \\
1.16\end{array}$ & $\begin{array}{l}5.78 \\
0.96\end{array}$ & 2,47 & 2.42 \\
\hline
\end{tabular}

${ }^{*} \mathrm{p}<0.05 \quad *{ }^{*} \mathrm{p}<0.01 * * * \mathrm{p}<0.001$

(Means with the same letter are significantly different from each other)

Table 3.3(4) shows that only four variables showed significant differences between the three levels of $\mathrm{E}$. The middle $\mathrm{E}$ group was found to have had significantly more siblings after the age of ten than the high $\mathrm{E}$ group $(\mathrm{F}(2,=4.43, \mathrm{p}<0.05)$ but no significant differences were found between these two groups and the low E group. It is also worthy 
of noting that no significant differences between the three groups were found with the number of siblings before the age of ten. The high $\mathrm{E}$ group was also found to be significantly more intelligent than the low E group $(F(2,74)=3.64, p<0.05) 68)$ although no significant differences were found between the middle E group and either of the other two groups. The high $\mathrm{E}$ group scored significantly higher on $\mathrm{E}$ than either of the other two groups, the middle E group scored significantly higher on E than the low E group $(F(2,74)=277.60, p<0.001)$. The low $E$ group scored higher on $N$ than the high $E$ group $(F 2,74)=6.04, p<0.01)$, no significant differences were found between either of these groups and the middle E group. No other significant differences were found between the three levels of $E$. 
Table 3.3(5) - The means and standard deviations for the 18 dependent variables for the three levels of the N Scale for the male offender sample group and the results of the ANOVAs carried out

\begin{tabular}{|c|c|c|c|c|c|c|}
\hline & & $\begin{array}{l}\text { LOW } \\
(\mathrm{N}=40)\end{array}$ & $\begin{array}{c}\text { N SCORE } \\
\text { MIDDLE } \\
(\mathrm{N}=30)\end{array}$ & $\begin{array}{c}\text { HIGH } \\
(\mathrm{N}=26)\end{array}$ & $d f$ & E value \\
\hline $\mathbf{A G E}$ & $\begin{array}{l}x \\
S D\end{array}$ & $\begin{array}{r}19.03 \\
1.13\end{array}$ & $\begin{array}{r}19.38 \\
1.09\end{array}$ & $\begin{array}{r}19.00 \\
1.14\end{array}$ & 2,69 & 1.19 \\
\hline ED & $\begin{array}{l}x \\
S D\end{array}$ & $\begin{array}{r}10.23 \\
1.90\end{array}$ & $\begin{array}{r}10.74 \\
0.71\end{array}$ & $\begin{array}{r}10.74 \\
0.76\end{array}$ & 2,67 & 1.89 \\
\hline CLASS & $\begin{array}{l}x \\
S D\end{array}$ & $\begin{array}{l}3.14 \\
0.93\end{array}$ & $\begin{array}{l}3.15 \\
1.04\end{array}$ & $\begin{array}{l}3.00 \\
1.00\end{array}$ & 2,45 & 1.71 \\
\hline SEG & $\begin{array}{l}x \\
S D\end{array}$ & $\begin{array}{l}7.86 \\
3.38\end{array}$ & $\begin{array}{l}8.20 \\
2.73\end{array}$ & $\begin{array}{l}8.41 \\
3.78\end{array}$ & 2,46 & 0.13 \\
\hline SIB & $\begin{array}{l}x \\
S D\end{array}$ & $\begin{array}{l}1.41 \\
1.21\end{array}$ & $\begin{array}{l}2.26 \\
1.87\end{array}$ & $\begin{array}{l}1.48 \\
1.36\end{array}$ & 2,69 & 2.97 \\
\hline SIB10 & $\begin{array}{l}x \\
S D\end{array}$ & $\begin{array}{l}1.11 \\
1.06\end{array}$ & $\begin{array}{l}1.56 \\
1.12\end{array}$ & $\begin{array}{l}1.16 \\
1.28\end{array}$ & 2,194 & 0.20 \\
\hline RAV & $\begin{array}{l}x \\
\mathrm{SD}\end{array}$ & $\begin{array}{r}38.60 \\
7.87\end{array}$ & $\begin{array}{r}39.73 \\
8.31\end{array}$ & $\begin{array}{l}39.23 \\
10.67\end{array}$ & 2,74 & 0.42 \\
\hline P & $\begin{array}{l}x \\
\mathrm{SD}\end{array}$ & $\begin{array}{l}5.03 \\
2.48\end{array}$ & $\begin{array}{l}4.70 \\
2.58\end{array}$ & $\begin{array}{l}4.35 \\
2.59\end{array}$ & 2,74 & 1.37 \\
\hline $\mathbf{E}$ & $\begin{array}{l}x \\
S D\end{array}$ & $\begin{array}{l}9.33 a \\
2.86\end{array}$ & $\begin{array}{l}9.23 \mathrm{~b} \\
2.24\end{array}$ & $\begin{array}{l}7.15 \mathrm{ab} \\
3.64\end{array}$ & 2,74 & $4.52 *$ \\
\hline $\mathbf{N}$ & $\begin{array}{l}\mathbf{x} \\
\mathrm{SD}\end{array}$ & $\begin{array}{l}2.83 a \\
1.11\end{array}$ & $\begin{array}{l}6.83 a \\
1.15\end{array}$ & $\begin{array}{c}10.12 \mathrm{a} \\
1.11\end{array}$ & 2,74 & $375.06 * \star x$ \\
\hline L & $\begin{array}{l}x \\
\text { SD }\end{array}$ & $\begin{array}{l}3.45 \\
2.49\end{array}$ & $\begin{array}{l}3.47 \\
2.45\end{array}$ & $\begin{array}{l}2.65 \\
2.38\end{array}$ & 2,74 & 2.37 \\
\hline SRD & $\begin{array}{l}x \\
\text { SD }\end{array}$ & $\begin{array}{r}22.58 \\
7.33\end{array}$ & $\begin{array}{r}20.85 \\
6.62\end{array}$ & $\begin{array}{r}22.46 \\
7.90\end{array}$ & 2,70 & 0.10 \\
\hline PER & $\begin{array}{l}x \\
\text { SD }\end{array}$ & $\begin{array}{l}3.95 \\
2.02\end{array}$ & $\begin{array}{l}3.62 \\
1.88\end{array}$ & $\begin{array}{l}3.96 \\
2.22\end{array}$ & 2,70 & 0.55 \\
\hline THEFT & $\begin{array}{l}x \\
S D\end{array}$ & $\begin{array}{l}5.45 \\
1.74\end{array}$ & $\begin{array}{l}5.19 \\
1.72\end{array}$ & $\begin{array}{l}5.15 \\
2.31\end{array}$ & 2,70 & 0.10 \\
\hline MODAL & $\begin{array}{l}x \\
S D\end{array}$ & $\begin{array}{l}4.14 \\
0.93\end{array}$ & $\begin{array}{l}4.21 \\
0.85\end{array}$ & $\begin{array}{l}4.16 \\
1.01\end{array}$ & 2,46 & 0.09 \\
\hline SRMS & $\begin{array}{l}x \\
\mathrm{SD}\end{array}$ & $\begin{array}{r}250.29 \\
34.59\end{array}$ & $\begin{array}{r}246.90 \\
32.98\end{array}$ & $\begin{array}{r}259.37 \\
32.61\end{array}$ & 2,47 & 0.86 \\
\hline GLOBAL & $\begin{array}{l}x \\
\text { SD }\end{array}$ & $\begin{array}{l}5.61 \\
1.03\end{array}$ & $\begin{array}{l}5.55 \\
1.10\end{array}$ & $\begin{array}{l}5.74 \\
1.05\end{array}$ & 2,47 & 0.22 \\
\hline
\end{tabular}

$* \mathrm{p}<0.05 * * \mathrm{p}<0.01 * * * \mathrm{p}<0.001$

(Means with the same letter are significantly different from each other)

Table 3.3(5) shows that only two variables yielded significant differences between the three levels of $\mathbf{N}$. The high $\mathbf{N}$ group scored significantly lower on $\mathrm{E}$ then both the low and middle $\mathrm{N}$ groups $(\mathrm{F}(2,74)=4.52, \mathrm{p}<0.05)$, no significant differences were obtained between the low and middle $\mathrm{N}$ groups on the $\mathrm{E}$ scale. The high $\mathrm{N}$ group scored 
significantly higher on $\mathrm{N}$ than both the middle and low $\mathrm{N}$ groups and the middle group scored significantly higher on this scale than the low $\mathrm{N}$ group $(\mathrm{F}(2,74(=375.06, \mathrm{p}<0.001)$.

\section{Male and Female Control Group}

With regard to the $\mathrm{P}$ scale, it was not possible to calculate analyses of variance for the high, middle and low scorers in the combined control group. This was the case since only 2 participants fell into the high $\mathrm{P}$ category, thus invalidating any analyses of variance which could be calculated. 
Table 3.3(6) - The means and standard deviations for the 18 dependent variables for the three levels of the $\mathrm{E}$ Scale for the male and female control sample group and the results of the ANOVAs carried out

\begin{tabular}{|c|c|c|c|c|c|c|}
\hline & & $\begin{array}{l}\text { LOW } \\
(N=21)\end{array}$ & $\begin{array}{c}\text { E SCORE } \\
\text { MIDDLE } \\
(\mathrm{N}=28)\end{array}$ & $\begin{array}{c}\text { HIGH } \\
(\mathrm{N}=59)\end{array}$ & df & F value \\
\hline AGE & $\begin{array}{l}x \\
S D\end{array}$ & $\begin{array}{r}19.58 \\
0.98\end{array}$ & $\begin{array}{r}19.67 \\
1.08\end{array}$ & $\begin{array}{r}19.50 \\
1.10\end{array}$ & 2,89 & 0.26 \\
\hline EDU & $\begin{array}{l}x \\
S D\end{array}$ & $\begin{array}{r}13.38 \\
1.16\end{array}$ & $\begin{array}{r}13.55 \\
1.09\end{array}$ & $\begin{array}{r}13.66 \\
1.08\end{array}$ & 2,89 & 0.55 \\
\hline CLASS & $\begin{array}{l}x \\
S D\end{array}$ & $\begin{array}{l}2.50 \\
1.00\end{array}$ & $\begin{array}{l}2.12 \\
0.86\end{array}$ & $\begin{array}{l}2.11 \\
0.88\end{array}$ & 2,85 & 1.35 \\
\hline SEG & $\begin{array}{l}X \\
S D\end{array}$ & $\begin{array}{l}5.80 \\
3.40\end{array}$ & $\begin{array}{l}4.96 \\
3.47\end{array}$ & $\begin{array}{l}5.02 \\
3.32\end{array}$ & 2,85 & 0.47 \\
\hline SIB & $\begin{array}{l}x \\
\text { SD }\end{array}$ & $\begin{array}{l}1.90 \\
1.30\end{array}$ & $\begin{array}{l}1.54 \\
1.04\end{array}$ & $\begin{array}{l}1.50 \\
1.11\end{array}$ & 2,89 & 1.25 \\
\hline SIB10 & $\begin{array}{l}x \\
S D\end{array}$ & $\begin{array}{l}1.52 \\
1.36\end{array}$ & $\begin{array}{l}1.25 \\
1.08\end{array}$ & $\begin{array}{l}1.24 \\
1.17\end{array}$ & $2, \quad 89$ & 0.53 \\
\hline RAV & $\begin{array}{l}x \\
S D\end{array}$ & $\begin{array}{r}49.48 \\
9.40\end{array}$ & $\begin{array}{r}49.74 \\
5.38\end{array}$ & $\begin{array}{r}51.58 \\
6.47\end{array}$ & 2,89 & 0.96 \\
\hline $\mathbf{P}$ & $\begin{array}{l}x \\
S D\end{array}$ & $\begin{array}{l}2.19 \\
1.66\end{array}$ & $\begin{array}{l}3.00 \\
2.11\end{array}$ & $\begin{array}{l}3.03 \\
2.07\end{array}$ & 2,90 & 0.76 \\
\hline $\mathbf{E}$ & $\begin{array}{l}x \\
S D\end{array}$ & $\begin{array}{l}2.43 a \\
1.29\end{array}$ & $\begin{array}{l}7.18 a \\
1.16\end{array}$ & $\begin{array}{c}10.76 a \\
1.10\end{array}$ & 2,90 & $428.29 * \star \star$ \\
\hline $\mathbf{N}$ & $\begin{array}{l}x \\
\text { SD }\end{array}$ & $\begin{array}{l}8.86 a \\
2.83\end{array}$ & $\begin{array}{l}6.64 a \\
3.02\end{array}$ & $\begin{array}{l}5.73 a \\
2.96\end{array}$ & 2,90 & $52.58 * \star \star$ \\
\hline I & $\begin{array}{l}x \\
S D\end{array}$ & $\begin{array}{l}3.71 \\
2.24\end{array}$ & $\begin{array}{l}2.93 \\
2.09\end{array}$ & $\begin{array}{l}2.88 \\
2.13\end{array}$ & 2,90 & 1.08 \\
\hline SRD & $\begin{array}{l}x \\
S D\end{array}$ & $\begin{array}{l}8.48 a \\
5.38\end{array}$ & $\begin{array}{r}11.18 \\
4.76\end{array}$ & $\begin{array}{c}12.42 \mathrm{a} \\
5.80\end{array}$ & 2,90 & $3.33 \star$ \\
\hline PER & $\begin{array}{l}x \\
S D\end{array}$ & $\begin{array}{l}1.00 \\
0.89\end{array}$ & $\begin{array}{l}1.11 \\
1.03\end{array}$ & $\begin{array}{l}1.37 \\
1.16\end{array}$ & 2,90 & 0.85 \\
\hline THEFT & $\begin{array}{l}x \\
S D\end{array}$ & $\begin{array}{l}0.90 \\
1.22\end{array}$ & $\begin{array}{l}1.36 \\
1.50\end{array}$ & $\begin{array}{l}1.51 \\
1.64\end{array}$ & 2,90 & 0.88 \\
\hline MODAL & $\begin{array}{l}x \\
\text { SD }\end{array}$ & $\begin{array}{l}5.43 \\
0.87\end{array}$ & $\begin{array}{l}5.36 \\
0.87\end{array}$ & $\begin{array}{l}5.66 \\
0.89\end{array}$ & 2,89 & 1.65 \\
\hline SRMS & $\begin{array}{l}x \\
S D\end{array}$ & $\begin{array}{r}327.62 \\
23.17\end{array}$ & $\begin{array}{r}323.46 \\
29.42\end{array}$ & $\begin{array}{r}327.71 \\
30.09\end{array}$ & 2,89 & 0.43 \\
\hline GLOBAL & $\begin{array}{l}x \\
\text { SD }\end{array}$ & $\begin{array}{l}7.76 \\
0.89\end{array}$ & $\begin{array}{l}7.64 \\
0.91\end{array}$ & $\begin{array}{l}7.83 \\
0.98\end{array}$ & 2,89 & 0.71 \\
\hline
\end{tabular}

${ }^{*} \mathrm{p}<0.05 \quad *{ }^{*} \mathrm{p}<0.01 * \star \star \mathrm{p} p<0.001$

(Means with the same letter are significantly different from each other)

Table 3.3(6) shows that only three variables yielded significant differences between the three levels of $\mathrm{E}$ for the control group. The high $\mathrm{E}$ group scored significantly higher on $\mathrm{E}$ than both the middle and low $\mathrm{E}$ groups, and the middle group scored significantly higher on $E$ than the low $E$ group $(F(2,90)=428.29, p<0.001)$. The low $E$ group scored 
higher on $\mathrm{N}$ than both the middle and low $\mathrm{E}$ groups, and the middle $\mathrm{E}$ group scored higher on $\mathrm{N}$ than the high $\mathrm{E}$ group $(\mathrm{F}(2,90)=52.58, \mathrm{p}<0.001)$. The high $\mathrm{E}$ group were significantly more delinquent than the low $E$ group $(F(2,90)=3.33, p<0.05)$, no significant differences were found between the middle E group and the other two groups. 
Table 3.3(7) - The means and standard deviations for the 18 dependent variables for the three levels of the $\mathrm{N}$ Scale for the male and female control sample group and the results of the ANOVAs carried out

\begin{tabular}{|c|c|c|c|c|c|c|}
\hline & & $\begin{array}{l}\text { LOW } \\
(N=32)\end{array}$ & $\begin{array}{c}\text { N SCORE } \\
\text { MIDDLE } \\
(\mathrm{N}=43)\end{array}$ & $\begin{array}{c}\text { EIGH } \\
(\mathrm{N}=33)\end{array}$ & de & F value \\
\hline AGE & $\begin{array}{l}x \\
\text { SD }\end{array}$ & $\begin{array}{r}19.65 \\
1.22\end{array}$ & $\begin{array}{r}19.47 \\
0.94\end{array}$ & $\begin{array}{r}19.59 \\
1.10\end{array}$ & 2,89 & 0.23 \\
\hline סDE & $\begin{array}{l}x \\
S D\end{array}$ & $\begin{array}{r}13.75 \\
1.19\end{array}$ & $\begin{array}{r}13.47 \\
1.08\end{array}$ & $\begin{array}{r}13.56 \\
1.01\end{array}$ & 2,89 & 0.55 \\
\hline CLASS & $\begin{array}{l}x \\
S D\end{array}$ & $\begin{array}{l}1.97 a \\
0.75\end{array}$ & $\begin{array}{l}2.00 \mathrm{~b} \\
0.86\end{array}$ & $\begin{array}{l}2.67 a b \\
0.96\end{array}$ & 2,85 & $4.39 *$ \\
\hline SEG & $\begin{array}{l}x \\
S D\end{array}$ & $\begin{array}{l}3.90 a \\
2.72\end{array}$ & $\begin{array}{l}5.50 \\
3.43\end{array}$ & $\begin{array}{l}5.97 a \\
3.58\end{array}$ & 2,85 & $3.09 *$ \\
\hline SIB & $\begin{array}{l}x \\
\text { SD }\end{array}$ & $\begin{array}{l}1.59 \\
1.13\end{array}$ & $\begin{array}{l}1.40 \\
1.06\end{array}$ & $\begin{array}{l}1.82 \\
1.21\end{array}$ & 2,89 & 1.13 \\
\hline SIB10 & $\begin{array}{l}x \\
S D\end{array}$ & $\begin{array}{l}1.44 \\
1.22\end{array}$ & $\begin{array}{l}1.21 \\
1.00\end{array}$ & $\begin{array}{l}1.27 \\
1.38\end{array}$ & 2,89 & 0.42 \\
\hline RAV & $\begin{array}{l}x \\
S D\end{array}$ & $\begin{array}{r}51.56 \\
6.22\end{array}$ & $\begin{array}{r}50.19 \\
7.85\end{array}$ & $\begin{array}{r}50.52 \\
6.34\end{array}$ & 2,89 & 0.24 \\
\hline $\mathbf{P}$ & $\begin{array}{l}x \\
S D\end{array}$ & $\begin{array}{l}3.56 \\
2.41\end{array}$ & $\begin{array}{l}2.84 \\
1.95\end{array}$ & $\begin{array}{l}2.21 \\
1.43\end{array}$ & 2,90 & 0.01 \\
\hline $\mathbf{E}$ & $\begin{array}{l}x \\
\text { SD }\end{array}$ & $\begin{array}{l}9.16 \\
2.60\end{array}$ & $\begin{array}{l}8.69 \\
3.12\end{array}$ & $\begin{array}{l}6.67 \\
4.03\end{array}$ & 2,90 & 0.47 \\
\hline $\mathbf{N}$ & $\begin{array}{l}x \\
\text { SD }\end{array}$ & $\begin{array}{l}2.72 a \\
1.11\end{array}$ & $\begin{array}{l}6.56 a \\
1.12\end{array}$ & $\begin{array}{c}10.33 a \\
1.05\end{array}$ & 2,90 & $297.24 * \star \star$ \\
\hline I & $\begin{array}{l}x \\
S D\end{array}$ & $\begin{array}{l}3.03 \\
2.13\end{array}$ & $\begin{array}{l}2.98 \\
2.13\end{array}$ & $\begin{array}{l}3.18 \\
2.23\end{array}$ & 2,90 & 0.17 \\
\hline SRD & $\begin{array}{l}x \\
\text { SD }\end{array}$ & $\begin{array}{r}12.31 \\
5.72\end{array}$ & $\begin{array}{r}10.84 \\
4.89\end{array}$ & $\begin{array}{r}11.03 \\
6.43\end{array}$ & 2,90 & 1.52 \\
\hline PER & $\begin{array}{l}x \\
\text { SD }\end{array}$ & $\begin{array}{l}1.28 \\
1.22\end{array}$ & $\begin{array}{l}1.19 \\
1.07\end{array}$ & $\begin{array}{l}1.24 \\
0.97\end{array}$ & 2,90 & 0.73 \\
\hline TEFFT & $\begin{array}{l}x \\
\text { SD }\end{array}$ & $\begin{array}{l}1.72 a \\
1.78\end{array}$ & $\begin{array}{l}0.91 a \\
1.06\end{array}$ & $\begin{array}{l}1.58 \\
1.70\end{array}$ & 2,90 & $4.87 \star \star$ \\
\hline MODAL & $\begin{array}{l}x \\
S D\end{array}$ & $\begin{array}{l}5.65 \\
0.84\end{array}$ & $\begin{array}{l}5.37 \\
0.87\end{array}$ & $\begin{array}{l}5.64 \\
0.93\end{array}$ & 2,89 & 1.17 \\
\hline SRMS & $\begin{array}{l}x \\
S D\end{array}$ & $\begin{array}{r}329.10 \\
29.47\end{array}$ & $\begin{array}{r}321.37 \\
29.62\end{array}$ & $\begin{array}{r}331.00 \\
25.71\end{array}$ & 2,89 & 0.78 \\
\hline GLOBAI & $\begin{array}{l}x \\
S D\end{array}$ & $\begin{array}{l}7.84 \\
1.04\end{array}$ & $\begin{array}{l}7.53 \\
0.93\end{array}$ & $\begin{array}{l}8.00 \\
0.79\end{array}$ & 2,89 & 2.24 \\
\hline
\end{tabular}

${ }^{*} p<0.05 * * p<0.01 * * * p<0.001$

(Means with the same letter are significantly different from each other)

Table 3.3(7) shows that four variables yielded significant differences between the three levels of $\mathrm{N}$. The high $\mathrm{N}$ group came from a significantly lower social class than both the low and middle $\mathrm{N}$ groups $(\mathrm{F}(2,85)=4.39, \mathrm{p}<0.05)$, no significant differences were found between the low and middle $\mathrm{N}$ groups. The high $\mathrm{N}$ group also came from a 
significantly lower socio-economic group than the low $N$ group $(F(2,85)=3.09, p<0.05)$, although no differences between the middle $\mathrm{N}$ group and the other two groups was found to exist. The high $\mathrm{N}$ group also scored significantly higher on $\mathrm{N}$ than both the middle and low $\mathrm{N}$ groups, and the middle $\mathrm{N}$ group scored significantly higher on $\mathrm{N}$ than the low $\mathrm{N}$ group $(F(2,90)=297.24, p<0.001)$. Finally, it was found that the low $N$ group had committed significantly more thefts than the middle $N$ group $(F(2,90)=4.87, p<0.01)$, no significant differences in thefts between the high $\mathbf{N}$ group and the other two groups.

\section{Cluster Analysis}

The results of the personality measures were subjected to Ward's (1963) cluster analysis method to discern the heterogeneity of personality types within two of the sample groups, namely the male offender sample and the male and female control sample. The resultant clusters were then compared on the personality variables using analysis of variance.

\section{Control Group Sample}

Examination of the error terms generated by Ward's method led to the adoption of a four cluster solution for the control sample group. Table 3.3 (8) shows the means scores for each cluster on the EPQ scales and the results of a one-way analysis of variance between the clusters. 
Table 3.3(8) - Means and standard deviations for the four cluster solution for the personality variables of the control sample group and the results of the one-way ANOVA carried out.

\begin{tabular}{|c|c|c|c|c|c|c|c|c|c|c|}
\hline \multicolumn{11}{|c|}{ Cluster Number } \\
\hline $\begin{array}{l}\text { EPQ } \\
\text { Scale }\end{array}$ & $\frac{C 1}{x}$ & $\frac{(N=14)}{S D}$ & $\frac{C 2 \quad 1}{x}$ & $\frac{(\mathrm{N}=7)}{\mathrm{SD}}$ & $\frac{c 3 \quad 1}{x}$ & $\frac{(N=15)}{S D}$ & $\frac{c 4}{x}$ & $\frac{(N=11)}{S D}$ & $d f$ & $F$ \\
\hline $\mathrm{P}$ & 2.29 & 1.38 & 2.14 & 41.46 & 2.73 & 31.75 & 3.55 & 52.54 & 3,43 & 1.23 \\
\hline$E$ & 9.00 & 2.96 & 8.00 & 4.97 & 6.53 & 33.94 & 8.09 & 92.43 & 3,43 & 1.21 \\
\hline $\mathrm{N}$ & 5.07 & 2.76 & 7.57 & 73.46 & 7.60 & 3.18 & 6.82 & 22.79 & 3,43 & 2.01 \\
\hline L & 3.14 & 2.11 & 3.71 & $\perp 2.21$ & 2.27 & 71.75 & 2.91 & 12.07 & 3,43 & 0.95 \\
\hline
\end{tabular}
$* p<0.05$

Table 3.3(8) shows that no significant differences were found in personality between the four clusters in the control sample.

\section{Male Offender Sample}

Examination of the error terms generated by Ward's method led to the adoption of a four cluster solution for the male offender sample group. Table 3.3(9) shows the means scores for each cluster on the EPQ scales and the results of a one-way analysis of variance between the clusters. 
Table 3.3(9) - Means and standard deviations for the four cluster solution for the personality variables of the male offender sample group and the results of the oneway ANOVA carried out.

\begin{tabular}{|c|c|c|c|c|c|c|c|c|c|c|}
\hline \multicolumn{11}{|c|}{ Cluster Number } \\
\hline $\begin{array}{c}\text { EPQ } \\
\text { Scale }\end{array}$ & $\frac{01 \text { (I }}{x}$ & $\frac{N=13)}{S D}$ & $\frac{02}{x}$ & $\frac{(N=15)}{S D}$ & $\frac{03 \quad 1}{x}$ & $\frac{N=10)}{S D}$ & $\frac{04}{x}$ & $\frac{(N=15)}{S D}$ & df & $\mathbf{F}$ \\
\hline$P$ & 5.25 & 2.38 & 4.00 & 2.45 & 4.78 & 2.11 & 6.14 & 42.28 & 3,46 & 2.11 \\
\hline$E$ & 9.33 & 2.39 & 8.13 & 33.91 & 8.67 & 1.80 & 9.50 & 2.98 & 3,46 & 0.61 \\
\hline $\mathrm{N}$ & 5.42 & 2.94 & 5.13 & 32.95 & 7.22 & 2.91 & 5.86 & 53.25 & 3,46 & 0.97 \\
\hline$L$ & 2.50 & 2.15 & 4.13 & 32.10 & 2.11 & 2.42 & 2.21 & 2.49 & 3,46 & 2.35 \\
\hline
\end{tabular}

${ }^{*} \mathrm{p}<0.05$

Table 3.3(9) shows that no significant differences were found in personality between the four clusters found in the offender group.

\section{Offender Group Clusters - Descriptions}

While the comparison of the clusters using ANOVA suggested that no differences in personality existed between them, this method ignores the personality combination (in terms of $\mathrm{P}, \mathrm{E}, \mathrm{N}$ and $\mathrm{L}$ ) identified by the clusters. To attempt to take this combination aspect into account, bar charts for the personality variables were constructed for each of the clusters. The figures below show the results. 
Figure 3.3(1) - Bar Chart to show the personality variables in Cluster 01, from the male offender sample group

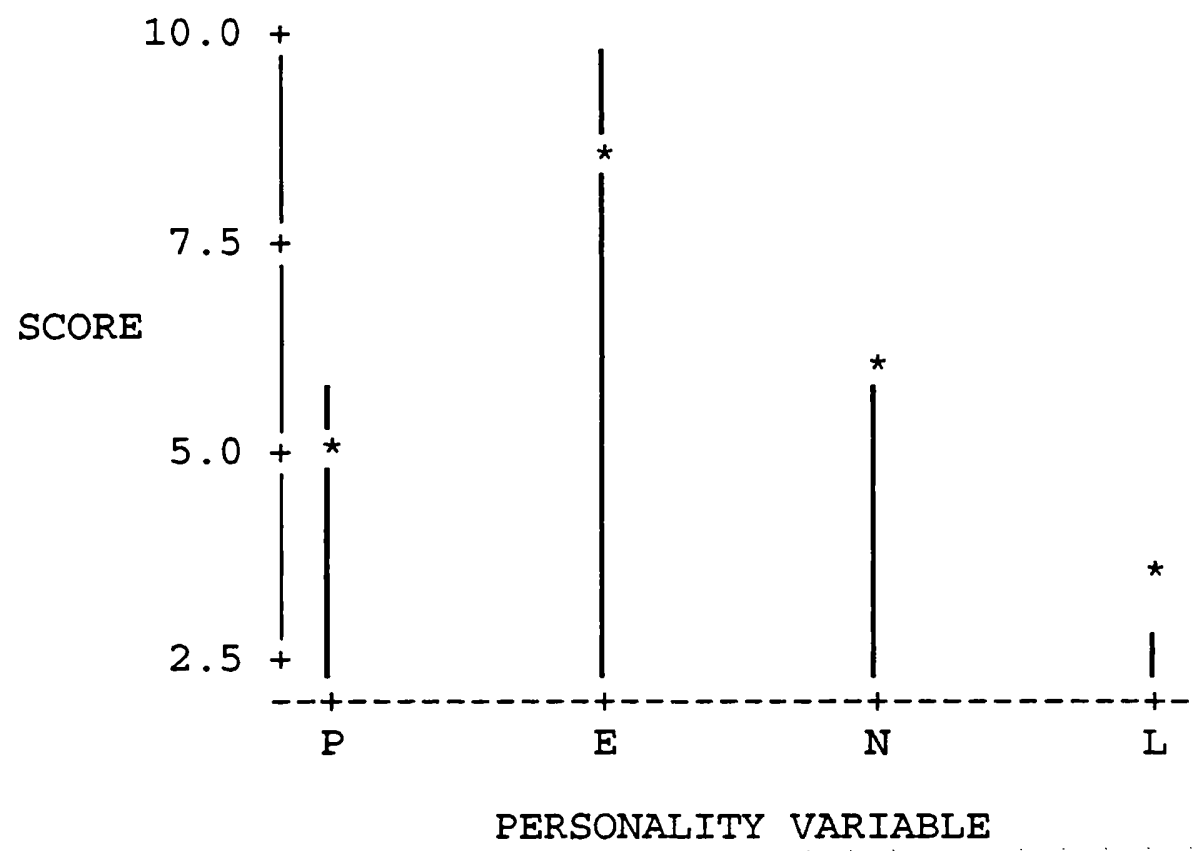

* indicates the offender group sample mean for each of the personality variables

Figure 3.3(1), suggests that the personality of the male offenders in cluster $\mathrm{O} 1$ is particularly defined by having high $\mathrm{E}$, while the other personality variables are close to the mean. 
Figure 3.3(2) - Bar Chart to show the personality variables in Cluster O2, from the male offender sample group

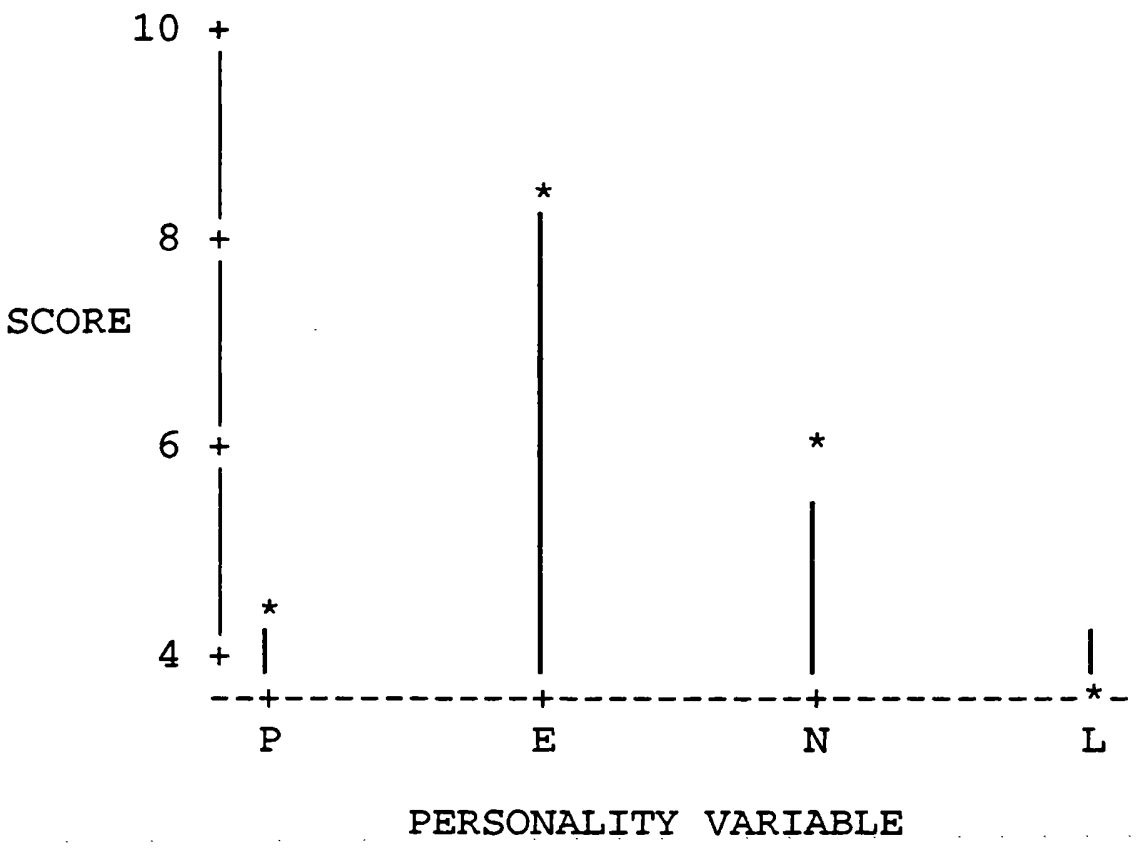

* indicates the offender group sample mean for each of the personality variables

Figure $3.3(2)$, suggests that the personality of individuals in cluster $\mathrm{O} 2$ is characterised by low $\mathrm{N}$ and high $\mathrm{L}$. 
Figure 3.3(3) - Bar Chart to show the personality variables in Cluster O3 from the male offender sample group

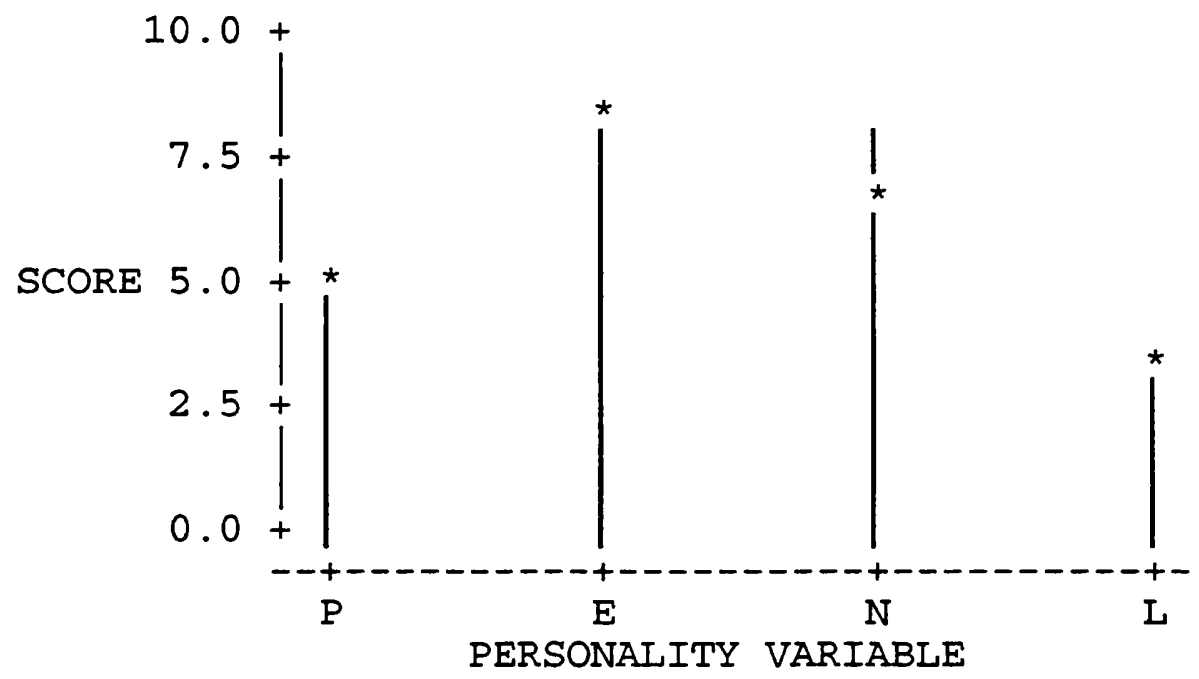

* indicates the offender group sample mean for each of the personality variables

Figure 3.3(3) suggests that individuals in cluster $\mathrm{O} 3$ are characterised by a high $\mathrm{N}$ score.

Figure 3.3(4) - Bar Chart to show the personality variables in Cluster 04 from the male offender sample group

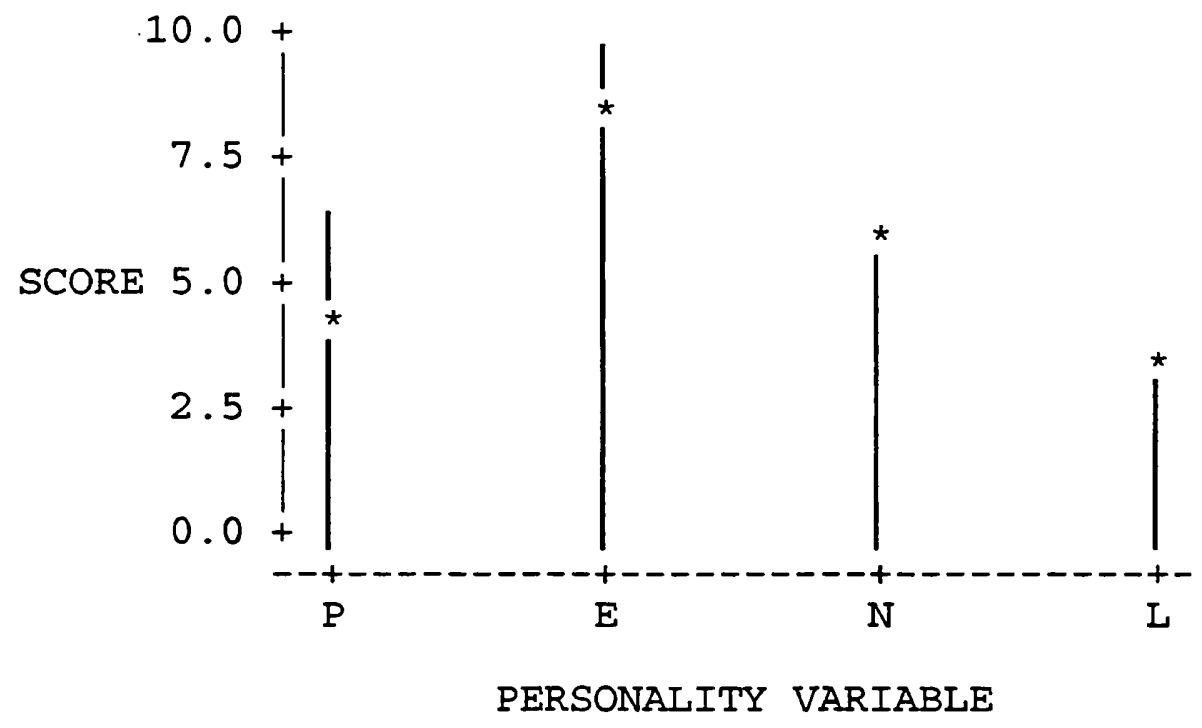

* indicates the offender group sample mean for each of the personality variables 
Figure 3.3(4) suggests that individuals in cluster $\mathrm{O} 4$ have their personality characterised by high $\mathrm{P}$ and $\mathrm{E}$ scores.

\section{Control Group Clusters - Descriptions}

The figures below show bar charts for the personality variables of the four clusters from the control group sample.

Figure 3.3(5) - Bar Chart to show the personality variables in Cluster C1 from the control sample group

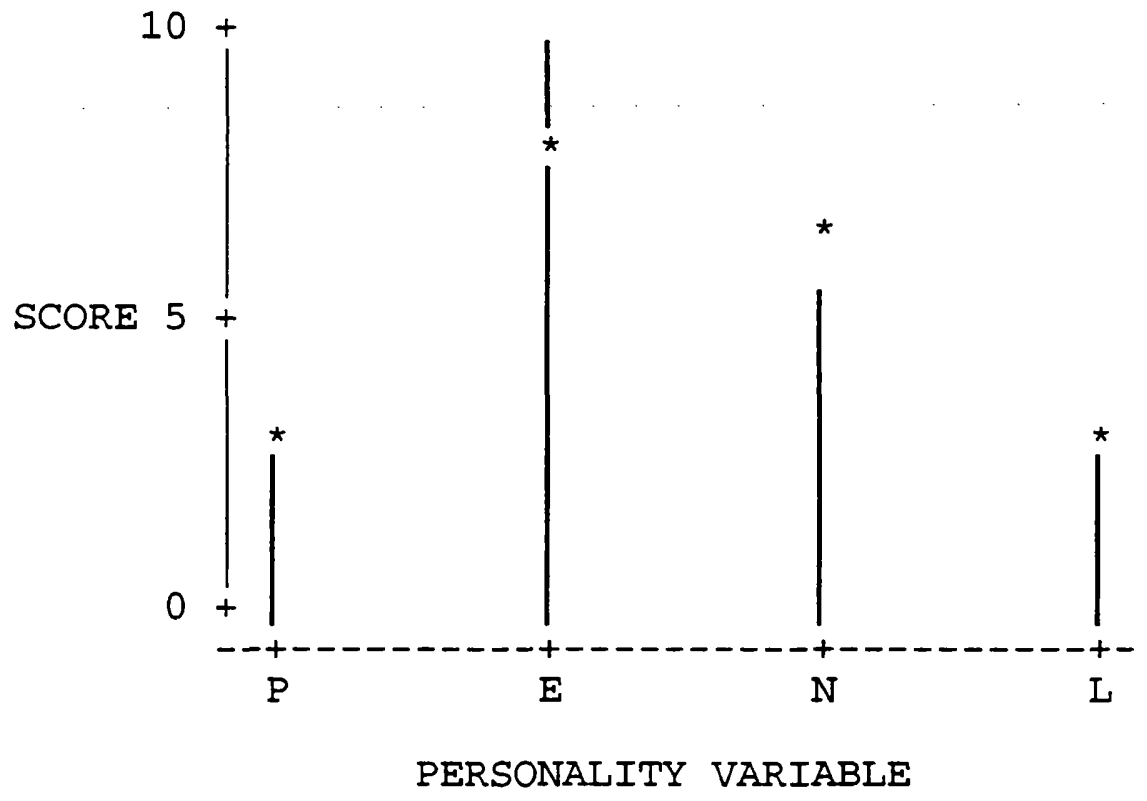

* indicates the offender group sample mean for each of the personality variables

Figure 3.3(5) suggests that individuals in cluster $\mathrm{Cl}$ have their personality characterised by high $\mathrm{E}$ and low $\mathrm{N}$ scores. 
Figure 3.3(6) - Bar Chart to show the personality variables in Cluster C2 from the control sample group

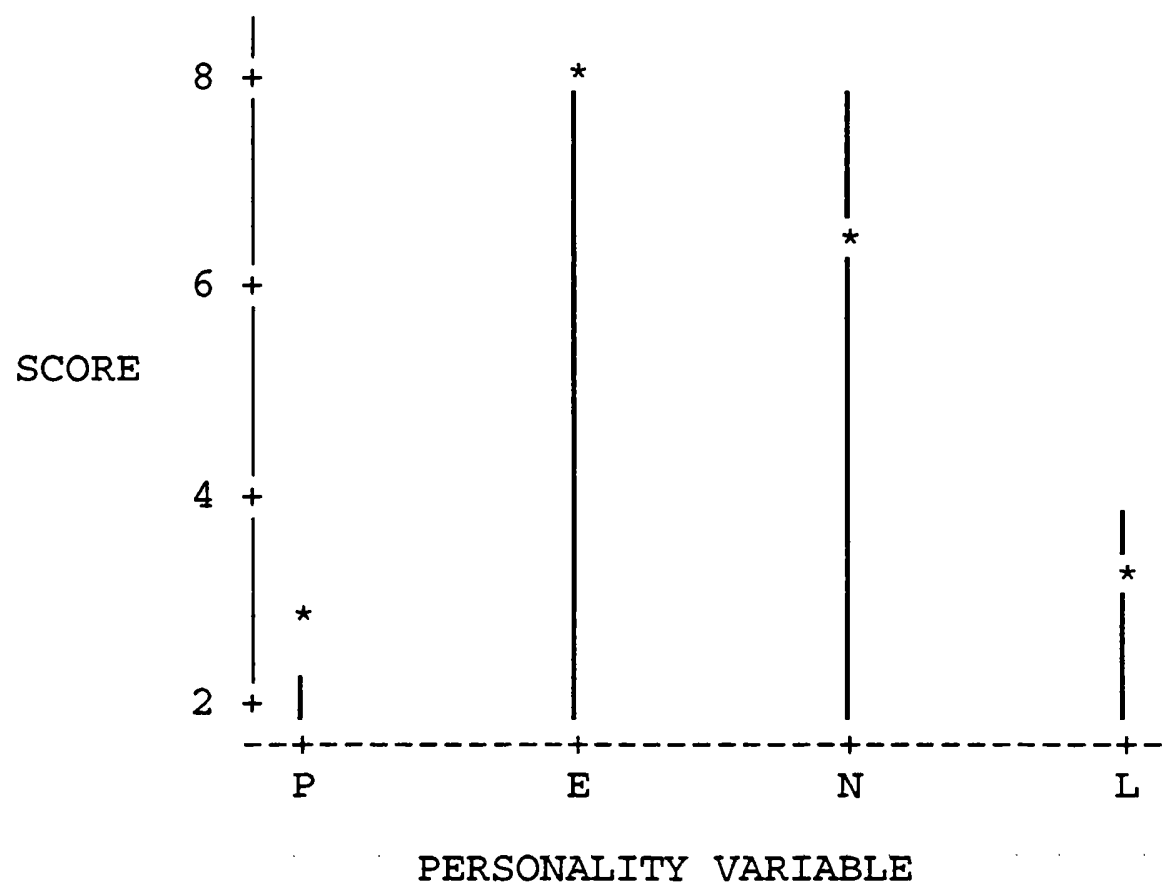

* indicates the offender group sample mean for each of the personality variables

Figure 3.3(6) suggests that individuals in cluster C2 have their personality characterised by high $\mathrm{N}$ and $\mathrm{L}$, and low $\mathrm{P}$ scores. 
Figure 3.3(7) - Bar Chart to show the personality variables in Cluster C3 from the control sample group

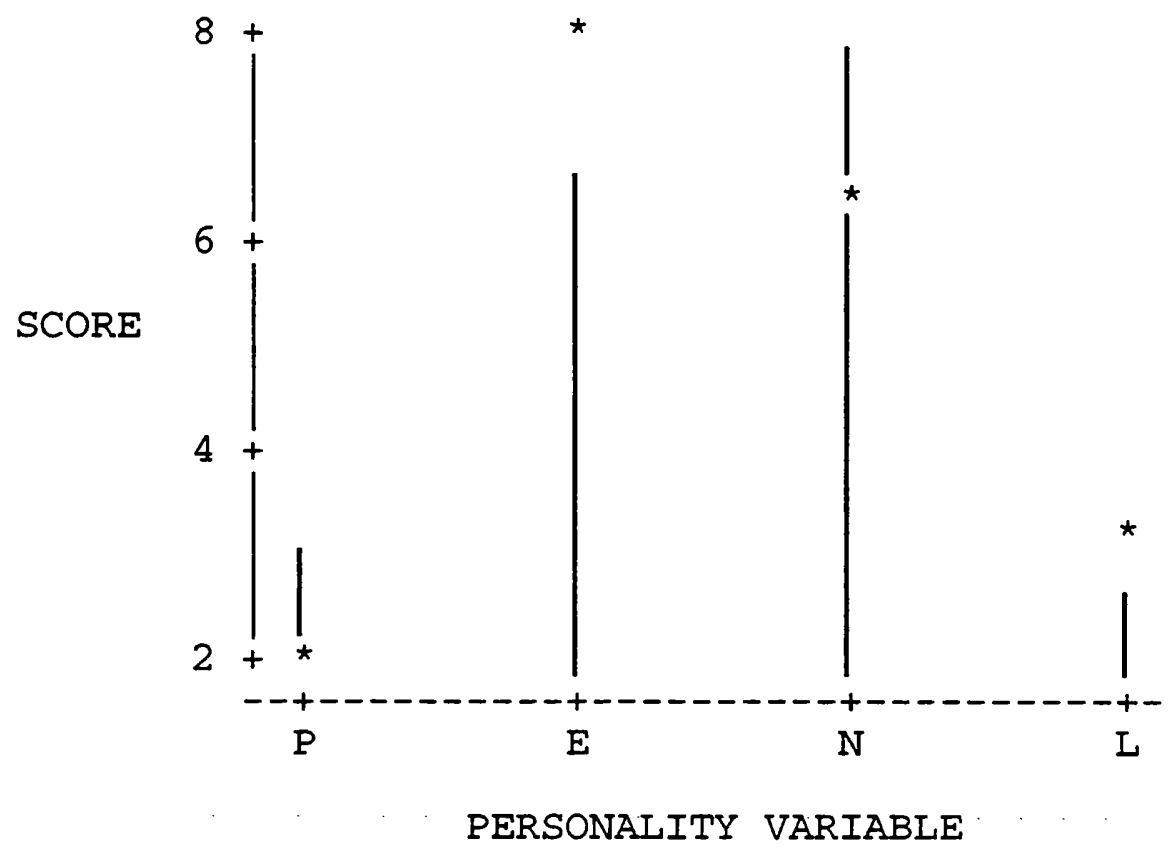

* indicates the offender group sample mean for each of the personality variables

Figure 3.3(7) suggests that individuals in cluster C3 have their personality characterised by high $\mathrm{P}$ and $\mathrm{N}$, and low $\mathrm{E}$ and $\mathrm{L}$ scores. 
Figure 3.3.(8) - Bar Chart to show the personality variables in Cluster C4 from the control sample group

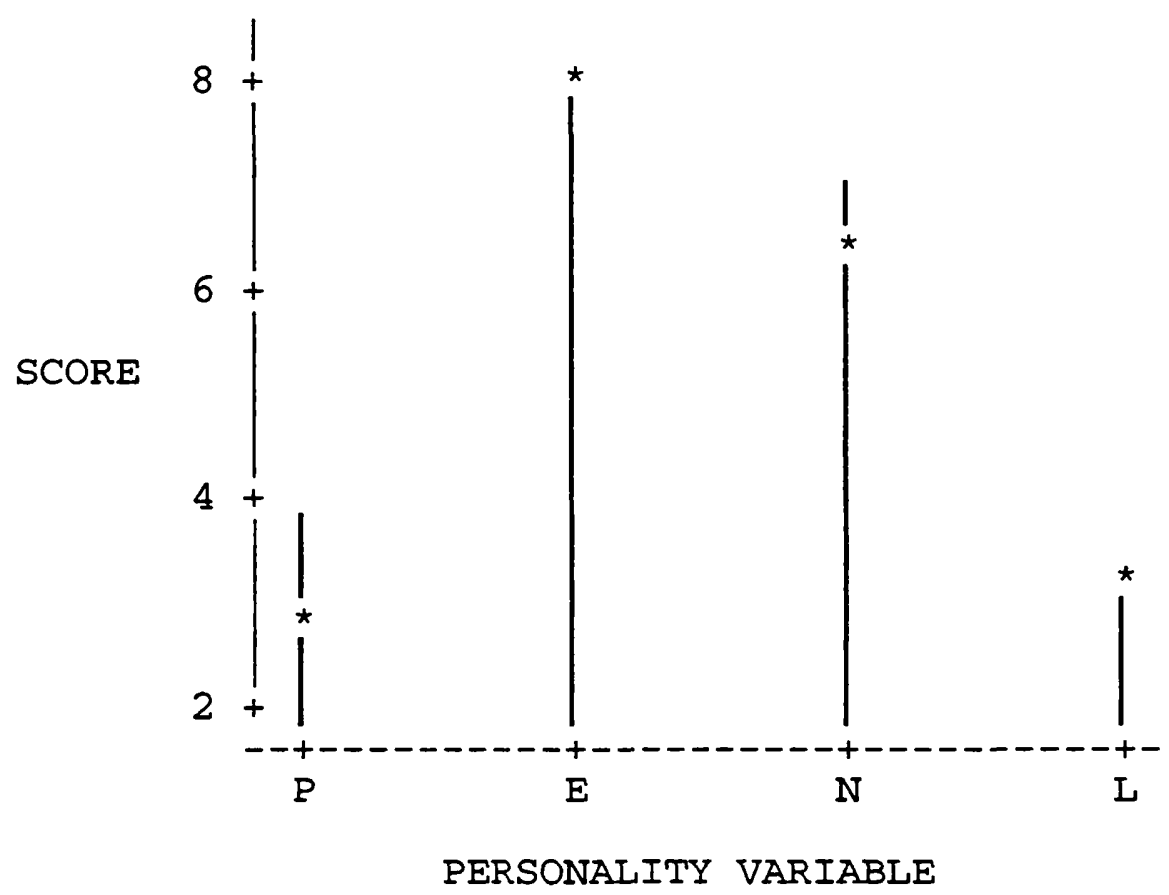

* indicates the offender group sample mean for each of the personality variables

Figure 3.3(8) suggests that individuals in cluster $\mathrm{C} 4$ have their personality characterised by high $\mathrm{P}$ scores.

Table 3.3(10) shows the summary descriptions of the personality characteristics of the clusters for both the offender and control groups.

Table 3.3(10) - A summary of the personality characteristics of the offender and control group clusters.

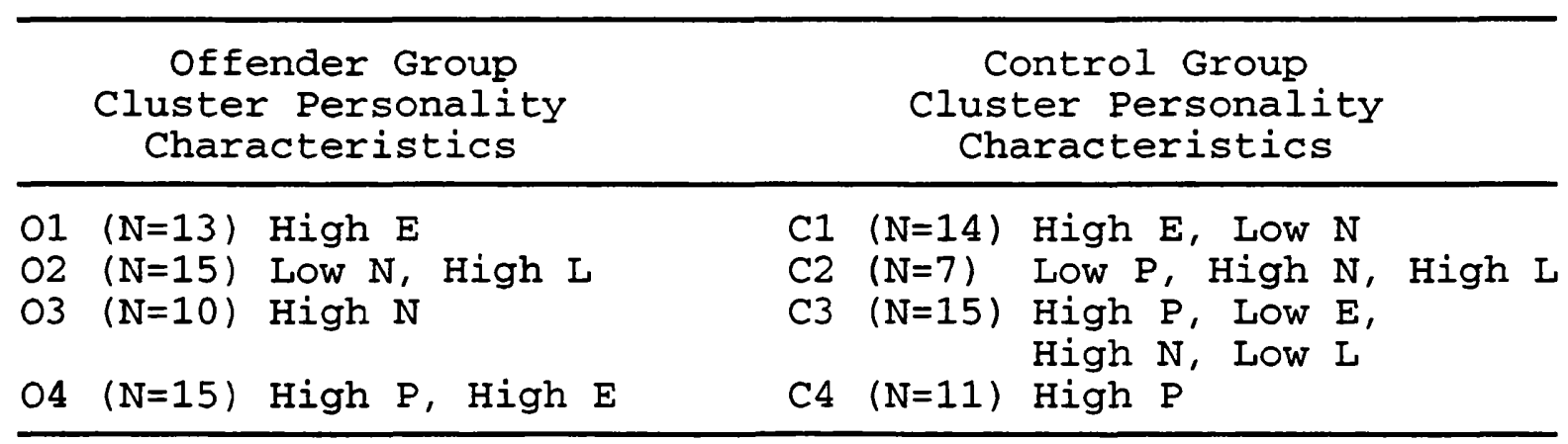




\section{Cluster Comparisons - Offender Group Sample}

The four clusters identified in the offender sample group were compared using analysis of variance on demographic, intelligence, moral reasoning and offending history variables.

\section{Demographic Variables}

The four clusters identified in the offender and non-offender sample groups were compared using analysis of variance (ANOVA) on the demographic variables age, education (EDU), class, socio-economic group (SEG), number of siblings before (SIB) and after (SIB10) the age of ten. Table 3.3(11) shows the results of the ANOVA carried out.

Table 3.3(11) - Means and standard deviations for the cluster solution for the demographic variables of the male offender sample group and the results of the oneway ANOVA carried out.

Cluster Number

\begin{tabular}{lcccccccccccccc}
\hline & \multicolumn{1}{c}{01} & $(N=13)$ & & 02 & $(N=15)$ & & 03 & $(N=10)$ & & 04 & $(N=15)$ & & df & $F$ \\
\hline AGE & 19.04 & 0.79 & 19.07 & 1.29 & 19.10 & 1.09 & 19.26 & 1.08 & 3, & 45 & 0.10 \\
EDU & 10.45 & 0.79 & 10.67 & 0.82 & 10.66 & 0.71 & 10.67 & 0.65 & 3, & 43 & 0.19 \\
CLASS & 3.40 & 1.07 & 2.77 & 1.01 & 3.33 & 1.37 & 3.43 & 0.53 & 3, & 32 & 1.03 \\
SEG & 8.10 & 2.77 & 7.38 & 3.73 & 8.00 & 4.05 & 10.13 & 2.64 & 3, & 33 & 1.15 \\
SIB & 2.42 & 1.08 & 1.87 & 1.46 & 2.40 & 2.59 & 1.08 & 0.97 & 3, & 45 & 1.80 \\
SIB10 & 2.09 & 1.30 & 1.47 & 1.36 & 1.30 & 1.16 & 1.08 & 0.97 & 3, & 44 & 1.41 \\
\hline
\end{tabular}

$\star p<0.05$

Table 3.3(11) shows that no significant differences in any of the demographic variables were found between the four clusters of the offender group. 
Table 3.3(12), shows the proportions and percentages of subjects of British and non-British ethnic origin, and the results of the chi-squared test carried out to determine the significance of any differences between the four clusters found.

Table 3.3(12) - Percentage of subjects of British and Non-British ethnic origin for the clusters in the offender sample group

\begin{tabular}{|c|c|c|c|}
\hline \multicolumn{4}{|c|}{ Ethnic Origin } \\
\hline \multicolumn{2}{|c|}{$\begin{array}{l}\text { Cluster } \\
\text { Number }\end{array}$} & \multirow{2}{*}{$\frac{\text { British }}{11}$} & Non-British \\
\hline 01 & n & & 02 \\
\hline $\mathrm{O} 2$ & $\mathrm{n}$ & 15 & 00 \\
\hline & 8 & 28.30 & 0.00 \\
\hline 03 & $n$ & 09 & 01 \\
\hline & 8 & 16.98 & 1.89 \\
\hline 04 & n & 11 & 04 \\
\hline & 8 & 20.75 & 7.55 \\
\hline Total & $\mathrm{n}$ & 46 & 07 \\
\hline & 8 & 86.79 & 13.21 \\
\hline
\end{tabular}

As can be seen from Table 3.3(12), the majority of subjects in each of the clusters was of British ethnic origin, and none of the differences between the clusters were found to be significant $\left(\mathrm{X}_{2}(3)=4.797, \mathrm{p}>0.05\right)$.

Intelligence and Moral Reasoning Variables

The four clusters identified in the offender sample group were compared using analysis of variance (ANOVA) on the intelligence (RAV) and moral reasoning variables: modal stage of moral reasoning (MODAL), sociomoral reasoning maturity score (SRMS), and global stage of moral reasoning (GLOBAL). Table 3.3(13) shows the results of the ANOVA's carried out. 
Table 3.3(13) - Means and standard deviations for the male offender sample cluster solution for intelligence and moral reasoning and the results of the one-way ANOVA carried out.

\begin{tabular}{|c|c|c|c|c|c|c|c|}
\hline \multicolumn{8}{|c|}{ Cluster Number } \\
\hline & & $\begin{array}{c}01 \\
(N=13)\end{array}$ & $\begin{array}{c}02 \\
(N=15)\end{array}$ & $\begin{array}{c}03 \\
(N=10)\end{array}$ & $\begin{array}{c}04 \\
(N=15)\end{array}$ & $d f$ & $F$ \\
\hline RAV & $\begin{array}{l}x \\
S D\end{array}$ & $\begin{array}{r}35.67 \\
9.46\end{array}$ & $\begin{array}{r}37.87 \\
8.54\end{array}$ & $\begin{array}{r}41.40 \\
4.20\end{array}$ & $\begin{array}{l}39.64 \\
11.68\end{array}$ & 3,47 & 0.81 \\
\hline MODAL & $\begin{array}{l}x \\
\text { SD }\end{array}$ & $\begin{array}{l}4.38 \\
0.92\end{array}$ & $\begin{array}{l}4.45 \\
0.82\end{array}$ & $\begin{array}{l}4.13 \\
0.99\end{array}$ & $\begin{array}{l}4.09 \\
0.94\end{array}$ & 3,34 & 0.39 \\
\hline SRMS & $\begin{array}{l}x \\
S D\end{array}$ & $\begin{array}{r}252.67 \\
33.19\end{array}$ & $\begin{array}{r}250.73 \\
35.60\end{array}$ & $\begin{array}{r}260.88 \\
21.78\end{array}$ & $\begin{array}{r}247.45 \\
44.50\end{array}$ & 3,35 & 0.23 \\
\hline GLOBAL & $\begin{array}{l}x \\
\text { SD }\end{array}$ & $\begin{array}{l}5.56 \\
1.13\end{array}$ & $\begin{array}{l}5.55 \\
1.04\end{array}$ & $\begin{array}{l}5.88 \\
0.64\end{array}$ & $\begin{array}{l}5.73 \\
1.35\end{array}$ & 3,35 & 0.81 \\
\hline
\end{tabular}

${ }^{\star} p<0.05$

Table 3.3(13) shows that no significance differences in intelligence or moral reasoning were found between the four clusters of the offender group.

\section{Offending History Variables}

The four clusters identified in the offender sample group were compared using analysis of variance (ANOVA) on the three offending history variables: general selfreported delinquency (SRD), crimes committed against the person (PER), and property crimes (THEFT). Table 3.3(14) shows the results of the ANOVAs 
Table 3.3(14) - Means and standard deviations for the male offender sample cluster solution for offending history and the results of the one-way ANOVA carried out.

\begin{tabular}{|c|c|c|c|c|c|c|c|}
\hline \multicolumn{8}{|c|}{ Cluster Number } \\
\hline & & $\begin{array}{c}01 \\
(N=13)\end{array}$ & $\begin{array}{c}02 \\
(N=15)\end{array}$ & $\begin{array}{c}03 \\
(N=10)\end{array}$ & $\begin{array}{c}04 \\
(N=15)\end{array}$ & $d f$ & $F$ \\
\hline SRD & $\begin{array}{l}x \\
\text { SD }\end{array}$ & $\begin{array}{r}22.15 \\
5.63\end{array}$ & $\begin{array}{r}19.07 \\
7.70\end{array}$ & $\begin{array}{r}25.67 \\
7.11\end{array}$ & $\begin{array}{r}25.46 \\
5.27\end{array}$ & 3,46 & $2.99 *$ \\
\hline PER & $\begin{array}{l}x \\
\text { SD }\end{array}$ & $\begin{array}{l}3.38 \\
1.56\end{array}$ & $\begin{array}{l}3.00 \\
2.00\end{array}$ & $\begin{array}{l}4.33 \\
2.35\end{array}$ & $\begin{array}{l}4.85 \\
1.68\end{array}$ & 3,46 & 2.70 \\
\hline THEFT & $\begin{array}{l}x \\
\text { SD }\end{array}$ & $\begin{array}{l}5.31 \\
1.55\end{array}$ & $\begin{array}{l}4.80 \\
2.27\end{array}$ & $\begin{array}{l}4.85 \\
1.68\end{array}$ & $\begin{array}{l}5.92 \\
1.12\end{array}$ & 3,46 & 1.68 \\
\hline
\end{tabular}

${ }^{\star} \mathrm{p}<0.05$

Table 3.3(14) shows that for crimes against the property and theft, no significant difference was apparent between the four clusters. For general delinquency, however, a significant difference was found, individuals cluster $\mathrm{O} 2$ had committed significantly fewer delinquent acts than the individuals in cluster $\mathrm{O} 3$.

Cluster Comparisons - Control Group Sample

The clusters identified in the control group sample were compared using analysis of variance on offending history variables. 
Table 3.3(15) - Means and standard deviations for the control sample cluster solution for offending history and the results of the one-way ANOVA carried out.

\begin{tabular}{|c|c|c|c|c|c|c|c|}
\hline \multicolumn{8}{|c|}{ Cluster Number } \\
\hline & & $\begin{array}{c}C 1 \\
(N=14)\end{array}$ & $\begin{array}{c}\mathrm{C} 2 \\
(\mathrm{~N}=07)\end{array}$ & $\begin{array}{c}\mathrm{C} 3 \\
(\mathrm{~N}=15)\end{array}$ & $\begin{array}{c}\mathrm{C} 4 \\
(\mathrm{~N}=11)\end{array}$ & $d f$ & $\mathbf{F}$ \\
\hline SRD & $\begin{array}{l}x \\
S D\end{array}$ & $\begin{array}{r}11.50 \\
5.32\end{array}$ & $\begin{array}{l}9.57 \\
4.65\end{array}$ & $\begin{array}{r}10.47 \\
4.53\end{array}$ & $\begin{array}{r}10.55 \\
5.26\end{array}$ & 3,43 & 0.25 \\
\hline PER & $\begin{array}{l}x \\
S D\end{array}$ & $\begin{array}{l}1.21 \\
1.05\end{array}$ & $\begin{array}{l}1.14 \\
1.07\end{array}$ & $\begin{array}{l}1.40 \\
0.63\end{array}$ & $\begin{array}{l}0.91 \\
0.94\end{array}$ & 3,43 & 0.62 \\
\hline THEFT & $\begin{array}{l}x \\
S D\end{array}$ & $\begin{array}{l}1.21 \\
1.76\end{array}$ & $\begin{array}{l}1.00 \\
0.82\end{array}$ & $\begin{array}{l}1.40 \\
1.24\end{array}$ & $\begin{array}{l}1.00 \\
1.26\end{array}$ & 3,43 & 0.23 \\
\hline
\end{tabular}

${ }^{*} p<0.05$

Table 3.3(15) shows that no significant differences were found in any of the offending history variables between the four clusters in the control group sample. 


\section{Summary/Discussion}

The results of this section, while supporting many of the predictions from Eysenck's theory, were less clear overall. For Psychoticism and Extraversion predictions were upheld to a certain extent while neuroticism was more of an anomaly.

With regard to the analyses of variance carried out in relation to the divisions of $\mathrm{P}$, $\mathrm{E}$ and $\mathrm{N}$ into three categories (high, middle and low) the results are summarised in sections relating to each of the offending history variables.

\section{Self-Reported Delinquency (SRD)}

Within the whole group sample, those who had scored in the High $\mathrm{P}$ range ( 9 to 12) were found to have scored significantly higher on SRD than those who scored in the middle $\mathrm{P}$ ( 5 to 8 ) or low $\mathrm{P}(0$ to 4 ) range, as would be predicted by Eysenck's theory.

Within the whole sample group those who scored in the High E range (9-12) had scored significantly higher on SRD than those who scored in the low E range (0 to 4). This was also found in the combined control group, but no significant differences were found between the three $\mathrm{E}$ ranges in the convicted offender group. Both the general findings of extraversion and psychoticism support the predictions and assertions of Eysenck's theory.

With regard to neuroticism, the only significant difference was found in the whole sample group, where those who had scored in the low $\mathrm{N}$ group had scored significantly higher on SRD. This finding is the exact opposite of that predicted which assumes that high $\mathrm{N}$ scorers would have committed the most offending.

\section{Crimes against the person/Violent offending (PER)}

In the whole sample group, those who had scored in the middle $\mathrm{P}$ range had committed significantly more violent offences than the low P scorers. This seems to 
support Eysenck's theory which proposes that high P scorers should commit the most antisocial offences.

Those who had scored in the high E range in the whole sample group had committed significantly more violent offences than the low E range scorers. In the convicted offender group and in the combined control group no significant differences were found in violent offending across the three ranges of $\mathrm{E}$. The finding in the whole sample group fits predictions from Eysenck's theory which suggests that high E scorers would commit a greater number of violent offences.

With regard to neuroticism $(\mathrm{N})$, in all three sample groups no significant differences in violent offending across the three ranges of $\mathrm{N}$ were found. This is contrary to Eysenck's theory's predictions that high $\mathrm{N}$ scorers would commit the greatest number of violent offences.

\section{Property Offences (THEFT)}

In the whole sample group, those who had scored in the High P range had committed significantly more thefts than those who had scored in both the low and middle $\mathrm{P}$ ranges. These results again support Eysenck's notion that high $\mathrm{P}$ scorers would commit more offences.

Those who had scored in the high E range within he whole sample group had scored significantly higher on theft than the low E range scorers. While this was predicted from Eysenck's theory, no significant differences were found in thefts committed across the three ranges of $\mathrm{E}$ in both the convicted offenders and the combined controls.

In both the whole sample group and the combined control group the low $\mathrm{N}$ range scorers had scored higher on thefts committed than the middle range scorers. Both these findings were opposite to that predicted by Eysenck's theory, which suggests that high $\mathrm{N}$ 
scorers would commit more offences. No significant differences were found in thefts committed across the three ranges of $\mathrm{N}$ in the convicted offender group, however.

The clusters showed conflicting results. While a predicted High P, High E cluster was found in the offender group but not in the comparison group clusters (similar to that found by McEwan, 1983), no cluster was found with the predicted combination of High P, $\mathrm{E}$ and $\mathrm{N}$. In addition, the predicted low $\mathrm{P}$, low $\mathrm{E}$ low $\mathrm{N}$ cluster was not found in the control group. Furthermore, the clusters did not significantly differ on many of the predicted variables (such as moral reasoning), except for the small significance found in general self-reported delinquency (SRD) between two of the offender group clusters. The whole nature of the clusters identified rested on subjective descriptions, since no significant differences were found in personality variables between them.

The discussion in Chapter 5 covers the results from this section in greater detail. 


\section{4 - MULTIPLE REGRESSION ANALYSIS}

\section{Introduction}

The data was subjected to multiple regression analysis where the self reported delinquency measures general self reported delinquency (SRD), crimes against the person (PER) and number of thefts (THEFT) were used. The following variables were regressed upon the three above scores: age, education (EDU) ethnic origin (ETHN), social class (CLASS), socio-economic group (SEG), number of siblings before the age of 10 (SIB), the number of siblings after the sage of ten (SIB10), intelligence (RAV), psychoticism (P), extraversion (E), neuroticism (N), Lie score (L), modal stage of moral reasoning (MODAL), sociomoral reflection maturity score (SRMS) and global stage of moral reasoning (GLOBAL).

This was undertaken to determine which variables collected contributed towards the amount of delinquency carried out, in other words which variables predicted delinquency. The overall aim of this analysis was to determine which variables contributed the most to self-reported delinquency in the general attempt to combine the various theories of the causation of crime. The models for each of the five sample groups (whole large sample, male offenders, male controls, female controls and combined comparison group) which best fitted the data are presented below. 
Whole Sample group

Table 3.4(1) - Results of the stepwise multiple regression analysis for the dependent variable SRD for the whole sample group

\begin{tabular}{lcrrrr}
\hline $\begin{array}{l}\text { Source of } \\
\text { Variance }\end{array}$ & SS & df & MS & F & p \\
\hline Regression & $\begin{array}{r}5534.67 \\
3809.08\end{array}$ & 136 & $\begin{array}{r}92.45 \\
28.01\end{array}$ & 32.94 & $<0.0001$ \\
Error & & & & \\
Total & 9343.75 & 142 & & & \\
\hline \hline \multicolumn{7}{c}{ Model } & & & & \\
\hline Variable & Parameter & Standard & SS & F & p \\
& Estimate & Error & & & \\
\hline Intercept & 25.80 & 9.26 & 217.39 & 7.76 & $<0.01$ \\
AGE & 1.16 & 0.48 & 165.43 & 5.91 & $<0.05$ \\
EDU & -1.42 & 0.32 & 542.94 & 19.39 & $<0.0001$ \\
P & 0.86 & 0.22 & 430.44 & 15.37 & $<0.0001$ \\
E & 0.29 & 0.14 & 127.79 & 4.56 & $<0.05$ \\
L & -1.26 & 0.20 & 1072.04 & 38.38 & $<0.0001$ \\
SRMS & -0.05 & 0.01 & 567.50 & 20.26 & $<0.0001$ \\
\hline
\end{tabular}

As can be seen from table 3.4(1), there are five variables which contributed to selfreported delinquency in the whole sample group, these are age, years spent in education, psychoticism (P), extroversion (E), lie score (L) and sociomoral reflection maturity score (SRMS). None of the other variables achieved the $p<0.05$ level of significance to be included in the model. 
Table 3.4(2) - Results of the stepwise multiple regression analysis for the dependent variable PER for the whole sample group

\begin{tabular}{|c|c|c|c|c|c|}
\hline $\begin{array}{l}\text { Source of } \\
\text { Variance }\end{array}$ & SS & $d f$ & MS & $F$ & $\mathrm{p}$ \\
\hline $\begin{array}{l}\text { Regression } \\
\text { Error } \\
\text { Total }\end{array}$ & $\begin{array}{l}307.19 \\
288.73 \\
595.92\end{array}$ & $\begin{array}{r}5 \\
137 \\
142\end{array}$ & $\begin{array}{l}61.44 \\
28.01\end{array}$ & 29.15 & $<0.0001$ \\
\hline Variable & $\begin{array}{l}\text { Parameter } \\
\text { Estimate }\end{array}$ & $\begin{array}{l}\text { Model } \\
\text { Standard } \\
\text { Error }\end{array}$ & SS & $F$ & $p$ \\
\hline $\begin{array}{l}\text { Intercept } \\
\text { AGE } \\
\text { EDU } \\
\text { E } \\
\text { L } \\
\text { SRMS }\end{array}$ & $\begin{array}{r}7.19 \\
0.27 \\
-0.44 \\
0.09 \\
-0.29 \\
-0.01\end{array}$ & $\begin{array}{l}2.55 \\
0.13 \\
0.08 \\
0.04 \\
0.06 \\
0.00\end{array}$ & $\begin{array}{r}16.91 \\
9.12 \\
58.78 \\
12.55 \\
59.48 \\
41.64\end{array}$ & $\begin{array}{r}8.03 \\
4.33 \\
27.89 \\
5.95 \\
28.22 \\
19.76\end{array}$ & $\begin{array}{l}<0.01 \\
<0.05 \\
<0.0001 \\
<0.025 \\
<0.0001 \\
<0.0001\end{array}$ \\
\hline
\end{tabular}

As can be seen from table 3.3(2) the variables: age, years spent in education (EDU), extroversion (E), lie score (L), sociomoral reflection maturity score (SRMS) fit into a model to explain the number of crimes committed against the person. None of the other variables reached the $\mathrm{p}<0.05$ level of significance for entry into the model. It can be noted that psychoticism is not included in this model whereas it is in the SRD model (see table 3.4(1) above). 
Table 3.4(3) - Results of the stepwise multiple regression analysis for the dependent variable THEFT for the whole sample group

\begin{tabular}{|c|c|c|c|c|c|}
\hline $\begin{array}{l}\text { Source of } \\
\text { Variance }\end{array}$ & SS & $d f$ & MS & F & $\mathrm{p}$ \\
\hline $\begin{array}{l}\text { Regression } \\
\text { Error } \\
\text { Total }\end{array}$ & $\begin{array}{l}551.69 \\
366.78 \\
595.92\end{array}$ & $\begin{array}{r}5 \\
137 \\
142\end{array}$ & $\begin{array}{r}110.34 \\
2.67\end{array}$ & 41.21 & $<0.0001$ \\
\hline Variable & $\begin{array}{l}\text { Parameter } \\
\text { Estimate }\end{array}$ & $\begin{array}{l}\text { Model } \\
\text { Standard } \\
\text { Error }\end{array}$ & SS & F & $\mathrm{p}$ \\
\hline $\begin{array}{l}\text { Intercept } \\
\text { EDU } \\
\text { ETHN } \\
\text { P } \\
\text { L } \\
\text { SRMS }\end{array}$ & $\begin{array}{r}12.56 \\
-0.37 \\
0.62 \\
0.24 \\
-0.31 \\
-0.02\end{array}$ & $\begin{array}{l}1.41 \\
0.09 \\
0.22 \\
0.07 \\
0.06 \\
0.00\end{array}$ & $\begin{array}{r}212.47 \\
45.51 \\
22.46 \\
35.93 \\
68.29 \\
99.48\end{array}$ & $\begin{array}{r}79.36 \\
17.00 \\
8.39 \\
13.42 \\
25.51 \\
37.16\end{array}$ & $\begin{array}{l}<0.0001 \\
<0.0001 \\
<0.01 \\
<0.0005 \\
<0.0001 \\
<0.0001\end{array}$ \\
\hline
\end{tabular}

Table 3.4(3) shows that for the variable THEFT the variables years in education (EDU), ethnic group (ETHN), psychoticism (P), lie score (L), sociomoral reflection maturity score (SRMS) contribute significantly to the model. None of the other variables reached the 0.05 level of significance required for introduction into the model. It is worthy to note that for theft psychoticism $(\mathrm{P})$ is included and $\mathrm{E}$ excluded compared to the model for PER which include $\mathrm{E}$ but not $\mathrm{P}$, and the SRD model which included both. 


\section{Male Offender Sample Group}

Table 3.4(4) - Results of the stepwise multiple regression analysis for the dependent variable SRD for the male offender sample group

\begin{tabular}{|c|c|c|c|c|c|}
\hline $\begin{array}{l}\text { Source of } \\
\text { Variance }\end{array}$ & SS & $d f$ & MS & $\mathrm{F}$ & $\mathrm{p}$ \\
\hline $\begin{array}{l}\text { Regression } \\
\text { Error } \\
\text { Total }\end{array}$ & $\begin{array}{l}1055.04 \\
1050.21 \\
2105.24\end{array}$ & $\begin{array}{r}3 \\
41 \\
44\end{array}$ & $\begin{array}{r}351.68 \\
25.61\end{array}$ & 13.73 & $<0.0001$ \\
\hline Variable & $\begin{array}{l}\text { Parameter } \\
\text { Estimate }\end{array}$ & $\begin{array}{l}\text { Model } \\
\text { Standard } \\
\text { Error }\end{array}$ & SS & $F$ & $\mathrm{p}$ \\
\hline $\begin{array}{l}\text { Intercept } \\
\text { SIB10 } \\
\text { P } \\
\text { L }\end{array}$ & $\begin{array}{r}25.59 \\
-1.79 \\
1.18 \\
-1.55\end{array}$ & $\begin{array}{l}2.04 \\
0.83 \\
0.34 \\
0.30\end{array}$ & $\begin{array}{r}4037.39 \\
120.01 \\
306.13 \\
680.08\end{array}$ & $\begin{array}{r}157.62 \\
4.69 \\
11.95 \\
26.55\end{array}$ & $\begin{array}{l}<0.0001 \\
<0.05 \\
<0.005 \\
<0.0001\end{array}$ \\
\hline
\end{tabular}

Table 3.4(4) shows that for the male offender group, the variables number of siblings after the age of ten (SIB10), psychoticism (P), and the lie score (L) fit into the model to explain self-reported delinquency (SRD). None of the other variable reached the $\mathrm{p}<0.05$ level of significance to be introduced into the model. It is interesting to note that the variables $\mathrm{P}$ and $\mathrm{L}$ were also included in the model to explain SRD in the whole sample group but no other similarities occurred. 
Table 3.4(5) - Results of the stepwise multiple regression analysis for the dependent variable PER for the male offender sample group

\begin{tabular}{|c|c|c|c|c|c|}
\hline $\begin{array}{l}\text { Source of } \\
\text { Variance }\end{array}$ & SS & $d f$ & MS & $F$ & $\mathrm{p}$ \\
\hline $\begin{array}{l}\text { Regression } \\
\text { Error } \\
\text { Total }\end{array}$ & $\begin{array}{r}64.36 \\
136.44 \\
200.80\end{array}$ & $\begin{array}{r}1 \\
43 \\
44\end{array}$ & $\begin{array}{r}64.36 \\
3.17\end{array}$ & 20.28 & $<0.0001$ \\
\hline Variable & $\begin{array}{l}\text { Parameter } \\
\text { Estimate }\end{array}$ & $\begin{array}{l}\text { Model } \\
\text { Standard } \\
\text { Error }\end{array}$ & SS & $F$ & $p$ \\
\hline $\begin{array}{l}\text { Intercept } \\
\mathrm{L}\end{array}$ & $\begin{array}{r}5.86 \\
-0.48\end{array}$ & $\begin{array}{l}0.44 \\
0.11\end{array}$ & $\begin{array}{r}556.02 \\
64.36\end{array}$ & $\begin{array}{r}175.23 \\
20.28\end{array}$ & $\begin{array}{l}<0.0001 \\
<0.0001\end{array}$ \\
\hline
\end{tabular}

Table 3.4(5) shows that only the lie score (L) was included in the model to describe PER in the male offender group, since none of the other variables reached the necessary $\mathrm{p}<0.05$ for inclusion in the model. This is in contrast to both the model for SRD and for the models found in the whole sample group, although all the models thus described have included $\mathrm{L}$.

Table 3.4(6) - Results of the stepwise multiple regression analysis for the dependent variable THEFT for the male offender sample group

\begin{tabular}{|c|c|c|c|c|c|}
\hline $\begin{array}{l}\text { Source of } \\
\text { Variance }\end{array}$ & SS & $d f$ & MS & F & $\mathrm{p}$ \\
\hline $\begin{array}{l}\text { Regression } \\
\text { Error } \\
\text { Total }\end{array}$ & $\begin{array}{r}77.19 \\
80.06 \\
157.24\end{array}$ & $\begin{array}{r}5 \\
39 \\
44\end{array}$ & $\begin{array}{r}15.44 \\
2.05\end{array}$ & 7.52 & $<0.0001$ \\
\hline Variable & $\begin{array}{l}\text { Parameter } \\
\text { Estimate }\end{array}$ & $\begin{array}{l}\text { Model } \\
\text { Standard } \\
\text { Error }\end{array}$ & SS & $F$ & $\mathrm{p}$ \\
\hline $\begin{array}{l}\text { Intercept } \\
\text { AGE } \\
\text { SIB10 } \\
\text { P } \\
\text { E } \\
\text { L }\end{array}$ & $\begin{array}{r}21.95 \\
-0.72 \\
-0.53 \\
0.22 \\
-0.17 \\
-0.42\end{array}$ & $\begin{array}{l}4.99 \\
0.23 \\
0.24 \\
0.11 \\
0.08 \\
0.09\end{array}$ & $\begin{array}{r}39.80 \\
20.57 \\
10.36 \\
8.95 \\
8.68 \\
40.96\end{array}$ & $\begin{array}{r}19.39 \\
10.02 \\
5.05 \\
4.36 \\
4.23 \\
19.95\end{array}$ & $\begin{array}{l}<0.0001 \\
<0.01 \\
<0.05 \\
<0.05 \\
<0.05 \\
<0.0001\end{array}$ \\
\hline
\end{tabular}


Table 3.4(6) shows that the variables age, number of siblings after the age of ten (SIB10), psychoticism (P), extroversion (E), and lie score $(\mathrm{L})$ were placed in the model to explain THEFT. None of the other variables reached the required $\mathrm{p}<0.05$ level of significance for inclusion in the model. It is interesting to note that $\mathrm{L}$ is included which has been the case for all the models described thus far, but also that

$\mathrm{P}$ was included which was also the case for the model for THEFT in the whole sample group and for the SRD model in the male offender group. SIB10 also seems to be a factor in the delinquency of the male offender group since it occurred both in the THEFT model and the SRD model for this group.

\section{Male and Female control groups Combined}

Table 3.4(7) - Results of the stepwise multiple regression analysis for the dependent variable SRD for the male and female control groups combined

\begin{tabular}{|c|c|c|c|c|c|}
\hline $\begin{array}{l}\text { Source of } \\
\text { Variance }\end{array}$ & SS & $d f$ & MS & $F$ & $p$ \\
\hline $\begin{array}{l}\text { Regression } \\
\text { Error } \\
\text { Total }\end{array}$ & $\begin{array}{r}932.57 \\
1840.05 \\
2772.62\end{array}$ & $\begin{array}{r}2 \\
95 \\
97\end{array}$ & $\begin{array}{r}446.29 \\
19.37\end{array}$ & 24.07 & $<0.0001$ \\
\hline Variable & $\begin{array}{l}\text { Parameter } \\
\text { Estimate }\end{array}$ & $\begin{array}{l}\text { Model } \\
\text { Standard } \\
\text { Error }\end{array}$ & SS & $F$ & $p$ \\
\hline $\begin{array}{l}\text { Intercept } \\
\text { P } \\
\text { L }\end{array}$ & $\begin{array}{r}12.05 \\
0.89 \\
-1.07\end{array}$ & $\begin{array}{l}1.06 \\
0.22 \\
0.21\end{array}$ & $\begin{array}{r}2484.40 \\
312.35 \\
500.97\end{array}$ & $\begin{array}{r}128.27 \\
16.13 \\
25.86\end{array}$ & $\begin{array}{l}<0.0001 \\
<0.0001 \\
<0.0001\end{array}$ \\
\hline
\end{tabular}

Table 3.4(7) shows that only psychoticism (P) and the lie score $(\mathrm{L})$ reached the necessary level of significance to be included in the model. It is interesting to note that $\mathrm{L}$ is still present in the model, with $\mathrm{P}$ which has been included in all but one of the models described thus far. 
Table 3.4(8) - Results of the stepwise multiple regression analysis for the dependent variable PER for the male and female control groups combined

\begin{tabular}{|c|c|c|c|c|c|}
\hline $\begin{array}{l}\text { Source of } \\
\text { Variance }\end{array}$ & SS & $d f$ & MS & $F$ & $\mathrm{p}$ \\
\hline $\begin{array}{l}\text { Regression } \\
\text { Error } \\
\text { Total }\end{array}$ & $\begin{array}{r}12.59 \\
87.46 \\
100.05\end{array}$ & $\begin{array}{r}1 \\
96 \\
97\end{array}$ & $\begin{array}{r}12.59 \\
0.91\end{array}$ & 13.82 & $<0.0005$ \\
\hline Variable & $\begin{array}{l}\text { Parameter } \\
\text { Estimate }\end{array}$ & $\begin{array}{l}\text { Model } \\
\text { Standard } \\
\text { Error }\end{array}$ & SS & $F$ & $\mathrm{p}$ \\
\hline $\begin{array}{l}\text { Intercept } \\
\text { L }\end{array}$ & $\begin{array}{r}1.70 \\
-0.17\end{array}$ & $\begin{array}{l}0.17 \\
0.05\end{array}$ & $\begin{array}{l}90.13 \\
12.59\end{array}$ & $\begin{array}{l}98.92 \\
13.82\end{array}$ & $\begin{array}{l}<0.0001 \\
<0.0005\end{array}$ \\
\hline
\end{tabular}

Table 3.4(8) shows that only the lie score (L) reached the required level of significance $(\mathrm{p}<0.05)$ for inclusion into the model for describing crimes against the person. This was also found in the male offender group and $\mathrm{L}$ was included in all previous models.

Table 3.4(9) - Results of the stepwise multiple regression analysis for the dependent variable THEFT for the male and female control groups combined

\begin{tabular}{|c|c|c|c|c|c|}
\hline $\begin{array}{l}\text { Source of } \\
\text { Variance }\end{array}$ & SS & $d f$ & MS & $F$ & $\mathrm{p}$ \\
\hline $\begin{array}{l}\text { Regression } \\
\text { Error } \\
\text { Total }\end{array}$ & $\begin{array}{r}76.02 \\
135.08 \\
211.10\end{array}$ & $\begin{array}{r}5 \\
92 \\
97 \\
\end{array}$ & $\begin{array}{r}15.20 \\
1.47\end{array}$ & 10.35 & $<0.0001$ \\
\hline Variable & $\begin{array}{l}\text { Parameter } \\
\text { Estimate }\end{array}$ & $\begin{array}{l}\text { Model } \\
\text { Standard } \\
\text { Error }\end{array}$ & SS & $\mathbf{F}$ & $\mathrm{p}$ \\
\hline $\begin{array}{l}\text { Intercept } \\
\text { AGE } \\
\text { ETHN } \\
\text { CLASS } \\
\text { P } \\
\text { L }\end{array}$ & $\begin{array}{r}-7.24 \\
0.36 \\
0.42 \\
0.29 \\
0.17 \\
-0.23\end{array}$ & $\begin{array}{l}2.50 \\
0.12 \\
0.17 \\
0.14 \\
0.06 \\
0.06\end{array}$ & $\begin{array}{r}12.31 \\
12.44 \\
9.35 \\
6.22 \\
10.92 \\
22.80\end{array}$ & $\begin{array}{r}8.39 \\
8.47 \\
6.37 \\
4.24 \\
7.44 \\
15.53\end{array}$ & $\begin{array}{l}<0.005 \\
<0.005 \\
<0.05 \\
<0.05 \\
<0.01 \\
<0.0005\end{array}$ \\
\hline
\end{tabular}

Table 3.4(9) shows that age, ethnic group (ETHN), social class (CLASS), psychoticism (P), and the lie score (L) were the only variables to reach the $\mathrm{p}<0.05$ level; of significance required for inclusion in the model describing theft. Again P and L were 
included and it is interesting to note that more variables describe theft than general delinquency or crimes against the person.

\section{Female Control Group}

Table 3.4(10) - Results of the stepwise multiple regression analysis for the dependent variable SRD for the female control group

\begin{tabular}{|c|c|c|c|c|c|}
\hline $\begin{array}{l}\text { Source of } \\
\text { Variance }\end{array}$ & SS & $d f$ & MS & $F$ & $\mathrm{p}$ \\
\hline $\begin{array}{l}\text { Regression } \\
\text { Error } \\
\text { Total }\end{array}$ & $\begin{array}{r}947.45 \\
792.62 \\
1740.07\end{array}$ & $\begin{array}{r}4 \\
65 \\
69\end{array}$ & $\begin{array}{r}236.86 \\
12.19\end{array}$ & 19.42 & $<0.0001$ \\
\hline Variable & $\begin{array}{l}\text { Parameter } \\
\text { Estimate }\end{array}$ & $\begin{array}{l}\text { Model } \\
\text { Standard } \\
\text { Error }\end{array}$ & SS & F & $\mathrm{p}$ \\
\hline $\begin{array}{l}\text { Intercept } \\
\text { SIB } \\
\text { SIB10 } \\
\text { P } \\
\text { L }\end{array}$ & $\begin{array}{r}11.27 \\
2.71 \\
-3.35 \\
0.84 \\
-1.02\end{array}$ & $\begin{array}{l}1.17 \\
0.74 \\
0.70 \\
0.19 \\
0.21\end{array}$ & $\begin{array}{r}1136.50 \\
164.52 \\
277.48 \\
228.33 \\
303.90\end{array}$ & $\begin{array}{l}93.20 \\
13.49 \\
22.75 \\
18.72 \\
24.92\end{array}$ & $\begin{array}{l}<0.0001 \\
<0.001 \\
<0.0001 \\
<0.0001 \\
<0.0001\end{array}$ \\
\hline
\end{tabular}

Table 3.4(10) shows that the variables which reached significance for the model to describe self-reported delinquency (SRD) were: number of siblings before (SIB) and after the age of ten (SIB10), psychoticism (P) and the lie score (L). This follows from the models which describe SRD for the other sample groups all of which included P and L. L was also included in all the previously described models for SRD, PER and THEFT. 
Table 3.4(11) - Results of the stepwise multiple regression analysis for the dependent variable PER for the female control group

\begin{tabular}{|c|c|c|c|c|c|}
\hline $\begin{array}{l}\text { Source of } \\
\text { Variance }\end{array}$ & SS & $d f$ & MS & $F$ & $\mathrm{p}$ \\
\hline $\begin{array}{l}\text { Regression } \\
\text { Error } \\
\text { Total }\end{array}$ & $\begin{array}{l}15.23 \\
51.64 \\
66.87\end{array}$ & $\begin{array}{r}2 \\
67 \\
69\end{array}$ & $\begin{array}{l}7.62 \\
0.77\end{array}$ & 9.88 & $<0.001$ \\
\hline Variable & $\begin{array}{l}\text { Parameter } \\
\text { Estimate }\end{array}$ & $\begin{array}{l}\text { Model } \\
\text { Standard } \\
\text { Error }\end{array}$ & SS & F & $\mathrm{p}$ \\
\hline $\begin{array}{l}\text { Intercept } \\
\mathrm{N} \\
\mathrm{I}\end{array}$ & $\begin{array}{r}1.02 \\
0.09 \\
-0.17\end{array}$ & $\begin{array}{l}0.31 \\
0.04 \\
0.05\end{array}$ & $\begin{array}{l}8.15 \\
4.90 \\
9.20\end{array}$ & $\begin{array}{r}10.58 \\
6.36 \\
11.94\end{array}$ & $\begin{array}{l}<0.01 \\
<0.025 \\
<0.005\end{array}$ \\
\hline
\end{tabular}

Table 3.4(11) shows that only neuroticism $(\mathrm{N})$, and the lie score (L) reached the necessary level of significance to be included in the model to describe crimes against the person (PER). Only $\mathrm{L}$ has been shown to be included in previously described models, $\mathrm{N}$ has been included only in this model and has not been one of the factors in describing any of the offending variables from other sample groups. 
Table 3.4(12) - Results of the stepwise multiple regression analysis for the dependent variable THEFT for the female control group

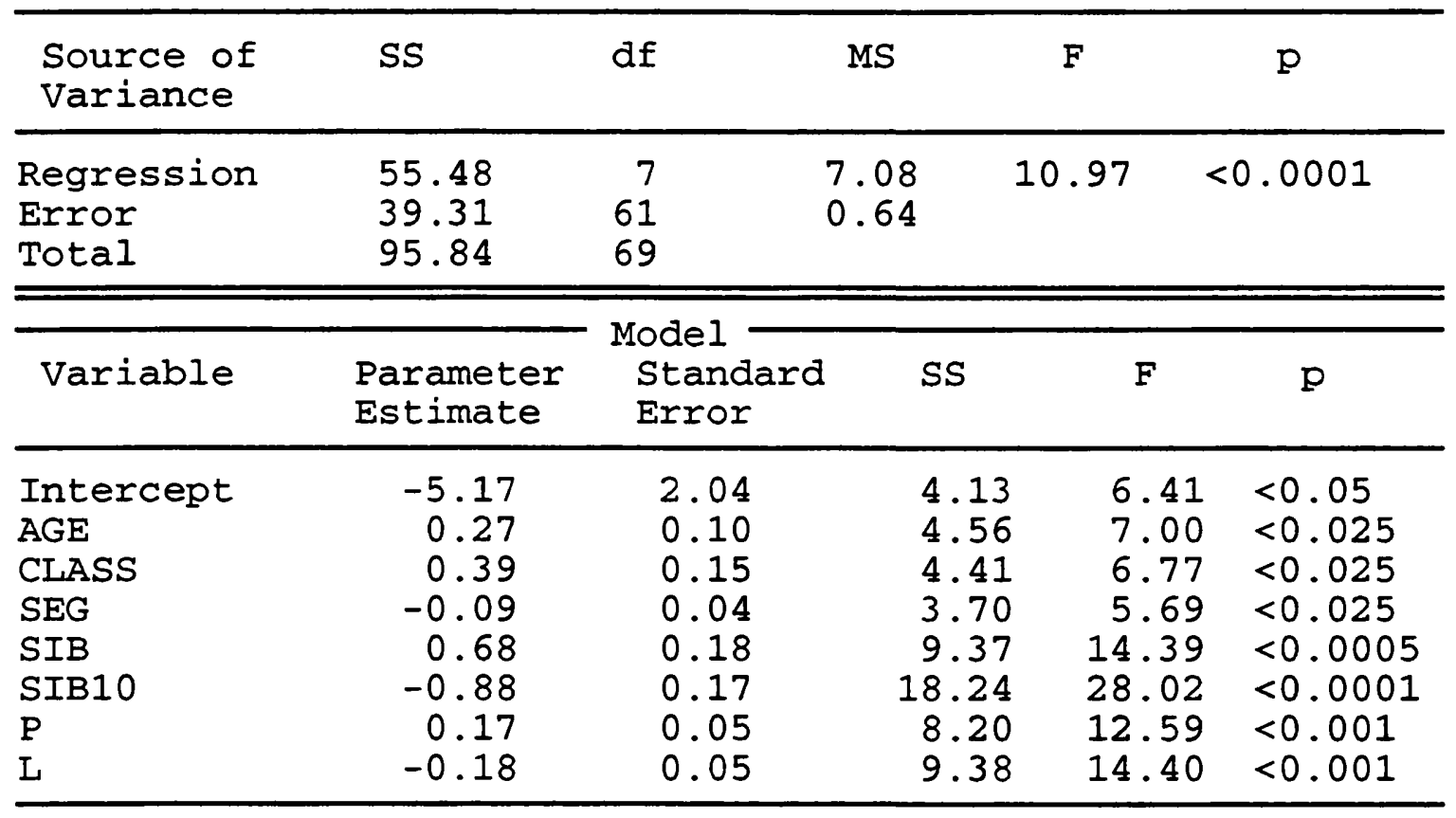

Table 3.4(12) shows that the variables age, social class (CLASS), socio-economic group (SEG), number of siblings before (SIB) and after (SIB10) the age of ten, psychoticism (P) and the lie score (L) achieved the required level of significance for inclusion into the model which described THEFT in the female control group. It is interesting to note that more of the variables were included in this model than in either of the other two models for the female control group, and that $\mathrm{L}$ was also included. 
Male Control Sample Group

Table 3.4(13) - Results of the stepwise multiple regression analysis for the dependent variable SRD for the male control group

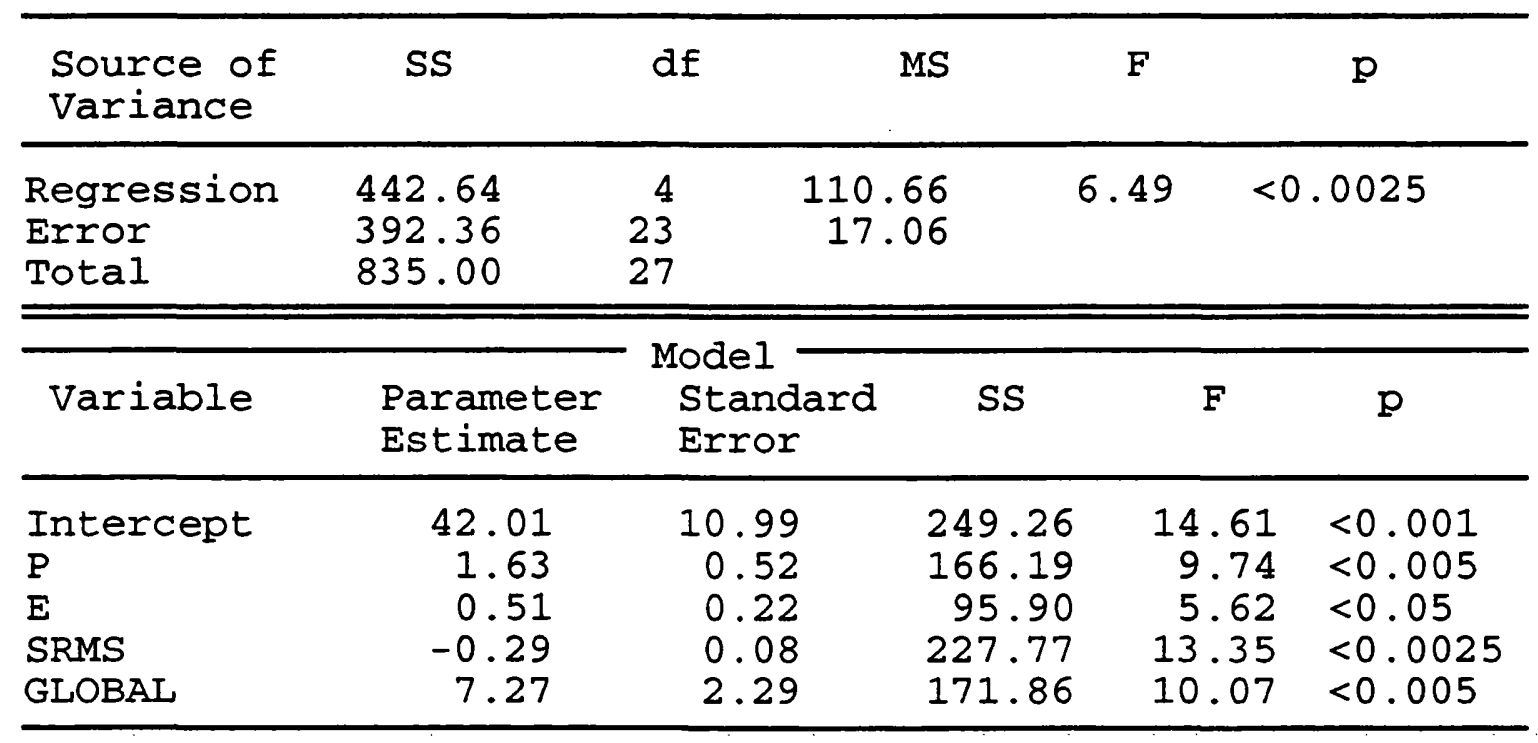

Table 3.4(13) shows that psychoticism (P), extroversion $(\mathrm{E})$, sociomoral reflection maturity score (SRMS), global stage of sociomoral reflection (GLOBAL) reached the necessary level of significance for inclusion into the model to describe SRD for the male control sample group. It is interesting to note that this is the first model which does not include $\mathrm{L}$, but it does include $\mathrm{P}$ and $\mathrm{E}$ which are recurring variables in previous models for SRD. 
Table 3.4(14) - Results of the stepwise multiple regression analysis for the dependent variable PER for the male control group

\begin{tabular}{|c|c|c|c|c|c|c|}
\hline $\begin{array}{l}\text { Source of } \\
\text { Variance }\end{array}$ & SS & $d f$ & \multicolumn{2}{|c|}{ MS } & $F$ & $\mathrm{p}$ \\
\hline $\begin{array}{l}\text { Regression } \\
\text { Error } \\
\text { Total }\end{array}$ & $\begin{array}{r}8.99 \\
20.01 \\
29.00\end{array}$ & $\begin{array}{r}2 \\
25 \\
27\end{array}$ & \multicolumn{2}{|c|}{$\begin{array}{l}4.49 \\
0.80\end{array}$} & 5.61 & $<0.01$ \\
\hline Variable & $\begin{array}{l}\text { Parameter } \\
\text { Estimate }\end{array}$ & \multicolumn{2}{|c|}{$\begin{array}{l}\text { Model } \\
\text { Standard } \\
\text { Error }\end{array}$} & SS & $F$ & $p$ \\
\hline $\begin{array}{l}\text { Intercept } \\
\text { EDU } \\
\text { SEG }\end{array}$ & $\begin{array}{r}8.27 \\
-0.43 \\
-0.16\end{array}$ & & & $\begin{array}{r}10.80 \\
6.28 \\
5.92\end{array}$ & $\begin{array}{r}13.49 \\
7.84 \\
7.39\end{array}$ & $\begin{array}{l}<0.0025 \\
<0.01 \\
<0.025\end{array}$ \\
\hline
\end{tabular}

Table 3.4(14) shows that only years in education (EDU) and socio-economic group (SEG) reached the $\mathrm{p}<0.05$ level of significance required for inclusion into the model. Again, $\mathrm{L}$ was not included and neither were the personality or moral reasoning variables. No variables reached the required level of significance for inclusion into the model for describing THEFT for the male control group. 


\section{Summary/Discussion}

In summary, it can be concluded that self-reported delinquency can be accounted for by a variety of different variables. Within the whole sample group, all of the models for SRD, PER and THEFT included both personality and moral reasoning variables. This suggests that the theories of Eysenck and Kohlberg are related and can account for offending within the same individuals. Another interesting result concerns the finding that P was included in the model for theft but not violent offending, while $E$ was included in the model for violent offending but not theft: an apparent contradiction to the predictions of Eysenck's theory, which suggests that both high P and E scorers would be related to higher offending behaviour. All the models found in the whole sample group, included number of years spent in education, and the models for SRD and violent offending (PER) both included Age. The model for theft in the whole sample group also included ethnic origin.

The models for the sub-groups generally included fewer variables than those found for the whole sample group. It is of interest that in the male offender, combined control and the female control groups no moral reasoning variables were included in the models for any of the offending history variables. In these three groups, $\mathrm{P}$ was included in the models for SRD and THEFT, but not in the models for PER. Extraversion (E) was only included in the model for theft in the convicted offender group. In the male control group, $\mathrm{P}$ and moral reasoning variables were included in the model for SRD, and no personality or moral reasoning variables were included in the model for PER.

It is also of note that $\mathrm{N}$ was only included in the model for PER in the female control group; and that $\mathrm{L}$ was included in all the models calculated, except for those found in the male control group.

The main discussion in chapter 5 features these points in greater detail. 


\section{5 - QUALITATIVE DESCRIPTIONS OF THE}

MORAL REASONING RESULTS

\section{Introduction}

In chapters 3.1 to 3.4 several of the results pointed to the notion that moral reasoning development is somehow delayed in convicted offenders and that moral reasoning maturity is associated with a lower rate of self-reported offending. While these findings support Kohlberg's theory of moral development it is difficult to relate, simply by numbers, stage and moral reasoning maturity scores to an individual's actual moral reasoning.

The purpose of this chapter is to illustrate the findings of the previous results chapters with examples drawn from the participants' responses to the Sociomoral reflection measure (SRM). Further, to identify some of those responses which did not fit into the classification system of the SRM (i.e., those responses which were found to be unscorable).

While this section may seem subjective, it is important to illustrate and note irregularities in the responses to the SRM in order to recapture some of the information lost in the process of assigning moral reasoning stage levels to each individual.

\section{Ilustration of Quantitative findings}

As was shown in table $3.1(5)$, in the whole sample group, the majority $(56.80 \%)$ of individuals were reasoning at modal stage 3. According to Gibbs and Widaman (1981) this stage is characterised by thinking which encompasses 'prosocial feelings, caring, and conduct' (p.29) as important aspects in making moral decisions. This stage was also that vhich most individuals in the offender group (48.44\%) and the combined control group (51.90\%) were reasoning. An example of a response which is considered to be at stage 3 
is seen in the responses of participant number 71 , who was in the convicted offender group. In response to the question: 'Why is it very important for a husband to do what his wife asks, even when he isn't sure whether that's the best thing to do?' this individual wrote 'because they married each other to have feelings and things like that'. This was scored at stage 3 because of its emphasis on marriage as a relationship which requires mutual feelings between partners. Participant 122, from the combined control group, in response to the question 'Why is it very important to keep a promise, if you can, to a friend?' wrote: 'Important in keeping friends - you would expect them to do the same for you. You should want to try to keep your promise to a friend'. Again, this was scored at stage 3 because of its emphasis on friendship and mutual help within a relationship.

According to moral reasoning development theory, in terms of it's relation to offending behaviour, stage 3 reasoning which would result in decisions to offend would generally revolve around issues of wether the offence would maintain or enhance personal relationships, or involve caring for others. However, moral reasoning which results in decisions not to offend would also revolve around these issues.

Thus far, the results seem to suggest that both offenders and controls were found to reason morally at stage 3. However, means calculated and analyses of variance results for sociomoral reflection maturity score (SRMS) suggest that offenders were significantly less mature in moral reasoning than the controls. This is accounted for in the distribution of moral reasoning stages in the remaining participants in both the offender and the combined control group.

In the convicted offender group, the next largest proportion of individuals after those reasoning at stage 3 were reasoning at modal stage $2(31.25 \%)$. Thus the convicted offenders were mainly in modal stages 2 and 3. This stage is characterised by a simplistic understanding of social rules not as external decrees, but as arising from exchanges with others. However, relationships are seen merely as quasi-economic exchanges (i.e., helping 
a friend is important if 'they've helped you, or may help you later'). This simple exchange principle, is exemplified in a response by participant 67 , from the convicted offender group, who, when asked to explain 'Why is it very important for children to do everything they can to help their parents?' wrote 'it is very important to help as much as you can a parent because they would help you'. This exchange principle also extends to ideas of 'paying someone back' for some injustice done to the individual. This type of reasoning was exemplified by a response from participant number 31 . This convicted offender wrote that it was unimportant not to take things that belonged to other people because 'they would do the same to you'.

Stage 2 reasoning which would result in decisions to offend would involve these exchange principles, whereby offending would be justified if, for instance, this 'paid back' an individual for unjust behaviour carried out towards the offender, or if the offence was carried out as a favour to a friend.

In the combined control group, the second most frequent moral reasoning stage was found to be stage $4(21.90 \%)$. Thus the combined controls were mainly in modal stages 3 and 4. Stage 4 is characterised by thinking which applies the relationship principles, central to stage 3 reasoning, to encompass larger systems in society, and full understanding of the nature of rules as flexible. This type of reasoning was exemplified by the response from participant number 127 , who was in the combined control group. This individual responded that it was important to obey the law because 'obeying the law usually ensures some kind of stability in society (e.g. you feel safer knowing people will get punished for robbing you). But laws do not always benefit everyone and you shouldn't feel you have to obey if you are suffering injustice (but you'll suffer for it).'

Using stage 4 of moral reasoning, decisions to offend would only be reached if, for example, the offence facilitates the workings of societal systems or if universal human rights are violated by societal systems. 
While the results of the moral reasoning aspect of the present study suggest that convicted individuals reason morally less maturely than non-convicted individuals, some other differences in moral reasoning seemed apparent. In the SRM, two sections deal specifically with the topics of 'Law and Property' and with 'Legal Justice'. It seems that some of the convicted individuals' responses to the questions in these sections were not scorable, and that they seemed to reason in different ways to those covered by the SRM scoring manual.

\section{Irregularities in Responses}

Some of the responses to questions relating to 'Law and Property' and 'Legal Justice' given by the convicted offenders, were deemed irregular because while they were unscorable, they dealt with reasoning not adequately encapsulated by the scoring manual of the SRM. These irregular responses were categorised into two groups.

The first, which was termed 'bitterness', encompassed responses which showed the convicted offenders' bitterness towards the perceived unfairness of the legal system. An example of such a response was found in participant number 15's responses: this individual wrote that it was not important for people to obey the law 'because when you try to obey the law, they always stick you up with something'. In response to the question: Why is it not important for people not to take things that belong to other people? participant number 1 responded: 'I find this a hard question as I am here [a young offenders' institution] for $21 / 2$ years for stealing, it doesn't seem terrible to me but some people think that it is. At least it doesn't cause physical pain'. This sentiment of unfairness is repeated in participant number 8's response to the same question: 'Because if you don't take you will never get what you want'. Unfairness and bitterness is echoed in participant number 63's response that it is important for judges to send people who break the law to jail 'because all judges are not fair they are all basters [sic]'. Similar responses 
were provided by participant numbers 73 and 31. Participant 31 further showed his disillusionment with the legal system by responding that it is not important to obey the law because 'I think that the law sucks'.

The second category of irregular responses to 'law and property' and 'legal justice' questions, included answers which reflected sentiments similar to 'bitterness'. This category was labelled 'rebellion' and included fewer responses than the 'bitterness' category. These responses reflected the respondents' bitterness towards legal processes in society but also provided a 'solution' to living with these processes. For example, participant number 81 suggested that it is very important for people to obey the law 'because if they ever want anything out of life they should decide wheather [sic] they are on one side of the law or the other'; and participant number 12 suggested that it is not important for people to obey the law because 'the lawes [sic] are made to be broock [sic]'.

\section{Summary/Discussion}

In general, the responses to the sociomoral reflection measure (SRM) seem to suggest that predictions from Kohlberg's theory were upheld in the present study; in other words suggesting that those who reason at lower stages of moral reasoning will more frequently engage in offending behaviour. However, there were many individuals in the control group who reasoned at the same modal moral reasoning stage (stage 3) as the convicted individuals. This suggests that moral reasoning stage is not the only predictor of offending since the non-convicted individuals reasoned morally in a similar way to the convicted individuals but had not been convicted themselves.

Furthermore, certain responses by the convicted offenders showed a degree of bitterness and rebellion towards the law and legal systems in society, possibly echoing anomie ideas proposed by Merton (1967). While these sentiments are no doubt related to 
incarceration to a certain extent, a question arises as to the effects of such bitterness on decisions to offend. It seems possible to suppose that because of bitterness towards society and the law, moral reasoning does not operate in the same way when dealing with issues which deal with offending behaviour.

The main discussion in Chapter 5 deals with these points in greater detail. 


\section{CHAPTER 4}

\section{1 - PERSONALITY AND MORAL REASONING IN SEVERELY DISTURBED AND DISRUPTIVE CHILDREN}

\section{Introduction}

The Youth Treatment Service (YTS) manages two specialised child care facilities for the Department of Health. These are known as Youth Treatment Centres: one, St. Charles Centre, is located in Essex and the other, Glenthorne Centre, is located near Birmingham. These two Centres provide 60 secure and 10 non-secure residential places for seriously disturbed and disruptive children.

The Centres were created to provide specialised treatment and care provisions for a relatively small group of children, for which it was felt, none of the other residential provisions were adequate. St. Charles was opened in 1971, and Glenthorne was opened in 1978.

The Youth Treatment Centres were not intended to serve a homogeneous group of children with one type of problem, but were intended to provide care for various problem children from all parts of the child care world. As a result the criteria for admission into either of the centres is deliberately not clear cut. The purpose of the Centres is to 'Help extremely disturbed boys and girls aged 13-18 whose special needs cannot be met elsewhere. Complex factors are likely to have impaired their social and emotional personal development and control. They may be a danger to themselves, others or both' (Dept. Health, 1991, p.1).

Children who are admitted to one of the Centres are either under restricting orders subject to care by a local authority or be subject to detention by the Home office following conviction under section 53 of the Children and Young Persons Act 1933. Local authority 
children must need to be looked after in secure accommodation and need long-term specialised help over and above that available elsewhere in the child care system.

Under Section 53(I) of the Children and Young Persons Act 1933, a person convicted of murder who was aged less than 18 years at the time of the offence will be detained 'during Her Majesty's pleasure', which is similar to a life sentence except that the offender may be detained 'in such a place and under such conditions that the Secretary of State may direct'. Under Section 53(2) of the same act individuals who are under 17 years and convicted offences other than murder for which an sentence of life imprisonment may be passed on an adult, may be sentenced to life. Such a sentence has virtually the same effect as being detained During Her Majesty's Pleasure.

To be admitted to one of the Youth Treatment Centres (YTCs) children detained under section 53 must also require treatment which the YTCs can provide but which cannot be provided elsewhere; be seen at risk of potentially suffering significant harm if placed in the penal system (i.e., prison); and placement in a Community Home with Education is not judged as appropriate.

Regardless of which Government body is responsible for the child, all children should display one or more of the following problems: serious delinquency, violent or very aggressive propensities, actual or potential danger to self/others or both, extremely disruptive in other settings, suicidal tendencies, self harm (e.g., mutilation), habitual absconding, and repeated failure to respond in other secure settings. In any case, children which have been diagnosed as mentally ill cannot be considered for admission into one of the Centres.

Barlow (1979) argues that probably the single most influential factor deciding an admission is the existence of an element of danger either to others or the child.

The ultimate goal of the Centres is to provide a treatment programme which will help the children return successfully to the community. 
Glenthorne Youth Treatment Centre is situated in Erdington near Birmingham and has facilities for 30 secure and 10 open places available in four residential units. Direct care is provided by qualified staff known as 'groupworkers' who are drawn from the professional areas of teaching, nursing, and social work. In 1990 to 1991, the annual level of occupancy was 52 residents, of whom 65 per cent were detained under section 53, with an average age at admission of 16 .

As described in detail by Reid (1982) a decision was made at Glenthorne to operate on an approach based on social learning theory. The management of the residents is achieved by the use of cognitive-behavioural methods, originally using a token economy but now using a "levels system" (Ostapiuk and Westwood, 1986).

While not all of the population at Glenthorne have been convicted of criminal offences, many of the other children may have committed serious acts, such as violence towards staff, that would be legally punishable. Reid (1982) described the major problem behaviours encountered at Glenthorne which the treatment regime has to deal with. These are shown in Table 8, and it can be noted that the majority of these behaviours fall within the confines of offences enforceable by the law, some of which are very serious. 
Figure 4.1(1) - Major Problems encountered in Glenthorne residents

1. Major Offense behaviours Murder

Manslaughter

Armed Robbery

Sexual Assaults

Arson

2. Minor offence behaviours Theft

Take and drive away

Burglary

Prostitution

3. 'Clinical' problems Obsessional rituals e.g. washing, dressing, thoughts

Enuresis

Faecal smearing

Anxiety

4. Behavioural deficits

Limited intellectual

ability

Lack of educational attainment

Lack of social skills

(verbal and non-verbal)

Lack of survival skills

(e.g. self-help, budgeting etc.)
5. Behavioural excesses

Physical violence (persons

and property)

Self-mutilations (head

banging, wrist slashing, overdoses)

Verbal violence

6. Institutional problem behaviours

Hostages

Sit in/barricades

Sexual behaviour

Violence

Attempted escapes

7. Problems of generalisation

Self-help skills

Job skills - interview

behaviour, work skills etc.

Family conflicts

Deviant peer-group

influences

Abscondings

From Reid (1982)

It is apparent, therefore that the residents of Glenthorne consist of a highly

specialised type of offender, some of whom have been convicted for their antisocial behaviours.

While a great deal of emphasis has been placed on the treatment implemented and the efficacy of this treatment (Barlow, 1979; Ostapiuk and Westwood, 1986; Reid, 1982), little attention has been given to classification of individual differences in these children as has been the case in the general offending population. In particular theories of offending, such as proposed by H. J. Eysenck and Kohlberg (see Chapter 1), have not been directly tested with these individuals. 
Because most of the residents of Glenthorne have committed offences which could be enforceable by law, it seems reasonable to predict that they would score highly on the personality dimensions of psychoticism $(\mathrm{P})$, extraversion $(\mathrm{E})$, and neuroticism $(\mathrm{N})$.

Similarly, the residents of Glenthorne would also be expected to reason at immature moral judgement levels, since, in addition to high offending levels, many of the children are characterised by a lack of intellectual, social, and survival skills all related to the acquisition of high levels of moral reasoning.

This study was conducted to investigate the applicability of Eysenck's personality and Kohlberg's moral reasoning theories of offending to the extremely disturbed and disruptive individuals resident at Glenthorne Youth Treatment Centre. The scores of these individuals' on Eysenck's Personality Questionnaire and the Sociomoral Reflection Measure (a measure of moral reasoning; Gibbs and Widaman, 1982) were compared to those of non-convicted individuals and convicted individuals held in a secure young offender institution.

\section{Method}

\section{$\underline{\text { Study Population }}$}

In total 223 young people took part. These were divided into three main groups. Two groups (described below) were the same as those used in the main study described in chapters 2 and 3.

101 were male young offenders, all convicted and serving sentences of less than 4 years at a young offenders institution. These individuals were volunteers drawn from the allocation unit of a large young offenders institution. Their ages ranged from 16.5 to 21.58 years with a mean of 19.14 years, and standard deviation of 1.12 . 
75 undergraduate psychology students who received course credits for taking part, and 33 volunteer school students of psychology and sociology were used as the comparison group. Of these 33 were male and 75 were female. Their age ranged from 16 to 21.83 years with a mean age of 19.56 , standard deviation of 1.07 .

The third group comprised of 14 individuals residing in secure units at Glenthorne Youth Treatment Centre. Of these, 10 were admitted under Section 53 of the Children and Young Person's act 1933, therefore could be considered serious young offenders. The remaining four participants were under local authority care but were all considered to be highly antisocial. 11 were male and 3 were female and their age ranged from 15.5 to 20.08 years with a mean of $17.02(\mathrm{sd}=1.34)$. 11 were of British ethnic origin, and 3 were of other ethnic origins.

\section{Design and Materials}

In all participants completed four standard self-administered psychological tests, and an additional background information questionnaire. Each individual was presented with these materials in a randomised order to control for order and fatigue effects.

a) Short Scale of the Eysenck Personality Questionnaire - Revised (H. J. Eysenck, S. B. G. Eysenck, and Barrett, 1985). This test is described at length in Chapter 2.

b) Sociomoral Reflection Measure (SRM, Gibbs and Widaman, 1982). This is a pencil and paper production-task measure of reflective moral thought and was described in detail in Chapter 2.

c) Self-Reported Delinquency measure (SRD, Elliott and Ageton, 1980; Elliott et al., 1983; Huizinga and Elliott, 1981). This measure was also described in detail in chapter 2. 
d) Raven's Standard Progressive Matrices (SPM, Raven, Court and Raven, 1985). This is a non-verbal, figure completion, test of intellectual capacity which was described in Chapter 2.

e) A final questionnaire elicited general information from the participants. This pertained to age, sex, ethnic origin, their age at leaving school, father's and mother's occupations, and the people with whom they lived up to and after the age of ten. This is included in appendix $\mathrm{A}$ and was detailed in Chapter 2.

\section{Procedure}

The participants were presented with all the above tests in a randomised order and asked to complete the questions as honestly as possible. There was no time limit given for completion but it was emphasised that individual's should not deliberate over any one question. All respondents were informed that no 'correct' answers existed and were reassured that all responses would be treated with strict anonymity, and that they shouldn't state their names anywhere on the questionnaires. The Glenthorne sample group was presented with the materials orally by the experimenter, to take into account the low literacy level of this sample.

\section{$\underline{\text { Analysis }}$}

The results were subjected to an exploratory analysis. Initially, frequency and percentage counts, means, standard deviations and Pearson's $\mathrm{r}$ correlation coefficients were calculated for all the combinations of the variables, in each of the three sample groups. From this initial analysis further analysis was carried out based on the results from the correlations and means obtained. The analysis which followed were analysis of variance. 
One-way analyses of variance were performed to investigate the significance of differences between the means on each of the variables collected for the three sample groups. These comparisons were conducted for the demographic variables, the personality variables, intelligence, moral reasoning variables, and offending history variables. In addition, the variables of age and education were used as co-variates in subsequent analysis of co-variance, in order to control for the potentially mitigating effects of these variables.

\section{Results}

\section{Frequencies and Percentages}

Frequency counts and percentages were calculated for all the categorical data collected from the Glenthorne sample group. Similar results for the whole sample group, the male offender group and the male and female group combined were shown in the previous result section. The variables used were ethnic origin (ETHN), social class (CLASS), socio-economic group (SEG), intelligence grade (intelligence score converted into one of five categories), modal and global stage of moral reasoning.

\section{Demographic Variables}

The number and percentages of individuals in the Glenthorne sample in each of the categories of the demographic variables of social class and socio-economic group are shown in the tables below. 
Table 4.1(1) - Frequencies and percentages for social class categories of the

Glenthorne sample group

\begin{tabular}{|c|c|c|}
\hline \multirow{2}{*}{$\begin{array}{l}\text { SOCIAI } \\
\text { CLASS }\end{array}$} & \multicolumn{2}{|c|}{$\begin{array}{l}\text { GLENTHORNE SAMPLE GROUP } \\
\qquad(\mathrm{N}=07)\end{array}$} \\
\hline & FREQ & 8 \\
\hline $\begin{array}{l}1 \\
2 \\
3 \\
4 \\
5\end{array}$ & $\begin{array}{l}00 \\
01 \\
05 \\
01 \\
00\end{array}$ & $\begin{array}{l}00.00 \\
14.29 \\
71.43 \\
14.29 \\
00.00\end{array}$ \\
\hline
\end{tabular}

Table 4.1(1) shows that while only 7 of the subjects could be classified according to social class, the majority of individuals in the Glenthome sample group came from social class 3 .

Table 4.1(2) - Frequencies and percentages for socio-economic group (SEG) categories of the Glenthorne sample group

\begin{tabular}{ccc}
\hline $\begin{array}{c}\text { SOCIO-ECONOMIC } \\
\text { GROUP }\end{array}$ & $\begin{array}{c}\text { GLENTHORNE } \\
\text { SAMPLE GROUP } \\
(\mathrm{N}=08) \\
8\end{array}$ \\
\hline $\mathbf{1}$ & FREQ & 00.00 \\
$\mathbf{2}$ & 00 & 00 \\
$\mathbf{3}$ & 01 & 12.50 \\
$\mathbf{4}$ & 00 & 00.00 \\
$\mathbf{5}$ & 00 & 00.00 \\
$\mathbf{6}$ & 00 & 00.00 \\
$\mathbf{7}$ & 01 & 12.50 \\
$\mathbf{8}$ & 01 & 12.50 \\
$\mathbf{9}$ & 00 & 00.00 \\
$\mathbf{1 0}$ & 02 & 25.00 \\
$\mathbf{1 1}$ & 02 & 25.00 \\
$\mathbf{1 2}$ & 00 & 00.00 \\
$\mathbf{1 3}$ & 00 & 00.00 \\
$\mathbf{1 4}$ & 00 & 00.00 \\
$\mathbf{1 5}$ & 00 & 00.00 \\
$\mathbf{1 7}$ & 00 & 00.00 \\
& 00 & 00.00 \\
& 01 & 12.50 \\
\hline
\end{tabular}

The majority of individuals in the Glenthorne group which could be classified into SEG, were in groups 9 and 10. 


\section{Moral Reasoning}

The tables below show the proportion and percentage of individuals reasoning at each of the modal and global stages of moral reasoning in the Glenthorne sample group.

Table 4.1(3) - Frequencies and percentages for modal stages of moral reasoning for the Glenthorne sample group

\begin{tabular}{ccc}
\hline & \multicolumn{2}{c}{ GLENTHORNE SAMPLE GROUP } \\
MODAL & FREQ & \multicolumn{1}{c}{ (N=13) } \\
\hline $\mathbf{1}$ & 00 & 00.00 \\
$\mathbf{1 / 2}$ & 00 & 00.00 \\
$\mathbf{2}$ & 09 & 69.23 \\
$\mathbf{2} / 3$ & 01 & 07.69 \\
3 & 03 & 23.08 \\
$\mathbf{3} 4$ & 00 & 00.00 \\
$\mathbf{4}$ & 00 & 00.00 \\
\hline
\end{tabular}

The majority of individuals in the Glenthorne group showed stage 2 moral reasoning.

Table 4.1(4) - Frequencies and percentages for global stages of moral reasoning for the Glenthorne sample group

\begin{tabular}{|c|c|c|}
\hline \multirow{2}{*}{$\begin{array}{l}\text { GLOBAL } \\
\text { STAGE }\end{array}$} & \multicolumn{2}{|c|}{ GLENTHORNE SAMPLE GROUP } \\
\hline & FREQ & 8 \\
\hline $\begin{array}{c}1 \\
1(2) \\
2(1) \\
2 \\
2(3) \\
3(2) \\
3 \\
3(4) \\
4(3) \\
4\end{array}$ & $\begin{array}{l}00 \\
00 \\
01 \\
06 \\
02 \\
02 \\
02 \\
00 \\
00 \\
00\end{array}$ & $\begin{array}{l}00.00 \\
00.00 \\
07.69 \\
46.15 \\
15.38 \\
15.38 \\
15.38 \\
00.00 \\
00.00 \\
00.00\end{array}$ \\
\hline
\end{tabular}


It can be seen that the majority of Glenthorne sample individual's tend to reason at global stage 2 .

Intelligence

Table 4.1(5) shows the proportion and percentage of intelligence scores for the Glenthorne sample group. The grades of intelligence are described below, and were calculated according to instructions in the manual for Raven's progressive matrices (Raven, Court and Raven, 1985).

Table 4.1(5) - Frequencies and Percentages for Intelligence grades for the Glenthorne sample group

\begin{tabular}{ccc}
\hline & \multicolumn{2}{c}{ GLENTHORNE SAMPLE GROOP } \\
INTELIIGENCE & \multicolumn{2}{c}{$(\mathrm{N}=14)$} \\
GRADE & FREQ & $\%$ \\
\hline I & 00 & 00.00 \\
II & 00 & 00.00 \\
III & 06 & 42.86 \\
IV & 06 & 42.86 \\
V & 02 & 14.29 \\
\hline
\end{tabular}

The above table shows that the majority of individuals were of intelligence grades III and IV, while two were of grade V, indicating intellectual deficiency.

\section{Correlational Analyses}

The data collected from the 14 serious offenders and 'problem' children were subjected to Pearson's r type correlational analysis. The correlations are reported in terms of demographic variables, personality variables, intelligence and moral reasoning variables, and offending history variables. 
Demographic Variables

Looking firstly at demographic variables, table 4.1(6) gives results for all the correlation coefficients calculated.

Table 4.1(6) - Correlation Coefficients for Demographic Variables in the Glenthorne sample

\begin{tabular}{lccccccr}
\hline & AGE & EDU & ETEN & CLASS & SEG & SIB & SIB10 \\
\hline AGE & $/$ & 0.43 & -0.50 & -0.17 & -0.21 & -0.33 & 0.20 \\
EDU & 0.43 & $/$ & -0.39 & $-0.77 *$ & -0.35 & -0.08 & 0.07 \\
ETHN & -0.50 & -0.39 & $/$ & 0.00 & 0.13 & 0.34 & 0.36 \\
CIASS & -0.17 & $-0.77 *$ & 0.00 & $/$ & $0.80 *$ & -0.17 & -0.09 \\
SEG & -0.21 & -0.35 & 0.13 & $0.80 *$ & $/$ & -0.52 & -0.28 \\
SIB & -0.33 & -0.08 & 0.34 & -0.17 & -0.52 & $/$ & $0.71 * *$ \\
SIB10 & 0.20 & 0.07 & 0.36 & -0.09 & -0.28 & $0.71 * *$ & $/$ \\
RAV & 0.48 & 0.48 & 0.14 & -0.48 & -0.47 & -0.14 & 0.21 \\
P & -0.13 & 0.12 & 0.04 & 0.00 & -0.21 & 0.00 & -0.09 \\
E & $-0.67 * *$ & -0.22 & $0.64 *$ & 0.00 & 0.07 & $0.56 *$ & 0.33 \\
N & 0.28 & 0.08 & 0.21 & -0.09 & 0.35 & -0.21 & 0.17 \\
L & -0.26 & 0.16 & 0.36 & -0.39 & 0.16 & 0.21 & 0.14 \\
SRD & 0.33 & -0.11 & 0.01 & 0.40 & 0.11 & -0.47 & -0.08 \\
PER & 0.41 & 0.25 & -0.10 & 0.12 & 0.34 & -0.47 & -0.04 \\
THEFT & 0.19 & -0.43 & 0.00 & 0.69 & -0.11 & -0.07 & 0.11 \\
MODAL & 0.17 & -0.44 & -0.27 & 0.61 & 0.31 & -0.48 & -0.41 \\
SRMS & 0.27 & -0.23 & -0.01 & 0.07 & -0.12 & -0.27 & -0.08 \\
GLOBAI & 0.23 & -0.30 & -0.06 & 0.21 & -0.23 & -0.21 & -0.08 \\
\hline
\end{tabular}

${ }^{*} \mathrm{p}<0.05 \quad * \star \mathrm{p}<0.01$

Age (AGE): Age was found to correlate significantly only with extraversion (E, $r=-$ $0.67, \mathrm{p}<0.01$ ), this negative correlation indicates that the older an individual, the lower the extraversion score.

Years spent in education (EDU): Years in education correlated significantly only with social class, and this was found to be negative (CLASS, $r=-0.77, p<0.05$ ), showing that those with greater number of years of education also tended to belong to higher social classes. 
Ethnic Origin (ETHN): correlated significantly with only with extraversion (E, $\mathrm{r}=0.64, \mathrm{p}<0.05$ ). This positive correlation shows that those from non-minority backgrounds tended to be more extraverted.

Social Class (CLASS): was found to correlate significantly and negatively with number of years of education (EDU, $r=-0.77, p<0.01$ ), indicating that the higher the social class to which an individual belonged, the greater the number of years spent in education. Social Class was also found to achieve significance with the positive correlation with the socio-economic group (SEG, $\mathrm{r}=0.80, \mathrm{p}<0.01$ ); showing that the higher the social class to which an individual belonged the higher the SEG.

Socio Economic Group (SEG): the only significant correlation obtained with this variable was the positive correlation with social class (CLASS) described above.

Number of siblings: both measures of family size, the number of siblings before (SIB) and after the age of ten (SIB10) correlated significantly positively with each other $(r=0.71, p<0.01)$. The number of siblings before the age of ten $(S I B)$ also produced a significant positive correlation with extraversion $(E, r=0.56, p<0.05)$

\section{Personality}

The Eysenck Personality Questionnaire produces scores on four scales for each individual, three of which provide a measure of personality: Psychoticism (P), Extroversion $(\mathrm{E})$, and Neuroticism $(\mathrm{N})$. The fourth scale is the Lie (L) scale which measures an individual's tendency to put forward a positive image of him/herself and therefore giving a measure of the validity of the scores on the other scales. Table 4.1(7) gives the coefficients calculated. 
Table 4.1(7) - Correlation Coefficients for Personality Variables in the Glenthorne

\section{Sample}

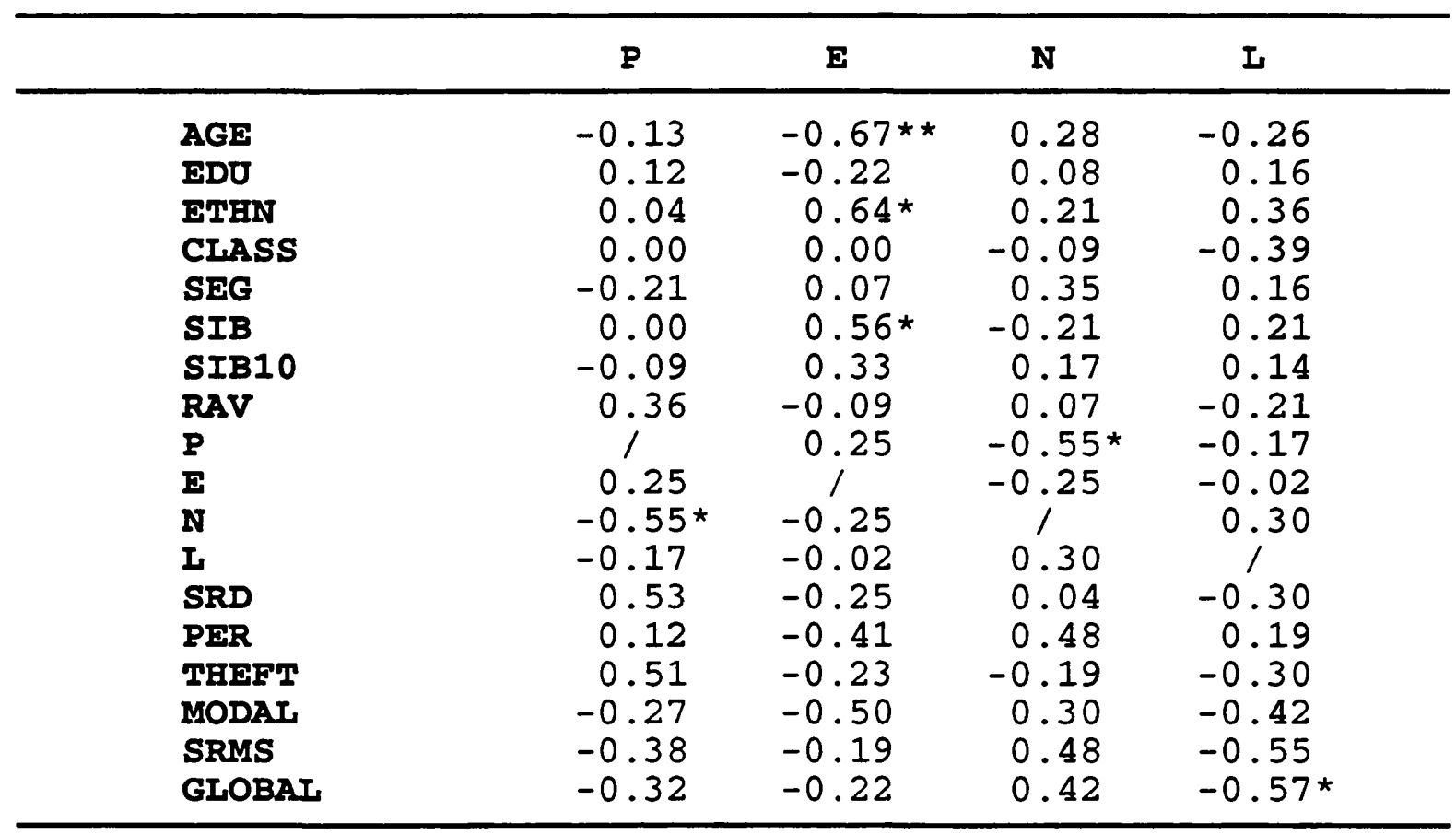

${ }^{*} \mathrm{p}<0.05 \quad \star * \mathrm{p}<0.01$

Psychoticism $(\mathrm{P})$ : correlated significantly only with neuroticism $(\mathrm{N}, \mathrm{r}=-0.55$, $\mathrm{p}<0.05)$. This positive association indicates that the higher the psychoticism of an individual, the lower the neuroticism of that individual.

Extraversion (E): correlated significantly negatively only with age (r=-0.67, $\mathrm{p}<0.01$ ), showing that the older individuals tended to have the higher $\mathrm{E}$ scores. E also produced two significant positive correlations, one with ethnic origin (ETHN, $r=0.64$, $\mathrm{p}<0.05)$ showing that those which belong to non-minority ethnic groups tended to be more extraverted; and one with the number of siblings before the age of ten (SIB, $r=0.56$, $\mathrm{p}<0.05)$, indicating that the larger the sibling group the greater the extraversion.

Neuroticism $(\mathrm{N})$ : correlated significantly only with psychoticism, described above.

Lie Scale $(\mathrm{L})$ : produced significant correlations only with global stage of moral reasoning (GLOBAL, $\mathrm{r}=-0.57, \mathrm{p}<0.05$ ), this negative correlation shows that the more 
mature the moral reasoning of an individual, the lower the $\mathrm{L}$ score and hence the lower the tendency to put forward a positive image of oneself.

Intelligence (RAV)

Non-verbal intelligence as measured by Raven's standard progressive matrices (Raven, Court and Raven, 1985) revealed many correlation coefficients upon analysis. Table 4.1(8) shows the results.

Table 4.1(8) - Correlation Coefficients for Intelligence and Moral Reasoning variables in the Glenthorne sample

\begin{tabular}{|c|c|c|c|c|}
\hline & RAV & MODAI & SRMS & GLOBAI \\
\hline AGE & 0.48 & 0.17 & 0.27 & 0.23 \\
\hline ED & 0.48 & -0.44 & -0.23 & -0.30 \\
\hline ETHN & 0.14 & -0.27 & -0.01 & -0.06 \\
\hline CLASS & -0.48 & 0.61 & 0.07 & 0.21 \\
\hline SEG & -0.47 & 0.31 & -0.12 & -0.23 \\
\hline SIB & -0.14 & -0.48 & -0.27 & -0.21 \\
\hline SIB10 & 0.21 & -0.41 & -0.08 & -0.08 \\
\hline RAV & / & -0.28 & 0.11 & 0.11 \\
\hline $\mathbf{P}$ & 0.36 & -0.27 & -0.38 & -0.32 \\
\hline $\mathbf{E}$ & -0.09 & -0.50 & -0.19 & -0.22 \\
\hline $\mathbf{N}$ & 0.07 & 0.30 & 0.48 & 0.42 \\
\hline L & -0.21 & -0.42 & -0.55 & $-0.57 \star$ \\
\hline SRD & 0.50 & 0.28 & 0.16 & 0.21 \\
\hline PER & 0.29 & 0.10 & 0.00 & -0.02 \\
\hline THEFT & 0.27 & 0.36 & 0.08 & 0.22 \\
\hline MODAI & -0.28 & / & $0.70 * \star$ & $0.75 * \star$ \\
\hline SRMS & 0.11 & $0.70 * \star$ & I & $0.97 * *$ \\
\hline GLOBAI & 0.11 & $0.75 * *$ & $0.97 * \star$ & / \\
\hline
\end{tabular}

${ }^{*} \underline{p}<0.05 \quad \star * \mathfrak{p}<0.01$

No significant correlations were obtained with the intelligence (RAV).

\section{Sociomoral Reflection (Moral Reasoning)}

The three measures of sociomoral reasoning: Modal stage (MODAL), sociomoral reflection maturity score (SRMS), and global stage of moral reasoning (GLOBAL) were 
correlated with all the other variables collected. The correlation coefficients are shown in Table 4.1(8).

All three measures of moral reasoning were found to correlate significantly and positively with each other. In addition, a negative correlation between global stage and the lie scale $(\mathrm{L})$ described under the personality variable correlations shown earlier, was found to be significant.

\section{Offending History}

The offending history of the subjects was represented in three measures: SelfReported Delinquency (SRD), crimes committed against the person (PER) and crimes committed against property (THEFT). Table 4.1(9) shows the resulting coefficients.

Table 4.1(9) - Correlation Coefficients for Offending History Variables in the Glenthorne Sample

\begin{tabular}{|c|c|c|c|}
\hline & SRD & PER & THEFT \\
\hline $\mathbf{A G E}$ & 0.33 & 0.41 & 0.19 \\
\hline EDD & -0.11 & 0.25 & -0.43 \\
\hline ETHN & 0.01 & -0.10 & 0.00 \\
\hline CIASS & 0.40 & 0.12 & 0.69 \\
\hline SEG & 0.11 & 0.34 & -0.11 \\
\hline SIB & -0.47 & -0.47 & -0.07 \\
\hline SIB10 & -0.08 & -0.04 & 0.11 \\
\hline RAV & 0.50 & 0.29 & 0.27 \\
\hline $\mathbf{P}$ & 0.53 & 0.12 & 0.51 \\
\hline $\mathbf{E}$ & -0.25 & -0.41 & -0.23 \\
\hline$\overline{\mathbf{N}}$ & 0.04 & 0.48 & -0.19 \\
\hline & -0.30 & 0.19 & -0.30 \\
\hline SRD & / & $0.68 * *$ & $0.80 * \star$ \\
\hline PER & $0.68 * *$ & / & 0.33 \\
\hline THEFT & $0.80 * \star$ & 0.33 & 1 \\
\hline MODAI & 0.28 & 0.10 & 0.36 \\
\hline SRMS & 0.16 & 0.00 & 0.08 \\
\hline GLOBAL & 0.21 & -0.02 & 0.22 \\
\hline
\end{tabular}

The only significant correlations to emerge from the offending history variables were the two positive correlations between general delinquency (SRD) and both crimes 
committed against the person (PER, $r=0.68, \mathrm{p}<0.01$ ) and property crimes (THEFT, $\mathrm{r}=0.80$, $\mathrm{p}<0.01)$. This shows that the greater the general delinquency, the greater the number of crimes against the person and thefts committed. Of interest, is the finding that the correlation between crimes against property and against the person did not reach significance.

\section{Analyses of Variance}

The differences in the means on all of the variables collected between the male offenders, male and female controls, and the Glenthorne YTC centre were analysed for significance using analysis of variance (ANOVA). The Tables below show the results

\section{Demographic Variables}

Table 4.1(10) shows the means and results of the ANOVA's carried out on the differences between the means of the three sample groups on demographic variables. 
Table 4.1(10) - Means and Standard Deviations for the Demographic variables for the Male Offenders, Male and Female Controls and Glenthorne sample and the results for the ANOVAs

\begin{tabular}{|c|c|c|c|c|c|c|}
\hline & & $\begin{array}{c}\text { MALE } \\
\text { OFFENDERS } \\
(\mathrm{N}=101)\end{array}$ & $\begin{array}{c}\text { MALE } \\
\text { AND FEMALE } \\
\text { CONTROLS } \\
(\mathrm{N}=108)\end{array}$ & $\begin{array}{c}\text { GLENTHORNE } \\
\text { SAMPLE } \\
(N=14)\end{array}$ & $d f$ & F value \\
\hline $\mathbf{A G E}$ & $\begin{array}{l}x \\
S D\end{array}$ & $\begin{array}{c}19.14 a \\
1.12\end{array}$ & $\begin{array}{c}19.56 a \\
1.07\end{array}$ & $\begin{array}{c}17.02 \mathrm{a} \\
1.34\end{array}$ & 2,210 & $32.33 * *$ \\
\hline EDU & $\begin{array}{l}x \\
S D\end{array}$ & $\begin{array}{c}10.52 \mathrm{a} \\
1.37\end{array}$ & $\begin{array}{c}13.58 \mathrm{a} \\
1.09\end{array}$ & $\begin{array}{l}8.25 a \\
2.70\end{array}$ & $2, \quad 204$ & 169.93 * * \\
\hline CIASS & $\begin{array}{l}x \\
S D\end{array}$ & $\begin{array}{l}3.06 a \\
0.96\end{array}$ & $\begin{array}{l}2.18 a \\
0.90\end{array}$ & $\begin{array}{l}3.00 \mathrm{~b} \\
0.58\end{array}$ & $2, \quad 171$ & $18.76 * \star$ \\
\hline SEG & $\begin{array}{l}x \\
S D\end{array}$ & $\begin{array}{l}8.17 \mathrm{~b} \\
3.14\end{array}$ & $\begin{array}{l}5.16 \mathrm{ab} \\
3.36\end{array}$ & $\begin{array}{l}8.75 a \\
4.27\end{array}$ & $2, \quad 174$ & $18.32 * *$ \\
\hline SIB & $\begin{array}{l}x \\
S D\end{array}$ & $\begin{array}{l}1.70 \\
1.52\end{array}$ & $\begin{array}{l}1.59 \\
1.13\end{array}$ & $\begin{array}{l}2.50 \\
1.45\end{array}$ & 2,207 & 2.91 \\
\hline SIB10 & $\begin{array}{l}x \\
\text { SD }\end{array}$ & $\begin{array}{l}1.29 a \\
1.18\end{array}$ & $\begin{array}{l}1.30 \mathrm{~b} \\
1.18\end{array}$ & $\begin{array}{l}2.86 a b \\
2.32\end{array}$ & 2,206 & $10.36 * *$ \\
\hline
\end{tabular}

${ }^{*} \mathrm{p}<0.05 ; * \star \mathrm{p}<0.001$

(NB: Means with the same letters are significantly different to each other)

Table 4.1(10) shows that all but one (SIB10 - number of siblings before the age of ten) of the demographic variables showed significant differences between the three sample groups.

The male and female control group was significantly older than both the male offender and the Glenthorne sample groups, and the male offender group was found to be significantly older than the Glenthorne sample group $(F(2,210)=32.33, p<0.001)$.

A similar pattern was repeated with years of education. The male and female controls had more years spent in education than both the male offenders and the Glenthorne groups, while the male offenders had significantly more years of education than the Glenthorne group $(F(2,204)=169.93, p<0.001)$.

The male and female control group came from a significantly higher class than the male offender group $(F(2,171)=18.75, \mathrm{p}<0.001)$, but post-hoc tests revealed no significant difference was between the Glenthorne sample and the other two sub-groups. 
The male and female control group came from a significantly higher socioeconomic group (SEG) than both the Glenthorne and the male offender samples $(F(2,174)=18.32$, $\mathrm{p}<0.001$ ), but the difference in SEG between the latter two groups, was found to be nonsignificant.

The Glenthorne sample group was found to have significant larger number of siblings after the age of ten than both the other two groups $(F(2,206)=10.36, p<0.001)$, but post-hoc tests showed that the male offender and control groups did not significantly differ in numbers of siblings.

\section{$\underline{\text { Personality }}$}

Table 4.1(11) shows the results of the ANOVA's carried out to determine the significance of differences in personality scores between the three sample groups.

Table 4.1(11) - Means and Standard Deviations for the Personality variables for the Male Offenders, Male and Female Controls and Glenthorne sample and the results for the ANOVAs

\begin{tabular}{|c|c|c|c|c|c|c|c|}
\hline & & $\begin{array}{c}\text { MALE } \\
\text { OFFENDERS } \\
(\mathrm{N}=101)\end{array}$ & $\begin{array}{c}\text { MALE } \\
\text { AND FEMALE } \\
\text { CONTROLS } \\
(\mathrm{N}=108)\end{array}$ & $\begin{array}{c}\text { GLENTHORNE - } \\
\text { SAMPLE } \\
(\mathrm{N}=14)\end{array}$ & $d f$ & $F$ & value \\
\hline $\mathbf{P}$ & $\begin{array}{l}x \\
S D\end{array}$ & $\begin{array}{l}4.74 a \\
2.53\end{array}$ & $\begin{array}{l}2.86 a \\
2.02\end{array}$ & $\begin{array}{l}4.00 \mathrm{~b} \\
2.11\end{array}$ & 2,208 & & $15.33 * \star$ \\
\hline $\mathbf{E}$ & $\begin{array}{l}x \\
S D\end{array}$ & $\begin{array}{l}8.71 \\
3.05\end{array}$ & $\begin{array}{l}8.21 \\
3.43\end{array}$ & $\begin{array}{l}9.07 \\
2.89\end{array}$ & 2,208 & & 0.50 \\
\hline $\mathbf{N}$ & $\begin{array}{l}x \\
S D\end{array}$ & $\begin{array}{l}6.05 \\
3.21\end{array}$ & $\begin{array}{l}6.57 \\
3.16\end{array}$ & $\begin{array}{l}5.85 \\
3.23\end{array}$ & 2,208 & & 0.67 \\
\hline I & $\begin{array}{l}x \\
S D\end{array}$ & $\begin{array}{l}3.24 \\
2.45\end{array}$ & $\begin{array}{l}3.06 \\
2.14\end{array}$ & $\begin{array}{l}4.36 \\
2.10\end{array}$ & 2,208 & & 2.11 \\
\hline
\end{tabular}

${ }^{*} \mathrm{p}<0.05 ;{ }^{*} \mathrm{*} p<0.001$

(NB: Means with the same letters are significantly different to each other)

The only significant difference to be found concerning the personality variables used was with psychoticism $(P ; F(2,208)=15.33$, $p<0.001)$, however, this did not involve 
the Glenthorne sample. The male offenders were found to have a significantly higher $\mathrm{P}$ score than the male and female control group, but no significant differences were found between the Glenthorne sample and the other two groups.

\section{Intelligence and Moral Reasoning}

Table 4.1(12) shows the results of the ANOVA's carried out to determine the significance of differences in intelligence and moral reasoning between the three sample groups.

Table 4.1(12) - Means and Standard Deviations for the Moral Reasoning variables for the Male Offenders, Male and Female controls and Glenthorne sample and the results for the ANOVAs

\begin{tabular}{|c|c|c|c|c|c|c|}
\hline & & $\begin{array}{c}\text { MALE } \\
\text { OFFENDERS } \\
(\mathrm{N}=101)\end{array}$ & $\begin{array}{c}\text { MALE } \\
\text { AND FEMALE } \\
\text { CONTROLS } \\
(\mathrm{N}=108)\end{array}$ & $\begin{array}{c}\text { GLENTHORNE } \\
\text { SAMPLE } \\
(\mathrm{N}=14)\end{array}$ & $d f$ & F value \\
\hline RAV & $\begin{array}{l}x \\
S D\end{array}$ & $\begin{array}{c}39.02 a \\
8.79\end{array}$ & $\begin{array}{c}50.70 \mathrm{ab} \\
6.90\end{array}$ & $\begin{array}{c}35.43 b \\
8.79\end{array}$ & 2,210 & $62.49 * \star$ \\
\hline MODAI & $\begin{array}{l}x \\
S D\end{array}$ & $\begin{array}{l}4.18 a \\
0.92\end{array}$ & $\begin{array}{l}5.53 \mathrm{ab} \\
0.88\end{array}$ & $\begin{array}{l}3.53 \mathrm{~b} \\
0.88\end{array}$ & 2,179 & $63.61 * \star$ \\
\hline SRMS & $\begin{array}{l}x \\
S D\end{array}$ & $\begin{array}{c}252.46 a \\
33.55\end{array}$ & $\begin{array}{c}326.58 a \\
28.50\end{array}$ & $\begin{array}{c}227.54 a \\
35.96\end{array}$ & 2,180 & $149.49 * *$ \\
\hline GLOBAL & $\begin{array}{l}x \\
S D\end{array}$ & $\begin{array}{l}5.65 a \\
1.05\end{array}$ & $\begin{array}{l}7.77 a \\
0.94\end{array}$ & $\begin{array}{l}4.84 a \\
1.28\end{array}$ & 2,180 & $118.91 * *$ \\
\hline
\end{tabular}

\footnotetext{
${ }^{*} p<0.05 ; * * p<0.001$

(NB: Means with the same letters are significantly different to each other)
}

Intelligence showed a significant difference $(F(2,210)=62.49, \mathrm{p}<0.001)$. The control group was found to be significantly more intelligence than both the male offenders and the Glenthorne group, but no significant difference was obtained between the latter two groups. 
The control group was found to reason morally at a higher modal stage than both the male offenders and the Glenthorne sample (MODAL, $F(2,179)=63.71, p<0.001$ ), but no significant difference was found between the latter two groups.

The control group was found to be significantly more mature in their moral reasoning and at a higher global stage of moral reasoning than both the male offenders and the Glenthorne sample. The male offenders were found to be more mature in their moral reasoning and at a higher global stage of moral reasoning than the Glenthorne sample.

\section{Offending History}

Table 4.1(13) shows the results of the ANOVA's carried out to determine the significance of differences in offending history between the three sample groups.

Table 4.1(13) - Means and Standard Deviations for the Offending History variables for the Male Offenders, Male and Female Controls and Glenthorne sample and the results for the ANOVAs

\begin{tabular}{|c|c|c|c|c|c|c|}
\hline & & $\begin{array}{c}\text { MALE } \\
\text { OFFENDERS } \\
(\mathrm{N}=101)\end{array}$ & $\begin{array}{c}\text { MALE } \\
\text { AND FEMALE } \\
\text { CONTROLS } \\
(\mathrm{N}=108)\end{array}$ & $\begin{array}{c}\text { GLENTEORNE } \\
\text { SAMPLE } \\
(N=14)\end{array}$ & $d f$ & $F$ value \\
\hline SRD & $\begin{array}{l}x \\
S D\end{array}$ & $\begin{array}{c}21.92 \mathrm{a} \\
7.31\end{array}$ & $\begin{array}{c}11.33 \mathrm{ab} \\
5.63\end{array}$ & $\begin{array}{c}19.43 \mathrm{~b} \\
7.57\end{array}$ & 2,207 & $63.90 * *$ \\
\hline PER & $\begin{array}{l}x \\
S D\end{array}$ & $\begin{array}{l}3.84 a \\
2.03\end{array}$ & $\begin{array}{l}1.23 \mathrm{ab} \\
1.08\end{array}$ & $\begin{array}{l}3.29 \mathrm{~b} \\
1.82\end{array}$ & $2, \quad 207$ & $64.20 * *$ \\
\hline THEFT & $\begin{array}{l}x \\
S D\end{array}$ & $\begin{array}{l}5.28 a \\
1.89\end{array}$ & $\begin{array}{l}1.35 \mathrm{ab} \\
1.54\end{array}$ & $\begin{array}{l}4.64 b \\
2.62\end{array}$ & 2,207 & $119.03 *$ * \\
\hline
\end{tabular}

${ }^{*} \mathrm{p}<0.05 ; * \star \mathrm{p}<0.001$

(NB: Means with the same letters are significantly different to each other)

All three offending history variables were found to be significant (SRD, $F(2$, 207) $=63.90, p<0.001 ; \operatorname{PER}, F(2,207)=64.20, p<0.001$ and $\operatorname{THEFT}, F(2,207)=119.03$, $\mathrm{p}<0.001$ ). 
Post-hoc analyses revealed that in all three cases of offending history variables, the control group was found to score significantly higher on offending than both the other two groups. The control group was less generally delinquent than both the male offenders and the Glenthorne sample, but no significant difference was found between the male offenders and the Glenthorne sample. The control group had also committed significantly fewer crimes against the person than both the male offenders and the Glenthorne sample, no significant differences in these scores were found between the male offenders and the Glenthorne sample.

\section{Analysis of Co-Variance (ANCOVA)}

Analyses of co-variance were carried out using age, education, socio-economic group (SEG), and number of siblings after the age of ten (SIB10) as simultaneous covariates. These were carried out in order to eliminate the potential effects of the significant differences in these demographic variables (as shown in table 4.1(10) between the three sample groups on the significance of differences in the personality, intelligence, moral reasoning and offending history variables.

Only the variables SRMS and Global stage of moral reasoning changed their level of significance when the demographic differences were taken into account. 
Table 4.1(14) - The Means and Standard Deviations for Moral Reasoning variables for the Male Offenders, Male and Female Controls and the Glenthorne sample and the results of the ANCOVAs with age, education, SEG and SIB10 as simultaneuos covariates

\begin{tabular}{|c|c|c|c|c|c|c|c|}
\hline & & $\begin{array}{c}\text { MALE } \\
\text { OFFENDERS } \\
(\mathrm{N}=101)\end{array}$ & $\begin{array}{c}\text { MALE } \\
\text { AND FEMALE } \\
\text { CONTROLS } \\
(\mathrm{N}=108)\end{array}$ & $\begin{array}{c}\text { GLENTEORNE } \\
\text { SAMPLE } \\
(\mathrm{N}=14)\end{array}$ & $d f$ & $\mathrm{~F}$ & value \\
\hline & $\begin{array}{l}x \\
\text { SD }\end{array}$ & $\begin{array}{c}252.46 a \\
33.55\end{array}$ & $\begin{array}{c}326.58 \mathrm{ab} \\
28.50\end{array}$ & $\begin{array}{c}227.54 b \\
35.96\end{array}$ & 3,174 & & $91.61 * \star$ \\
\hline GLOBAL & $\begin{array}{l}x \\
\text { SD }\end{array}$ & $\begin{array}{l}5.65 a \\
1.05\end{array}$ & $\begin{array}{l}7.77 \mathrm{ab} \\
0.94\end{array}$ & $\begin{array}{l}4.84 b \\
1.28\end{array}$ & 3,174 & & $72.46 * \star$ \\
\hline
\end{tabular}

${ }^{\star} \mathrm{p}<0.05 ; \quad *{ }^{*} \mathrm{p}<0.001$

(NB: Means with the same letters are significantly different to each other)

Table 4.1(14) shows that when significant differences in demographic variables were co-varied changes in the significance of sociomoral reasoning maturity (SRMS) and global stage of moral reasoning were found. The significant differences between SRMS and global stage found between the male offenders and the Glenthorne group, as shown in table 4.1(12) was not found. This suggests that earlier described difference was due to the differences in demographic/background variables and not due to other factors such as offending status. 


\section{Discussion}

The present discussion section is organised in sections pertaining to the theories which were tested, namely: H. J. Eysenck's personality theory and Kohlberg's moral reasoning theory. In addition, predictions pertaining to intelligence and demographic variables are considered. Particular attention is placed on the group comparisons between the residents of Glenthorne and the convicted young offenders and the non-convicted individuals.

\section{Personality and Glenthorne Residents}

Both some of the correlations and some of the group comparisons using analyses of variance are relevant to identifying the applicability of Eysenck's personality theory to the Glenthorne sample.

\section{Correlational analyses}

Table 4.1(7) shows that no significant correlation coefficients between any of the personality variables and any of the offending history variables were found. This indicates that no relationship existed between the personality variables and offending history, as would be expected according to H. J. Eysenck's theory. This finding could be a result of the very small sample size $(n=14)$ of the Glenthorne sample, although this represents approximately 18 per cent of the total population of residents in Youth Treatment Centres. Previous research has found a variety of associations between P, E and N and self-reported offending (Furnham, 1984; Powell, 1977; Rushton and Chrisjohn, 1981) in contrast to the present study. 


\section{Analyses of Variance}

The analysis of variance shown in Table 4.1(11) shows a little more support for Eysenck's theory, although this is by no means overwhelming. No significant difference exists in $\mathrm{E}$ or $\mathrm{N}$ across the three sample groups, indicating that $\mathrm{E}$ and $\mathrm{N}$ are not distinguishing between convicted offenders, Glenthorne residents and non-convicted individuals. S. B. G. Eysenck, Rust and H. J. Eysenck (1977) Mitchell et al. (1980) found that violent offending was related to specific personality combinations involving $\mathrm{P}, \mathrm{E}$ and $\mathrm{N}$ and thus from the level of anti-social behaviour and offending exhibited by the Glenthorne residents it would be expected that they would be distinguished by high $\mathrm{E}$ and N scores.

P showed a similar pattern, with no significant differences between either of the other two sample groups and the Glenthorne sample group. Although the previously identified higher $\mathrm{P}$ score in convicted offenders was also found to be significantly higher than that of the controls.

These differences remained the same even when age was used as a co-variate in the subsequent analyses of co-variance, showing that the results were not due to the significant age difference found between the three sample groups.

However, the differences between the Glenthorne sample and cannot be equated to differences in offending only. The residents of Glenthorne differ on other variables apart from offending, and applying H. J Eysenck's theory to these individuals may not be valid. For the same reason, it is inappropriate to compare the present results with those of previous studies since personality does not seem to have been investigated in this manner previously. 


\section{Moral Reasoning and Glenthorne Residents}

Again, both the correlational analysis and the group comparisons using analyses of variance were useful in testing predictions made by Kohlberg's theory of moral reasoning.

\section{Correlational Analyses}

None of the correlations between the moral reasoning variables and the offending history variables were found to be significant, in contrast to predictions. Previous studies have also found little relationship between moral reasoning and self-reported offending (Emler et al., 1978; Lanza-Kaduce et al., 1983; Renwick and Emler, 1984; Tsujimoto and Nardi, 1978). While most of these studies used inadequate measures of moral reasoning and/or self-reported offending, the present study used fairly robust tests, and a significant association between moral reasoning and self-reported offending was found in the main study (the results were reported in chapter 3 ). The discrepant results in the Glenthorne study could be partly due to the small sample size used.

\section{Analyses of Variance}

These results were more in line with predictions. In all measures of moral reasoning the Glenthorne residents were found to reason at lower stages than the combined control group. Furthermore, in terms of sociomoral reflection maturity score (SRMS) and global stage of reasoning, the Glenthorne individuals were found to be significantly less mature than the convicted offender group.

This is in line with predictions that offenders will be delayed in their moral reasoning. However, offending is not the only variable upon which the Glenthorne sample differed from the convicted and control groups. Many Glenthorne residents have profound problems in terms of social adjustment. Moral reasoning is associated with social adjustment and therefore it follows that residents of Glenthorne would have lower moral 
reasoning maturity than convicted offenders who are held within the penal system, who do not have problems (or have less severe problems) of social adjustment. Many of the residents at Glenthorne convicted under section 53 of the Children and Young Person's act, are placed within a Youth Treatment Centre because of problems of adjusting to the prison regime, which reflects the social adjustment differences between Glenthorne residents and convicted offenders.

The subsequent analyses of co-variance using demographics as co-variates showed no differences in the pattern of significance between the Glenthorne sample and the comparison group. In this case, the significant age, educational and family size differences between these two sample groups cannot be said to account for the results pertaining to moral reasoning.

The differences in moral reasoning between the Glenthorne sample and the male offenders when demographic differences were taken into account in ANCOVAs became non-significant. This suggests that the earlier reported significant differences in moral reasoning were a result of age, education and family size differences. This is predicted by the theory which suggests that age and educational levels are related to the development of moral reasoning maturity. The larger family size of the Glenthorne residents could indicate greater economic deprivation which may have resulted in the slower development of moral reasoning.

Comparisons with previous research are not possible since comparable studies do not seem to have been carried out using residents of Youth Treatment Centres.

\section{Intelligence of Glenthorne Residents}

The results showed that most of the individuals in the Glenthorne sample were of grade III or IV, showing that the individuals were either of average or below average intellect as was the case for convicted offenders (see chapter 3.1). 


\section{Correlational Analyses}

No significant correlations were found between intelligence score (RAV) and any of the offending history variables as would be predicted. This indicates that the offending level of the Glenthorne residents is not linked to their intellectual level. This contrasts with several reviews which concluded that intelligence is positively related to self-reported offending (Quay, 1987; Reichel, 1987), although as has already been pointed out, residents of Glenthorne do not only differ from the two other groups in terms of offending level. The discrepancy may again be attributed to the very small number of individuals which comprised the Glenthorne sample

\section{Analyses of Variance}

The Glenthorne sample was found to have significantly lower intellectual level than the combined comparison group, but no significant difference was found between the intelligence levels of the Glenthorne and the convicted offender sample groups. This fits in with predictions from previous studies (Quay, 1987; Reichel, 1987), which suggests that intelligence level is lower in offenders. It seems that with regard to intellect, the residents of Glenthorne are comparable to offenders held within the penal system. However, as has been previously noted, Glenthorne residents do not differ in terms of offending alone and thus comparisons with previous studies or theories incorporating offending and intelligence may not be very appropriate.

\section{Demographics and Glenthorne Residents}

Some evidence was found that Glenthorne residents differed from convicted offenders and controls on demographic variables. 


\section{Correlational Analyses}

No significant correlations were found between any of the demographic variables and any of the three offending history variables. This is contrary to predictions relating to variables such as socioeconomic status and education level. Elliot and Ageton (1980) found that lower socio-economic status was associated with higher self-reported delinquency and West (1982) reported that an association existed between self-reported delinquency and a larger number of siblings. Again, these discrepancies are attributed to the small number of participants included in the Glenthorne sample.

\section{Analyses of Variance}

Several significant differences were obtained between the three sample groups pertaining to the demographic variables. The Glenthorne sample had attended significantly fewer years of education than both the convicted offenders and the combined comparison group. This is to be expected since these individuals are characterised by severe family problems and movements from one institution to another. It may also reflect a deficiency in the way that educational level was measured since 'years at school' would have little relevance to the residents of Glenthorne, many of whom have been in institutions for a greater part of their lives.

While no significant differences were obtained in social class, the Glenthorne sample was found to come from a significantly lower socioeconomic group (SEG) than both the comparison and the offender groups. While it was expected that the residents of Glenthorne would come from lower SEGs than the comparison group it is not clear why they should come from an even lower SEG than the convicted offenders. It may be that economic and social deprivation is of utmost importance in determining the disturbance in the individuals who become residents in a Youth Treatment Centre. 
Lastly, the Glenthorne sample was found to have significantly greater number of siblings before (SIB) and after the age of 10 years (SIB10) than the comparison group, although there were no significance in the differences in the number of siblings with the convicted offender group. This is again predicted from the offending nature of the Glenthorne residents (West, 1982), and perhaps contributes to the economic and social deprivation which may play a part in the problems inherent in the residents of Glenthorne.

\section{Interrelations between Variables}

Only one significant correlation associated any of the variables with each other. The lie scale (L) score correlated significantly negatively with global stage of moral reasoning. This suggests that the higher the tendency to respond honestly, the higher the global stage of moral reasoning. This may reflect the motivation level of the participants, those who responded honestly tended to give more reasoned responses which would be allocated a higher moral reasoning stage. However, only global stage was found to be significantly correlated not any of the other two measures of moral reasoning and therefore not a great deal of significance can be attributed to the finding.

No other associations were found between personality, moral reasoning and intelligence in contrast to the results of the main study. This can also be attributed to the small sample size of the Glenthorne group.

In summary, Glenthorne residents were characterised by low moral reasoning (lower than convicted offenders), lower intelligence, and generally associated with deprived backgrounds. No differences were apparent, however, in personality variables. This suggests that it is environmental issues which are more important in predicting those which will become residents of a Youth Treatment Centre, rather than genetically determined personality factors. This is in contrast to convicted offenders, who tend to be less deprived and have personality factors which predispose them to offending behaviour. This study 
mainly suffered from the small size of the Glenthorne sample. However, while 14 individuals constitutes a small sample, this represents approximately 18 per cent of all individuals resident in the two Youth Treatment Centres. Efforts need to be made to include a larger number of these individuals in further studies.

Another criticism of this study was the use of the comparison groups. Residents of Glenthorne cannot all be equated with convicted offenders and therefore a third sample comprising children in care at other institutions could have proved useful.

Further research needs to make the improvements to the methodology suggested, but in addition there are other questions that need to be addressed. Firstly, the differences between the convicted and non-convicted residents of Youth Treatment Centres needs to be made although the problems of adequate sample size may prove to be a constraint. Secondly, the effect of treatment on moral reasoning and intelligence scores need to be investigated. This could be investigated either longitudinally or cross-sectionally.

In conclusion, it was found that Glenthorne residents had lower moral reasoning, and socio-economic background than both convicted and non-convicted individuals, and lower intelligence than non-convicted individuals only. No differences were found in their personality variables. This suggests that predictions of being a resident of Glenthorne, are generally based on external factors such as social, economic and educational factors rather than constitutional factors.

This study is discussed further in the main discussion section (Chapter 5). 


\section{2 - RESPONSE BIAS AND LAY CONCEPTIONS OF PERSONALITY AND MORAL REASONING IN YOUNG OFFENDERS}

\section{Introduction}

Self-reported inventories such as the Eysenck Personality Questionnaire (EPQ) have often been criticised in one form or another for being open to response bias. There is considerable evidence to support the notion that respondents can successfully dissemble personality inventories based on the motivation present to do so (e.g Jacobs and Barron, 1968; Furnham and Henderson, 1982; Wesman, 1952; and see also Anastasi, 1990).

Wrightsman (1977) and Anastasi (1990) have summarised the main types of response bias to which self-report questionnaires can be prone.

Social desirability, whereby respondents are motivated to 'fake good' and choose answers that create a favourable impression or 'fake bad' thereby making themselves seem more psychologically disturbed than they actually are. This type of response bias cannot simply be considered 'faking' however, since, as Edwards (1957a, 1957b) first pointed out, social desirability bias is largely not deliberate deception but more a tendency to put forward a positive facade, of which the respondent is generally unaware.

The second type of response bias, is acquiescence, which consists of a continuous scale with consistent 'yeasayers' at one extremity and consistent 'naysayers' at the other. In the middle of this scale are the respondents who tend to give 'mid-point' answers, and in addition some respondents may tend to give responses at either extremity.

Deviation, whereby respondents tend to give unusual or uncommon responses, was proposed by Berg (1967). Finally, carelessness and inconsistency of responding have also been identified as potential sources of bias.

These response bias sets can seriously threaten the validity and reliability of selfreported tests, and, especially for measures employed in clinical settings, a considerable 
amount of research has been devoted to various attempts to overcome bias. These include, providing measures of social desirability within a test (e.g. Lie scale in EPQ; H. J. Eysenck and S. B. G. Eysenck, 1975), correlating the test scores with self-reported measures of social desirability (e.g. the Social desirability Scale; Edwards, 1957b) and measuring the susceptibility of the test to bias by asking respondents to fake 'good' or 'bad' and so on, and comparing these results to respondents who were asked to be honest in their answers. Obviously, certain tests are more prone to certain types of bias than others, and solutions are not applicable to all self-reported tests.

Research which relies on psychometric tests, is obviously prone to response bias, and this is especially true when the research involves specific populations which may be more motivated to fake responses, or put forward a socially desirable image.

The studies described in the previous sections could be criticised for being prone to response bias which could seriously undermine the conclusions. This is especially the case considering that convicted offenders, may be motivated to produce socially desirable responses to the self-reported scales used, as well as bias produced by their fear and suspicion. Within these studies, the two measures which may be most prone to bias are the EPQ, and the Sociomoral Reflection Measure (SRM).

Furnham and Henderson (1982) investigated the response bias of the Eysenck Personality Questionnaire (EPQ) by asking respondents to fake either socially desirable ('good') undesirable ('bad') or mentally disturbed ('mad') responses. They found that individuals conceptualised 'mad' responses in terms of lower psychoticism scores than 'bad' responses, although in both cases the faked $\mathrm{P}$ score was higher than that found in any abnormal group tested by H. J. Eysenck and S. B. G. Eysenck (1975), which included both psychotics and drug addicts. In both the 'mad' and 'bad' fakers the neuroticism score was comparable to neurotics tested by H. J. Eysenck and S. B. G. Eysenck (1975). They also found that 'good' responses were characterised by higher extraversion and lower 
neuroticism than bad responses. Velicer and Weiner (1975), asked respondents to fake responses of either a salesman, a librarian and the 'ideal self', and found that the more sophisticated the faked response, the higher the Extraversion, Lie and Neuroticism scale.

The EPQ, deals with the problem of response bias by including the Lie scale which measures general social desirability, since it is assumed that this is the greatest source of bias. However, while Furnham and Henderson (1982) concluded that the Lie scale is fairly successful in reducing the amount of bias in responses to the EPQ, it still remains unclear if it is a suitable control for bias in such a complex phenomena as offending behaviour.

The construction and validation of the SRM, on the other hand has not dealt with any specific forms of bias. This measure, does however, seem particularly prone to socially desirable responses, especially in convicted offenders. The scale deals with social dilemmas which cover issues of theft and imprisonment, and it seems reasonable to assume that convicted respondents would tend to give socially desirable responses, which could actually reduce their total moral reasoning maturity score. It is implied by the SRM constructors that the justification element of the test is enough to control this bias although it is not clear whether respondents can fake higher or lower stage responses.

This study examined the effect of offending behaviour upon response bias by asking non-convicted individuals to fake the responses of convicted offenders on the EPQ and the SRM. While the technique of faking has been employed by previous researchers to study response bias (e.g. Furnham and Henderson, 1982), faking offenders' responses on these tests has not been previously investigated. In addition to investigating response bias, the results of the study were also applied to investigate how similar lay theories of offending may be to the formal theories of offending proposed by H. J. Eysenck (1964, $1970,1977)$ and Kohlberg (1958) as discussed in Chapter 1.

It seems reasonable to assume that lay conceptions of criminality may involve similar notions to those suggested by both Eysenck and Kohlberg. Furnham (1988) argued 
that while lay explanations of delinquency exist which are based on sociological factors (such as the environment), and psychoanalytic factors (such as sub-conscious desires), many people advocate psychological explanations which involve a criminal type. In other words, lay people tend to believe that certain factors present in an individual (such as personality) will result in that individual becoming an offender. Both the theories of $\mathrm{H}$. J. Eysenck and Kohlberg advance individual differences explanations of criminality, which may well reflect aspects of lay theories of criminality. Several tentative hypothesis were possible based on previous research findings. Firstly, it was expected that the EPQ would be prone to response bias, but that the lay conception of offending would not be reflected in the EPQ scores in the same manner as predicted by Eysenck's theory of criminality since lay perceptions are couched in different ways to those described by EPQ personality scores. Secondly, the SRM was expected to be very resistant to bias in responding since moral reasoning theory predicts that it would be extremely difficult for individual respondents to justify moral arguments other than their own.

\section{Method}

\section{Study Population}

In total 257 young people took part. These were divided into three main groups. The first two groups (described below) were the same as those used in the main study described in chapters 3.1 to 3.3 .

There were 101 male young offenders, all convicted and serving sentences of less than 4 years at a young offenders institution. These individuals were volunteers drawn from the allocation unit of a large young offenders institution. Their ages ranged from 16.5 to 21.58 years with a mean of 19.14 years, and standard deviation of 1.12 . 
A total of 75 undergraduate psychology students who received course credits for taking part, and 33 volunteer school students of psychology and sociology were used as the comparison group. Of these 33 were male and 75 were female. Their age ranged from 16 to 21.83 years with a mean age of 19.56 , standard deviation of 1.07 .

The third group comprised of 48 undergraduate psychology students who were randomly assigned to the experimental group. 38 were female and 9 were male and their age ranged from 17 to 21 years with a mean of $18.93(s d=0.92)$. These participants received course credits for taking part in the study.

\section{$\underline{\text { Design and Materials }}$}

In all participants completed three standard self-administered psychological tests.

a) Short Scale of the Eysenck Personality Questionnaire - Revised (H. J. Eysenck, S. B. G. Eysenck, and Barrett, 1985), this is a yes/no personality questionnaire which provides four scores per respondent - Psychoticism, Extraversion, Neuroticism, and Lie scale. This test is discussed in detail in Chapter 2.

b) Sociomoral Reflection Measure (SRM, Gibbs and Widaman, 1982). This is a pencil and paper production-task measure of reflective moral thought. The questionnaire was described in detail in Chapter 2.

c) Self-Reported Delinquency measure (SRD, Elliott and Ageton, 1980; Elliott et al., 1983; Huizinga and Elliott, 1981). This measure was also discussed at length in Chapter 2.

In addition, participants provided information pertaining to age and sex. 


\section{Procedure}

The participants in the male offender and comparison groups were presented with the above materials in a randomised order and asked to complete the questions as honestly as possible. There was no time limit given for completion but it was emphasised that individuals should not deliberate over any one question. All respondents were informed that no 'correct' answers existed and were reassured that all responses would be treated with strict anonymity, and that they should not state their names anywhere on the questionnaires.

The participants in the Faking Group firstly were asked to complete the SRD measure under the same instructions as the other groups. Following the completion of this test, the individuals in this group were given the remaining two measures in a random order. In this condition, the participants were given the following instructions (adapted from Furnham and Henderson, 1982):

'When completing these two questionnaires, we would like you to answer the questions in order to give the impression that you were a criminal; that is present yourself as you would imagine a convicted offender might. You need not be honest in your answers'.

These instructions were repeated orally to the participants approximately half way through the testing session. Participants were also told that they did not have a time limit to complete the materials, but were asked not to deliberate too long on any one question.

\section{$\underline{\text { Analysis }}$}

The correlations and frequencies for both the male offender and the comparison groups have been reported in Chapter 3.1 and will not be reported here.

For the Faking Group, however, frequency and percentage counts, means, standard deviations and Pearson's r correlations were calculated. 
Following this, one-way analyses of variance were performed to investigate differences between the means on each of the variables collected (age, personality, moral reasoning and offending history) for the three sample groups. In addition, age was used as a co-variate in subsequent analyses of co-variance, in order to control for the potentially mitigating effects of age differences across the three groups.

\section{Results}

\section{Frequencies and Percentages}

Frequency counts and percentages were calculated for all the categorical type data collected from the 'Fake' offender sample group. Similar results for the whole sample group, the male offender group and the male and female group combined were shown in the previous main result section. The variables used were sex, modal and global stage of moral reasoning.

\section{Moral Reasoning}

The tables below show the proportion and percentage of individuals reasoning at each of the modal and global stages of moral reasoning in the 'Fake' offender sample group. 
Table 4.2(1) - Frequencies and Percentages for Modal Stages of Moral Reasoning for the 'Fake' Offender sample group

\begin{tabular}{ccc}
\hline MODAL & \multicolumn{2}{c}{$\begin{array}{c}\text { 'FAKE' OFFENDER GROOP } \\
(N=46)\end{array}$} \\
STAGE & FREQ & $\%$ \\
\hline 1 & 00 & 00.00 \\
$1 / 2$ & 00 & 00.00 \\
2 & 15 & 32.61 \\
$2 / 3$ & 00 & 00.00 \\
3 & 26 & 56.52 \\
$3 / 4$ & 03 & 06.52 \\
4 & 02 & 04.35 \\
\hline
\end{tabular}

The majority of individuals in the faking group were found to reason morally at stage 3.

Table 4.2(2) - Frequencies and Percentages for Global Stages of Moral Reasoning for the 'Fake' Offender sample group

\begin{tabular}{ccc}
\hline GLOBAL & 'FAKE' OFFENDER GROOP \\
STAGE & FREQ & \multicolumn{2}{c}{$\%$} \\
\hline $\mathbf{1}$ & 00 & 00.00 \\
$\mathbf{1}(2)$ & 00 & 00.00 \\
$\mathbf{2 ( 1 )}$ & 00 & 00.00 \\
$\mathbf{2}$ & 01 & 02.17 \\
$\mathbf{2 ( 3 )}$ & 08 & 17.02 \\
$\mathbf{3 ( 2 )}$ & 08 & 17.02 \\
$\mathbf{3}$ & 23 & 48.93 \\
$\mathbf{3 ( 4 )}$ & 05 & 10.64 \\
$\mathbf{4 ( 3 )}$ & 02 & 04.26 \\
$\mathbf{4}$ & 00 & 00.00 \\
\hline
\end{tabular}

It can be seen that the majority of the individuals in the faking group reasoned morally at global stage 3 . 


\section{Correlational Analyses}

The data collected from the sample of individuals which completed the questionnaires while attempting to fake a young offender's responses were subjected to a Pearson's r correlational analysis. The variables were correlated with each other and are reported in terms of the category of these variables: demographic variables, personality variables, intelligence and moral reasoning variables, and offending history variables.

\section{Demographic Variables}

Looking firstly at demographic variables, only age was included in the investigation, the correlations calculated between age and the other variables are shown in Table 4.2(3).

Table 4.2(5) - Correlation Coefficients for Age and Personality Variables in the 'Fake' Offender Sample

\begin{tabular}{|c|c|c|c|c|c|}
\hline & $\mathbf{A G E}$ & $\mathbf{P}$ & $\mathbf{E}$ & $\mathbf{N}$ & $I$ \\
\hline $\begin{array}{l}\text { AGE } \\
\text { P } \\
\mathbf{E} \\
\mathbf{N} \\
\mathbf{L} \\
\text { SRD } \\
\text { PER } \\
\text { THEFT } \\
\text { MODAI } \\
\text { SRMS } \\
\text { GLOBAL }\end{array}$ & $\begin{array}{r}\prime \\
-0.02 \\
-0.04 \\
0.09 \\
0.03 \\
0.14 \\
-0.04 \\
0.29 \\
-0.07 \\
-0.13 \\
-0.09\end{array}$ & $\begin{array}{l}-0.02 \\
. \\
-0.25 \\
-0.23 \\
-0.68 * \star \\
0.00 \\
0.12 \\
0.06 \\
-0.36 * \\
-0.54 * * \\
-0.42 * \star\end{array}$ & $\begin{array}{c}-0.05 \\
-0.25 \\
/ \\
-0.35^{\star} \\
0.21 \\
0.20 \\
0.12 \\
0.14 \\
0.01 \\
0.13 \\
0.09\end{array}$ & $\begin{array}{c}0.09 \\
-0.23 \\
-0.35 * \\
/ \\
0.07 \\
-0.21 \\
-0.23 \\
-0.17 \\
0.14 \\
0.19 \\
0.14\end{array}$ & $\begin{array}{c}0.03 \\
-0.68 * \star \\
0.21 \\
0.07 \\
1 \\
-0.04 \\
0.04 \\
-0.09 \\
0.21 \\
0.38 * \star \\
0.31 *\end{array}$ \\
\hline
\end{tabular}

$* p<0.05 \quad * * p<0.01$

Age (AGE): no significant correlations were obtained between age and the other variables. 
$\underline{\text { Personality }}$

Table 4.2(5) gives the correlation coefficients calculated for the 'fake' personality scores.

Psychoticism (P): only showed negative significant correlations:

1) Lie scale ( $\mathrm{L}, \mathrm{r}=-0.68, \mathrm{p}<0.01$ ), indicating that the higher the psychoticism of an individual, the lower the L score: in other words the lower the tendency to answer in a purely socially desirable manner.

2) Modal stage of moral reasoning (MODAL, $r=-0.36, p<0.05$ ), indicating that the higher the psychoticism, the lower the stage of moral reasoning.

3) Sociomoral Reflection Maturity Score (SRMS, $r=-0.54, p<0.01$ ), the higher the psychoticism, the less mature the sociomoral reflection of that individual.

4) Global stage of moral reasoning (GLOBAL, $p=-0.42, p<0.01$ ), the higher the psychoticism, the lower the global stage of moral reasoning undertaken by an individual.

Extraversion (E): only showed one significant correlation with neuroticism $(\mathrm{N}, \mathrm{r}=-$ $0.35, \mathrm{p}<0.05)$, indicating that the higher the extraversion of an individual the lower the neuroticism.

Neuroticism $(\mathrm{N})$ : correlated significantly only with extraversion, described above.

Lie Scale (L): produced three significant correlations:

1) Psychoticism (P), described above; 2) Sociomoral Reflection maturity score (SRMS, $\mathrm{p}=0.38, \mathrm{p}<0.01$ ), indicating that the higher the tendency to answer the EPQ with socially desirable responses, the higher the maturity of moral reasoning; 3) Global Stage of moral reasoning (GLOBAL, $r=0.31, \mathrm{p}<0.05$ ), showing that the higher the tendency to answer the EPQ with socially desirable responses, the higher the global stage of moral reasoning. 
$\underline{\text { Sociomoral Reflection (Moral Reasoning) }}$

The three measures of sociomoral reasoning: Modal stage (MODAL), sociomoral reflection maturity score (SRMS), and global stage of moral reasoning (GLOBAL) were correlated with all the other variables. The correlation coefficients are shown in Table 4.2(6).

Table 4.2(6) - Correlation Coefficients for and Sociomoral Reasoning Variables in the 'Fake' Offender sample

\begin{tabular}{|c|c|c|c|}
\hline & MODAI & SRMS & GLOBAL \\
\hline AGE & -0.07 & -0.13 & -0.09 \\
\hline $\mathbf{P}$ & $-0.36 *$ & $-0.54 * \star$ & $-0.42 * \star$ \\
\hline $\mathbf{E}$ & 0.01 & 0.13 & 0.09 \\
\hline $\mathbf{N}$ & 0.14 & 0.19 & 0.14 \\
\hline I & 0.21 & 0.38 & $0.31 *$ \\
\hline SRD & 0.25 & 0.26 & 0.28 \\
\hline PER & 0.24 & $0.31 *$ & 0.34 * \\
\hline THEFT & 0.05 & 0.05 & 0.10 \\
\hline MODAI & / & $0.79 * \star$ & $0.70 * \star$ \\
\hline SRMS & $0.79 * *$ & I & $0.93 * *$ \\
\hline GLOBAI & $0.70 * \star$ & $0.93 * \star$ & 1 \\
\hline
\end{tabular}

$* \mathrm{p}<0.05 \quad * * \mathrm{p}<0.01$

All three of the moral reasoning variables correlated significantly and negatively with psychoticism $(\mathrm{P})$ described above, and global stage of moral reasoning produced a significant positive correlation with the lie scale (L) also described above. All three (fake) moral reasoning scores correlated significantly positively at the $\mathrm{p}<0.01$ level with each other, showing that those individuals which scored highly on one measure of moral reasoning also scored highly on the other two scores.

The 'faked' Sociomoral Reflection Reasoning Score (SRMS) correlated significantly with crimes committed against the person (PER, $r=0.31, p<0.05$ ), indicating that the greater the maturity of moral reasoning, the more crimes against the person committed. 
Global stage of moral reasoning also correlated significantly and positively with crimes committed against the person ( $P E R,=0.34, p<0.05$ ), again showing that the higher the global stage of moral reasoning, the greater the number of crimes committed against the person.

\section{Offending History}

The actual offending history of the 'faking' group was represented in three measures: Self Reported Delinquency (SRD), crimes committed against the person (PER) and crimes committed against property (THEFT). Table 4.2(7) shows the resulting coefficients.

Table 4.2(7) - Correlation Coefficients for Offending History Variables in the 'Fake' offender Sample

\begin{tabular}{lccc}
\hline & SRD & PER & THEFT \\
\hline AGE & 0.14 & -0.04 & 0.29 \\
$\mathbf{P}$ & 0.00 & 0.12 & 0.06 \\
$\mathbf{E}$ & 0.20 & 0.12 & 0.14 \\
$\mathbf{N}$ & -0.21 & -0.23 & -0.17 \\
$\mathbf{I}$ & -0.04 & 0.04 & -0.09 \\
SRD & $/$ & $0.71 * \star$ & $0.78 * \star$ \\
PER & $0.71 * \star$ & $/$ & $0.59 * \star$ \\
THEFT & $0.78 * \star$ & $0.59 \star \star$ & $/$ \\
MODAI & 0.25 & 0.24 & 0.05 \\
SRMS & 0.26 & $0.31 *$ & 0.05 \\
GLOBAI & 0.28 & $0.34 *$ & 0.10 \\
\hline
\end{tabular}

$\star \mathrm{p}<0.05 \quad * * \mathrm{P}<0.01$

All three of the offending history variables, correlated significantly and positively with each other at the $p<0.01$ level, showing that the higher the general delinquency of an individual, the higher greater the number of crimes of property and against the person committed. In addition this also shows that the greater the number of thefts carried out, the greater the number of crimes committed against the person. 
Crimes against the person (PER) correlated positively with both sociomoral reflection maturity score (SRMS) and global stage of moral reasoning (GLOBAL) which were described in the moral reasoning section above.

\section{Analyses of Variance}

The differences between the scores on all of the variables between the male offender, male and female control group, and the 'fake' offender groups were analysed using analysis of variance (ANOVA). The means and results of the ANOVA's carried out are shown in the tables below.

\section{$\underline{\text { Age and Personality }}$}

Table 4.2(8) shows the results of the ANOVA's carried out to determine the significance of the differences in age and the four personality variables between the three sample groups. 
Table 4.2(8) - Means and Standard Deviations for Age and Personality Variables for the Male Offenders, Male and Female Controls and the 'Fake' Offenders and the results of the ANOVAs Calculated

\begin{tabular}{|c|c|c|c|c|c|c|}
\hline & & $\begin{array}{c}\text { MALE } \\
\text { OFFENDERS } \\
(\mathrm{N}=101)\end{array}$ & $\begin{array}{c}\text { MALE } \\
\text { AND FEMALE } \\
\text { CONTROLS } \\
(\mathrm{N}=108)\end{array}$ & $\begin{array}{c}\text { FAKE } \\
\text { OEFGNDER } \\
\text { SAMPLE } \\
(\mathrm{N}=48)\end{array}$ & $d f$ & F value \\
\hline AGE & $\begin{array}{l}x \\
S D\end{array}$ & $\begin{array}{c}19.14 \mathrm{a} \\
1.12\end{array}$ & $\begin{array}{c}19.56 \mathrm{ab} \\
1.07\end{array}$ & $\begin{array}{c}18.94 b \\
0.92\end{array}$ & 2,246 & $7.01 * \star$ \\
\hline $\mathbf{P}$ & $\begin{array}{l}x \\
S D\end{array}$ & $\begin{array}{l}4.74 a \\
2.53\end{array}$ & $\begin{array}{l}2.86 a \\
2.02\end{array}$ & $\begin{array}{l}8.08 a \\
3.79\end{array}$ & $2, \quad 242$ & $66.81 * \star$ \\
\hline $\mathbf{E}$ & $\begin{array}{l}x \\
S D\end{array}$ & $\begin{array}{l}8.71 \\
3.05\end{array}$ & $\begin{array}{l}8.21 \\
3.43\end{array}$ & $\begin{array}{l}7.69 \\
3.49\end{array}$ & $2, \quad 242$ & 0.97 \\
\hline $\mathbf{N}$ & $\begin{array}{l}x \\
S D\end{array}$ & $\begin{array}{l}6.05 \\
3.21\end{array}$ & $\begin{array}{l}6.57 \\
3.16\end{array}$ & $\begin{array}{l}6.33 \\
2.73\end{array}$ & 2,242 & 0.54 \\
\hline I & $\begin{array}{l}x \\
S D\end{array}$ & $\begin{array}{l}3.24 a \\
2.45\end{array}$ & $\begin{array}{l}3.06 \mathrm{~b} \\
2.14\end{array}$ & $\begin{array}{l}1.44 \mathrm{ab} \\
2.03\end{array}$ & $2, \quad 242$ & $10.93 * *$ \\
\hline
\end{tabular}

${ }^{*} \mathrm{p}<0.05 ; \quad *{ }^{*} \mathrm{p}<0.001$

(NB: Means with the same letters are significantly different to each other)

Age was found to differ significantly between the three groups $(F(1,246)=7.01$, $\mathrm{p}<0.001$ ). The male and female control group was found to be significantly older than the both the male and the 'fake' offender groups.

In terms of personality, only psychoticism (P) and the lie scale (L) showed differences which reached significance. The 'fake' offenders scored higher on $\mathrm{P}$ than both the male offenders and the male and female controls, while the male offenders scored higher on $\mathrm{P}$ than the male and female controls $(\mathrm{F}(1,242)=66.81, \mathrm{p}<0.001)$.

The 'fake' offenders scored significantly lower on $L$ than both the male offenders and the control group $(\mathrm{F}(2,242)=10.93, \mathrm{p}<0.001)$. No significant difference was found between the male offenders and the control group. 


\section{Moral Reasoning}

Table 4.2(9) shows the results of the ANOVAs carried out to determine the significance of the differences in moral reasoning variables between the three sample groups.

Table 4.2(9) - Means and Standard Deviations for Moral Reasoning Variables for the Male Offenders, Male and Female Controls and the 'Fake' Offenders and the results of the ANOVAs Calculated

\begin{tabular}{|c|c|c|c|c|c|c|}
\hline & & $\begin{array}{c}\text { MALE } \\
\text { OFFENDERS } \\
(\mathrm{N}=101)\end{array}$ & $\begin{array}{c}\text { MAIE } \\
\text { AND FEMALE } \\
\text { CONTROLS } \\
(\mathrm{N}=108)\end{array}$ & $\begin{array}{c}\text { FAKE } \\
\text { OFFENDER } \\
\text { SAMPLE } \\
(\mathrm{N}=48)\end{array}$ & $d f$ & F value \\
\hline MODAI & $\begin{array}{l}x \\
\text { SD }\end{array}$ & $\begin{array}{l}4.18 a \\
0.92\end{array}$ & $\begin{array}{l}5.53 \mathrm{ab} \\
0.88\end{array}$ & $\begin{array}{l}4.51 b \\
1.14\end{array}$ & $2, \quad 214$ & $46.53 * \star$ \\
\hline SRMS & $\begin{array}{l}x \\
S D\end{array}$ & $\begin{array}{c}252.46 a \\
33.55\end{array}$ & $\begin{array}{c}326.58 \mathrm{a} \\
28.50\end{array}$ & $\begin{array}{c}288.67 a \\
36.83\end{array}$ & 2,216 & $110.78 * *$ \\
\hline GLOBAL & $\begin{array}{l}x \\
S D\end{array}$ & $\begin{array}{l}5.65 a \\
1.05\end{array}$ & $\begin{array}{l}7.77 a \\
0.94\end{array}$ & $\begin{array}{l}6.63 a \\
1.28\end{array}$ & 2,216 & $92.35 * *$ \\
\hline
\end{tabular}

${ }^{*} p<0.05 ; * * p<0.001$

(NB: Means with the same letters are significantly different to each other)

With reference to moral reasoning, all three measures showed significant differences across the three sample groups. For modal stage of moral reasoning, the male and female control group reasoned at a significantly higher modal stage than both the male and the 'fake' offender groups $(F(1,214)=46.53, \mathrm{p}<0.001)$, although significance was not achieved for the modal stage difference between the latter two groups. The male and female controls both reasoned at a more mature level (SRMS, $F(1,216)=110.78, p<0.001$ ) and a higher global stage (GLOBAL, $F(2,216)=92.35, \mathrm{p}<0.001)$ than both the male offenders and the 'fake' offenders. The 'fake' offenders also reasoned more maturely and at a higher global stage than the male offenders. 
Offending History

Table 4.2(10) shows the results of the ANOVAs carried out to determine the significance of the differences in offending history between the three sample groups.

Table 4.2(10) - Means and Standard Deviations for Offending History Variables for the Male Offenders, Male and Female Controls and the 'Fake' Offenders and the results of the ANOVAs Calculated

\begin{tabular}{|c|c|c|c|c|c|c|}
\hline & & $\begin{array}{c}\text { MALE } \\
\text { OFFENDERS } \\
(\mathrm{N}=101)\end{array}$ & $\begin{array}{c}\text { MALE } \\
\text { AND FEMALE } \\
\text { CONTROLS } \\
(\mathrm{N}=108)\end{array}$ & $\begin{array}{c}\text { FAKE } \\
\text { OFFENDER } \\
\text { SAMPIE } \\
(\mathrm{N}=48)\end{array}$ & $d f$ & F value \\
\hline SRD & $\begin{array}{l}x \\
S D\end{array}$ & $\begin{array}{c}21.92 \mathrm{ab} \\
7.31\end{array}$ & $\begin{array}{c}11.33 a \\
5.63\end{array}$ & $\begin{array}{c}11.10 \mathrm{~b} \\
5.69\end{array}$ & $2, \quad 242$ & $79.92 * \star$ \\
\hline PER & $\begin{array}{l}x \\
S D\end{array}$ & $\begin{array}{l}3.84 \mathrm{ab} \\
2.03\end{array}$ & $\begin{array}{l}1.23 a \\
1.08\end{array}$ & $\begin{array}{l}1.02 \mathrm{~b} \\
1.25\end{array}$ & $2, \quad 242$ & $85.71 * \star$ \\
\hline THEFT & $\begin{array}{l}x \\
S D\end{array}$ & $\begin{array}{l}5.28 \mathrm{ab} \\
1.89\end{array}$ & $\begin{array}{l}1.35 a \\
1.54\end{array}$ & $\begin{array}{l}1.19 \mathrm{~b} \\
1.45\end{array}$ & 2,242 & $160.19 *$ \\
\hline
\end{tabular}

\footnotetext{
${ }^{*} \mathrm{p}<0.05 ; \quad * * \mathrm{p}<0.001$

(NB: Means with the same letters are significantly different to each other)
}

All three offending history variables showed significant differences. In all three cases male offenders committed significantly more general delinquency (SRD, $\mathrm{F}(2$, $242)=79.92, \mathrm{p}<0.001)$, crimes against the person $(\mathrm{PER}, \mathrm{F}(2,242)=85.71, \mathrm{p}<0.001)$ and thefts $(F(2,242)=160.19, \mathrm{p}<0.001)$ than both the male and female controls and the 'fake' offender groups. None of the differences between the male and female controls and the 'fake' offenders reached significance, for any of the offending history variables.

\section{Analysis of Co-variance}

The significant age difference between the male offenders, 'fake' offenders and the control group, could indicate that the differences between the three groups on the other variables could be due to age differences and not to offender status. For this reason 
further ANCOVA's were carried out using age as a co-variate. This procedure found that age was not responsible for the significant differences described above. 


\section{Discussion}

Following on from the main hypothesis, the present study aimed to investigate response bias to the EPQ and the SRM. This was achieved by examining lay individuals' ability to 'fake' offenders' responses on these tests. This examined two aspects: firstly how lay individuals conceptualise the personality and judgments of moral dilemmas of offenders; secondly whether the conceptions of offending described by H. J. Eysenck and Kohlberg are intuitive to lay individuals without the benefit of detailed knowledge of personality and moral reasoning.

However, the results would only be valid if the faking group was comparable to the non-convicted control group. If the fakers had been found to offended to the same degree as the convicted group, they could be responding as offenders and not as lay people. The results reported in table $4.2(10)$ showed that the faking group had committed significantly fewer offences than the convicted group but not the control group. This shows, as would be expected since they were drawn from a similar population, that both the fakers and the controls were adequately comparable.

With the original hypotheses in mind, the present discussion is divided into two main sections, one dealing with personality and the one with moral reasoning.

\section{Personality}

The main findings relating to lay conceptions of criminal personality were provided by the analyses of variance.

The results showed that with reference to personality variables only $\mathrm{P}$ showed significant differences across the three sample groups. The fake group was found to have significantly higher $\mathrm{P}$ scores than both the male offenders and the combined comparison group; while the male offenders had significantly higher P scores than the comparison group, as was reported in Chapter 3 and is discussed in Chapter 5. These findings suggest 
that $\mathrm{P}$ is predictive of both actual and lay conceptions of offending. With regard to $\mathrm{E}$ and $\mathrm{N}$ scores, no significant differences were obtained between the three groups on these variables.

Furnham and Henderson (1982) found that individuals which faked 'mad' responses also had higher P scores. Previous research (Furnham and Henderson, 1982; Velicer and Weiner, 1975) found differences in $\mathrm{E}$ and $\mathrm{N}$ scoring of various faking responses, in contrast to the present study, where $\mathrm{E}$ and $\mathrm{N}$ were not found to be predictive of either actual or lay conceptions of offending.

The fact that the fake group over-estimated the score of $\mathrm{P}$ when compared to the actual $\mathrm{P}$ scores of the convicted offenders is similar to the finding by Furnham and Henderson (1982) that 'mad' fakers scored higher on P than mental patients. This does not detract from the notion that lay people associate offending behaviour with high $\mathrm{P}$ scores in support of Eysenck's theory. In contrast to Eysenck's predictions, lay people do not associate $\mathrm{E}$ and $\mathrm{N}$ with offending. However, as pointed out by H. J. Eysenck, S. B. G. Eysenck and Barrett (1985) the P scales measures psychopathy rather than psychoticism, and hence can be seen as an extreme stereotype of offenders in general and therefore it would not be surprising that lay people endorse $\mathrm{P}$ items on the EPQ as being related to offending.

The Lie scale $(\mathrm{L})$ produced some interesting results. While the comparison and offender groups showed no significant differences, the fake offender group was found to have a significantly lower $\mathrm{L}$ score than both the other two groups.

Furnham and Henderson (1982) concluded that the L score was a good discriminator of those faking 'good' and 'bad' responses. They did not conclude any points relating to those faking 'mad' responses which in their study did not show any significant differences in L. In the present study, the results suggest that participants in the faking group were actually responding in a more socially desirable manner than either of 
the other groups. This is hardly surprising since the individual's in the fake group were responding according to their conception of an offender. Many of the Lie scale's items relates to honesty and petty crime (e.g. 'Have you ever taken anything (even a pin or a button) that belonged to someone else?'), which convicted offenders generally would have been expected to commit, therefore giving a false impression of honesty. What is

significant about the lower $\mathrm{L}$ score is that the majority of the fake group individuals did not suggest that offenders would in fact give false responses to the questionnaire, as may be expected from the general stereotype of offenders as dishonest.

\section{Moral Reasoning}

It may have been expected that the Sociomoral Reflection Measure (SRM) would have been less susceptible to bias and 'faking' since it intuitively seems to be less related to its actual purpose. In addition, as Walker et al. (1984) found, regression in moral stages is not possible, which is what would be required of the faking group to adequately fake offenders' responses to the SRM.

The analyses of variance results suggested that the SRM is indeed 'fakeable'. The findings showed that the faking group scored at a significantly higher moral stage than the offender group (for all three measures of moral reasoning), yet significantly lower than the comparison group (for SRMS and Global stage but not modal stage). Overall, this finding suggests that while lay individuals understand that the development of moral reasoning of offenders is lacking, they underestimate the degree to which this is so. This could be related to the finding that regression in moral reasoning is very difficult, so that an individual faced with the task of faking a lower stage invariably resort to higher stage principles to explain their reasoning. 
Previous research seems to have overlooked the possibility of response bias in the SRM and therefore it is not possible to compare the results of the present study to previous research results.

\section{Interrelation between Personality and Moral Reasoning}

The correlation results shown in tables 4.2(5) to 4.2(7) also indicated how personality and moral reasoning interacted within the fake group and gave indications as to the complexity of lay perceptions of offending.

As would be expected, no significant correlations were found between $\mathrm{E}$ and $\mathrm{N}$ and moral reasoning, since $\mathrm{E}$ and $\mathrm{N}$ were found not to differ across the three groups with relation to offending category (control, convicted offender, fake offender).

$\mathrm{P}$ was found to correlate significantly negatively with all three measures of moral reasoning. This indicates that the higher the $\mathrm{P}$ score the lower the stage of moral reasoning, and suggests that the faking group had some notion of the interactive nature of the two factors in predicting offending. The L scale correlated significantly positively with SRMS and Global but not modal stage of moral reasoning. This indicates that the greater the lie score the higher the stage of moral reasoning. If the hypothesis that the lie scale is a measure of offending behaviour in the faking group, rather than a measure of social desirability, is accepted, then it follows that the higher the offending behaviour (characterised by a low L score) the lower the moral reasoning stage. It may be that the $\mathrm{L}$ score is acting as an unsophisticated version of a self-reported delinquency scale in the faking group since it deals with minor offending and dishonesty.

In summary, it may be concluded that both the EPQ and the SRM are prone to response bias of some kind. Secondly, it can be concluded that lay theories include variables which have been included in formal theories and that the degree of sophistication of lay theories is reasonably high. 
It must be pointed out that the present study could have been improved by the addition of a fourth sample group. This could have involved a group of convicted offenders (comparable to the convicted group presented here) who would complete the two questionnaires while faking 'good'. In other words this group would be required to attempt to fill in the tests while imagining they had never committed an offence. This would provide an indication of how the tests are prone to social desirability bias, since offending behaviour is presumed to be socially undesirable.

The instructions given to the faking group, underestimated the respondents sophistication in their theories of crime causation, which is known to include different types of offending (Furnham and Henderson, 1983; Hollin and Howells, 1987). By asking respondents to fake being 'an offender' could have meant that they were forced to make generalisations they would not usually endorse.

Further research into the issue of response bias and lay perceptions of offending and their relation to personality and moral reasoning theory needs to include more specific descriptions of offending. This may be achieved by detailing a case study of an offence and asking participants to fake the responses of the offender involved. In addition the fourth sample group mentioned above needs to be included in order to have adequate comparisons. A further element to be investigated involves asking participants to detail, in their own words, how they view the involvement of moral judgement and personality and relating this to actual theory.

In general, it seems that lay individuals do have a similar view to offenders' characteristics as have formal theories. With regard to Eysenck's theory, lay perceptions seem to be more accurate than the theory in predicting actual results, while moral reasoning theories slightly underestimate reality.

Further discussion of the results reported in this study is included in Chapter 5. 


\section{CHAPTER 5}

\section{DISCUSSION}

In the studies presented in this thesis, the emphasis was placed on testing the offending behaviour theories of H. J. Eysenck (1964; 1970; 1977) and Kohlberg (1969); as well as other theories of criminality pertaining to intelligence and family background variables. Additionally, the interrelations between these theories were examined, and the issues of serious offending and response bias to the psychometric tests were also taken into account.

These theories were investigated in relation to both official measures of offending (i.e. conviction) and to self-reported levels of offending behaviour.

\section{Official Measures of Delinquency}

Official measures of delinquency were investigated by means of the analyses of variance, the results of which are shown in chapter 3.2 and the cluster analyses shown in chapter 3.3. These results showed that the convicted offender group was found to differ significantly from the comparison groups on several variables.

Results of the analyses of variance showed that the convicted offenders were significantly less intelligent than the control group. This supports predictions based on previous research. A review by Hirschi and Hindelang (1977) concluded that convicted offenders had lower IQ scores than non-convicted controls. This finding was also supported by Moffit et al. (1981); Moffitt and Silva (1989); Quay (1987); Reichel (1987); Reichel and Magnusson (1988); and West and Farrington (1977).

The convicted offenders where also found to be significantly less mature in their moral reasoning, and it was established that the differences in moral reasoning were not a result of either significantly lower intelligence or fewer years spent in education on the 
part of the convicted offenders. This finding provides support for Kohlberg's theory of criminality and matches previous predictions.

This result supports most of the findings from previous studies. In a review, Thornton (1987) reported that the majority of studies using official measures of delinquency found convicted offenders reasoned at lower stages of moral reasoning than comparison groups (e.g. Jennings et al., 1983). Blasi (1980), who reviewed 15 studies of moral reasoning in convicted offenders, also concluded that offenders had lower stages of moral reasoning than comparison groups. Nelson, Smith and Dodd (1990) conducted a meta-analysis of studies which had specifically tested the hypothesis of moral reasoning immaturity in delinquents and found strong support for the position that convicted delinquents were more immature in their moral reasoning than non-offenders. Similarly, Lee and Prentice (1988) found that convicted individuals had significantly lower stages of moral reasoning than non-convicted controls. The findings of studies which used the sociomoral reflection measure (SRM) as an indication of moral reasoning level (as in the present study) were also supported by the findings of the present study: Gibbs, Widaman and Colby (1982), and Gavaghan, Arnold and Gibbs (1983) both found that convicted offenders reasoned at significantly lower stages of moral reasoning than controls.

In relation to personality, convicted offenders were found to have significantly higher psychoticism scores than the comparison groups, but no differences in extraversion or neuroticism were found between these two groups. Furthermore, when the personality scores were looked at in combination using cluster analysis (reported in Chapter 3.3), a high $\mathrm{P}$ and $\mathrm{E}$ combination was found in the convicted offenders group but not in the control group.

H. J. Eysenck's $(1964,1970,1977)$ theory predicted that convicted offenders would be significantly higher on psychoticism $(P)$, extraversion $(E)$ and neuroticism $(N)$ than non- 
offenders. The present study only supported the prediction that convicted individuals were higher on $\mathrm{P}$.

The majority of previous research into H. J. Eysenck's $(1964,1970,1977)$ theory of criminality found that convicted individuals had significantly higher psychoticism scores than non-convicted controls (Bartol, 1980; H. J. Eysenck, 1987; H. J. Eysenck and Gudjonsson, 1989; Feldman, 1977; Powell, 1977). Most studies also found that convicted offenders scored higher on neuroticism than controls, a finding which was absent in the present study. However, as Eysenck's (1964) hypothesis suggests, neuroticism is less important in predicting delinquency at younger ages since ' $\mathrm{N}$ acts as a drive which multiplies with habit' (H. J. Eysenck, 1973), with adults when antisocial tendencies have developed into habits, the amplification of the habit by anxiety (higher in high $\mathrm{N}$ scorers) assumes greater importance, whereas in younger individuals the habit has not yet formed. In addition, some studies have found that extraversion (E) was higher in convicted individuals compared to controls (e.g. H. J. Eysenck, 1977). Hollin (1989) noted, however, that some studies showed no relation between conviction and extraversion, as found in the present study, and others showed that convicted offenders had significantly lower E than controls (e.g. S. B. G. Eysenck and H. J. Eysenck, 1971). As S. B. G. Eysenck and H. J. Eysenck (1971) suggested, this finding may be due to the fact that the E scale is composed of both sociability and impulsiveness, with the only the latter being associated with offending. Furthermore, different scores on both $\mathrm{N}$ and $\mathrm{E}$ have been found to be related to different types of offending (H. J. Eysenck, 1977; 1987) and data on this was not collected in the present study with reference to conviction.

However, H. J. Eysenck's theory relies on the combination of high P, E and N to explain criminality, therefore it would predict that convicted offenders would include a high $\mathrm{P}, \mathrm{E}$ and $\mathrm{N}$ cluster which would be absent in non-offenders. The high P-high $\mathrm{E}$ cluster found in the convicted group only partially supports this prediction, since $\mathrm{N}$ was 
not included. The theory also predicts that non-convicted individuals would include a low $\mathrm{P}, \mathrm{E}$ and $\mathrm{N}$ cluster which would be absent in convicted offenders. The present study did not find this personality combination in either the offenders or the controls.

Previous studies which investigated clusters of personality types and criminality were partly supported by the present study's finding. McEwan (1983) found a High Phigh E personality combination in convicted offenders as was found in the present study. In contrast, McGurk and McDougall (1981) and McEwan and Knowles (1984) found a high P-high E-high $\mathrm{N}$ personality combination in convicted offenders. Similar to the present study's results, McGurk and McDougall (1981) found a High P cluster and a High E-Low $\mathbf{N}$ cluster in their non-convicted comparison group. However, they also found a Low E-Low $\mathrm{N}$ cluster in this group, in contrast to the present study. It can be concluded that the pattern of clusters identified were similar to those obtained by previous studies and that differences can be attributed to methodological differences between the studies and to the definitions of 'high' and 'low' in the present study.

The present study both partially supports and contradicts the results of previous studies which investigated both moral reasoning and personality and their relation to official measures of offending. Addad and Leslau (1990) found that convicted offenders were higher on neuroticism and immoral judgement but not on extraversion; while Furnham and Barrett (1988) found no differences in moral reasoning between offenders and controls but found that both $\mathrm{E}$ and $\mathrm{P}$ were higher in delinquents. The fact that the present study found differences in moral reasoning can be attributed to the use of a more accurate measure of moral reasoning. The discrepancies in personality variables have already been discussed.

Finally, the convicted offenders were found to tend to come from socially and economically lower status backgrounds than the controls. This finding supports the findings of Fergusson et al. (1990), Wadsworth (1979), West (1982). However, results 
from the Cambridge study in delinquent development (West, 1982) predicted that convicted offenders would have a larger number of siblings which was not upheld in the present study, which could be due to the manner in which number of siblings were measured. The questions which asked for information relating to number of siblings, may not have been phrased in the best manner to obtain the information required and did not take into account the possibility of an individual coming from a broken family or being brought up in a children's home.

In summary, it can be concluded that official measures of delinquency were found to be associated with high psychoticism, low moral reasoning stage, low intelligence, and low socio-economic status.

\section{Self-Reported Delinquency}

Self-reported delinquency was investigated by using three variables: general selfreported delinquency (SRD), violent offences/crimes against the person (PER), and property offences (THEFT). The analyses which related to these variables were the correlational analyses (Chapter 3.1), the use of personality variables as independent variables (Chapter 3.3), the cluster analyses (Chapter 3.3), and the multiple regression analyses (chapter 3.4).

The correlations reported in Chapter 3.1 showed that psychoticism $(\mathrm{P})$ was found to be positively associated with both general self-reported delinquency (SRD) and thefts committed (THEFT). P was also found to be positively associated with violent offending (PER) although only in the whole sample group and not in the sample sub-groups.

Extraversion (E) was found to be positively related to self-reported delinquency and violent offending, but not thefts. However, E was not found to be associated with offending in all sample sub-groups. With regard to neuroticism (N), the only significant associations found were conflicting. In the female control group, $\mathrm{N}$ was found to be positively related to 
violent offending while in the male control group $\mathrm{N}$ was found to be negatively associated with violent offending.

These results have implications for Eysenck's theory of crime. Strong support for the prediction that $\mathrm{P}$ would be positively associated with self-reported offending was found. However, while there was support for both the positive associations between $\mathrm{E}$ and $\mathrm{N}$ and self-reported offending, it was not conclusive (this was especially the case for $\mathrm{N}$ where in one sample $\mathrm{N}$ was negatively associated with self-reported offending). These findings were similar to those found by Rushton and Chrisjohn (1981) who found positive correlations between $\mathrm{P}$ and $\mathrm{E}$ and self-reported offending, but no association with $\mathrm{N}$. Furnham (1984) found an association between high P and E scores but found a negative association between $\mathrm{N}$ scores and self-reported offending, similar to that found in the male control group of the present study. Powell (1977) found that self-reported offending correlated positively with $\mathrm{P}$, but was only associated with $\mathrm{E}$ and $\mathrm{N}$ within certain age ranges.

Other studies (Allsop and Feldman, 1976; Jamison, 1980; Silva et al., 1987) found full support for H. J. Eysenck's theory by reporting positive associations between P, E and $\mathrm{N}$ and self-reported offending, which was found in the female control group. The discrepancies in the relation of $\mathrm{N}$ to self-reported offending can be explained by reference to Eysenck's (1964) hypothesis that $\mathrm{N}$ is more important in predicting offending in older individuals when the anti-social tendencies have been developed into a habit. In the present study, many of the participants were relatively young and therefore it would be expected that $\mathrm{N}$ may not have been very important. The association between $\mathrm{E}$ and selfreported offending was not found in all sample groups probably as a result of the scale encompassing both sociability and impulsiveness, with only the latter being related to offending (H. J. Eysenck and S. B. G. Eysenck, 1971). Therefore, it would not be expected that $\mathbf{E}$ would be related to offending in all sample groups. 
Previous research into types of offences and personality have tended to have been carried out using official rather than self-reported measures of offending. Nevertheless, parallels can be drawn from previous studies. S. B. G. Eysenck, Rust and H. J. Eysenck (1977) found that offenders not specialising in any particular type of offending had high $\mathrm{P}$, $\mathrm{E}$ and $\mathrm{N}$, while conmen had lower $\mathrm{P}$ scores. Violent offenders were characterised by high $\mathrm{P}$, low $\mathrm{N}$ and high $\mathrm{E}$ scores, while property offenders were characterised by high $\mathrm{P}$, low $\mathrm{N}$ and low E. Mitchell et al. (1980) found support for the notion that violent offenders tended to have lower $\mathrm{N}$ scores. The present study's results generally support these previous results, which found that general, violent and property offending is related to high P scores, and that high $\mathrm{E}$ scores are associated with violent but not property offending. Since $E$ is composed of both sociability and impulsiveness, and the latter is related to offending, it would not be expected that $\mathrm{E}$ would be found to be related to offending in all sample groups. The results also found that low $\mathrm{N}$ was related to violent offending in the male control sample, but the opposite was found in the female control sample group. The discrepancy found in $\mathrm{N}$ could be accounted for by Eysenck's (1964) hypothesis that $\mathrm{N}$ is more important in predicting delinquent behaviour in older individuals than those used in the present study.

However, the present study contradicts the results of Hindelang and Weis (1972) who found that high $\mathrm{E}$ and $\mathrm{N}$ scores were associated with general delinquency but not with major theft or aggression.

In summary, it can be said that the correlational analysis provided a great deal of support for the notion that self-reported offending is related to high $\mathrm{P}$ and $\mathrm{E}$ scores. High E scores were also found to be associated with violent offending and some evidence was provided for an association between low $\mathrm{N}$ scores and violent offending. 
The results of dividing the personality scales into high, middle and low shown in Chapter 3.3 also provided some support for H. J. Eysenck's theory of crime. The results also had implications for personality and type of offending.

In the convicted offender group, none of the levels of extraversion (E) and neuroticism $(\mathrm{N})$ were found to differ in any of the types of self-reported offending. In the whole sample group, the high P group was found to have significantly higher SRD and theft scores, but it was the middle P group which had the significantly higher violent offending score. The high E group in the whole sample was significantly higher on SRD, violent offending and thefts. The low $\mathrm{N}$ group in the whole sample was found to have significantly higher SRD and theft scores.

In the combined control sample, the high E group had significantly higher SRD scores and the low $\mathbf{N}$ group had significantly higher theft scores. Previous research, showed a varying degree of agreement with the predictions of H. J. Eysenck's personality theory of crime in relation to self-reported offending. The review by Furnham and Thompson (1991) found several studies which supported the notion that high SRD scorers scored higher on P, E and N (Allsop and Feldman, 1976; Jamison, 1980, Silva et al. 1987). Other studies (Powell, 1977; Furnham and Thompson, 1991; Rushton and Chrisjohn, 1981), however, have found no significant associations between self-reported offending and either E, $\mathrm{N}$ or both. The present study partially supported Eysenck's theory: ii two sample groups, high $\mathrm{E}$ was found to be associated with high self-reported delinquency to some degree and high $\mathrm{P}$ was associated with higher SRD in the whole sample.

However, the finding most contradictory of Eysenck's theory was that found in several of the sample groups, that low $\mathrm{N}$ was associated with higher self-reported offending. This result was also found by Furnham (1984) who explained the discrepancy in terms of Eysenck's (1964) original hypothesis that $\mathrm{N}$ is more important in predicting offending behaviour in adults when the anti-social tendencies have developed into a habit. 
The relationship between personality combinations and self-reported offending, which was investigated using the cluster analyses shown in Chapter 3.3, was found to be less successful in matching predictions from theory and previous research. The only significant difference in self-reported delinquency scores across the clusters identified in both the convicted offenders and the combined controls was between two of the offender group clusters. The cluster characterised by high extraversion was found to have a lower general self-reported delinquency score than the cluster characterised by high Neuroticism. No differences in self-reported offending were found across the clusters identified in the combined control group.

Previous research which has used the method of clustering to investigate personality in combination (McGurk and McDougall, 1981; McEwan, 1983; McEwan and Knowles, 1984) have not investigated self-reported offending. Therefore, it is not possible to directly compare the present study's to previous research findings. It was expected, however, that the cluster characterised by high E-high $\mathrm{P}$ would have the greatest selfreported offending score. The finding that the high E cluster in the offender group had a larger SRD score than the high $\mathrm{N}$ cluster supports Eysenck's theory if it is assumed (as did Eysenck, 1964) that $\mathrm{N}$ is more important in predicting offending in older individuals when anti-social habits have been developed. In younger individuals, as in the participants of the present study, E may be more important in determining offending level and hence the significant difference. In addition, differences in offending rates of the clusters may not have been found due to the definitions of 'high' and 'low', which were defined somewhat subjectively.

Overall, evidence from the ANOVAs carried out on three levels of P, E and N and the cluster analyses support Eysenck's theory in relation to self-reported offending. High P and $\mathrm{E}$ scorers were found to have committed more self-reported offending and low $\mathrm{N}$ was associated with less offending, although this was attributed to the young age of the 
participants. The clusters found, which were similar to those obtained in previous research, show that a personality combination characterised by high $\mathrm{E}$ was associated with self-reported offending, again providing support for Eysenck's theory.

Similarly supporting findings were found in the correlational analyses (Chapter 3.2) in relation to moral reasoning and self-reported offending, where lower stages of moral reasoning were associated with greater self-reported offending. In the whole sample group, all three moral reasoning scores were positively associated with all three measures of selfreported delinquency. However, in both the male offender and female control groups no significant associations were found between moral reasoning and self-reported offending, while in the male control group only sociomoral reflection maturity score (SRMS) was found to be positively associated with all three types of self-reported offending. In the combined control group, violent offending/crimes against the person (PER) was found to be positively associated with both SRMS and global stage of moral reasoning.

These results provide fairly strong support for Kohlberg's criminality theory. The predictions that low moral reasoning stages would be associated with high self-reported offending were upheld in some sample groups. However, for some sample groups, moral reasoning was only associated with certain types of offending, which suggests that moral reasoning is differentially predictive of offending depending on sample group and type of offending (cf. Thornton and Reid, 1982). Previous studies which have used self-reported measures of offending in general tended to find very little association between offending and moral reasoning maturity in contrast to the findings of the present study (Emler et al., 1978; Lanza-Kaduce et al., 1983; Renwick and Emler, 1984; Tsujimoto and Nardi, 1978). The present study represents an advance in terms of associating moral reasoning to selfreported delinquency, and it is possible that the measures of moral reasoning used in the previous studies were not accurate enough to detect subtler differences in moral reasoning between high and low self-reported offenders. It is also possible that the measure of self- 
reported violent and property offences used in the present study did not accurately reflect subtle differences in offending behaviour resulting from lower moral reasoning maturity. The absence of associations between the measures of self-reported offending and modal stage score can be attributed to the fact that the latter score may not be sufficiently discriminating in terms of moral reasoning stage compared to global stage and especially the sociomoral reflection maturity score. In general, it can be concluded that high selfreported offending was found to be associated with lower stages of moral reasoning.

Intelligence scores were found to be positively correlated with all three selfreported offending scores in the whole sample group only. In the sample sub-groups no significant associations were found between intelligence and self-reported offending. This supported the prediction from previous studies that intelligence is related to offending behaviour.

Hirschi (1969) found a significant positive association between intelligence and self-reported delinquency. The reviews by Quay (1987) and Reichel (1987) included several studies which found that intelligence was positively associated with self-reported delinquency. The reason why the association was only found in the whole sample group, and not in the convicted and control groups could be attributed to the effect of intelligence being in a small high range in the controls and a small low range in the controls. When these two groups were combined to form the whole sample group, a greater range of intelligence scores were obtained. In conclusion, it can be said that high self-reported offending was found to be related to low intelligence.

No significant correlations were found between number of siblings and self-reported offending. High socioeconomic status (SES) was found to be correlated with lower selfreported delinquency of all three types in the whole sample group. However, SES was not significantly associated with self-reported offending in the sample sub-groups, with the exception of high socio-economic groups being associated with violent offending in the 
female control group. In contrast, the predicted association between a larger number of siblings and high self-reported offending was not found.

Elliot and Ageton (1980) also found that low socio-economic status was significantly associated with self-reported delinquency. Rutter and Giller (1983) found that SES may be more important in predicting violent offending as was found in the female control group. The reason why the association was not found in all the sample sub-groups could be due to the fact that in the sub-groups smaller ranges of SES existed which created a larger range when they were combined to form the whole sample group. However, the association between a larger number of siblings and offending, as was found by West (1982), was not found in the present study. This absence could be due to the phrasing of the questions which elicited information regarding number of siblings. The questions did not take into account the possibility of an individual coming from a broken home and/or a children's home. To a great extent the questions assumed that the participants childhood was relatively stable, which is not always the case especially in convicted individuals.

In conclusion, high self-reported delinquency was found to be associated with low socio-economic status but was not found to be associated with family size.

In summary, self-reported offending was found to be associated with high psychoticism and extraversion and that personality combinations characterised by high extraversion tended to score higher on self-reported delinquency. High self-reported delinquency was also found to be associated with low moral reasoning stages, low intelligence and low socio-economic status. Additionally, high $\mathrm{E}$ and high $\mathrm{N}$ scores were found to be associated with violent offending.

This contrasted with the results relating to official measures of offending in terms of extraversion, since official offending was found to be associated with high $\mathrm{P}$, low moral reasoning stage, low intelligence and low socio-economic status. It may be the case that extraversion is only seen to be important in predicting offending when degree of offending 
is taken into account, which is not the case when official measures of offending are used. These findings support previous findings and the theories of H. J. Eysenck and Kohlberg. The exception to this was an association between offending and neuroticism (N) which can be explained with reference to the hypothesis (H. J. Eysenck, 1964) that $\mathrm{N}$ is not important in predicting offending at younger ages.

\section{Interrelations between Variables}

The present study also examined the interaction between the variables studied: personality, moral reasoning, intelligence and family background; and their relation with criminality. In particular, emphasis was placed on the way in which personality and moral reasoning variables were associated with each other, in order to reveal the ways in which the criminality theories of $\mathrm{H}$. J. Eysenck and Kohlberg interact.

The results of the correlational analyses (Chapter 3.1); the use of personality as an independent variable analyses (Chapter 3.3); the cluster analyses (Chapter 3.3) and the multiple regression analyses (Chapter 3.4) all provided evidence to suggest that the variables were indeed related to each other.

The correlational analyses reported in Chapter 3.1 showed, to a certain extent, that personality was related to moral reasoning. In the whole sample group, psychoticism (P) was found to be negatively related to all three moral reasoning variables, although no other significant correlations were found between the personality variables and moral reasoning in any of the other sample groups. Martin (1985) partially supported this finding, since he found that high $\mathrm{P}$ and $\mathrm{E}$ scorers were associated with values which opposed social norms, which could be argued are related to lower stages of moral reasoning.

Some of the correlations also suggested that the three personality variables $(\mathrm{P}, \mathrm{E}$ and $\mathrm{N}$ ) were also related to each other. In the whole sample and the combined control groups, both psychoticism $(\mathrm{P})$ and extraversion $(\mathrm{E})$, correlated significantly and negatively 
with neuroticism $(\mathrm{N})$, and in the male control group only $\mathrm{E}$ was negatively correlated with $\mathrm{N}$. In the convicted offender and the female control groups, no significant correlations were found between $\mathrm{P}, \mathrm{E}$ and $\mathrm{N}$. These associations are counter to the norms shown in the Eysenck personality questionnaire (EPQ) manual which suggests that the three variables are unrelated to each other (H.J. Eysenck and S.B. G. Eysenck, 1975).

The association between $\mathrm{P}$ and moral reasoning provided some evidence for the fact that both personality and moral reasoning are related in the same individuals, and that the higher the $\mathrm{P}$ score, the lower the moral reasoning stage. Both these factors (high $\mathrm{P}$ and low moral reasoning) were also found to associated with both official and convicted measures of offending which could act as mediating variables. However, if this was the case, extraversion and neuroticism would also be predicted to be associated with moral reasoning which was not the case. This could be due to the fact that $\mathrm{N}$ is more important in predicting adult offending as described earlier, and that $E$ included both sociability and impulsiveness with only the latter related to offending.

Some evidence was also found to support the notion that personality was associated with intelligence. In the whole sample group, but not in the other sample groups, psychoticism correlated significantly and negatively with intelligence. In the convicted offender group, but not in any other sample group, extraversion correlated positively with intelligence. Both high psychoticism and low intelligence were also found to be associated with offending behaviour which again could be acting as a mediating variable. However, while high $\mathrm{E}$ was found to be associated with offending, high intelligence was not. H. J. Eysenck and S. B. G. Eysenck (1975) also reported that P was negatively correlated with intelligence, although no associations between $\mathrm{E}$ and intelligence were reported. It is possible that the sociability element of E stimulates individuals to achieve educationally which then provides an advantage in completing intelligence questionnaires. 
Intelligence and moral reasoning were found to be strongly associated. In all sample groups significant positive correlations were found between intelligence and moral reasoning. This finding was predicted by Kohlberg's theory of moral reasoning development (Kohlberg, 1976), which hypothesises that intellectual development parallels moral development.

The results shown in Chapter 3.3 where personality was investigated as an independent variable, also provided some evidence to suggest that the variables measured were related to each other. In the whole sample group the low P scorers had significantly higher moral reasoning as shown in the sociomoral reflection maturity score (SRMS) and global stage score. No other differences were found in moral reasoning across the levels of P, E and N. These results are similar to those found by Martin (1985) who found that high $\mathrm{P}$ and $\mathrm{E}$ scorers held values which opposed social norms (which could be equated with lower stages of moral reasoning). The finding that $\mathrm{E}$ was not related to moral reasoning may again be explained with reference to the hypothesis that $\mathrm{E}$ consists of sociability and impulsiveness with only the latter related to anti-social values. The confounding effect of sociability could have prevented the association between $\mathrm{E}$ and moral reasoning.

In the whole group sample the high $\mathrm{P}$ group was found to have significantly lower intelligence than the low P group; while in the convicted offender group those which had scored in the high $\mathrm{E}$ range had significantly higher intelligence. No other significant differences in intelligence across the levels of personality in any of the sample groups were found to be significant. The norms presented in the Eysenck Personality Questionnaire (EPQ; H. J. Eysenck and S. B. G. Eysenck, 1975) showed that P, but not E or N, is negatively related to intelligence. It is possible that high $\mathrm{E}$ was related to high intelligence because the sociability element of $\mathrm{E}$ stimulates individuals to achieve educationally which would give them an advantage in completing intelligence questionnaires. 
The results of the analyses of variance calculated to compare the clusters identified in both the convicted offender and the combined control groups (reported in Chapter 3.3), showed that no difference in either moral reasoning or intelligence existed across any of the clusters. This finding was counter to the expectation that personality combinations would have differed in terms of other variables.

The results of the correlations and the use of personality as an independent variable provide evidence to suggest that personality, moral reasoning and intelligence are related to each other. Coupled with the findings that these variables are also related to offending, it seems probable that they all interact to contribute towards offending behaviour.

The results of the multiple regression analyses reported in chapter 3.4 produced models which showed the variables which best predicted self-reported offending in the sample groups. These provided an indication of the way in which the variables measured interacted to predict criminality. However, as was found in relation to other analyses regarding self-reported offending, certain differences according to sample group and type of offending were apparent.

The strongest finding was that psychoticism (P) was included in all the models of self-reported offending except for the model of general self-reported delinquency (SRD) in the male control group. This supports H. J. Eysenck's (1964) theory and the absence of P in the model of the male control group could be a result of the small size of the group. Extraversion (E) was included in the models for: SRD in the whole sample and the male control groups; for violent offending (PER) in the whole sample group; and for theft in the convicted offender group. Since high extraversion was found to be associated with general, violent and property offending as discussed earlier in this chapter, the models may simply be reflecting the associations. Neuroticism (N), however, was only included in the model for violent offending (PER) in the female control group. The correlational analyses reported in Chapter 3.2 and discussed earlier, found that low $\mathrm{N}$ scores were associated with 
greater violent offending, perhaps this effect was reflected in the model for the female controls.

It is interesting to note that the lie score (L) of the Eysenck personality questionnaire was included in all the models apart from those found in the male control group. This could indicate that the honesty of the participants is very important in predicting offending, or that the items in the L scale are similar to the items in the selfreported delinquency scale (since both scales involve items which describe socially undesirable behaviours).

Furthermore, moral reasoning of one form or another (either sociomoral reflection maturity or global stage of moral reasoning) was included in all the models in the whole sample group and in the model for general self-reported delinquency (SRD) in the male control group. The absence of moral reasoning in certain models for some sample groups may be due to small ranges in the scores of moral reasoning stages in the sub-groups which were combined to make the whole sample group.

In addition, some of the models included either one or both of the number of siblings variables, which is the only evidence found in the present study to support the notion of West (1982) that those individuals with a large number of siblings will tend to offend. Many of the models included years spent in education, and some socio-economic status variables. Intelligence was completely absent from any model, suggesting that it is not lower intelligence itself which predicts offending behaviour in convicted offenders but that there is a related mediating variable which may be moral reasoning and/or psychoticism.

The results of the regression analyses further contribute to the notion that moral reasoning, personality and socio-economic factors contribute to self-reported offending. In contrast to the findings from the correlational analysis, however, intelligence was not found directly to predict offending, even though this was found to be strongly associated to both 
official and self-reported measures of offending. This can be explained by assuming that intelligence is related to offending behaviour through the mediating factors of moral reasoning and psychoticism which were also found to be related to offending and intelligence.

In summary, it was found that offending (both official and self-reported) was related to high psychoticism and extraversion, lower moral reasoning maturity, and lower intelligence (perhaps through mediation by moral reasoning and lower socio-economic status). Neuroticism was not found to be important in predicting offending in the age group used, but was assumed to be involved in older individuals when offending behaviour had developed into a habit. These variables were also found to interact to predict offending behaviours. Some of these variables (notably extraversion and neuroticism) were found to be related to specific types of offending: namely violent versus property offences.

A cautionary note must be included with reference to completion of the sociomoral reflection measure (SRM) by convicted offenders. As was suggested in Chapter 3.5, some of the responses were unscorable by virtue of encompassing reasoning elements not taken into account in the manual. This could indicate that different social values exist in convicted offenders which could interfere with the way in which moral reasoning operates in decisions to offend. It seems reasonable to assume that the acquisition of correct social rules is required prior to moral reasoning being predictive of offending. If an individual does not know (or agree) that a particular behaviour is anti-social he or she is unable to reason in favour of not offending.

This seems to provide a link between H. J. Eysenck's theory, which is largely based upon the acquisition of social rules, and Kohlberg's theory which, based on the suggestion in Chapter 3.5, also requires knowledge of social rules for efficient moral reasoning. 


\section{Model of Offending Behaviour}

The findings of the present study suggest that a tentative model of offending largely based on H. J. Eysenck and Kohlberg's theories can be put forward.

An individual with a personality, largely based upon genetic factors, which is described by the Eysenck Personality Questionnaire (EPQ) as high psychoticism (P) high extraversion $(\mathrm{E})$ and high neuroticism $(\mathrm{N})$ would tend to engage in more anti-social activity for two reasons. Firstly, high $\mathrm{P}$ is characterised by hedonistic, egocentric and unempathic behaviours which tend to be anti-social. Secondly, high E results in a genetic tendency for poor conditionability (for reasons explained in H. J. Eysenck, 1964, 1970, 1977, 1987) and therefore the individual will not adequately learn not to engage in antisocial activities. Poor conditionability could also lead to the individual not adequately learning social rules in society, which in turn could lead to the individual not being able to apply social rules correctly in making moral reasoning decisions. Moral reasoning would also tend to be immature since the development of high moral reasoning requires high intelligence and high $\mathbf{P}$ is related to low intellectual capacity. An individual with immature moral reasoning capacity, and a deficit in knowledge concerning socially approved rules, will tend to offend if presented with opportunities to do so (partially for reasons described by Kohlberg, 1976). High neuroticism $(\mathrm{N})$, is characterised by high anxiety which multiplies the anti-social activities once they have developed into a habit in adulthood. Low socio-economic status is associated with less parental and economic support for both social and academic learning. These factors would tend to aggravate an individual's low intelligence and poor conditioning against anti-social behaviour.

This model takes into account most of the results found in the present study. Although it must be noted that the impulsivity aspect of extraversion may be more important in developing offending behaviour than the sociability aspect. The contribution 
of $\mathrm{N}$ is not very clear since some support was found to suggest that low $\mathrm{N}$ was related to high offending at young ages which does not seem to fit the above model.

Additionally, most of these 'person' variables may be aggravated by 'situational' ones such as current living circumstances, early upbringing, and crisis in an individual's life to result in offending behaviour. Thus, the model also incorporates situational variables included in Clarke's (1977) model of criminality. Figure 5.1 illustrates the model presented. 
Figure 5.1 - Diagram to illustrate Model of offending behaviour (partially adapted from Clarke, 1977)

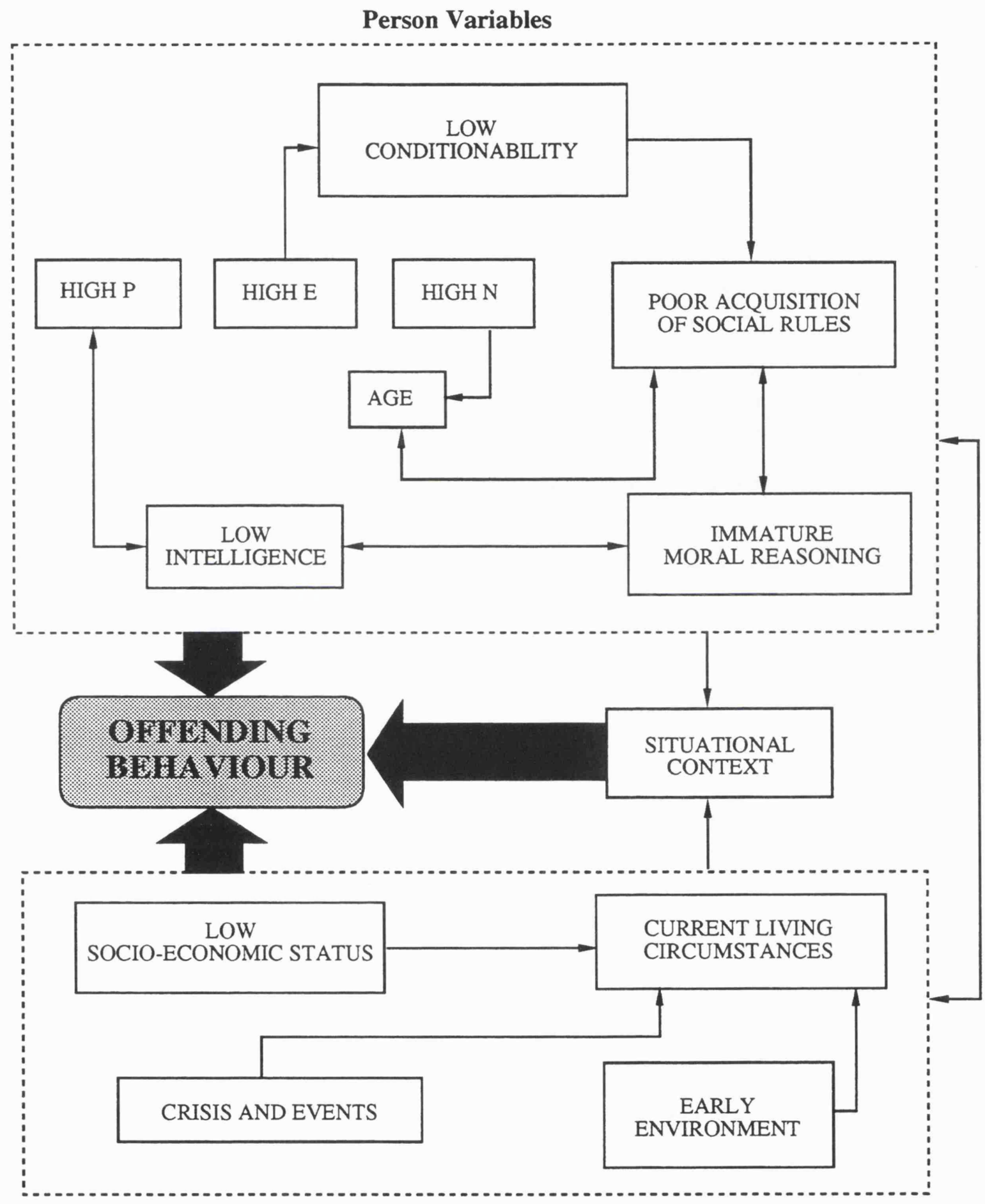

Situational Variables

No Direction

Likely Direction of Relationship 


\section{Disturbed Children and Response Bias}

Chapter 4 included the findings of two studies. One which investigated the personality, moral reasoning, intelligence and family background of seriously disturbed children, and another which investigated response bias to the Eysenck personality questionnaire (EPQ) and the Sociomoral Reflection Measure (SRM).

The findings relating to the personality, moral reasoning, intelligence and social background of disturbed children resident at Glenthorne Youth Treatment Centre showed parallels with the results relating to convicted offenders. Both the Glenthorne group and the convicted offenders had a similar level of intelligence, which was lower than that of the comparison group. However, as already has been noted the relationship between intelligence and offending may be mediated by other variables. Moral reasoning, which may be a mediating variable between intelligence and offending behaviour in the Glenthorne group, was found to be significantly lower in the Glenthorne sample than in both the convicted group and the non-convicted comparison group. The Glenthorne group were also found to be of lower socio-economic status and to have spent fewer years in education than both the convicted and the control groups. However, no differences in any of the personality variables were found between the Glenthorne groups and either the convicted or the control group.

All associations between the offending committed by the Glenthorne residents and the variables measured were found to be non-significant. Therefore, the significant differences discussed above cannot be directly attributed to the offending level of these individuals. The Glenthorne residents are different to convicted offenders and controls in more ways than just their offending behaviours. Thus, comparison of the present study's results to previous research which has looked at the variables predictive of offending behaviour would not be relevant. 
In conclusion it seems that, in contrast to convicted individuals, Glenthorne residents are not characterised by genetically determined personality variables but rather by general familial deprivation which results in the poor development of moral reasoning and intelligence. This conclusion fits the model suggested above, whereby, low socioeconomic status, which is associated with social and economic deprivation, would tend to reduce the social conditioning and intelligence of individuals, and result in lower stages of moral reasoning. Faced with a situational context where an individual would have to decide whether or not to offend, he or she would have a greater tendency to decide to offend or an inability to control anti-social behaviour.

The results reported in Chapter 4.2 showed that the tests employed to measure personality and moral reasoning were prone to a degree of response bias. In addition, the results also suggested that lay perceptions of offending include concepts also included in the formal theories of H. J. Eysenck and Kohlberg and tend to be complex. Based on social stereotypes of offenders, it seems possible that convicted individuals may overestimate their 'criminality' in their responses to the Eysenck Personality Questionnaire while comparison groups would underestimate their 'criminality'. This would result in artificial differences in personality between offenders and controls. The results of the 'faking' study presented herein suggest that it would be the P scale which would be most discriminating if this bias was present.

Previous research has almost invariably shown a significant difference in $\mathrm{P}$ between convicted offenders and controls. The proportion of these results which could be due to this 'stereotype' bias is unknown and needs to be more carefully and clearly examined.

\section{Criticisms of Methodology}

Like many studies investigating offending behaviour, the present study has its limitations. The first concerns the use of the self-reported delinquency questionnaire. 
While many improvements were made to this measure, the possibility that the participants were not responding honestly cannot be dismissed. The results of the Lie (L) scale score to the EPQ however, suggest that generally participants were responding honestly and the negative correlation between $\mathrm{L}$ and self-reported offending suggest some degree of inaccurate reporting. In addition, the violent and property offence scales were a general indication rather than an accurate prediction of these types of offending carried out, and hence the predictions made regarding these two scales cannot be considered very strong.

The second problem with the methods employed was the composition of the comparison groups. These groups were predominantly middle-classed, above-average intelligence and educational achievement, in addition, a large proportion of the combined control group was female. The convicted offender group consisted of lower classes, below-average intelligence, less educational achievement, and was entirely composed of males. While these differences may be predictors of delinquency and were taken into account in co-variance analyses, there may be other mediating variables which were not taken into account. In addition, no controls were taken with respect to types of offences for which the offender group had been convicted. Different types of offence are related to different personality combinations according to Eysenck's theory, as well as the implications for different types of offences being associated with different stages of moral reasoning. However, since many convicted individuals have been previously convicted for different offences it is highly unlikely that they can be accurately categorised as one type of offender. This issue is further complicated by the fact that some convicted individuals are frequent offenders and others are 'one off' offenders, and therefore it is not possible accurately to classify offenders as one type or another.

The problem of literacy level in the convicted offender group must also be addressed. The literacy level/reading age required to understand and accurately respond to the sociomoral reflection measure (SRM) is relatively high. It is possible that the reading 
age of convicted offenders is too low for the accurate assessment of their moral reasoning in the SRM. However, while this factor cannot be completely dismissed, the facts that the convicted offenders were only one moral stage lower than the controls; that the results were similar to those reported in previous research; and that participants were given the options of verbal presentations and clarifications of the SRM suggest that the bias created by literacy was not overly important.

Finally, some caution must be observed when interpreting the results of the cluster analyses since none of the clusters in each sample group differed significantly on each of the personality variables. In essence, the personality clusters identified may not be accurate representations of personality combinations. However, statistical significance may not be the optimum manner to distinguish personality combinations, since it is to be expected that there is a great deal of overlap in personality scores in a group of individuals.

\section{Further Research}

Further research into the prediction of offending behaviour needs to look specifically at the impulsivity aspect of the extraversion scale and its relation to offending when moral reasoning is also measured. This also needs to be investigated with reference to personality combinations in terms of cluster analysis. Age is another variable which needs to be carefully examined: It needs to be established if the importance of neuroticism in the prediction of offending does become stronger in older participants as suggested by H. J. Eysenck (1964) and Furnham (1984). Self-reported violent and property offending needs to be measured more accurately using a greater variety of offences and improving participants' frequency estimates for each offence. Furthermore, recent versus lifetime delinquency levels need to be examined. It seems that moral reasoning, as a developing factor which changes over time, would be expected to be associated with recent rather than 
lifetime delinquency and personality, which is a 'fixed' variable may show the opposite pattern.

The model of offending behaviour proposed in the present study has various testable aspects. The relation between poor conditioning and social rules needs to be more carefully examined by investigating the relation between knowledge of social rules and moral reasoning maturity, similar to the way Martin (1985) examined the relation of personality and social values. Further efforts need to be spent looking at explanations for the association between psychoticism and intelligence.

In conclusion, support for both Eysenck's and Kohlberg's theories were found and, initial steps were taken in incorporating various factors previously found to be associated with offending into a testable model of offending behaviour. This follows the call by Hollin (1989) for psychologically informed criminological models of offending behaviour. The tentative model presented here concentrates mainly on psychological factors but nevertheless represents an attempt to study criminal behaviour as a 'phenomenon deserving explanation in its own right' (Hollin, 1989; p. 61). 


\section{REFERENCES}

Abel, G. C., Gunningham-Rathner, J., Becker, J. V., and McHugh, J. (1983). Motivating sex offenders for treatment with feedback of their psychological assessment. Paper presented at the World Congress of Behavior Therapy, Washington, DC.

Addad, M., and Leslau, A. (1990). 'Immoral judgement, extraversion, neuroticism, and criminal behaviour, International Journal of offender Therapy and Comparative Criminology, 34, 1-13.

Allsop, J., and Feldman, M. (1975). Extraversion, Neuroticism and Psychoticism and antisocial behaviour in school girls. Social Behaviour and Personality, 2, 184-190. Allsop, J., and Feldman, M. (1976). Personality and antisocial behaviour in school-boys. British Journal of Criminology, 16, 337-351.

Anastasi, A. (1990). Psychological Testing (Sixth Edn.). Singapore: Macmillan.

Asch, S. (1952). Social Psychology Englewood Cliffs NJ: Prentice-Hall.

Bachman, J. G., Johnston, L. D. and O'Malley, P. M. (1987). Monitoring the Future: questionnaire Responses from the Nation's High School Seniors 1986. Ann Arbor: Institution for Social Research, University of Michigan.

Bale, R. N. (1979). When Four Months Equals a Year: Inconsistencies in Students Reports of Drug Use. Ann Arbor: Survey Research Center, University of Michigan. Barlow, G. (1979). Youth Treatment Centre. In C. Payne and K. J. White (Eds.), Caring for deprived children. London: Croom Helm.

Barrett, P. and Eysenck, S. B. G. (1984). The assessment of personality factors across 25 countries. Personality and Individual Differences, 5, 615-632.

Bartol, C. R. (1980). Criminal Behaviour: A Psychosocial Approach, Englewood Cliffs, NJ: Prentice-Hall. 
Bayless, D., Boesel, D. and Piper, L. (1978). Effects of survey conditions on victimization response and response quality in surveying school crime. Paper Presented at the American Statistical Association meetings, San Diego, California.

Berg, I. A. (1967). The deviation hypothesis: A broad statement of its assumptions and postulates. In I. A. Berg (Ed.), Response Set in Personality assessment. Chicago: Aldine.

Binder, A. (1988). Juvenile Delinquency. Annual Review of Psychology, 39, 253-282.

Blasi, A. (1980). Bridging moral cognition and moral action: a critical review of the literature. Psychological Bulletin, 88, 1-45.

Bloom, A., (1977). Two dimensions of moral reasoning: social principledness and social humanism in cross-cultural perspective. Journal of Cross-Cultural Psychology 101, 29-44.

Brown, R., and Herrnstein, R., (1975). Moral reasoning and Conduct. In Psychology. Boston: Iittle, Brown.

Burt, C. (1925). The Young Delinquent. London: University of London Press.

Byrne, D. (1975). Role-Taking in adolescence and adulthood. Unpublished doctoral dissertation, Harvard University.

Caplan, N. S. (1965). Intellectual Functioning. In H. C. Quay (ed.) Juvenile Delinquency. Research and Theory. Princeton, N. J.: Van Nostrand.

Clarke, R. V. G. (1977). Psychology and Crime. Bulletin of the British Psychological Association, 30, 280-283.

Chaiken, J. M., Chaiken, M. R., and Rolph, J, E. (1982). Varieties of Criminal Behaviour. Santa Monica: The Rand Corporation.

Colby, A. (1978). Evolution of a moral-development theory. In W. Dannon (Ed.). New Direction for Child Development: Moral Development Vol. 2. San francisco: Jossey-Bass.

Colby, A., Kohlberg, L., Gibbs, J., and Lieberman, M. (1983). A longitudinal study of moral judgement. Monograph of the Society for Research in Child Development, Vol. 48 no. 4. 
Colby, A., Kohlberg, L., Hewe, A., Candee, D., Gibbs, J., and Power, C. (1987). The Measurement of Moral Judgement Vol. 2: Standard Issues Scoring Manual. New York: Cambridge University Press.

Conley, J. J. (1984). The hierarchy of consistency: A review and model of longitudinal findings on adult individual differences in intelligence, personality, and selfopinion. Personality and Individual Differences, 5, 1126.

Conley, J. J. (1984). Longitudinal stability of personality traits: A multitrait-multimethod-multioccasion analysis. Journal of Personality and Social Psychology, 49, 12661282 .

Daum, J., and Bieliauskas, Y. (1983). Father Absence and Moral development of Male Delinquents. Psychological Reports, 53, 223-228.

Davison, M., and Robbins, S. (1978). The reliability and validity of objective indices of moral development. Applied Psychological Measurement 2, 391-403.

Department of Health (1991). Youth Treatment Service:

Background Information

Dewolfe, T., Jackson, L., and Winterberger, P. (1988). A Comparison of Moral Reasoning and Moral Character in Male and Female Incarcerated Felons. Sex Roles, 18, 583-593. Edwards, A. L. (1957a). The Social Desirability Variable in Personality Assessment and Research. New York: Dryden. Edwards, A. I. (1957b). Manual for the Edwards Personal Preference Schedule. New York: Psychological Corporation. Elliott, D. S. (1982). A review essay on "Measuring Delinquency" by M. J. Hindelang, T. Hirschi, and J. G. Weis. Criminology, 20, 527-537.

Elliott, D. S., and Ageton, S. S. (1980). Reconciling race and class differences in self-reported and official estimates of delinquency. American Sociological Review, 45, 95-110.

Elliott, D. S., and Huizinga, D. (1983). Social Class and delinquent behavior in a national youth panel: 19761980. Criminology, 21, 149-177. 
Elliott, D. S., and Huizinga, D. (1988). Improving Selfreported measures of delinquency. Paper prepared for the NATO workshop on Self-Reported Measures of Delinquency June 26-30.

Elliott, D. S., Huizinga, D., and Ageton, S. S. (1982). Explaining delinquency and drug use. The national youth survey project report No. 21. Boulder, Co : Behavioral Research Institute.

Elliott, D. S., Ageton, S. S., Huizinga, D., knowles, B., and Canter, R. (1983). The Prevalence and Incidence of Delinquent Behavior: 1976-1980 (The National Youth Survey Project Report number 26). Boulder CO: Behavioral Research Institute.

Emler, N., Heather, N., and Winton, M. (1978). Delinquency and the development of moral reasoning. British Journal of Social and Clinical Psychology, 17, 325-331.

Enright, R., Franklin, C., and Manheim, L. (1980). Children's distributive justice reasoning: a standardized and objective scale. Developmental Psychology 16, 193-202.

Eysenck, H. J. (1959). Manual of the Maudsley Personality Inventory. London: University of London Press.

Eysenck, H. J. (1964). Crime and Personality. London: Routledge \& Kegan Paul.

Eysenck, H. J. (1970). Crime and Personality (2nd edn). London: Granada.

Eysenck, H. J. (1973). Personality, learning and 'anxiety'. In H. J. Eysenck (ed.) Handbook of Abnormal Psychology (2nd Edn.). London: Pitman.

Eysenck, H. J. (1976). Sex and Personality. London: Open Books.

Eysenck, H. J. (1977). Crime and Personality (3rd edn). London: Routledge \& Kegan Paul.

Eysenck, H. J. (ed) (1981). A Model for Personality. New York: Springer.

Eysenck, H. J. (1982). The sociology of psychological knowledge, the genetic interpretation of IQ, and MarxistLeninist ideology. Bulletin of the British Psychological Society, 35, 449-451

Eysenck, H. J. (1984). Crime and Personality, in D. J. Muller, D. E. Blackman, and A. J. Chapman (eds) Psychology and Law. Chichester: Wiley. 
Eysenck, H. J. (1987). Personality theory and the problems of criminality, in B. J. McGurk, D. M. Thornton, and M. Williams (eds). Applying Psychology to Imprisonment: Theory and Practice. London: HMSO.

Eysenck, H. J., and Eysenck, M. W. (1985). Personality and Individual Differences. New York: Plenum Press. Eysenck, H. J., and Eysenck, S. B. G. (1968). A factorial study of psychoticism as a dimension of personality, Multivariate Behavioural Research (special issue), 15-31. Eysenck, H. J., and Eysenck, S. B. G. (1975). Manual of the Eysenck Personality Questionnaire (Junior \& Adult), Sevenoaks, Kent: Hodder and Stoughton.

Eysenck, H. J., and Eysenck, S. B. G. (1976). Psychoticism as a Dimension of Personality. London: Hodder \& Stoughton. Eysenck, H. J., and Eysenck, S. B. G. (1983). Recent Advances in the cross-cultural study of personality. In $\mathrm{J}, \mathrm{N}$. Butcher and C. D. Spielberger (Eds.), Advances in Personality Assessment (Vol. 2). Hillsdale N. J.: Erlbaum.

Eysenck, S. B. G., and Eysenck, H. J. (1971). Crime and Personality: Item analysis of questionnaire responses. British Journal of Criminology, 11, 49-62.

Eysenck, S. B. G., Eysenck, H. J., and Barrett, P. (1985). A revised version of the psychoticism scale, Personality and Individual Differences 6, 21-29.

Eysenck, H. J., and Gudjonsson, G. H. (1989). The Causes and Cures of Criminality. New York: Plenum Press.

Eysenck, S. B. G., Rust, J., and Eysenck, H. J. (1977).

Personality and the classification of adult offenders. British Journal of Criminology, 17, 169-179.

Eysenck, H. J., and Zuckerman, M. (1978). The relationship between sensation-seeking and Eysenck's dimensions of personality. British Journal of Psychology, 69, 483-487. Farrington, D. P. (1979). Longitudinal Research on crime and delinquency In N. Morris and M. Tonry (Eds.) Criminal Justice: An Annual Review of the Research (Vol. 1) Chicago: University of Chicago Press.

Farrington, D. P. (1987). Epidemiology. In H. C. Quay (ed.) Handbook of Juvenile Delinquency. New York: Wiley. 
Farrington, D. P., Gallagher, B., Morley, L., St. Ledger, R. J., and West, D. J. (1988) Are there any successful men from criminogenic backgrounds? . Psychiatry, 51, 116130 .

Farrington, D. P., Grundy, G., and West D. J. (1975) . The familial transmission of criminality Medicine, Science and the Law, 15, 177-186.

Feldman, M. P. (1977). Criminal Behaviour: A Psychological Analysis. Chichester: Wiley.

Fergusson, D. M., Horwood, L. J., and Lawton, J. M. (1990). Vulnerability to childhood problems and family social background. Journal of Child Psychology and Psychiatry, 7, 1145-1160.

Friedman. W., Robinson, A., and Friedman, B. (1987). Sex Differences in Moral Judgement? A Test of Gilligan's Theory. Psychology of Women Quarterly, 11, 37-46.

Froming, W., and McGolgan, E. (1979). Comparing the Defining Issues Test and the Moral Dilemma Interview. Developmental Psychology 15, 658-659.

Furnham, A. (1981). Personality and active preference. British Journal of Social Psychology, 20, 57-68.

Furnham, A. (1984). Personality Social skills, anomie and delinquency - a self report study of a group of a group of normal non-delinquent adolescents. Journal of Child Psychology and Psychiatry 25, 409-420.

Furnham, A. (1988). Lay Theories, Everyday Understanding of Problems in the Social Sciences. Exeter: Pergamon.

Furnham, A., and Barratt, L. (1988). Moral judgement and personality differences in "problem children" and delinquents. Personality and Individual Differences 9, 187-188.

Furnham, A., and Henderson, M. (1982). The good, the bad and the mad: Response bias in self-report measures. Personality and Individual Differences, 3, 311-320. Furnham, A., and Henderson, M. (1983b). Lay theories of delinquency European Journal of Psychology, 13, 107-120.

Furnham, A., and Thompson, J. (1991). Personality and SelfReported Delinquency, Personality and Individual Differences 12, 585-593. 
Gavaghan, M., Arnold, K. and Gibbs, J. (1983). Moral Judgement in Delinquents and Nondelinquents: Recognition versus production measures. The Journal of Psychology, 114, 267-274.

Gibbons, D. C. (1975). Offender typologies - two decades later. British Journal of Criminology 15, 140-156. Gibbs, J., and Schnell, S. V. (1985). Moral Development 'versus' Socialization. American Psychologist, 40, 10711080 .

Gibbs, J., and Widaman, $\mathrm{K}$ (1982). Social Intelligence: measuring the development of sociomoral reflection. Englewood Cliffs, N. J.: Prentice-Hall.

Gibbs, J., Widaman, K., and Colby, A. (1982). Construction and Validation of a Simplified, Group-administrable Equivalent to the Moral Judgement Interview. Child Development 53, 895-910.

Gibbs, J., Arnold, K, and Burkhart, J. (1984). Sex Differences in the Expression of Moral Judgement. Child Development, 55, 1040-1043.

Gibbs, J., Arnold, K., Ahlborn, H., and Cheesman, F. (1984). Facilitation of Sociomoral Reasoning in Delinquents. Journal of Consulting and Clinical Psychology, 52, 37-45. Gibbs, J., Arnold, K., Morgan, R., Scwartz, E., Gavaghan, M., and Tappan, M. (1984). Construction and Validation of a Multiple-choice Measure of Moral Reasoning. Child Development, 55, 527-536.

Gibson, H. B. (1967). Self reported delinquency among school boys and their attitudes to the police. British Social and Clinical Psychology 6, 168-173.

Gibson, H. B. (1969). Early delinquency in relation to broken homes. Journal of Child Psychology, 10, 195-204.

Gilligan, C. (1977). In a different voice. Harvard Educational review, 47, 365-378.

Gilligan, C. (1982). In a Different Voice: Psychological Theory and Women's Development. Cambridge, Mass: Harvard University Press.

Goddard, H. H. (1914). Feeblemindedness: Its Causes and Consequences. New York: Macmillan.

Gold, M. (1966). Undetected delinquent behavior. Journal of Research in Crime and Delinquency, 3, 27-46. 
Gold, M. and Reimer, D. J. (1975). Changing patterns of delinquent behavior among Americans 13 through 16 years old: 1967-1972. Crime and Delinquency Literature, 7, 483-517.

Hessing, D. J., Elffers, H. and Weigel, R. H. (1988).

Exploring the limits of self-reports and reasoned action: An investigation of the psychology of tax evading behavior. Journal of Personality and Social Psychology, 54, 405-413.

Higgins, A., Power, C., and Kohlberg, L. (1984). The Relationship of Moral Atmosphere to Judgments of Responsibility. In M. W. Kurtines and J. I. Gewirtz (Eds.), Morality, Moral Behaviour and Moral Development. New York: John Wiley and Sons.

Hindelang, M., and Weis, J. G. (1972). Personality and selfreported delinquency: an application of cluster analysis. Criminology, 10, 268-276.

Hindelang, M. J., Hirschi, T., and Weis, J. G. (1981). Measuring Delinquency. Beverly Hills: Sage Publications. Hirschi, T. (1969). Causes of Delinquency. Berkeley: University of California Press.

Hirschi, T. and Hindelang, M. J. (1977). Intelligence and delinquency: a revisionist review American Sociological Review, 42, 571-587.

Hoffman, M. (1971). Father absence and Conscience Development Developmental Psychology, 4, 400-406.

Hogan, R. (1970). A dimension of moral judgement. Journal of Consulting and Clinical Psychology 35, 205-212.

Hogan, R., and Dickstein, E. (1972). A measure of moral values. Journal of Consulting and Clinical Psychology 39, 210-214.

Hollin, C. (1989). Psychology and Crime: An Introduction to Criminological Psychology. London: Routledge.

Hollin, C. (1990). Cognitive-behavioral Interventions with Young Offenders. Elmsford, NY: Pergamon Press.

Hollin, C., and Howells, K. (1987). Lay explanations of delinquency: Global or offence specific? British Journal of Social Psychology, 26, 203-210.

Holstein, C. (1976). Irreversible, stepwise sequence in the development of Moral Judgement: a longitudinal study of males and females. Child Development, 47, 51-61. 
Hood, R., and Sparkes, R. (1970). Key Issues in Criminology. London: World University Library.

Huizinga, D., and Elliott, D. S. (1981). A Longitudinal study of delinquency and drug use in a national sample of youth: An assessment of causal order (The National Youth Survey Report number 16). Boulder, CO: Behavioural Research Institute.

Huizinga, D., and Elliott, D. S. (1986). Reassessing the reliability and validity of self-report delinquency measures Journal of Quantitative Criminology, 2, 293327 .

Jacobs, A, and Barron, R. (1968). Falsification of the Guilford-Zimmerman Temperament Survey: II. Making a poor impression. Psychological Reports, 23, 1271-1277.

Jamison, R. N. (1980). Psychoticism, deviancy and perception of risk in normal children. Personality and Individual Differences 1, 87-91.

Jennings, W., Kilkenny, R., and Kohlberg, L. (1983). Moral Development Theory and Practice for Youthful and Adult offenders. In W. S. Laufer and J. M. Day (Eds.), Personality Theory, Moral Development, and Criminal Behaviour. Massachusetts: Lexington Books.

Judd, D. (1980). Father Absence, Delinquent Behavior and the Moral Development of Females Ages 14 through 17 years. Unpublished Ph.D. thesis, University of Chicago. Jurkovic, G. (1976). The relationship of moral and cognitive development to dimensions of juvenile delinquency (Doctoral Dissertation, University of Texas at Austin). Dissertation Abstracts International, 36, 5262B.

Jurkovic, G. (1980). The Juvenile Delinquent as a moral philosopher: a structural-developmental perspective. Psychological Bulletin, 88, 709-727.

Jurkovic, G. and Prentice, N. (1977). Relations of Moral and Cognitive Development to the Dimensions of Juvenile Delinquency. Journal of Abnormal Psychology, 86, 414420 .

Kantner, J. (1976). The Relationship between moral judgement and personality variables in adult offenders (Doctoral dissertation, Purdue University, 1975). Dissertation Abstracts International, 36, 5262B-5263B. 
Kantner, J. (1985). Moral Judgement and Criminal Behavior: A follow-up of prison release and parole behaviour.

Estudos de Psicologia, 2, 54-60.

Keilitz, I. and Dunivant, N. (1986). The relationship between learning disability and juvenile delinquency: current state of knowledge. Remedial and Special Education, 7, 18-26.

Kidder, L., and Cohn, E. (1979). Public views of crime and crime prevention. In I. Frieze, D. Baral and J. Carroll (Eds.), New Approaches to social problems. San Francisco: Jossey-Bass .

Kohlberg, L. (1958). The development of modes of moral thinking and choice in the years ten to sixteen. Unpublished doctoral dissertation, University of Chicago.

Kohlberg, L. (1963a). The development of children's orientations towards a moral order. I: Sequence in the development of human thought. Vita Humana, 6, 11-33.

Kohlberg, L. (1963b). Moral Development and identification. In H. Stevenson (Ed.). Child Psychology 62nd Yearbook of the National Society for the Study of Education. Chicago: University of Chicago Press.

Kohlberg, L. (1964). Development of moral character and moral ideology. In M. L. Hoffman and L. W. Hoffman (Eds.), Review of child development research (Vol. I). New York: Russell Sage Foundation.

Kohlberg, L. (1966). A cognitive-developmental analysis of children's sex-role concepts and attitudes. In $\mathrm{E}$. Maccoby (Ed.), The Development of Sex differences. Stanford, Ca: Stanford University Press.

Kohlberg, L. (1969). Stage and Sequence: The cognitive-developmental approach to socialization. In D. Goslin (Ed.) Handbook of Socialisation theory and research. New York: Rand McNally.

Kohlberg, L. (1976). Moral stages and moralization: The cognitive-behavioural model approach. In T. Lickona (Ed.), Moral Development and Behaviour: Theory Research and Social Issues. New York: Holt Reinhart \& Winston. Kohlberg, L. (1981). The meaning and measurement of moral development. Heinz werner Memorial Lecture Series Vol. 13. Worcester, Mass.: Clark University Press. 
Kohlberg, L., and Freundlich, D. (1977). Moral judgement in youthful offenders. Unpublished manuscript, Harvard University.

Kolvin, I., Miller, F. J. W., Fleeting, M., and Kolvin, P. A. (1988). Social and parenting factors affecting criminaloffence rates: Findings from the Newcastle thousand family study (1947-1980). British Journal of Psychiatry, $152,80-90$.

Krebs, R. (1967). Some Relationships between Moral Judgement, Attention and Resistance to Temptation. Unpublished Ph.D. thesis, University of Chicago.

Kurtines, W., and Greif, E. (1974). The development of moral thought. Review and evaluation of Kohlberg's approach. Psychological Bulletin, 81, 453-470.

Lanza-Kaduce, L., Radosevich, M., and Krohn, M. (1983). Cognitive Moral Development, Neutralizing Definitions and Delinquency. In W. S. Laufer and J. M. Day (Eds.), Personality Theory, Moral Development, and Criminal Behaviour. Massachusetts: Lexington Books.

Lee. M., and Prentice, N. (1988). Interrelations of Empathy, Cognition, and Moral Reasoning with Dimensions of Juvenile Delinquency. Journal of Abnormal Child Psychology, 16, 127-139.

Leming, J. (1978). Cheating Behaviour, Situational Influences and Moral Development. Journal of Educational Research, 71, 214-217.

Lentz, W. (1966). Social status and attitudes towards delinquency control. Journal of Research into Crime and Delinquency, 3, 147-154.

Levine, C. (1979). Stage Acquisition and stage use. An appraisal of stage displacement explanations of variation in moral reasoning. Human Development, 22, 145-164.

Lombroso, L. (1876). L'uomo Delinquente. Milan.

Maitland, K., and Goldman, J. (1974). Moral Judgement as a function of peer group interaction. Journal of Personality and Social Psychology, 30, 699-704.

Malinowski, C. (1978). Unpublished paper cited in J. Rest (1979), Development in Judging Moral Issues. Minneapolis: University of Minnesota Press. 
Marston, K. (1978). Unpublished paper cited in J. Rest (1979), Development in Judging Moral Issues. Minneapolis: University of Minnesota Press.

Martin, A. L. (1985). Values and personality: a survey of their relationship in the case of juvenile delinquency, Personality and Individual Differences, 6, 519-522. Martin, R., Shafto, M., and Van Deinse, W. (1977). The reliability, validity and design of the Defining Issues Tests. Developmental Psychology 13, 460-468.

McColgan, E. (1975). Social Cognition in Delinquents, Predelinquents, and Non-delinquents. Unpublished Doctoral dissertation, University of Minnesota.

McCord, J. (1978). A Longitudinal study of the link between broken homes and criminality. Paper Presented at the National Council on Family Relations.

McCord, J. (1979). Some child rearing antecedents of criminal behavior in adult men. Journal of Personality and Social Psychology, 9, 1477-1486.

McCue, S., Booth, S., and Root, J. (1976). Do young prisoners understate their extraversion on personality inventories? British Journal of Criminology, 16, 282-283. McEwan, A. W. (1983). Eysenck's theory of criminality and the personality types and offences of young delinquents. Personality and Individual Differences, 4, 201-204.

McEwan, A. W. and knowles, C. (1984). Delinquent personality types and the situational contexts of their crimes, Personality and Individual Differences, 5, 339-344. McGurk, B. J., and McDougall, C. (1981). A new approach to Eysenck's theory of criminality. Personality and Individual Differences, 2, 338-340.

Merrill, M. A. (1947). Problems of Child Delinquency. Boston: Houghton Mifflin.

Merton, R. (1967). Social structure and anomie. In R. Grallombards (Ed.), Juvenile Delinquency. New York: wiley.

Milgram, S. (1963). Behavioral study of obedience. Journal of Abnormal and Social Psychology, 67, 371-378.

Mitchell, J., Rogers, R., Cavanaugh, J., and Wasyliw, 0 . (1980). The role of trait anxiety in violent and nonviolent delinquent behaviour. American Journal of Forensic Psychiatry. 
Moffitt, T. E. and Silva, P. A. (1989). A prospective replication of protective effects of IQ in subjects at high risk for juvenile delinquency. Journal of Consulting and Clinical Psychology, 57, 719-724. Moffitt, T. E., Gabrialli, W. F., Mednick, S. A. and Schulsinger, F. (1981). Socioeconomic status, IQ and delinquency Journal of Abnormal Psychology, 90, 152-157.

Moon, Y. (1986). A review of cross-cultural studies on moral judgement development using the defining issues test. Behavior Science Research, 20, 147-177.

Nelson, J., Smith, D. and Dodd, J. (1990). The moral reasoning of juvenile offenders: A meta-analysis. Journal of Abnormal Child Psychology, 18, 231-239.

Nilsson, I., Crafoord, J., Hedengren, M., and Ekehammar, B. (1989). Generalizability of the Sociomoral Reflection Measure: A study of Swedish children and adolescents. Reports from the Department of Psychology, University of Stockholm, 700 .

Offord, D. R., Poushinski, M. F., and Sullivan, K. (1978).

School performance, IQ and delinquency British Journal of Criminology, 18, 110-127.

Office of Population Censuses and Surveys (1991). Standard Occupational Classification (Vol. 3). London: HMSO. Ostapiuk, E. B. and Westwood, S. (1986). Glenthorne Youth Treatment Centre: Working with adolescents in gradations of security. In $C$. Hollin and $K$. Howells (Eds.), Clinical Approaches to criminal behaviour. Issues in Criminological and Legal Psychology, No. 9. Leicester: British Psychological Society.

Page, R., and Bode, J. (1980). Comparison of measures of moral reasoning and development of a new objective measure. Educational and Psychological Measurement, 40, 317-329. Passingham, W. (1972). Crime and Personality: A review of Eysencks theory. In V. D. Nebylitsyn and J. A. Gray (eds), Biological Bases of Individual Behaviour. London: Academic Press.

Piaget, J. (1932). The Moral Judgement of the Child. London: Routledge \& Kegan Paul.

Piaget, J. (1967). Six Psychological studies. New York: Random House. 
Powell, G. E. (1977). Psychoticism and social deviancy in children, Advances in Behaviour Research and Therapy, 1, 27-56.

Power, M. J., Ash, P. M., Schoenberg, G. E., and Sorey, E. C. (1974). Delinquency and the Family. British Journal of Social Work, 4, 13-38.

Pulkkinen, L. (1983). Finland: The search for alternatives to aggression, In A. P. Goldstein and M. H. Segal (Eds.), Aggression in a Global Perspective. New York: Pergamon.

Quay, H. C. (1987). Intelligence. In H. C. Quay (ed.) Handbook of Juvenile Delinquency. New York: Wiley. Rahman, A., and Husain, A. (1984). Personality and female prisoners criminals in Bangladesh. Personality and Individual Differences, 5, 473-474.

Raven, J. C., Court, J. H., and Raven, J. (1985). A manual for Raven's progressive matrices and vocabulary scales. London: H. K. Lewis.

Reichel, H. (1987). The intelligence - criminality relationship: a critical review. Reports from the Department of Psychology, the University of Stockholm, supp1. 66.

Reichel, H. and Magnusson, D. (1988). The relationship of intelligence to registered criminality, an exploratory study. Reports from the Department of Psychology, University of Stockholm, 67.

Reid, I (1982). The development and maintenance of a behavioural regime in a Youth Treatment centre. In M. P. Feldman (Ed.), Developments in the study of criminal behaviour, Vol. 1: The prevention and control of offending. Chichester: Wiley.

Renwick, S., and Emler, N. (1984). Moral reasoning and Delinquent Behaviour amongst Students. British Journal of Social Psychology, 23, 281-283.

Rest, J. (1975). Longitudinal study of the Defining Issues Test of moral judgement: a strategy for analyzing developmental change. Developmental Psychology 11, 738748 .

Rest, J. (1979). Development in Judging Moral Issues. Minneapolis: University of Minnesota Press. 
Rest, J., (1980). Developmental Psychology and values education. In B. Munsey (Ed.). Moral Development, Moral Education, and Kohlberg: Basic Issues in Philosophy, Psychology, religion, and Education. Birmingham, Ala.: Religious Education.

Rest, J. (1986). Moral Development: Advances in Research and Theory. New York: Praeger.

Rest, J., Cooper, D., Coder, R., Masanz, J., and Anderson, D. (1974). Judging the important issues in moral dilemmas-an objective test of development. Developmental Psychology 10, 491-501.

Rholes, W., Bailey, S., and McMillan, I, (1982). Experiences that Motivate Moral Development. Journal of Experimental Social Psychology, 18, 524-536.

Richman, N., Stevenson, J., and Graham, P. J. (1982). PreSchool to School: A Behavioural Study. London: Academic Press.

Robins, L. (1978). Sturdy childhood predictors of adult antisocial behavior Psychological Medicine, 8, 611-622.

Robins, L., West, P. A., and Herjanic, B. I. (1975). Arrests and delinquency in two generations: A study of black urban families and their children Journal of Child Psychology and Psychiatry, 76, 125-140.

Ross, R., and Fabiano, E. (1985). Time to think: A cognitive model of delinquency prevention and offender rehabilitation. Johnson City, TN: Institute of Social Sciences and Arts.

Royce, J. R., and Powell, A. (1983). A Theory of personality and individual differences: Factors, Systems and Processes. Englewood Cliffs, NJ: Prentice-Hall.

Rushton, J. P., and Chrisjohn, R. (1981). Extroversion, Neuroticism and Psychoticism and Self Reported Delinquency. Personality and Individual Differences, 2, 11-20.

Rutter, M. (1971). Parent-child separation: Psychological effects on the children. Journal of Child Psychology and Psychiatry, 12, 233-260.

Rutter, M. and Giller, H. (1983). Juvenile Delinquency: Trends and Perspectives. Harmondsworth: Penguin. 
Schwartz, S., Feldman, R., Brown, M, and Heingarter, A. (1969). Some Personality Correlates of Conduct in Two Situations of Moral Conflict. Journal of Personality, $37,41-57$.

Schwenkmezger, P. (1983). Risikoverhalten, Rissikobereitscheft und Delinquenz: Theoretische Grundlagen und differentialdiagnostische Untersuchungen. Zeitschrift fur Differentielle und Diagnostische Psychologie, 4, 223239.

Schuman, H., and Presser, S. (1981). Questions and Answers in Attitude Surveys. New York: Academic Press.

Selman, R. I. (1976). Social-Cognitive Understanding: A guide to Educational and Clinical Practice. In T. Lickona (Ed.), Moral Development and Behaviour: Theory Research and Social Issues. New York: Holt Reinhart \& Winston.

Shapland, J., Rushton, J. P., and Campbell, A. (1975) . Crime and Personality - further evidence. Bulletin of the British Psychological Society, 28, 977-978.

Short, J. F., and Nye, F. I. (1957). Reported behavior as a criterion of deviant behavior. Social Problems, 5, 207213 .

Siegal, L. J. (1986). Criminology (2nd. edn.). St. Paul, Minn: West Publishing.

Silva, F., Martorell, L., and Salvador, A. (1987). Assessment of anti-social behaviour in children and adolescents. Personality and Individual Differences, 8, 977-978.

Sinclair, I., and Chapman, B. (1973). A typological and dimensional study of a sample of prisoners. British Journal of Criminology, 13, 341-353.

Snyder, J, and Patterson, G. (1987). Family interaction and delinquent behavior. In H. C. Quay (ed.) Handbook of Juvenile Delinquency. New York: Wiley.

Sudman, S., and Bradburn, N. M. (1982). Asking Questions: A Practical Guide to Questionnaire Design. San Francisco: Jossey-Bass Publishers.

Sutherland, E. H. (1931). Mental Deficiency and crime. In $\mathrm{K}$. Young (ed.) Social Attitudes. New York: Holt.

Taylor, T. (1978). The construction of an objective method of assessing morality and the testing of Kohlberg's hierarchical theory. Psychologia Africana, 17, 169-200. 
Thornton, D. (1981). Moral Judgement and Criminal Behaviour.

Unpublished Ph.D. thesis, University of Exeter.

Thornton, D. (1987). Moral Development Theory. In B. McGurk,

D. M. Thornton, and M. Williams (Eds.), Applying

Psychology to Imprisonment. Theory and Practice.

London: HMSO.

Thornton, D., and Reid, R. (1982). Moral Reasoning and Type of

Criminal offence. British Journal of Social Psychology,

21, 231-238.

Toch, H. (1979). Perspectives of the Offender. In H. Toch

(ed.) Psychology of Crime and Criminal Justice. London:

Holt Rinehart and Winston.

Tsujimoto, R., and Nardi, P. (1978). A comparison of

Kohlberg's and Hogan's Theories of Moral Development.

Social Psychology, 41, 235-245.

Velicer, W., and Weiner, B. (1975). Effects of sophistication

and faking sets on the Eysenck Personality Inventory.

Psychological Reports, 37, 71-73.

Wadsworth, M. E. J. (1979). Roots of delinquency: Infancy,

adolescence and crime Oxford. England: Robertson.

Walker, L. (1984). Sex Differences in the Development of Moral reasoning. Child Development, 55, 677-691.

Walker, L., De Vries, B., and Richard, S. (1984). The

Hierarchical Nature of Stages of Moral Development.

Developmental Psychology, 20, 960-966.

Ward, S. H. (1963). Hierarchical groupings to optimise an

objective function. Journal of American Statistical

Association, 58, 236-244.

Weis, J. G (1986). Issues in measurement of criminal careers.

in A. Blumstein and J. Cohen (eds.), Criminal Careers and Career Criminals (Vol. II). Washington, DC: National Academic Press.

Wesman, A. G. (1952). Faking personality test scores in a simulated employment situation. Journal of Applied Psychology, 36, 112-113.

West, D. J. (1982). Delinquency: Its Roots Careers and

Prospects. London: Heineman

West, D. J., and Farrington, D. P. (1973). Who Becomes

Delinquent? London: Heineman Educational.

West, D. J., and Farrington, D. P. (1977). The Delinquent Way of Life. London: Heineman Educational. 
Woodward, M. (1955). The role of low intelligence in delinquency British Journal of Delinquency, 5, 281-303. Wrightsman, L. (1977). Social Psychology. Wadsworth: London. 


\section{Appendix A}

Questionnaire used to collect family background information for all studies

Please answer all the questions as fully as possible, if you have any questions, please ask.
Are you:
Male
Female
(circle one)

What is your date of birth?

How many years of education have

you had after your 16th birthday?

What would you describe your ethnic origins as? (please tick as appropriate)

African Asian

Caribbean English/Scottish/Welsh/ Irish

Other European (Please specify.

other Countries (Please specify

What is your father's job?

(if known)

What is your mother's job?

(if known) 
Who did you live with up to your tenth birthday? (put down all the people but state their relation to you, e.g. 'brother', 'sister', 'mum', not their names):

Did any of these permanently leave after your tenth birthday? (circle one)

YES NO

If 'YES' please indicate who left and your age at that time: 
Large Scale and Glenthorne Study - Chapters 3 and 4.1

CODING - Key to data

VARIABLE NUMBER

NAME

1

2

3

4

5

6

7

8

9

10

11

12

13

14

15

16

17

18

19
Subject/CASE Number

SEX

$0=$ Male

1 = Female

AGE in Years

Years in EDUcation

ETHNIC Origins
$0=$ African
$1=$ Asian
$2=$ Caribbean
$3=$ English/Scottish etc.
$4=$ Other European
$5=$ Other

Socio-economic status

Social Class (CLASS)

Socio-Economic Group (SEG)

Number of Siblings:

Before age of 10 (SIB)

After age of 10 (SIB10)

OFFender Category

$0=$ Convicted Offender

1 = Student Control

3 = School Control

$4=$ Glenthorne offender

5 = Glenthorne non-offender

RAVen's Matrices Score

EPQ Scores

Psychoticism (P)

Extraversion (E)

Neuroticism (N)

Lie Scale (L)

Self-Reported Delinquency:

Total Score (SRD)

Crimes Against Persons (PERSON)

General Theft Score (THEFT)

Socio-Moral Reflection Measure:

MODAL Score:

1 = Stage 1 


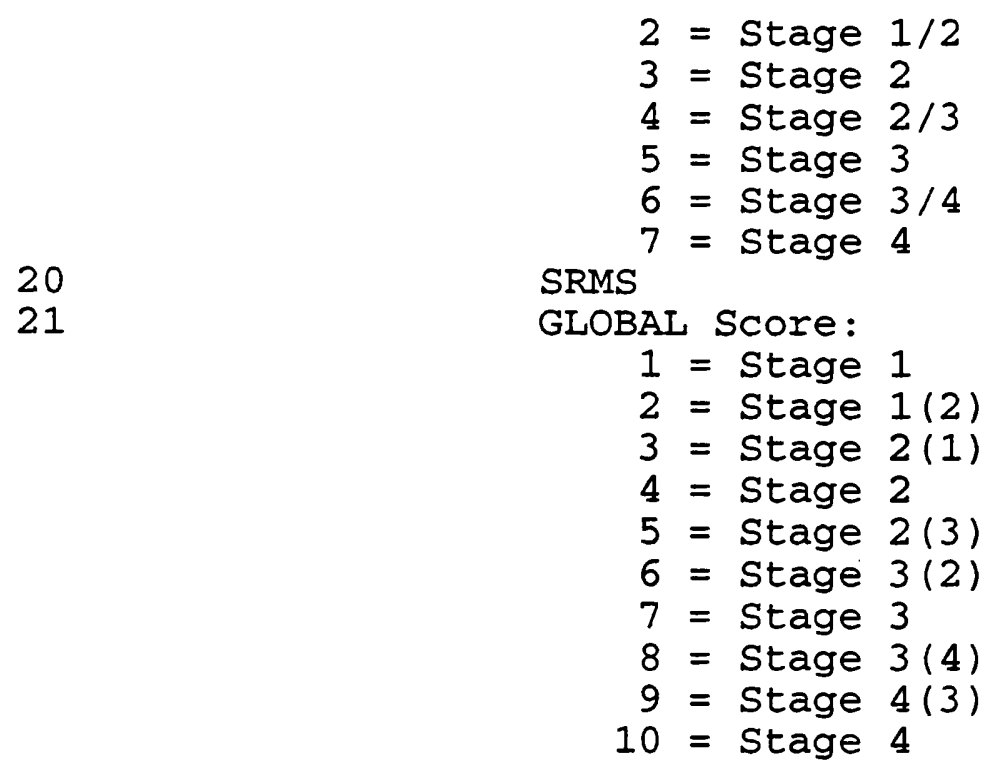

N.B.: Missing data is indicated by a '.' 
$\begin{array}{lllllllllllllllllllll}001 & 0 & 19.17 & 10 & 3 & 1 & 03 & 01 & 01 & 0 & 54 & 03 & 12 & 12 & 02 & 27 & 4 & 6 & 2 & 317 & 7\end{array}$ $\begin{array}{llllllllllllllllllllll}002 & 0 & 18.17 & 11 & 3 & 5 & 10 & 03 & 03 & 0 & 39 & 05 & 11 & 03 & 02 & 24 & 4 & 6 & 3 & 250 & 6\end{array}$

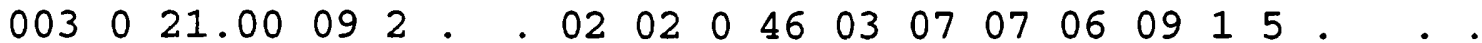
$\begin{array}{lllllllllllllllll}004 & 0 & 10 & 3 & . & 03 & 03 & 0 & 44 & 05 & 11 & 02 & 07 & 16 & 4 & 5\end{array}$.

$\begin{array}{llllllllllllllllllllll}005 & 0 & 21.04 & 10 & 3 & 3 & 09 & 02 & 01 & 0 & 55 & 05 & 02 & 12 & 02 & 26 & 3 & 7 & 5 & 319 & 7\end{array}$ $\begin{array}{lllllllllllllllllllll}006 & 0 & 18.25 & 11 & 3 & . & . & 02 & 02 & 0 & 51 & 08 & 11 & 06 & 01 & 28 & 4 & 7 & 5 & 315 & 7\end{array}$ $\begin{array}{lllllllllllllllllllll}007 & 0 & 18.83 & 09 & 3 & 3 & 12 & 02 & 01 & 0 & 31 & 04 & 07 & 04 & 07 & 16 & 1 & 5 & 3 & 220 & 4\end{array}$ $\begin{array}{lllllllllllllllllllll}008 & 0 & 18.33 & 11 & 3 & 3 & 09 & 01 & 01 & 0 & 48 & 05 & 12 & 03 & 02 & 26 & 4 & 7 & 5 & 325 & 7\end{array}$ $\begin{array}{lllllllllllllllllllll}009 & 0 & 17.75 & 11 & 3 & 2 & 02 & 01 & 01 & 0 & 50 & 01 & 12 & 03 & 04 & 23 & 4 & 6 & 4 & 225 & 4\end{array}$ $\begin{array}{lllllllllllllllllllll}010 & 0 & 17.42 & 08 & 3 & 3 & 09 & 02 & 02 & 0 & 44 & 07 & 09 & 02 & 02 & 29 & 7 & 6 & 4 & 250 & 6\end{array}$ $\begin{array}{lllllllllllllllllllll}011 & 0 & 19.58 & 11 & 3 & 3 & 09 & 01 & 01 & 0 & 40 & 06 & 10 & 04 & 01 & 32 & 7 & 5 & 5 & 243 & 5\end{array}$ $\begin{array}{lllllllllllllllllllll}012 & 0 & 18.25 & 11 & 3 & 5 & 11 & 03 & 03 & 0 & 34 & 08 & 06 & 04 & 07 & 09 & 0 & 5 & 5 & 256 & 6\end{array}$ $\begin{array}{lllllllllllllllllllll}013 & 0 & 20.58 & 11 & 3 & 1 & 04 & 02 & 02 & 0 & 39 & 01 & 11 & 08 & 04 & 10 & 2 & 1 & 5 & 283 & 7\end{array}$ $\begin{array}{lllllllllllllllllllll}014 & 0 & 17.92 & 11 & 3 & . & . & 09 & 00 & 0 & 41 & 04 & 10 & 08 & 01 & 28 & 5 & 6 & 5 & 271 & 6\end{array}$ $\begin{array}{lllllllllllllll}015 & 0 & 18.00 & 09 & 3 & 5 & 02 & 03 & 03 & 0 & 40 & 07 & 08 & 08 & 03\end{array}$

$\begin{array}{lllllllllllllllllllll}016 & 0 & 20.33 & 11 & 3 & 3 & 09 & 03 & 03 & 0 & . & . & . & . & . & . & . & . & 5 & 293 & 7\end{array}$ $\begin{array}{lllllllllllllllllllll}017 & 0 & 20.92 & 11 & 3 & 4 & 10 & 01 & 01 & 0 & 42 & 02 & 12 & 07 & 05 & 21 & 6 & 4 & 5 & 243 & 5\end{array}$ $\begin{array}{lllllllllllllllllllll}018 & 0 & 19.67 & 11 & 3 & 4 & 10 & 01 & 01 & 0 & 42 & 02 & 12 & 07 & 05 & 21 & 6 & 4 & 5 & 243 & 5\end{array}$ $\begin{array}{lllllllllllllllllll}019 & 0 & 19.83 & 11 & 3 & 2 & 12 & 04 & 04 & 0 & 33 & 11 & 08 & 05 & 03 & 12 & 1 & 6 & .\end{array}$

$\begin{array}{lllllllllllllllllllll}020 & 0 & 17.75 & 11 & 3 & 2 & 12 & 02 & 01 & 0 & 43 & 01 & 09 & 11 & 07 & 17 & 3 & 5 & 5 & 264 & 6\end{array}$ $\begin{array}{lllllllllllllllllllll}021 & 0 & 19.67 & 11 & 3 & 1 & 04 & 01 & 01 & 0 & 36 & 02 & 08 & 11 & 02 & 22 & 3 & 7 & 3 & 238 & 5\end{array}$ $\begin{array}{lllllllllllllllllllll}022 & 0 & 18.17 & 08 & 3 & 5 & 11 & 02 & 02 & 0 & 24 & 07 & 11 & 04 & 00 & 30 & 4 & 7 & 5 & 267 & 6\end{array}$ $\begin{array}{lllllllllllllllllllll}023 & 0 & 18.33 & 11 & 3 & 4 & 06 & 01 & . & 0 & 35 & 06 & 12 & 02 & 04 & 23 & 4 & 3 & 5 & 279 & 7\end{array}$

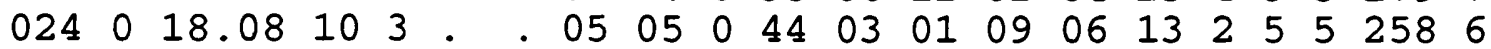
$\begin{array}{llllllllllllllllll}025 & 0 & 20.08 & 10 & 3 & 4 & 10 & 02 & 02 & 0 & 24 & 06 & 04 & 07 & 04 & 13 & 2 & 1 .\end{array}$

$\begin{array}{lllllllllllllllllllll}026 & 0 & 17.08 & 10 & 3 & 4 & 11 & 02 & 02 & 0 & 22 & 07 & 08 & 02 & 07 & 25 & 4 & 7 & 3 & 183 & 4\end{array}$ $\begin{array}{lllllllllllllllllllll}027 & 0 & 19.00 & 09 & 3 & . & . & 00 & 00 & 0 & 22 & 09 & 12 & 03 & 03 & 23 & 5 & 6 & 3 & 190 & 4\end{array}$ $\begin{array}{lllllllllllllllllllll}028 & 0 & 17.25 & 11 & 3 & . & . & 06 & 00 & 0 & 40 & 05 & 11 & 08 & 05 & 22 & 3 & 7 & 4 & 250 & 6\end{array}$

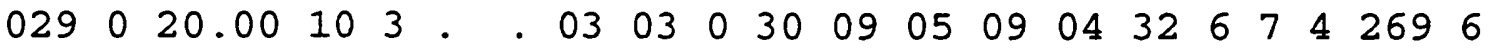
$\begin{array}{lllllllllllllllllllll}030 & 0 & 18.00 & . & 3 & . & .00 & 00 & 0 & 11 & 03 & 07 & 10 & 04 & 23 & 4 & 7 & 3 & 214 & 4\end{array}$ $\begin{array}{lllllllllllllllllllll}031 & 0 & 17.75 & 11 & 3 & 4 & 10 & 03 & 02 & 0 & 29 & 04 & 08 & 07 & 02 & 29 & 6 & 7 & 5 & 263 & 6\end{array}$ $\begin{array}{lllllllllllllllllllll}032 & 0 & 19.17 & 10 & 3 & . & . & 02 & 02 & 0 & 24 & 10 & 02 & 00 & 11 & 25 & 4 & 7 & 4 & 250 & 6\end{array}$ $\begin{array}{lllllllllllllllllllll}033 & 0 & 19.08 & 10 & 3 & 3 & 06 & 02 & 00 & 0 & 40 & 04 & 09 & 04 & 06 & 26 & 6 & 6 & 3 & 238 & 5\end{array}$ $\begin{array}{lllllllllllllllllllll}034 & 0 & 19.67 & 11 & 3 & . & . & 03 & 01 & 0 & 38 & 06 & 09 & 11 & 02 & 29 & 1 & 7 & 5 & 256 & 6\end{array}$ $\begin{array}{lllllllllllllllllllll}035 & 0 & 17.83 & . & 3 & . & . & 02 & 02 & 0 & 40 & 06 & 10 & 05 & 01 & 25 & 4 & 5 & 4 & 250 & 6\end{array}$ $\begin{array}{lllllllllllllllllllll}036 & 0 & 19.42 & 11 & 3 & . & . & 02 & 02 & 0 & 40 & 06 & 10 & 05 & 01 & 25 & 4 & 5 & 4 & 250 & 6\end{array}$

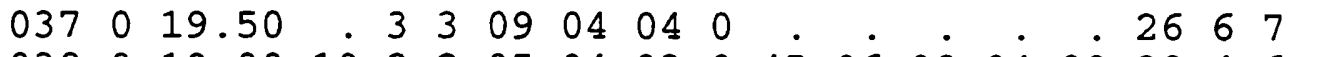

$\begin{array}{lllllllllllllllllll}038 & 0 & 19.00 & 10 & 2 & 2 & 05 & 04 & 03 & 0 & 45 & 06 & 08 & 04 & 00 & 20 & 4 & 6 & .\end{array}$

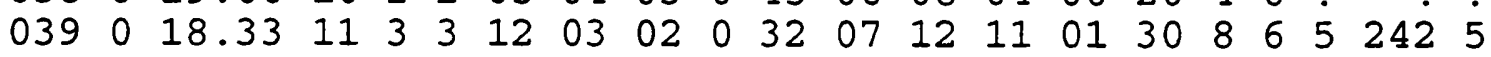
$\begin{array}{llllllllllllllllllllllll}040 & 0 & 17.83 & 09 & 3 & 3 & 06 & 02 & 02 & 0 & 40 & 05 & 08 & 02 & 02 & 14 & 3 & 3 & . & . & .\end{array}$ $\begin{array}{lllllllllllllllllllll}041 & 0 & 19.00 & 11 & 3 & 2 & 05 & 04 & 04 & 0 & 23 & 03 & 11 & 06 & 05 & 18 & 4 & 5 & 4 & 250 & 6\end{array}$ $\begin{array}{lllllllllllllllllllll}042 & 0 & 17.33 & 08 & 3 & 3 & 09 & 02 & 02 & 0 & 40 & 05 & 05 & 09 & 04 & 22 & 6 & 4 & . & . & .\end{array}$ $\begin{array}{lllllllllllllllllllll}043 & 0 & 18.58 & 09 & 3 & 3 & 07 & 02 & 01 & 0 & 37 & 11 & 04 & 07 & 11 & 26 & 2 & 6 & 5 & 258 & 6\end{array}$ $\begin{array}{lllllllllllllllllllll}044 & 0 & 20.50 & 11 & 3 & 3 & 09 & 02 & 01 & 0 & 49 & 02 & 11 & 07 & 03 & 17 & 5 & 3 & 4 & 250 & 6\end{array}$ $\begin{array}{lllllllllllllllllllll}045 & 0 & 21.08 & 10 & 3 & 4 & 07 & 00 & 00 & 0 & 26 & 03 & 01 & 12 & 04 & 28 & 5 & 6 & 3 & 200 & 4\end{array}$ $\begin{array}{lllllllllllllllllllll}046 & 0 & 21.42 & 11 & 3 & 1 & 04 & 01 & 01 & 0 & 41 & 03 & 12 & 02 & 04 & 15 & 4 & 1 & 4 & 233 & 6\end{array}$ $\begin{array}{lllllllllllllllllllll}047 & 0 & 20.42 & 11 & 3 & . & . & 03 & 03 & 0 & 41 & 08 & 09 & 02 & 01 & 28 & 5 & 5 & 5 & 243 & 5\end{array}$ $\begin{array}{lllllllllllllllllllll}048 & 0 & 20.00 & 11 & 3 & 4 & 10 & 02 & 02 & 0 & 44 & 06 & 10 & 07 & 03 & 22 & 3 & 4 & 200 & 4\end{array}$ $\begin{array}{lllllllllllllllllllll}049 & 0 & 19.75 & 11 & 3 & 3 & 09 & 02 & 02 & 0 & 46 & 04 & 08 & 03 & 02 & 33 & 8 & 7 & 5 & 308 & 7\end{array}$ $\begin{array}{lllllllllllllllllllll}050 & 0 & 20.00 & 11 & 3 & 4 & 11 & 01 & 01 & 0 & 45 & 04 & 06 & 06 & 00 & 33 & 6 & 7 & 3 & 243 & 5\end{array}$ $\begin{array}{lllllllllllllllllllll}051 & 0 & 18.58 & 11 & 3 & 3 & 06 & 01 & 01 & 0 & 44 & 04 & 12 & 04 & 01 & 32 & 7 & 7 & 5 & 293 & 7\end{array}$ $\begin{array}{lllllllllllllllllllll}052 & 0 & 19.00 & 11 & 3 & 3 & 06 & 01 & 01 & 0 & 44 & 04 & 12 & 04 & 01 & 32 & 7 & 7 & 5 & 293 & 7\end{array}$ $\begin{array}{lllllllllllllllllllll}053 & 0 & 19.75 & 11 & 3 & . & 16 & 00 & 00 & 0 & 57 & 09 & 09 & 11 & 01 & 34 & 6 & 7 & 4 & 275 & 7\end{array}$ $\begin{array}{lllllllllllllllllllll}054 & 0 & 19.00 & 11 & 3 & 3 & 06 & 01 & 00 & 0 & 35 & 05 & 11 & 11 & 04 & 23 & 4 & 6 & 5 & 244 & 5\end{array}$ $\begin{array}{lllllllllllllllllllll}055 & 0 & 18.50 & 11 & 3 & 2 & 01 & 00 & 00 & 0 & 40 & 04 & 09 & 09 & 01 & 21 & 2 & 7 & 5 & 217 & 4\end{array}$ $\begin{array}{llllllllllllllllll}056 & 0 & 19.42 & . & 3 & . & 0 & 01 & 01 & 0 & 28 & 07 & 09 & 10 & 01 & 17 & 2 & 7\end{array}$.

$\begin{array}{lllllllllllllllllllll}057 & 0 & 20.25 & 11 & 3 & 3 & 12 & 03 & 03 & 0 & 36 & 08 & 07 & 09 & 00 & 30 & 7 & 6 & 3 & 263 & 6\end{array}$ $\begin{array}{lllllllllllllllllllllll}058 & 0 & 20.25 & 11 & 3 & . & . & 00 & 00 & 0 & 44 & 02 & 12 & 04 & 08 & 11 & 2 & 5 & 5 & 258 & 6\end{array}$ 
$\begin{array}{lllllllllllllllllllll}059 & 0 & 19.58 & 11 & 3 & 3 & 09 & 00 & 00 & 0 & 25 & 03 & 09 & 05 & 01 & 17 & 3 & 6 & 3 & 183 & 4\end{array}$ $\begin{array}{lllllllllllllllllllll}060 & 0 & 21.00 & 11 & 3 & . & . & 00 & 00 & 0 & 51 & 02 & 06 & 09 & 00 & 30 & 7 & 7 & . & . & .\end{array}$ $\begin{array}{lllllllllllllllllllll}061 & 0 & 20.25 & 11 & 3 & 3 & 09 & 02 & 01 & 0 & 43 & 04 & 11 & 08 & 03 & 27 & 5 & 6 & 5 & 275 & 7\end{array}$ $\begin{array}{llllllllllllllllll}062 & 0 & 18.75 & 11 & 3 & 4 & 10 & 01 & 01 & 0 & 48 & 03 & 05 & 01 & 02 & 19 & 2 & 7\end{array}$

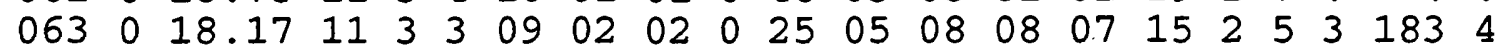
$\begin{array}{lllllllllllllllllllll}064 & 0 & 19.42 & 11 & 3 & . & 16 & 00 & 00 & 0 & 39 & 00 & 12 & 03 & 05 & 11 & 2 & 3 & 5 & 242 & 5\end{array}$ $\begin{array}{lllllllllllllllllll}065 & 0 & 18.17 & 11 & 3 & . & 0 & 0 & 00 & 0 & 42 & 07 & 07 & 04 & 04 & 15 & 3 & 4\end{array}$. $\begin{array}{lllllllllllllllllll}066 & 0 & 18.00 & 11 & 3 & 5 & 11 & 02 & 01 & 0 & 37 & 00 & 07 & 09 & 01 & 09 & 1 & 2\end{array}$. $\begin{array}{llllllllllllllllllllll}067 & 0 & 19.92 & 11 & 3 & 3 & 06 & 02 & 01 & 0 & 21 & 03 & 04 & 02 & 02 & 23 & 1 & 6 & 3 & 256 & 6\end{array}$ $\begin{array}{lllllllllllllllllllll}068 & 0 & 19.92 & 11 & 3 & 3 & 09 & 01 & 01 & 0 & 48 & 06 & 12 & 09 & 00 & 28 & 7 & 6 & 5 & 294 & 7\end{array}$ $\begin{array}{llllllllllllllllll}069 & 0 & 18.33 & 11 & 3 & . & . & 00 & 00 & 0 & 29 & 04 & 02 & 09 & 00 & 29 & 6 & 4\end{array}$.

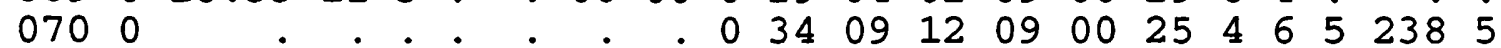

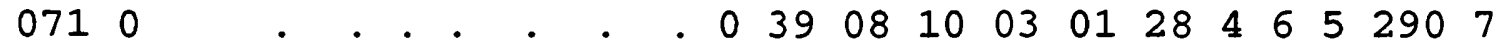
$\begin{array}{lllllllllllllllllllllll}072 & 0 & 20.92 & 11 & 3 & 3 & 09 & 04 & 02 & 0 & 45 & 07 & 12 & 04 & 04 & 29 & 4 & 7 & . & .\end{array}$ $\begin{array}{lllllllllllllllllllll}073 & 0 & 18.17 & 11 & 3 & 3 & 09 & 02 & 02 & 0 & 28 & 03 & 06 & 09 & 07 & 09 & 1 & 0 & . & . & .\end{array}$ $\begin{array}{lllllllllllllllllllll}074 & 0 & 21.58 & 11 & 3 & . & . & 0 & 0 & 00 & 0 & 27 & 03 & 00 & 01 & 03 & 15 & 1 & 5 & . & \text {. }\end{array}$ $\begin{array}{lllllllllllllllllll}075 & 0 & 0 & . & . & 0 & 0 & 0 & 0 & 0 & 0 & 0 & 0 & 11 & 08 & 02 & 22 & 3 & 6\end{array}$.

$\begin{array}{llllllllllllllllll}076 & 0 & 16.50 & 11 & 3 & 3 & 09 & 00 & 00 & 0 & 40 & 08 & 09 & 02 & 02 & 32 & 7 & 5\end{array}$. $\begin{array}{lllllllllllllll}077 & 0 & 20.50 & 12 & 3 & 3 & 06 & 00 & 00 & 0 & 31 & 03 & 10 & 05 & 04\end{array}$

$\begin{array}{lllllllllllllllllllll}078 & 0 & 18.08 & 11 & 3 & . & . & 00 & 00 & 0 & 45 & 02 & 10 & 10 & 03 & 28 & 6 & 6 & \dot{6} & 250 & \dot{6}\end{array}$ $\begin{array}{lllllllllllllllllllll}079 & 0 & 19.00 & 12 & 3 & 2 & 05 & 03 & 03 & 0 & 51 & 03 & 06 & 10 & 04 & 14 & 2 & 3 & 5 & 300 & 7\end{array}$ $\begin{array}{lllllllllllllllllllll}080 & 0 & 18.92 & 11 & 3 & 3 & 09 & 01 & 00 & 0 & 43 & 02 & 12 & 02 & 02 & 32 & 6 & 6 & 3 & 243 & 5\end{array}$

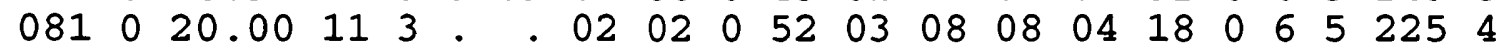

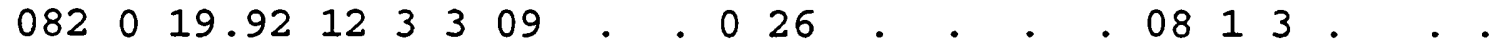
$\begin{array}{llllllllllllllllllll}083 & 0 & 18.00 & 11 & 3 & 3 & 09 & 02 & 01 & 0 & 44 & 02 & 00 & 11 & 01 & 09 & 2 & 0 & . & .\end{array}$ $\begin{array}{llllllllllllllllll}084 & 0 & 19.25 & 11 & 3 & . & . & 03 & 03 & 0 & 39 & 01 & 10 & 06 & 08 & 11 & 1 & 3\end{array}$

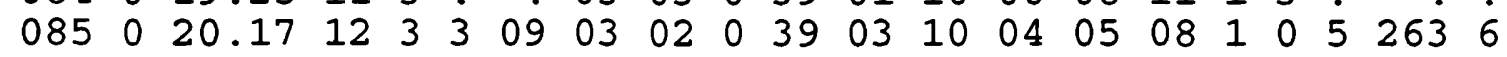
$\begin{array}{lllllllllllllllllllll}086 & 0 & 19.42 & 11 & 3 & 2 & 01 & 03 & 00 & 0 & 35 & 05 & 10 & 04 & 04 & 23 & 2 & 6 & 3 & 229 & 5\end{array}$ $\begin{array}{llllllllllllll}087 & 0 & . & . & . & . & . & . & 0 & 47 & 05 & 12 & 05 & 03\end{array}$

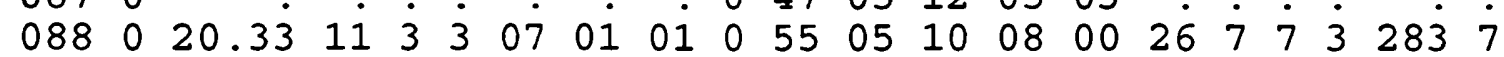
$\begin{array}{llllllllllllllllll}089 & 0 & 20.17 & 11 & 3 & 3 & 09 & 00 & 00 & 0 & 42 & 02 & 10 & 08 & 05 & 18 & 4 & 6\end{array}$.

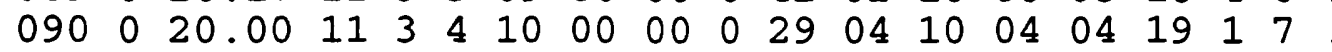
$\begin{array}{llllllllllllllllllllll}091 & 0 & 19.83 & 11 & 3 & 4 & 11 & 01 & 01 & 0 & 42 & 08 & 05 & 07 & 02 & 29 & 5 & 7 & 3 & 220 & 4\end{array}$ $\begin{array}{lllllllllllllllllllll}092 & 0 & 17.42 & 11 & 3 & 3 & 09 & 00 & 00 & 0 & 48 & 02 & 09 & 11 & 08 & 09 & 1 & 0 & 4 & 270 & 6\end{array}$ $\begin{array}{lllllllllllllllllllll}093 & 0 & 17.92 & 11 & 3 & . & . & 01 & 01 & 0 & 39 & 03 & 08 & 04 & 03 & 18 & 4 & 6 & 3 & 175 & 4\end{array}$ $\begin{array}{llllllllllllllllll}094 & 0 & 19.92 & 10 & 4 & 3 & 09 & 00 & 00 & 0 & 38 & 05 & 10 & 02 & 05 & 28 & 6 & 5\end{array}$. $\begin{array}{lllllllllllllllllllll}095 & 0 & 18.58 & 11 & 3 & 2 & 02 & 00 & 00 & 0 & 42 & 01 & 11 & 03 & 06 & 21 & 3 & 7 & 5 & 242 & 5\end{array}$ $\begin{array}{lllllllllllllllllll}096 & 0 & 19.17 & 10 & 2 & . & . & 0 & 0 & 00 & 0 & 47 & 08 & 11 & 02 & 01 & 33 & 6 & 7\end{array}$. $\begin{array}{lllllllllllllllllll}097 & 0 & 20.08 & 10 & 3 & . & 0 & 0 & 00 & 0 & 46 & 02 & 08 & 02 & 00 & 12 & 3 & 2\end{array}$. 0980

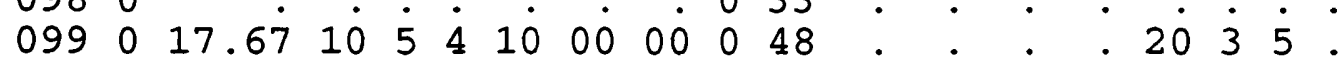

$\begin{array}{lllllllllllllll}100 & 0 & 18.08 & 10 & 1 & 1 & 04 & . & . & 0 & 45 & 04 & 09 & 08 & 02\end{array}$

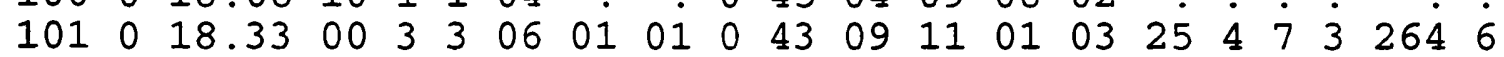
$\begin{array}{lllllllllllllllllllll}102 & 0 & 19.33 & 14 & 1 & 1 & 04 & 01 & 01 & 1 & 58 & 01 & 12 & 06 & 03 & 09 & 2 & 0 & 7 & 392 & 10\end{array}$ $\begin{array}{lllllllllllllllllllll}103 & 0 & 20.08 & 13 & 3 & 1 & 04 & 05 & 05 & 1 & 59 & 02 & 12 & 03 & 05 & 20 & 3 & 3 & 7 & 356 & 9\end{array}$ $\begin{array}{lllllllllllllllllllll}104 & 0 & 18.83 & 13 & 3 & 3 & 09 & 00 & 00 & 1 & 55 & 02 & 01 & 12 & 01 & 07 & 1 & 1 & 5 & 336 & 8\end{array}$ $\begin{array}{lllllllllllllllllllll}105 & 0 & 18.33 & 14 & 3 & 2 & 02 & 00 & 00 & 1 & 44 & 02 & 08 & 04 & 08 & 07 & 1 & 1 & 5 & 338 & 8\end{array}$ $\begin{array}{lllllllllllllllllllll}106 & 1 & 18.83 & 13 & 1 & 2 & 01 & . & . & 1 & 54 & 02 & 09 & 05 & 05 & 04 & 1 & 0 & 5 & 331 & 8\end{array}$

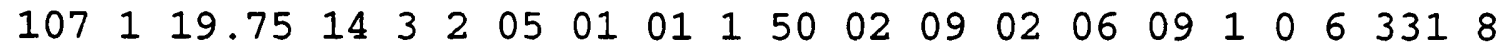
$\begin{array}{lllllllllllllllllllll}108 & 1 & 18.75 & 14 & 3 & 2 & 05 & 02 & 02 & 1 & 47 & 07 & 10 & 08 & 01 & 16 & 1 & 2 & 5 & 336 & 8\end{array}$

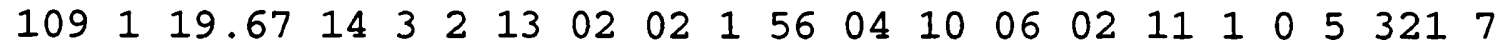
$\begin{array}{lllllllllllllllllllll}110 & 1 & 21.25 & 15 & 3 & 2 & 01 & 03 & 03 & 1 & 54 & 03 & 11 & 03 & 01 & 06 & 1 & 0 & 5 & 336 & 8\end{array}$ $\begin{array}{lllllllllllllllllllll}111 & 1 & 20.08 & 14 & 3 & 2 & 05 & 02 & 02 & 1 & 53 & 04 & 08 & 11 & 04 & 10 & 0 & 0 & 7 & 325 & 7\end{array}$ $\begin{array}{lllllllllllllllllllll}112 & 1 & 18.42 & 14 & 3 & 2 & 12 & 01 & 01 & 1 & 55 & 04 & 11 & 08 & 02 & 11 & 1 & 0 & 5 & 313 & 7\end{array}$ $\begin{array}{lllllllllllllllllllll}113 & 1 & 21.08 & 15 & 3 & . & . & 02 & 02 & 1 & 49 & 04 & 07 & 10 & 01 & 14 & 0 & 2 & 7 & 350 & 9\end{array}$ $\begin{array}{lllllllllllllllllllll}114 & 1 & 18.25 & 13 & 3 & 2 & 05 & 01 & 01 & 1 & 56 & 02 & 12 & 04 & 04 & 13 & 1 & 1 & 7 & 356 & 9\end{array}$ $\begin{array}{lllllllllllllllllllll}115 & 1 & 19.00 & 14 & 3 & 1 & 04 & 02 & 02 & 1 & 45 & 03 & 10 & 06 & 03 & 15 & 1 & 0 & 5 & 344 & 8\end{array}$ $\begin{array}{lllllllllllllllllllll}116 & 1 & 18.67 & 13 & 3 & 2 & 01 & 01 & 00 & 1 & 39 & 02 & 12 & 09 & 04 & 12 & 1 & 3 & 7 & 363 & 9\end{array}$ $\begin{array}{lllllllllllllllllllll}117 & 1 & 18.25 & 13 & 3 & 2 & 01 & 02 & 02 & 1 & 51 & 03 & 08 & 01 & 03 & 10 & 0 & 0 & 5 & 319 & 7\end{array}$ $\begin{array}{lllllllllllllllllllll}118 & 1 & 19.58 & 14 & 3 & 3 & 06 & 02 & 02 & 1 & 52 & 01 & 05 & 06 & 06 & 08 & 1 & 0 & 5 & 344 & 8\end{array}$ $\begin{array}{lllllllllllllllllllll}119 & 1 & 19.08 & 14 & 3 & 1 & 04 & 02 & 00 & 1 & 49 & 00 & 11 & 05 & 05 & 10 & 0 & 0 & 5 & 275 & 7\end{array}$ 
$\begin{array}{llllllllllllllllllllll}120 & 1 & 18.50 & 13 & 3 & 2 & 01 & 00 & 00 & 1 & 53 & 02 & 11 & 11 & 01 & 12 & 1 & 2 & 7 & 363 & 9\end{array}$ $\begin{array}{lllllllllllllllllllll}121 & 1 & 18.50 & 13 & 3 & 2 & 01 & 00 & 00 & 1 & 56 & 02 & 12 & 03 & 01 & 11 & 1 & 1 & 5 & 344 & 8\end{array}$ $\begin{array}{lllllllllllllllllllll}122 & 1 & 18.83 & 13 & 3 & 1 & 04 & 01 & 01 & 1 & 52 & 03 & 08 & 05 & 04 & 06 & 0 & 0 & 5 & 344 & 8\end{array}$ $\begin{array}{lllllllllllllllllllll}123 & 0 & 20.50 & 14 & 3 & 1 & 04 & 03 & 03 & 1 & 52 & 05 & 09 & 03 & 00 & 12 & 1 & 1 & 5 & 343 & 8\end{array}$ $\begin{array}{lllllllllllllllllllll}124 & 1 & 18.33 & 13 & 3 & 3 & 06 & 02 & 02 & 1 & 56 & 01 & 10 & 11 & 02 & 07 & 2 & 1 & 7 & 356 & 9\end{array}$ $\begin{array}{lllllllllllllllllllll}125 & 1 & 18.56 & 13 & 3 & 2 & 05 & 01 & 00 & 1 & 52 & 00 & 08 & 09 & 01 & 12 & 1 & 1 & 6 & 350 & 9\end{array}$ $\begin{array}{lllllllllllllllllllll}126 & 1 & 20.00 & 13 & 3 & 2 & 01 & 02 & 02 & 1 & 53 & 09 & 06 & 02 & 03 & 11 & 0 & 1 & 7 & 363 & 9\end{array}$ $\begin{array}{lllllllllllllllllllll}127 & 0 & 19.75 & 14 & 3 & 2 & 01 & 02 & 00 & 1 & 51 & 03 & 01 & 11 & 03 & 10 & 1 & 1 & 7 & 350 & 9\end{array}$ $\begin{array}{lllllllllllllllllllll}128 & 1 & 20.75 & 15 & 3 & 1 & 04 & 00 & 00 & 1 & 52 & 03 & 10 & 05 & 06 & 07 & 1 & 0 & 5 & 321 & 7\end{array}$ $\begin{array}{lllllllllllllllllllll}129 & 1 & 19.83 & 13 & 5 & 1 & 04 & 02 & 00 & 1 & 58 & 05 & 11 & 10 & 04 & 16 & 3 & 2 & 5 & 331 & 8\end{array}$ $\begin{array}{lllllllllllllllllllll}130 & 1 & 19.83 & 14 & 1 & 2 & 01 & 02 & 02 & 1 & 58 & 00 & 11 & 04 & 03 & 02 & 0 & 0 & 7 & 344 & 8\end{array}$

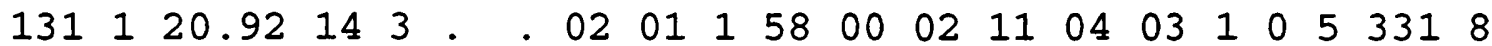
$\begin{array}{lllllllllllllllllllll}132 & 0 & 19.67 & 13 & 3 & 3 & 06 & 01 & 01 & 1 & 58 & 04 & 00 & 12 & 01 & 18 & 3 & 4 & 6 & 307 & 7\end{array}$

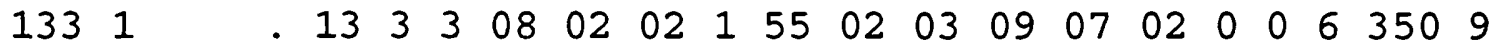
$\begin{array}{lllllllllllllllllllll}134 & 1 & 18.75 & 13 & 3 & 3 & 06 & 00 & 00 & 1 & 48 & 02 & 12 & 03 & 04 & 06 & 0 & 1 & 5 & 314 & 7\end{array}$ $\begin{array}{lllllllllllllllllllll}135 & 1 & 18.58 & 13 & 3 & 3 & 09 & 01 & 01 & 1 & 51 & 00 & 03 & 03 & 05 & 08 & 0 & 0 & 5 & 338 & 8\end{array}$ $\begin{array}{lllllllllllllllllllll}136 & 1 & 18.50 & 13 & 3 & 2 & 05 & 02 & 02 & 1 & 54 & 03 & 03 & 03 & 05 & 04 & 0 & 0 & 5 & 325 & 7\end{array}$ $\begin{array}{lllllllllllllllllllll}137 & 1 & 19.08 & 13 & 3 & 1 & 04 & 02 & 02 & 1 & 53 & 03 & 03 & 07 & 02 & 08 & 0 & 1 & 5 & 325 & 7\end{array}$ $\begin{array}{lllllllllllllllllllll}138 & 1 & 19.00 & 13 & 3 & 1 & 04 & 02 & 02 & 1 & 55 & 02 & 11 & 07 & 04 & 07 & 0 & 0 & 5 & 344 & 8\end{array}$ $\begin{array}{lllllllllllllllllllll}139 & 1 & 20.50 & 13 & 3 & 1 & 04 & 01 & 01 & 1 & 53 & 02 & 03 & 07 & 03 & 04 & 1 & 0 & 7 & 381 & 10\end{array}$ $\begin{array}{lllllllllllllllllllll}140 & 1 & 19.42 & 14 & 3 & 1 & 04 & 01 & 01 & 1 & 52 & 05 & 08 & 04 & 05 & 12 & 1 & 0 & 5 & 329 & 8\end{array}$ $\begin{array}{lllllllllllllllllllll}141 & 1 & 18.58 & 13 & 3 & 1 & 04 & 01 & 01 & 1 & 55 & 02 & 12 & 07 & 01 & 10 & 2 & 0 & 5 & 343 & 8\end{array}$ $\begin{array}{lllllllllllllllllllll}142 & 0 & 19.17 & 14 & 3 & 1 & 04 & 04 & 04 & 1 & 51 & 05 & 10 & 06 & 00 & 23 & 3 & 4 & 6 & 331 & 8\end{array}$ $\begin{array}{lllllllllllllllllllll}143 & 0 & 19.92 & 14 & 3 & 2 & 01 & 02 & 02 & 1 & 43 & 02 & 08 & 02 & 00 & 14 & 2 & 3 & 5 & 300 & 7\end{array}$ $\begin{array}{lllllllllllllllllllll}144 & 1 & 20.50 & 16 & 3 & 2 & 05 & 01 & 01 & 1 & 47 & 00 & 04 & 11 & 06 & 01 & 0 & 0 & 5 & 319 & 7\end{array}$ $\begin{array}{lllllllllllllllllllll}145 & 1 & 19.92 & 14 & 3 & 2 & 01 & 02 & 02 & 1 & 52 & 01 & 02 & 09 & 02 & 10 & 2 & 1 & 5 & 294 & 7\end{array}$ $\begin{array}{lllllllllllllllllllll}146 & 1 & 19.83 & 14 & 3 & 3 & 06 & 04 & 04 & 1 & 49 & 00 & 11 & 01 & 02 & 08 & 2 & 1 & 5 & 343 & 8\end{array}$ $\begin{array}{lllllllllllllllllllll}147 & 1 & 17.67 & 13 & 3 & 2 & 01 & 02 & 02 & 1 & 54 & 02 & 12 & 06 & 07 & 02 & 0 & 0 & 5 & 319 & 7\end{array}$ $\begin{array}{lllllllllllllllllllll}148 & 1 & 18.58 & 13 & 3 & 1 & 04 & 02 & 02 & 1 & 59 & 07 & 10 & 01 & 04 & 07 & 0 & 0 & 6 & 313 & 7\end{array}$ $\begin{array}{lllllllllllllllllllll}149 & 1 & 19.83 & 12 & 3 & 2 & 01 & 02 & 02 & 1 & 58 & 03 & 12 & 07 & 04 & 13 & 1 & 1 & 6 & 331 & 8\end{array}$ $\begin{array}{lllllllllllllllllllll}150 & 1 & 18.75 & 14 & 3 & 2 & 01 & 01 & 01 & 1 & 59 & 01 & 09 & 05 & 04 & 09 & 1 & 1 & 6 & 350 & 9\end{array}$ $\begin{array}{lllllllllllllllllllll}151 & 1 & 17.42 & 13 & 3 & 3 & 06 & 02 & 00 & 1 & 52 & 00 & 04 & 10 & 00 & 06 & 1 & 0 & 4 & 331 & 8\end{array}$ $\begin{array}{lllllllllllllllllllll}152 & 1 & 18.83 & 13 & 3 & 2 & 01 & 01 & 01 & 1 & 48 & 03 & 08 & 06 & 03 & 06 & 0 & 0 & 7 & 369 & 9\end{array}$ $\begin{array}{lllllllllllllllllllll}153 & 1 & 19.92 & 15 & 3 & 2 & 05 & 01 & 01 & 1 & 56 & 00 & 08 & 07 & 03 & 10 & 2 & 1 & 5 & 293 & 7\end{array}$ $\begin{array}{lllllllllllllllllllll}154 & 1 & 19.50 & 13 & 3 & 3 & 09 & 02 & 02 & 1 & 55 & 04 & 00 & 08 & 01 & 15 & 1 & 2 & 5 & 321 & 7\end{array}$ $\begin{array}{lllllllllllllllllllll}155 & 1 & 18.33 & 13 & 3 & 3 & 06 & 00 & 00 & 1 & 42 & 03 & 11 & 05 & 06 & 05 & 1 & 1 & 7 & 350 & 9\end{array}$ $\begin{array}{lllllllllllllllllllll}156 & 1 & 21.83 & 15 & 3 & 2 & 01 & 01 & 01 & 1 & 58 & 03 & 12 & 05 & 00 & 14 & 1 & 2 & 7 & 338 & 8\end{array}$ $\begin{array}{lllllllllllllllllllll}157 & 1 & 18.42 & 13 & 3 & 2 & 05 & 01 & 01 & 1 & 49 & 00 & 08 & 10 & 05 & 07 & 0 & 0 & 5 & 344 & 8\end{array}$ $\begin{array}{lllllllllllllllllllll}158 & 1 & 18.08 & 13 & 3 & 4 & 10 & 01 & 00 & 1 & 53 & 04 & 12 & 12 & 05 & 09 & 1 & 0 & 5 & 343 & 8\end{array}$ $\begin{array}{lllllllllllllllllllll}159 & 1 & 19.83 & 14 & 1 & 3 & 09 & 03 & 03 & 1 & 43 & 02 & 01 & 10 & 02 & 12 & 2 & 2 & 7 & 363 & 9\end{array}$ $\begin{array}{lllllllllllllllllllll}160 & 1 & 19.33 & 14 & 3 & 1 & 04 & 02 & 02 & 1 & 55 & 02 & 12 & 09 & 04 & 10 & 0 & 0 & 7 & 356 & 9\end{array}$ $\begin{array}{lllllllllllllllllllll}161 & 0 & 21.16 & 14 & 3 & 1 & 04 & 02 & 00 & 1 & 57 & 05 & 05 & 02 & 05 & 24 & 3 & 5 & 6 & 350 & 9\end{array}$ $\begin{array}{lllllllllllllllllllll}162 & 0 & 20.33 & 15 & 3 & 2 & 02 & 02 & 02 & 1 & 58 & 07 & 09 & 04 & 02 & 13 & 1 & 3 & 5 & 325 & 7\end{array}$ $\begin{array}{lllllllllllllllllll}163 & 0 & 21.58 & 16 & 3 & 2 & 01 & 01 & 01 & 1 & 56 & 03 & 10 & 01 & 01 & 15 & 2 & 3\end{array}$.

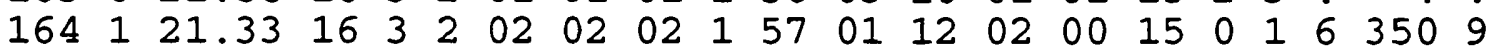
$\begin{array}{lllllllllllllllllllll}165 & 0 & 21.00 & 15 & 3 & 1 & 03 & 01 & 01 & 1 & . & 05 & 08 & 06 & 00 & 19 & 3 & 3 & 5 & 300 & 7\end{array}$ $\begin{array}{lllllllllllllllllllll}166 & 0 & 18.75 & 14 & 1 & 1 & 04 & 01 & 01 & 1 & 56 & 03 & 10 & 03 & 01 & 15 & 1 & 3 & 6 & 350 & 9\end{array}$ $\begin{array}{lllllllllllllllllllll}167 & 0 & 20.67 & 15 & 3 & 3 & 09 & 01 & 00 & 1 & 57 & 05 & 12 & 08 & 01 & 18 & 1 & 2 & 5 & 300 & 7\end{array}$ $\begin{array}{lllllllllllllllllllll}168 & 0 & 21.83 & 16 & 3 & 2 & 01 & 06 & 05 & 1 & 50 & 03 & 02 & 11 & 04 & 15 & 1 & 3 & 5 & 286 & 7\end{array}$ $\begin{array}{lllllllllllllllllllll}169 & 0 & 20.33 & 15 & 3 & 2 & 05 & 00 & 00 & 1 & 58 & 03 & 07 & 08 & 04 & 09 & 1 & 0 & 5 & 325 & 7\end{array}$ $\begin{array}{lllllllllllllllllllll}170 & 0 & 18.42 & 13 & 3 & 3 & 09 & 01 & 00 & 1 & 57 & 04 & 08 & 09 & 05 & 04 & 0 & 2 & 5 & 325 & 7\end{array}$ $\begin{array}{lllllllllllllllllllll}171 & 0 & 20.33 & 15 & 3 & 2 & 02 & 02 & 02 & 1 & 52 & 02 & 11 & 06 & 02 & 15 & 2 & 2 & 6 & 313 & 7\end{array}$ $\begin{array}{lllllllllllllllllllll}172 & 0 & 19.50 & 14 & 3 & 1 & 04 & 01 & 01 & 1 & 53 & 01 & 08 & 08 & 02 & 13 & 2 & 1 & 5 & 342 & 8\end{array}$ $\begin{array}{lllllllllllllllllllll}173 & 0 & 21.67 & 16 & 5 & 2 & 05 & 01 & 01 & 1 & 58 & 04 & 09 & 04 & 01 & 18 & 1 & 6 & 5 & 314 & 7\end{array}$ $\begin{array}{lllllllllllllllllllll}174 & 0 & 20.17 & 15 & 3 & 1 & 04 & 01 & 01 & 1 & 51 & 02 & 09 & 03 & 01 & 06 & 1 & 2 & 7 & 363 & 9\end{array}$ $\begin{array}{lllllllllllllllllllll}175 & 0 & 20.00 & 14 & 3 & . & . & 01 & 00 & 1 & 56 & 04 & 06 & 06 & 01 & 11 & 1 & 1 & 6 & 331 & 8\end{array}$ $\begin{array}{lllllllllllllllllllll}176 & 0 & 20.42 & 15 & 3 & 2 & 05 & 01 & 01 & 1 & 56 & 02 & 11 & 08 & 04 & 13 & 0 & 1 & 5 & 342 & 8\end{array}$ $\begin{array}{lllllllllllllllllllll}177 & 1 & 21.42 & 15 & 3 & 4 & 10 & 03 & 00 & 3 & 53 & 03 & 12 & 11 & 00 & 30 & 3 & 6 & 5 & 338 & 8\end{array}$ $\begin{array}{lllllllllllllllllllll}178 & 1 & 19.42 & 13 & 3 & 3 & 08 & 01 & 00 & 3 & 42 & 02 & 10 & 11 & 00 & 18 & 2 & 3 & 5 & 344 & 8\end{array}$ $\begin{array}{lllllllllllllllllllll}179 & 1 & 20.25 & 13 & 3 & 2 & 02 & 00 & 00 & 3 & 43 & 04 & 08 & 03 & 06 & 08 & 1 & 1 & 5 & 293 & 7\end{array}$ $\begin{array}{lllllllllllllllllllll}180 & 1 & 18.67 & 12 & 3 & 2 & 02 & 01 & 00 & 3 & 55 & 02 & 03 & 10 & 04 & 16 & 2 & 1 & 5 & 329 & 8\end{array}$ 
$\begin{array}{lllllllllllllllllllll}181 & 1 & 18.75 & 13 & 3 & 1 & 04 & 01 & 01 & 3 & 43 & 01 & 05 & 07 & 03 & 08 & 1 & 0 & 5 & 294 & 7\end{array}$ $\begin{array}{lllllllllllllllllllll}182 & 1 & 18.92 & 12 & 3 & 4 & 11 & 01 & 00 & 3 & 20 & 00 & 02 & 08 & 04 & 05 & 0 & 0 & 5 & 288 & 7\end{array}$ $\begin{array}{lllllllllllllllllllll}183 & 1 & 21.58 & 15 & 1 & 3 & 12 & 02 & 02 & 3 & 46 & 03 & 07 & 10 & 00 & 09 & 1 & 0 & 5 & 275 & 7\end{array}$ $\begin{array}{lllllllllllllllllllll}184 & 1 & 18.83 & 12 & 3 & 3 & 06 & 03 & 03 & 3 & 43 & 08 & 12 & 06 & 02 & 11 & 2 & 2 & 5 & 281 & 7\end{array}$ $\begin{array}{lllllllllllllllllllll}185 & 1 & 19.25 & 13 & 1 & 3 & 09 & 04 & 03 & 3 & 46 & 03 & 11 & 08 & 09 & 06 & 0 & 0 & 5 & 281 & 7\end{array}$

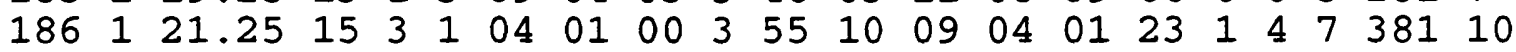
$\begin{array}{lllllllllllllllllllll}187 & 1 & 19.17 & 13 & 3 & 3 & 09 & 01 & 01 & 3 & 48 & 06 & 09 & 06 & 03 & 11 & 1 & 1 & 5 & 294 & 7\end{array}$ $\begin{array}{lllllllllllllllllllll}188 & 1 & 21.75 & 11 & 1 & 3 & 12 & 04 & 03 & 3 & 46 & 07 & 06 & 08 & 01 & 20 & 3 & 3 & 3 & 244 & 5\end{array}$ $\begin{array}{lllllllllllllllllllll}189 & 1 & 20.50 & 14 & 1 & 3 & 12 & 00 & 00 & 3 & 31 & 03 & 11 & 08 & 00 & 19 & 5 & 1 & 7 & 307 & 7\end{array}$ $\begin{array}{lllllllllllllllllllll}190 & 1 & 20.25 & 14 & 3 & 1 & 04 & 00 & 00 & 3 & 53 & 05 & 04 & 07 & 03 & 17 & 2 & 3 & 7 & 321 & 7\end{array}$ $\begin{array}{lllllllllllllllllllll}191 & 1 & 20.33 & 12 & 1 & 4 & 10 & 02 & 02 & 3 & 55 & 03 & 12 & 09 & 07 & 14 & 2 & 0 & 5 & 329 & 8\end{array}$ $\begin{array}{lllllllllllllllllllll}192 & 1 & 18.58 & 12 & 3 & 2 & 02 & 01 & 01 & 3 & 48 & 01 & 05 & 06 & 00 & 13 & 3 & 1 & 5 & 319 & 7\end{array}$ $\begin{array}{lllllllllllllllllllll}193 & 1 & 18.58 & 12 & 3 & 3 & 09 & 00 & 00 & 3 & 40 & 01 & 12 & 05 & 04 & 08 & 1 & 0 & 5 & 314 & 7\end{array}$ $\begin{array}{lllllllllllllllllllll}194 & 1 & 18.42 & 12 & 3 & . & . & 01 & 01 & 3 & 49 & 01 & 10 & 10 & 02 & 24 & 3 & 5 & 5 & 275 & 7\end{array}$ $\begin{array}{lllllllllllllllllllll}195 & 1 & 19.58 & 13 & 2 & 4 & 11 & 02 & 01 & 3 & 50 & 05 & 12 & 04 & 03 & 15 & 2 & 2 & 7 & 319 & 7\end{array}$ $\begin{array}{lllllllllllllllllllll}196 & 1 & 19.58 & 14 & 3 & 2 & 02 & 01 & 00 & 3 & 51 & 01 & 08 & 12 & 03 & 14 & 1 & 3 & 5 & 275 & 7\end{array}$ $\begin{array}{lllllllllllllllllllll}197 & 1 & 17.92 & 11 & 1 & 3 & 09 & 03 & 02 & 3 & 36 & 03 & 08 & 05 & 02 & 09 & 0 & 1 & 5 & 344 & 8\end{array}$ $\begin{array}{lllllllllllllllllllll}198 & 1 & 19.92 & 14 & 1 & 2 & 02 & 03 & 03 & 3 & 27 & 04 & 04 & 11 & 06 & 04 & 2 & 0 & 5 & 314 & 7\end{array}$ $\begin{array}{lllllllllllllllllllll}199 & 1 & 19.67 & 13 & 3 & 2 & 05 & 01 & 01 & 3 & 51 & 00 & 10 & 07 & 07 & 04 & 0 & 0 & 5 & 294 & 7\end{array}$ $\begin{array}{lllllllllllllllllllll}200 & 1 & 19.50 & 14 & 3 & 2 & 02 & 01 & 01 & 3 & 55 & 04 & 10 & 02 & 03 & 10 & 1 & 0 & 6 & 350 & 9\end{array}$

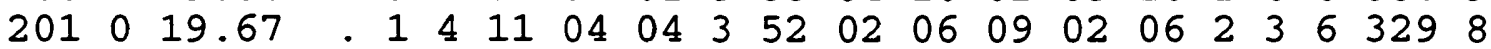

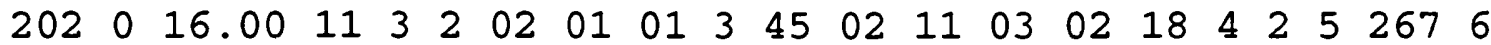
$\begin{array}{lllllllllllllllllllll}203 & 0 & 19.67 & 13 & 3 & 2 & 05 & 00 & 00 & 3 & 50 & 02 & 11 & 09 & 05 & 11 & 1 & 1 & 7 & 357 & 9\end{array}$ $\begin{array}{lllllllllllllllllllll}204 & 0 & 20.00 & 14 & 3 & . & . & 01 & 00 & 3 & 39 & 06 & 10 & 00 & 02 & 23 & 5 & 5 & 5 & 250 & 6\end{array}$ $\begin{array}{lllllllllllllllllllll}205 & 0 & 19.42 & 13 & 3 & 5 & 11 & 03 & 03 & 3 & 49 & 01 & 02 & 12 & 08 & 02 & 0 & 0 & 5 & 342 & 8\end{array}$ $\begin{array}{lllllllllllllllllllll}206 & 0 & 19.58 & 13 & 1 & 3 & 09 & 00 & 00 & 3 & 54 & 01 & 09 & 08 & 01 & 14 & 1 & 2 & 4 & 269 & 6\end{array}$ $\begin{array}{lllllllllllllllllllll}207 & 0 & 19.58 & 11 & 1 & 3 & 09 & 03 & 03 & 3 & 48 & 05 & 04 & 04 & 07 & 11 & 1 & 0 & 5 & 329 & 8\end{array}$ $\begin{array}{lllllllllllllllllllll}208 & 0 & 19.25 & 13 & 3 & 3 & 09 & 01 & 01 & 3 & 33 & 04 & 12 & 02 & 03 & 20 & 3 & 5 & 5 & 269 & 6\end{array}$ $\begin{array}{lllllllllllllllllllll}209 & 0 & 20.92 & 14 & 3 & 4 & 10 & 03 & 03 & 3 & 43 & 04 & 08 & 10 & 02 & 19 & 1 & 5 & 5 & 343 & 8\end{array}$ $\begin{array}{lllllllllllllllllllll}210 & 1 & 17.08 & 07 & 3 & . & . & 02 & 02 & 4 & 42 & 09 & 11 & 03 & 04 & 28 & 4 & 7 & 3 & 208 & 4\end{array}$ $\begin{array}{lllllllllllllllllllll}211 & 0 & 16.17 & 01 & 3 & 4 & 10 & 03 & 03 & 5 & 25 & 02 & 11 & 06 & 01 & 21 & 2 & 7 & 5 & 281 & 7\end{array}$ $\begin{array}{lllllllllllllllllllll}212 & 1 & 17.25 & 10 & 3 & 2 & 02 & 04 & 04 & 5 & 39 & 02 & 11 & 07 & 04 & 08 & 1 & 0 & 3 & 271 & 6\end{array}$ $\begin{array}{lllllllllllllllllllll}213 & 0 & 16.42 & . & 3 & . & 17 & 01 & 01 & 5 & 20 & 01 & 09 & 10 & 07 & 11 & 4 & 0 & 4 & 225 & 4\end{array}$ $\begin{array}{lllllllllllllllllllll}214 & 0 & 15.83 & 06 & 3 & 3 & 06 & 05 & 05 & 5 & 23 & 04 & 09 & 02 & 08 & 12 & 1 & 6 & 3 & 167 & 3\end{array}$ $\begin{array}{lllllllllllllllllll}215 & 0 & 15.50 & 08 & 3 & 3 & 10 & 01 & 01 & 4 & 34 & 06 & 11 & 05 & 04 & 31 & 5 & 6 & .\end{array}$

$\begin{array}{lllllllllllllllllllll}216 & 0 & 16.75 & 08 & 3 & . & . & 02 & 02 & 4 & 41 & 05 & 08 & 08 & 03 & 22 & 2 & 7 & 5 & 279 & 7\end{array}$ $\begin{array}{lllllllllllllllllllll}217 & 0 & 16.92 & 10 & 1 & 3 & 09 & 02 & 01 & 4 & 31 & 04 & 10 & 01 & 02 & 09 & 0 & 1 & 3 & 200 & 4\end{array}$ $\begin{array}{lllllllllllllllllllll}218 & 1 & 17.17 & 09 & 3 & . & . & 02 & 02 & 4 & 43 & 04 & 08 & 09 & 07 & 22 & 5 & 4 & 3 & 192 & 4\end{array}$ $\begin{array}{lllllllllllllllllllll}219 & 0 & 16.33 & 11 & 2 & . & . & 05 & 05 & 4 & 31 & 06 & 12 & 04 & 04 & 17 & 4 & 5 & 3 & 200 & 4\end{array}$

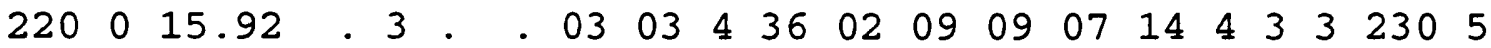
$\begin{array}{lllllllllllllllllllll}221 & 0 & 20.08 & 10 & 0 & 3 & 07 & 00 & 00 & 4 & 35 & 03 & 00 & 07 & 03 & 27 & 6 & 7 & 5 & 257 & 6\end{array}$ $\begin{array}{lllllllllllllllllllll}222 & 0 & 17.17 & 09 & 3 & . & . & 02 & 02 & 4 & 48 & 05 & 09 & 01 & 03 & 24 & 3 & 6 & 3 & 210 & 4\end{array}$ $\begin{array}{lllllllllllllllllllll}223 & 0 & 19.75 & 10 & 3 & 3 & 09 & 03 & 09 & 4 & 48 & 03 & 09 & 10 & 04 & 26 & 5 & 6 & 3 & 238 & 5\end{array}$ 
Faking Study data - Chapter 4.2

CODING - Key to data

VARIABLE NUMBER

1

2

3

4

5

6

7

8

9

10

11

12

13

14
NAME

Subject/CASE Number

SEX :

$0=$ Male

1 = Female

AGE in Years

OFFender Category:

0 = Convicted Offender

1 = Student Control

2 = Faking offender

3 = School Control

EPQ Scores:

Psychoticism (P)

Extraversion (E)

Neuroticism (N)

Lie Scale (L)

Self-Reported Delinquency:

Total Score (SRD)

Crimes Against Persons (PERSON)

General Theft Score (THEFT)

Socio-Moral Reflection Measure (SRM) : MODAL Score:

$$
\begin{aligned}
& 1=\text { Stage } 1 \\
& 2=\text { Stage } 1 / 2 \\
& 3=\text { Stage } 2 \\
& 4=\text { Stage } 2 / 3 \\
& 5=\text { Stage } 3 \\
& 6=\text { Stage } 3 / 4 \\
& 7=\text { Stage } 4
\end{aligned}
$$

SRMS

$$
\begin{aligned}
1 & =\text { Stage } 1 \\
2 & =\text { Stage } 1(2) \\
3 & =\text { Stage } 2(1) \\
4 & =\text { Stage } 2 \\
5 & =\text { Stage } 2(3) \\
6 & =\text { Stage } 3(2) \\
7 & =\text { Stage } 3 \\
8 & =\text { Stage } 3(4) \\
9 & =\text { Stage } 4(3) \\
10 & =\text { Stage } 4
\end{aligned}
$$

GLOBAL Score:

N.B.: Missing data is indicated by a '.' 


\section{Data}

$\begin{array}{llllllllllllll}01 & 1 & 21 & 2 & 06 & 09 & 08 & 02 & 10 & 0 & 1 & 6 & 350 & 9\end{array}$ $\begin{array}{llllllllllllll}02 & 1 & 20 & 2 & 11 & 05 & 10 & 00 & 02 & 0 & 0 & 5 & 243 & 5\end{array}$ $\begin{array}{llllllllllllll}03 & 1 & 20 & 2 & 10 & 12 & 01 & 00 & 14 & 0 & 1 & 3 & 236 & 5\end{array}$ $\begin{array}{llllllllllllll}04 & 0 & 18 & 2 & 12 & 12 & 06 & 00 & 12 & 3 & 1 & 5 & 314 & 7\end{array}$ $\begin{array}{llllllllllllll}05 & 1 & 19 & 2 & 02 & 12 & 04 & 06 & 06 & 1 & 0 & 5 & 319 & 7\end{array}$ $\begin{array}{llllllllllllll}06 & 1 & 19 & 2 & 12 & 08 & 05 & 01 & 10 & 0 & 0 & 5 & 275 & 7\end{array}$ $\begin{array}{llllllllllllll}07 & 0 & 19 & 2 & 04 & 06 & 03 & 01 & 10 & 1 & 1 & 5 & 306 & 7\end{array}$ $\begin{array}{llllllllllllll}08 & 1 & 21 & 2 & 11 & 05 & 07 & 02 & 16 & 1 & 4 & 3 & 238 & 5\end{array}$ $\begin{array}{llllllllllllll}09 & 0 & 19 & 2 & 06 & 00 & 12 & 04 & 09 & 1 & 1 & 5 & 342 & 8\end{array}$ $\begin{array}{llllllllllllll}10 & 1 & 18 & 2 & 12 & 06 & 05 & 01 & 04 & 1 & 0 & 3 & 236 & 5\end{array}$ $\begin{array}{llllllllllllll}11 & 1 & 19 & 2 & 11 & 03 & 10 & 00 & 09 & 2 & 0 & 3 & 275 & 7\end{array}$ $\begin{array}{llllllllllllll}12 & 1 & 19 & 2 & 12 & 03 & 04 & 00 & 09 & 2 & 1 & 6 & 329 & 8\end{array}$ $\begin{array}{llllllllllllll}13 & 1 & 20 & 2 & 08 & 09 & 10 & 01 & 06 & 0 & 2 & 5 & 264 & 6\end{array}$ $\begin{array}{llllllllllllll}14 & 1 & 21 & 2 & 12 & 10 & 05 & 00 & 08 & 1 & 0 & 3 & 242 & 5\end{array}$ $\begin{array}{llllllllllllll}15 & 1 & 19 & 2 & 09 & 05 & 05 & 04 & 12 & 2 & 1 & 5 & 271 & 6\end{array}$ $\begin{array}{llllllllllllll}16 & 1 & 19 & 2 & 11 & 10 & 08 & 01 & 06 & 0 & 0 & 3 & 283 & 7\end{array}$ $\begin{array}{llllllllllllll}17 & 1 & 18 & 2 & 09 & 01 & 11 & 00 & 03 & 0 & 0 & 5 & 269 & 6\end{array}$ $\begin{array}{llllllllllllll}18 & 1 & 19 & 2 & 08 & 10 & 08 & 00 & 07 & 0 & 0 & . & 300 & 7\end{array}$ $\begin{array}{llllllllllllll}19 & 1 & 19 & 2 & 12 & 07 & 04 & 00 & 07 & 0 & 0 & 3 & 213 & 4\end{array}$ $\begin{array}{llllllllllllll}20 & 1 & 19 & 2 & 10 & 04 & 09 & 01 & 17 & 3 & 3 & 5 & 275 & 7\end{array}$ $\begin{array}{llllllllllllll}21 & 0 & . & 2 & 04 & 05 & 06 & 00 & 16 & 2 & 3 & 5 & 319 & 7\end{array}$ $\begin{array}{llllllllllllll}22 & 1 & 17 & 2 & 11 & 11 & 04 & 00 & 09 & 0 & 0 & 5 & 263 & 6\end{array}$ $\begin{array}{llllllllllllll}23 & 1 & 19 & 2 & 12 & 08 & 02 & 01 & 04 & 0 & 2 & 3 & 275 & 7\end{array}$ $\begin{array}{llllllllllllll}24 & 1 & 19 & 2 & 06 & 02 & 07 & 02 & 09 & 0 & 2 & 5 & 288 & 7\end{array}$ $\begin{array}{llllllllllllll}25 & 1 & 19 & 2 & 01 & 12 & 05 & 10 & 12 & 2 & 1 & 5 & 321 & 7\end{array}$ $\begin{array}{llllllllllllll}26 & 1 & 20 & 2 & 03 & 12 & 07 & 03 & 12 & 0 & 2 & 5 & 306 & 7\end{array}$ $\begin{array}{llllllllllllll}27 & 1 & 19 & 2 & 11 & 07 & 04 & 00 & 20 & 2 & 5 & 3 & 240 & 5\end{array}$ $\begin{array}{llllllllllllll}28 & 1 & 18 & 2 & 11 & 07 & 07 & 01 & 07 & 0 & 0 & 3 & 258 & 6\end{array}$ $\begin{array}{llllllllllllll}29 & 1 & 19 & 2 & 11 & 01 & 05 & 00 & 11 & 0 & 0 & 7 & 325 & 7\end{array}$ $\begin{array}{llllllllllllll}30 & 0 & 20 & 2 & 07 & 02 & 11 & 02 & 17 & 1 & 0 & 5 & 307 & 7\end{array}$ $\begin{array}{llllllllllllll}31 & 1 & 19 & 2 & 10 & 04 & 06 & 00 & 05 & 0 & 0 & 3 & 250 & 6\end{array}$ $\begin{array}{llllllllllllll}32 & 1 & 18 & 2 & 08 & 08 & 10 & 00 & 16 & 2 & 1 & 5 & 319 & 7\end{array}$ $\begin{array}{llllllllllllll}33 & 1 & 19 & 2 & 04 & 09 & 04 & 02 & 09 & 1 & 0 & 5 & 293 & 7\end{array}$ $\begin{array}{llllllllllllll}34 & 1 & 19 & 2 & 02 & 08 & 08 & 03 & 14 & 1 & 2 & 5 & 307 & 7\end{array}$ $\begin{array}{llllllllllllll}35 & 0 & 18 & 2 & 10 & 04 & 03 & 00 & 15 & 1 & 1 & 3 & 257 & 6\end{array}$ $\begin{array}{llllllllllllll}36 & 1 & 19 & 2 & 02 & 12 & 04 & 03 & 10 & 0 & 1 & 3 & 250 & 6\end{array}$ $\begin{array}{llllllllllllll}37 & 1 & 18 & 2 & 11 & 09 & 09 & 00 & 06 & 0 & 1 & 3 & 242 & 5\end{array}$ $\begin{array}{llllllllllllll}38 & 1 & 18 & 2 & 02 & 09 & 11 & 02 & 11 & 0 & 1 & 5 & 344 & 8\end{array}$ $\begin{array}{llllllllllllll}39 & 1 & 18 & 2 & 03 & 11 & 07 & 02 & 12 & 0 & 0 & 7 & 343 & 8\end{array}$ $\begin{array}{llllllllllllll}40 & 0 & 18 & 2 & 11 & 11 & 05 & 00 & 17 & 1 & 2 & 5 & 319 & 7\end{array}$ $\begin{array}{llllllllllllll}41 & 1 & 18 & 2 & 02 & 09 & 08 & 07 & 10 & 1 & 0 & 5 & 338 & 8\end{array}$ $\begin{array}{llllllllllllll}42 & 0 & 18 & 2 & 11 & 11 & 03 & 01 & 20 & 3 & 3 & 5 & 293 & 7\end{array}$ $\begin{array}{llllllllllllll}43 & 0 & 18 & 2 & 11 & 11 & 03 & 01 & 20 & 3 & 3 & 5 & 293 & 7\end{array}$ $\begin{array}{llllllllllllll}44 & 1 & 19 & 2 & 00 & 12 & 09 & 03 & 08 & 1 & 1 & 5 & 325 & 7\end{array}$ $\begin{array}{llllllllllllll}45 & 1 & 21 & 2 & 08 & 11 & 07 & 00 & 30 & 3 & 6 & 5 & 294 & 7\end{array}$ $\begin{array}{llllllllllllll}46 & 1 & 18 & 2 & 05 & 09 & 06 & 01 & 07 & 1 & 0 & 5 & 319 & 7\end{array}$ $\begin{array}{llllllllllllll}47 & 1 & 19 & 2 & 12 & 06 & 06 & 00 & 05 & 0 & 0 & 3 & 238 & 5\end{array}$ $\begin{array}{llllllllllllll}48 & 0 & 19 & 2 & 11 & 11 & 02 & 01 & 24 & 6 & 4 & 6 & 350 & 9\end{array}$ 
SRM Scoring Check - Data from 20 randomly selected cases taken from the data above

Coding - Key to data

VARIABLE NUMBER

NAME

1

Subject/CASE Number 2

Re-Score of Socio-Moral Reflection Measure (SRM): MODAL Score:

$$
\begin{aligned}
& 1=\text { Stage } 1 \\
& 2=\text { Stage } 1 / 2 \\
& 3=\text { Stage } 2 \\
& 4=\text { Stage } 2 / 3 \\
& 5=\text { Stage } 3 \\
& 6=\text { Stage } 3 / 4 \\
& 7=\text { Stage } 4
\end{aligned}
$$

3

SRMS

GLOBAL Score:

$$
\begin{aligned}
1 & =\text { Stage } 1 \\
2 & =\text { Stage } 1(2) \\
3 & =\text { Stage } 2(1) \\
4 & =\text { Stage } 2 \\
5 & =\text { Stage } 2(3) \\
6 & =\text { Stage } 3(2) \\
7 & =\text { Stage } 3 \\
8 & =\text { Stage } 3(4) \\
9 & =\text { Stage } 4(3) \\
10 & =\text { Stage } 4
\end{aligned}
$$

First Scoring of Socio-Moral Reflection Measure (SRM): 5

6
7 MODAL Score:

$$
\begin{aligned}
& 1=\text { Stage } 1 \\
& 2=\text { Stage } 1 / 2 \\
& 3=\text { Stage } 2 \\
& 4=\text { Stage } 2 / 3 \\
& 5=\text { Stage } 3 \\
& 6=\text { Stage } 3 / 4 \\
& 7=\text { Stage } 4
\end{aligned}
$$

SRMS

GLOBAL Score:

$$
\begin{aligned}
1 & =\text { Stage } 1 \\
2 & =\text { Stage } 1(2) \\
3 & =\text { Stage } 2(1) \\
4 & =\text { Stage } 2 \\
5 & =\text { stage } 2(3) \\
6 & =\text { stage } 3(2) \\
7 & =\text { Stage } 3 \\
8 & =\text { Stage } 3(4) \\
9 & =\text { Stage } 4(3) \\
10 & =\text { Stage } 4
\end{aligned}
$$

N.B.: Missing data is indicated by a '.' 
Data

$\begin{array}{lllllll}054 & 5 & 243 & 5 & 5 & 244 & 5\end{array}$

$\begin{array}{lllllll}110 & 5 & 325 & 7 & 5 & 336 & 8\end{array}$

$\begin{array}{lllllll}207 & 5 & 314 & 7 & 5 & 329 & 8\end{array}$

$\begin{array}{lllllll}057 & 5 & 292 & 7 & 5 & 263 & 6\end{array}$

$\begin{array}{lllllll}104 & 5 & 300 & 7 & 5 & 336 & 8\end{array}$

$\begin{array}{lllllll}071 & 5 & 280 & 6 & 5 & 290 & 7\end{array}$

$\begin{array}{lllllll}018 & 4 & 233 & 5 & 5 & 243 & 5\end{array}$

$\begin{array}{lllllll}045 & 3 & 200 & 4 & 3 & 200 & 4\end{array}$

$\begin{array}{lllllll}052 & 5 & 275 & 7 & 5 & 293 & 7\end{array}$

$\begin{array}{lllllll}086 & 5 & 283 & 7 & 4 & 229 & 5\end{array}$

$\begin{array}{lllllll}010 & 4 & 250 & 6 & 4 & 250 & 6\end{array}$

$\begin{array}{lllllll}204 & 5 & 267 & 6 & 5 & 250 & 6\end{array}$

$\begin{array}{lllllll}067 & 3 & 244 & 5 & 3 & 256 & 6\end{array}$

$\begin{array}{lllllll}012 & 5 & 258 & 6 & 5 & 271 & 6\end{array}$

$\begin{array}{lllllll}011 & 5 & 267 & 6 & 5 & 243 & 5\end{array}$

$\begin{array}{lllllll}122 & 5 & 306 & 7 & 5 & 344 & 8\end{array}$

$\begin{array}{llllllll}162 & 6 & 331 & 8 & 5 & 325 & 7\end{array}$

$\begin{array}{lllllll}184 & 5 & 307 & 7 & 5 & 281 & 7\end{array}$

$\begin{array}{lllllll}095 & 1 & 210 & 4 & 5 & 242 & 5\end{array}$

$046 . .42336$ 


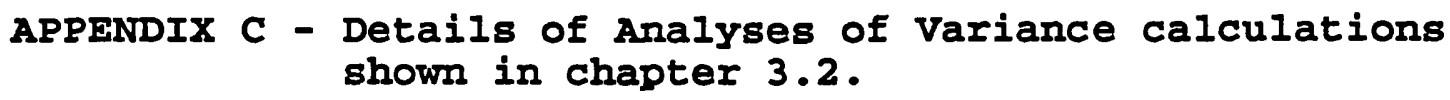

Comparisons between Male offenders and Male Controls

\begin{tabular}{|c|c|c|c|c|c|}
\hline $\begin{array}{l}\text { Source of } \\
\text { Variance }\end{array}$ & SS & $d f$ & MS & $F$ & $p$ \\
\hline $\begin{array}{l}\text { Var: AGE } \\
\text { Model } \\
\text { Error } \\
\text { Total }\end{array}$ & $\begin{array}{r}13.18 \\
157.17 \\
170.35\end{array}$ & $\begin{array}{r}1 \\
126 \\
127\end{array}$ & $\begin{array}{r}13.18 \\
1.25\end{array}$ & 10.57 & $<0.01$ \\
\hline $\begin{array}{l}\text { Var: EDU } \\
\text { Model } \\
\text { Error } \\
\text { Total }\end{array}$ & $\begin{array}{l}282.10 \\
215.93 \\
498.02\end{array}$ & $\begin{array}{r}1 \\
122 \\
123\end{array}$ & $\begin{array}{r}282.10 \\
1.77\end{array}$ & 159.39 & $<0.0001$ \\
\hline $\begin{array}{l}\text { Var: CLASS } \\
\text { Model } \\
\text { Error } \\
\text { Total }\end{array}$ & $\begin{array}{r}17.15 \\
93.96 \\
111.11\end{array}$ & $\begin{array}{r}1 \\
97 \\
98\end{array}$ & $\begin{array}{r}17.15 \\
0.97\end{array}$ & 17.71 & $<0.0001$ \\
\hline $\begin{array}{l}\text { Var: SEG } \\
\text { Model } \\
\text { Error } \\
\text { Total }\end{array}$ & $\begin{array}{r}198.87 \\
985.43 \\
1184.30\end{array}$ & $\begin{array}{r}1 \\
99 \\
100\end{array}$ & $\begin{array}{r}198.87 \\
9.95\end{array}$ & 19.98 & $<0.0001$ \\
\hline $\begin{array}{l}\text { Var: SIB } \\
\text { Model } \\
\text { Error } \\
\text { Total }\end{array}$ & $\begin{array}{r}0.00 \\
282.63 \\
283.63\end{array}$ & $\begin{array}{r}1 \\
125 \\
126\end{array}$ & $\begin{array}{l}0.00 \\
2.26\end{array}$ & 0.00 & $>0.05$ \\
\hline $\begin{array}{l}\text { Var: SIB10 } \\
\text { Model } \\
\text { Error } \\
\text { Total }\end{array}$ & $\begin{array}{r}0.44 \\
203.22 \\
203.66\end{array}$ & $\begin{array}{r}1 \\
124 \\
125\end{array}$ & $\begin{array}{l}0.44 \\
1.64\end{array}$ & 0.27 & $>0.05$ \\
\hline $\begin{array}{l}\text { Var: P } \\
\text { Model } \\
\text { Error } \\
\text { Total }\end{array}$ & $\begin{array}{r}57.30 \\
686.00 \\
743.30\end{array}$ & $\begin{array}{r}1 \\
127 \\
128\end{array}$ & $\begin{array}{r}57.30 \\
5.40\end{array}$ & 10.61 & $<0.01$ \\
\hline $\begin{array}{l}\text { Var: E } \\
\text { Model } \\
\text { Error } \\
\text { Total }\end{array}$ & $\begin{array}{r}18.16 \\
1270.08 \\
1288.23\end{array}$ & $\begin{array}{r}1 \\
127 \\
128\end{array}$ & $\begin{array}{l}18.16 \\
10.00\end{array}$ & 1.82 & $>0.05$ \\
\hline $\begin{array}{l}\text { Var: N } \\
\text { Model } \\
\text { Error } \\
\text { Total }\end{array}$ & $\begin{array}{r}0.24 \\
1370.98 \\
1371.22\end{array}$ & $\begin{array}{r}1 \\
127 \\
126\end{array}$ & $\begin{array}{r}0.24 \\
10.79\end{array}$ & 0.02 & $>0.05$ \\
\hline
\end{tabular}




\begin{tabular}{|c|c|c|c|c|c|}
\hline $\begin{array}{l}\text { Model } \\
\text { Error } \\
\text { Total }\end{array}$ & $\begin{array}{r}8.94 \\
729.13 \\
738.06\end{array}$ & $\begin{array}{r}1 \\
127 \\
128\end{array}$ & $\begin{array}{l}8.94 \\
5.74\end{array}$ & 1.56 & $>0.05$ \\
\hline $\begin{array}{l}\text { Var: } \\
\text { Model } \\
\text { Error } \\
\text { Total }\end{array}$ & $\begin{array}{l}1658.66 \\
6039.45 \\
7698.12\end{array}$ & $\begin{array}{r}1 \\
126 \\
127\end{array}$ & $\begin{array}{r}1658.66 \\
47.93\end{array}$ & 34.60 & $<0.0001$ \\
\hline $\begin{array}{l}\text { Var: } \\
\text { Model } \\
\text { Error } \\
\text { Total }\end{array}$ & $\begin{array}{l}115.91 \\
429.96 \\
545.88\end{array}$ & $\begin{array}{r}1 \\
126 \\
127\end{array}$ & $\begin{array}{r}115.91 \\
3.41\end{array}$ & 33.97 & $<0.0001$ \\
\hline $\begin{array}{l}\text { Var: } \\
\text { Model } \\
\text { Error } \\
\text { Total }\end{array}$ & $\begin{array}{l}208.91 \\
422.96 \\
631.88\end{array}$ & $\begin{array}{r}1 \\
126 \\
127\end{array}$ & $\begin{array}{r}208.91 \\
3.36\end{array}$ & 62.23 & $<0.0001$ \\
\hline $\begin{array}{l}\text { Var: } \\
\text { Model } \\
\text { Error } \\
\text { Total }\end{array}$ & $\begin{array}{r}3976.77 \\
8798.17 \\
12774.95\end{array}$ & $\begin{array}{r}1 \\
129 \\
130\end{array}$ & $\begin{array}{r}3976.77 \\
68.20\end{array}$ & 58.31 & $<0.0001$ \\
\hline $\begin{array}{l}\text { Var: } 1 \\
\text { Model } \\
\text { Error } \\
\text { Total }\end{array}$ & $\begin{array}{r}37.79 \\
75.85 \\
113.64\end{array}$ & $\begin{array}{r}1 \\
97 \\
98\end{array}$ & $\begin{array}{r}37.79 \\
0.78\end{array}$ & 48.32 & $<0.0001$ \\
\hline $\begin{array}{l}\text { Var: } \\
\text { Model } \\
\text { Error } \\
\text { Total }\end{array}$ & $\begin{array}{l}111964.45 \\
106333.74 \\
218298.19\end{array}$ & $\begin{array}{l}1 \\
98 \\
99\end{array}$ & $\begin{array}{r}111964.45 \\
1085.03\end{array}$ & 103.19 & $<0.0001$ \\
\hline $\begin{array}{l}\text { Var: } \\
\text { Model } \\
\text { Error } \\
\text { Total }\end{array}$ & $\begin{array}{r}90.60 \\
106.40 \\
197.00\end{array}$ & $\begin{array}{l}1 \\
98 \\
99\end{array}$ & $\begin{array}{r}90.60 \\
1.09\end{array}$ & 83.44 & $<0.0001$ \\
\hline
\end{tabular}

Comparisons between Male offenders and Male and Female Controls

\begin{tabular}{|c|c|c|c|c|c|}
\hline $\begin{array}{l}\text { Source of } \\
\text { Variance }\end{array}$ & SS & $d f$ & MS & $F$ & $\mathrm{p}$ \\
\hline $\begin{array}{l}\text { Var: AGE } \\
\text { Model } \\
\text { Error } \\
\text { Total }\end{array}$ & $\begin{array}{r}8.88 \\
238.54 \\
247.43\end{array}$ & $\begin{array}{r}1 \\
200 \\
201\end{array}$ & $\begin{array}{l}8.88 \\
1.19\end{array}$ & 7.54 & $<0.01$ \\
\hline $\begin{array}{l}\text { Var: EDU } \\
\text { Model } \\
\text { Error } \\
\text { Total }\end{array}$ & $\begin{array}{l}462.50 \\
297.03 \\
759.53\end{array}$ & $\begin{array}{r}1 \\
197 \\
198\end{array}$ & $\begin{array}{r}462.50 \\
1.51\end{array}$ & 306.74 & $<0.0001$ \\
\hline
\end{tabular}


Var: CLASS

Model

Error

31.31

145.26

1

31.31

$36.43<0.0001$

Total

$176.57 \quad 170$

0.86

Var: SEG

Model

Error

Total

$379.12 \quad 1$

$1826.46 \quad 171$

$2208.58 \quad 172$

$\begin{array}{r}379.12 \\ 10.68\end{array} \quad 35.44<0.0001$

Var: SIB

Model

Error

$0.64 \quad 1$

$349.57 \quad 199$

0.64

$0.00>0.05$

Total

$\begin{array}{ll}349.57 & 199 \\ 350.21 & 200\end{array}$

1.76

Var: SIB10

Model

Error

$\begin{array}{rr}0.00 & 1 \\ 277.59 & 198\end{array}$

0.00

1.40

$0.27>0.05$

Total

$277.59 \quad 199$

Var: $P$

Model

Error

Total

179.34

1041.41

1220.75

202

179.34

34.79

$<0.0001$

203

Var: E

Model

Error

Total

$12.47 \quad 1$

$2137.94 \quad 202$

$2150.41 \quad 203$

5.16

10.58

Var: N

Model

Error

Total

13.85 2049.15

2063.00

202

13.85

$1.37>0.05$

Var: L

Model

Error

Total

1.72

Var: SRD

Model

Error

Total

1061.16

1

202

$1062.88 \quad 203$

10.14

$1.18>0.05$

1.72

$0.33>0.05$

Var: PER

Model

Error

Total

5671.37

8408.48

201

5671.37

$135.57<0.0001$

$14079.85 \quad 202$

41.83

Var: THEFT

Model

Error

344.46

511.84

856.31

1
201
202

344.46

$135.27<0.0001$

Total

$\begin{array}{rr}781.55 & 1 \\ 587.96 & 201\end{array}$

$1369.51 \quad 202$
781.55
2.93

267.18

$<0.0001$ 


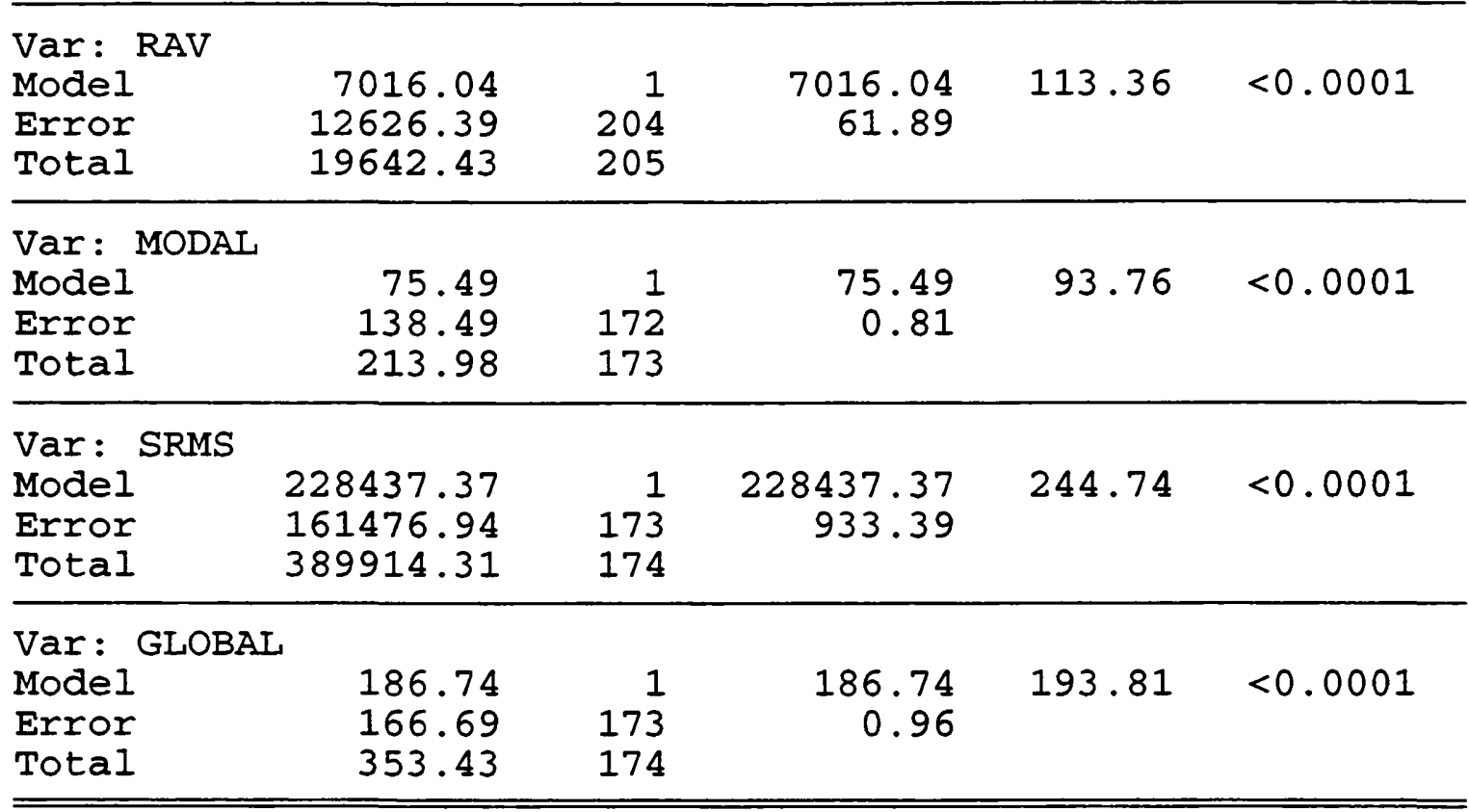

Comparisons between Male offenders and Female Controls

\begin{tabular}{|c|c|c|c|c|c|}
\hline $\begin{array}{l}\text { Source of } \\
\text { Variance }\end{array}$ & SS & $d f$ & MS & $\mathbf{F}$ & $\mathrm{p}$ \\
\hline $\begin{array}{l}\text { Var: AGE } \\
\text { Model } \\
\text { Error } \\
\text { Total }\end{array}$ & $\begin{array}{r}3.27 \\
194.07 \\
197.34\end{array}$ & $\begin{array}{r}1 \\
167 \\
168\end{array}$ & $\begin{array}{l}3.27 \\
1.18\end{array}$ & 2.81 & $>0.05$ \\
\hline $\begin{array}{l}\text { Var: EDU } \\
\text { Model } \\
\text { Error } \\
\text { Total }\end{array}$ & $\begin{array}{l}345.47 \\
245.14 \\
590.61\end{array}$ & $\begin{array}{r}1 \\
165 \\
166\end{array}$ & $\begin{array}{r}345.47 \\
1.49\end{array}$ & 232.53 & $<0.0001$ \\
\hline $\begin{array}{l}\text { Var: CLASS } \\
\text { Model } \\
\text { Error } \\
\text { Total }\end{array}$ & $\begin{array}{r}26.13 \\
113.04 \\
139.17\end{array}$ & $\begin{array}{r}1 \\
138 \\
139\end{array}$ & $\begin{array}{r}26.13 \\
0.82\end{array}$ & 31.90 & $<0.0001$ \\
\hline $\begin{array}{l}\text { Var: SEG } \\
\text { Model } \\
\text { Error } \\
\text { Total }\end{array}$ & $\begin{array}{r}320.45 \\
1523.94 \\
1844.39\end{array}$ & $\begin{array}{r}1 \\
140 \\
141\end{array}$ & $\begin{array}{r}320.45 \\
10.89\end{array}$ & 29.44 & $<0.0001$ \\
\hline $\begin{array}{l}\text { Var: SIB } \\
\text { Model } \\
\text { Error } \\
\text { Total }\end{array}$ & $\begin{array}{r}1.08 \\
280.04 \\
281.11\end{array}$ & $\begin{array}{r}1 \\
166 \\
167\end{array}$ & $\begin{array}{l}1.08 \\
1.69\end{array}$ & 0.64 & $>0.05$ \\
\hline $\begin{array}{l}\text { Var: SIB10 } \\
\text { Model } \\
\text { Error } \\
\text { Total }\end{array}$ & $\begin{array}{r}0.09 \\
202.78 \\
202.87\end{array}$ & $\begin{array}{r}1 \\
165 \\
166\end{array}$ & $\begin{array}{l}0.09 \\
1.23\end{array}$ & 0.07 & $>0.05$ \\
\hline
\end{tabular}




\begin{tabular}{|c|c|c|c|c|c|}
\hline $\begin{array}{l}\text { Var: } \\
\text { Model } \\
\text { Error } \\
\text { Total }\end{array}$ & $\begin{array}{r}174.01 \\
956.04 \\
1130.05\end{array}$ & $\begin{array}{r}1 \\
169 \\
170\end{array}$ & $\begin{array}{r}174.01 \\
5.66\end{array}$ & 30.76 & $<0.0001$ \\
\hline $\begin{array}{l}\text { Var: } \\
\text { Model } \\
\text { Error } \\
\text { Total }\end{array}$ & $\begin{array}{r}4.73 \\
1743.38 \\
1748.11\end{array}$ & $\begin{array}{r}1 \\
169 \\
170\end{array}$ & $\begin{array}{r}4.73 \\
10.32\end{array}$ & 0.46 & $>0.05$ \\
\hline $\begin{array}{l}\text { Var: } \\
\text { Model } \\
\text { Error } \\
\text { Total }\end{array}$ & $\begin{array}{r}21.10 \\
1650.42 \\
1671.52\end{array}$ & $\begin{array}{r}1 \\
169 \\
170\end{array}$ & $\begin{array}{r}21.10 \\
9.77\end{array}$ & 2.16 & $>0.05$ \\
\hline $\begin{array}{l}\text { Var: I } \\
\text { Model } \\
\text { Error } \\
\text { Total }\end{array}$ & $\begin{array}{r}0.00 \\
893.17 \\
893.17\end{array}$ & $\begin{array}{r}1 \\
169 \\
170\end{array}$ & $\begin{array}{l}0.00 \\
5.28\end{array}$ & 0.00 & $>0.05$ \\
\hline $\begin{array}{l}\text { Var: } \\
\text { Model } \\
\text { Error } \\
\text { Total }\end{array}$ & $\begin{array}{r}5671.76 \\
7124.03 \\
12795.79\end{array}$ & $\begin{array}{r}1 \\
168 \\
169\end{array}$ & $\begin{array}{r}5671.76 \\
42.40\end{array}$ & 133.75 & $<0.0001$ \\
\hline $\begin{array}{l}\text { Var: } \\
\text { Model } \\
\text { Error } \\
\text { Total }\end{array}$ & $\begin{array}{l}329.08 \\
460.32 \\
788.59\end{array}$ & $\begin{array}{r}1 \\
168 \\
169\end{array}$ & $\begin{array}{r}329.08 \\
2.74\end{array}$ & 120.31 & $<0.0001$ \\
\hline $\begin{array}{l}\text { Var: } \\
\text { Model } \\
\text { Error } \\
\text { Total }\end{array}$ & $\begin{array}{r}803.15 \\
451.67 \\
1254.82\end{array}$ & $\begin{array}{r}1 \\
168 \\
169\end{array}$ & $\begin{array}{r}803.15 \\
2.69\end{array}$ & 298.73 & $<0.0001$ \\
\hline $\begin{array}{l}\text { Var: } \\
\text { Model } \\
\text { Error } \\
\text { Total }\end{array}$ & $\begin{array}{r}5346.26 \\
11344.55 \\
16690.81\end{array}$ & $\begin{array}{r}1 \\
172 \\
173\end{array}$ & $\begin{array}{r}5346.26 \\
65.96\end{array}$ & 81.06 & $<0.0001$ \\
\hline $\begin{array}{l}\text { Var: } 1 \\
\text { Model } \\
\text { Error } \\
\text { Total }\end{array}$ & $\begin{array}{r}66.18 \\
118.44 \\
184.62\end{array}$ & $\begin{array}{r}1 \\
140 \\
141\end{array}$ & $\begin{array}{r}66.18 \\
0.85\end{array}$ & 78.23 & $<0.0001$ \\
\hline $\begin{array}{l}\text { Var: } \\
\text { Model } \\
\text { Error } \\
\text { Total }\end{array}$ & $\begin{array}{l}201383.61 \\
130288.87 \\
331672.48\end{array}$ & $\begin{array}{r}1 \\
141 \\
142\end{array}$ & $\begin{array}{r}201383.61 \\
924.03\end{array}$ & 217.94 & $<0.0001$ \\
\hline $\begin{array}{l}\text { Var: } \\
\text { Model } \\
\text { Error } \\
\text { Total }\end{array}$ & $\begin{array}{l}165.31 \\
133.53 \\
298.84\end{array}$ & $\begin{array}{r}1 \\
141 \\
142\end{array}$ & $\begin{array}{r}165.31 \\
0.95\end{array}$ & 174.56 & $<0.0001$ \\
\hline
\end{tabular}


Comparisons between Male and Female Controls

\begin{tabular}{|c|c|c|c|c|c|}
\hline $\begin{array}{l}\text { Source of } \\
\text { Variance }\end{array}$ & SS & $d f$ & MS & $F$ & $\mathrm{p}$ \\
\hline $\begin{array}{l}\text { Var: AGE } \\
\text { Model } \\
\text { Error } \\
\text { Total }\end{array}$ & $\begin{array}{r}4.69 \\
116.48 \\
121.17\end{array}$ & $\begin{array}{r}1 \\
105 \\
106\end{array}$ & $\begin{array}{l}4.69 \\
1.11\end{array}$ & 4.23 & $<0.05$ \\
\hline $\begin{array}{l}\text { Var: EDU } \\
\text { Model } \\
\text { Error } \\
\text { Total }\end{array}$ & $\begin{array}{r}6.92 \\
119.16 \\
126.07\end{array}$ & $\begin{array}{r}1 \\
105 \\
106\end{array}$ & $\begin{array}{l}6.92 \\
0.72\end{array}$ & 6.10 & $<0.05$ \\
\hline $\begin{array}{l}\text { Var: CLASS } \\
\text { Model } \\
\text { Error } \\
\text { Total }\end{array}$ & $\begin{array}{r}0.02 \\
83.47 \\
83.50\end{array}$ & $\begin{array}{r}1 \\
101 \\
102\end{array}$ & $\begin{array}{l}0.02 \\
0.83\end{array}$ & 0.03 & $>0.05$ \\
\hline $\begin{array}{l}\text { Var: SEG } \\
\text { Model } \\
\text { Error } \\
\text { Total }\end{array}$ & $\begin{array}{r}0.03 \\
1149.48 \\
1149.51\end{array}$ & $\begin{array}{r}1 \\
101 \\
102\end{array}$ & $\begin{array}{r}0.03 \\
11.38\end{array}$ & 0.00 & $>0.05$ \\
\hline $\begin{array}{l}\text { Var: SIB } \\
\text { Model } \\
\text { Error } \\
\text { Total }\end{array}$ & $\begin{array}{r}0.56 \\
135.35 \\
135.91\end{array}$ & $\begin{array}{r}1 \\
105 \\
106\end{array}$ & $\begin{array}{l}0.56 \\
1.29\end{array}$ & 0.43 & $>0.05$ \\
\hline $\begin{array}{l}\text { Var: SIB10 } \\
\text { Model } \\
\text { Error } \\
\text { Total }\end{array}$ & $\begin{array}{r}0.75 \\
147.68 \\
148.43\end{array}$ & $\begin{array}{r}1 \\
105 \\
106\end{array}$ & $\begin{array}{l}0.75 \\
1.41\end{array}$ & 0.53 & $>0.05$ \\
\hline $\begin{array}{l}\text { Var: P } \\
\text { Model } \\
\text { Error } \\
\text { Total }\end{array}$ & $\begin{array}{r}5.85 \\
429.06 \\
434.92\end{array}$ & $\begin{array}{r}1 \\
106 \\
107\end{array}$ & $\begin{array}{l}5.85 \\
4.05\end{array}$ & 1.45 & $>0.05$ \\
\hline $\begin{array}{l}\text { Var: E } \\
\text { Model } \\
\text { Error } \\
\text { Total }\end{array}$ & $\begin{array}{r}6.31 \\
1249.79 \\
1256.10\end{array}$ & $\begin{array}{r}1 \\
106 \\
107\end{array}$ & $\begin{array}{r}6.31 \\
11.79\end{array}$ & 0.54 & $>0.05$ \\
\hline $\begin{array}{l}\text { Var: N } \\
\text { Model } \\
\text { Error } \\
\text { Total }\end{array}$ & $\begin{array}{r}8.48 \\
1059.92 \\
1068.41\end{array}$ & $\begin{array}{r}1 \\
106 \\
107\end{array}$ & $\begin{array}{r}8.48 \\
10.00\end{array}$ & 0.85 & $>0.05$ \\
\hline $\begin{array}{l}\text { Var: I } \\
\text { Model } \\
\text { Error } \\
\text { Total }\end{array}$ & $\begin{array}{r}8.35 \\
483.32 \\
491.67\end{array}$ & $\begin{array}{r}1 \\
106 \\
107\end{array}$ & $\begin{array}{l}8.35 \\
4.56\end{array}$ & 1.83 & $>0.05$ \\
\hline
\end{tabular}




\begin{tabular}{|c|c|c|c|c|c|}
\hline $\begin{array}{l}\text { Var: SRD } \\
\text { Model } \\
\text { Error } \\
\text { Total }\end{array}$ & $\begin{array}{r}265.48 \\
3122.52 \\
3388.00\end{array}$ & $\begin{array}{r}1 \\
106 \\
107\end{array}$ & $\begin{array}{r}265.48 \\
29.46\end{array}$ & 9.01 & $<0.01$ \\
\hline $\begin{array}{l}\text { Var: PER } \\
\text { Model } \\
\text { Error } \\
\text { Total }\end{array}$ & $\begin{array}{r}9.00 \\
116.21 \\
125.21\end{array}$ & $\begin{array}{r}1 \\
106 \\
107\end{array}$ & $\begin{array}{l}9.00 \\
1.10\end{array}$ & 8.21 & $<0.01$ \\
\hline $\begin{array}{l}\text { Var: THEFT } \\
\text { Model } \\
\text { Error } \\
\text { Total }\end{array}$ & $\begin{array}{r}48.65 \\
203.98 \\
252.63\end{array}$ & $\begin{array}{r}1 \\
106 \\
107\end{array}$ & $\begin{array}{r}48.65 \\
1.92\end{array}$ & 25,28 & $<0.0001$ \\
\hline $\begin{array}{l}\text { Var: RAV } \\
\text { Model } \\
\text { Error } \\
\text { Total }\end{array}$ & $\begin{array}{r}59.62 \\
4990.81 \\
5050.43\end{array}$ & $\begin{array}{r}1 \\
105 \\
106\end{array}$ & $\begin{array}{l}59.62 \\
47.53\end{array}$ & 1.25 & $>0.05$ \\
\hline $\begin{array}{l}\text { Var: MODAL } \\
\text { Model } \\
\text { Error } \\
\text { Total }\end{array}$ & $\begin{array}{r}0.05 \\
82.59 \\
82.64\end{array}$ & $\begin{array}{r}1 \\
105 \\
106\end{array}$ & $\begin{array}{l}0.05 \\
0.79\end{array}$ & 0.06 & $>0.05$ \\
\hline $\begin{array}{l}\text { Var: SRMS } \\
\text { Model } \\
\text { Error } \\
\text { Total }\end{array}$ & $\begin{array}{r}261.20 \\
85808.88 \\
86070.07\end{array}$ & $\begin{array}{r}1 \\
105 \\
106\end{array}$ & $\begin{array}{l}261.20 \\
817.23\end{array}$ & 0.32 & $>0.05$ \\
\hline $\begin{array}{l}\text { Var: GLOBAL } \\
\text { Model } \\
\text { Error } \\
\text { Total }\end{array}$ & $\begin{array}{r}0.28 \\
92.88 \\
93.16\end{array}$ & $\begin{array}{r}1 \\
105 \\
106\end{array}$ & $\begin{array}{l}0.28 \\
0.88\end{array}$ & 0.32 & $>0.05$ \\
\hline
\end{tabular}

ANALYSES OF COVARIANCE

Comparisons between Male offenders and Male Controls (using age, EDV, Class and SEG as co-variates)

\begin{tabular}{|c|c|c|c|c|c|}
\hline $\begin{array}{l}\text { Source of } \\
\text { Variance }\end{array}$ & SS & $d f$ & MS & $F$ & $\mathrm{p}$ \\
\hline $\begin{array}{l}\text { Var: P } \\
\text { Model } \\
\text { Error } \\
\text { Total }\end{array}$ & $\begin{array}{r}87.70 \\
373.92 \\
461.62\end{array}$ & $\begin{array}{r}5 \\
88 \\
93\end{array}$ & $\begin{array}{r}17.54 \\
4.25\end{array}$ & 4.13 & $<0.01$ \\
\hline $\begin{array}{l}\text { Var: E } \\
\text { Model } \\
\text { Error } \\
\text { Total }\end{array}$ & $\begin{array}{r}82.79 \\
844.67 \\
927.46\end{array}$ & $\begin{array}{r}5 \\
88 \\
93\end{array}$ & $\begin{array}{r}16.56 \\
9.60\end{array}$ & 1.72 & $>0.05$ \\
\hline
\end{tabular}




\begin{tabular}{|c|c|c|c|c|c|}
\hline $\begin{array}{l}\text { Var: } N \\
\text { Model } \\
\text { Error } \\
\text { Total }\end{array}$ & $\begin{array}{r}43.29 \\
955.18 \\
998.47\end{array}$ & $\begin{array}{r}5 \\
88 \\
93\end{array}$ & $\begin{array}{r}8.66 \\
10.85\end{array}$ & 0.80 & $>0.05$ \\
\hline $\begin{array}{l}\text { Var: L } \\
\text { Model } \\
\text { Error } \\
\text { Total }\end{array}$ & $\begin{array}{r}19.69 \\
478.02 \\
497.71\end{array}$ & $\begin{array}{r}5 \\
88 \\
93\end{array}$ & $\begin{array}{l}3.94 \\
5.43\end{array}$ & 0.73 & $>0.05$ \\
\hline $\begin{array}{l}\text { Var: S } \\
\text { Model } \\
\text { Error } \\
\text { Total }\end{array}$ & $\begin{array}{l}1467.19 \\
4077.93 \\
5545.12\end{array}$ & $\begin{array}{r}5 \\
87 \\
92\end{array}$ & $\begin{array}{r}293.44 \\
46.87\end{array}$ & 6.26 & $<0.001$ \\
\hline $\begin{array}{l}\text { Var: P } \\
\text { Model } \\
\text { Error } \\
\text { Total }\end{array}$ & $\begin{array}{l}117.13 \\
307.45 \\
424.58\end{array}$ & $\begin{array}{r}5 \\
87 \\
92\end{array}$ & $\begin{array}{r}23.43 \\
3.53\end{array}$ & 6.63 & $<0.0001$ \\
\hline $\begin{array}{l}\text { Var: T } \\
\text { Model } \\
\text { Error } \\
\text { Total }\end{array}$ & $\begin{array}{l}170.10 \\
338.41 \\
508.52\end{array}$ & $\begin{array}{r}5 \\
87 \\
92\end{array}$ & $\begin{array}{r}34.02 \\
3.89\end{array}$ & 8.75 & $<0.0001$ \\
\hline $\begin{array}{l}\text { Var: } \\
\text { Model } \\
\text { Error } \\
\text { Total }\end{array}$ & $\begin{array}{l}3865.24 \\
5293.75 \\
9158.99\end{array}$ & $\begin{array}{r}5 \\
89 \\
94\end{array}$ & $\begin{array}{r}773.05 \\
59.48\end{array}$ & 13.00 & $<0.0001$ \\
\hline $\begin{array}{l}\text { Var: M } \\
\text { Model } \\
\text { Error } \\
\text { Total }\end{array}$ & $\begin{array}{l}35.64 \\
59.77 \\
95.41\end{array}$ & $\begin{array}{r}5 \\
70 \\
75\end{array}$ & $\begin{array}{l}7.13 \\
0.85\end{array}$ & 8.35 & $<0.0001$ \\
\hline $\begin{array}{l}\text { Var: S } \\
\text { Model } \\
\text { Error } \\
\text { Total }\end{array}$ & $\begin{array}{r}99361.97 \\
76326.91 \\
175688.88\end{array}$ & $\begin{array}{r}5 \\
71 \\
76\end{array}$ & $\begin{array}{r}19872.39 \\
1075.03\end{array}$ & 18.49 & $<0.0001$ \\
\hline $\begin{array}{l}\text { Var: G } \\
\text { Model } \\
\text { Error } \\
\text { Total }\end{array}$ & $\begin{array}{r}82.74 \\
78.25 \\
160.99\end{array}$ & $\begin{array}{r}5 \\
71 \\
76\end{array}$ & $\begin{array}{r}16.55 \\
1.10\end{array}$ & 15.01 & $<0.0001$ \\
\hline
\end{tabular}

Comparisons between Male offenders and Male and Female Controls (using age, EDV, class and SEG as co-variates)

\begin{tabular}{lrrrrr}
\hline $\begin{array}{l}\text { Source of } \\
\text { Variance }\end{array}$ & SS & df & MS & F & P \\
\hline Var: P & & & & & \\
Model & 174.01 & 5 & 34.80 & 7.98 & $<0.0001$ \\
Error & 693.24 & 159 & 4.36 & & \\
Total & 867.25 & 164 & & & \\
\hline
\end{tabular}




\begin{tabular}{|c|c|c|c|c|c|}
\hline $\begin{array}{l}\text { Var: E } \\
\text { Model } \\
\text { Error } \\
\text { Total }\end{array}$ & $\begin{array}{r}50.04 \\
1663.09 \\
1713.13\end{array}$ & $\begin{array}{r}5 \\
159 \\
164\end{array}$ & $\begin{array}{l}10.01 \\
10.46\end{array}$ & 0.96 & $>0.05$ \\
\hline $\begin{array}{l}\text { Var: N } \\
\text { Model } \\
\text { Error } \\
\text { Total }\end{array}$ & $\begin{array}{r}81.72 \\
1548.25 \\
1629.98\end{array}$ & $\begin{array}{r}5 \\
159 \\
164\end{array}$ & $\begin{array}{r}16.34 \\
9.74\end{array}$ & 1.68 & $>0.05$ \\
\hline $\begin{array}{l}\text { Var: L } \\
\text { Model } \\
\text { Error } \\
\text { Total }\end{array}$ & $\begin{array}{r}27.56 \\
773.02 \\
800.58\end{array}$ & $\begin{array}{r}5 \\
159 \\
164\end{array}$ & $\begin{array}{l}5.51 \\
4.86\end{array}$ & 1.13 & $>0.05$ \\
\hline $\begin{array}{l}\text { Var: S } \\
\text { Model } \\
\text { Error } \\
\text { Total }\end{array}$ & $\begin{array}{r}4672.59 \\
5867.97 \\
10540.55\end{array}$ & $\begin{array}{r}5 \\
158 \\
163\end{array}$ & $\begin{array}{r}934.52 \\
37.14\end{array}$ & 25.16 & $<0.0001$ \\
\hline $\begin{array}{l}\text { Var: P } \\
\text { Model } \\
\text { Error } \\
\text { Total }\end{array}$ & $\begin{array}{l}297.57 \\
374.67 \\
672.24\end{array}$ & $\begin{array}{r}5 \\
158 \\
163\end{array}$ & $\begin{array}{r}59.51 \\
2.37\end{array}$ & 25.10 & $<0.0001$ \\
\hline $\begin{array}{l}\text { Var: T } \\
\text { Model } \\
\text { Error } \\
\text { Total }\end{array}$ & $\begin{array}{r}591.44 \\
461.31 \\
1052.75\end{array}$ & $\begin{array}{r}5 \\
158 \\
163\end{array}$ & $\begin{array}{r}118.29 \\
2.92\end{array}$ & 40.51 & $<0.0001$ \\
\hline $\begin{array}{l}\text { Var: } \\
\text { Model } \\
\text { Error } \\
\text { Total }\end{array}$ & $\begin{array}{r}6341.37 \\
8535.58 \\
14876.95\end{array}$ & $\begin{array}{r}5 \\
160 \\
165\end{array}$ & $\begin{array}{r}1268.27 \\
53.35\end{array}$ & 23.77 & $<0.0001$ \\
\hline $\begin{array}{l}\text { Var: M } \\
\text { Model } \\
\text { Error } \\
\text { Total }\end{array}$ & $\begin{array}{r}68.22 \\
115.96 \\
184.18\end{array}$ & $\begin{array}{r}5 \\
141 \\
146\end{array}$ & $\begin{array}{r}13.64 \\
0.82\end{array}$ & 16.59 & $<0.0001$ \\
\hline $\begin{array}{l}\text { Var: S } \\
\text { Model } \\
\text { Error } \\
\text { Total }\end{array}$ & $\begin{array}{l}179407.04 \\
126695.53 \\
306102.57\end{array}$ & $\begin{array}{r}5 \\
142 \\
147\end{array}$ & $\begin{array}{r}35881.41 \\
892.22\end{array}$ & 40.22 & $<0.0001$ \\
\hline $\begin{array}{l}\text { Var: G. } \\
\text { Model } \\
\text { Error } \\
\text { Total }\end{array}$ & $\begin{array}{l}149.08 \\
133.95 \\
283.03\end{array}$ & $\begin{array}{r}5 \\
142 \\
147\end{array}$ & $\begin{array}{r}29.82 \\
0.94\end{array}$ & 31.61 & $<0.0001$ \\
\hline
\end{tabular}


Comparisons between Male and Female Controls (using age and EDO as co-variates)

\begin{tabular}{|c|c|c|c|c|c|}
\hline $\begin{array}{l}\text { Source of } \\
\text { Variance }\end{array}$ & SS & $d f$ & MS & $F$ & $p$ \\
\hline $\begin{array}{l}\text { Var: P } \\
\text { Model } \\
\text { Error } \\
\text { Total }\end{array}$ & $\begin{array}{r}47.43 \\
385.98 \\
433.41\end{array}$ & $\begin{array}{r}3 \\
102 \\
105\end{array}$ & $\begin{array}{r}15.81 \\
3.78\end{array}$ & 4.18 & $<0.01$ \\
\hline $\begin{array}{l}\text { Var: E } \\
\text { Model } \\
\text { Error } \\
\text { Total }\end{array}$ & $\begin{array}{r}39.85 \\
1183.66 \\
1223.51\end{array}$ & $\begin{array}{r}3 \\
102 \\
105\end{array}$ & $\begin{array}{l}13.28 \\
11.60\end{array}$ & 1.14 & $>0.05$ \\
\hline $\begin{array}{l}\text { Var: N } \\
\text { Model } \\
\text { Error } \\
\text { Total }\end{array}$ & $\begin{array}{r}14.00 \\
1042.42 \\
1056.42\end{array}$ & $\begin{array}{r}3 \\
102 \\
105\end{array}$ & $\begin{array}{r}4.66 \\
10.21\end{array}$ & 0.46 & $>0.05$ \\
\hline $\begin{array}{l}\text { Var: I } \\
\text { Model } \\
\text { Error } \\
\text { Total }\end{array}$ & $\begin{array}{r}28.72 \\
446.20 \\
474.92\end{array}$ & $\begin{array}{r}3 \\
102 \\
105\end{array}$ & $\begin{array}{l}9.57 \\
4.37\end{array}$ & 2.19 & $>0.05$ \\
\hline $\begin{array}{l}\text { Var: SRD } \\
\text { Model } \\
\text { Error } \\
\text { Total }\end{array}$ & $\begin{array}{r}589.08 \\
2681.33 \\
3270.42\end{array}$ & $\begin{array}{r}3 \\
102 \\
105\end{array}$ & $\begin{array}{r}196.36 \\
26.29\end{array}$ & 7.47 & $<0.001$ \\
\hline $\begin{array}{l}\text { Var: PER } \\
\text { Model } \\
\text { Error } \\
\text { Total }\end{array}$ & $\begin{array}{r}15.16 \\
107.94 \\
123.10\end{array}$ & $\begin{array}{r}3 \\
102 \\
105\end{array}$ & $\begin{array}{l}5.05 \\
1.06\end{array}$ & 4.78 & $<0.001$ \\
\hline $\begin{array}{l}\text { Var: THEFT } \\
\text { Model } \\
\text { Error } \\
\text { Total }\end{array}$ & $\begin{array}{r}62.84 \\
185.25 \\
248.08\end{array}$ & $\begin{array}{r}3 \\
102 \\
105\end{array}$ & $\begin{array}{r}20.95 \\
1.82\end{array}$ & 11.53 & $<0.0001$ \\
\hline $\begin{array}{l}\text { Var: RAV } \\
\text { Model } \\
\text { Error } \\
\text { Total }\end{array}$ & $\begin{array}{r}377.84 \\
4652.13 \\
5029.96\end{array}$ & $\begin{array}{r}3 \\
101 \\
104\end{array}$ & $\begin{array}{r}125.95 \\
46.06\end{array}$ & 2.73 & $<0.05$ \\
\hline $\begin{array}{l}\text { Var: MODAL } \\
\text { Model } \\
\text { Error } \\
\text { Total }\end{array}$ & $\begin{array}{r}2.53 \\
79.66 \\
82.19\end{array}$ & $\begin{array}{r}3 \\
101 \\
104\end{array}$ & $\begin{array}{l}0.84 \\
0.79\end{array}$ & 1.07 & $>0.05$ \\
\hline $\begin{array}{l}\text { Var: SRMS } \\
\text { Model } \\
\text { Error } \\
\text { Total }\end{array}$ & $\begin{array}{r}3954.29 \\
81555.04 \\
85509.33\end{array}$ & $\begin{array}{r}3 \\
101 \\
104\end{array}$ & $\begin{array}{r}1318.10 \\
807.48\end{array}$ & 1.63 & $>0.05$ \\
\hline
\end{tabular}


Var: GLOBAL

Model

Error

2.79

88.77

3

0.93

$1.06>0.05$

Total

91.56

101

0.88

$1.06>0.05$

Comparisons between Male offenders and Female Controls (using EDU, Class and SEG as co-variates)

\begin{tabular}{|c|c|c|c|c|c|}
\hline $\begin{array}{l}\text { Source of } \\
\text { Variance }\end{array}$ & SS & $d f$ & MS & $F$ & $p$ \\
\hline $\begin{array}{l}\text { Var: P } \\
\text { Model } \\
\text { Error } \\
\text { Total }\end{array}$ & $\begin{array}{l}167.30 \\
627.97 \\
795.26\end{array}$ & $\begin{array}{r}4 \\
131 \\
135\end{array}$ & $\begin{array}{r}41.82 \\
4.79\end{array}$ & 8.72 & $<0.0001$ \\
\hline $\begin{array}{l}\text { Var: E } \\
\text { Model } \\
\text { Error } \\
\text { Total }\end{array}$ & $\begin{array}{r}26.61 \\
1327.26 \\
1353.88\end{array}$ & $\begin{array}{r}4 \\
131 \\
135\end{array}$ & $\begin{array}{r}6.65 \\
10.13\end{array}$ & 0.66 & $>0.05$ \\
\hline $\begin{array}{l}\text { Var: N } \\
\text { Model } \\
\text { Error } \\
\text { Total }\end{array}$ & $\begin{array}{r}60.94 \\
1232.12 \\
1293.06\end{array}$ & $\begin{array}{r}4 \\
131 \\
135\end{array}$ & $\begin{array}{r}15.23 \\
9.41\end{array}$ & 1.62 & $>0.05$ \\
\hline $\begin{array}{l}\text { Var: L } \\
\text { Model } \\
\text { Error } \\
\text { Total }\end{array}$ & $\begin{array}{r}3.60 \\
648.22 \\
651.82\end{array}$ & $\begin{array}{r}4 \\
131 \\
135\end{array}$ & $\begin{array}{l}0.90 \\
4.95\end{array}$ & 0.18 & $>0.05$ \\
\hline $\begin{array}{l}\text { Var: SRD } \\
\text { Model } \\
\text { Error } \\
\text { Total }\end{array}$ & $\begin{array}{l}4652.28 \\
5114.31 \\
9766.59\end{array}$ & $\begin{array}{r}4 \\
130 \\
134\end{array}$ & $\begin{array}{r}1163.07 \\
39.34\end{array}$ & 29.56 & $<0.0001$ \\
\hline $\begin{array}{l}\text { Var: PER } \\
\text { Model } \\
\text { Error } \\
\text { Total }\end{array}$ & $\begin{array}{l}288.22 \\
341.52 \\
629.73\end{array}$ & $\begin{array}{r}4 \\
130 \\
134\end{array}$ & $\begin{array}{r}72.05 \\
2.63\end{array}$ & 27.43 & $<0.0001$ \\
\hline $\begin{array}{l}\text { Var: THEFT } \\
\text { Model } \\
\text { Error } \\
\text { Total }\end{array}$ & $\begin{array}{l}615.51 \\
359.57 \\
975.08\end{array}$ & $\begin{array}{r}4 \\
130 \\
134\end{array}$ & $\begin{array}{r}153.88 \\
2.77\end{array}$ & 55.63 & $<0.0001$ \\
\hline $\begin{array}{l}\text { Var: RAV } \\
\text { Model } \\
\text { Error } \\
\text { Total }\end{array}$ & $\begin{array}{r}5049.02 \\
7579.30 \\
12628.32\end{array}$ & $\begin{array}{r}4 \\
133 \\
137\end{array}$ & $\begin{array}{r}1262.25 \\
56.99\end{array}$ & 22.15 & $<0.0001$ \\
\hline $\begin{array}{l}\text { Var: MODAL } \\
\text { Model } \\
\text { Error } \\
\text { Total }\end{array}$ & $\begin{array}{r}63.11 \\
96.86 \\
159.97\end{array}$ & $\begin{array}{r}4 \\
114 \\
118\end{array}$ & $\begin{array}{r}15.78 \\
0.85\end{array}$ & 18.57 & $<0.0001$ \\
\hline
\end{tabular}


Var: SRMS

Model

Error

Total

161591.24

103240.23

264831.47

115 119

Var: GLOBAL

Model

Error

Total

135.06

107.53

242.59

115

119
40397.81

897.74

$45.00<0.0001$

$33.77 \quad 36.11<0.0001$

0.94

$\begin{array}{rrrr}4 & 33.77 & 36.11 & <0.0001\end{array}$

(2) 
APPENDIX D - RESULTS OF THREE-WAY ANALYSES OF VARIANCE FOR THE
THREE LEVELS OF $P, E$ AND N SHOWN IN CBAPTER 3.3

Comparisons within the whole sample group

\begin{tabular}{|c|c|c|c|c|c|}
\hline $\begin{array}{l}\text { Source of } \\
\text { Variance }\end{array}$ & SS & $d f$ & MS & $F$ & $\mathrm{p}$ \\
\hline $\begin{array}{l}\text { Var: AGE } \\
P \\
E \\
N \\
P{ }^{\star} E \\
E{ }^{\star} N \\
P{ }^{\star} N \\
P E^{\star} N \\
\text { Error } \\
\text { Total }\end{array}$ & $\begin{array}{r}1.63 \\
1.34 \\
0.95 \\
5.03 \\
3.56 \\
2.28 \\
4.26 \\
224.25 \\
243.30\end{array}$ & $\begin{array}{r}2 \\
2 \\
2 \\
4 \\
4 \\
4 \\
6 \\
173 \\
197\end{array}$ & $\begin{array}{l}0.82 \\
0.67 \\
0.48 \\
1.26 \\
0.89 \\
0.57 \\
0.71 \\
1.30\end{array}$ & $\begin{array}{l}0.63 \\
0.52 \\
0.37 \\
0.97 \\
0.69 \\
0.44 \\
0.55\end{array}$ & $\begin{array}{l}>0.05 \\
>0.05 \\
>0.05 \\
>0.05 \\
>0.05 \\
>0.05 \\
>0.05\end{array}$ \\
\hline $\begin{array}{l}\text { Var: EDU } \\
P \\
E \\
N \\
P{ }^{\star} E \\
E^{\star} N \\
P^{\star} N \\
P E^{\star} N \\
\text { Error } \\
\text { Total }\end{array}$ & $\begin{array}{r}107.45 \\
1.03 \\
4.14 \\
14.57 \\
1.80 \\
9.00 \\
24.60 \\
590.80 \\
753.39\end{array}$ & $\begin{array}{r}2 \\
2 \\
2 \\
4 \\
4 \\
4 \\
6 \\
171 \\
195\end{array}$ & $\begin{array}{r}53.73 \\
0.52 \\
2.07 \\
3.64 \\
0.45 \\
2.25 \\
4.10 \\
3.45\end{array}$ & $\begin{array}{r}15.55 \\
0.15 \\
0.60 \\
1.05 \\
0.13 \\
0.65 \\
1.19\end{array}$ & $\begin{array}{l}<0.0001 \\
>0.05 \\
>0.05 \\
>0.05 \\
>0.05 \\
>0.05 \\
>0.05\end{array}$ \\
\hline $\begin{array}{l}\text { Var: CLASS } \\
P \\
E \\
N \\
P^{\star} E \\
E^{\star} N \\
P^{\star} N \\
P^{\star} E^{\star} N \\
\text { Error } \\
\text { Total }\end{array}$ & $\begin{array}{r}6.77 \\
2.74 \\
2.16 \\
1.11 \\
0.59 \\
1.10 \\
1.62 \\
157.61 \\
173.71\end{array}$ & $\begin{array}{r}2 \\
2 \\
2 \\
4 \\
4 \\
3 \\
4 \\
145 \\
166\end{array}$ & $\begin{array}{l}3.39 \\
1.37 \\
1.08 \\
0.28 \\
0.15 \\
0.37 \\
0.41 \\
1.09\end{array}$ & $\begin{array}{l}3.12 \\
1.26 \\
0.99 \\
0.26 \\
0.14 \\
0.34 \\
0.37\end{array}$ & $\begin{array}{l}<0.05 \\
>0.05 \\
>0.05 \\
>0.05 \\
>0.05 \\
>0.05 \\
>0.05\end{array}$ \\
\hline $\begin{array}{l}\text { Var: SEG } \\
P \\
E \\
N \\
P * E \\
E^{\star} N \\
P^{\star} N \\
P * E^{\star} N \\
\text { Error } \\
\text { Total }\end{array}$ & $\begin{array}{r}98.81 \\
5.11 \\
53.97 \\
8.22 \\
37.92 \\
123.04 \\
9.05 \\
1837.88 \\
2174.00\end{array}$ & $\begin{array}{r}2 \\
2 \\
2 \\
4 \\
4 \\
4 \\
4 \\
146 \\
168\end{array}$ & $\begin{array}{r}49.41 \\
2.56 \\
26.99 \\
2.06 \\
9.48 \\
30.76 \\
2.26 \\
12.59\end{array}$ & $\begin{array}{l}3.92 \\
0.20 \\
2.14 \\
0.16 \\
0.75 \\
2.44 \\
0.18\end{array}$ & $\begin{array}{l}<0.05 \\
>0.05 \\
<0.05 \\
>0.05 \\
>0.05 \\
<0.05 \\
>0.05\end{array}$ \\
\hline
\end{tabular}




\begin{tabular}{|c|c|c|c|c|c|}
\hline $\begin{array}{l}\text { Var: SIB } \\
P \\
E \\
N \\
P \star E \\
E \star N \\
P{ }^{\star} N \\
P E^{\star} N \\
\text { Error } \\
\text { Total }\end{array}$ & $\begin{array}{r}11.17 \\
4.45 \\
3.36 \\
10.76 \\
7.32 \\
1.16 \\
3.57 \\
298.30 \\
340.09\end{array}$ & $\begin{array}{r}2 \\
2 \\
2 \\
4 \\
4 \\
4 \\
6 \\
173 \\
197\end{array}$ & $\begin{array}{l}5.59 \\
2.23 \\
1.68 \\
2.69 \\
1.83 \\
0.29 \\
0.60 \\
1.72\end{array}$ & $\begin{array}{l}3.24 \\
1.29 \\
0.98 \\
1.56 \\
1.06 \\
0.17 \\
0.34\end{array}$ & $\begin{array}{l}<0.05 \\
>0.05 \\
>0.05 \\
>0.05 \\
>0.05 \\
>0.05 \\
>0.05\end{array}$ \\
\hline $\begin{array}{l}\text { Var: SIB1 } \\
P \\
E \\
N \\
P^{\star} E \\
E^{\star} N \\
P^{\star} N \\
P^{\star} E \star N \\
\text { Error } \\
\text { Total }\end{array}$ & $\begin{array}{r}6.15 \\
7.20 \\
1.02 \\
10.83 \\
8.99 \\
0.57 \\
5.43 \\
225.45 \\
265.64\end{array}$ & $\begin{array}{r}2 \\
2 \\
2 \\
4 \\
4 \\
4 \\
6 \\
172 \\
196\end{array}$ & $\begin{array}{l}3.08 \\
3.60 \\
0.51 \\
2.71 \\
2.25 \\
0.14 \\
0.91 \\
1.31\end{array}$ & $\begin{array}{l}2.35 \\
2.75 \\
0.39 \\
2.06 \\
1.71 \\
0.11 \\
0.34\end{array}$ & $\begin{array}{l}>0.05 \\
>0.05 \\
>0.05 \\
>0.05 \\
>0.05 \\
>0.05 \\
>0.05\end{array}$ \\
\hline $\begin{array}{l}\text { Var: RAV } \\
P \\
E \\
N \\
P \star E \\
E{ }^{\star} N \\
P^{\star} N \\
P E^{\star} N \\
\text { Error } \\
\text { Total }\end{array}$ & $\begin{array}{r}967.40 \\
307.58 \\
35.05 \\
196.77 \\
340.13 \\
69.21 \\
879.14 \\
16324.31 \\
19119.58\end{array}$ & $\begin{array}{r}2 \\
2 \\
2 \\
4 \\
4 \\
4 \\
6 \\
178 \\
202\end{array}$ & $\begin{array}{r}483.70 \\
153.79 \\
17.53 \\
49.19 \\
85.03 \\
17.30 \\
146.52 \\
91.71\end{array}$ & $\begin{array}{l}5.27 \\
1.68 \\
0.19 \\
0.54 \\
0.93 \\
0.19 \\
1.60\end{array}$ & $\begin{array}{l}<0.01 \\
>0.05 \\
>0.05 \\
>0.05 \\
>0.05 \\
>0.05 \\
>0.05\end{array}$ \\
\hline $\begin{array}{l}\text { Var: } P \\
P \\
E \\
N \\
P{ }^{\star} E \\
E^{\star} N \\
P^{\star} N \\
P^{\star} E E^{\star} N \\
\text { Error } \\
\text { Total }\end{array}$ & $\begin{array}{r}934.18 \\
2.88 \\
1.72 \\
4.98 \\
0.65 \\
2.81 \\
2.54 \\
270.98 \\
1220.75\end{array}$ & $\begin{array}{r}2 \\
2 \\
2 \\
4 \\
4 \\
4 \\
6 \\
179 \\
203\end{array}$ & $\begin{array}{r}467.09 \\
1.44 \\
0.86 \\
1.25 \\
0.16 \\
0.70 \\
0.42 \\
1.51\end{array}$ & $\begin{array}{r}308.55 \\
0.95 \\
0.57 \\
0.82 \\
0.11 \\
0.46 \\
0.28\end{array}$ & $\begin{array}{l}<0.0001 \\
>0.05 \\
>0.05 \\
>0.05 \\
>0.05 \\
>0.05 \\
>0.05\end{array}$ \\
\hline $\begin{array}{l}\text { Var: } E \\
P \\
E \\
N \\
P \star E \\
E \star N \\
P \star N \\
P \star E \star N \\
\text { Error } \\
\text { Total }\end{array}$ & $\begin{array}{r}35.41 \\
1845.17 \\
2.88 \\
11.60 \\
1.85 \\
9.88 \\
3.35 \\
240.25 \\
2150.41\end{array}$ & $\begin{array}{r}2 \\
2 \\
2 \\
4 \\
4 \\
4 \\
6 \\
179 \\
203\end{array}$ & $\begin{array}{r}17.05 \\
922.59 \\
1.44 \\
2.90 \\
0.46 \\
2.47 \\
0.56 \\
1.34\end{array}$ & $\begin{array}{r}13.19 \\
687.38 \\
1.07 \\
2.16 \\
0.34 \\
1.84 \\
0.42\end{array}$ & $\begin{array}{l}<0.0001 \\
<0.0001 \\
>0.05 \\
>0.05 \\
>0.05 \\
>0.05 \\
>0.05\end{array}$ \\
\hline
\end{tabular}




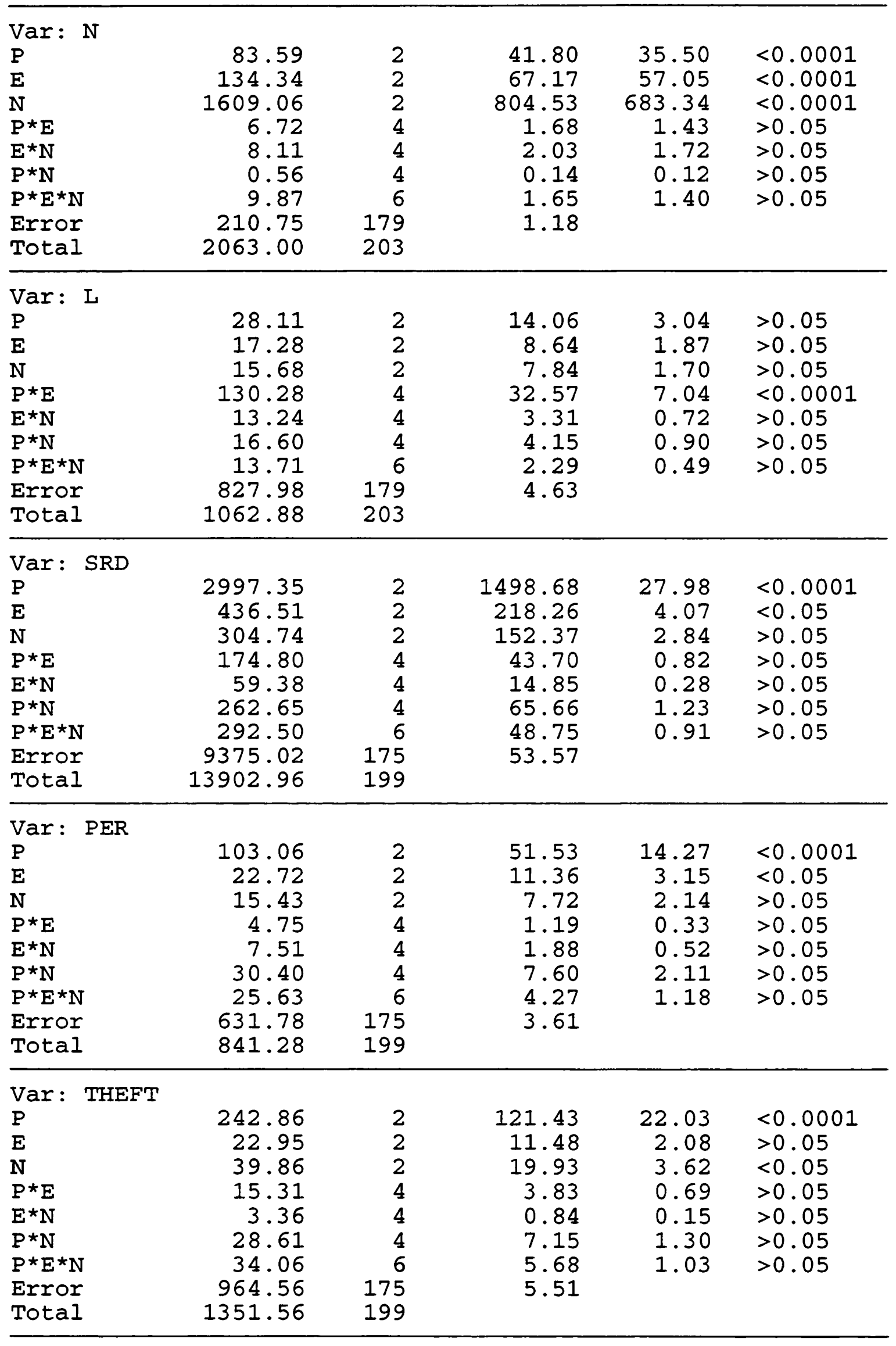




\begin{tabular}{|c|c|c|c|c|c|}
\hline $\begin{array}{l}\text { Var: MODAL } \\
P \\
E \\
N \\
P{ }^{*} E \\
E^{\star} N \\
P{ }^{*} N \\
P E^{\star} N \\
\text { Error } \\
\text { Total }\end{array}$ & $\begin{array}{r}7.73 \\
3.20 \\
0.20 \\
7.52 \\
4.66 \\
3.23 \\
9.75 \\
177.65 \\
213.98\end{array}$ & $\begin{array}{r}2 \\
2 \\
2 \\
4 \\
4 \\
4 \\
5 \\
149 \\
172\end{array}$ & $\begin{array}{l}3.87 \\
1.60 \\
0.10 \\
1.88 \\
1.17 \\
0.81 \\
1.95 \\
1.19\end{array}$ & $\begin{array}{l}3.24 \\
1.34 \\
0.08 \\
1.58 \\
0.98 \\
0.68 \\
1.03\end{array}$ & $\begin{array}{l}<0.05 \\
>0.05 \\
>0.05 \\
>0.05 \\
>0.05 \\
>0.05 \\
>0.05\end{array}$ \\
\hline $\begin{array}{l}\text { Var: SRMS } \\
P \\
E \\
N \\
P^{\star} E \\
E^{\star} N \\
P^{\star} N \\
P^{\star} E^{\star} N \\
\text { Error } \\
\text { Total }\end{array}$ & $\begin{array}{r}28880.69 \\
4682.41 \\
741.13 \\
11590.06 \\
1047.77 \\
8165.09 \\
7502.58 \\
327281.63 \\
389891.36\end{array}$ & $\begin{array}{r}2 \\
2 \\
2 \\
4 \\
4 \\
4 \\
5 \\
150 \\
173\end{array}$ & $\begin{array}{r}14440.35 \\
2341.21 \\
370.57 \\
2897.52 \\
261.94 \\
2041.27 \\
1500.52 \\
2181.88\end{array}$ & $\begin{array}{l}6.62 \\
1.07 \\
0.17 \\
1.33 \\
0.12 \\
0.94 \\
0.69\end{array}$ & $\begin{array}{l}<0.01 \\
>0.05 \\
>0.05 \\
>0.05 \\
>0.05 \\
>0.05 \\
>0.05\end{array}$ \\
\hline $\begin{array}{l}\text { Var: GLOBAI } \\
P \\
E \\
N \\
P \star E \\
E^{\star} N \\
P^{\star N} N \\
P^{\star} E \star N \\
\text { Error } \\
\text { Total }\end{array}$ & $\begin{array}{r}20.55 \\
4.72 \\
1.14 \\
5.94 \\
0.62 \\
8.26 \\
10.34 \\
301.86 \\
353.43\end{array}$ & $\begin{array}{r}2 \\
2 \\
2 \\
4 \\
4 \\
4 \\
5 \\
150 \\
173\end{array}$ & $\begin{array}{r}10.28 \\
2.36 \\
0.57 \\
1.49 \\
0.16 \\
2.07 \\
2.07 \\
2.01\end{array}$ & $\begin{array}{l}5.11 \\
1.17 \\
0.28 \\
0.74 \\
0.08 \\
1.03 \\
1.03\end{array}$ & $\begin{array}{l}<0.01 \\
>0.05 \\
>0.05 \\
>0.05 \\
>0.05 \\
>0.05 \\
>0.05\end{array}$ \\
\hline
\end{tabular}

Comparisons within the convicted offender group

\begin{tabular}{lrrrrr}
\hline $\begin{array}{l}\text { Source of } \\
\text { Variance }\end{array}$ & SS & df & MS & F & p \\
\hline Var: AGE & 3.59 & 2 & 1.80 & 1.51 & $>0.05$ \\
$P$ & 2.49 & 2 & 1.25 & 1.05 & $>0.05$ \\
$E$ & 2.84 & 2 & 1.42 & 1.19 & $>0.05$ \\
$N$ & 7.48 & 4 & 1.87 & 1.57 & $>0.05$ \\
$P^{\star} E$ & 4.88 & 4 & 1.22 & 1.02 & $>0.05$ \\
$E^{\star} N$ & 8.93 & 4 & 2.23 & 1.88 & $>0.05$ \\
$P \star N$ & 0.68 & 6 & 0.11 & 0.19 & $>0.05$ \\
$P^{\star} E \star N$ & 82.16 & 69 & 1.19 & & \\
Error & 113.05 & 90 & & & \\
Total & & & & & \\
\hline
\end{tabular}




\begin{tabular}{|c|c|c|c|c|c|}
\hline $\begin{array}{l}\text { Var: EDU } \\
P \\
E \\
N \\
P^{\star} E \\
E^{\star} N \\
P^{\star} N \\
P^{\star} E E^{\star} N \\
\text { Error } \\
\text { Total }\end{array}$ & $\begin{array}{r}32.32 \\
0.09 \\
4.41 \\
21.49 \\
3.23 \\
18.83 \\
9.83 \\
78.04 \\
168.25\end{array}$ & $\begin{array}{r}2 \\
2 \\
2 \\
4 \\
4 \\
4 \\
3 \\
67 \\
88\end{array}$ & $\begin{array}{r}16.16 \\
0.05 \\
2.21 \\
5.37 \\
0.81 \\
4.71 \\
3.28 \\
1.16\end{array}$ & $\begin{array}{r}13.87 \\
0.04 \\
1.89 \\
4.61 \\
0.69 \\
4.04 \\
2.82\end{array}$ & $\begin{array}{l}<0.0001 \\
>0.05 \\
>0.05 \\
<0.01 \\
>0.05 \\
>0.05 \\
<0.05\end{array}$ \\
\hline $\begin{array}{l}\text { Var: CLASS } \\
P \\
E \\
N \\
P^{\star} E \\
E^{\star} N \\
P \star N \\
P \star E \star N \\
\text { Error } \\
\text { Total }\end{array}$ & $\begin{array}{r}6.25 \\
2.84 \\
3.35 \\
3.03 \\
1.35 \\
0.10 \\
0.03 \\
43.92 \\
60.86\end{array}$ & $\begin{array}{r}2 \\
2 \\
2 \\
4 \\
4 \\
2 \\
2 \\
45 \\
63\end{array}$ & $\begin{array}{l}3.13 \\
1.42 \\
1.68 \\
0.76 \\
0.34 \\
0.05 \\
0.02 \\
0.98\end{array}$ & $\begin{array}{l}3.20 \\
1.46 \\
1.71 \\
0.78 \\
0.34 \\
0.05 \\
0.02\end{array}$ & $\begin{array}{l}>0.05 \\
>0.05 \\
>0.05 \\
>0.05 \\
>0.05 \\
>0.05 \\
>0.05\end{array}$ \\
\hline $\begin{array}{l}\text { Var: SEG } \\
P \\
E \\
N \\
P \star E \\
E \star N \\
P{ }^{\star} N \\
P \star E \star N \\
\text { Error } \\
\text { Total }\end{array}$ & $\begin{array}{r}32.26 \\
14.65 \\
2.78 \\
26.45 \\
9.81 \\
71.65 \\
9.47 \\
507.18 \\
674.26\end{array}$ & $\begin{array}{r}2 \\
2 \\
2 \\
4 \\
4 \\
3 \\
2 \\
46 \\
65\end{array}$ & $\begin{array}{r}16.13 \\
7.33 \\
1.39 \\
6.61 \\
2.45 \\
23.88 \\
4.74 \\
11.03\end{array}$ & $\begin{array}{l}1.46 \\
0.66 \\
0.13 \\
0.60 \\
0.22 \\
2.17 \\
0.43\end{array}$ & $\begin{array}{l}>0.05 \\
>0.05 \\
>0.05 \\
>0.05 \\
>0.05 \\
<0.05 \\
>0.05\end{array}$ \\
\hline $\begin{array}{l}\text { Var: SIB } \\
P \\
E \\
N \\
P{ }^{\star} E \\
E^{\star} N \\
P{ }^{\star} N \\
P E^{\star} N N \\
\text { Error } \\
\text { Total }\end{array}$ & $\begin{array}{r}7.69 \\
2.41 \\
14.22 \\
7.72 \\
3.56 \\
2.58 \\
0.55 \\
165.04 \\
203.76\end{array}$ & $\begin{array}{r}2 \\
2 \\
2 \\
4 \\
4 \\
4 \\
3 \\
69 \\
90\end{array}$ & $\begin{array}{l}3.85 \\
1.21 \\
7.11 \\
1.93 \\
0.89 \\
0.65 \\
0.18 \\
2.39\end{array}$ & $\begin{array}{l}1.61 \\
0.50 \\
2.97 \\
0.81 \\
1.06 \\
0.27 \\
0.08\end{array}$ & $\begin{array}{l}>0.05 \\
>0.05 \\
>0.05 \\
>0.05 \\
>0.05 \\
>0.05 \\
>0.05\end{array}$ \\
\hline $\begin{array}{l}\text { Var: SIB10 } \\
P \\
E \\
N \\
P \star E \\
E^{\star} N \\
P \star N \\
P \star E \star N \\
\text { Error } \\
\text { Total }\end{array}$ & $\begin{array}{r}7.86 \\
10.69 \\
4.25 \\
6.85 \\
1.48 \\
1.91 \\
2.02 \\
82.06 \\
117.12\end{array}$ & $\begin{array}{r}2 \\
2 \\
2 \\
4 \\
4 \\
4 \\
3 \\
68 \\
89\end{array}$ & $\begin{array}{l}3.93 \\
5.35 \\
2.13 \\
1.71 \\
0.37 \\
0.48 \\
0.67 \\
1.21\end{array}$ & $\begin{array}{l}3.26 \\
4.43 \\
1.76 \\
1.42 \\
0.31 \\
0.40 \\
0.56\end{array}$ & $\begin{array}{l}<0.05 \\
<0.05 \\
>0.05 \\
>0.05 \\
>0.05 \\
>0.05 \\
>0.05\end{array}$ \\
\hline
\end{tabular}




\begin{tabular}{|c|c|c|c|c|c|}
\hline $\begin{array}{l}\text { Var: RAV } \\
P \\
E \\
N \\
P \star E \\
E{ }^{\star} N \\
P^{\star} N \\
P \star E \star N \\
\text { Error } \\
\text { Total }\end{array}$ & $\begin{array}{r}148.79 \\
484.99 \\
55.90 \\
168.11 \\
610.13 \\
439.74 \\
445.19 \\
4935.64 \\
7288.50\end{array}$ & $\begin{array}{r}2 \\
2 \\
2 \\
4 \\
4 \\
4 \\
3 \\
74 \\
95\end{array}$ & $\begin{array}{r}74.40 \\
242.50 \\
27.95 \\
42.03 \\
152.53 \\
109.94 \\
148.40 \\
66.70\end{array}$ & $\begin{array}{l}1.12 \\
3.64 \\
0.42 \\
0.63 \\
2.29 \\
1.65 \\
2.22\end{array}$ & $\begin{array}{l}>0.05 \\
<0.05 \\
>0.05 \\
>0.05 \\
>0.05 \\
>0.05 \\
>0.05\end{array}$ \\
\hline $\begin{array}{l}\text { Var: } P \\
P \\
E \\
N \\
P \star E \\
E^{\star} N \\
P^{\star} N \\
P \star E^{\star} N \\
\text { Error } \\
\text { Total }\end{array}$ & $\begin{array}{r}491.90 \\
3.05 \\
3.62 \\
3.48 \\
4.03 \\
1.32 \\
1.02 \\
98.07 \\
606.49\end{array}$ & $\begin{array}{r}2 \\
2 \\
2 \\
4 \\
4 \\
4 \\
3 \\
74 \\
95\end{array}$ & $\begin{array}{r}245.95 \\
1.53 \\
1.81 \\
0.87 \\
1.01 \\
0.33 \\
0.34 \\
1.33\end{array}$ & $\begin{array}{r}185.58 \\
1.15 \\
1.37 \\
0.66 \\
0.76 \\
0.25 \\
0.26\end{array}$ & $\begin{array}{l}<0.0001 \\
>0.05 \\
>0.05 \\
>0.05 \\
>0.05 \\
>0.05 \\
>0.05\end{array}$ \\
\hline $\begin{array}{l}\text { Var: } E \\
P \\
E \\
N \\
P \star E \\
E \star N \\
P \star N \\
P \star E \star N \\
\text { Error } \\
\text { Total }\end{array}$ & $\begin{array}{r}21.69 \\
732.58 \\
11.92 \\
5.52 \\
4.06 \\
4.27 \\
4.16 \\
97.64 \\
881.83\end{array}$ & $\begin{array}{r}2 \\
2 \\
2 \\
4 \\
4 \\
4 \\
3 \\
74 \\
95\end{array}$ & $\begin{array}{r}10.85 \\
366.29 \\
5.96 \\
1.38 \\
1.02 \\
1.07 \\
1.39 \\
1.32\end{array}$ & $\begin{array}{r}8.22 \\
277.60 \\
4.52 \\
1.05 \\
0.77 \\
0.81 \\
1.05\end{array}$ & $\begin{array}{l}<0.001 \\
<0.0001 \\
<0.05 \\
>0.05 \\
>0.05 \\
>0.05 \\
>0.05\end{array}$ \\
\hline $\begin{array}{l}\text { Var: N } \\
P \\
E \\
N \\
P^{\star} E \\
E^{\star} N \\
P^{\star} N \\
P^{\star} E \star N \\
\text { Error } \\
\text { Total }\end{array}$ & $\begin{array}{r}17.43 \\
13.56 \\
842.05 \\
7.00 \\
11.92 \\
1.55 \\
4.16 \\
83.07 \\
980.74\end{array}$ & $\begin{array}{r}2 \\
2 \\
2 \\
4 \\
4 \\
4 \\
3 \\
74 \\
95\end{array}$ & $\begin{array}{r}8.72 \\
6.78 \\
421.03 \\
1.75 \\
2.98 \\
0.39 \\
1.39 \\
1.12\end{array}$ & $\begin{array}{r}7.76 \\
6.04 \\
375.06 \\
1.56 \\
2.65 \\
0.35 \\
1.24\end{array}$ & $\begin{array}{l}<0.001 \\
<0.01 \\
<0.0001 \\
>0.05 \\
<0.05 \\
>0.05 \\
>0.05\end{array}$ \\
\hline $\begin{array}{l}\text { Var: L } \\
P \\
E \\
N \\
P^{\star} E \\
E^{\star} N \\
P^{\star N} N \\
P^{\star} E \star N \\
\text { Error } \\
\text { Total }\end{array}$ & $\begin{array}{r}32.05 \\
8.66 \\
23.68 \\
120.94 \\
2.41 \\
10.40 \\
2.06 \\
369.28 \\
569.49\end{array}$ & $\begin{array}{r}2 \\
2 \\
2 \\
4 \\
4 \\
4 \\
3 \\
74 \\
95\end{array}$ & $\begin{array}{r}16.03 \\
4.33 \\
11.84 \\
30.24 \\
0.60 \\
2.60 \\
0.67 \\
4.63\end{array}$ & $\begin{array}{l}3.21 \\
0.87 \\
2.37 \\
6.06 \\
0.12 \\
0.52 \\
0.14\end{array}$ & $\begin{array}{l}<0.05 \\
>0.05 \\
>0.05 \\
<0.001 \\
>0.05 \\
>0.05 \\
>0.05\end{array}$ \\
\hline
\end{tabular}




\begin{tabular}{|c|c|c|c|c|c|}
\hline $\begin{array}{l}\text { Var: SRD } \\
P \\
E \\
N \\
P^{\star} E \\
E^{\star} N \\
P^{\star} N \\
P^{\star} E^{\star} N \\
\text { Error } \\
\text { Total }\end{array}$ & $\begin{array}{r}491.68 \\
168.77 \\
65.63 \\
152.80 \\
101.76 \\
245.21 \\
168.95 \\
3409.93 \\
4804.73\end{array}$ & $\begin{array}{r}2 \\
2 \\
2 \\
4 \\
4 \\
4 \\
3 \\
70 \\
91\end{array}$ & $\begin{array}{r}245.84 \\
84.39 \\
32.82 \\
38.20 \\
25.44 \\
61.30 \\
56.32 \\
41.71\end{array}$ & $\begin{array}{l}5.05 \\
1.73 \\
0.67 \\
0.78 \\
0.52 \\
1.26 \\
1.16\end{array}$ & $\begin{array}{l}<0.01 \\
>0.05 \\
>0.05 \\
>0.05 \\
>0.05 \\
>0.05 \\
>0.05\end{array}$ \\
\hline $\begin{array}{l}\text { Var: PER } \\
P \\
E \\
N \\
P{ }^{\star} E \\
E^{\star} N \\
P{ }^{\star} N \\
P E^{\star} N \\
\text { Error } \\
\text { Total }\end{array}$ & $\begin{array}{r}10.65 \\
19.65 \\
4.50 \\
1.14 \\
14.95 \\
22.43 \\
11.31 \\
288.52 \\
373.16\end{array}$ & $\begin{array}{r}2 \\
2 \\
2 \\
4 \\
4 \\
4 \\
3 \\
70 \\
91\end{array}$ & $\begin{array}{l}5.33 \\
9.83 \\
2.25 \\
0.29 \\
3.74 \\
5.61 \\
3.77 \\
4.12\end{array}$ & $\begin{array}{l}1.29 \\
2.38 \\
0.55 \\
0.07 \\
0.91 \\
1.36 \\
0.91\end{array}$ & $\begin{array}{l}>0.05 \\
>0.05 \\
>0.05 \\
>0.05 \\
>0.05 \\
>0.05 \\
>0.05\end{array}$ \\
\hline $\begin{array}{l}\text { Var: THEFT } \\
P \\
E \\
N \\
P^{\star} E \\
E^{\star} N \\
P{ }^{\star} N \\
P E^{\star} N \\
\text { Error } \\
\text { Total }\end{array}$ & $\begin{array}{r}25.74 \\
4.49 \\
0.73 \\
7.58 \\
20.94 \\
6.52 \\
9.43 \\
251.65 \\
327.08\end{array}$ & $\begin{array}{r}2 \\
2 \\
2 \\
4 \\
4 \\
4 \\
3 \\
70 \\
91\end{array}$ & $\begin{array}{r}12.87 \\
2.25 \\
0.37 \\
1.90 \\
5.24 \\
1.63 \\
3.14 \\
3.60\end{array}$ & $\begin{array}{l}3.58 \\
0.62 \\
0.10 \\
0.53 \\
1.46 \\
0.45 \\
0.87\end{array}$ & $\begin{array}{l}<0.05 \\
>0.05 \\
>0.05 \\
>0.05 \\
>0.05 \\
>0.05 \\
>0.05\end{array}$ \\
\hline $\begin{array}{l}\text { Var: MODAL } \\
P \\
E \\
N \\
P \star E \\
E \star N \\
P \star N \\
P \star E \star N \\
\text { Error } \\
\text { Total }\end{array}$ & $\begin{array}{r}0.38 \\
3.75 \\
0.16 \\
3.66 \\
1.66 \\
5.93 \\
1.70 \\
37.92 \\
55.17\end{array}$ & $\begin{array}{r}2 \\
2 \\
2 \\
4 \\
4 \\
3 \\
2 \\
46 \\
65\end{array}$ & $\begin{array}{l}0.19 \\
1.88 \\
0.08 \\
0.92 \\
0.42 \\
1.98 \\
0.85 \\
0.82\end{array}$ & $\begin{array}{l}0.23 \\
2.27 \\
0.09 \\
1.11 \\
0.98 \\
2.40 \\
1.03\end{array}$ & $\begin{array}{l}>0.05 \\
>0.05 \\
>0.05 \\
>0.05 \\
>0.05 \\
>0.05 \\
>0.05\end{array}$ \\
\hline $\begin{array}{l}\text { Var: SRMS } \\
P \\
E \\
N \\
P \star E \\
E \star N \\
P \star N \\
P \star E \star N \\
\text { Error } \\
\text { Total }\end{array}$ & $\begin{array}{r}494.35 \\
4042.34 \\
2045.47 \\
7746.83 \\
1407.79 \\
798.63 \\
1560.91 \\
55642.20 \\
73738.51\end{array}$ & $\begin{array}{r}2 \\
2 \\
2 \\
4 \\
4 \\
3 \\
2 \\
47 \\
66\end{array}$ & $\begin{array}{r}247.18 \\
2021.17 \\
1023.74 \\
1936.71 \\
351.95 \\
266.21 \\
780.46 \\
1183.88\end{array}$ & $\begin{array}{l}0.21 \\
1.71 \\
0.86 \\
1.64 \\
0.30 \\
0.22 \\
0.66\end{array}$ & $\begin{array}{l}>0.05 \\
>0.05 \\
>0.05 \\
>0.05 \\
>0.05 \\
>0.05 \\
>0.05\end{array}$ \\
\hline
\end{tabular}




\begin{tabular}{lrrrrr}
\hline Var: GLOBAL & & & & & \\
$\mathrm{P}$ & 0.94 & 2 & 0.47 & 0.39 & $>0.05$ \\
$\mathrm{E}$ & 5.77 & 2 & 2.89 & 2.42 & $>0.05$ \\
$\mathrm{~N}$ & 0.53 & 2 & 0.27 & 0.22 & $>0.05$ \\
$\mathrm{P} \star \mathrm{E}$ & 3.60 & 4 & 0.90 & 0.75 & $>0.05$ \\
$\mathrm{E} \star \mathrm{N}$ & 2.16 & 4 & 0.54 & 0.45 & $>0.05$ \\
$\mathrm{P} * \mathrm{~N}$ & 1.22 & 3 & 0.41 & 0.34 & $>0.05$ \\
$\mathrm{P} * \mathrm{E} * \mathrm{~N}$ & 1.33 & 2 & 0.67 & 0.56 & $>0.05$ \\
Error & 56.12 & 47 & 1.19 & & \\
Total & 71.67 & 66 & & & \\
\hline \hline
\end{tabular}

Comparisons within the Combined Male and Female control group

\begin{tabular}{|c|c|c|c|c|c|}
\hline $\begin{array}{l}\text { Source of } \\
\text { Variance }\end{array}$ & SS & $d f$ & MS & $\mathbf{F}$ & $p$ \\
\hline $\begin{array}{l}\text { Var: AGE } \\
P \\
E \\
N \\
P \star E \\
E^{\star} N \\
P \star N \\
P \star E \star N \\
\text { Error } \\
\text { Total }\end{array}$ & $\begin{array}{r}5.18 \\
0.60 \\
0.52 \\
5.08 \\
5.76 \\
0.30 \\
0.93 \\
102.80 \\
121.17\end{array}$ & $\begin{array}{r}2 \\
2 \\
2 \\
3 \\
4 \\
2 \\
2 \\
89 \\
106\end{array}$ & $\begin{array}{l}2.59 \\
0.30 \\
0.26 \\
1.69 \\
1.44 \\
0.15 \\
0.47 \\
1.16\end{array}$ & $\begin{array}{l}2.24 \\
0.26 \\
0.23 \\
1.47 \\
1.25 \\
0.13 \\
0.40\end{array}$ & $\begin{array}{l}>0.05 \\
>0.05 \\
>0.05 \\
>0.05 \\
>0.05 \\
>0.05 \\
>0.05\end{array}$ \\
\hline $\begin{array}{l}\text { Var: EDU } \\
P \\
E \\
N \\
P^{\star} E \\
E^{\star} N \\
P^{\star} N \\
P^{\star} E \star N \\
\text { Error } \\
\text { Total }\end{array}$ & $\begin{array}{r}0.57 \\
1.30 \\
1.31 \\
3.29 \\
9.92 \\
0.25 \\
4.26 \\
105.19 \\
126.07\end{array}$ & $\begin{array}{r}2 \\
2 \\
2 \\
3 \\
4 \\
2 \\
2 \\
89 \\
106\end{array}$ & $\begin{array}{l}0.29 \\
0.65 \\
0.66 \\
1.10 \\
2.40 \\
0.13 \\
2.13 \\
1.18\end{array}$ & $\begin{array}{l}0.24 \\
0.55 \\
0.55 \\
0.93 \\
2.10 \\
0.10 \\
1.80\end{array}$ & $\begin{array}{l}>0.05 \\
>0.05 \\
>0.05 \\
>0.05 \\
>0.05 \\
>0.05 \\
<0.05\end{array}$ \\
\hline $\begin{array}{l}\text { Var: CLASS } \\
P \\
E \\
N \\
P^{\star} E \\
E^{\star} N \\
P^{\star} N \\
P^{\star} E \star N \\
\text { Error } \\
\text { Total }\end{array}$ & $\begin{array}{r}2.25 \\
2.03 \\
6.62 \\
1.27 \\
1.65 \\
3.62 \\
2.05 \\
64.01 \\
83.50\end{array}$ & $\begin{array}{r}2 \\
2 \\
2 \\
3 \\
4 \\
2 \\
2 \\
85 \\
102\end{array}$ & $\begin{array}{l}1.13 \\
1.02 \\
3.31 \\
0.42 \\
0.41 \\
1.81 \\
1.03 \\
0.75\end{array}$ & $\begin{array}{l}1.49 \\
1.35 \\
4.39 \\
0.56 \\
0.55 \\
2.41 \\
1.36\end{array}$ & $\begin{array}{l}>0.05 \\
>0.05 \\
<0.05 \\
>0.05 \\
>0.05 \\
>0.05 \\
>0.05\end{array}$ \\
\hline
\end{tabular}




\begin{tabular}{|c|c|c|c|c|c|}
\hline $\begin{array}{l}\text { Var: SEG } \\
P \\
E \\
N \\
P^{\star} E \\
E^{\star} N \\
P^{\star} N \\
P^{\star} E^{\star} N \\
\text { Error } \\
\text { Total }\end{array}$ & $\begin{array}{r}22.84 \\
10.23 \\
67.38 \\
4.87 \\
99.15 \\
11.50 \\
8.15 \\
925.39 \\
1149.51\end{array}$ & $\begin{array}{r}2 \\
2 \\
2 \\
3 \\
4 \\
2 \\
2 \\
85 \\
102\end{array}$ & $\begin{array}{r}11.42 \\
5.12 \\
33.69 \\
1.62 \\
24.79 \\
5.75 \\
4.08 \\
10.89\end{array}$ & $\begin{array}{l}1.05 \\
0.47 \\
3.09 \\
0.15 \\
2.28 \\
0.53 \\
0.37\end{array}$ & $\begin{array}{l}>0.05 \\
>0.05 \\
>0.05 \\
>0.05 \\
>0.05 \\
>0.05 \\
>0.05\end{array}$ \\
\hline $\begin{array}{l}\text { Var: SIB } \\
P \\
E \\
N \\
P \star E \\
E{ }^{\star} N \\
P N^{\star} \\
P \star E \star N \\
\text { Error } \\
\text { Total }\end{array}$ & $\begin{array}{r}3.42 \\
3.25 \\
2.94 \\
1.97 \\
4.81 \\
0.08 \\
4.18 \\
115.27 \\
135.91\end{array}$ & $\begin{array}{r}2 \\
2 \\
2 \\
3 \\
4 \\
2 \\
2 \\
89 \\
106\end{array}$ & $\begin{array}{l}1.71 \\
1.63 \\
1.47 \\
0.66 \\
1.20 \\
0.04 \\
2.09 \\
1.30\end{array}$ & $\begin{array}{l}1.32 \\
1.25 \\
1.13 \\
0.51 \\
0.93 \\
0.03 \\
1.61\end{array}$ & $\begin{array}{l}>0.05 \\
>0.05 \\
>0.05 \\
>0.05 \\
>0.05 \\
>0.05 \\
>0.05\end{array}$ \\
\hline $\begin{array}{l}\text { Var: SIB10 } \\
P \\
E \\
N \\
P^{\star} E \\
E^{\star} N \\
P^{\star} N \\
P^{\star} E^{\star} N \\
\text { Error } \\
\text { Total }\end{array}$ & $\begin{array}{r}1.21 \\
1.50 \\
1.19 \\
2.81 \\
8.63 \\
2.19 \\
4.81 \\
126.09 \\
148.43\end{array}$ & $\begin{array}{r}2 \\
2 \\
2 \\
3 \\
4 \\
2 \\
2 \\
89 \\
106\end{array}$ & $\begin{array}{l}0.61 \\
0.75 \\
0.60 \\
0.94 \\
2.16 \\
1.10 \\
2.41 \\
1.42\end{array}$ & $\begin{array}{l}0.43 \\
0.53 \\
0.42 \\
0.66 \\
1.52 \\
0.77 \\
1.70\end{array}$ & $\begin{array}{l}>0.05 \\
>0.05 \\
>0.05 \\
>0.05 \\
>0.05 \\
>0.05 \\
>0.05\end{array}$ \\
\hline $\begin{array}{l}\text { Var: RAV } \\
P \\
E \\
N \\
P^{\star} E \\
E^{\star} N \\
P^{\star} N \\
P^{\star} E^{\star} N \\
\text { Error } \\
\text { Total }\end{array}$ & $\begin{array}{r}26.66 \\
98.81 \\
24.89 \\
18.35 \\
83.62 \\
77.47 \\
145.70 \\
4574.93 \\
5050.43\end{array}$ & $\begin{array}{r}2 \\
2 \\
2 \\
3 \\
4 \\
2 \\
2 \\
89 \\
106\end{array}$ & $\begin{array}{r}13.33 \\
49.41 \\
12.45 \\
6.12 \\
20.91 \\
38.74 \\
72.85 \\
51.40\end{array}$ & $\begin{array}{l}0.26 \\
0.96 \\
0.24 \\
0.12 \\
0.41 \\
0.75 \\
1.42\end{array}$ & $\begin{array}{l}>0.05 \\
>0.05 \\
>0.05 \\
>0.05 \\
>0.05 \\
>0.05 \\
>0.05\end{array}$ \\
\hline $\begin{array}{l}\text { Var: } P \\
P \\
E \\
N \\
P \star E \\
E \star N \\
P \star N \\
P \star E \star N \\
\text { Error } \\
\text { Total }\end{array}$ & $\begin{array}{r}275.56 \\
2.55 \\
0.04 \\
1.88 \\
1.35 \\
1.86 \\
1.89 \\
149.89 \\
434.92\end{array}$ & $\begin{array}{r}2 \\
2 \\
2 \\
3 \\
4 \\
2 \\
2 \\
90 \\
107\end{array}$ & $\begin{array}{r}137.78 \\
1.28 \\
0.02 \\
0.63 \\
0.34 \\
0.93 \\
0.95 \\
1.67\end{array}$ & $\begin{array}{r}82.73 \\
0.76 \\
0.01 \\
0.38 \\
0.20 \\
0.56 \\
0.54\end{array}$ & $\begin{array}{l}<0.0001 \\
>0.05 \\
>0.05 \\
>0.05 \\
>0.05 \\
>0.05 \\
>0.05\end{array}$ \\
\hline
\end{tabular}




\begin{tabular}{|c|c|c|c|c|c|}
\hline $\begin{array}{l}\text { Var: } E \\
P \\
E \\
N \\
P \star E \\
E{ }^{\star} \\
P{ }^{\star} \\
P E^{\star} N \\
\text { Error } \\
\text { Total }\end{array}$ & $\begin{array}{r}6.90 \\
1114.56 \\
1.23 \\
9.18 \\
3.83 \\
2.64 \\
0.65 \\
117.11 \\
1256.10\end{array}$ & $\begin{array}{r}2 \\
2 \\
2 \\
3 \\
4 \\
2 \\
2 \\
90 \\
107\end{array}$ & $\begin{array}{r}3.45 \\
557.28 \\
0.62 \\
3.06 \\
0.96 \\
1.32 \\
0.33 \\
1.30\end{array}$ & $\begin{array}{r}2.65 \\
428.29 \\
0.47 \\
2.35 \\
0.74 \\
1.02 \\
0.25\end{array}$ & $\begin{array}{l}>0.05 \\
<0.0001 \\
>0.05 \\
>0.05 \\
>0.05 \\
>0.05 \\
>0.05\end{array}$ \\
\hline $\begin{array}{l}\text { Var: N } \\
P \\
E \\
N \\
P \star E \\
E \star N \\
P \star N \\
P \star E \star N \\
\text { Error } \\
\text { Total }\end{array}$ & $\begin{array}{r}73.05 \\
131.89 \\
745.56 \\
2.56 \\
0.46 \\
0.40 \\
1.61 \\
112.87 \\
1068.41\end{array}$ & $\begin{array}{r}2 \\
2 \\
2 \\
3 \\
4 \\
2 \\
2 \\
90 \\
107\end{array}$ & $\begin{array}{r}36.53 \\
65.95 \\
372.78 \\
0.85 \\
0.12 \\
0.20 \\
0.81 \\
1.25\end{array}$ & $\begin{array}{r}29.12 \\
52.58 \\
297.24 \\
0.68 \\
0.09 \\
0.16 \\
0.64\end{array}$ & $\begin{array}{l}<0.0001 \\
<0.0001 \\
<0.0001 \\
>0.05 \\
>0.05 \\
>0.05 \\
>0.05\end{array}$ \\
\hline $\begin{array}{l}\text { Var: L } \\
P \\
E \\
N \\
P \star E \\
E^{\star} N \\
P \star N \\
P \star E \star N \\
\text { Error } \\
\text { Total }\end{array}$ & $\begin{array}{r}8.31 \\
9.42 \\
1.48 \\
11.49 \\
47.17 \\
20.72 \\
0.67 \\
392.40 \\
491.67\end{array}$ & $\begin{array}{r}2 \\
2 \\
2 \\
3 \\
4 \\
2 \\
2 \\
90 \\
107\end{array}$ & $\begin{array}{r}4.16 \\
4.71 \\
0.74 \\
3.83 \\
11.79 \\
10.36 \\
0.34 \\
4.36\end{array}$ & $\begin{array}{l}0.95 \\
1.08 \\
0.17 \\
0.88 \\
2.70 \\
2.38 \\
0.08\end{array}$ & $\begin{array}{l}>0.05 \\
>0.05 \\
>0.05 \\
>0.05 \\
<0.05 \\
>0.05 \\
>0.05\end{array}$ \\
\hline $\begin{array}{l}\text { Var: SRD } \\
P \\
E \\
N \\
P{ }^{\star} E \\
E^{\star} N \\
P{ }^{\star} N \\
P{ }^{\star} E{ }^{\star} N \\
\text { Error } \\
\text { Total }\end{array}$ & $\begin{array}{r}482.45 \\
176.38 \\
80.45 \\
154.19 \\
67.11 \\
43.69 \\
2.34 \\
2381.40 \\
3388.00\end{array}$ & $\begin{array}{r}2 \\
2 \\
2 \\
3 \\
4 \\
2 \\
2 \\
90 \\
107\end{array}$ & $\begin{array}{r}241.23 \\
88.19 \\
40.23 \\
51.34 \\
16.78 \\
21.85 \\
1.17 \\
26.46\end{array}$ & $\begin{array}{l}9.12 \\
3.33 \\
1.52 \\
1.94 \\
0.63 \\
0.83 \\
0.04\end{array}$ & $\begin{array}{l}<0.001 \\
<0.05 \\
>0.05 \\
>0.05 \\
>0.05 \\
>0.05 \\
>0.05\end{array}$ \\
\hline $\begin{array}{l}\text { Var: PER } \\
P \\
E \\
N \\
P{ }^{\star} E \\
E^{\star} N \\
P{ }^{\star} N \\
P{ }^{\star} E{ }^{\star} N \\
\text { Error } \\
\text { Total }\end{array}$ & $\begin{array}{r}10.90 \\
1.87 \\
1.62 \\
3.41 \\
6.70 \\
1.07 \\
0.33 \\
99.31 \\
125.21\end{array}$ & $\begin{array}{r}2 \\
2 \\
2 \\
3 \\
4 \\
2 \\
2 \\
90 \\
107\end{array}$ & $\begin{array}{l}5.45 \\
0.94 \\
0.81 \\
1.14 \\
1.68 \\
0.54 \\
0.17 \\
1.10\end{array}$ & $\begin{array}{l}4.94 \\
0.85 \\
0.73 \\
1.03 \\
1.52 \\
0.48 \\
0.15\end{array}$ & $\begin{array}{l}<0.01 \\
>0.05 \\
>0.05 \\
>0.05 \\
>0.05 \\
>0.05 \\
>0.05\end{array}$ \\
\hline
\end{tabular}




\begin{tabular}{|c|c|c|c|c|c|}
\hline $\begin{array}{l}\text { Var: THEFT } \\
P \\
E \\
N \\
P * E \\
E^{\star} N \\
P{ }^{\star} N \\
P * E \star N \\
\text { Error } \\
\text { Total }\end{array}$ & $\begin{array}{r}19.27 \\
3.65 \\
20.17 \\
6.02 \\
9.95 \\
7.03 \\
0.30 \\
186.23 \\
252.63\end{array}$ & $\begin{array}{r}2 \\
2 \\
2 \\
3 \\
4 \\
2 \\
2 \\
90 \\
107\end{array}$ & $\begin{array}{r}9.64 \\
1.83 \\
10.09 \\
2.01 \\
2.49 \\
3.52 \\
0.15 \\
2.07\end{array}$ & $\begin{array}{l}4.66 \\
0.88 \\
4.87 \\
0.97 \\
1.20 \\
1.70 \\
0.07\end{array}$ & $\begin{array}{l}<0.05 \\
>0.05 \\
<0.01 \\
>0.05 \\
>0.05 \\
>0.05 \\
>0.05\end{array}$ \\
\hline $\begin{array}{l}\text { Var: MODAL } \\
P \\
E \\
N \\
P^{\star} E \\
E^{\star} N \\
P^{\star} N \\
P^{\star} E \star N \\
\text { Error } \\
\text { Total }\end{array}$ & $\begin{array}{r}5.29 \\
2.38 \\
1.69 \\
2.40 \\
2.85 \\
0.76 \\
2.94 \\
64.32 \\
82.64\end{array}$ & $\begin{array}{r}2 \\
2 \\
2 \\
3 \\
4 \\
3 \\
2 \\
89 \\
106\end{array}$ & $\begin{array}{l}2.65 \\
1.19 \\
0.85 \\
0.80 \\
0.71 \\
0.25 \\
1.47 \\
0.72\end{array}$ & $\begin{array}{l}3.66 \\
1.65 \\
1.17 \\
1.11 \\
0.99 \\
0.52 \\
2.04\end{array}$ & $\begin{array}{l}<0.05 \\
>0.05 \\
>0.05 \\
>0.05 \\
>0.05 \\
>0.05 \\
>0.05\end{array}$ \\
\hline $\begin{array}{l}\text { Var: SRMS } \\
P \\
E \\
N \\
P^{\star} E \\
E^{\star} N \\
P^{\star} N \\
P^{\star} E^{\star} N \\
\text { Error } \\
\text { Total }\end{array}$ & $\begin{array}{r}8286.02 \\
663.44 \\
1190.92 \\
653.64 \\
1602.50 \\
888.07 \\
4686.85 \\
68098.65 \\
86070.07\end{array}$ & $\begin{array}{r}2 \\
2 \\
2 \\
3 \\
4 \\
2 \\
2 \\
89 \\
106\end{array}$ & $\begin{array}{r}4143.01 \\
331.72 \\
595.46 \\
217.88 \\
400.63 \\
444.04 \\
2343.43 \\
765.15\end{array}$ & $\begin{array}{l}5.41 \\
0.43 \\
0.78 \\
0.28 \\
0.52 \\
0.58 \\
3.06\end{array}$ & $\begin{array}{l}<0.01 \\
>0.05 \\
>0.05 \\
>0.05 \\
>0.05 \\
>0.05 \\
>0.05\end{array}$ \\
\hline $\begin{array}{l}\text { Var: GLOBAL } \\
P \\
E \\
N \\
P \star E \\
E \star N \\
P \star N \\
P \star E \star N \\
\text { Error } \\
\text { Total }\end{array}$ & $\begin{array}{r}10.04 \\
1.10 \\
3.44 \\
0.87 \\
1.08 \\
0.44 \\
7.79 \\
68.40 \\
93.16\end{array}$ & $\begin{array}{r}2 \\
2 \\
2 \\
3 \\
4 \\
2 \\
2 \\
89 \\
106\end{array}$ & $\begin{array}{l}5.02 \\
0.55 \\
1.72 \\
0.29 \\
0.27 \\
0.22 \\
3.90 \\
0.77\end{array}$ & $\begin{array}{l}6.53 \\
0.71 \\
2.24 \\
0.38 \\
0.35 \\
0.29 \\
5.07\end{array}$ & $\begin{array}{l}<0.01 \\
>0.05 \\
>0.05 \\
>0.05 \\
>0.05 \\
>0.05 \\
<0.01\end{array}$ \\
\hline
\end{tabular}


APPENDIX E - Details of Cluster Analyses, and Analyses of Variance calculations relating to the clusters shown in chapter 3.3 .

\section{Ward's Clusters Analyses Results}

Convicted Offender group

Eigenvalues of the Covariance Matrix

\begin{tabular}{lcccc}
\hline & Eigenvalue & Difference & Proportion & Cumulative \\
\hline 1 & 11.9344 & 3.39890 & 0.373128 & 0.37313 \\
2 & 8.5355 & 1.76067 & 0.266862 & 0.63999 \\
3 & 6.7748 & 2.03482 & 0.211814 & 0.85180 \\
4 & 4.7400 &. & 0.148196 & 1.00000 \\
\hline \hline
\end{tabular}

ANOVA Comparisons between the four clusters in the convicted offender group (clusters 01 to 04 )

\begin{tabular}{|c|c|c|c|c|c|}
\hline $\begin{array}{l}\text { Source of } \\
\text { Variance }\end{array}$ & SS & $d f$ & MS & $F$ & $p$ \\
\hline $\begin{array}{l}\text { Var: AGE } \\
\text { Model } \\
\text { Error } \\
\text { Total }\end{array}$ & $\begin{array}{r}0.37 \\
53.63 \\
54.00\end{array}$ & $\begin{array}{r}3 \\
45 \\
48\end{array}$ & $\begin{array}{l}0.12 \\
1.19\end{array}$ & 0.10 & $>0.05$ \\
\hline $\begin{array}{l}\text { Var: EDU } \\
\text { Model } \\
\text { Error } \\
\text { Total }\end{array}$ & $\begin{array}{r}0.38 \\
28.73 \\
29.11\end{array}$ & $\begin{array}{r}3 \\
45 \\
48\end{array}$ & $\begin{array}{l}0.13 \\
9.58\end{array}$ & 0.19 & $>0.05$ \\
\hline $\begin{array}{l}\text { Var: CLASS } \\
\text { Model } \\
\text { Error } \\
\text { Total }\end{array}$ & $\begin{array}{r}3.24 \\
33.76 \\
37.00\end{array}$ & $\begin{array}{r}3 \\
32 \\
35\end{array}$ & $\begin{array}{l}1.08 \\
1.06\end{array}$ & 1.03 & $>0.05$ \\
\hline $\begin{array}{l}\text { Var: SEG } \\
\text { Model } \\
\text { Error } \\
\text { Total }\end{array}$ & $\begin{array}{r}38.45 \\
366.85 \\
405.30\end{array}$ & $\begin{array}{r}3 \\
33 \\
36\end{array}$ & $\begin{array}{l}12.82 \\
11.12\end{array}$ & 1.15 & $>0.05$ \\
\hline $\begin{array}{l}\text { Var: SIB } \\
\text { Model } \\
\text { Error } \\
\text { Total }\end{array}$ & $\begin{array}{r}13.71 \\
113.97 \\
127.67\end{array}$ & $\begin{array}{r}3 \\
45 \\
48\end{array}$ & $\begin{array}{l}4.57 \\
2.53\end{array}$ & 1.80 & $>0.05$ \\
\hline $\begin{array}{l}\text { Var: SIB10 } \\
\text { Model } \\
\text { Error } \\
\text { Total }\end{array}$ & $\begin{array}{r}6.32 \\
65.66 \\
71.98\end{array}$ & $\begin{array}{r}3 \\
44 \\
47\end{array}$ & $\begin{array}{l}2.11 \\
1.49\end{array}$ & 1.41 & $>0.05$ \\
\hline
\end{tabular}




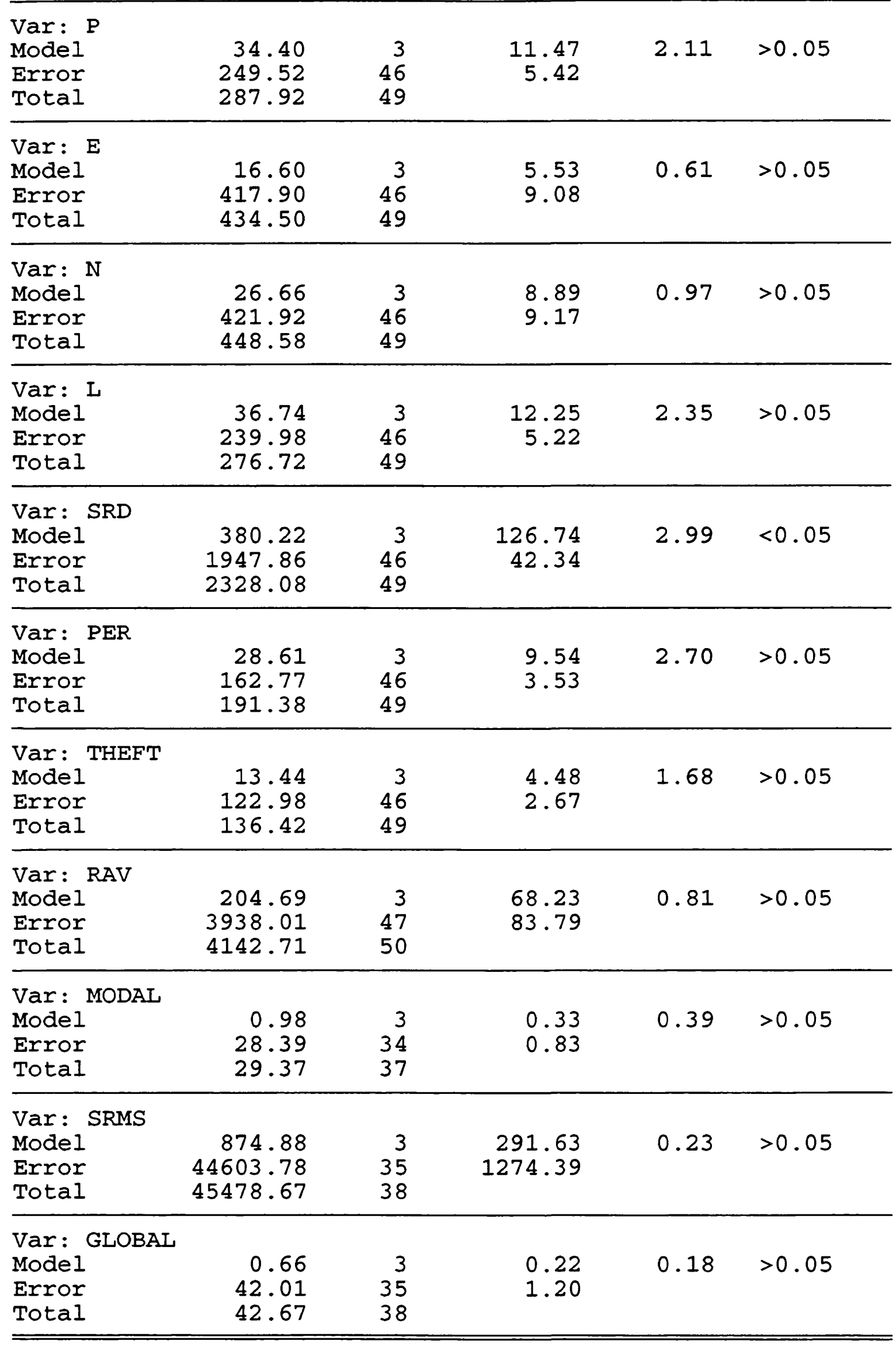


Ward's Clusters Analyses Results

Combined Control group

Eigenvalues of the Covariance Matrix

\begin{tabular}{ccccc}
\hline & Eigenvalue & Difference & Proportion & Cumulative \\
\hline $\mathbf{1}$ & 14.7689 & 7.45670 & 0.486074 & 0.48607 \\
2 & 7.3122 & 2.36833 & 0.240659 & 0.72673 \\
3 & 4.9439 & 1.58478 & 0.162713 & 0.88945 \\
4 & 3.3591 &. & 0.110554 & 1.00000 \\
\hline \hline
\end{tabular}

ANOVA comparisons between the four clusters in the combined control group (clusters C1 to C4)

\begin{tabular}{|c|c|c|c|c|c|}
\hline $\begin{array}{l}\text { Source of } \\
\text { Variance }\end{array}$ & SS & $d f$ & MS & $\mathrm{F}$ & $p$ \\
\hline $\begin{array}{l}\text { Var: AGE } \\
\text { Model } \\
\text { Error } \\
\text { Total }\end{array}$ & $\begin{array}{r}6.53 \\
42.71 \\
49.24\end{array}$ & $\begin{array}{r}3 \\
43 \\
46\end{array}$ & $\begin{array}{l}2.18 \\
0.99\end{array}$ & 2.19 & $>0.05$ \\
\hline $\begin{array}{l}\text { Var: EDU } \\
\text { Model } \\
\text { Error } \\
\text { Total }\end{array}$ & $\begin{array}{r}4.59 \\
35.87 \\
40.46\end{array}$ & $\begin{array}{r}3 \\
42 \\
45\end{array}$ & $\begin{array}{l}1.53 \\
0.85\end{array}$ & 1.79 & $>0.05$ \\
\hline $\begin{array}{l}\text { Var: CLASS } \\
\text { Model } \\
\text { Error } \\
\text { Total }\end{array}$ & $\begin{array}{r}3.44 \\
19.53 \\
22.98\end{array}$ & $\begin{array}{r}3 \\
40 \\
43\end{array}$ & $\begin{array}{l}1.15 \\
0.49\end{array}$ & 2.35 & $>0.05$ \\
\hline $\begin{array}{l}\text { Var: SEG } \\
\text { Model } \\
\text { Error } \\
\text { Total }\end{array}$ & $\begin{array}{r}19.68 \\
414.86 \\
434.55\end{array}$ & $\begin{array}{r}3 \\
40 \\
43\end{array}$ & $\begin{array}{r}6.56 \\
10.37\end{array}$ & 0.63 & $>0.05$ \\
\hline $\begin{array}{l}\text { Var: SIB } \\
\text { Model } \\
\text { Error } \\
\text { Total }\end{array}$ & $\begin{array}{r}2.47 \\
73.96 \\
76.43\end{array}$ & $\begin{array}{r}3 \\
42 \\
45\end{array}$ & $\begin{array}{l}0.82 \\
1.76\end{array}$ & 0.47 & $>0.05$ \\
\hline $\begin{array}{l}\text { Var: SIB10 } \\
\text { Model } \\
\text { Error } \\
\text { Total }\end{array}$ & $\begin{array}{r}2.88 \\
76.60 \\
79.48\end{array}$ & $\begin{array}{r}3 \\
42 \\
45\end{array}$ & $\begin{array}{l}0.96 \\
1.82\end{array}$ & 0.53 & $>0.05$ \\
\hline $\begin{array}{l}\text { Var: P } \\
\text { Model } \\
\text { Error } \\
\text { Total }\end{array}$ & $\begin{array}{r}12.45 \\
145.37 \\
157.83\end{array}$ & $\begin{array}{r}3 \\
43 \\
46\end{array}$ & $\begin{array}{l}4.15 \\
3.38\end{array}$ & 1.23 & $>0.05$ \\
\hline
\end{tabular}




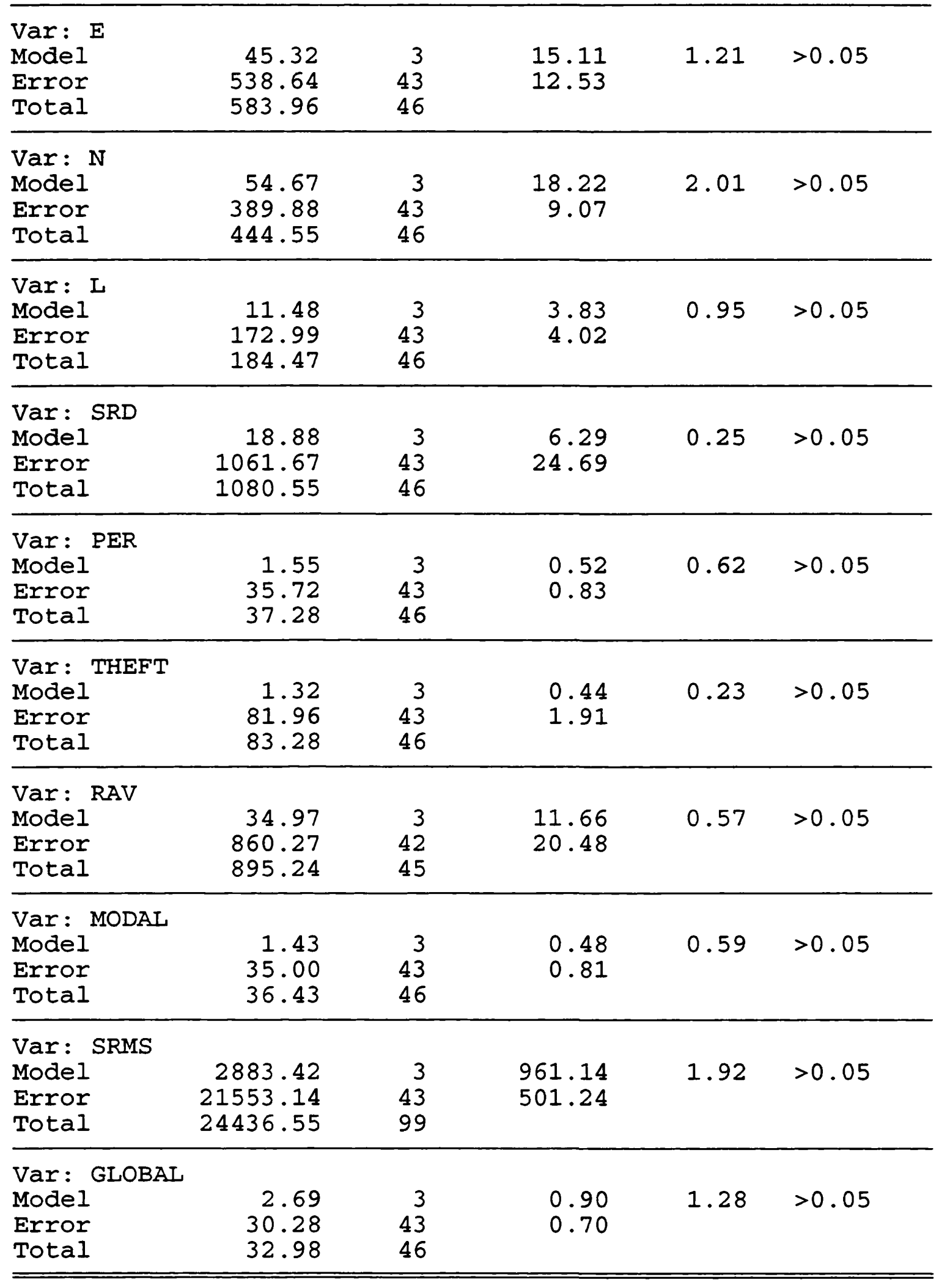


APPENDIX F - DETAILS OF ANAIYSES OF VARIANCE FROM THE GLENTHORNE AND FAKING STODIES REPORTED IN CHAPTER 4.

Glenthorne study results (Chapter 4.1)

Comparisons between the Glenthorne sample, convicted offenders and combined control groups

\begin{tabular}{|c|c|c|c|c|c|}
\hline $\begin{array}{l}\text { Source of } \\
\text { Variance }\end{array}$ & SS & $d f$ & MS & $F$ & $\mathrm{p}$ \\
\hline $\begin{array}{l}\text { Var: AGE } \\
\text { Model } \\
\text { Error } \\
\text { Total }\end{array}$ & $\begin{array}{r}79.55 \\
258.37 \\
337.92\end{array}$ & $\begin{array}{r}2 \\
210 \\
212\end{array}$ & $\begin{array}{r}39.77 \\
1.23\end{array}$ & 32.33 & $<0.0001$ \\
\hline $\begin{array}{l}\text { Var: EDU } \\
\text { Model } \\
\text { Error } \\
\text { Total }\end{array}$ & $\begin{array}{l}623.76 \\
374.42 \\
998.18\end{array}$ & $\begin{array}{r}2 \\
204 \\
206\end{array}$ & $\begin{array}{r}311.88 \\
1.84\end{array}$ & 169.93 & $<0.0001$ \\
\hline $\begin{array}{l}\text { Var: CLASS } \\
\text { Model } \\
\text { Error } \\
\text { Total }\end{array}$ & $\begin{array}{c}31.85 \\
145.18 \\
2177.03\end{array}$ & $\begin{array}{r}2 \\
171 \\
173\end{array}$ & $\begin{array}{r}15.93 \\
0.85\end{array}$ & 18.76 & $<0.0001$ \\
\hline $\begin{array}{l}\text { Var: SEG } \\
\text { Model } \\
\text { Error } \\
\text { Total }\end{array}$ & $\begin{array}{r}409.21 \\
1942.80 \\
2352.01\end{array}$ & $\begin{array}{r}2 \\
174 \\
176\end{array}$ & $\begin{array}{r}204.60 \\
11.17\end{array}$ & 18.32 & $<0.0001$ \\
\hline $\begin{array}{l}\text { Var: SIB } \\
\text { Model } \\
\text { Error } \\
\text { Total }\end{array}$ & $\begin{array}{r}10.34 \\
367.64 \\
377.98\end{array}$ & $\begin{array}{r}2 \\
207 \\
209\end{array}$ & $\begin{array}{l}5.17 \\
1.78\end{array}$ & 2.91 & $>0.05$ \\
\hline $\begin{array}{l}\text { Var: SIB10 } \\
\text { Model } \\
\text { Error } \\
\text { Total }\end{array}$ & $\begin{array}{r}33.51 \\
333.12 \\
366.63\end{array}$ & $\begin{array}{r}2 \\
206 \\
208\end{array}$ & $\begin{array}{r}16.76 \\
1.62\end{array}$ & 1.363 & $<0.0001$ \\
\hline $\begin{array}{l}\text { Var: P } \\
\text { Model } \\
\text { Error } \\
\text { Total }\end{array}$ & $\begin{array}{r}156.09 \\
1058.88 \\
1214.98\end{array}$ & $\begin{array}{r}2 \\
208 \\
210\end{array}$ & $\begin{array}{r}78.05 \\
5.09\end{array}$ & 15.33 & $<0.0001$ \\
\hline $\begin{array}{l}\text { Var: E } \\
\text { Model } \\
\text { Error } \\
\text { Total }\end{array}$ & $\begin{array}{r}10.41 \\
2183.82 \\
2194.23\end{array}$ & $\begin{array}{r}2 \\
208 \\
210\end{array}$ & $\begin{array}{r}5.20 \\
10.50\end{array}$ & 0.50 & $>0.05$ \\
\hline $\begin{array}{l}\text { Var: } N \\
\text { Model } \\
\text { Error } \\
\text { Total }\end{array}$ & $\begin{array}{r}13.80 \\
2139.17 \\
2152.98\end{array}$ & $\begin{array}{r}2 \\
208 \\
210\end{array}$ & $\begin{array}{r}6.90 \\
10.28\end{array}$ & 0.67 & $>0.05$ \\
\hline
\end{tabular}




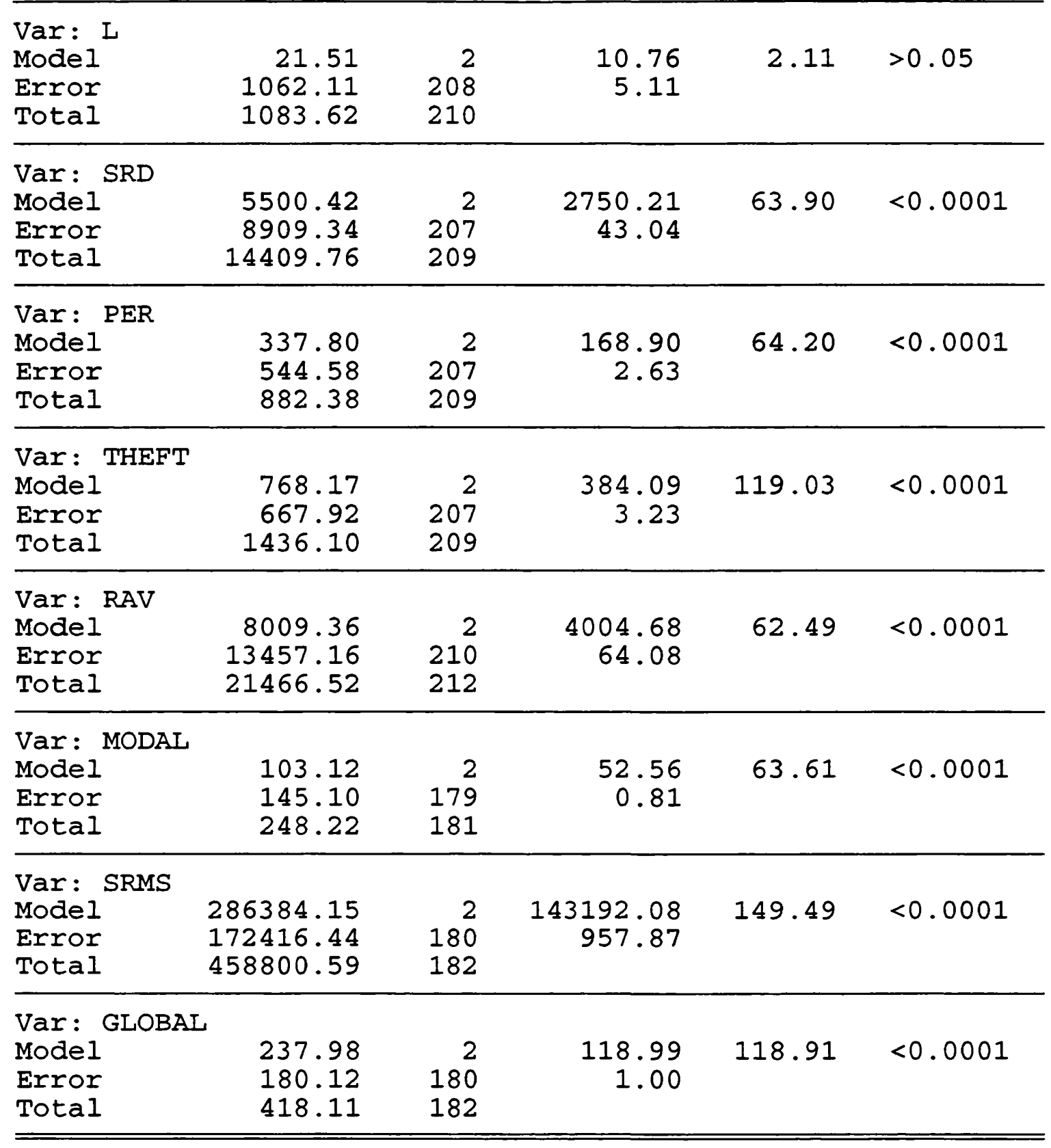

Analyses of Covariance - Comparisons between the Glenthorne sample, convicted offenders and combined control groups using age, EDD, SEG and SIB10 as co-variates

\begin{tabular}{lrrrrr}
\hline $\begin{array}{l}\text { Source of } \\
\text { Variance }\end{array}$ & SS & df & MS & F & P \\
\hline $\begin{array}{l}\text { Var: P } \\
\text { Model }\end{array}$ & $\begin{array}{r}179.82 \\
730.67\end{array}$ & 163 & 29.97 & 6.69 & $<0.0001$ \\
Error & 910.49 & 169 & 4.48 & & \\
Total & & & & & \\
\hline Var: E & 32.98 & 6 & 5.50 & 0.51 & $>0.05$ \\
Model & 1773.31 & 163 & 10.87 & & \\
Error & 1806.29 & 169 & & & \\
Total & & & & & \\
\hline
\end{tabular}




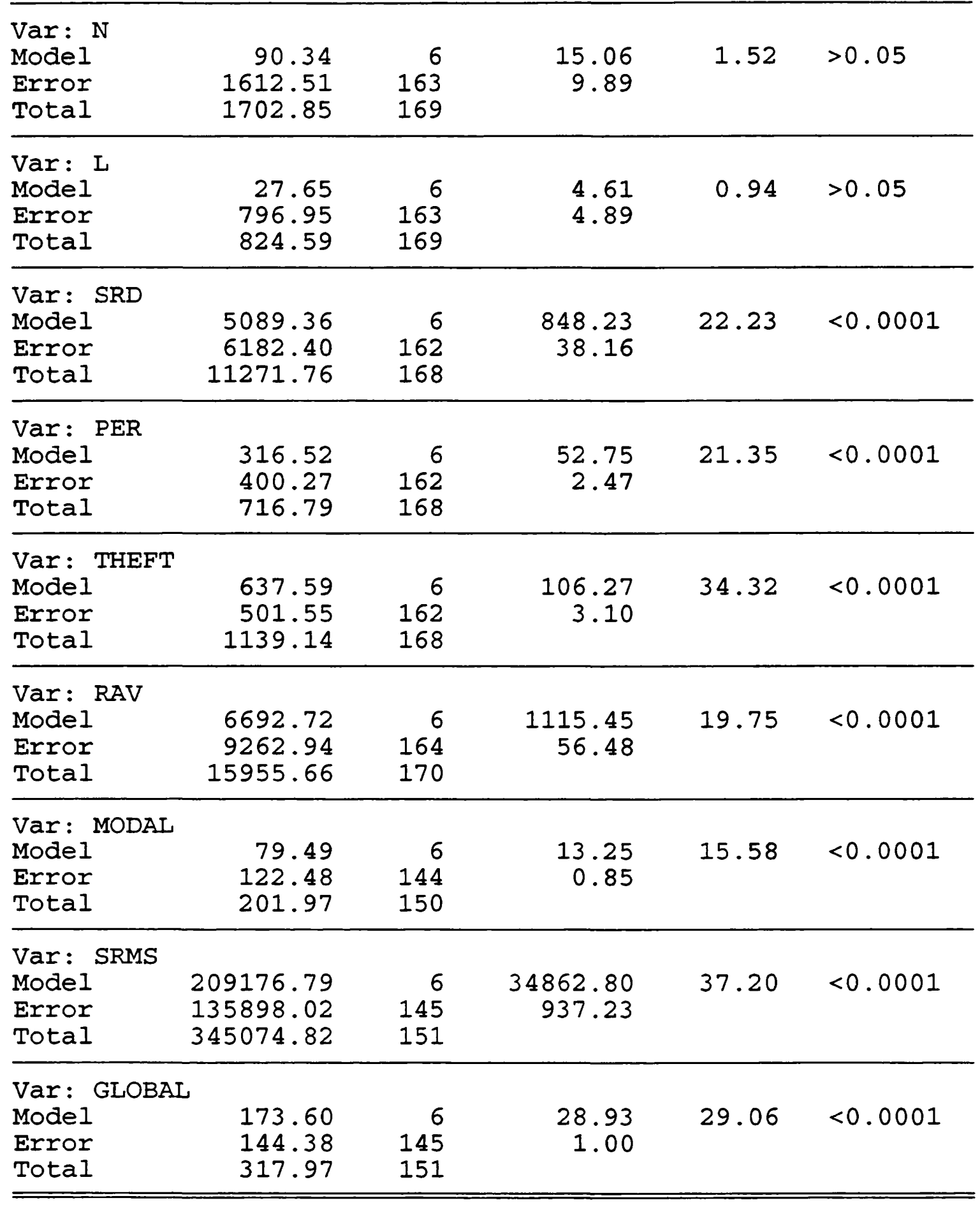


Faking Study results (Chapter 4.2)

Comparisons between the Fake offender sample, convicted offenders and combined control groups

\begin{tabular}{|c|c|c|c|c|c|}
\hline $\begin{array}{l}\text { Source of } \\
\text { Variance }\end{array}$ & SS & $d f$ & MS & $F$ & $p$ \\
\hline $\begin{array}{l}\text { Var: AGE } \\
\text { Model } \\
\text { Error } \\
\text { Total }\end{array}$ & $\begin{array}{r}15.81 \\
277.35 \\
293.17\end{array}$ & $\begin{array}{r}2 \\
246 \\
248\end{array}$ & $\begin{array}{l}7.91 \\
1.13\end{array}$ & 7.01 & $<0.01$ \\
\hline $\begin{array}{l}\text { Var: P } \\
\text { Model } \\
\text { Error } \\
\text { Total }\end{array}$ & $\begin{array}{r}918.79 \\
1664.10 \\
2582.88\end{array}$ & $\begin{array}{r}2 \\
242 \\
244\end{array}$ & $\begin{array}{r}459.39 \\
6.88\end{array}$ & 66.81 & $<0.0001$ \\
\hline $\begin{array}{l}\text { Var: E } \\
\text { Model } \\
\text { Error } \\
\text { Total }\end{array}$ & $\begin{array}{r}21.23 \\
2639.89 \\
2661.13\end{array}$ & $\begin{array}{r}2 \\
242 \\
244\end{array}$ & $\begin{array}{l}10.62 \\
10.91\end{array}$ & 0.97 & $>0.05$ \\
\hline $\begin{array}{l}\text { Var: N } \\
\text { Model } \\
\text { Error } \\
\text { Total }\end{array}$ & $\begin{array}{r}10.56 \\
2354.32 \\
2364.88\end{array}$ & $\begin{array}{r}2 \\
242 \\
244\end{array}$ & $\begin{array}{l}5.28 \\
9.73\end{array}$ & 0.54 & $>0.05$ \\
\hline $\begin{array}{l}\text { Var: I } \\
\text { Model } \\
\text { Error } \\
\text { Total }\end{array}$ & $\begin{array}{r}108.94 \\
1205.80 \\
1314.73\end{array}$ & $\begin{array}{r}2 \\
242 \\
244\end{array}$ & $\begin{array}{r}54.47 \\
4.98\end{array}$ & 10.93 & $<0.0001$ \\
\hline $\begin{array}{l}\text { Var: SRD } \\
\text { Model } \\
\text { Error } \\
\text { Total }\end{array}$ & $\begin{array}{r}6430.22 \\
9734.98 \\
16165.20\end{array}$ & $\begin{array}{r}2 \\
242 \\
244\end{array}$ & $\begin{array}{r}3215.11 \\
40.23\end{array}$ & 79.92 & $<0.0001$ \\
\hline $\begin{array}{l}\text { Var: PER } \\
\text { Model } \\
\text { Error } \\
\text { Total }\end{array}$ & $\begin{array}{l}411.94 \\
581.53 \\
993.47\end{array}$ & $\begin{array}{r}2 \\
242 \\
244\end{array}$ & $\begin{array}{r}205.97 \\
2.40\end{array}$ & 85.71 & $<0.0001$ \\
\hline $\begin{array}{l}\text { Var: THEFT } \\
\text { Model } \\
\text { Error } \\
\text { Total }\end{array}$ & $\begin{array}{r}900.79 \\
680.41 \\
1581.20\end{array}$ & $\begin{array}{r}2 \\
242 \\
244\end{array}$ & $\begin{array}{r}450.39 \\
2.81\end{array}$ & 160.19 & $<0.0001$ \\
\hline $\begin{array}{l}\text { Var: MODAL } \\
\text { Model } \\
\text { Error } \\
\text { Total }\end{array}$ & $\begin{array}{r}85.39 \\
196.38 \\
281.77\end{array}$ & $\begin{array}{r}2 \\
214 \\
216\end{array}$ & $\begin{array}{r}42.69 \\
0.92\end{array}$ & 46.53 & $<0.0001$ \\
\hline $\begin{array}{l}\text { Var: SRMS } \\
\text { Model } \\
\text { Error } \\
\text { Total }\end{array}$ & $\begin{array}{l}227833.07 \\
222109.61 \\
449942.68\end{array}$ & $\begin{array}{r}2 \\
216 \\
218\end{array}$ & $\begin{array}{r}113916.54 \\
1028.29\end{array}$ & 110.78 & $<0.0001$ \\
\hline
\end{tabular}


Var: GLOBAL

Model

Error

186.42

218.00

2

404.42

216

93.21

$92.35<0.0001$

Total

218

1.01

Analyses of variance with EDD as a co-variate - Comparisons between the Fake offenders, convicted offenders and combined control groups

\begin{tabular}{|c|c|c|c|c|c|}
\hline $\begin{array}{l}\text { Source of } \\
\text { Variance }\end{array}$ & SS & $d f$ & MS & $F$ & $p$ \\
\hline $\begin{array}{l}\text { Var: P } \\
\text { Model } \\
\text { Error } \\
\text { Total }\end{array}$ & $\begin{array}{r}921.78 \\
1661.10 \\
2582.88\end{array}$ & $\begin{array}{r}3 \\
241 \\
244\end{array}$ & $\begin{array}{r}307.26 \\
6.89\end{array}$ & 44.58 & $<0.0001$ \\
\hline $\begin{array}{l}\text { Var: E } \\
\text { Model } \\
\text { Error } \\
\text { Total }\end{array}$ & $\begin{array}{r}32.86 \\
2628.27 \\
2661.13\end{array}$ & $\begin{array}{r}3 \\
241 \\
244\end{array}$ & $\begin{array}{l}10.95 \\
10.91\end{array}$ & 1.00 & $>0.05$ \\
\hline $\begin{array}{l}\text { Var: } N \\
\text { Model } \\
\text { Error } \\
\text { Total }\end{array}$ & $\begin{array}{r}12.30 \\
2352.58 \\
2364.88\end{array}$ & $\begin{array}{r}3 \\
241 \\
244\end{array}$ & $\begin{array}{l}4.10 \\
9.76\end{array}$ & 0.42 & $>0.05$ \\
\hline $\begin{array}{l}\text { Var: L } \\
\text { Model } \\
\text { Error } \\
\text { Total }\end{array}$ & $\begin{array}{c}125.79 \\
1188.95 \\
1314.73\end{array}$ & $\begin{array}{c}3 \\
241 \\
244\end{array}$ & $\begin{array}{r}41.93 \\
4.93\end{array}$ & 8.50 & $<0.0001$ \\
\hline $\begin{array}{l}\text { Var: SRD } \\
\text { Model } \\
\text { Error } \\
\text { Total }\end{array}$ & $\begin{array}{r}6596.86 \\
9568.34 \\
16165.20\end{array}$ & $\begin{array}{r}3 \\
241 \\
244\end{array}$ & $\begin{array}{r}2198.95 \\
39.70\end{array}$ & 55.39 & $<0.0001$ \\
\hline $\begin{array}{l}\text { Var: PER } \\
\text { Model } \\
\text { Error } \\
\text { Total }\end{array}$ & $\begin{array}{l}412.27 \\
581.20 \\
993.47\end{array}$ & $\begin{array}{r}3 \\
242 \\
244\end{array}$ & $\begin{array}{r}137.42 \\
2.41\end{array}$ & 56.98 & $<0.0001$ \\
\hline $\begin{array}{l}\text { Var: THEFT } \\
\text { Model } \\
\text { Error } \\
\text { Total }\end{array}$ & $\begin{array}{r}919.80 \\
661.40 \\
1581.20\end{array}$ & $\begin{array}{r}3 \\
241 \\
244\end{array}$ & $\begin{array}{r}306.60 \\
2.74\end{array}$ & 111.72 & $<0.0001$ \\
\hline $\begin{array}{l}\text { Var: MODAL } \\
\text { Model } \\
\text { Error } \\
\text { Total }\end{array}$ & $\begin{array}{r}85.67 \\
196.10 \\
281.77\end{array}$ & $\begin{array}{r}3 \\
213 \\
216\end{array}$ & $\begin{array}{r}28.56 \\
0.92\end{array}$ & 31.02 & $<0.0001$ \\
\hline
\end{tabular}


Var: SRMS

Model

Error

Total

227870.71

222071.98

449942.68

Var: GLOBAL

Model

Error

186.44

217.98

Total

215

218

404.42
3
215

218

75956.90

1032.89

218

$73.54<0.0001$

62.15

1.01

$61.30<0.0001$

$\begin{array}{rrrr}3 & 62.15 & 61.30<0.0001 \\ 5 & 1.01 & & \\ 8 & & \end{array}$

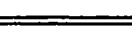

